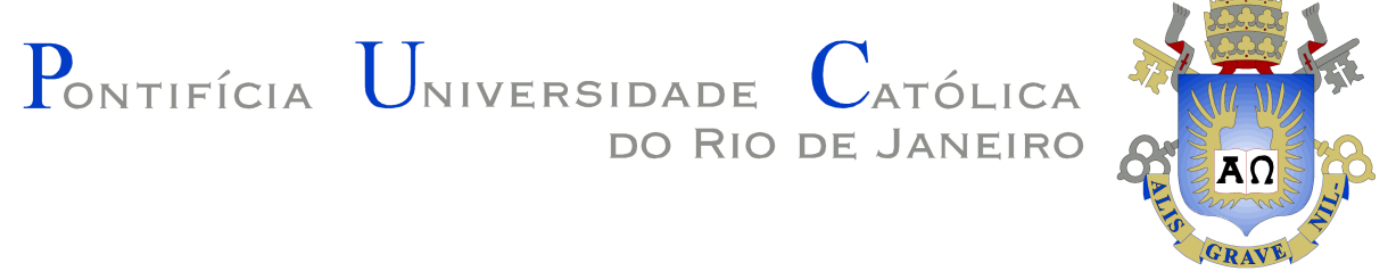

Diana Carolina Parada Quinayá

\title{
Fabricação e Caracterização de Materiais Compósitos Resina Epóxi/Fibras de Bucha (Luffa cylindrica)
}

\section{Tese de Doutorado}

Tese apresentada como requisito parcial para obtenção do grau de Doutor pelo Programa de PósGraduação em Engenharia de Materiais e de Processos Químicos e Metalúrgicos da PUC-Rio.

Orientador: Prof. José Roberto Moraes D'Almeida

Rio de Janeiro Abril de 2017 


\title{
DIANA CAROLINA PARADA QUINAYÁ
}

\section{Fabricação e Caracterização de Materiais Compósitos Resina Epóxi/Fibras de Bucha (Luffa cylindrica)}

\author{
Tese apresentada como requisito parcial para \\ obtenção do grau de Doutor pelo Programa de Pós- \\ Graduação em Engenharia de Materiais e de \\ Processos Químicos e Metalúrgicos do Departamento \\ de Engenharia Química e de Materiais do Centro \\ Técnico Científico da PUC-Rio. Aprovada pela \\ Comissão Examinadora abaixo assinada.
}

Prof. José Roberto Moraes d'Almeida Orientador e Presidente Departamento de Engenharia Química e de Materiais - PUC-Rio

Prof. Flávio de Andrade Silva Departamento de Engenharia Civil e Ambiental - PUC-Rio

Prof. Omar Pandoli Departamento de Engenharia de Química - PUC-Rio

Profa. Verônica Maria de Araújo Calado Universidade Federal de Rio de Janeiro - UFRJ

Profa. Renata Antoun Simão Universidade Federal de Rio de Janeiro - UFRJ

Prof. Márcio da Silveira Carvalho Coordenador Setorial de Pós-Graduação do Centro Técnico Científico da PUC-Rio

Rio de Janeiro, 20 de abril de 2017. 
Todos os direitos reservados. É proibida a reprodução total ou parcial do trabalho sem autorização da autora, do orientador e da universidade.

\section{Diana Carolina Parada Quinayá}

Graduou-se em Engenharia Química (Universidad Industrial de Santander - Colômbia) em 2007. Mestre em Engenharia de Materiais pela Universidad Industrial de Santander, onde foi integrante do grupo de pesquisa em corrosão (GIC). As áreas de atual interesse são Polímeros, Materiais Compósitos, Fibras Lignocelulósicas e Caracterização mecânica.

Ficha Catalográfica

Parada Quinayá, Diana Carolina

Fabricação e caracterização de materiais compósitos resina epóxi/fibras de bucha (Luffa cylindrica) / Diana Carolina Parada Quinayá ; orientador: José Roberto M. D'Almeida. - 2017.

266 f. : il. color. ; $30 \mathrm{~cm}$

Tese (doutorado)-Pontifícia Universidade Católica do Rio de Janeiro, Departamento de Engenharia Química e de Materiais, 2017.

Inclui bibliografia

1. Engenharia de Materiais - Teses. 2. Engenharia Química - Teses. 3. Bucha vegetal. 4. Óleo vegetal epoxidado. 5. Bio-epóxi. 6. Compósitos. 7. Técnica de Excitação por Impulso. I. D’Almeida, José Roberto M. II. Pontifícia Universidade Católica do Rio de Janeiro. Departamento de Engenharia Química e de Materiais. III. Título. 


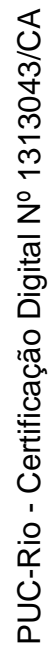

À memória de meus avós Maria del Carmen Torres e Evaristo Quinayá 


\section{Agradecimentos}

A Deus que renova minhas forças e me abençoa cada dia.

Ao meu orientador o professor José Roberto, pelo conhecimento transmitido e pela confiança depositada. Por ter me aceito como sua orientada e ter me guiado e ensinado com a melhor disposição até o final.

Aos professores Ana Lúcia Fampa e Flávio Silva pelos valiosos aportes e sugestões durante a apresentação da proposta.

Ao professor Omar Pandoli pelo tempo dedicado ao análise das fibras por AFM e os ensinamentos envolvidos.

Ao professor Marcos de Mauricio pela ajuda com a aquisição das imagens no MEV.

À professora Veronica Calado pela disponibilização do laboratório e equipamentos para a realização da caracterização térmica de resinas e compósitos.

Ao Marques pela adequação do molde para a fabricação dos compósitos e o corte dos corpos de prova.

Ao Marcelo Nogueira da Cardolite no Brasil por disponibilizar os reagentes para a preparação de resinas de cardanol.

À BBC Industria e Comercio Ltda. pelas amostras de óleo de soja epoxidado.

Ao meu namorado Rodrigo Albergaria por seu apoio, sempre disposto a me ajudar no cumprimento das minhas metas. Por me incentivar e comemorar comigo cada pequena conquista e também por me confortar quando as coisas não resultavam como eu esperava. Suas palavras de ânimo e seu abraço foram fundamentais para eu superar os momentos mais difíceis.

Aos amigos brasileiros que tenho conhecido nestes quatro anos por me receber de braços abertos - hoje sinto um imenso carinho pelo Brasil! Especialmente a Carmem Vianna e Amaury Albergaria por terem me acolhido em sua casa como uma filha, e a Claudia Sousa e Clara de Lacerda, pela amizade e momentos compartilhados. 
Aos meus pais pelas suas orações.

Aos companheiros da PUC-Rio pelas trocas de ideias e pelos aprendizados. Ao estudante de iniciação científica Daniel Vieira pela colaboração no laboratório e a todas as pessoas que contribuíram direta e indiretamente.

À PUC-Rio pela isenção de mensalidades do Doutorado e à CAPES pela bolsa concedida. 


\section{Resumo}

Quinayá, Diana Carolina Parada; D’Almeida, José Roberto Moraes (Orientador); Fabricação e caracterização de materiais compósitos resina epóxi/fibras de bucha (Luffa cylindrica). Rio de Janeiro, 2017. 266p. Tese de Doutorado - Departamento de Engenharia Química e de Materiais, Pontifícia Universidade Católica do Rio de Janeiro.

Resinas epóxi do éter diglicidílico de bisfenol A (DGEBA) são amplamente usadas como matriz de materiais compósitos. No entanto, o principal monômero utilizado para a sua produção, o Bisfenol A (BPA), apresenta significativos efeitos negativos na saúde humana. Implicações ambientais que limitam o uso BPA fazem necessária a substituição dos monômeros base para a preparação de resinas epóxi por outros mais seguros e ambientalmente sustentáveis. Por outro lado, resinas epóxi preparadas a partir de fontes renováveis constituem uma alternativa ao uso de resinas derivadas do petróleo na produção de materiais compósitos. Assim, óleos naturais derivados de fontes vegetais são considerados uma matéria-prima alternativa para a obtenção de resinas epóxi de base biológica por causa da sua disponibilidade e uma ampla variedade de possibilidades para transformações químicas. Além disso, materiais compósitos fabricados a partir de resinas termoendurecíveis de origem vegetal e fibras lignocelulósicas como material de reforço, poderiam contribuir com a produção sustentável de materiais de baixo custo e menor densidade que possuam propriedades estruturais funcionais. Neste trabalho propõe-se a preparação de laminados utilizando como matriz resinas epóxi biobaseadas obtidas a partir de óleo de soja epoxidado e cardanol epoxidado (proveniente da casca de castanha de caju) e fibras lignocelulósicas de bucha (Luffa cylindrica) como reforço. Os efeitos estruturais, morfológicos e térmicos de tratamentos superficiais de hornificação, mercerização e acetilação nas fibras foram estudados usando espectroscopia no infravermelho por transformada de Fourier (FTIR), difração de raios X (DRX), microscopia eletrônica de varredura (MEV), microscopia de força atômica (AFM) e análise termogravimétrica (TGA). Compósitos DGEBA/Bucha e Resina natural/Bucha foram fabricados pelo método lay-up manual e suas propriedades mecânicas foram avaliadas por meio de ensaios de flexão em três pontos e da técnica não destrutiva de excitação por impulso (TEI). 
Esta técnica também foi utilizada para a determinação experimental dos módulos dinâmicos e das propriedades de amortecimento dos compósitos durante o envelhecimento por UV e por absorção de água. O comportamento dinâmicomecânico dos compósitos foi avaliado por meio da análise dinâmico-mecânica (DMA). Resinas preparadas com 50\% de cardanol epoxidado e 50\% de resorcinol curadas com diamina de isoforona apresentaram melhores propriedades térmicas e mecânicas, comparados com sistemas com óleo de soja epoxidado, com uma temperatura de transição vítrea média de $74^{\circ} \mathrm{C}$ e módulo de armazenamento de 880,5 MPa, constituindo uma alternativa mais sustentável para a fabricação de materiais compósitos pela substituição do sistema bisfenol A clássico analisado também neste trabalho, com valores $\mathrm{Tg}=77,5^{\circ} \mathrm{C}$ e E'=849 $\mathrm{MPa}$. A adição de fibras de bucha em forma de manta permitiu a obtenção de compósitos com modos de fratura controlada. Além disso, foi observada uma melhora na aderência na interfase fibra-resina em compósitos com $30 \%$ de fibras de bucha mercerizada.

\section{Palavras-chave}

Bucha vegetal; Óleo vegetal epoxidado; Bio-epóxi; Compósitos; Hornificação; Acetilação; Mercerização; Técnica de Excitação por impulso. 


\section{Abstract}

Quinayá, Diana Carolina Parada; D’Almeida, José Roberto Moraes (Advisor); Fabrication and characterization of epoxy resin/Luffa cylindrica composite materials. Rio de Janeiro, 2017. 266p. Tese de Doutorado - Departamento de Engenharia Química e de Materiais, Pontifícia Universidade Católica do Rio de Janeiro.

Diglycidyl ether of bisphenol A (DGEBA) currently represents the most widely used type of epoxy resin in the world in several applications. However, the main monomer used for its production, Bisphenol A (BPA) is considered an endocrine disruptor with estrogenic activity that has significant negative effects on human health. Environmental implications and laws limiting the use of BPA in several countries make it necessary to replace the base monomers for the preparation of epoxy resins with safer and more environmentally sustainable ones. Epoxy resins prepared from renewable sources are an alternative to the use of petroleum resins in the production of composite materials. Thus, natural oils derived from vegetable sources are considered as an alternative raw material for obtaining biologically based epoxy resins because of their availability, their relatively low price and a wide variety of possibilities for chemical transformations. On the other hand, composite materials made from thermosetting resins of vegetable origin and lignocellulosic fibers as reinforcement material could contribute to the sustainable production of low cost and lower density materials that have functional structural properties. This work proposes the preparation of composite materials, using biobased epoxy resins obtained from epoxidized soybean oil and epoxidized cardanol from cashew nuts as well as lignocellulosic (Luffa cylindrica) fibers modified by surface treatments of hornification, mercerization and acetylation. The structural, morphological and thermal effects of surface treatments on the fibers were studied using Fourier transform infrared spectroscopy (FTIR), X-ray diffraction (XRD), scanning electron microscopy (SEM) and thermogravimetric analysis (TGA). DGEBA/Luffa and Biobased resin/Luffa fiber composites were fabricated by the manual lay-up method and their mechanical properties were evaluated by three-point bending tests and the non- 
destructive impulse excitation technique (TEI). This technique was also used for the experimental determination of the dynamic modules and the damping properties of the laminates obtained during UV aging and water absorption. The effect of the introduction of the binder fibers and the different treatments performed on the fibers on the dynamic-mechanical behavior of the composites was performed by dynamicmechanical analysis (DMA). Resins prepared with 50\% epoxidized cardanol and $50 \%$ resorcinol cured with isophorone diamine presented better thermal and mechanical properties, compared to systems with epoxidized soybean oil, with an average glass transition temperature of $74^{\circ} \mathrm{C}$ and a storage modulus of $880,5 \mathrm{MPa}$, constituting a sustainable alternative for the manufacture of composite materials by replacing the classic bisphenol A system also analyzed in this work, with values $\mathrm{Tg}=77.5^{\circ} \mathrm{C}$ and $\mathrm{E}{ }^{\prime}=849 \mathrm{MPa}$. The addition of luffa fibers allowed the production of composites with controlled fracture modes. In addition, an improvement in the fiber-resin interface adhesion was observed in composites with $30 \%$ mercerized fibers.

\section{Keywords}

Luffa fiber; Epoxidized vegetable oil; Biobased epoxy; Composites; Hornification; Acetylation; Mercerization; Pulse Excitation Technique. 


\section{Sumário}

1 Introdução 29

1.1. Objetivo Principal 32

1.2. Objetivos Específicos 32

2 Revisão Bibliográfica 33

2.1. Materiais Compósitos 33

2.2. Polímeros termofixos $\quad 35$

2.2.1. Resinas Epóxi (RE) 37

2.3. Fibras Lignocelulósicas 53

2.3.1. Celulose 56

2.3.2. Hemicelulose 57

2.3.3. Lignina 58

2.3.4. Bucha Vegetal (Luffa cylindrica) 58

2.3.5. Modificação de fibras lignocelulósicas 63

2.4. Cristalinidade 71

2.5. Técnica de Excitação por Impulso (TEI) [276], [277]. 76

2.6. Microscopia de Força Atômica (AFM) 78

2.7. Análise Térmica 84

2.8. Análise Dinâmico-Mecânica (DMA) 86

2.9. Absorção de Umidade 88

3 Materiais e Métodos Experimentais $\quad 91$

3.1. Materiais 91

3.2. Modificação das fibras 93

3.3. Caraterização das fibras de bucha 94

3.3.1. Microscopia Eletrônica de Varredura (MEV) 95

3.3.2. Difração de Raios X (DRX) 96

3.3.3. Espectroscopia no Infravermelho com transformada de Fourier (FTIR) 97

3.3.4. Microscopia de Força Atômica (AFM) 97

3.3.5. Análise Termogravimétrica (TGA) 99 
3.4. Preparação de Resinas Epóxi 100

3.5. Caraterização térmica de resinas 102

3.6. Caracterização mecânica das resinas 102

3.7. Fabricação de Compósitos 103

3.8. Caraterização dos Compósitos 105

3.8.1. Análise dinâmico-mecânica (DMA) 106

3.8.2. Ensaio não destrutivo: Técnica de Excitação por Impulso 107

3.8.3. Ensaio de flexão Estática 109

3.8.4. Microscopia Eletrônica de Varredura (MEV) 109

3.8.5. Absorção de água 110

4 Resultados 112

4.1. Caracterização das fibras de bucha 112

4.1.1. Microscopia Eletrônica de Varredura (MEV) 113

4.1.2. Difração de Raios $X(D R X) \quad 120$

4.1.3. Espectroscopia do Infravermelho com transformada de Fourier (FTIR)

4.1.4. Análise Termogravimétrica (TGA) 132

4.1.5. Microscopia de Força Atômica (AFM) 134

4.2. Caracterização Térmica de Resinas epóxi 139

4.2.1. Analise Dinâmico-Mecânica (DMA) 142

4.3. Caraterização de Compósitos Epóxi/Bucha 146

4.3.1. Absorção de Água 149

4.3.2. Técnica de flexão em três pontos 156

4.3.3. Técnica de Excitação por Impulso (TEI) 163

4.3.4. Efeito do tempo de imersão em água sobre as propriedades mecânicas dos materiais. 169

4.3.5. Análise da superfície de fratura 177

4.3.6. Analise Dinâmico-Mecânica (DMA) 183

5 Conclusões 197

5.1. Sugestões para Trabalhos Futuros 198

6 Referências bibliográficas 
Apêndice A1 - Valores de ajuste para a deconvolução de espectros DRX

Apêndice A2 - Espectro FTIR das fibras de bucha.

Apêndice A3 - Aparência superficial dos compósitos bisfenol/bucha antes e após de absorção em água de mar.

Apêndice A4 - Módulo de Young vs Densidade

Apêndice A5 -Termogramas por TGA das resinas analisadas

Apêndice A6 - Curvas tensão-deformação 


\section{Lista de Figuras}

Figura 1 - Classificação de compósitos poliméricos convencionais, segundo a disposição do reforço [12].

Figura 2 - Classificação de fibras usadas como fase de reforço em materiais compósitos.

Figura 3 - Estrutura de grupos epóxi funcionais a) oxirano. b) glicidil.

Figura 4 - Representação da estrutura química de a) Bisfenol A e b) Epicloridrina [4].

Figura 5- Representação esquemática do mecanismo de reação simplificada de epicloridrina e bisfenol A [47].

Figura 6 - Rotas renovável e petroquímica para a obtenção de epicloridrina. Adaptado de [50].

Figura 7 - Recursos renováveis para a síntese de pré-polímeros epóxi e agentes de cura bio-baseados [51], [52], [53], [54],[55],[56],[57].

Figura 8 - Produção mundial de óleos vegetais 2016/17.

Figura 9 - Estrutura molecular de um triglicérido (R representa as cadeias de hidrocarbonetos de ácidos graxos).

Figura 10 - Composição de ácidos graxos de óleos vegetais comuns [64], [65].

Figura 11 - Estrutura de ácidos graxos insaturados comuns em óleos vegetais. a) Ácido oleico (C18:1). b) Ácido linoleico (C18:2). c) Ácido linoloneico (C:18:3)

Figura 12 - Estruturas químicas de ácidos graxos saturados presentes nos óleos vegetais mais representativos a) ácido mirístico b) ácido palmítico c) ácido esteárico.

Figura 13 - Epoxidação de óleo de soja [98]

Figura 14 - Caju detalhe de castanhas e da casca (mesocarpo esponjoso) [125].

Figura 15 - Produção mundial de castanha de caju [126].

Figura 16 - Estruturas químicas dos principais componentes na casca da castanha de caju. $\mathrm{R}=\mathrm{C}_{15} \mathrm{H}_{31-2 \mathrm{n}}$, com valores de $\mathrm{n}$ entre 0 e 3 .

a) ácido anacárdico b) cardol c) cardanol d) 2-metil cardol e) urushiol. 48 
Figura 17 - Fases no processo de obtenção do cardanol a) Frutos de caju b) casca da noz de caju c) extração do líquido da casca da noz de caju (LCC) d) cardanol obtido por destilação de LCC [132], [133], [134].

Figura 18 - Cadeia alifática do cardanol $(\mathrm{R})$

Figura 19 - Síntese de a) cardanol mono-epoxidado (EC)

b) cardanol di-epoxidado (DEC) [55],

Figura 20 - Estrutura química do epóxi di-funcional comercial derivado do cardanol (NC-514) [153].

Figura 21 - Classificação de principais fibras lignocelulósicas segundo a origem.

Figura 22 - Gráfico de propriedades materiais naturais, módulo de Young vs. densidade [182].

Figura 23 - Estrutura hierárquica da madeira [182].

Figura 24 - Estrutura molecular parcial da celulose com o monômero $\beta$ D-glucose como unidade fundamental e celobiose como unidade estrutural [191].

Figura 25 - Representação do arranjo espacial de celulose, hemicelulose e lignina na parede secundária de uma fibra vegetal [195].

Figura 26 - Imagem TEM que exibe a parede da célula de madeira ultra-estruturada, com lamela média (CML) e camadas da parede celular secundária (S1, S2, S3) (Direita). Esquema da arquitetura da lignocelulose em nano escala (Esquerda) [193].

Figura 27 - Distribuição mundial de Luffa cylindrica[200].

Figura 28 - Fruto maduro e descascado (Luffa cylindrica). a) Vista lateral b) Vista frontal com corte. $c$ ) Vista frontal sem cortes.

Figura 29 - Regiões da bucha vegetal.

Figura 30 - Fruto maduro de bucha, descascado e cortado.

a) Superfície interna da parede intermediaria. b) Núcleo central.

c) Superfície externa da parede intermediaria.

Figura 31 - Esquema da acetilação parcial da celulose [162], [174]. 
Figura 32 - Ilustração esquemática apresentando o efeito hipotético do tratamento alcalino sobre a estrutura de fibras lignocelulósicas (a) fibra não tratada (b) Fibra mercerizada [240].

Figura 33. Contração da secção transversal de uma fibra durante o processo de hornificação [254], [259].

Figura 34 - Difratograma para Celulose lb com orientação aleatória dos cristalitos [261].

Figura 35 - IC de Avicel PH-101 para diferentes métodos de medição [265].

Figura 36 - Espectro de difração de raios $X$ de celulose microcristalina, ilustrando método da altura dos picos (Peak height) para calcular o IC [265].

Figura 37 - Espectro de difração de raios $X$ de celulose

microcristalina, ilustrando o método da deconvolução dos picos para calcular o IC [265].

Figura 38 - Espectro de difração de raios $X$ de celulose microcristalina, ilustrando o método da subtração da área amorfa para calcular o IC [265].

Figura 39- Diagrama de funcionamento do AFM [279].

Figura 40 - Sonda (cantilever e ponta). Detalhe do raio de curvatura. 79 Figura 41 - Modos de operação do AFM (a) Modo contato (b) Modo não contato $(c)$ Modo contato intermitente.

Figura 42 - Curva de força de interação ponta-superfície versus distância.

Figura 43 - Curva de força e posição piezoeléctrica $Z$ em função do tempo, incluindo a força de pico (C) e a adesão (D). Curva Força vs. Z (direita).

Figura 44 - Curva Força vs. Separação com a informação das propriedades nanomecânicas que podem ser obtidas usando o modelo DMT.

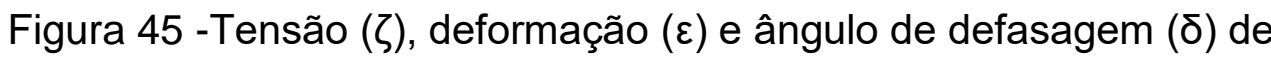
uma análise dinâmico-mecânica.

Figura 46 - Curvas esquemáticas correspondentes à difusão linear 
de Fick (LF) e quatro possíveis categorias de comportamento não-

Fickiano (A, B, C, D) [313].

Figura 47 - Fibras de bucha vegetal. a) Manta fibrosa $\left(150 \times 200 \times 3 \mathrm{~mm}^{3}\right)$

b) Fibras curtas 93

Figura 48 - Métodos de modificação superficial de fibras de bucha. 93

Figura 49 - Esquema da caraterização de fibras de bucha. 95

Figura 50 - Microscópio eletrônico de varredura JEOL JSM-6510LV 95

Figura 51 - Amostras de fibras de bucha para observação no MEV. 96

Figura 52 - Espectrofotômetro Perkin Elmer, modelo Spectrum $400 . \quad 97$

Figura 53 - Microscópio de força atômica (AFM) Multimode-8 98

Figura 54 - (a) Amostra de fibras de bucha analisadas. (b) Sondas

TAP525A utilizadas para a análise por AFM (para amostras com módulo de Young entre 1 e $20 \mathrm{GPa}$ ). 98

Figura 55 - Equipamento Pyris 1 TGA. 99

Figura 56 - Estrutura química da Isoforona Diamina (IPDA). 100

Figura 57 - (a) Máquina Universal de Ensaios - AME com 200kgf de capacidade. (b) Detalhe do ensaio de flexão em três pontos do corpo de prova de resina 30\%ESO-70\%Bisfenol A. 102

Figura 58 - Esquema dos componentes dos compósitos fabricados $\quad 103$

Figura 59 - Esquema de fabricação de compósitos reforçados com fibras de bucha pelo método de lay-up manual.

104

Figura 60 - Corpos de prova de compósitos $(80 \times 25 \times 3 \mathrm{~mm})(a)$

Bisfenol/fibras de bucha (b) ESO30/fibras de bucha (c) C50/fibras de bucha (d) Bisfenol/fibras curtas de bucha.

105

Figura 61 - Esquema de fabricação de compósitos reforçados com fibras de bucha curtas.

Figura 62 - Esquema da caraterização dos compósitos fabricados. 106

Figura 63 - Equipamento DMA7 (PerkinElmer). Detalhe do dispositivo de ensaio de flexão em três pontos empregado (Direita).

Figura 64 - Corpos de prova para o ensaio DMA com dimensões de $19,5 \times 6,5 \times 3 \mathrm{~mm}$.

Figura 65 - Imagem ilustrativa de a) Modo fundamental flexional

b) Modo fundamental de torção.

Figura 66 - Sistema Sonelastic $\circledast$ (a) Captador omnidirecional 
CA-EL-PD para altas frequências (até $30 \mathrm{kHz}$ ). (b) Pulsador eletromagnético automático Sonelastic $\circledast$ IED.

Figura 67 - Montagem de corpos de prova fraturados para observação por MEV. 109

Figura 68 - Água de mar sintética Blue Treasure (Reef Sea Salt). 110

Figura 69 - Variação do diâmetro de fibras de bucha.

Figura 70 - Esquema da ubiquação do ponto de corte das fibras para a medição do diâmetro.

Figura 71 - Imagem por MEV de fibras de bucha na superfície externa da parede intermediária da esponja bucha (30x).

Figura 72 - Imagem por MEV da seção transversal de fibras na superfície externa da bucha 200x. Detalhe: Lúmen e micro células.

Figura 73 - Imagem por MEV de micro células na seção transversal de fibras de bucha.

Figura 74 - Imagem por MEV da seção transversal de fibra individual da superfície externa da luffa. 200x.

Figura 75 - Imagem por MEV do agrupamento de fibras na superfície interna e no núcleo da bucha

Figura 76 - Imagem por MEV da seção transversal de aglomerado de fibras no interior da bucha (superfície interna e núcleo da bucha) 90x. Detalhe: Secção transversal das fibras 200x.

Figura 77 - Imagem por MEV de fibras de bucha sem tratamento.

(a) 200x, (b) 500X, (c) 1000x, (d) 5000X.

Figura 78 - Imagem por MEV de fibras de bucha hornificadas.

(a) 30x, (b) 200x, (b) 500x, (c) 1000x.

Figura 79 - Imagem por MEV da superfície da fibra de bucha hornificada.

Figura 80 - Espectro EDS sobre a superfície da fibra de bucha hornificada.

Figura 81 - Espectro EDS de protuberância sobre fibra de bucha hornificada.

Figura 82 - Imagem por MEV de fibras de bucha mercerizadas

(NaOH 2\%, 90 min). (a) 30x, (b) 200x, (c) 500x, (d) 1000x.

Figura 83 - Imagem por MEV de fibras de bucha acetiladas. 
(a) 30x, (b) 200x, (c) 500x, (d) 1000x. 120

Figura 84 - Padrão DRX para a fibra de bucha 121

Figura 85 - Determinação de área amorfa no espectro DRX de fibra de bucha acetilada (Método 1).

Figura 86 - Padrão de DRX para as fibra de bucha (a) Área total (amorfa + cristalina) (b) Área cristalina.

Figura 87 - Padrão DRX para fibras de bucha hornificadas (a) Área total (amorfa + cristalina) (b) Área cristalina.

Figura 88 - Padrão DRX para fibras de bucha mercerizadas (a) Área total (amorfa + cristalina) (b) Área cristalina.

Figura 89 - Padrão DRX para fibras de bucha acetiladas a) Área total (amorfa + cristalina) b) Área cristalina.

Figura 90 - Deconvolução dos picos no espectro DRX de fibras de bucha sem tratamento.

Figura 91 - Deconvolução dos picos no espectro DRX de fibras de bucha hornificadas.

Figura 92 - Deconvolução dos picos no espectro DRX de fibras de bucha mercerizadas.

Figura 93 - Deconvolução dos picos no espectro DRX de fibras de bucha acetiladas.

Figura 94 - Espectro FTIR das fibras de bucha como recebidas e com os diferentes tratamentos.

Figura 95 - Comportamento térmico de fibras de bucha.

Figura 96 - Curva de perda de massa vs temperatura e primeira derivada para fibras de bucha (a) Sem tratamento. (b) Hornificadas. (c) Mercerizadas. (d) Acetiladas.

Figura 97 - Imagens AFM no modo de contato intermitente

(Peak Force Tapping Mode)

Figura 98 - Imagem 3D da superfície de fibra de bucha indicando a altura em nm.

Figura 99 - (a) Imagem (PeakForce) $(2 \times 2 \mu \mathrm{m})$ da topografia de Fibras de bucha. $(b)$ imagem PF-QNM $(2 \times 2 \mu \mathrm{m})$ possui informação do módulo de Young.

Figura 100 - (a) Imagem Peak Force Tapping $(1 \times 1 \mu \mathrm{m})$ da topografia 
de fibras de bucha. (b) Imagem PF QNM $(1 \times 1 \mu \mathrm{m})$ possui informação do módulo de Young.

Figura 101 - (a) Imagem Peak Force Tapping (500 x 500nm) da topografia de fibras de bucha. (b) Imagem PF QNM (500 x 500nm) possui informação do módulo de Young.

Figura 102 - (a) Imagen Peak Force Tapping $(1 \times 1 \mu \mathrm{m})$ da topografia de fibras de bucha. (b) Imagem PF QNM $(1 \times 1 \mu \mathrm{m})$ possui informação do módulo de Young.

Figura 103 - Perfil da superfície.

Figura 104 - Termograma de resina Cardanol/Resorcinol (50\%) curada com fenalcamina NX.

Figura 105 - Termograma de resina Cardanol/Resorcinol (50\%) curada com diamina IPDA.

Figura 106 - Módulos de armazenamento para resinas epóxi de

bisfenol, ESO-bisfenol e cardanol-resorcinol.

Figura 107 - Tan $\delta$ para resinas epóxi de bisfenol, ESO-bisfenol e cardanol-resorcinol.

Figura 108 - Módulo de perda para resinas epóxi de bisfenol, ESObisfenol e cardanol-resorcinol.

Figura 109 - Corpos de prova de compósitos Bisfenol/bucha mercerizada.

Figura 110 - Esquema da caraterização dos compósitos fabricados. 148 Figura 111 - Corpo de prova de compósito epóxi/bucha fabricado a partir de (a) manta de bucha; (b) fibras curtas (moídas) de bucha. 148 Figura 112 - Variação de massa com t para compósitos com fibras de bucha sem modificação em (a) água destilada (b) água de mar. 151 Figura 113 - Variação de massa com t para compósitos com fibra de bucha mercerizadas em (a) água destilada (b) água de mar. Figura 114 - Variação de massa com t para compósitos com fibras de bucha hornificadas em (a) água destilada (b) água de mar. Figura 115 - Variação de massa com t para compósitos com fibras de bucha acetiladas em (a) água destilada (b) água de mar. Figura 116 - Comparação da média do módulo em flexão de resinas puras e do compósito C50-M30 usando o teste LSD de 
Fisher, com nível de significância de 0,05.

Figura 117 - Valores médios de módulo em flexão de resinas puras e do compósito C50 com 30\% de fibras de bucha mercerizadas.

Figura 118 - Valores médios de módulo em flexão de resinas ESO30

e ESO50 e compósitos ESO30 com fibras de bucha.

Figura 119 - Comparação da média do módulo em flexão de compositos de ESO usando o teste LSD de Fisher, com nível de significância de 0,05.

Figura 120 - Valores médios de módulo em flexão de compósitos bisfenol com fibras de bucha.

Figura 121 - Comparação da média do módulo em flexão de compositos de bisfenol usando o teste LSD de Fisher, com nível de significância de 0,05.

Figura 122 - Curva tensão - deformação para resinas bisfenol (B), resorcinol (R) e ESO-bisfenol (ESO30).

Figura 123 - Curva tensão - deformação para compósitos de bisfenol reforçados com $30 \%$ fibras de bucha sem tratamento (U30) e tratadas por mercerização (M30), hornificação (H30) e acetilação (A30).

Figura 124 - Curva tensão - deformação para compósitos

ESO-bisfenol reforçados com $30 \%$ fibras de bucha sem tratamento (U30) e tratadas por mercerização (M30) e hornificação (H30).

Figura 125 - Curva tensão - deformação para compósito de resina cardanol reforçado com fibras 30\% de bucha mercerizada (C50-M30). 163 Figura 126 - Sinal no tempo de ressonância para o compósito epóxi bisfenol/bucha natural, após a excitação por impulso mecânico.

Figura 127 - Efeito do teor de fibras nos compósitos bisfenol/bucha sem tratamento.

Figura 128 - Propriedades elásticas de compósitos com 30\% de fibras de bucha mercerizada, e matriz de resina bisfenol, ESO-bisfenol e cardanol-resorcinol. (a) Módulo (b) amortecimento

Figura 129 - Módulo de resina bisfenol e compósitos bisfenol/bucha $20 \%$, com diferentes tratamentos. Comparação da média usando o teste LSD de Fisher, com nível de significância de 0,05 . 
Figura 130 - (a) Módulo de resina bisfenol e compósitos bisfenol/Bucha 30\% com diferentes tratamentos. (b) Comparação da média usando o teste LSD de Fisher, com nível de significância de 0,05 .

Figura 131 - (a) Módulo de resinas ESO30 e ESO50 e compósitos ESO/Bucha e C50/Bucha. (b) Comparação da média usando o teste LSD de Fisher, com nível de significância de 0,05.

Figura 132 - Evolução do módulo de elasticidade em flexão com o tempo de imersão em água destilada, para compósitos com fibras de bucha sem tratamento.

Figura 133 - Evolução do módulo de elasticidade em flexão com o tempo de imersão em água destilada, para compósitos com fibras de bucha mercerizadas.

Figura 134 - Evolução do módulo de elasticidade em flexão com o tempo de imersão em água destilada, para compósitos com fibras de bucha hornificadas.

Figura 135 - Evolução do módulo de elasticidade em flexão com o tempo de imersão em água destilada, para compósitos com fibras de bucha acetiladas.

Figura 136 - Dados de módulo de elasticidade e massa dos corpos de prova de compósitos bisfenol/bucha acetilada (A20) em água de mar.

Figura 137 -Variação do módulo elástico dos materiais com a absorção em água de mar.

Figura 138 - Evolução do fator de amortecimento com o tempo de imersão em água destilada, para compósitos com fibras de bucha sem tratamento.

Figura 139 - Evolução do fator de amortecimento com o tempo de imersão em água destilada, para compósitos com fibras de bucha mercerizada.

Figura 140 - Evolução do fator de amortecimento com o tempo de imersão em água destilada, para compósitos com fibras de bucha hornificada.

Figura 141 - Evolução do fator de amortecimento com o tempo de 
imersão em água destilada, para compósitos com fibras de bucha acetilada.

Figura 142 - Valores de amortecimento para materiais depois do ensaio de absorção em água de mar.

Figura 143 - Variação do amortecimento dos materiais com a absorção em água de mar.

Figura 144 - Detalhe da superfície de fratura de resina (a) Bisfenol.

(b) ESO30. 250x.

Figura 145 - Detalhe da superfície de fratura de resina de resorcinol. 178

Figura 146 - Detalhe da superfície de fratura de resina (a) bisfenol 100x. (b) ESO30 250x.

Figura 147 - (a) Detalhe da interface fibra/resina na superfície de fratura de compósitos bisfenol com $10 \%$ de fibras de bucha sem tratamento (U10). 27x. (b) Detalhe a 45x. (c) Detalhe a 85x.

Figura 148 - (a) Superfície de fratura de compósito bisfenol com 20\% de bucha sem tratamento (U20). 50x. (b) Detalhe a 250x.

Figura 149 - Superfície de fratura de compósito bisfenol com 40\% de bucha sem tratamento (U40), 50x.

Figura 150 - (a) Superfície de fratura de compósito bisfenol com 20\% de bucha mercerizada (M20). 50x. (b) Detalhe a 250x.

Figura 151 - (a) Superfície de fratura de compósito bisfenol com $20 \%$ de bucha hornificada (H20). 40x. (b) Detalhe a 200x.

Figura 152 - (a) Superfície de fratura de compósito bisfenol com 30\% de bucha acetilada (A20). 40x. (b) Detalhe a 150x.

Figura 153 - Superfície de fratura de compósito cardanol-resorcinol com $30 \%$ de fibras de bucha mercerizadas. (a) 100x. (b)(c) 250x.

Figura 154 - Módulo de armazenamento de compósitos com 30\% de fibras de bucha mercerizada.

Figura 155 - Módulo de armazenamento de resina epóxi bisfenol e compósitos Epóxi/Bucha sem tratamento com diferentes

Porcentagens de fibra de bucha.

Figura 156 - Módulo de armazenamento de resina cardanol-

resorcinol e o compósito com $30 \%$ de fibra de bucha mercerizada.

Figura 157 - Módulo de armazenamento de compósitos de matriz 
epóxi bisfenol reforçados com $30 \%$ de fibras de bucha com e sem tratamento.

Figura 158 - Módulo de armazenamento de resina epóxi ESO30 e seus compósitos com $30 \%$ de fibras de bucha.

Figura 159 - Tan $\delta$ de resina cardanol-resorcinol e o compósito com $30 \%$ de fibras de bucha mercerizada.

Figura 160 - Tan $\delta$ de resina epóxi bisfenol e compósitos de matrix epóxi bisfenol reforçados com 10, 20 e 40\% de fibras de bucha.

Figura 161 - Valores de Tan $\delta$ para a resina de bisfenol e para os compósitos bisfenol/bucha fabricados.

Figura 162 - Valores máximos de tan $\delta$ para a resina ESO-bisfenol e compósitos ESO-bisfenol/fibras de bucha.

Figura 163 - Módulo de perda de resina epóxi bisfenol e compósitos de matriz epóxi bisfenol reforçados com 10, 20 e 40\% de fibras de bucha.

Figura 164 - Módulo de perda de compósitos de matriz epóxi bisfenol reforçados com $30 \%$ de fibras de bucha com e sem tratamento.

Figura 165 - Módulo de perda de resina ESO-bisfenol e compósitos reforçados com $30 \%$ de fibras de bucha com e sem tratamento.

Figura 166 - Módulo de perda de resina cardanol-resorcinol e compósitos com $30 \%$ de fibras de bucha mercerizadas. 


\section{Lista de Tabelas}

Tabela 1 - Resinas termoendurecíveis importantes e seu campo de aplicação [43].

Tabela 2. Composição química de Luffa cylindrica [201], [204], [206]. 59

Tabela 3 Composição química XPS de Luffa cylindrica [206]

Tabela 4 - Propriedades mecânicas em flexão de compósitos poliéster/bucha como função da concentração de $\mathrm{NaOH}$ [236].

Tabela 5 - Especificações da resina epóxi comercial MC 150/5 (Bisfenol A).

Tabela 6 - Especificações do óleo epoxidado SOYFLEX 6250 (ESO). 91 Tabela 7 - Especificações da resina NC-514 (Cardanol). 92

Tabela 8 - Especificações da resina RDGE-H (Resorcinol). 92

Tabela 9 - Especificações do agente de cura FD 144 (IPDA) 92

Tabela 10 - Especificações de agente de cura NX-5620 (Fenalcamina) 92 Tabela 11 - Formulação para a preparação de resinas a partir de óleo de soja epoxidado (ESO).

Tabela 12 - Formulação para a preparação de resinas de bisfenol A (MC150/5), cardanol (NC-514) e resorcinol (RDGE-H).

Tabela 13 - Formulação de resinas preparadas a partir de misturas de bisfenol (MC150/5) e ESO.

Tabela 14 - Formulação para a preparação de resinas com conteúdo de cardanol (NC-514) e Resorcinol (RDGE-H).

Tabela 15 - Compósitos fabricados e caracterizados.

Tabela 16 - Análise técnico da água de mar sintética Blue Treasure e água de mar natural, fornecida pelos fabricantes.

Tabela 17 - Índice de cristalinidade de fibras de bucha pelo método 1 (subtração da área amorfa).

Tabela 18 - Índice de cristalinidade de fibras de bucha pelo método 2 (deconvolução dos picos).

Tabela 19 - Índice de cristalinidade de fibras de bucha pelo método 3 (altura dos picos). 
Tabela 20 - Picos características de absorção de fibra de bucha sem tratamento $(\mathrm{N})$, Hornificadas $(\mathrm{H})$, Mercerizadas $(\mathrm{M})$ e Acetiladas (A) [162],[340][337].

Tabela 21 - Parâmetros obtidos a partir da análise térmica de fibras de bucha.

Tabela 22 - Temperaturas de início de degradação ( $\left.T_{\text {onset }}\right)$ e temperaturas de pico $\left(T_{p}\right)$ de resinas epóxi preparadas.

Tabela 23 - Resinas utilizadas para a preparação de matriz epóxi.

Tabela 24 - Parâmetros de ajuste da equação de Kissinger para as resinas Bisfenol, ESO-Bisfenol e Cardanol-Resorcinol curadas com amina IPDA.

Tabela 25 - Temperaturas de onset medidas nas curvas de E' versus temperatura.

Tabela 26 - Módulos de armazenamento (MPa) para as resinas puras a diferentes temperaturas.

Tabela 27 - Temperaturas de transição vítrea medidas nas curvas de $\tan \delta$ e E".

Tabela 28 - Resinas preparadas e usadas como matriz.

Tabela 29 - Compósitos fabricados.

Tabela 30 - Parâmetros de difusão para os compósitos bisfenol/ bucha em água destilada.

Tabela 31 - Parâmetros de difusão para os compósitos bisfenol/ bucha em água de mar.

Tabela 32 - Valores médios de parâmetros do ensaio de flexão em três pontos para resinas epóxi bisfenol, ESO-bisfenol e resorcinol. 156 Tabela 33 - Módulo elástico de resinas epóxi por TEI.

Tabela 34 - Valor médio para o módulo de elasticidade em flexão e amortecimento de compósitos.

Tabela 35 - Valor médio para o módulo de compósitos com matriz bisfenol.

Tabela 36 - Variação média do módulo elástico em função do tempo de imersão em água de mar.

Tabela 37 - Variação do módulo elástico dos materiais com a absorção em água de mar. 
Tabela 38 - Módulo de Armazenamento (MPa) para compósitos com $30 \%$ de fibras de bucha mercerizada e, matriz bisfenol, cardanol resorcinol e ESO-bisfenol.

Tabela 39 - Módulo de armazenamento (MPa) para resina bisfenol e compósitos com 10, 20 e 30\% de fibra de bucha sem tratar.

Tabela 40 - Módulo de armazenamento (MPa) para resina cardanolresorcinol e o compósito com $30 \%$ de fibra de bucha mercerizada.

Tabela 41 - Módulos de armazenamento para resina bisfenol e compósitos com $30 \%$ de fibras de bucha tratadas.

Tabela 42 - Módulos de armazenamento para resina bisfenol e compósitos com $20 \%$ de fibras de bucha.

Tabela 43 - Módulos de armazenamento para resina ESO30 e compósitos com $30 \%$ de fibras de bucha.

Tabela 44 - Temperaturas de transição vítrea medidas nas curvas de $\tan \delta$ e E".

Tabela 45 - Valores máximos de tan $\delta$ e E", temperaturas de transição vítrea medidas nas curvas de E', E” e tan $\delta$. 


\section{Siglas e Abreviaturas}

LM: Lamela média

EEW: Peso equivalente de epóxi

AHEW: Peso equivalente amina

DGEBA: Éter diglicidílico de bisfenol A

EVO: Óleo vegetal epoxidado

ESO: Óleo de soja epoxidado

TEl: Técnica de excitação por impulso

AFM: Microscopia de força atômica

TM-AFM: Modo em contato intermitente

QNM: Mapeamento de propriedades nanomecânicas

DMT: Modelo Derjaguin-Muller-Toporov

MEV: Microscopia eletrônica de varredura

EDS: Espectroscopia por dispersão de energia de raios $X$

DMA: Análise dinâmico-mecânica

DRX: Difração de raios $X$ 


\section{Introdução}

Resinas epóxi são amplamente usadas em diversas aplicações como revestimentos, adesivos, placas de circuitos e outros materiais eletrônicos [1]. O seu uso como matrizes de materiais compósitos na indústria aeroespacial e em aplicações estruturais também é bastante amplo [2], [3], [4]. O éter diglicidílico de bisfenol A (DGEBA) representa atualmente o tipo de resina epóxi mais utilizadas no mundo [5] [1] . No entanto, o principal monômero utilizado para a sua produção, o Bisfenol A (BPA), é considerado um disruptor endócrino [6], [7] com atividade estrogênica que apresenta significativos efeitos negativos na saúde humana [8], incluindo alterações no sistema imunológico, atividade enzimática e fertilidade [9], [10]. Implicações ambientais e leis que limitam o uso de BPA em vários países [11] fazem necessária a substituição dos monômeros base para a preparação de resinas epóxi por outros mais seguros e ambientalmente sustentáveis.

Óleos naturais, derivados de fontes vegetais, são considerados uma matériaprima alternativa para a obtenção de resinas epóxi de base biológica por causa da disponibilidade, preço relativamente baixo e uma ampla variedade de possibilidades para transformações químicas [12], [5], [13], [14], [15]. Além disso, resinas epóxi preparadas a partir de fontes renováveis vegetais constituem uma alternativa ao uso de resinas derivadas do petróleo na produção de polímeros reforçados por fibras (PRF) [16], [17].

Por outro lado, por ser um país com elevado potencial agrícola e biodiversidade, o Brasil tem evidentes oportunidades de desenvolver compósitos, por meio da exploração sustentável de uma grande variedade de fibras lignocelulósicas, com possibilidades de aplicação como elemento de reforço de resinas termo-endurecíveis [18]. Consequentemente, materiais compósitos fabricados a partir de resinas termo-endurecíveis de origem vegetal e fibras lignocelulósicas como material de reforço, poderiam contribuir com a produção sustentável de materiais de baixo custo que possuam propriedades estruturais funcionais [19] [20], [21]. A bucha (Luffa cylindrica) é um material lignocelulósico que tem sido considerado para seu uso como reforço de compósitos de matriz polimérica, pois apresenta como vantagem sua estrutura característica de manta 
natural contínua [22]. A planta de luffa possui frutos com uma estrutura fortemente fibrosa, de grande compactação, resistente e durável, com baixa densidade, elevada área superficial por volume, e custo razoável, o que torna o seu uso uma alternativa natural em diferentes aplicações, tal como artigos esportivos, fabricação de material de embalagem, isolamentos acústicos e térmicos, dispositivos médicos e de filtragem, entre outras [23], [24] [25].

Apesar das vantagens significativas do uso de materiais naturais, existem algumas desvantagens relacionadas com a fraca interação na interface fibra lignocelulósica/matriz epóxi. Por outro lado, a alta absorção de umidade de materiais lignocelulósicos pode resultar em inchamento das fibras e afetar a estabilidade dimensional do compósito. Assim, para a aplicação destas fibras como material de reforço, é importante a realização de tratamentos superficiais para promover melhoras de adesão na interface fibra/matriz [26].

Por meio deste trabalho propõe-se a preparação de materiais compósitos, usando como matriz resinas epóxi obtidas a partir de óleo de soja epoxidado e cardanol epoxidado, proveniente da casca de castanha de caju, assim como fibras lignocelulósicas de bucha modificadas superficialmente mediante tratamentos de hornificação, mercerização e acetilação.

Materiais compósitos com fibras naturais têm sido utilizados nos últimos anos na indústria automotiva para a fabricação de algumas partes da carroceria [27]. No Brasil, fibras de bucha e seus compósitos com baixa densidade poderiam ter aplicação para a substituição total ou parcial de materiais tradicionais na fabricação de elementos para esportes náuticos tais como pranchas e quilhas para surf, diminuindo os custos de fabricação e conferindo um valor adicional aos produtos finais pelo uso de materiais sustentáveis e abundantes no pais [28], [29], [30] .

Os efeitos estruturais, morfológicos e térmicos dos tratamentos superficiais nas fibras foram estudados usando espectroscopia no infravermelho por transformada de Fourier (FTIR), difração de raios X (DRX), microscopia eletrônica de varredura (MEV) e análise termogravimétrica (TGA). Compósitos DGEBA/Bucha e Resina natural/Bucha foram fabricados pelo método lay-up manual e foi avaliado o efeito da porcentagem de fibras e dos tratamentos 
superficiais nas propriedades mecânicas por meio de ensaios de flexão e a técnica não destrutiva de excitação por impulso (TEI). Esta técnica também foi utilizada para a determinação experimental dos módulos dinâmicos e as propriedades de amortecimento dos laminados obtidos durante o envelhecimento por absorção de água. A morfologia das superfícies fraturadas assim como as propriedades viscoelásticas dos compósitos laminados obtidos, foram caracterizadas por microscopia eletrônica de varredura (MEV) e análise dinâmico-mecânica (DMA), respectivamente. Analisando-se comparativamente as curvas DMA para os compósitos, obteve-se o efeito causado, pela introdução das fibras de bucha e pelos diferentes tratamentos realizados nas fibras, no comportamento dinâmicomecânico. 


\subsection{Objetivo Principal}

O objetivo principal deste trabalho é desenvolver e caracterizar materiais compósitos com matriz epóxi obtida a partir de fontes naturais, reforçados com fibras de bucha vegetal.

\subsection{Objetivos Específicos}

- Caracterizar as propriedades das fibras de bucha tratadas e não tratadas.

- Modificar superficialmente fibras de bucha por mercerização, hornificação e acetilação e comparar o seu efeito sobre o comportamento mecânico dos compósitos obtidos.

- Fabricar materiais compósitos de matriz epóxi reforçada com fibras de bucha modificadas superficialmente e investigar o seu efeito sobre as propriedades térmicas e mecânicas dos compósitos obtidos.

- Comparar as propriedades mecânicas, térmicas e de absorção de água dos compósitos obtidos com outros materiais reforçados com fibras vegetais

- Avaliar a variação do módulo elástico dos compósitos em função do tempo de envelhecimento por técnica não destrutiva.

- Caracterizar resinas epóxi derivadas de óleo de soja epoxidado e de cardanol epoxidado, utilizando diferentes agentes de cura. 


\section{Revisão Bibliográfica}

\subsection{Materiais Compósitos}

Os materiais compósitos, consistem essencialmente em uma matriz ou fase contínua, que pode ser polimérica, metálica ou cerâmica, e um reforço que pode ter várias morfologias, como apresentado na classificação mostrada na Figura 1. Ao conjugar as propriedades de dois tipos de constituintes distintos se busca obter um material com propriedades superiores, portanto, os materiais compósitos têm uma ampla gama de aplicações em diversas áreas [31].

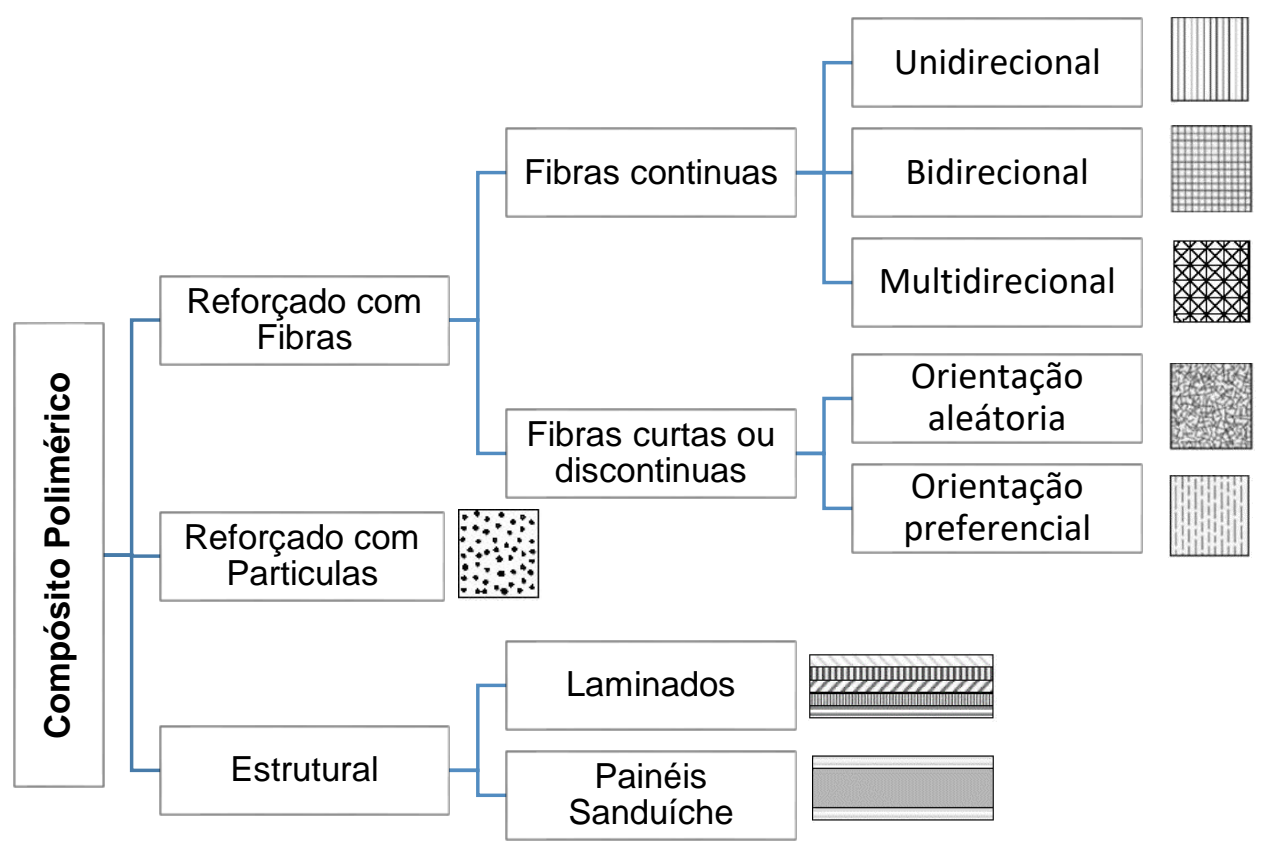

Figura 1 - Classificação de compósitos poliméricos convencionais, segundo a disposição do reforço [12].

A indústria dos polímeros reforçados com fibras (PRF) foi desenvolvida a partir da década de 1940 com a fabricação de materiais compósitos reforçados com fibras sintéticas [32]. As fibras nestes materiais são os elementos que suportam a carga e fornecem resistência e rigidez, enquanto a matriz polimérica atua como o elemento que transfere as tensões externamente aplicadas às fibras [33] e, no caso de reforços vegetais, têm como função os proteger da degradação ambiental. PRF's têm sido usados em diferentes aplicações domésticas e industriais, adaptando-se e melhorando suas propriedades continuamente [17]. Os desenvolvimentos em tecnologia de materiais compósitos reforçados com fibras ocorreram 
essencialmente durante os últimos 20-30 anos, principalmente nas indústrias da aviação e biomédica [31] . No esquema da Figura 2 aparecem diferentes tipos de fibras utilizados como reforços de materiais compósitos. As mais utilizadas têm sido as fibras sintéticas de carbono, de vidro e aramidas (Kevlar), as quais são produzidas com uma faixa de propriedades bem definidas [34].

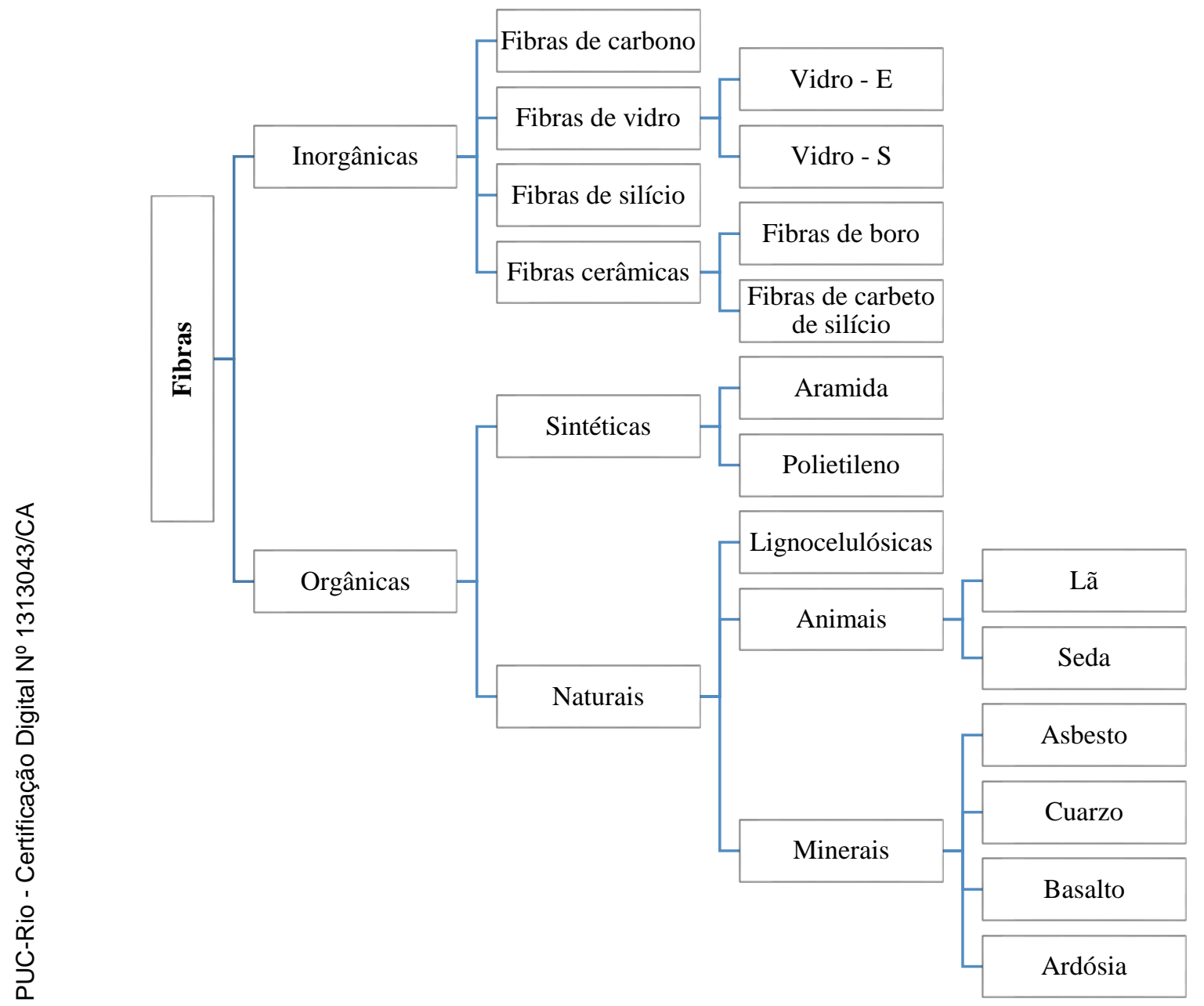

Figura 2 - Classificação de fibras usadas como fase de reforço em materiais compósitos.

Contudo, ao longo das últimas décadas, nota-se um crescente interesse em fibras lignocelulósicas como substituto das fibras sintéticas devido a seu menor custo, origem renovável, alto desempenho mecânico e baixo peso [21], [35], [36], [37], [38], [39], [40].

O desempenho mecânico de materiais compósitos é geralmente associado com as propriedades de seu reforço. No entanto, os materiais usados como matriz também desempenham um papel importante [33]. Os compósitos poliméricos podem ser classificados com base no tipo de polímero usado como matriz, termoplástico ou termoendurecível. Enquanto os polímeros termoplásticos podem 
ser moldados várias vezes, devido à sua característica de se tornarem fluidos com o aumento da temperatura e se solidificarem com o decréscimo da mesma, os termofixos não apresentam este comportamento devido às ligações cruzadas entre as cadeias moleculares [34]. No entanto, termofixos são frequentemente selecionados para a fabricação de compósitos poliméricos avançados por sua vida útil longa e alta resistência química [41].

\subsection{Polímeros termofixos}

Os primeiros passos para o desenvolvimento dos chamados polímeros termofixos, termorrígidos ou termoendurecíveis, foram feitos a partir do descobrimento do processo de vulcanização da borracha natural em 1839 por Goodyear nos Estados Unidos e por Hancock na Inglaterra, originando as primeiras experiências em torno das reações de reticulação [42]. Contudo, foi apenas em 1909 que Leo Baekeland patenteou um processo de cura por ativação térmica e de pressão de resinas fenólicas, assim como o processo de moldagem, que permitiram produzir artigos úteis para o comércio, dando início à indústria de plásticos termofixos. Esta resina fenol-formaldeído tornou-se amplamente conhecida sob o nome de baquelita. Na década de 1940 foram fabricados pela primeira vez em larga escala poliésteres insaturados, especialmente na forma de compósitos de fibra de vidro, para aplicação na indústria naval. Finalmente, os polímeros epóxi foram introduzidos comercialmente em 1947 [42]. A particularidade que caracteriza essencialmente estes materiais é a presença de uma rede densamente reticulada formada por ligações covalentes entre cadeias lineares poliméricas ou pela reação de reagentes monoméricos numa configuração tridimensional, que dificulta ou mesmo impede movimentos macromoleculares e o escorregamento intermolecular [43]. Quanto maior o número de grupos funcionais presentes nos reagentes, maior será o potencial de reticulação da reação [42].

As reações de reticulação, ocorrem com mais facilidade e rapidez na presença do calor podendo ocorrer também em temperatura ambiente. Devido à irreversibilidade da reação em uma escala macro, são materiais cuja fase final de produção é caracterizada por uma insolubilidade e infusibilidade substancial, de modo que, uma vez reticulados, não podem ser processados reversivelmente a temperaturas elevadas [42]. Embora não seja possível a reciclagem de termofixos 
por processos tradicionais, estas resinas possuem vantagens significativas sobre os termoplásticos, incluindo maior estabilidade dimensional, alta resistência à fluência, menor escoamento sob tensão, maior resistência aos solventes e, em geral, um menor coeficiente de expansão térmica [44]. Por outro lado, ao contrário dos termoplásticos que, por definição, são reversivelmente fusíveis e usualmente de elevado peso molecular e alta viscosidade, as resinas termofixas são formadas de forma irreversível a partir de precursores de baixo peso molecular e baixa viscosidade, o que permite que concentrações mais elevadas de fibras ou cargas sejam incorporadas em matrizes de materiais compósitos, mantendo ainda uma boa molhabilidade das fibras e dispersão das cargas [44]. As principais resinas termoendurecíveis usadas como matrizes em compósitos são listadas na tabela 1 [43].

Tabela 1 - Resinas termoendurecíveis importantes e seu campo de aplicação [43].

\begin{tabular}{|c|c|c|}
\hline Resina & Precursores & Aplicações \\
\hline Epóxi & $\begin{array}{l}\text { Epicloridrina } \\
(\mathrm{ECH}) \text { e bisfenóis }\end{array}$ & $\begin{array}{c}\text { Compósitos para a indústria automotiva, construção } \\
\text { naval e aplicações aeroespaciais, engenharia de } \\
\text { adesivos, tintas e revestimento de superfície, } \\
\text { laminados elétricos. }\end{array}$ \\
\hline Fenólica & $\begin{array}{l}\text { Fenol e } \\
\text { formaldeído }\end{array}$ & $\begin{array}{c}\text { Compósitos para eletrodomésticos, automóveis, } \\
\text { construção de aeronaves e acessórios, indústria } \\
\text { elétrica e de iluminação, adesivos para madeira, } \\
\text { compósitos de moldagem, ligantes de fundição, } \\
\text { moldes laminados. }\end{array}$ \\
\hline $\begin{array}{l}\text { Poliéster não } \\
\text { saturado }\end{array}$ & $\begin{array}{l}\text { Ácidos } \\
\text { dicarboxílicos, } \\
\text { dióis e diluentes } \\
\text { reativos }\end{array}$ & $\begin{array}{l}\text { Compósitos para equipamentos mecânicos e } \\
\text { construção de edifícios, indústrias eléctricas e de } \\
\text { iluminação, revestimentos de superfície }\end{array}$ \\
\hline Vinil-éster & $\begin{array}{l}\text { Resina epóxi e } \\
\text { ácido acrílico ou } \\
\text { metacrílico }\end{array}$ & $\begin{array}{c}\text { Compósitos para equipamentos mecânicos e } \\
\text { construção de edifícios, construção naval, indústrias } \\
\text { eléctricas }\end{array}$ \\
\hline $\begin{array}{l}\text { Poliuretano } \\
\text { (PU) }\end{array}$ & $\begin{array}{l}\text { Diisocianato e } \\
\text { oligômero } \\
\text { funcionalizado com } \\
\text { hidroxila (poliol) }\end{array}$ & $\begin{array}{l}\text { Revestimentos, adesivos, materiais encapsulantes, } \\
\text { cimentos resistentes a ácidos, espumas, adesivos. }\end{array}$ \\
\hline Poliimidas & $\begin{array}{l}\text { Diaminas e } \\
\text { dianidrido }\end{array}$ & $\begin{array}{c}\text { Revestimentos e compósitos para aplicações de alta } \\
\text { temperatura }\end{array}$ \\
\hline Furano & Álcool furfurílico & $\begin{array}{c}\text { Compósitos, processamento de materiais refratários, } \\
\text { compósitos de moldagem, rodas de moagem, } \\
\text { cimentos resistentes a ácidos }\end{array}$ \\
\hline
\end{tabular}


Entre os termo-endurecíveis, as resinas epóxi representam um dos grupos mais importantes, devido à grande variedade de propriedades que esses materiais podem exibir, como consequência da variedade de sistemas epóxi-endurecedor que existe, bem como a influência de variáveis de processamento, como a razão epóxi/endurecedor e o tempo e temperatura de cura, sobre as propriedades finais mostradas pelas resinas [33]. A seguir se apresenta uma breve descrição sobre a química, propriedades e aplicações de resinas epóxi termo-endurecíveis.

\subsubsection{Resinas Epóxi (RE)}

As resinas epóxi (RE) são polímeros termofixos de grande interesse na indústria pela versatilidade e por suas propriedades [2]. Uma quantidade considerável de produtos fabricados com resinas epóxi têm sido utilizados em diferentes aplicações nas indústrias de construção, aeroespacial, automotiva, naval, elétrica/eletrônica e de consumo doméstico [2], [5], [45]. O termo genérico epóxi (ou epóxido) é usado para definir tanto resinas de base (não curadas) quanto resinas reticuladas, produto das reações de cura [5], [44].

Quimicamente, um epóxido contém mais do que um grupo funcional epóxi situado terminalmente, cíclica ou internamente numa molécula. Um dos grupos epóxi mais comuns é o óxido de etileno, que se refere a um anel químico triangular formado por um átomo de oxigênio ligado a dois grupos radicais (Figura $3 a$ ). Este grupo conhecido também como anel oxirano é altamente reativo e sofre reações de abertura do anel com certa facilidade. Outra forma, não menos comum, de surgirem estes grupos é sob a forma de glicidil ou grupo glicidilo (Figura 3b) [5].

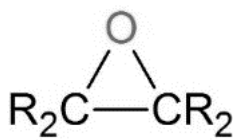

$a$

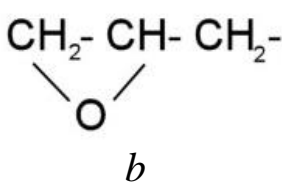

$b$

Figura 3 - Estrutura de grupos epóxi funcionais $a$ ) oxirano. $b$ ) glicidil

A maior produção comercial de resinas epóxi no mundo tem sido baseada no produto da reação entre o 2,2-bis(4-hidroxifenil)propano (Bisfenol A) e a 1chloropropene 2-oxide (Epicloridrina), cuja estrutura química se apresenta na Figura 4. O produto final consiste numa família de epóxidos com grau de 
polimerização $(n)$ variável entre 0 a 12 , sendo o mais comum o diglicidil éter de bisfenol A (DGEBA) com $n \approx 0.2$. O valor de $n$ pode ser ajustado alterando as condições de síntese, sendo que quando $(n<0,5)$ as resinas são líquidas [46].

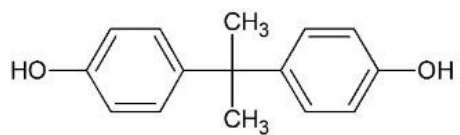

$a$

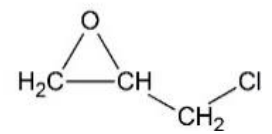

$b$

Figura 4 - Representação da estrutura química de $a$ ) Bisfenol A e b) Epicloridrina [4].

A Figura 5 apresenta o mecanismo das reações químicas entre bisfenol A e epicloridrina (ECH). A molécula de bisfenol A está em sua forma aniônica (os átomos de hidrogênio dos grupos fenol são retirados, deixando uma carga negativa sobre os átomos de oxigênio), e assim cada molécula de Epicloridrina pode se ligar a duas moléculas do ânion do bisfenol A. As ligações podem ocorrer através de uma reação de substituição nucleofílica de segunda ordem, com a saída do grupo cloreto ou através da abertura do anel epóxido quando o átomo de oxigênio deixa o átomo de carbono deficiente de elétrons. Uma vez formada a estrutura Epicloridrina bisfenol A - Epicloridrina a reação continua e como resultado é obtido o DGEBA [47].

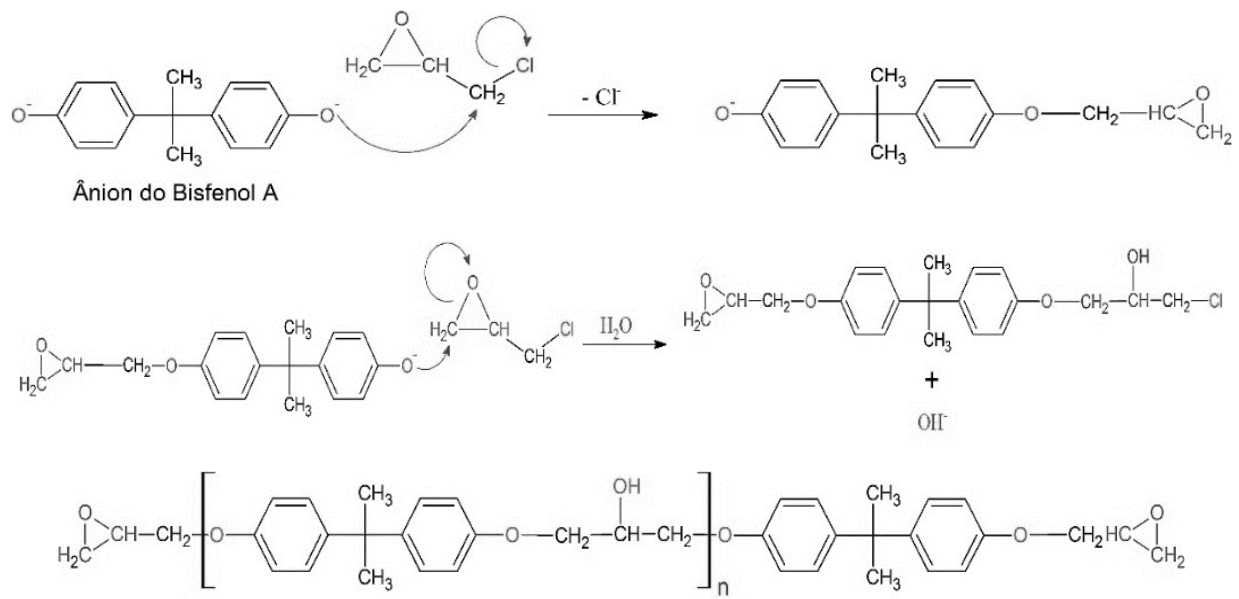

Figura 5- Representação esquemática do mecanismo de reação simplificada de epicloridrina e bisfenol A [47].

No entanto, também é possível obter outro tipo de resina epóxi pela epoxidação direta das ligações duplas dos ácidos graxos de óleos vegetais, como se verá na seção 2.2.1.1. 
Produtos de base petroquímica têm requisitos de energia bruta mais elevados do que os produtos químicos derivados da biomassa [48]. A epicloridrina obtida a partir de glicerol renovável (subproduto da produção de biodiesel), como se mostra na Figura 6, é comercialmente disponível e pode ser usada para obter DGEBA parcialmente bio-baseado [49].
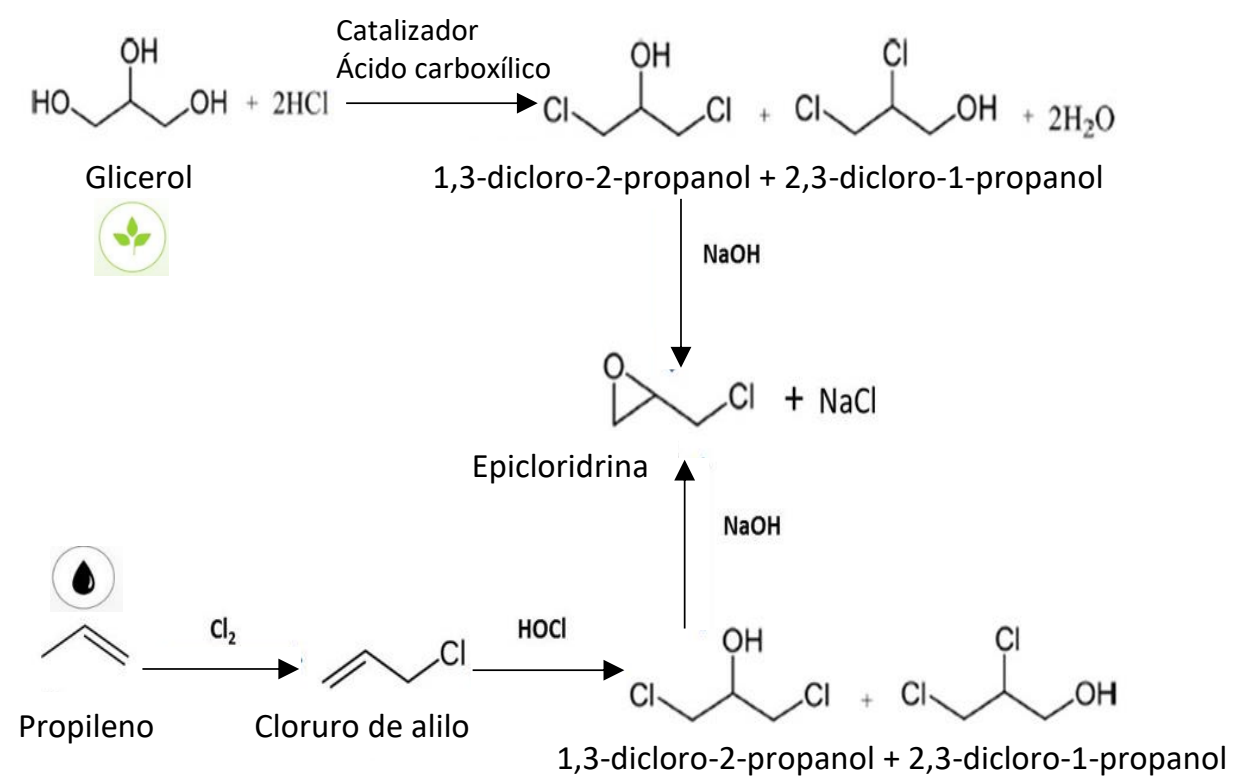

Figura 6 - Rotas renovável e petroquímica para a obtenção de epicloridrina. Adaptado de [50].

Alguns recursos renováveis estudados para a síntese de pré-polímeros epóxi e agentes de cura bio-baseados aparecem no esquema da Figura 7. Estes prépolímeros, combinados com uma grande variedade de reagentes, podem formar resinas epóxi cujo desempenho dependerá da estrutura do pré-polímero epóxi, da natureza do agente de cura, da extensão e da densidade de reticulação. Utilizando agentes de cura bio-baseados, também é possível obter redes epóxi totalmente biobaseadas. 


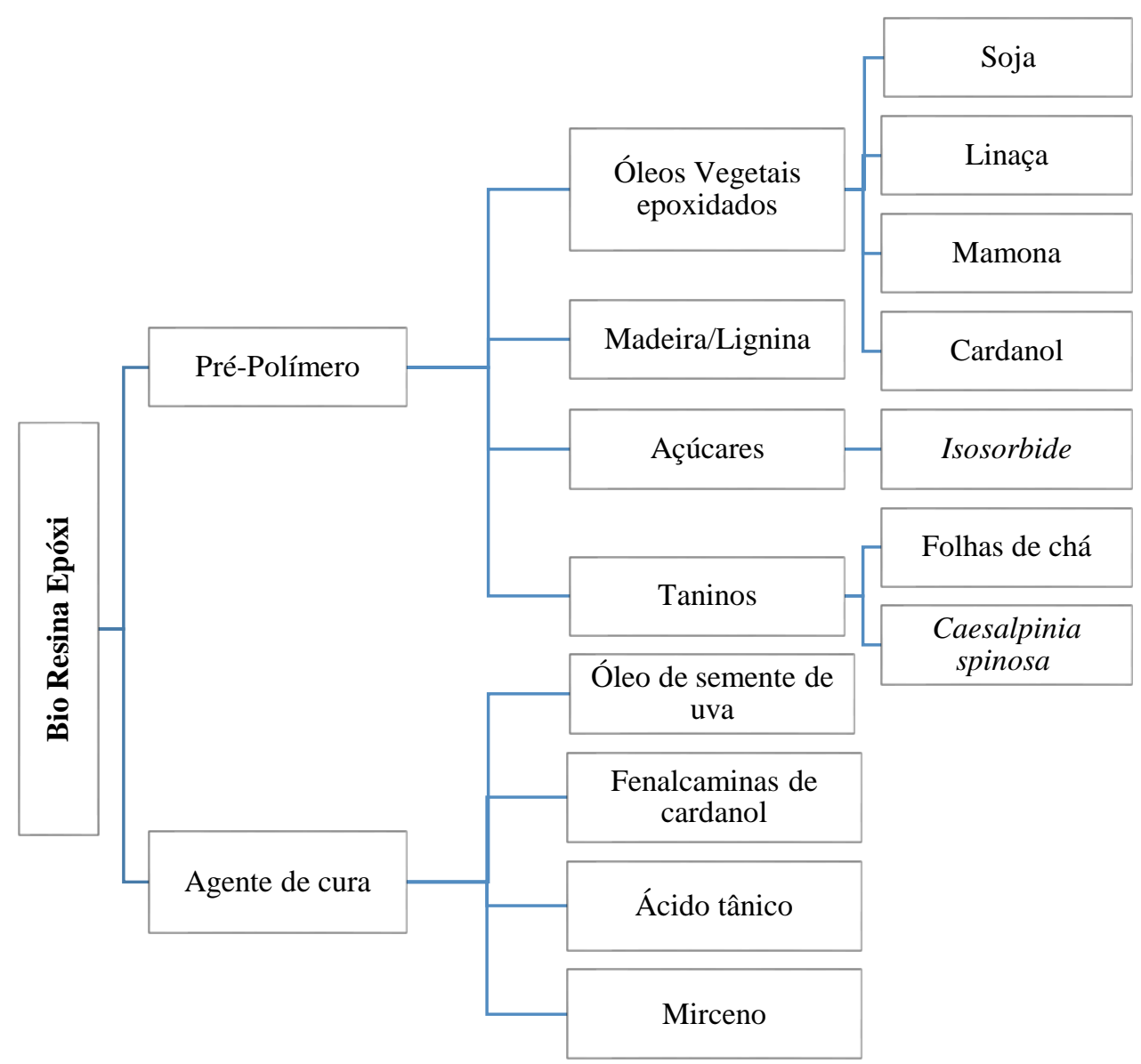

Figura 7 - Recursos renováveis para a síntese de pré-polímeros epóxi e agentes de cura bio-baseados [51], [52], [53], [54],[55],[56],[57].

\subsubsection{Resinas Epóxi derivadas de óleos vegetais epoxidados}

Cerca de 180 milhões de toneladas de óleos vegetais foram produzidos em 2015/2016 no mundo e, como aparece na Figura 8, quatro espécies vegetais representam 78\% dessa produção: palma, soja, colza (canola) e girassol. A produção de soja no Brasil em 2015, foi de 96,5 milhões de toneladas métricas em 2015 [58].

Como o segundo maior produtor de soja no mundo, o Brasil responde por $30 \%$ da produção global de soja e 18,4\% de óleo de soja. Cerca de $12 \%$ das exportações de óleo de soja no mundo são realizadas pelo Brasil [59]. Em 2015 as exportações de óleo de soja totalizaram 163.500 toneladas, 151,2\% acima do ano anterior [60], com rendimento de US\$ 1,17 bilhão, de acordo com dados do MIT[59]. 


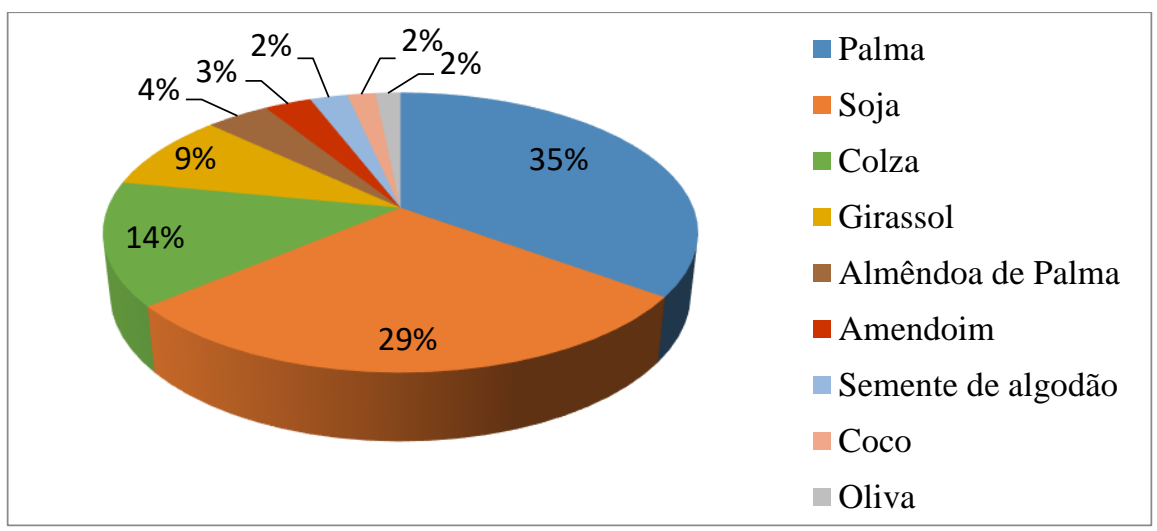

Figura 8 - Produção mundial de óleos vegetais 2016/17.

Óleos vegetais são formados principalmente por triglicérides (Figura 9). Um triglicéride é um éster formado pela poli condensação de uma molécula de glicerol com três moléculas de ácidos graxos [61]. A molécula de glicerol contém três grupos hidroxila (-OH), enquanto que nos ácidos graxos, o grupo carboxila ($\mathrm{COOH})$, está ligado a uma cadeia alifática longa, não ramificada. O comprimento desta cadeia alifática varia numa vasta gama, mas em óleos vegetais comuns o comprimento da cadeia compreende usualmente de 14 a 22 átomos de carbono [62].<smiles>CC(=O)OCC(COC(C)=O)OC(C)=O</smiles>

Figura 9 - Estrutura molecular de um triglicérido ( $\mathrm{R}$ representa as cadeias de hidrocarbonetos de ácidos graxos)

Os ácidos graxos podem ser saturados, assim como mono, di- ou triinsaturados, dependendo do número de ligações duplas nas cadeias alifáticas. $\mathrm{O}$ gráfico da Figura 10 apresenta o conteúdo de ácidos graxos em alguns óleos vegetais [63] (tendo em vista que, o termo C18 indica o número de átomos de carbono e o número depois dos dois pontos indica o número de ligações duplas). Enquanto que a estrutura dos principais ácidos graxos presentes em óleos vegetais é apresentada nas Figuras 11 e 12. 


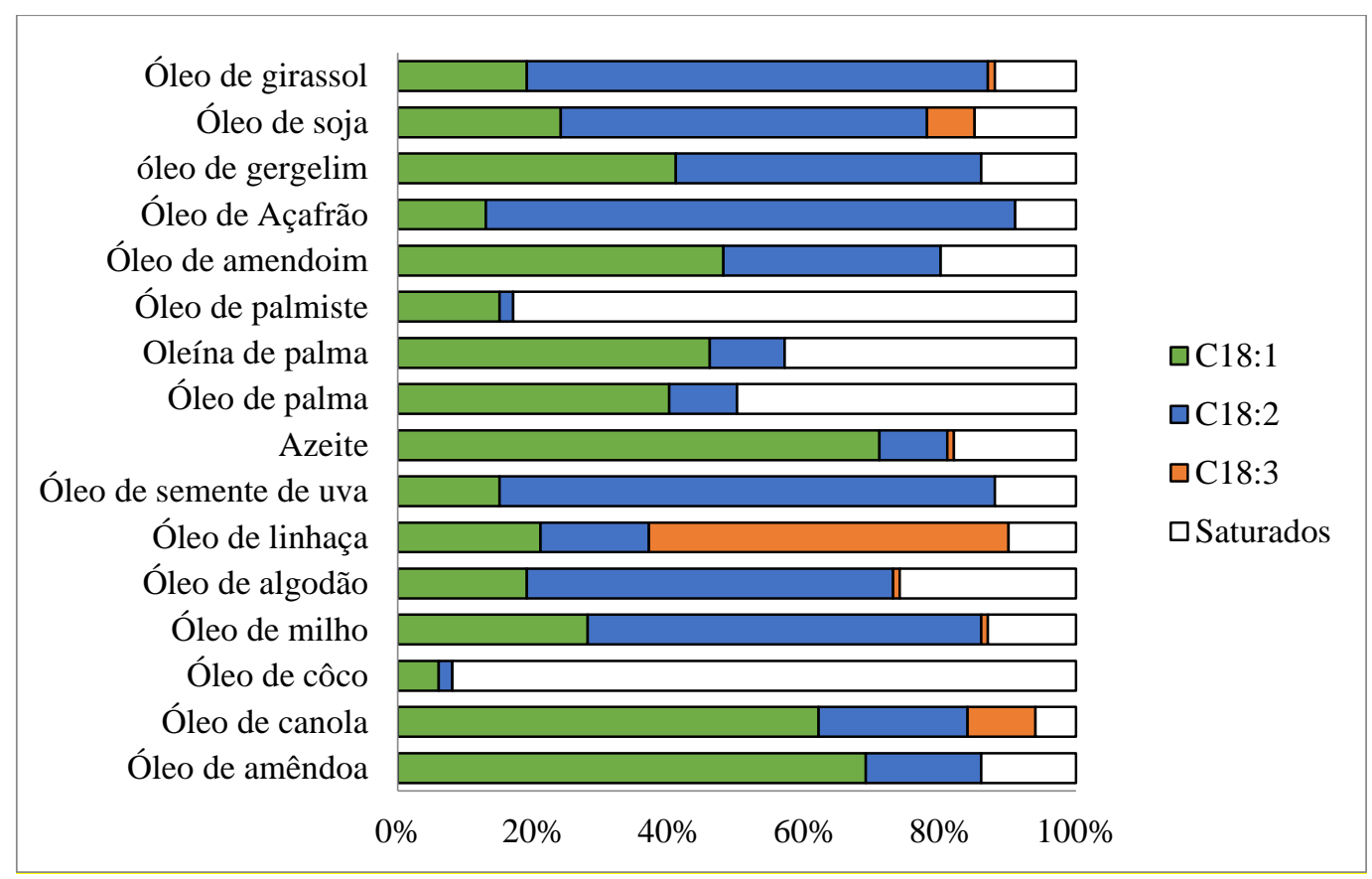

Figura 10 - Composição de ácidos graxos de óleos vegetais comuns [64], [65].<smiles>CC/C=C/C=C/C/C=C/CCCCCCCCC(=O)O</smiles>

Figura 11 - Estrutura de ácidos graxos insaturados comuns em óleos vegetais. a) Ácido oleico (C18:1). b) Ácido linoleico (C18:2). c) Ácido linoloneico (C:18:3)

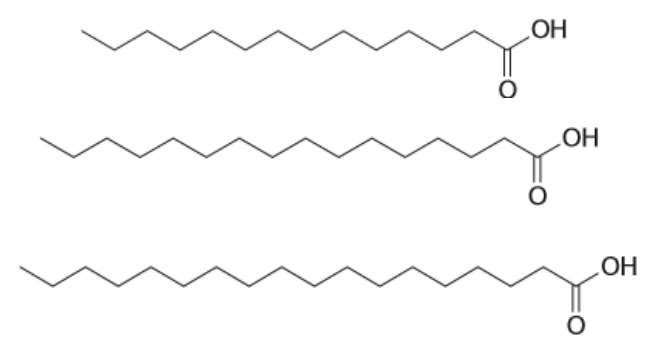

(a)

Figura 12 - Estruturas químicas de ácidos graxos saturados presentes nos óleos vegetais mais representativos a) ácido mirístico b) ácido palmítico c) ácido esteárico.

A epoxidação é uma das reações de funcionalização mais importantes em óleos vegetais [12]. Óleos vegetais epoxidados (EVO) oferecem matéria prima renovável e de baixo custo, promissora para muitas aplicações industriais [66], [67]. Esses óleos epoxidados têm sido tradicionalmente usados como lubrificantes [68], [69], plastificantes e estabilizadores [70], em formulações para tintas e recobrimentos [71], [72] e como diluentes em resinas epóxi derivadas de petróleo [73], [74] entre outros. No entanto, nos últimos anos o uso de EVO's tem se 
estendido também à produção de resinas epóxi sustentáveis, porque compartilham muitas das características das resinas epóxi termoendurecíveis convencionais derivadas de petróleo [14] e são uma boa alternativa para reduzir o impacto ambiental negativo, uma vez que são obtidos a partir de recursos renováveis [74], [56], [75], [76]. Aliás, reporta-se a preparação de pré-polímeros epóxi a partir de diversas fontes vegetais tais como EVOs de sementes de soja [77], [78], linhaça [79], girassol [80], mamona [81], [78], colza (canola) [80], algodão [82], fruta do conde [83], crambe [84], Mesua férrea [85], mahua (Madhuca longifolia) [86], Pongamia (Millettia pinnata), Vernonia galamensis [87], dentre outras fontes.

Os ácidos graxos presentes em óleos vegetais possuem ligações duplas entre átomos de carbono, que dão a possibilidade de modificar a sua estrutura química pelo método de epoxidação, que forma anéis oxirano onde anteriormente havia ligações $(C=C)$ [88], [89]. A epoxidação de óleos vegetais pode ser realizada por diferentes reações [74], [90]; a mais comum é a reação de Prileschajew, conduzida na presença de perácidos (ácido peracético ou ácido performico) [91]. No entanto, a utilização de ácidos fortes pode conduzir à formação de subprodutos indesejáveis, tais como epóxidos de anel aberto [91]. Outras vias para a obtenção de EVOs inclui o uso de resinas de troca iônica [92], enzimas [93], peróxido de hidrogênio [94] catalizadores heterogêneos e outros [95], [12], [96]. Resinas epóxi do tipo diglicidil éter podem ser obtidas a partir de óleos vegetais pelo produto da condensação de monoglicéridos de óleo vegetal com epicloridrina na presença ou ausência de outro diol convencional (bisfenol) [74].

Como foi abordado anteriormente, o óleo de soja é um recurso renovável abundante e é considerado um dos óleos vegetais mais importantes em termos de quantidade produzida e uso a nível industrial [61]. Possui um conteúdo de ácidos graxos insaturados (oleico, linoleico e linolênico) de aproximadamente $85 \%$ (Figura 10). Este alto grau de instauração possibilita a sua polimerização [97]. Na Figura 13 aparece a estrutura química simplificada do óleo de soja e o óleo de soja epoxidado (ESO).
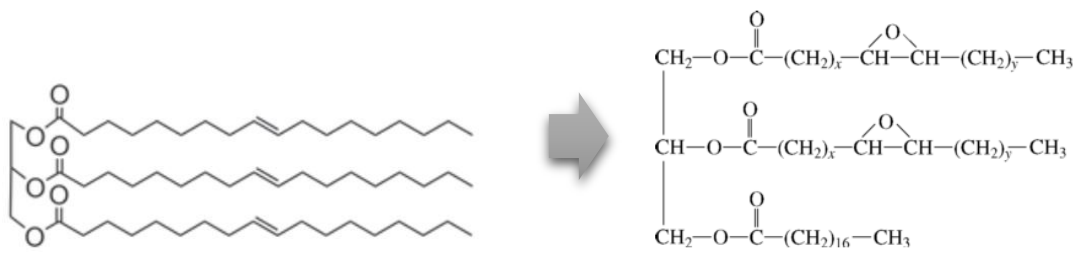

Figura 13 - Epoxidação de óleo de soja [98] 
Alguns óleos vegetais epoxidados estão disponíveis comercialmente. O SOYFLEX 6250 é um óleo de soja epoxidado (ESO) com uma funcionalidade de 4.1 - 4.6 anéis epóxi por triglicéride. O óleo de linhaça epoxidado (ELO), com alto teor de epóxi, também está disponível comercialmente como Vikoflex 7190.

A reticulação das cadeias de triglicérides de óleos vegetais epoxidados é possível quebrando o anel oxirano e incorporando agentes de reticulação convencionais, tais como aminas e anidridos [99], [100]. Outros agentes de reticulação que têm sido estudados compreendem catalisadores termicamente latentes (e.g. hexafluoroantimonato de benzilsulfônio) [101], sistemas diamina/ácido [83] e outros [74]. Alternativas para a reticulação de óleos vegetais epoxidados com agentes de cura ambientalmente amigáveis são encontradas também [102], [103]. Crivello et al. (1997) realizaram a cura de óleos de soja e linho epoxidados utilizando irradiação de luz visível e ultravioleta [104]. Stemmelen, M. et al. (2011) estudaram a obtenção de resinas epóxi verdes utilizando óleo de sementes de uva funcionalizado com grupos amina como agente de cura de óleo de linho epoxidado [54].

A obtenção de resinas epóxi baseadas em óleo de soja epoxidado (ESO) curado com anidridos e aminas foi estudada nos últimos anos [61]. Petzhold et al. (2002) realizaram a caraterização térmica e dinâmico-mecânica de resinas termoendurecíveis preparadas a partir de óleo de soja epoxidados (ESO) curado com anidridos cíclicos (ftálico, hexahidroftálico, maleico, dodecenilsuccínico e succínico), na presença de aminas terciárias. Foi encontrada uma variação nas propriedades dependendo do tipo de anidrido utilizado, da relação molar anidrido/epóxido e do teor de grupos epóxi. Foram obtidos materiais com menores $\mathrm{Tg}$ e densidades de reticulação para resinas curadas com anidrido succínico e dodecenilsuccínico e uma diminuição da $\mathrm{Tg}$ com a diminuição da razão anidrido/epóxi para $r=0,5$ e do grau de epoxidação dos óleos de soja utilizados [99].

Contudo, devido à cadeia alifática flexível longa do óleo de soja, resinas convencionais baseadas em petróleo são frequentemente utilizadas junto com ESO para obter a rigidez e resistência necessárias para algumas aplicações finais [55]. As resinas epóxi convencionais geralmente possuem uma boa miscibilidade com o ESO e suas misturas podem ser co-reticuladas numa matriz homogênea usando endurecedores utilizados para resinas epóxi tradicionais [105]. Ratna e Banthia 
(2000) modificaram uma resina epóxi do tipo éter diglicidílico de bisfenol A, curada com Tris-2,4,6- (N, N-dimetilamino metil) fenol, usando ESO. A resistência ao impacto e a força de junção adesiva da resina epóxi foram melhoradas e foi reportado que com adição de uma concentração de $20 \%$ em peso de ESR foram obtidas as resistências ao impacto máximas [98].

Park et al. (2004) utilizaram ESO em diferentes concentrações para a modificação da resina epóxi 4,4-tetra-diglicidil-diaminodifenilmetano (TGDDM), encontrando que as propriedades de flexibilidade e tenacidade das resinas foram melhoradas com adição de até $10 \%$ de ESO. Os resultados indicaram uma superioridade do ESO frente às borrachas liquidas como modificadores da dureza [106]. Park et al. (2008) também reportaram melhoras significativas na resistência ao impacto Izod e na resistência ao cisalhamento de resinas epóxi de éter diglicidílico de bisfenol A (DGEBA) com teores ESO de até $40 \%$ em peso. As composições resultantes exibiram propriedades mecânicas comparáveis com resinas epóxi derivadas de petróleo, com relativamente baixa adsorção de água e resistência química elevada [107].

Chandrashekhara et al. (2005) têm estudado as propriedades térmicas e dinâmico-mecânicas de sistemas epóxi, obtidos da mistura de resina Shell Epon 9500 com resinas baseadas em óleo de soja [108]. Estas resinas foram preparadas pela transesterificação de óleo de soja seguida pela epoxidação dos ésteres de ácidos graxos com grupos alilo e metil, EAS e EMS respetivamente [109] [110]. Os agentes de cura usados foram uma amina alifática e anidrido ftálico. Como resultado obtiveram uma vasta gama de materiais poliméricos com diferentes propriedades mecânicas dependendo da concentração de EAS e EMS, que mostraram eficiência no amortecimento de ruído e vibração [111]. Por outro lado, também foi estudado o efeito da adição destes sistemas epóxi nas propriedades de uma resina epóxi à base de bisfenol-A, encontrando uma melhora na resistência à ruptura, resistência à flexão, resistência ao impacto e um aumento na tenacidade à fratura que foi atribuída ao menor grau de reticulação [112].

Resinas epóxi foram obtidas a partir de óleos epoxidados de soja e de mamona na presença de anidridos por Park et al. (2008). As propriedades termomecânicas do material obtido pela combinação de estes EVOs com DGEBA foram estudadas e se encontrou que a estabilidade térmica dos sistemas diminuiu à medida que o teor de EVO aumentou, devido à baixa densidade de reticulação do sistema 
DGEBA/EVO [113]. Erhan et al. (2010) reportaram a síntese de polímeros baseados em óleo de soja com agentes de cura amina com altos pesos moleculares utilizando métodos de polimerização catiônica [114]. Gupta et al. (2011) prepararam resinas epóxi a partir da reação de ESO com um agente de cura anidrido e verificaram que a variação da relação anidrido/epóxi entre 0,7 e 1,3 teve um efeito significativo na temperatura de transição vítrea das resinas obtidas [115]. Através da modificação destes sistemas baseados em ESO, usando uma resina epóxi convencional (DGEBA) em proporção variável, obtiveram também uma melhoria no módulo de armazenamento e a densidade de reticulação com um aumento no teor de endurecedor de reticulação mais elevadas [105], [115]. Formulações preparadas por Altuna et al. (2011) pela substituição parcial de pré-polímero DGEBA com quantidades variáveis de ESO, utilizando anidrido metiltetrahidroftálico (MTHPA) como agente de cura resultaram em resinas epóxi termoendurecíveis e transparentes. Observou-se que as propriedades mecânicas de impacto, a temperatura de transição do vítrea e a densidade de reticulação das resinas totalmente curadas não foram alteradas significativamente, com substituição de até $40 \%$ de DGEBA por ESO na formulação. O valor de E' no estado vítreo foi de $93 \%$ do valor para a resina DGEBA pura, a $\mathrm{Tg}$ diminuiu apenas $11^{\circ} \mathrm{C}$ aproximadamente, e a resistência ao impacto aumentou cerca de 38\% [100].

España et al. (2012) estudaram a influência da razão ESO/anidrido nas propriedades mecânicas de resinas curadas com anidrido maleico. Encontraram que os materiais preparados com uma razão 1:1 obtiveram as melhores resultados de módulo em flexão, dureza Shore D e impacto Charpy [116]. Resinas epóxi glicidil éster foram obtidas a partir de ácidos graxos epoxidados derivados de óleo de soja (EGS) e óleo de linhaça (EGL). A caraterização revelou que os produtos apresentaram um maior teor de oxirano, reatividade maior e viscosidade menor do que o ESO e ELO [117].

Samper et al. (2012) desenvolveram materiais a partir de óleos epoxidados de linhaça e soja usando anidrido maleico e ftálico como agentes de reticulação, etilenoglicol como iniciador e dimetilbencilamina como catalizador para acelerar a reação. Encontraram que resinas 80ELO20ESO com resistência à flexão de 33,4 MPa, módulo de flexão de $676.4 \mathrm{MPa}$, dureza shore D por volta de 64 e energia de impacto de aproximadamente $4.2 \mathrm{~kJ} / \mathrm{m}^{2}$ apresentaram possibilidades de ser utilizadas como matrizes em compósitos verdes [118]. 


\subsubsection{Resinas Epóxi derivadas de Cardanol}

O cajueiro (Anacardium occidentale Linn) é uma árvore nativa da América tropical, da família Anacardiaceae. É encontrado também na Índia, Vietnã, Tanzânia, Moçambique, Nigéria e Filipinas [119][120]. "Do cajueiro, praticamente tudo se aproveita: as folhas novas, quando cozidas e colocadas sobre feridas promovem cicatrização. A madeira, muito resistente à água do mar, é empregada na fabricação do cavername de pequenos barcos e na construção civil” [121]. Na Figura 14 é apresentado o fruto do cajueiro, o qual é composto pelo pedúnculo superdesenvolvido (usado para preparar bebidas, polpa e conservas), anexado à castanha que consta de uma casca externa, uma casca interna e a amêndoa que posterior ao processamento para separar a casca, é consumida como castanha, farinha ou no preparo de doces [121]. A espessura da casca de castanha de caju é de cerca de $0,32 \mathrm{~cm}$ [122]. Uma matriz macia de favo de mel, entre a casca externa e interna, contém um líquido castanho escuro e tóxico por seu conteúdo de urushiol [123]. O torrado das castanhas torna a casca frágil e permite a separação da amêndoa interior. Para produzir cada tonelada de castanha de caju são precisas entre 10 e 15 toneladas de caju [124].

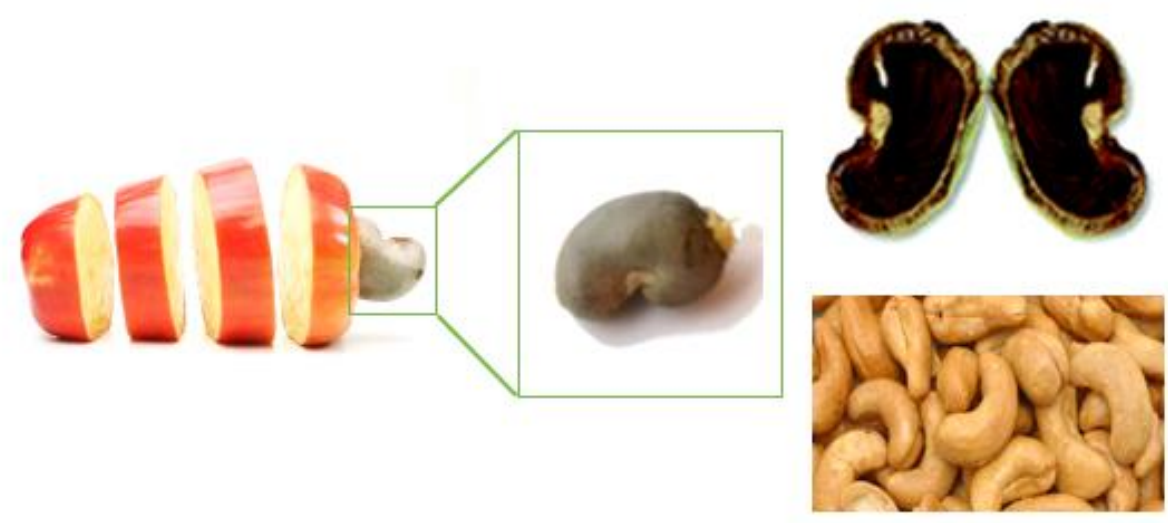

Figura 14 - Caju detalhe de castanhas e da casca (mesocarpo esponjoso) [125].

Dados da produção mundial de caju são apresentados na Figura 15. O Vietnã (US \$ 1,67 bilhões) e a Índia (US \$ 1,02 bilhão) lideraram as exportações de castanha de caju com mais de 237.500 toneladas métricas e 128.827 toneladas, respectivamente [126]. O Brasil se encontra entre os principais produtores com uma participação importante no mercado da castanha de caju [127] junto com Costa do Marfim (US \$ 721 milhões), Tanzânia (US \$ 231 milhões) e Guiné Bissau [119]. 


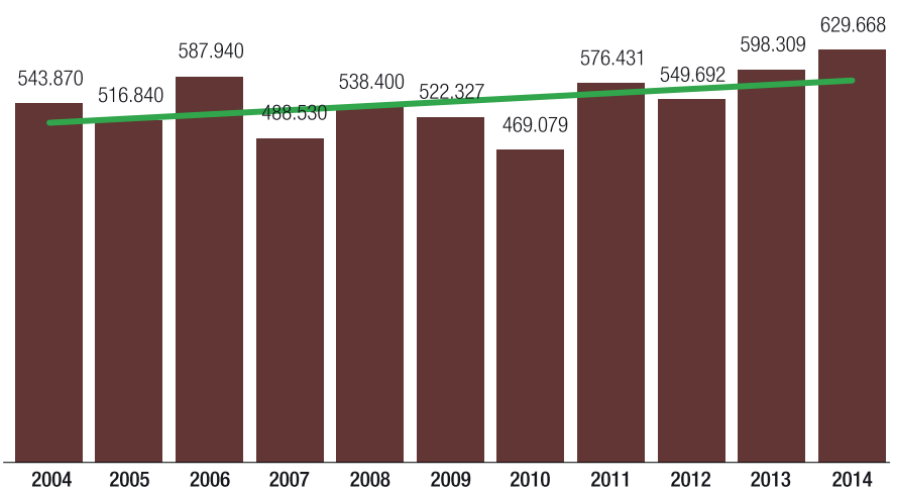

Figura 15 - Produção mundial de castanha de caju (Toneladas métricas) [126].

A substância obtida a partir do líquido do mesocarpo da casca da castanha de caju (LCC) ou (CNSL) pelas suas iniciais em inglês (cashew nut shell liquid), que equivale aproximadamente a $25 \%$ da castanha [128], é um subproduto da indústria de caju com uma produção anual de aproximadamente 2,6 milhões de toneladas [122]. O LCC constitui uma das principais fontes de fenóis naturais e possui quatro componentes principais com uma cadeia de carbono-C15 insaturada [129], ácido anacárdico, cardanol, cardol e 2-metilcardol, cujas estruturas químicas são apresentadas na Figura 16. Devido ao seu carácter fenólico e a longa cadeia alquilo (que varia no seu grau de instauração) ligada ao núcleo de benzeno na suas moléculas, o LCC é considerado uma matéria-prima versátil e seus principais componentes encontram aplicações em vários campos da indústria [129], [130].<smiles>[R]c1cccc(O)c1C(=O)O</smiles>

$a$<smiles>Oc1cccc(F)c1</smiles>

$b$<smiles>[R]c1cc(O)cc(O)c1</smiles>

$c$<smiles>[R]c1cc(O)c(C)c(O)c1</smiles>

$d$<smiles>[R]c1cccc(O)c1O</smiles>

$e$

Figura 16 - Estruturas químicas dos principais componentes na casca da castanha de caju. $\mathrm{R}=\mathrm{C}_{15} \mathrm{H}_{31-2 \mathrm{n}}$, com valores de n entre 0 e 3. a) ácido anacárdico $b$ ) cardol $c$ ) cardanol $d$ ) 2metil cardol $e$ ) urushiol.

Um esquema das fases do processo de obtenção do cardanol é apresentado na Figura 17. O tratamento térmico do LCC induz a descarboxilação parcial de ácido anacárdico, que é completada pela subsequente destilação de purificação. O resultado é o cardanol de grau industrial, na forma de um óleo amarelo contendo cerca de $90 \%$ de cardanol, com menores percentagens de cardol e metilcardol [131]. 

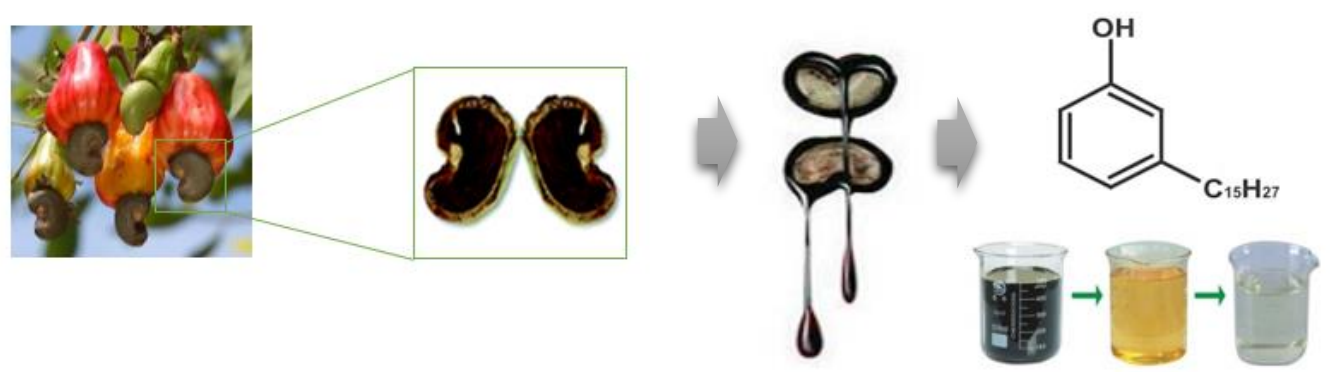

Figura 17 - Fases no processo de obtenção do cardanol a) Frutos de caju b) casca da noz de caju c) extração do líquido da casca da noz de caju (LCC) d) cardanol obtido por destilação de LCC [132], [133], [134].

O cardanol possui uma longa cadeia alifática insaturada na posição meta, que pode ser facilmente reticulada [129]. Conforme ilustrado na Figura 18 a cadeia lateral alifática pode ter uma, duas ou três ligações duplas de carbono.

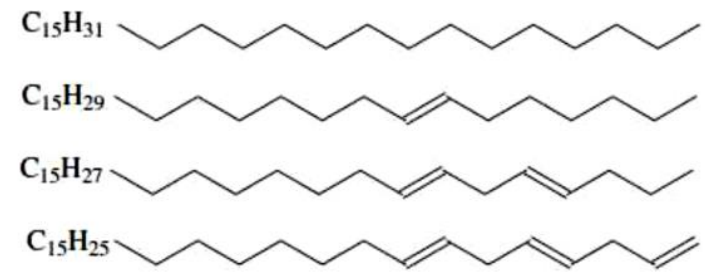

Figura 18 - Cadeia alifática do cardanol (R)

Sendo o componente principal do LCC, o cardanol é uma matéria prima renovável versátil [131], [135], [136], [137]. Devido à sua estrutura, oferece diferentes possibilidades em aplicações industriais como aditivos para lubrificantes, antioxidantes, estabilizadores, retardadores de chama, tintas e vernizes e polímeros.

Os polímeros à base de cardanol podem ser classificados em quatro grupos: Resinas fenólicas, resinas epóxi, acrilatos (ou metacrilatos) e resinas de éster vinílico [138].

Vários estudos sobre a síntese e caracterização de uma série de resinas fenólicas tipo novolac e resol, baseadas em cardanol, têm sido reportados na literatura [139],[140]. Pré-polímeros epóxi baseados em cardanol [141], têm sido sintetizados pela reação de cardanol-fenol com epicloridrina, na presença de hidróxido (Figura 19) [130], [142], [143], [144], [145]. Por outro lado, resinas de éster vinílica à base de LCC são produzidas pela reação do cardanol epoxidado (EC) com ácido metacrílico [138], [144], [146]. 


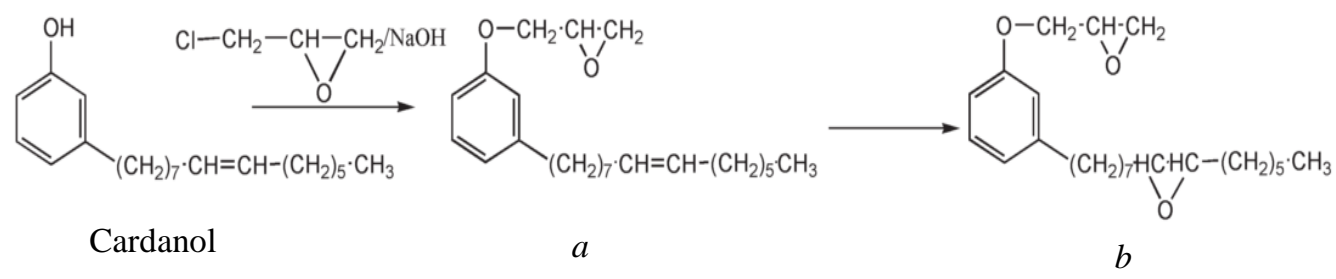

Figura 19 - Síntese de $a$ ) cardanol mono-epoxidado (EC) $b$ ) cardanol di-epoxidado (DEC) [55],

O EC tem sido utilizado como material de partida para o desenvolvimento de resinas biobaseadas [142], [147], [148], [149] e agentes de endurecimento de baixo custo para resinas epóxi [150].

Patel et al. (1989) sintetizaram cardanol diepoxidado (DEC) com um peso equivalente epóxi de 284,3 g/eq. Este apresenta dois grupos epóxido, o primeiro, do tipo glicidilo, foi introduzido pela reação de um grupo hidroxila do cardanol com epicloridrina e o outro foi produzido pela epoxidação da ligação dupla utilizando peroxiácido. Foi estudado o comportamento da cura de BDEGA/DEC com diferentes anidridos como agentes de cura [151]. Kanehashi et al. (2013) sintetizaram uma resina epóxi baseada em cardanol, para ser usada como recobrimento, pela reação entre um pré-polímero de epóxi cardanol (ECP) e compostos de amina. O ECP foi curado a temperatura ambiente com aminas etilenodiamina (EDA), dietilenotriamina (DETA) e tetraetilenopentamina (TEPA). Foi encontrando que o revestimento obtido apresentou uma maior estabilidade química em comparação com revestimentos comerciais de cardanol. A análise térmica revelou que o revestimento estava em estado de borracha a temperatura ambiente devido às cadeias laterais flexíveis do ECP [142]. Um éter glicidílico difuncional, produto da epoxidação de cardanol, está disponível comercialmente na empresa Cardolite - o produto NC-514 - com peso equivalente de epóxi por volta de 400 g/eq [143] (Figura 20). Este reagente exibe a reatividade e características químicas de uma resina de tipo bisfenol A tradicional e pode ser curado com aminas para produzir resinas epóxi [152].
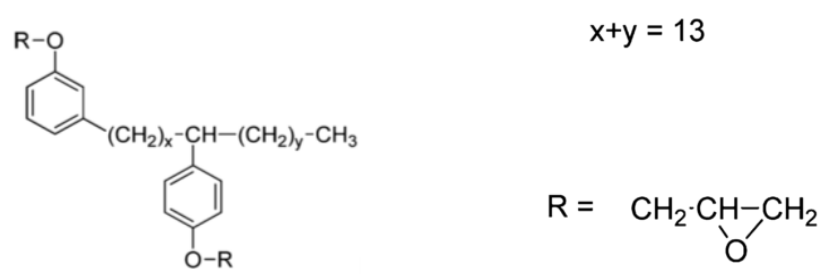

Figura 20 - Estrutura química do epóxi di-funcional comercial derivado do cardanol (NC514) [153]. 
A cadeia alifática que separa os grupos aromáticos permite que esta resina seja utilizada também em conjunto com monômeros epóxi tradicionais para aumentar a flexibilidade, resistência à água, resistência à abrasão e resistência química de revestimentos sem afetar adversamente outras propriedades [147]. Jaillet et al. (2014), analisaram cardanol epoxidado comercial (NC-514) utilizando cromatografia de exclusão de tamanho e ressonância magnética nuclear (RMN) para determinar sua estrutura. Também foram obtidas resinas epóxi, pela cura do NC-514 com diamina de isoforona (IPDA) e diamina Jeffamine D400, que foram caracterizadas térmica e mecanicamente e comparadas com resinas DGEBA. As resinas NC-514/IPDA apresentaram valores de Tg entre 41 e $50{ }^{\circ} \mathrm{C}$ menores que os valores para resinas DGEBA/IPDA convencionais, com Tg entre 73 e $158{ }^{\circ} \mathrm{C}$. Foram atribuídos estes resultados à longa cadeia alifática presente no cardanol. A melhor formulação para a resina NC-514/ Jeffamine D400 atingiu valores de Tg de apenas $13^{\circ} \mathrm{C}$ [152]. Em um trabalho posterior Darroman et al. (2016) utilizaram três reagentes epóxi como aditivos para melhorar as propriedades dos poli-epóxidos NC-514/aminas. Com a adição de éter diglicidílico de resorcinol e DGEBA hidrogenado (hBADGE) se encontrou um aumento significativo na $\mathrm{T}_{\mathrm{g}}$ e na dureza, enquanto a adição de triglicidil éter de TMP conduz a uma maior estabilidade térmica das redes, corroborando assim que pela mistura de vários reagentes epóxi é possível melhorar as propriedades de resinas cardanol para seu uso em várias aplicações [147]. Maiorana et al. (2015) estudaram a preparação de resinas epóxi pela mistura de diglicidil éteres de difenolatos com éster metílico (DGEDP-Me), com uma resina epóxi flexível proveniente de cardanol epoxidado NC-514, usando um agente de cura diamina. Micrografias de MEV das superfícies fraturadas confirmaram a presença de uma fase única nos materiais curados. Todas as composições de resina foram transparentes e com temperatura de transição alfa, confirmando a miscibilidade da resina. Os valores de módulo de armazenagem para as resinas curadas variaram de 3000 a $1000 \mathrm{MPa}$ e as temperaturas de transição alfa variaram linearmente $\left(158\right.$ a $\left.27^{\circ} \mathrm{C}\right)$ em função da composição.

Ambrožič et al. (2015) sintetizaram um surfactante de benzoxazina a partir de cardanol epoxidado, com resina epóxi de bisfenol A (BAP) e óleo de soja epoxidado (ESO) como fase dispersa. O tensoativo apresentou uma excelente compatibilidade com ambas as resinas e foi copolimerizado com ambas. A introdução da polibenzoxazina na rede epóxi melhorou as propriedades 
termomecânicas, aumentando o módulo de armazenamento de películas de copolímero curadas, o que foi atribuído a uma maior densidade de reticulação, pelas reticulações adicionais formadas entre grupos epóxi e grupos $\mathrm{OH}$ livres (pela abertura do anel do surfactante). A estabilidade da emulsão foi aumentada com o aumento da concentração de surfactante e com aumento na quantidade de ESO. A temperatura de transição vítrea foi reduzida apenas ligeiramente [148], [154].

\subsubsection{Agentes de cura}

O endurecimento de uma resina epóxi, para dar uma estrutura reticulada tridimensional, ocorre na presença de agentes de cura ou endurecedores que são capazes de reagir com o grupo funcional epóxi para abrir o anel epóxido. A estrutura e a funcionalidade dos agentes de cura desempenham um papel importante na cinética de cura, no tempo de gelificação, no grau de cura, na viscosidade, no ciclo de cura e nas propriedades finais do material [33], [155]. Sua escolha depende de uma variedade de fatores incluindo o custo, o método de processamento, as condições de cura, as limitações ambientais e as propriedades mecânicas, químicas, elétricas e térmicas desejadas na resina curada. Em alguns casos, para promover as reações de cura, são necessários catalizadores [156].

Geralmente são usados agentes de cura tais como anidridos, aminas (aromáticas, alifáticas e ciclo alifáticas), polifenóis ou amidas [157], [158]. Esta reação de cura pode gerar também reações de homopolimerização, nas quais os grupos hidroxilas presentes na molécula epóxi reagem com os grupos epóxido [159].

O peso equivalente de epóxido (EEW) é o peso de resina necessário para obter um equivalente de grupo funcional epóxi é utilizado para calcular proporções estequiométricas de reagentes para reação ou cura de resinas epóxi. EEW é relacionado com o teor de epóxido da resina epóxi (\%) através da eq. 1:

$$
E E W=\frac{\text { massa molecular do grupo epóxido }}{\% \text { teor de epóxido }} \quad \text { Equação } 1
$$

A pesquisa de agentes de cura ambientalmente sustentáveis, tem aumentado nos últimos anos incluindo o uso de uma ampla gama de bioprodutos para sua preparação [54], [141], [158]. 
A reação de Mannich de quantidades equimolares de cardanol, formaldeído e certas poliaminas produz agentes de cura parcialmente biobaseados, conhecidos comofenalcaminas, que são obtidos com uma tecnologia sustentável, uma vez que o cardanol é derivado de uma fonte renovável e não interfere na cadeia alimentícia [153], [160]. A estrutura química do cardanol confere algumas propriedades valiosas como agente de cura. $\mathrm{O}$ anel aromático confere resistência química, os grupos hidroxila aumentam a adesão e facilitam a cura a baixas temperaturas, a cadeia alifática C15 concede flexibilidade e, devido ao seu carácter apolar, proporciona resistência à umidade, que auxilia na proteção contra a corrosão [102]. Yuan Liu et al. (2014) utilizaram cardanol em combinação com outros compostos fenólicos, paraformaldeído, hexametilenodiamina (HDA) e dietilenotriamina (DETA) para a preparação de fenalcaminas estáveis, pela reação de Mannich, que forneceram melhoras na tenacidade, módulo e Tg quando usadas como agentes de cura de resinas epóxi [161].

Agentes de cura para resinas epóxi foram preparados pela reação de líquido do mesocarpo da casca da castanha de caju (LCC) com dietilenotetramina. Também foram preparadas poliaminas fenólicas para curar resinas epóxi usando misturas de LCC com fenol, cresol ou outros fenóis alquilados [143]. Ghodsieh et al. (2014) estudaram a reação de resinas epóxi de bisfenol com porcentagens de ESO entre 10 e 30\% curadas com ácido sebácico como um endurecedor de base biológica, encontrando que a reação de cura do epóxido com $30 \%$ em peso de ESO foi controlada por difusão e que a energia de ativação da reação de cura com o endurecedor biológico foi maior em relação àquela realizada com endurecedor comum à base de amina [103].

\subsection{Fibras Lignocelulósicas}

O uso de fibras lignocelulósicas como material de reforço em compósitos com matrizes, tanto cimentícias como poliméricas, tem aumentado nas últimas décadas devido a algumas de suas vantagens em relação às fibras sintéticas. As fibras lignocelulósicas são provenientes de fontes renováveis de alta disponibilidade, são neutras em relação a emissão de $\mathrm{CO}_{2}$ e possuem menor custo por unidade de volume. Adicionalmente apresentam vantagens significativas, tais como baixa densidade, bons atributos de redução de ruído, não-abrasividade e menor consumo 
de energia para sua obtenção, entre outras [16], [26], [37], [162], [163], [164]. A Figura 21 apresenta a classificação de fibras lignocelulósicas com enorme potencial para utilização como fase de reforço em materiais compósitos para aplicações tradicionais e industriais como na fabricação de móveis, substratos para aquacultura e hidroponia, compensados para isolamento térmico e acústico, além de usos no setor automotivo, indústria aeroespacial e construção civil [18], [24], [29], [165], [166], [167], [168], [27],

$\mathrm{Na}$ literatura existe uma grande quantidade de estudos do comportamento de diferentes materiais compósitos com fibras lignocelulósicas como sisal [169],[170], coco [171], juta [172], bambu [173], piassava [174], [175], curauá [174], bagaço de cana-de-açúcar [176], [177], bananeira [178], pupunha [179], algodão [172], [180], plantas ornamentais [181], entre outras.

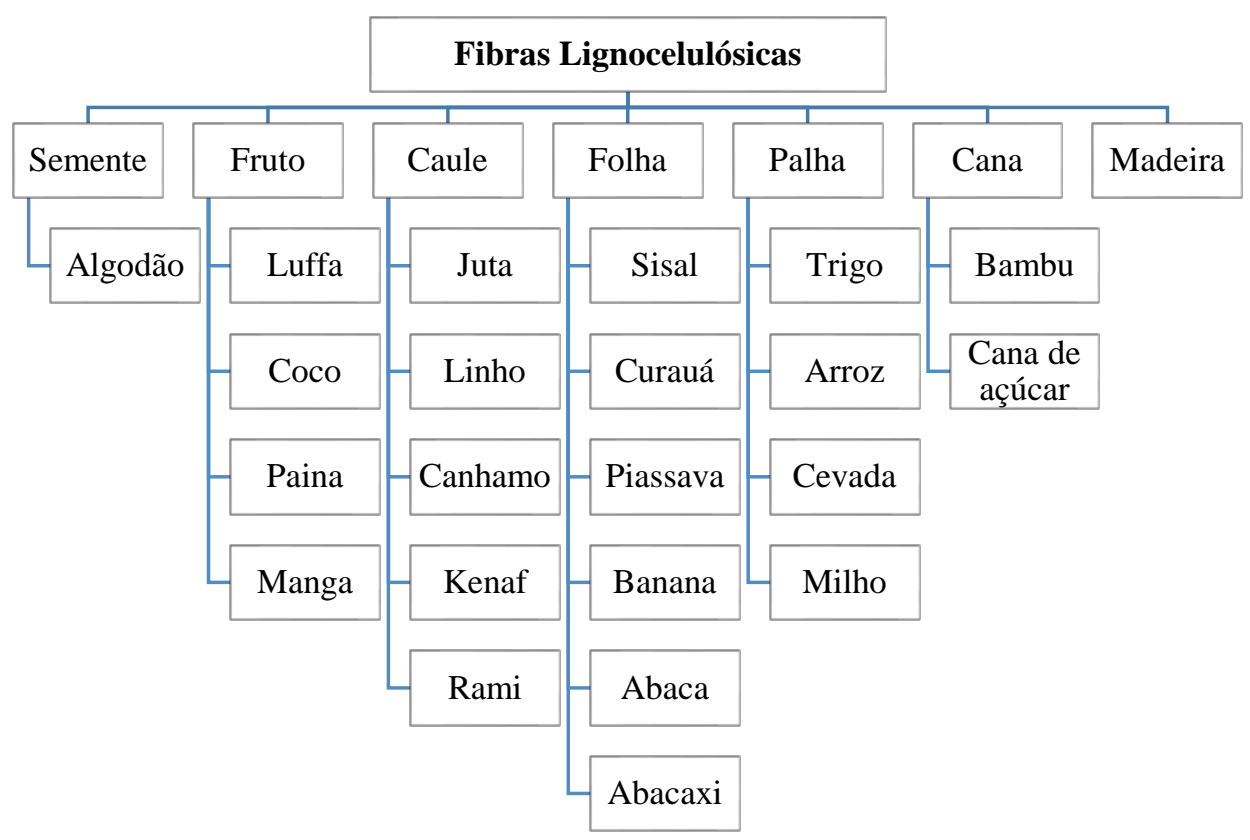

Figura 21 - Classificação de principais fibras lignocelulósicas segundo a origem.

As fibras lignocelulósicas são constituídas essencialmente por celulose, mas também por quantidades significativas de hemiceluloses, lignina, pectina, açúcares livres, amido, proteínas, compostos orgânicos e sais minerais inorgânicos [165]. O teor de celulose, que é o constituinte que se encontra em maior proporção, tem grande influência nas propriedades mecânicas das fibras vegetais e pode mudar, dependendo da espécie e da idade da planta [26], [182]. A composição química das fibras depende da fonte da qual provêm, então, dependendo de onde são extraídas, 
elas vão exibir diferentes propriedades químicas e físicas que estão correlacionadas com seu papel biológico na planta [29]. Por exemplo, as fibras lignocelulósicas extraídas do caule possuem valores de resistência à tração e rigidez altos, relacionadas com altas porcentagens de celulose [165], [183].

A Figura 22 apresenta o gráfico de Ashby (módulo de Young vs. densidade) para materiais naturais de interesse, incluindo algumas fibras lignocelulósicas. As diretrizes de rigidez $\mathrm{E} / \rho, \mathrm{E}^{1 / 2} / \rho$ e $\mathrm{E}^{1 / 3} / \rho$, identificam materiais estruturalmente eficientes que são leves e rígidos e representam os índices do material para um modo particular de carregamento [182]. Como pode se observar na Figura 22, ressaltado em amarelo, o polímero natural com maior eficiência em termos de tração, medido pelo índice $\mathrm{E} / \rho$, é a celulose que excede ao aço por um fator de cerca de 2,6 [184].

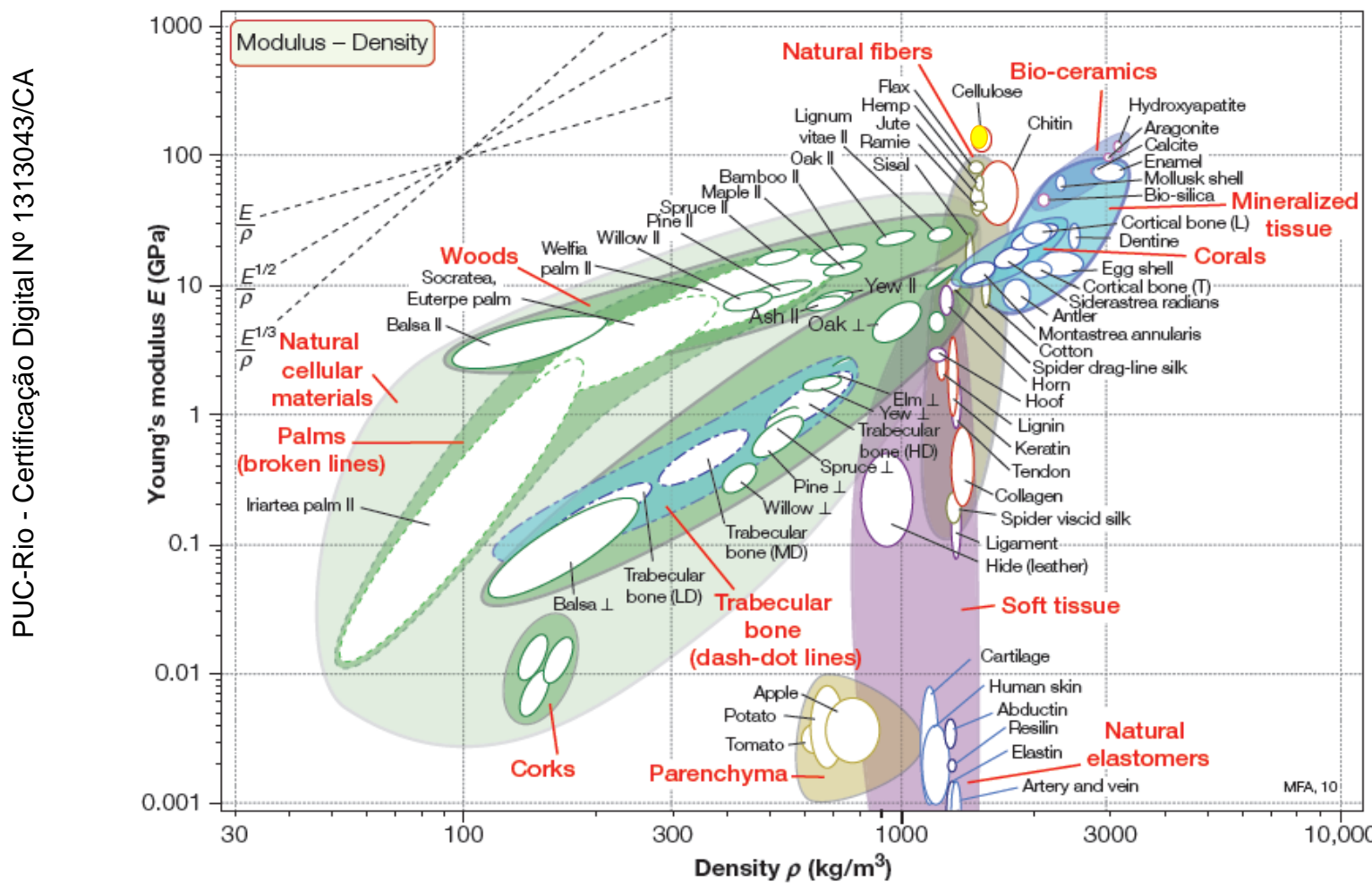

Figura 22 - Gráfico de propriedades materiais naturais, módulo de Young vs. densidade [182].

Por outro lado, a madeira, a palma e o bambu são particularmente eficientes em flexão e resistentes à flambagem, quando carregados paralelamente ao grão, como indicado pelos valores elevados do índice de flexão $\mathrm{E}^{1 / 2} / \rho$ [182]. 


\subsubsection{Celulose}

A celulose, com fórmula química básica $\left(\mathrm{C}_{6} \mathrm{H}_{10} \mathrm{O}_{5}\right)_{n}$ é o biopolímero mais abundante e é o principal componente das fibras vegetais. Tem importância tanto por sua abundância quanto por seu aproveitamento tecnológico, sendo a base de uma grande quantidade de produtos como papel, fibras e aditivos [185]. A hierarquia complexa das configurações que compõem as fibras vegetais está ilustrada na Figura 23. A parede celular é constituída pela parede primária (externa), três camadas secundárias ( $\mathrm{S} 1, \mathrm{~S} 2, \mathrm{~S} 3)$ e o lúmen. A celulose, hemiceluloses e lignina têm diferentes distribuições nestas camadas. Estas camadas diferem entre si em relação à sua estrutura bem como à sua composição química [186]. As microfibras estão incorporadas na lamela média, em uma matriz de lignina e pectina [187]. As micro fibrilas de celulose ( 250 Å de diâmetro) aparecem representadas nas camadas secundárias, como linhas torcidas em relação ao eixo vertical da célula. O ângulo que formam é chamado de ângulo de microfibra e desempenha um papel crucial na resistência e a rigidez das fibras vegetais [188], [189].

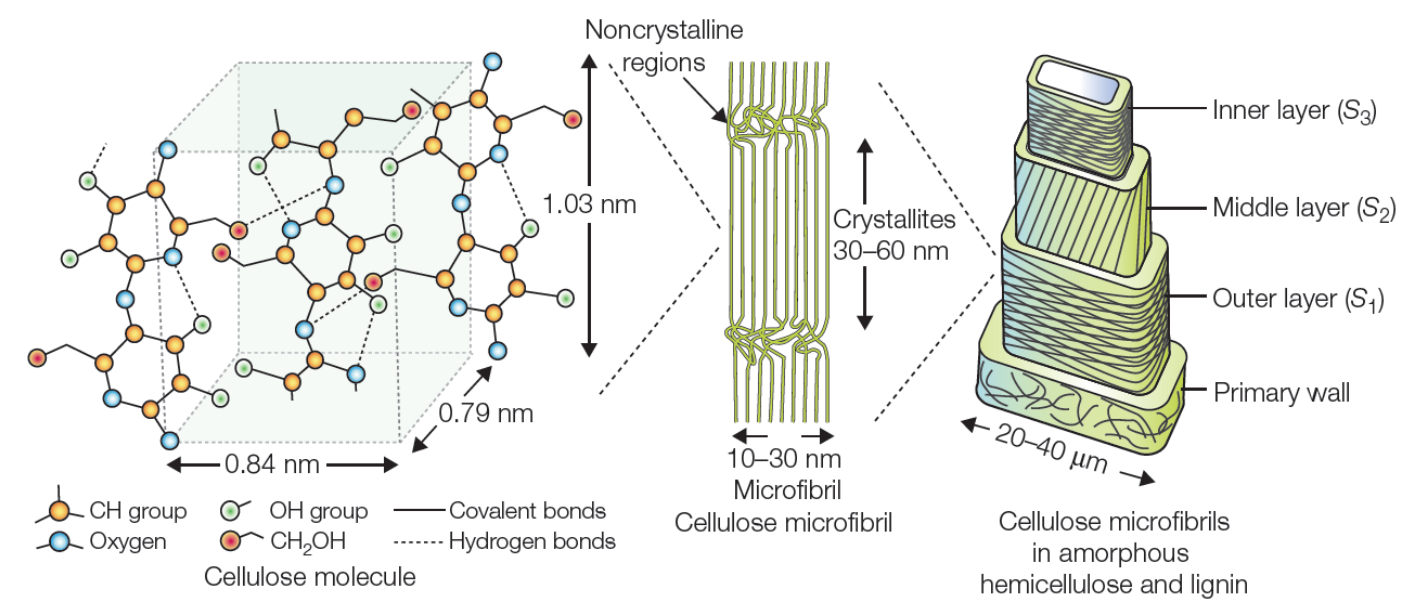

Figura 23 - Estrutura hierárquica da madeira [182].

Em sua estrutura supramolecular, a celulose apresenta regiões altamente ordenadas ou cristalinas e áreas menos ordenadas ou amorfas, onde as cadeias possuem uma orientação aleatória [190]. As regiões cristalinas são constituídas por moléculas alinhadas com um comprimento entre 30 e 60 nm [182] e estão conformadas por micro fibrilas, que são formadas pela união de unidades de $\beta$ Dglucose através de ligações $\beta$-1,4-glicosídicas [191], unidas umas às outras ao longo de seu comprimento por ligações de hidrogênio [192] (Figura 24). 


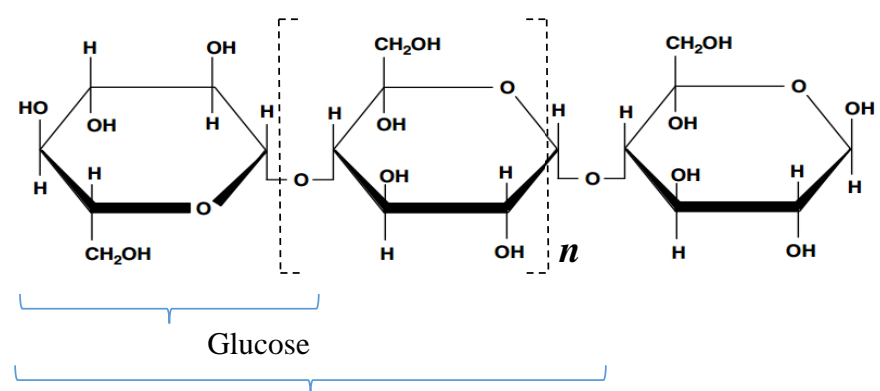

Celobiose

Figura 24 - Estrutura molecular parcial da celulose com o monômero $\beta$ D-glucose como unidade fundamental e celobiose como unidade estrutural [191].

\subsubsection{Hemicelulose}

As hemiceluloses referem-se a uma mistura de polissacarídeos ramificados com baixo grau de polimerização ( $\mathrm{DP} \approx 200$ ), que pode ser contrastado com a celulose (DP> 10 000). Além disso, enquanto a estrutura molecular da celulose é a mesma em todas as plantas, a estrutura e a composição de monossacarídeos nas hemiceluloses varia muito entre os diferentes grupos filogenéticos de plantas [193]. A estrutura ramificada das hemiceluloses diminui a energia das ligações e também a cristalinidade, tornando-a mais facilmente hidrolisada que a celulose [194]. Devido à sua natureza não cristalina, as hemiceluloses são mais suscetíveis à despolimerização do que a celulose (especialmente em condições ácidas) [195]. No entanto, as hemiceluloses desempenham um papel nas propriedades mecânicas das paredes celulares das planta. A parede secundária pode ser vista como um compósito, onde as fibrilas celulósicas cristalinas atuam como fibras de reforço e as hemiceluloses amorfas (e ligninas) estabelecem uma matriz flexível (Figura 25) [193].

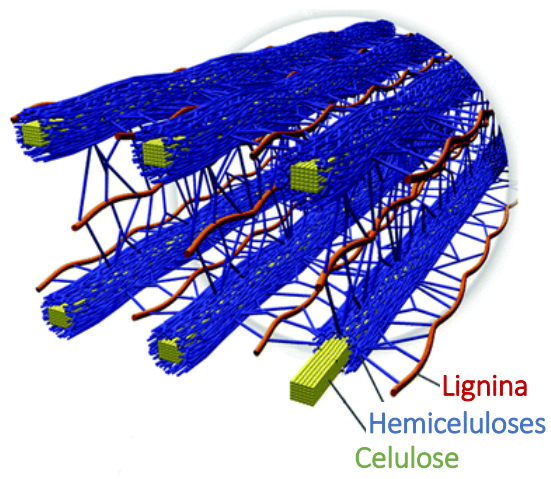

Figura 25 - Representação do arranjo espacial de celulose, hemicelulose e lignina na parede secundária de uma fibra vegetal [195]. 
As hemiceluloses são formadas por açúcares que podem se dividir em diferentes grupos: pentoses ( $\beta$-D-xilose, $\alpha$-L-arabinose), hexoses ( $\beta$-D-glucose, $\beta$ D-manose, $\alpha$-D-galactose), ácidos hexurónicos (ácido $\beta$-D-glucurônico, ácido $\alpha$-Dmetilglucurônico, ácido $\beta$-D-galactourônico) [196].

\subsubsection{Lignina}

A lignina é um polímero polifenólico natural, complexo e tridimensional, composto por três unidades de fenilpropano, o-p-hidroxifenil, guaiacil e siringil. É insolúvel em água e proporciona impermeabilização, reforço estrutural e resistência a ataques físicos e biológicos nas paredes celulares [195]. As proporções das unidades monoméricas são altamente variáveis e dependem principalmente das espécies lignocelulósicas [197]. A lignina é totalmente amorfa e está associada à hemicelulose covalentemente, formando uma matriz que envolve as micro fibrilas de celulose. Na Figura 26 é possível observar uma representação idealizada da estrutura e distribuição de um polímero de lignina amorfa e de uma fibrila elementar de celulose rodeada com hemicelulose dentro da parede celular das microfibras [193].

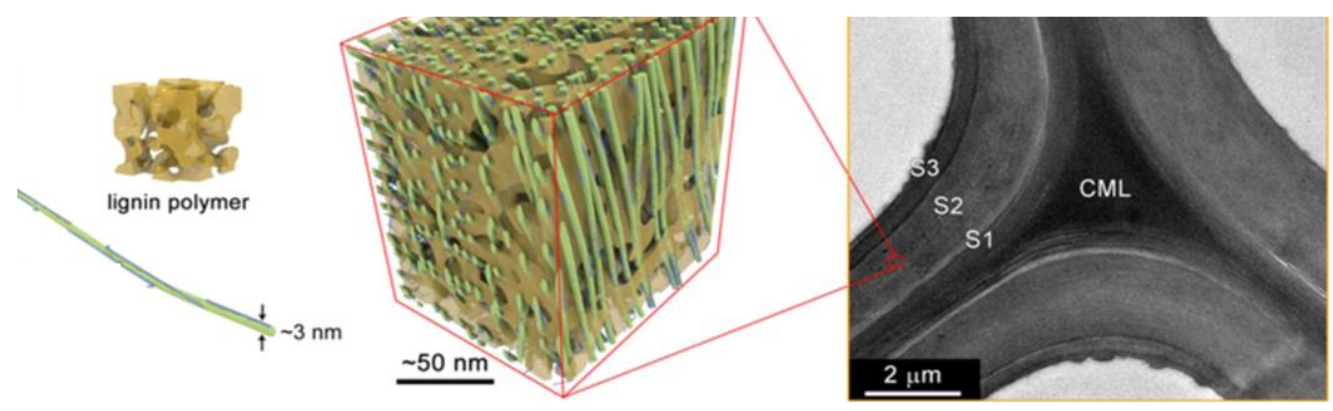

Figura 26 -Imagem TEM que exibe a parede da célula de madeira ultra-estruturada, com lamela média (CML) e camadas da parede celular secundária (S1, S2, S3) (Direita).

Esquema da arquitetura da lignocelulose em nano escala (Esquerda) [193].

\subsubsection{Bucha Vegetal (Luffa cylindrica)}

A bucha, também conhecida como esponja vegetal, é uma planta tropical com plantio de fácil crescimento que pertence à família Cucurbitaceae e cujo fruto possui um sistema vascular fibroso, quando está totalmente amadurecido[198]. Acreditase que tenha sido domesticada na Ásia tropical, possivelmente na Índia, chegando à China por volta de 600 d.C., assim como no Egito, durante a Idade Média. Tem sido cultivada no Oriente Médio, Índia, China, Japão e Malásia, há séculos. Hoje é 
encontrada em regiões tropicais (Figura 27), sendo que as principais áreas de produção são China, Coreia, Índia, Japão, América Central e Brasil [199].

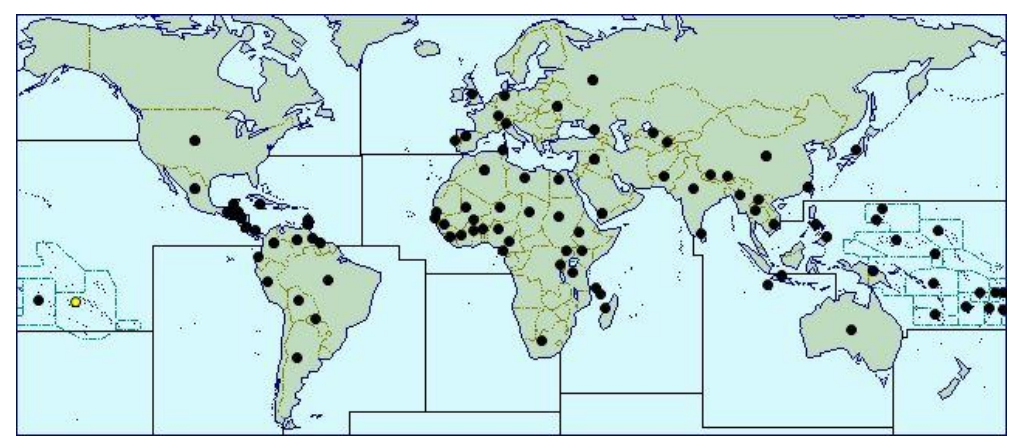

Figura 27 - Distribuição mundial de Luffa cylindrica [200].

No Brasil a espécie Luffa cylindrica é produzida em maior quantidade, sendo a mais explorada das oito espécies existentes desta planta herbácea [201]. A bucha constitui uma das fontes mais importantes de fibra no Brasil, assim como a piaçava (Attalea funifera) e curauá (Ananas comosus L.) e seu cultivo possui uma crescente importância econômica [202]. Foi verificado que a espécie Luffa cylindrica possui fibras com um alto teor de celulose e relativamente baixo conteúdo de lignina (de tipo siringila e guaiacila) [203], [204], [205]. A tabela 2 apresenta a composição química de fibras de bucha.

Tabela 2. Composição química de Luffa cylindrica [201], [204], [206].

\begin{tabular}{|c|c|}
\hline Componente & Conteúdo (\%) \\
\hline Holocelulose & $82,4-83$ \\
\hline$\alpha$-Celulose & $54,2-65,5$ \\
\hline Hemicelulose & $17,5-19,4$ \\
\hline Lignina & $11,2-15,2$ \\
\hline Extrativos & $3,1-3,2$ \\
\hline Cinzas & $0,4-0,7$ \\
\hline
\end{tabular}

Tanobe et al. (2005) estimaram os valores para a concentração de elementos químicos na superfície de fibras de bucha, por meio de espectroscopia de fotoelétrons, excitados por raios X. Quando a razão O/C atinge um valor de 0,83, obtém-se na amostra celulose pura. Se esta razão estiver no intervalo entre 0,31 e 0,40, obtém-se lignina pura. A tabela 3 apresenta a composição elementar de fibras de bucha [206]. 
Tabela 3 Composição química XPS de Luffa cylindrica [206]

\begin{tabular}{|c|c|c|}
\hline Elementos & $\%$ & O/C \\
\cline { 1 - 2 } $\mathrm{C}$ & 64.0 & \multirow{2}{*}{0.54} \\
\cline { 1 - 2 } $\mathrm{O}$ & 34.9 & \\
\hline $\mathrm{N}$ & 1.2 & \\
\hline
\end{tabular}

Como mostrado na Figura 28, o fruto seco da bucha apresenta uma morfologia com arranjo espacial 3-D. O tamanho e características físicas das buchas são dependentes do local de origem. Na região de São Paulo, são produzidos frutos cilindros com comprimento entre 10 e $120 \mathrm{~cm}$ e diâmetro entre $6-15 \mathrm{~cm}$, com 3 vazios como se pode observar na Figura $28 b$.

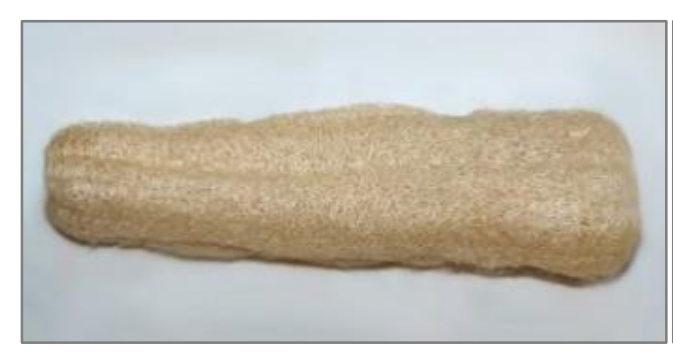

$a$

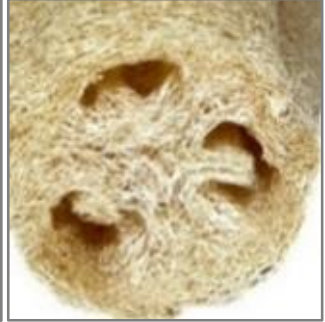

$b$

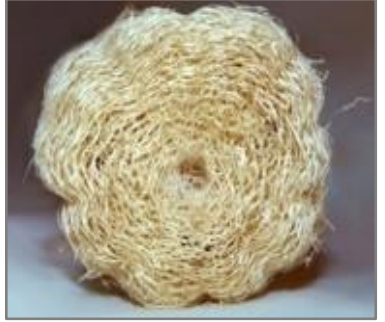

$c$

Figura 28 - Fruto maduro e descascado (Luffa cylindrica). a) Vista lateral b) Vista frontal com corte. $c$ ) Vista frontal sem cortes.

A estrutura do sistema vascular fibroso da esponja de bucha pode ser dividida em duas regiões principais, como é mostrado na Figura 29: um núcleo central, e a parede intermediária, que possui uma superfície interna e uma superfície externa indicadas também na Figura. A parede intermediária pode ser separada do núcleo como mostrado na Figura 30 e utilizada como uma manta natural fibrosa após a separação das sementes [203]. Esta estrutura de manta natural contínua é uma das principais vantagens da bucha frente a outras fibras lignocelulósicas, pois pode ser usada diretamente na fabricação de compósitos, já que não precisa ser tecida [174]. 


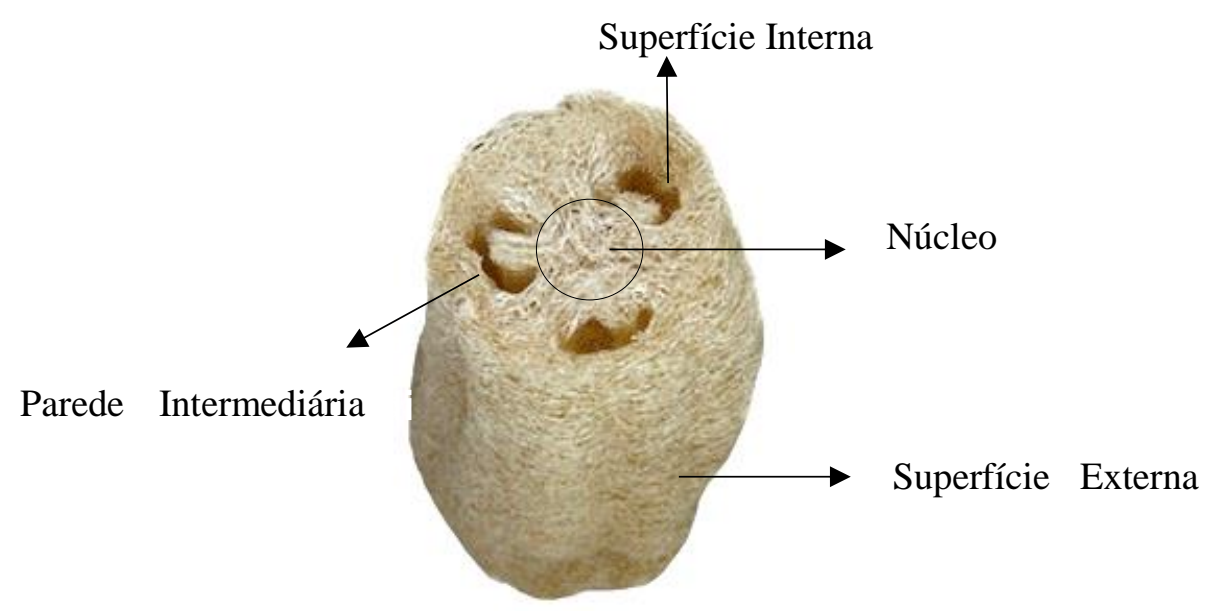

Figura 29 - Regiões da bucha vegetal.

O núcleo central da esponja possui uma estrutura semelhante com a estrutura de favo de mel, como mostrado na Figura $30 \mathrm{~b}$, em tanto que as fibras da parede intermediária estão dispostas multidireccionalmente (Figura 29a, 29c) [22].

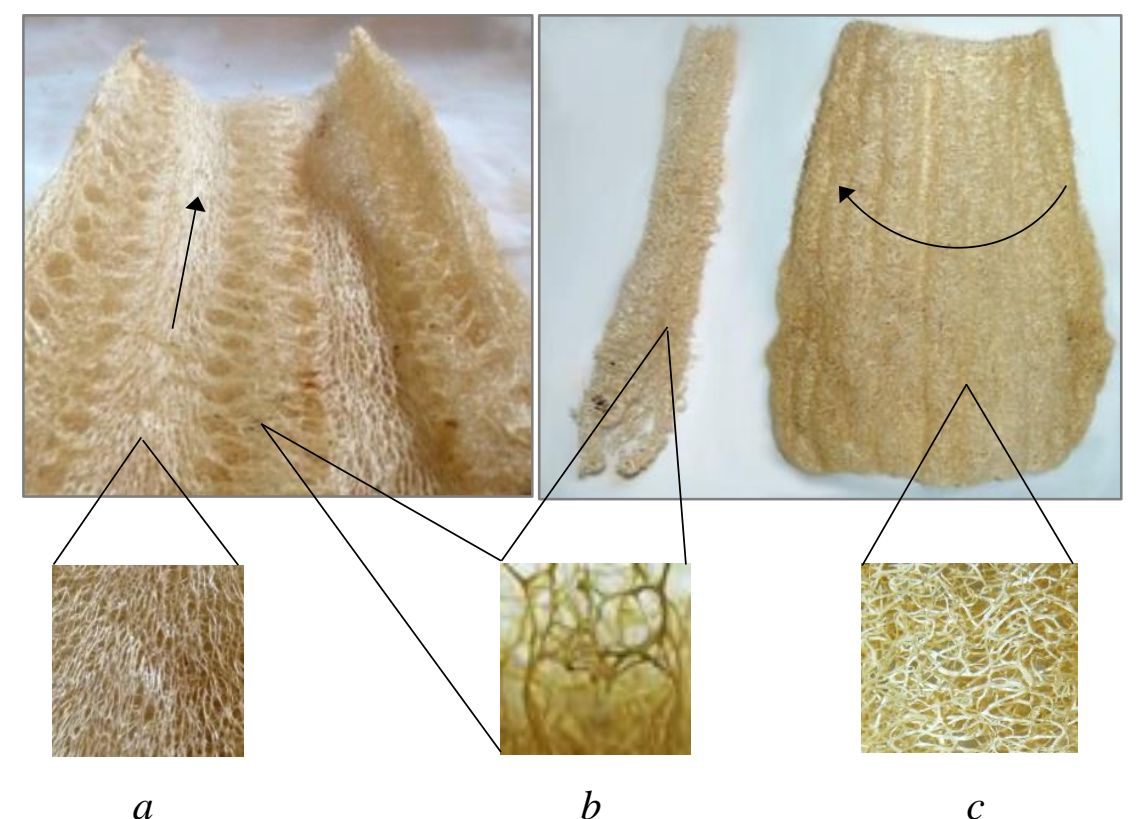

Figura 30 - Fruto maduro de bucha, descascado e cortado. a) Superfície interna da parede intermediaria. $b$ ) Núcleo central. $c$ ) Superfície externa da parede intermediaria.

Oliveira (2013) realizou a medição do módulo de elasticidade de fibras de bucha por ensaio de tração e encontrou um valor médio de 2512,04MPa $\pm 691 \mathrm{MPa}$ para as fibras medidas [207]. No entanto, ensaios de tração de fibras precisam ser realizados com fibras sem bifurcações, sendo difícil encontrar esse tipo de amostras na esponja bucha. Outros estudos reportaram fibras de bucha com densidade de 353 
$\mathrm{Kg} / \mathrm{m}^{3}$ e módulo de Young de $1332 \mathrm{MPa}$ [208]. Porém, no artigo citado não é detalhado como foram obtidos esses resultados, e ainda pelo texto é difícil definir se são dados referentes às fibras individuais ou a mantas inteiras testadas. Siqueira et al. (2010) realizaram a caracterização mecânica de filmes com nanofibras obtidas a partir de bucha. Reportaram um módulo de Young de $2.41 \pm 0.215 \mathrm{GPa}$ para filmes com whiskers e 3.05 \pm 1.07 GPa para celulose microfibrilada (MFC) [204]. Uma fórmula empírica para a determinação do módulo de Young de fibras de bucha foi encontrada também para a predição do E a partir da densidade das fibras [209].

O principal uso da bucha no Brasil é na fabricação de esponjas de banho, bem como esteiras, palmilhas, chinelos, artesanatos e outros produtos. Fatores como uma alta área superficial por volume, baixa densidade e custo razoável são características que tornam a bucha uma alternativa adequada para outros possíveis usos tais como em componentes de amortecedores, revestimentos à prova de som, material de embalagem e filtros industriais [205], [198], [210]. Outras aplicações das fibras de bucha incluem seu uso em sistemas de tratamento de água como adsorvente para a remoção de chumbo [211], íons de metais pesados [212], [213] e corantes de azul de metileno [214] e verde brilhante [215] em soluções aquosas, assim como em matrizes de imobilização de bactérias e leveduras [210]. Nanocristales de celulose extraídos das fibras de bucha também têm sido estudados para sua aplicação na indústria farmacêutica, alimentícia e cosmética [216] e o óleo das sementes de bucha tem sido também extraído para usos industriais, por exemplo, na produção de biocombustíveis [217].

No entanto, a bucha cultivada em várias regiões de Brasil não é aproveitada em sua totalidade. Produtores relatam que os resíduos produzidos acabam sendo eliminados, junto com cerca de um quarto dos frutos com qualidade inferior, que não podem ser usados para fabricação dos produtos convencionais.

Além do seu baixo custo, abundância e não toxicidade, as fibras formam uma manta natural contínua que representa grandes vantagens práticas no processo de fabricação de compósitos [162], [203], [218], [219]. Compósitos reforçados por fibras de bucha demostraram ter um modo de falha mais controlado quando comparados com resinas sem reforço [22], [174]. Foi relatada a melhora das propriedades de tração e absorção de água do polipropileno usando fibra de bucha [20]. Compósitos amido termoplástico (TPS)/bucha [220] e poliéster/bucha [174] 
[221], [222], [207] também têm sido estudados. As fibras de bucha demostraram ter uma forte interação com a matriz TPS. A força de aderência foi demonstrada pela sua compatibilidade, presumivelmente, devido às suas estruturas químicas semelhantes, analisadas por meio de FTIR. Micrografias de MEV revelaram que a superfície da fibra de bucha foi revestida pela matriz de TPS e não houve separação entre elas. Esta pode ser a razão para a melhoria das propriedades térmicas e de tração dos compósitos de fibra TPS/bucha [220].

\subsubsection{Modificação de fibras lignocelulósicas}

Apesar das vantagens significativas do uso de materiais naturais como reforço em materiais compósitos de matriz polimérica, existem também desvantagens relacionadas com o uso de fibras lignocelulósicas. Em comparação com as fibras sintéticas convencionais, que são produzidas com uma faixa definida de propriedades, as propriedades mecânicas e térmicas características das fibras naturais variam consideravelmente [223]. Isso é uma consequência da variabilidade na composição de cada tipo de fibra, tamanho e diâmetro da fibra, orientação das fibrilas, além de condições climáticas e do plantio, entre outros fatores [26]. Outros problemas existentes são a absorção de umidade de materiais lignocelulósicos, que pode resultar no inchamento e afetar a estabilidade dimensional de compósitos e a fraca interação superficial com algumas matrizes poliméricas. Assim, para a aplicação de fibras lignocelulósicas como material de reforço, é importante sua caracterização e a modificação superficial da superfície com o objetivo de diminuir a absorção de água por parte das fibras e promover melhoras na adesão com a fase matriz [26], [224], [225].

\subsubsection{Acetilação}

A acetilação é um método aplicado originalmente para estabilizar e proteger a madeira contra a umidade, melhorando a estabilidade dimensional e a resistência quanto à degradação ambiental [226]. O método de acetilação descreve uma reação que introduz um grupo funcional acetila num composto orgânico [26]. Este método de esterificação foi aplicado na modificação superficial de diversas fibras lignocelulósicas utilizadas em materiais compósitos [174], [224], [227], [228], [229], [230], [231]. O princípio do método é a reação dos grupos hidroxila (OH-) 
da fibra com os grupos acetila $\left(\mathrm{CH}_{3} \mathrm{CO}-\right)$ do anidrido acético [229]. Os grupos hidroxila nas regiões cristalinas da fibra estão intimamente empacotados, havendo fortes ligações entre cadeias. Assim, os grupos $-\mathrm{OH}$ que reagem mais facilmente são os dos constituintes amorfos da fibra, isto é, lignina, hemiceluloses, e celulose amorfa [186], [227]. Não obstante, o processo de acetilação pode ser acelerado usando catalisadores, o que permitiria atingir também os grupos hidroxila da celulose cristalina que não são facilmente acessíveis [26]. Além do ácido sulfúrico, ácido perclórico e cloreto de zinco têm sido utilizados como catalisadores para a acetilação [186]. A reação que acontece durante o processo de acetilação nas fibras lignocelulósicas, é representado como:
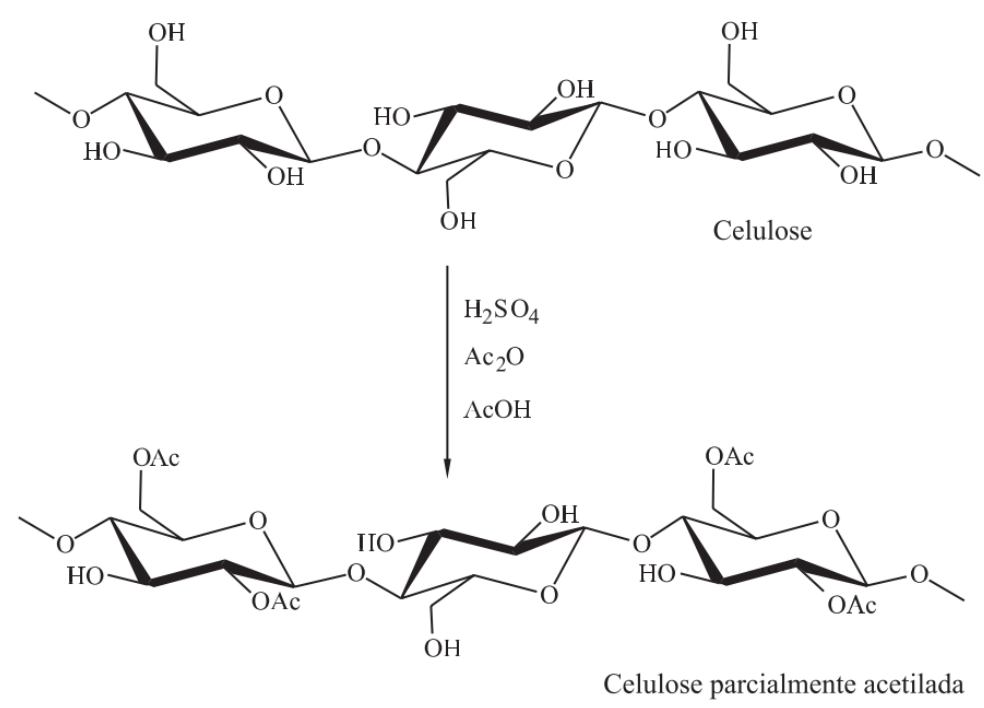

Figura 31 - Esquema da acetilação parcial da celulose [162], [174].

A absorção de umidade em fibras naturais é devida principalmente à coesão de moléculas de hidrogênio aos grupos hidroxila livres da celulose, presentes na parede celular [26]. Por conseguinte, ao substituir os grupos hidroxila da parede celular de fibras lignocelulósicas com grupos acetila pela modificação química de acetilação, a superfície das fibras se torna mais hidrofóbica [174], [225]. Redução de cerca de $50 \%$ da absorção de umidade para fibras de juta acetiladas e até $65 \%$ para fibras de pinho acetiladas foram reportadas na literatura [26]. A acetilação também aumentou a energia livre superficial e a capacidade de interação polar de fibras de linho [232]. O tratamento de acetilação em fibras lignocelulósicas também foi útil na melhora da adesão fibra-matriz em compósitos poliméricos [174], [233]. Ao reduzir a natureza higroscópica das fibras naturais a acetilação pode também aumentar a estabilidade dimensional de compósitos reforçados por fibras [229]. 
A redução na polaridade das fibras de bucha alcançada por meio do tratamento de acetilação, aumenta a compatibilidade da bucha tratada com matrizes poliméricas apolares usualmente empregadas em compósitos [162]. D’Almeida, et al. (2005) estudaram o efeito do tratamento de acetilação, usando uma solução de anidrido acético e ácido acético com ácido sulfúrico como catalisador sobre a estrutura e a morfologia superficial de fibras de bucha e apresentaram os mecanismos envolvidos na reação destes compostos com as fibras lignocelulósicas. O efeito do tratamento foi analisado por MEV e FTIR. Os resultados indicaram que houve uma reação parcial dos grupos hidroxila presentes na superfície da bucha, causando uma redução na polaridade da fibra. Também foi observada a remoção da camada superficial das fibras de bucha, expondo a sua estrutura fibrilar interna, aumentando a área disponível para a adesão [162]. A modificação química por acetilação também foi realizada em fibras de piaçava e curauá, previamente mercerizadas com $15 \%$ e $5 \%$ de $\mathrm{NaOH}$, respetivamente. Os tratamentos apresentaram como resultado fibras de piaçava mais hidrofóbicas. Por outro lado, as fibras de curauá foram totalmente destruídas pelo tratamento de acetilação [174]. A modificação química de fibras de sisal por acetilação, melhorou as características de adesão interfacial das fibras com uma matriz de polipropileno [234] e com uma matriz de polietileno reciclado de alta densidade [233]. A modificação por acetilação de fibras de linho, melhorou a eficiência na transferência de tensões na interface em compósitos linho/polipropileno [235].

\subsubsection{Tratamento alcalino (Mercerização)}

O processo de alcalinização baseia-se no mesmo princípio que o processo de mercerização para as fibras de algodão, no qual as fibras naturais são tratadas com uma solução alcalina, tal como hidróxido de sódio $(\mathrm{NaOH})$, resultando numa alteração das propriedades das fibras. Originalmente, o tratamento foi realizado para melhorar o brilho e a afinidade com corantes, mas diversas pesquisas tem revelado que a alcalinização também tem um efeito positivo nas propriedades de materiais compósitos fabricados com fibras tratadas por este método [26], [224], [225], [227], [234], [236], [237], [238], [239], [240]. Este tratamento alcalino consiste na imersão das fibras numa solução de $\mathrm{NaOH}$ com concentração, temperatura e tempo de imersão pré-determinados [26]. A adição de hidróxido de 
sódio aquoso $(\mathrm{NaOH})$ às fibras naturais promove a ionização do grupo hidroxila para o alcóxido. Segundo alguns autores, os grupos hidroxila hidrófilos na celulose são parcialmente removidos e devido a isto, a resistência à umidade é melhorada [223], [241]. A reação representada pela eq. 2 ocorre como resultado do tratamento alcalino [242], considerando que os grupos $\mathrm{OH}$ presentes nas fibras correspondem principalmente às hidroxilas alcoólicas [243]:

$$
\text { Fibra }-\mathrm{OH}+\mathrm{NaOH} \rightarrow \text { Fibra }-\mathrm{O}-\mathrm{Na}+\mathrm{H}_{2} \mathrm{O}
$$

Equação 2

O tratamento alcalino promove a remoção de constituintes parcialmente amorfos nas fibras [236], [244]. As hemiceluloses são solúveis em baixas concentrações de álcali, enquanto que a lignina sofre hidrólise básica resultando em fenol, siringol e guaiacol [245]. Também é removida certa porção de pectina, cera e materiais oleosos solúveis em solução alcalina. Como resultado, a superfície da fibra torna-se mais limpa e a adesão mecânica aumenta, causando melhoras na capacidade de transferência de tensão [223]. Por outro lado, ao serem removidos esses compostos, a fração cristalina da celulose aumenta, dando como resultado aumentos no índice de cristalinidade das fibras tratadas [240]. Além disso, o tratamento alcalino também transforma a forma cristalina da celulose I em celulose II que é termodinamicamente mais estável [242], [246], [247]. Fibras lignocelulósicas tratadas com $\mathrm{NaOH}$ também apresentam uma maior rugosidade superficial e o aumento da área de contato promove uma melhor aderência com matrizes poliméricas por ancoramento mecânico [236].

$\mathrm{Na}$ Figura 32 se apresenta um esquema do possível efeito do tratamento alcalino sobre a estrutura de fibras lignocelulósicas.
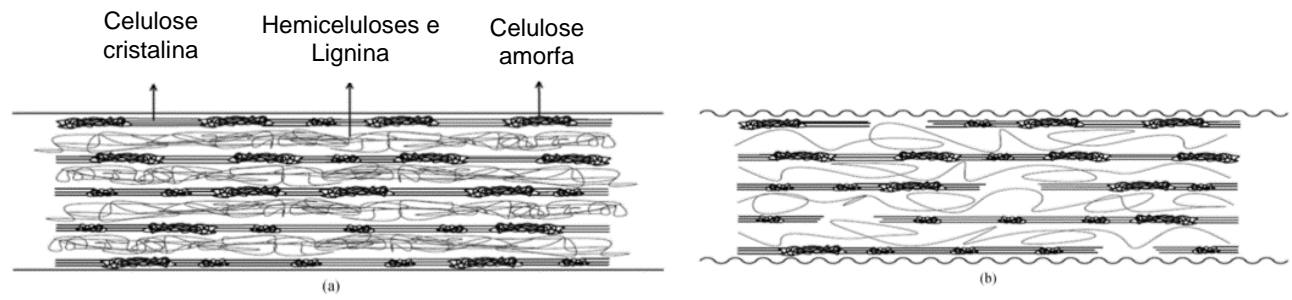

Figura 32 - Ilustração esquemática apresentando o efeito hipotético do tratamento alcalino sobre a estrutura de fibras lignocelulósicas (a) fibra não tratada (b) Fibra mercerizada [240].

É provável que a região interfibrilar seja menos densa e menos rígida depois do tratamento alcalino. Por um lado, isso torna possível para as cadeias de celulose nativa se rearranjar com um melhor empacotamento ao longo da direção da deformação por tração [234], mas também sugere que o tratamento alcalino poderia 
criar vazios na estrutura da fibra, responsáveis pela diminuição do módulo de Young [26], [247]. No entanto, foi reportado o aumento nas propriedades mecânicas de compósitos utilizando fibras de sisal tratadas com álcali, sugerindo que os vazios criados pelo tratamento foram preenchidos com PLA durante processos de injeção, melhorando a adesão mecânica e o entrelaçamento interfacial [247]. A literatura reporta que a rugosidade superficial resultante do tratamento com soda cáustica melhora a adesão fibra-matriz por entrelaçamento mecânico e o aumento de grupos hidroxila, especialmente com matrizes termo-endurecíveis, que contêm grupos funcionais polares [248]. Boynard et al. (2003) estudaram o efeito de tratamentos de mercerização com solução aquosa de $\mathrm{NaOH}$ (entre 1 - 60\%), realizados tanto a temperatura ambiente quanto a $100^{\circ} \mathrm{C}$, sobre as caraterísticas morfológicas e estruturais de fibras de bucha e sobre as propriedades de compósitos poliéster/bucha tratada. A análise da superfície com MEV sugeriu a remoção da camada exterior de lignina e hemicelulose na superfície das fibras aumentando a rugosidade e a área de contato. A solução com $\mathrm{NaOH}$ a $5 \%$ proporcionou compósitos com as melhores propriedades mecânicas à flexão. Esta melhora foi atribuída a uma maior interligação mecânica entre as fibras e a resina poliéster pelas alterações morfológicas na superfície [236]. Na tabela 4 estão apresentados os resultados obtidos por Boynard relacionando as propriedades mecânicas de compósitos de bucha em função da porcentagem de $\mathrm{NaOH}$ usado no tratamento superficial das fibras.

Tabela 4 - Propriedades mecânicas em flexão de compósitos poliéster/bucha como função da concentração de $\mathrm{NaOH}$ [236].

\begin{tabular}{|c|c|c|c|c|}
\hline \multirow{2}{*}{$\begin{array}{c}\text { NaOH } \\
(\%)\end{array}$} & \multicolumn{2}{|c|}{$\begin{array}{c}\text { Tratamento à temperatura } \\
\text { ambiente }\end{array}$} & \multicolumn{2}{c|}{ Tratamento à $\mathbf{1 0 0}^{\circ} \mathrm{C}$} \\
\cline { 2 - 5 } & $\begin{array}{c}\text { Resistência à } \\
\text { flexão (MPa) }\end{array}$ & $\begin{array}{c}\text { Módulo } \\
\text { Elástico (GPa) }\end{array}$ & $\begin{array}{c}\text { Resistência à } \\
\text { flexão (MPa) }\end{array}$ & $\begin{array}{c}\text { Módulo Elástico } \\
(\mathbf{G P a})\end{array}$ \\
\hline- & $41,6 \pm 17,2$ & $2,63 \pm 0,91$ & $41,6 \pm 17,2$ & $2,63 \pm 0,91$ \\
\hline 1 & - & - & $44,9 \pm 7,3$ & $2,52 \pm 0,85$ \\
\hline 5 & $46,4 \pm 10,3$ & $3,22 \pm 1,05$ & $47,1 \pm 8,3$ & $3,02 \pm 1,14$ \\
\hline 10 & $41,1 \pm 9,5$ & $2,41 \pm 0,48$ & - & - \\
\hline 20 & $41,7 \pm 11,1$ & $2,51 \pm 0,91$ & - & - \\
\hline 40 & $29,8 \pm 12,3$ & $1,83 \pm 1,01$ & - & - \\
\hline 60 & $38,8 \pm 3,2$ & $2,30 \pm 0,16$ & - & \\
\hline
\end{tabular}

Tanobe et al. (2005) caracterizaram fibras de bucha tratadas com solução aquosa $2 \% \mathrm{NaOH}$ e com metacrilamida (1-3\%) em tempos de tratamento variáveis. Mudanças químicas e morfológicas na superfície das fibras, após os tratamentos 
químicos foram evidenciadas usando FTIR, MEV, DRX e XPS. Ambos os métodos de tratamento indicaram o aumento da área superficial. Porém, o tratamento com metacrilamida prejudicou a integridade das fibras de forma permanente. $\mathrm{O} \mathrm{NaOH}$, por outro lado, apresentou o mesmo efeito benéfico, sem causar um dano exagerado às fibras [206].

Sgriccia, et al. (2008) realizaram experimentos para caracterizar a superfície de fibras de kenaf e cânhamo tratadas por mercerização e com agentes silano e o efeito dos tratamentos sobre a absorção de água em compósitos. Verificaram que compósitos com matriz epóxi reforçados com fibras tratadas com 5\% de $\mathrm{NaOH}$ durante uma hora e temperatura ambiente apresentaram um comportamento mais hidrofílico do que compósitos com fibras tratadas com silano ou com álcali e silano. Imagens de MEV da superfície das fibras tratadas indicaram que, enquanto o tratamento alcalino removeu a lignina e a hemicelulose da superfície das fibras naturais o tratamento com silano revestiu as fibras [249].

Ghali et al. (2009) trataram fibras de bucha pelo método alcalino com diferentes temperaturas e concentrações de $\mathrm{NaOH}$. A análise por MEV revelou uma alteração das características topográficas superficiais e análises por DRX revelaram um aumento na cristalinidade das fibras. Com o tratamento realizado com $4 \%$ $\mathrm{NaOH}$, a $120^{\circ} \mathrm{C}$, durante $3 \mathrm{~h}$, foi obtido um incremento maior no índice de cristalinidade das fibras [244]. Barreto et al. (2010) estudaram o comportamento de materiais compósitos de bioresina fenólica reforçada com fibras naturais de juta modificadas utilizando tratamento alcalino com soluções de $\mathrm{NaOH}$ (5 e 10\%).

A melhora na estabilidade térmica das fibras foi verificada por análise termogravimétrica. Os compósitos de fibra de juta apresentaram melhoras nas propriedades mecânicas com fibras tratadas com $\mathrm{NaOH}$ a 5\% [250]. Ghali et al. (2011) caracterizaram fibras de bucha através de MEV e FTIR, verificando a remoção de impurezas na superfície após os tratamentos químicos das fibras (mercerização e acetilação). Quanto ao comportamento hidrofílico, encontraram que a acetilação foi o processo mais eficiente para diminuir a absorção de água tanto em fibras de bucha quanto em compósitos poliéster/bucha, comparado com tratamentos com $\mathrm{NaOH}$ e combinado $(\mathrm{NaOH}+$ peróxido de hidrogênio) [221]. 
Yousif et al. (2012) estudaram as propriedades de flexão de resinas epóxi reforçadas com fibras de kenaf unidirecionais tratadas com solução de $\mathrm{NaOH}$ a $6 \%$. Os resultados revelaram que o reforço de epóxi com fibras de kenaf tratadas aumentou a resistência à flexão do compósito em cerca de $36 \%$, enquanto que as fibras não tratadas introduziram uma melhoria de $20 \%$. Isto deveu-se principalmente à melhoria do tratamento alcalino na adesão interfacial das fibras que impediram o descolamento ou remoção das fibras [251].

Yan et al. (2012) fabricaram compósitos de resina epóxi reforçados com fibras de linho e bambu em forma de tecidos. Foi investigada a influência do tratamento alcalino (com solução de $\mathrm{NaOH}$ a $5 \%$ em peso durante $30 \mathrm{~min}$ ) sobre as propriedades de tração, a morfologia superficial e as propriedades mecânicas. O tratamento alcalino teve um efeito negativo na resistência à tração e no módulo dos fios de linho e bambu. No entanto, após o tratamento, as propriedades de tração e flexão de todos os compósitos aumentaram. A resistência à tração e à flexão do compósito epóxi/linho tratado aumentou $21,9 \%$ e $16,1 \%$, respectivamente, em comparação com o não tratado. Pela análise das superfícies fraturadas à tração se encontrou que depois do tratamento todos os compósitos apresentaram uma melhoria da aderência interfacial epóxi/fibra [238].

Tanobe, et al. (2014) encontraram que o tratamento de fibras de bucha com metacrilamida foi eficiente na diminuição da absorção de água dos compósitos poliéster/bucha modificadas com metacrilamida. Para fibras tratadas com $2 \%$ $\mathrm{NaOH}$ durante 90 minutos, se obtiveram compósitos com energia de fratura mais elevada e as melhores propriedades de tração. Para estas condições de modificação, o módulo de Young aumentou de $~ 3200 \mathrm{MPa}$ para $5200 \mathrm{MPa}$, além de ter uma resistência à tração maior $22 \mathrm{MPa}$ em comparação com aqueles com fibras não tratadas $14 \mathrm{MPa}[222]$.

\subsubsection{Hornificação}

"Hornificação" é um termo usado para descrever alterações estruturais irreversíveis que fibras lignocelulósicas experimentam como consequência de ciclos repetidos de remoção de água e hidratação [252], [253]. Originalmente, este 
processo foi expressado pela palavra alemã "verhornung", traduzida para o inglês pela primeira vez como "cornification" e mais tarde tendo mudado para "hornification" [254]. O fenômeno de hornificação consiste na formação de regiões pseudocristalinas na estrutura da parede celular de fibras vegetais, como resultado da histerese, quando ocorre o contato entre as cadeias de celulose, com a remoção de água. Algumas características das fibras lignocelulósicas são alteradas pelo processo, apresentando redução do diâmetro médio, menor capacidade de hidratação, menor flexibilidade e maior estabilidade dimensional da fibra [254], [255], [256], [257], [258]. Além disso, este processo tem demostrado uma redução na espessura da parede celular [254].

A hornificação pode ser realizada por prensagem e secagem das fibras à temperatura ambiente ou por secagem forçada no forno. A capacidade de retenção de água das fibras celulósicas diminui de forma irreversível pela formação de ligações de hidrogênio nas cadeias de celulose quando sujeitas a ciclos de secagem e re-umedecimento [259]. A Figura 33 apresenta uma representação dos estágios de hornificação de uma fibra lignocelulósica.

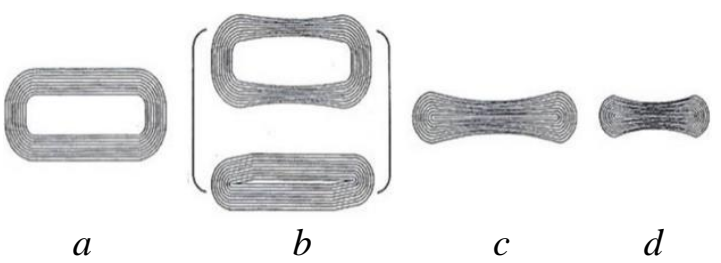

Figura 33. Contração da secção transversal de uma fibra durante o processo de hornificação [254], [259].

A etapa (a) representa a fibra molhada antes da secagem. Na etapa $(b)$, a drenagem da água começa a provocar alterações morfológicas na parede celular e as lamelas começam a aproximar-se devido às forças capilares. Durante esta fase o lúmen pode entrar em colapso. Com a secagem adicional, os espaços entre lamelas continuam encolhendo para o estágio $(c)$. No final da secagem, no estágio $(d)$, a remoção de água ocorre na estrutura fina da parede da fibra. $\mathrm{O}$ encolhimento ocorrido no estágio (d) é considerado irreversível [259].

O colapso da parede de fibra começa e tem o efeito mais significativo após o primeiro ciclo de secagem e continua a ocorrer após cada ciclo de secagem e remolhagem. No entanto, alguns autores reportam que este comportamento é 
estabilizado após dois ou três ciclos [254]. Brancato (2008) apresentou os resultados do estudo de superfícies de fibras hornificadas por AFM, quantificando as alterações com o objetivo de determinar os efeitos da hornificação [252].

Ciclos de secagem e umedecimento, tem sido realizados sobre polpas celulósicas de eucalipto e pinus branqueadas e não branqueadas, com o objetivo de otimizar suas características e permitir uma maior durabilidade e desempenho de compósitos com matriz de cimento [256]. Ferreira et al. (2012) avaliaram a influência da hornificação de fibras de sisal no seu comportamento físico (variações dimensionais e absorção de água), mecânico (comportamento sob cargas de tração direta) e microestrutural (modificações superficiais da fibra e sua estrutura). Os resultados indicaram maior estabilidade dimensional, redução na capacidade de absorção de água, aumento na resistência à tração e na capacidade de deformação e redução no módulo de elasticidade das fibra de sisal em consequência do processo de hornificação realizado. Além disso, acréscimos na carga de arrancamento foram observados indicando uma maior aderência da fibra hornificada à matriz de cimento [257]. Também têm sido estudado o efeito da hornificação sobre propriedades de fibras de sisal, curauá e juta e sobre as características de interface com matrizes de cimento livre de hidróxido de cálcio. Os resultados indicaram que a resistência à tração da fibra de sisal aumentou 5\% após o tratamento, enquanto que foi observada uma redução de $16 \%$ na rigidez e um aumento da capacidade de deformação. Para as fibras de curauá, o tratamento de hornificação resultou em aumento de resistência à tração e rigidez em cerca de $29 \%$ e $113 \%$, respectivamente, mantendo a mesma capacidade de deformação. Nas fibras de juta, o tratamento resultou na redução da resistência à tração (3\%) e do módulo de Young (13\%) [260].

\subsection{Cristalinidade}

Para determinar a cristalinidade em fibras lignocelulósicas é necessária a determinação precisa do conteúdo de celulose. A proporção da parte cristalina em cadeias de celulose é normalmente expressa em \% ou pelo índice de cristalinidade (IC). A difração de raios-X é um método utilizado para estudar a cristalinidade devido à difração dos picos de celulose cristalina (Figura 34). No entanto, a dispersão de raios $\mathrm{X}$ correspondente à parte amorfa das amostras (hemicelulose, lignina, celulose amorfa) também é considerada [187]. 


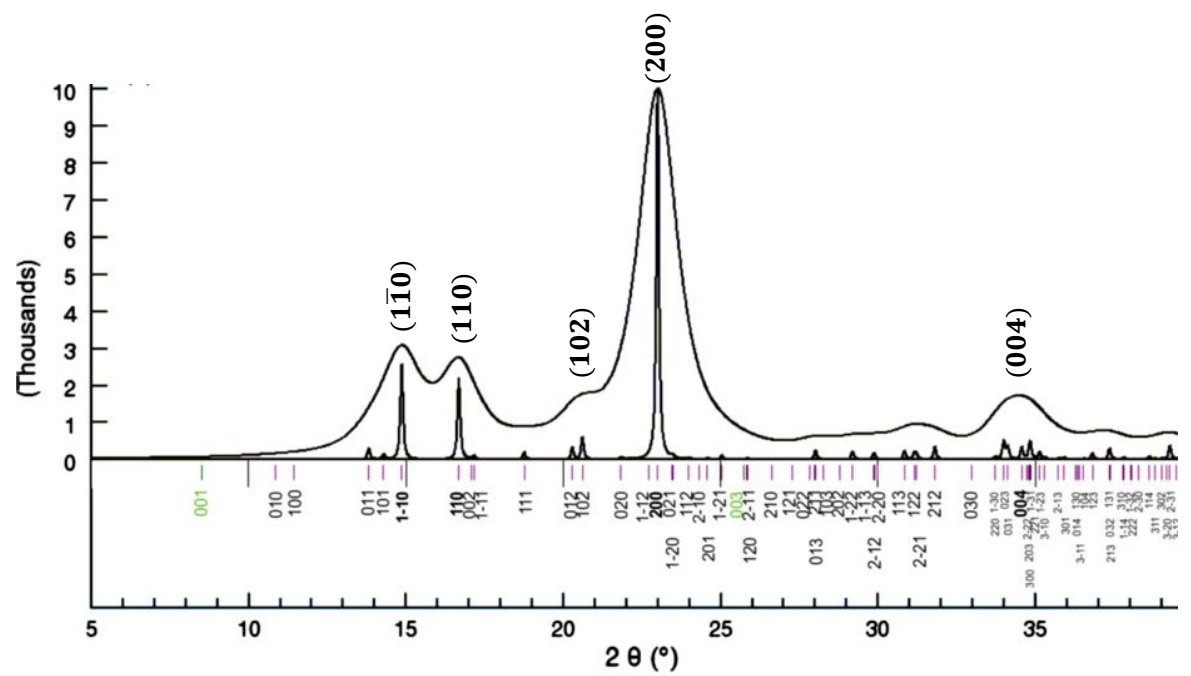

Figura 34 - Difratograma para Celulose $\mathrm{I}_{\mathrm{b}}$ com orientação aleatória dos cristalitos [261].

A determinação do índice de cristalinidade por meio de difratogramas DRX fornece uma avaliação da estrutura cristalina ou do conjunto de componentes cristalinos e amorfos presentes no material, o qual é útil para interpretar as mudanças na estrutura da celulose após os tratamentos biológicos e físico-químicos [204], [244], [262]. A região cristalina da fibra, possui maior resistência à tração, ao alongamento e à solvatação (absorção de solvente). A resistência à tração na região cristalina é 15 vezes maior do que o valor apresentado na região amorfa, onde a fibra possui maior flexibilidade. Tem-se demostrado empiricamente que a resistência à tração e módulo de elasticidade de fibras lignocelulósicas, dependem do conteúdo de celulose ao quadrado [263].

Conforme dito anteriormente, o índice de cristalinidade (IC) da celulose é usado para interpretar mudanças na estrutura da celulose após os tratamentos físicoquímicos e biológicos. No entanto, o IC varia significativamente, dependendo da escolha do método de medição [264], [265], [266], [267] que incluem DRX [268], RMN de estado sólido [266], espectroscopia de infravermelho (IV) [269] e espectroscopia Raman [270]. A Figura 35 apresenta valores de cristalinidade para o IC de Avicel PH-101, um tipo de celulose amplamente relatada em diferentes pesquisas. Estes valores foram obtidos por diferentes autores utilizando quatro técnicas de medição diferentes. 


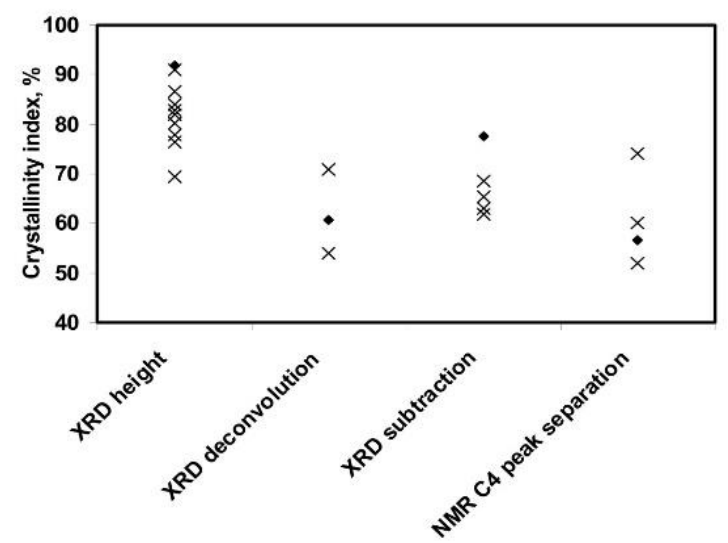

Figura 35 - IC de Avicel PH-101 para diferentes métodos de medição [265].

O IC calculado a partir de espectros de FT-IR, DRX ou medições de RMN tem sido comparado por vários autores. No entanto, a determinação de IC utilizando espectroscopia de transformada de Fourier (FT-IR) medindo as alturas relativas dos picos ou áreas não é uma técnica de medição absoluta e dá apenas valores relativos, dado que o espectro sempre contém contribuições de regiões cristalinas e amorfas.

A medição do IC por DRX fornece uma avaliação qualitativa ou semiquantitativa das quantidades de componentes celulósicos amorfos e cristalinos em uma amostra. Para calcular o IC de celulose a partir dos espectros de DRX, têm sido utilizados diferentes métodos, que serão detalhados a seguir.

\subsubsection{Método da altura dos picos}

Este método foi desenvolvido especialmente para o estudo do índice de cristalinidade de celuloses nativas. Diversas variantes deste método foram propostos por Ant-Wuorinen, Klark, Wakelin e Segal. O método empírico de Segal et al. (1959) é o mais amplamente usado. Está baseado na intensidade medida em dois pontos no difratograma [271]. Na Figura 36 se apresenta um espectro DRX de celulose microcristalina, com os picos de intensidade usado para o cálculo do IC por este método. Neste processo é medida a intensidade de interferência no plano cristalino $002\left(I_{002}, 2 \theta=22,7^{\circ}\right)$ e o espalhamento amorfo $\left(I_{a m}, 2 \theta=18^{\circ}\right)$. O índice de cristalinidade é calculado usando a eq. 3 [262], a partir da razão entre a altura do pico de intensidade cristalino $\left(I_{002}-I_{a m}\right)$ e a intensidade total $\left(I_{002}\right)$.

$$
I C=\frac{I_{002}-I_{a m}}{I_{002}} \times 100
$$

onde, 
$I C=$ índice de cristalinidade

$I_{a m}=$ intensidade de difração amorfa (representa somente material amorfo)

$I_{002}=$ intensidade máxima de difração (representa material tanto cristalino como amorfo)

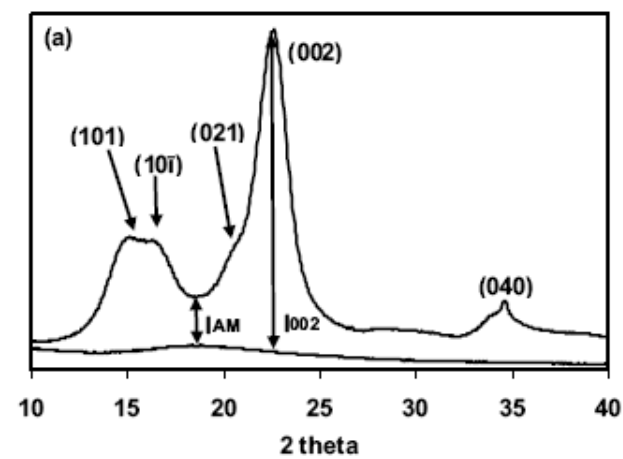

Figura 36 - Espectro de difração de raios X de celulose microcristalina, ilustrando método da altura dos picos (Peak height) para calcular o IC [265].

Este método é considerado útil para comparar as s relativas entre várias amostras. No entanto, alguns autores sugerem que não deve ser utilizado como um método para estimar a quantidade de material cristalino e amorfo numa amostra de celulose. Entre outros motivos, porque existem pelo menos quatro picos cristalinos, mas apenas o pico mais alto (002) é utilizado no cálculo. Isso exclui as contribuições dos outros picos cristalinos, enfatizando o resultado apenas em uma contribuição. Além disso, os picos no espectro de difração de celulose são muito amplos e variam consideravelmente na sua largura [265]. Então, uma comparação simples de altura não pode fornecer uma estimativa razoável de cristalinidade de celulose, pois a variação na largura do pico, também pode ser afetada pelo tamanho de cristalito [272].

\subsubsection{Método da deconvolução dos picos}

Este método requer um software para separar as contribuições amorfa e cristalina no espectro de difração, utilizando um processo de ajuste de curva. Para a deconvolução dos espectros de DRX, algumas hipóteses têm de ser feitas, tais como a forma e o número de picos. Funções Gaussiana [273], de Lorentz [274] e Voigt [272] têm sido utilizadas. A Figura 37 apresenta os picos cristalinos individuais que são extraídos a partir de perfis de intensidade de difração [265]. 


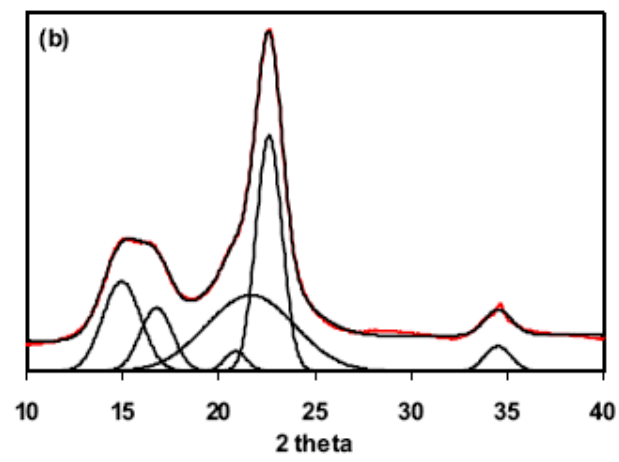

Figura 37 - Espectro de difração de raios X de celulose microcristalina, ilustrando o método da deconvolução dos picos para calcular o IC [265].

A análise quantitativa das fases cristalina e amorfa das curvas experimentais se dá pela integração matemática e somatória das áreas. Assim, o IC é calculado a partir da relação entre a área de todos os picos cristalinos e a área total [265].

\subsubsection{Método da subtração da área amorfa.}

Outros métodos, são fundamentados na extração das áreas cristalinas e não cristalinas do difratograma. No método de Jayme-Knolle (J-K) [275], o fundo incoerente é eliminado e, então, a área de dispersão não-cristalina é aproximada por um triângulo com vértices em $2 \theta$ de $10,18,5$ e 30 graus. De acordo com o método descrito por Ruland [267] o índice de cristalinidade é determinado após a subtração da contribuição não cristalina do difratograma total da amostra, utilizando a difração de um padrão amorfo como base (Figura 38). O IC é calculado dividindo a área do difratograma restante devido a celulose cristalina pela área total do difratograma original.

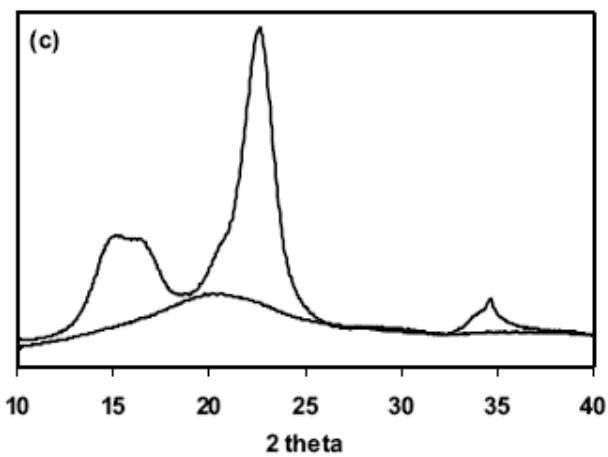

Figura 38 - Espectro de difração de raios X de celulose microcristalina, ilustrando o método da subtração da área amorfa para calcular o IC [265]. 
Os métodos mencionados, J-K, Ruland e outros, com base na separação das áreas cristalinas e não cristalinas, têm algumas desvantagens. Um deles é o erro gerado pela inclusão de uma parte dos picos na dispersão não cristalina (amorfa), o que pode ocasionar a redução dos valores dos IC calculados.

Thygesen e colaboradores compararam algumas técnicas de análise diferentes envolvendo DRX e relataram que o IC de celulose micro cristalina (Avicel) variou significativamente, de 39\% a 67\%, dependendo da técnica utilizada [267]. Park, et al., estudaram diferentes métodos de medição de índices de difração de celulose e encontraram que o método mais amplamente utilizado, e que envolve a medição de apenas duas alturas no difratograma de raios-X, produz valores de cristalinidade significativamente mais elevados do que outros métodos. Neste estudo, fizeram comparações críticas entre as diferentes técnicas usando DRX. Além disso, mediram IC de celuloses de oito fontes diferentes para demonstrar a dissimilaridade nos resultados que pode ser obtida usando métodos diferentes [265].

\subsection{Técnica de Excitação por Impulso (TEI) [276], [277].}

A Técnica de Excitação por Impulso (TEI) é um ensaio não destrutivo para a determinação dos módulos de elasticidade dinâmicos e do amortecimento de materiais através das frequências naturais de vibração. Esta técnica mede de forma não destrutiva o módulo de Young (E), o módulo de cisalhamento $(\mathrm{G})$, a razão de Poisson (v), o amortecimento $(\xi)$. Estas frequências são obtidas por meio de um impacto mecânico de curta duração, seguido da captação da resposta acústica por um sensor, de acordo com as condições de contorno impostas (vibração no modo flexional ou torsional). Este som, ou resposta acústica, é composto pelas frequências naturais de vibração da amostra que são proporcionais aos módulos elásticos e sua amplitude decai de acordo com o amortecimento do material. A resposta acústica é transformada em sinais elétricos e processada para a obtenção do espectro de frequências (transformada de Fourier).

$\mathrm{O}$ equipamento utilizado para a obtenção das frequências naturais pelo método de excitação por impulso é composto basicamente de um sistema de suporte 
com um pulsador e um transdutor/receptor ou captador acústico, que converte a energia mecânica de vibração em um sinal elétrico.

A partir da frequência de ressonância fundamental são calculados os módulos dinâmicos, considerando a geometria, a massa, as dimensões do corpo de prova e a frequência de ressonância fundamental obtida pelo equipamento. Para geometrias simples, como placas, existe uma relação unívoca entre as frequências naturais de vibração com as dimensões, a massa e os módulos de elasticidade do corpo de prova. Assim, conhecendo-se as dimensões, a massa e as frequências naturais de vibração, o cálculo dos módulos elásticos é imediato. Esta técnica tem sido aplicada para a caraterização de módulos elásticos de madeiras e materiais compósitos.

O fator de amortecimento é uma quantidade adimensional que caracteriza o quão rápido decresce a amplitude da vibração de ressonância de um material após a sua excitação mecânica. Esta propriedade está diretamente relacionada com os mecanismos internos de dissipação de energia no material como, por exemplo, o atrito interno. $\mathrm{O}$ fator de amortecimento corresponde ao parâmetro $\zeta$ na eq. 4 [278], que descreve o decremento logarítmico na amplitude da vibração.

$$
\mathrm{A}(\mathrm{t})=\mathrm{A}_{\mathrm{o}} \cdot \mathrm{e}^{-\zeta \omega_{\mathrm{o}} \mathrm{t}} \cos \left(\omega_{\mathrm{d}} \mathrm{t}+\varphi\right) \quad \text { Equação } 4
$$

onde $A_{0}$ é a amplitude inicial de vibração, $\varphi$ é a fase inicial da vibração e $\omega_{d}$ é a frequência natural amortecida dada pela eq. 5 [278]:

$$
\omega_{d}=\omega_{o} \cdot \sqrt{1-\zeta^{2}} \quad \text { Equação } 5
$$

onde $\omega_{o}$ é a frequência natural.

O Fator de qualidade Q refere-se ao consumo de energia por ciclo de oscilação e está correlacionado com o fator de amortecimento pela eq. 6 [278]:

$$
Q=\frac{1}{2 \zeta} \quad \text { Equação } 6
$$

Tan $(\varphi)$ é uma notação comum no campo dos polímeros e indica a razão entre o componente complexo e real do módulo de elasticidade. Esse parâmetro está relacionado com o amortecimento e fator Q pela eq. 7 e a eq. 8 [278]:

$$
\begin{aligned}
\tan \varphi=\frac{1}{Q} & & \text { Equação 7 } \\
\tan \varphi=2 \zeta & & \text { Equação 8 }
\end{aligned}
$$


As frequências de ressonância de um material estão relacionadas com os módulos elásticos. Para um corpo de prova de forma retangular, os módulos dinâmicos flexional (E) e torsional $(\mathrm{G})$ podem ser calculados com a eq. 9 e a eq. 10 [278].

$$
\begin{array}{ll}
E=0,9465\left(\frac{m f_{f}^{2}}{b}\right)\left(\frac{L^{3}}{t^{3}}\right) T_{1} & \text { Equação 9 } \\
G=\frac{4 L m f_{T}^{2}}{b}[B /(1+A)] & \text { Equação } 10
\end{array}
$$

onde, $m$ é a massa da barra, $L$ o comprimento, $b$ a largura, $t$ a espessura; $f_{f}$ é a frequência de ressonância fundamental flexional, $T_{l}$ é um fator de correção para o modo fundamental flexional dado, $f_{T}$ é a frequência fundamental para o modo torsional, A e B são fatores de correção. Os métodos dinâmicos permitem obter informações tanto quantitativas (módulos elásticos) quanto qualitativas sobre a integridade de um componente mecânico.

\subsection{Microscopia de Força Atômica (AFM)}

O microscópio de força atômica (AFM) é um microscópio do grupo dos microscópios de varredura por sonda, ou SPM (do inglês Scanning Probe Microscopy), que consiste basicamente de uma sonda, um sistema de detecção (laser e fotodiodo), um sistema de movimentação (cerâmicas piezelétricas) e um sistema de controle (software e hardware), conforme o esquema na Figura 39.

O extremo da sonda possui uma ponta nanométrica que se aproxima da superfície da amostra, forças de interação entre átomos da ponta e átomos da superfície são transmitidas o cantilever que responde à força exercida sobre ele com uma deflexão, permitindo assim uma análise topográfica tridimensional da superfície da amostra. Para determinar a deflexão, é usado um sistema de detecção composto por um feixe de laser, que incide sobre o cantilever, e por um fotodiodo sensível à posição que coleta o sinal do feixe refletido do cantilever. O sinal coletado é monitorado pelo sistema de controle que comanda o processo de varredura. 


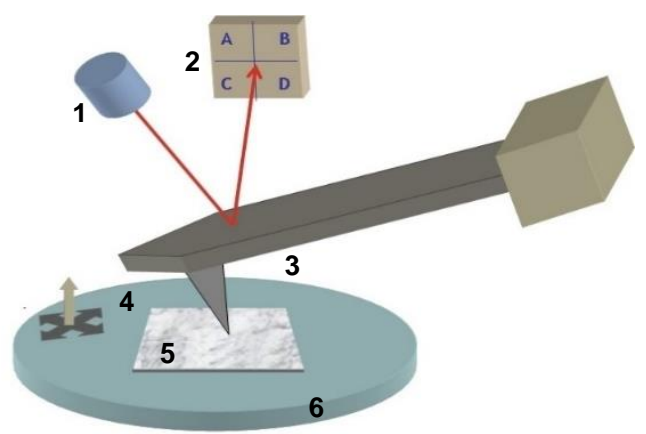

Figura 39- Diagrama de funcionamento do AFM. (1) laser, (2) Fotodiodo (detector), (3) cantilever, (4) ponta, (5) amostra, (6) cerâmica piezelétrica [279].

A sonda é um conjunto constituído pela ponta suportada em um cantilever (Figura 40). O cantilever pode ter formato retangular ou triangular e é caracterizado pela constante de mola (Spring constant) - que determina o quanto sensível o cantilever será às forças que atuarão sobre ele - e a frequiência de ressonância. As pontas podem ter formato piramidal ou cônico e são fabricadas com diversos materiais. $\mathrm{O}$ valor do raio da curvatura na extremidade da ponta é o fator que determina o poder de resolução. Dependendo da distância entre a ponta e a superfície da amostra, muda o tipo de força de interação entre elas, e a partir disso se definem os modos de operação do AFM, modo contato (domínio de forças repulsivas), modo não-contato (domínio de forças atrativas) e o modo contato intermitente (Figura 41).

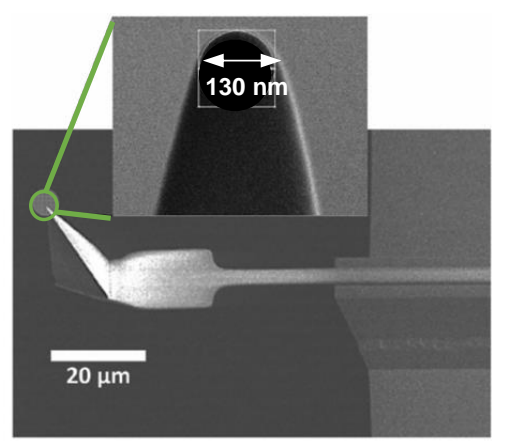

Figura 40 - Sonda (cantilever e ponta). Detalhe do raio de curvatura.

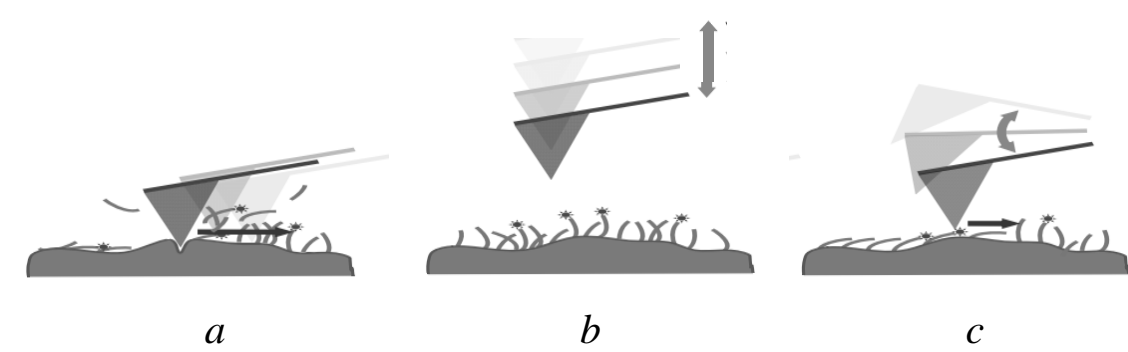

Figura 41 - Modos de operação do $\operatorname{AFM~(a)~Modo~contato~(b)~Modo~não~contato~(c)~}$ Modo contato intermitente. 
A curva de força em função da distância é uma outra forma de se analisar esta interação. Na Figura 42 pode-se observar esta relação, a qual permite avaliar o modo de trabalho do sistema.

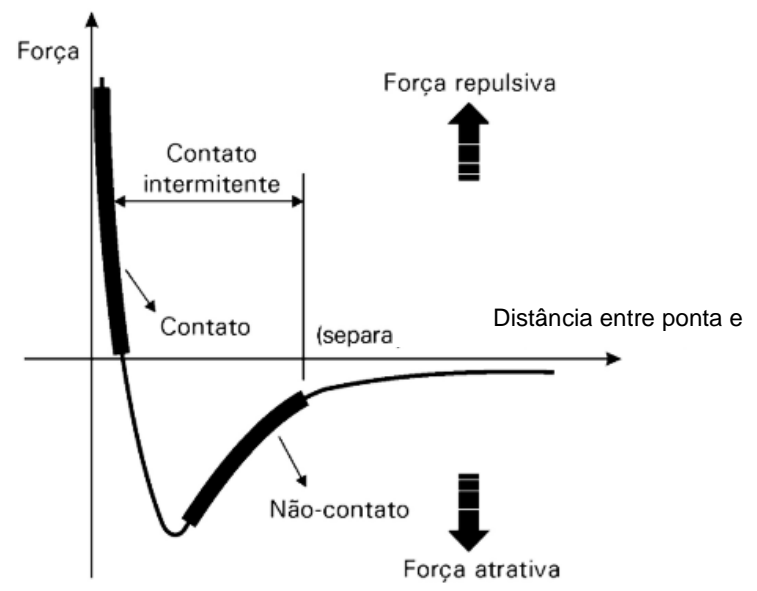

Figura 42 - Curva de força de interação ponta-superfície versus distância.

No modo de contato a ponta varre a amostra mantendo a menor distância possível, na faixa das distâncias interatômicas. As forças envolvidas são forças de repulsão, sendo necessário um cuidado grande para que a ponta não danifique a amostra. No método de não contato somente interagem forças de interação de longo alcance (Van der Waals, força eletrostática, força de dipolo magnético). Durante a aquisição de imagens quando operado no modo de contato intermitente, o cantiléver vibra por intermédio de um sistema piezoelétrico próximo a sua frequência de ressonância, a sua amplitude de oscilação é mantida constante, enquanto a sonda é aproximada à amostra gerando uma redução da amplitude da oscilação [280]. Assim, durante a varredura pode-se coletar a diferença de fase entre o sinal de estímulo de vibração do cantilever (vibração do piezelétrico oscilador) e o sinal de resposta do cantilever (oscilação do sinal no fotodiodo). As variações na diferença de fase entre os sinais são geradas por regiões da superfície da amostra com diferentes propriedades (dureza, tenacidade, aderência, etc.)[281].

Essa técnica vem sendo aplicada com bons resultados em alguns tipos de amostras consideradas macias, como por exemplo polímeros [280], [282] fibras lignocelulósicas [283], [284] e materiais biológicos [285], [286], [287] pois ao contrário do modo contato, o modo contato intermitente elimina a influência da força lateral que pode deformar ou até danificar as amostras [280], [288], [289]. No modo Peak Force Tapping (QNM), quando a sonda interage com a superfície, e a 
medida que a ponta varre a amostra, uma série contínua de curvas de força versus distância, é adquirida (Figura 43).
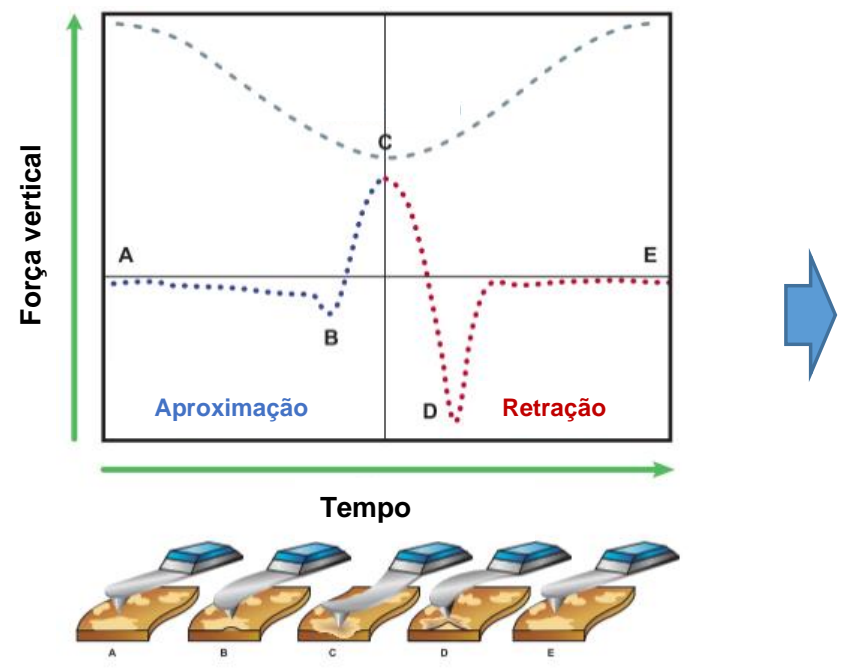

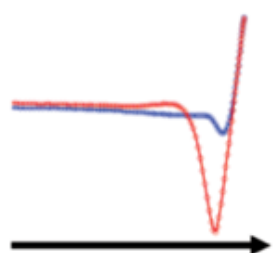

Posição Z

Figura 43 - Curva de força e posição piezoeléctrica $\mathrm{Z}$ em função do tempo, incluindo a força de pico (C) e a adesão (D). Curva Força vs. Z (direita).

A linha superior cinza representa a posição $\mathrm{Z}$ da modulação em função do tempo, a linha azul representa a força medida na sonda durante a aproximação da ponta à amostra e a linha vermelha representa a força enquanto a ponta se afasta da amostra. Quando a ponta está longe da superfície (ponto A) há pouca ou nenhuma força na ponta. A medida que a ponta se aproxima da superfície, o cantilever é puxado para baixo em direção à superfície por forças atrativas (geralmente van der Waals, eletrostática ou forças capilares). No ponto B, as forças atrativas superam a rigidez e a ponta é puxada para a superfície. A ponta permanece então na superfície e a força aumenta até que a posição $\mathrm{Z}$ da modulação alcance a sua posição mais baixa no ponto C. Isto é, onde ocorre a força de pico que é mantida constante pelo feedback do sistema durante o período de interação. A sonda então começa a se retirar e a força diminui até atingir um mínimo no ponto D. A adesão é dada pela força neste ponto. O ponto onde a ponta sai da superfície é chamado o ponto de pull-off. Uma vez que a frequência de modulação é de cerca de $2 \mathrm{kHz}$, o tempo do ponto A ao ponto E é de cerca de 0,5 ms. A Figura $91 \mathrm{~b}$ mostra os mesmos dados da Figura 91a, mas com a força em função da distância. Uma vez que a deflexão do cantilever é medida em função do tempo, é possível eliminar a variável de tempo e obter o gráfico da força contra a posição Z [290]. Para fins de ajuste, é mais útil o gráfico Força vs. Separação, onde a separação é calculada a partir da posição piezoeléctrica Z e da deflexão no cantilever [290]. 
A Figura 44 mostra um gráfico típico que ilustra o tipo de informação que pode ser obtida. As quantidades mais utilizadas são o módulo de elasticidade [291], a aderência da amostra, a dissipação de energia e a deformação máxima [292].

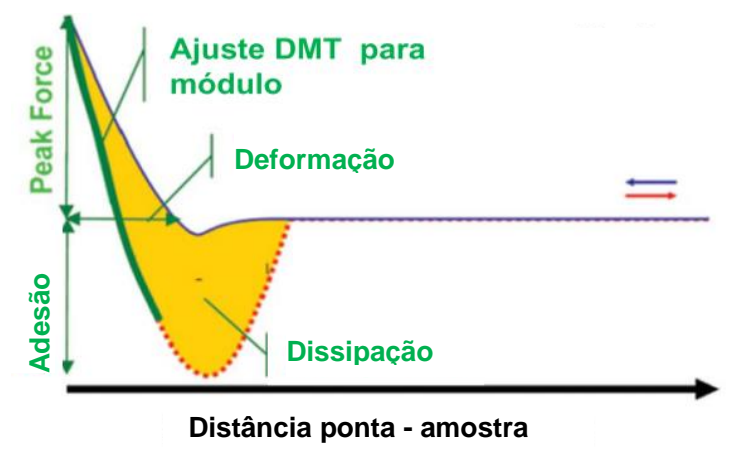

Figura 44 - Curva Força vs. Separação com a informação das propriedades nanomecânicas que podem ser obtidas usando o modelo DMT.

Para obter o módulo de Young, a curva de retração é ajustada (ver a linha verde na Figura 44) usando o modelo Derjaguin-Muller-Toporov (DMT).

As propriedades elásticas de fibras de colágeno foram estudadas utilizando a nanoidentação por AFM. As curvas de força de nanoindentação utilizando a técnica de contato intermitente mostraram um valor médio de módulo de Young de 1,2 GPa [286]. A nanoindentação também permitiu a avaliação das propriedades nanomecânicas de componentes individuais e conjuntos de proteínas. A utilidade desta técnica foi notável por sua capacidade de analisar as amostras em condições fisiológicas in situ permitindo a análise e extrapolação de dados mecânicos de biomoléculas altamente frágeis [286].

Gindl, W. e Schöberl, T. (2004) [293] estudaram os efeitos da variabilidade estrutural em paredes celulares de madeira de abeto por ensaios de nanoindentação. Encontraram que o módulo elástico da parede celular secundária diminuiu significativamente com o aumento do ângulo de microfibrila enquanto a dureza da parede celular secundária não foi estatisticamente diferente da dureza da lamela média, embora com uma alta variabilidade no ângulo de microfibrilha de celulose. Os autores encontraram incertezas na medição de propriedades nanomecânicas de fibras de madeira devido a que os valores de rigidez entre 13 e $21 \mathrm{GPa}$, obtidos a partir do ensaio de nanoindentação na direção longitudinal da madeira foram muito 
menores do que os valores de módulo obtidos a partir de ensaios de tração de fibras individuais de madeira (60-80 GPa) [294].

Tze et al. (2007) determinaram as propriedades mecânicas de fibras de madeira nativas, utilizando a técnica de nanoindentação por AFM. Os valores de dureza e rigidez dos anéis anuais de um pinheiro com ângulos de microfibrilha (AMF) entre 14 e 36 foram examinados. Foi encontrado um padrão dos valores do módulo em função dos AMF. Os resultados indicaram diferenças nos valores experimentais e preditos (modelados) influenciadas entre outros fatores pelos níveis de umidade das amostras durante a indentação [295].

L. Zou et al (2009) Estudaram a estrutura de fibras de bambu conformada por nano-grãos de celulose poligonal com um diâmetro de 21-198 nm na parede celular e realizaram ensaios mecânicos a nanoescala nas paredes celulares de fibras individuais por nanoindentação. Os mecanismos de reforço de fibras de bambu foram discutidos com referência à estrutura hierárquica e as propriedades mecânicas de componentes individuais de bambu. Foi reportado o módulo de elasticidade da parede celular das fibras com um valor de 10,4 $\pm 1,8 \mathrm{GPa}$ e foi encontrado que as paredes celulares das fibras apresentaram um módulo de elasticidade três vezes maior do que as paredes celulares do parênquima $(3,4 \pm 1,3$ GPa) e valores de dureza comparáveis com valores de $0,44 \pm 0,09$ e 0,43 $\pm 0,22$ respectivamente [296].

As propriedades nanomecânicas da parede celular de caule de algodão (Gossypium herbaceu), de talo de soja (Glycine max), palha de mandioca (Manihot esculent), palha de arroz (Oryza sativa L.) e palha de trigo (Triticum aestivum L.) foram investigados por meio de nano-indentação por AFM para avaliar o seu potencial como materiais de reforço. O módulo de elasticidade da palha de trigo foi superior ao das outras quatro fibras com um valor de 20,8 GPa. Foi determinado o módulo de elasticidade nas paredes celulares dos cinco talos de palhas por nanoindentação com valores entre 16,3 e 20,8 GPa. Isto indicou que as fibras do caule estudadas têm propriedades nanomecânicas relativamente melhores do que as fibras de madeira ou de lyocell [284]. 
Liang, et al (2014) Avaliaram as propriedades nanomecânicas de fibras de kenaf impregnadas quimicamente com nanopartículas inorgânicas. Os autores obtiveram imagens da topografia de superfície e determinaram o módulo das fibras utilizando AFM. Encontraram que a presença de nanopartículas inorgânicas de $\mathrm{CaCO}_{3}$ na superfície das fibras aumentou a rugosidade superficial média quadrática em 5,8\% e diminuiu a natureza hidrofílica das fibras, o que foi evidenciado por uma diminuição de 59,4\% na força de aderência entre a fibra e a ponta AFM hidrofílica. Além disso, pela impregnação com $\mathrm{CaCO}_{3}$ se obtivera fibras de kenaf com módulo de Young de $120 \mathrm{GPa}$ o que indicou um aumentou no módulo de 344\% com o tratamento de impregnação realizado [283].

Um método de nanoindentação com base em microscopia de força atômica foi empregado tamém para estudar como a estrutura de empacotamento de microfibrilas afeta o módulo de elasticidade de paredes celulares de plantas primárias totalmente hidratadas. O sistema avaliado por Xi et al. (2015) foi a parede celular de uma camada de cebola. Os resultados experimentais mostraram que a variação da rede de pectina, utilizando diferentes reagentes químicos, teve impactos significativos sobre o módulo da parede celular. A técnica de AFM utilizada permitiu detectar eficazmente as variações nas propriedades da parede celular, demonstrando a sua viabilidade como uma ferramenta para caracterizar as paredes de células vegetais no seu estado hidratado [297].

\subsection{Análise Térmica}

Os ensaios de análise termogravimétrica (TGA), e sua derivada (DTG), permitem a análise da variação de massa em função da temperatura e fornecem informações relevantes no estudo da estabilidade e das transições térmicas dos materiais [43]. Resinas epóxi são materiais termoendurecíveis com a formação de reticulações químicas durante o processo de cura, portanto, não fundem quando aquecidas (ao contrário dos materiais termoplásticos), mas sofrem um ligeiro amaciamento (alteração de fase) a temperaturas elevadas. Em polímeros termorrígidos, a temperatura de transição vítrea $\left(\mathrm{T}_{\mathrm{g}}\right)$ é determinada a partir da variação de um conjunto de propriedades físicas com a temperatura. A Tg não é uma transição termodinâmica discreta, mas um intervalo de temperatura sobre o 
qual a mobilidade das cadeias de polímero aumenta significativamente. Assim, a Tg indica a gama de temperaturas em que um polímero termoendurecível muda de estado duro, rígido ou "vítreo" para um estado mais flexível ou "elástico" e não deve ser confundida com o ponto de fusão $\left(\mathrm{T}_{\mathrm{m}}\right)$. $\mathrm{A} \mathrm{T}_{\mathrm{g}}$ é determinada por uma série de fatores como a estrutura química da resina epóxi, o tipo de endurecedor e o grau de cura e é normalmente medida utilizando técnicas de DSC, TGA ou DMA com algumas variações entre os resultados por cada técnica.

A energia de ativação de um material pode ser determinada usando o método Kissinger a partir de análises térmicas diferenciais. Esse método assume que a reação obedece a uma cinética de ordem n, que pode ser descrita pela eq. 11 , no qual a energia de ativação $\left(E_{a}\right)$ e o fator pré-exponencial $(A)$ são assumidos como constantes [298].

$$
\ln \left(\frac{\beta}{T_{P}^{2}}\right)=\ln \left(\frac{A R}{E_{a}}\right)-\frac{E_{a}}{R T_{P}} \quad \text { Equação } 11
$$

onde, $\beta=d T / d t$ é a taxa de aquecimento $(\mathrm{K} / \mathrm{min}), \mathrm{T}_{\mathrm{p}}$ é a temperatura de pico $(\mathrm{K})$, $A$ é o fator pré-exponencial $\left(\mathrm{min}^{-1}\right), E_{a}$ é a energia de ativação $(\mathrm{KJ} / \mathrm{mol})$. O gráfico $\ln \left(\frac{\beta}{T_{P}^{2}}\right)$ versus $\frac{1}{T_{P}}$, permite estimar $E_{a}$ e $A$, calculando a inclinação do ajuste linear e a interseção com o eixo y [299].

Boynard e d'Almeida (2000) avaliaram a estabilidade térmica de fibras de bucha através da caraterização com a técnica de análise termogravimétrica (TGA). Os diagramas TGA indicaram perdas de peso a $100{ }^{\circ} \mathrm{C}$ relacionadas com a evaporação da água retida nas fibras. Além disso, um pico acentuado observado na curva da primeira derivada indicou a homogeneidade do sistema de fibras de bucha e finalmente, segundo os resultados obtidos se encontrou que não ocorreu degradação das fibras até $250{ }^{\circ} \mathrm{C}$ [219]. Petzhold et al. (2002) estudaram a estabilidade térmica de sistemas ESO/anidrido/amina pela análise termogravimétrica (TGA). As resinas epóxi curadas foram termicamente estáveis geralmente até $300{ }^{\circ} \mathrm{C}$ e observou-se uma diminuição na estabilidade térmica quando a razão molar $\mathrm{R}$ de anidrido/epóxi aumentou [99]. Tanobe et al. (2005) também caracterizaram a estabilidade térmica de fibras de bucha provenientes do Brasil, (antes e após tratamento químico com soluções aquosas de $\mathrm{NaOH}$ e metacrilamida). O perfil da curva de TGA para as fibras sem tratamento nenhum foi semelhante ao obtido por Boynard e d'Almeida (2000). Diferentes regiões foram associadas com a perda de massa em diferentes temperaturas. Na região entre 200 - 
$260{ }^{\circ} \mathrm{C}$ ocorreu a degradação de hemicelulose, entre $240-350{ }^{\circ} \mathrm{C}$ ocorreu a degradação da celulose e entre $280-500{ }^{\circ} \mathrm{C}$ ocorreu a degradação da lignina. A temperaturas acima de $500{ }^{\circ} \mathrm{C}$ ocorre carbonização com perda acentuada de material. As fibras tratadas exibiram um ligeiro aumento na resistência térmica, e embora não tenha sido possível detectar variações significativas entre os tratamentos, ambos os métodos tiveram como resultado aumento da estabilidade térmica [206]. Tanobe et al. (2014) caracterizaram compósitos de bucha/matriz poliéster, através de ensaios de DSC e TGA. Verificaram que a perda de massa das amostras dos compósitos com fibras tratadas e sem tratar não varia significativamente até atingir $230^{\circ} \mathrm{C}$. No entanto, acima dessa temperatura os compósitos preparados com fibras modificadas superficialmente, apresentaram perdas de massa ligeiramente menores. Além disso, todos os compósitos apresentaram um perfil homogêneo durante a decomposição térmica, com degradação a partir de aproximadamente $270{ }^{\circ} \mathrm{C}$ [222].

As propriedades térmicas dos compósitos bucha/amido termoplástico (TPS) foram caracterizadas através de análise termogravimétrica (TGA) por Kaewtatip e Thongmee (2012). Os resultados confirmaram que a incorporação de fibra de bucha melhorou a estabilidade térmica do TPS [220]. Saw et al. (2013) realizaram a avaliação de compósitos epóxi/bucha. A decomposição de epóxi puro começou a uma temperatura de $238^{\circ} \mathrm{C}$ e a decomposição total ocorreu a $700^{\circ} \mathrm{C}$, enquanto que os compósitos começaram a perder peso na faixa de 255 a $335{ }^{\circ} \mathrm{C}$ deixando uma certa quantidade de resíduo carbonizado. Os resultados indicam um aumento na estabilidade térmica dos compósitos com a incorporação das fibras [241].

\subsection{Análise Dinâmico-Mecânica (DMA)}

O ensaio dinâmico-mecânico (DMA) estuda as propriedades de materiais em função da temperatura, do tempo, da frequência, de uma deformação, e/ou a combinação de tais parâmetro e tem sido uma ferramenta importante na interpretação da interfase nos compósitos. A natureza das propriedades mecânicas da ligação interfacial entre a fibra e a matriz tem uma contribuição muito significativa para o desempenho dos compósitos. O nível de interações na interface fibra-matriz em materiais compósitos reforçados com fibras lignocelulósicas tem sido interpretado por vários autores com ajuda de dados obtidos com o ensaio DMA 
[300], [301]. DMA é uma técnica confiável para a determinação da Tg de materiais compósitos por sua alta sensibilidade e por permitir que os materiais sejam analisados de forma uniforme [302]. Um dos principais objetivos desta técnica é relacionar as propriedades macroscópicas, como as propriedades termomecânicas, com relaxações moleculares, as quais podem ser ocasionadas por mudanças conformacionais e/ou deformações microscópicas geradas pela movimentação molecular [303].

Como se mostra no esquema da Figura 45, uma tensão oscilante é aplicada em uma amostra para criar uma série de curvas tensão-deformação em uma determinada frequência ou tempo. O deslocamento (deformação) e a amplitude resultante da força aplicada são medidos para que se possa, após, calcular os módulos elástico e viscoso do material. Assim, ensaios de DMA permitem medir o módulo elástico em flexão (armazenamento (E')), o módulo de perda (E') e o fator de amortecimento ( $\tan \delta$ ) (razão entre o módulo de perda e o de armazenamento) de materiais compósitos em função da temperatura.

O módulo de armazenamento ( $E$ ') é uma medida da energia máxima armazenada no material durante um ciclo de oscilação e seu valor dá uma ideia do comportamento de rigidez e a capacidade que possui um material para suportar cargas, com deformação visco elástica recuperável [304].

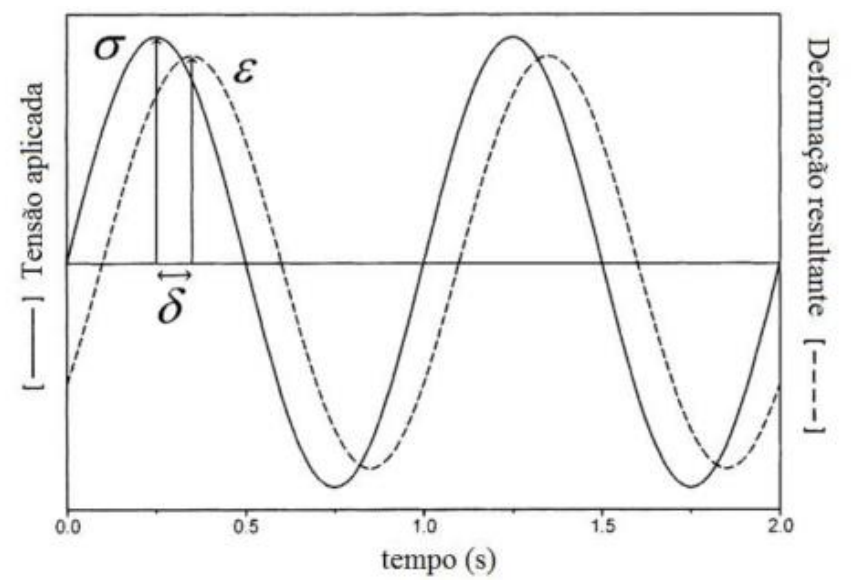

Figura 45 -Tensão $(\zeta)$, deformação $(\varepsilon)$ e ângulo de defasagem $(\delta)$ de uma análise dinâmico-mecânica.

O módulo de perda (E') representa o componente viscoso do material. Um valor de $\mathrm{E}$ "mais elevado reflete uma maior capacidade de dissipar a energia mecânica sob a forma de calor durante a deformação. O módulo de perda, é 
proporcional à quantidade de energia que foi dissipada como calor pela amostra [267].

A razão entre o módulo de perda pelo de armazenamento E''/E' resulta na tangente do ângulo de fase, notado tan $\delta$, também conhecido como fator de dissipação ou amortecimento. É uma propriedade sem dimensão e é uma medida de quão bem o material pode dispersar (absorver ou emitir) energia - em outras palavras, indica a capacidade de amortecimento da vibração durante a deformação mecânica, ou seja, a energia de dissipação do material [305].

\subsection{Absorção de Umidade}

A absorção de umidade em resinas epóxi e compósitos reforçados com madeira ou fibras vegetais causa alterações dimensionais, que são a principal razão para a redução das propriedades mecânicas e tem grande influência na sua durabilidade [306], [307]. Assim, em vista de possíveis aplicações de laminados ou produtos fabricados a partir destes materiais expostos à umidade ou em ambientes externos, é importante a compreensão dos processos de difusão de umidade em compósitos poliméricos [308]. A absorção de umidade nos materiais compósitos é governada pela natureza higroscópica das fibras naturais usadas como enchimento, e a penetração de água nos compósitos que pode ser explicada por três mecanismos principais [309]. i) A difusão de moléculas de água dentro das micro-lacunas entre cadeias de polímeros; ii) O transporte capilar de moléculas de água para as lacunas e falhas na interface entre as fibras e a resina devido à instabilidade e impregnação incompletas; iii) O transporte de moléculas de água por micro fendas na matriz que são formadas durante o processo de composição [310]. A difusão é definida como um processo no qual as moléculas de água se movimentam de uma região de maior concentração para uma de menor concentração [311]. A água penetra desde a superfície até a massa do compósito, até o equilíbrio ser atingido. Diferentes abordagens analíticas permitem modelar o comportamento de difusão de água em polímeros e compósitos. A segunda lei de difusão de Fick (eq. 12) pode ser aplicada à absorção de umidade em compósitos epóxi [312], [306], [313].

$$
\frac{\partial \mathrm{c}}{\partial t}=D \frac{\partial^{2} c}{\partial x^{2}}
$$


onde, c é a concentração do fluido, $D$ é o coeficiente de difusão, x é a distância ao longo do gradiente de difusão. A solução da eq. 12 é dada pela eq. 13 [314]:

$$
\frac{M_{\%}}{M_{\infty}}=1-\frac{8}{\pi^{2}} \sum_{n=0}^{\infty} \frac{1}{(2 n+1)^{2}} \exp \left[-D(2 n+1)^{2} \pi^{2} t / h^{2}\right] \quad \text { Equação } 13
$$

onde $M \%$ é a massa de água absorvida em um tempo t, $M_{\infty}$ é a massa de água absorvida na saturação e $h$ é a espessura dos corpos de prova.

Simplificações desta equação para valores onde $\mathrm{M} \% / M_{\infty}<0,5$ e $\mathrm{M} \% / M_{\infty}>$ 0,5 estão dadas na eq. 14 e na eq. 15 respectivamente [314].

$$
\begin{array}{cc}
\frac{M_{\%}}{M_{\infty}}=\frac{4}{h} \sqrt{\frac{D t}{\pi}} & \text { Equação } 14 \\
\frac{M_{\%}}{M_{\infty}}=1-\exp \left[-7,3\left(\sqrt{D t / h^{2}}\right)^{\mathbf{0 , 7 5}}\right] & \text { Equação } 15
\end{array}
$$

Assim, a absorção de fluidos em compósitos poliméricos pode ser identificada por meio das curvas esquemáticas que relacionam o ganho de peso com o tempo, conforme a Figura 46, que apresenta diferentes comportamentos de difusão. A curva sólida na Figura 46 aplica-se ao comportamento linear Fickiano (LF) freqüentemente usado para descrever sistemas poliméricos estáveis expostos a fluidos. As curvas "A" e "B" são variações típicas correspondentes tanto a polímeros puros como a compósitos reforçados com fibras. A variação do tipo A corresponde a um caso em que o ganho de peso nunca atinge o equilíbrio, e o tipo B representa a circunstância em que há dois estágios de difusão. Os materiais que mostram dados de ganho de peso como mostrado nas curvas "C" e "D" representam uma resposta irreversível, muitas vezes associada à perda de integridade do material e possíveis falhas estruturais. Um rápido aumento de conteúdo de fluido, acompanhado por um crescimento do dano que leva à decomposição de material, grandes deformações e falhas ocasionais, conduz a uma curva C. Enquanto que a curva "D" está relacionada com a perda de peso que é atribuível à quebra química ou física do material [313]. 


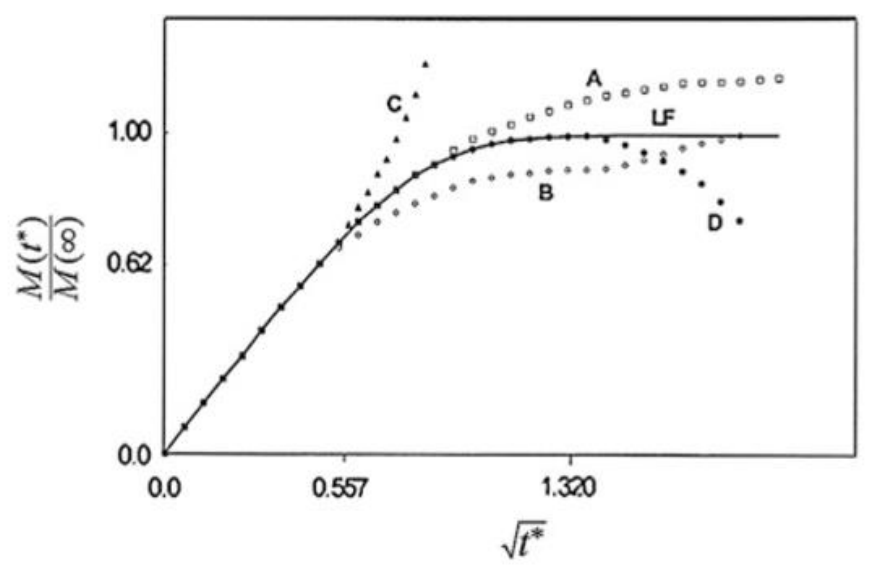

Figura 46 - Curvas esquemáticas correspondentes à difusão linear de Fick (LF) e quatro possíveis categorias de comportamento não-Fickiano (A, B, C, D) [313].

Em sistemas onde a absorção produz uma resposta não fickiana, vários modelos físicos tem sido aplicados a polímeros para descrever o processo de difusão da água em fibras naturais, como a lei de Fick de dupla etapa [315], a teoria de Langmuir [313], ou seguindo a equação proposta por McKague [218] [316]. A proteção de fibras naturais dos efeitos ambientais, por meio de tratamentos físicoquímicos tem sido amplamente estudada [162], [26], [227], [224], [317]. Entre outras razões, isso tem sido incentivado devido à sensibilidade das fibras à umidade, o que leva a alterações dimensionais e perda de propriedades mecânicas nos compósitos. 


\section{Materiais e Métodos Experimentais}

\subsection{Materiais}

Para a preparação dos materiais compósitos foram utilizadas uma resina epóxi comercial (MC 150/5, Epoxyfiber), oriunda da reação de epicloridrina com bisfenol A e resinas preparadas a partir de óleo de soja epoxidado (SOYFLEX 6250), adquirida da empresa BBC Indústria e Comércio, do éter diglicidílico de cardanol (NC-514 da Cardolite) e do éter diglicidílico de resorcinol (RDGE-H da CVC Thermoset Specialties).

Os agentes de cura utilizados foram: anidrido ftálico (PA) em presença de trietilameina (TEA) como catalizador, uma poliamina ciclo alifática primária baseada em isoforona diamina (IPDA) (FD 144, Epoxyfiber), e um agente de cura baseado no líquido da casca de caju (NX-5620 da Cardolite). Nas tabelas 5-10 estão apresentadas algumas especificações para as resinas e agentes de cura.

Tabela 5 - Especificações da resina epóxi comercial MC 150/5 (Bisfenol A).

\begin{tabular}{|c|c|}
\hline Estado físico & Líquido \\
\hline Viscosidade a $25^{\circ} \mathrm{C}(\mathrm{mPas})$ & $500-700$ \\
\hline Cor $(\mathrm{Gardner})$ & 0,5 máx. \\
\hline Peso específico a $20^{\circ} \mathrm{C}\left(\mathrm{g} / \mathrm{cm}^{3}\right)$ & 1,03 \\
\hline Consumo teórico $(\mathrm{kg}$ para cada $\mathrm{kg}$ de fibra $)$ & 1,2 \\
\hline Tempo de gel $(\mathrm{min})$ & $60-70$ \\
\hline EEW & 204 \\
\hline
\end{tabular}

Tabela 6 - Especificações do óleo epoxidado SOYFLEX 6250 (ESO).

\begin{tabular}{|c|c|}
\hline Oxigênio oxirânico & Min 6,5 \\
\hline Índice de Iodo $\left(\mathrm{cg} \mathrm{I}_{2} / \mathrm{g}\right)$ & Máx 4,0 \\
\hline Índice de Acidez $(\mathrm{mg} \mathrm{KOH} / \mathrm{g})$ & Máx 1,0 \\
\hline Cor $($ Gardner $)$ & 2 \\
\hline Peso específico $\left(\mathrm{g} / \mathrm{cm}^{3}\right)$ & $0,990+/-0,003$ \\
\hline Índice de refração $25^{\circ} \mathrm{C}$ & $1,472+/-0,003$ \\
\hline Flash Point $\left({ }^{\circ} \mathrm{C}\right)$ & Min. 290 \\
\hline EEW & 230 \\
\hline
\end{tabular}


Tabela 7 - Especificações da resina NC-514 (Cardanol).

\begin{tabular}{|c|c|}
\hline Viscosidade a $25^{\circ} \mathrm{C}(\mathrm{cps})$ & $10.000-35.000$ \\
\hline EEW & $350-500$ \\
\hline Cloro hidrolisável (\%) & $\leq 3$ \\
\hline Perda Volátil (\% peso) & $\leq 2$ \\
\hline Nível de uso recomendado (\% peso total) & $2-25$ \\
\hline Densidade $\left(\mathrm{g} / \mathrm{cm}^{3}\right)$ & 1,10 \\
\hline Ponto de inflamação $\left({ }^{\circ} \mathrm{C}\right)$ & 90 \\
\hline
\end{tabular}

Tabela 8 - Especificações da resina RDGE-H (Resorcinol).

\begin{tabular}{|c|c|}
\hline Viscosidade a $25^{\circ} \mathrm{C}(\mathrm{cps})$ & $25-371$ \\
\hline EEW & 120 \\
\hline Cloro hidrolisável, máx. (\%) & 0,07 \\
\hline Epicloridrina residual, máx. (ppm) & 0 \\
\hline
\end{tabular}

Tabela 9 - Especificações do agente de cura FD 144 (IPDA)

\begin{tabular}{|c|c|}
\hline Estado físico & Líquido \\
\hline Viscosidade a $25^{\circ} \mathrm{C}(\mathrm{mPas})$ & 40 \\
\hline Cor $($ Gardner $)$ & 0,2 máx. \\
\hline Peso específico a $20^{\circ} \mathrm{C}\left(\mathrm{g} / \mathrm{cm}^{3}\right)$ & 1,02 \\
\hline Proporção de uso* $(\mathrm{grs})$ & 20 \\
\hline Proporção de uso $(\mathrm{ml})$ & 20 \\
\hline
\end{tabular}

*Para $100 \mathrm{~g}$ de MC150/5

Tabela 10 - Especificações de agente de cura NX-5620 (Fenalcamina)

\begin{tabular}{|c|c|}
\hline Amine Value & $470-510$ \\
\hline Viscosidade a $25^{0} \mathrm{C} \mathrm{cPs}$ & $830-876$ \\
\hline Densidade a $25^{\circ} \mathrm{C} \mathrm{g} / \mathrm{cm}^{3}$ & $0,99-1,01$ \\
\hline Flash Point ${ }^{0} \mathrm{C}$ & 104 \\
\hline AHEW g/eq. & $82 / 40$ \\
\hline phr recomendado (EEW-190) & $35-45$ \\
\hline Perda Volátil \% peso & $\leq 5$ \\
\hline
\end{tabular}

Esponjas de bucha vegetal, da espécie Luffa cylindrica, provenientes do estado de São Paulo foram usadas como material lignocelulósico para o reforço dos 
compósitos. Inicialmente, as esponjas foram lavadas com água durante 2 horas e secas em um forno a $80{ }^{\circ} \mathrm{C}$ até manter um peso constante.

As esponjas foram cortadas para separar a parede intermediária do núcleo e gerar o formato de manta natural fibrosa, como foi mostrado na Figura 30. Durante o processo de corte as sementes foram retiradas e posteriormente, as mantas fibrosas foram prensadas e recortadas em lâminas do tamanho do molde metálico utilizado para a fabricação de compósitos laminados, como é mostrado na Figura 47a.

Por outro lado, as fibras tomadas do núcleo central da bucha foram processadas em um moinho de facas SOLAB SL-30, para obter fibras cortas (47b) e utilizadas também para a fabricação de compósitos.
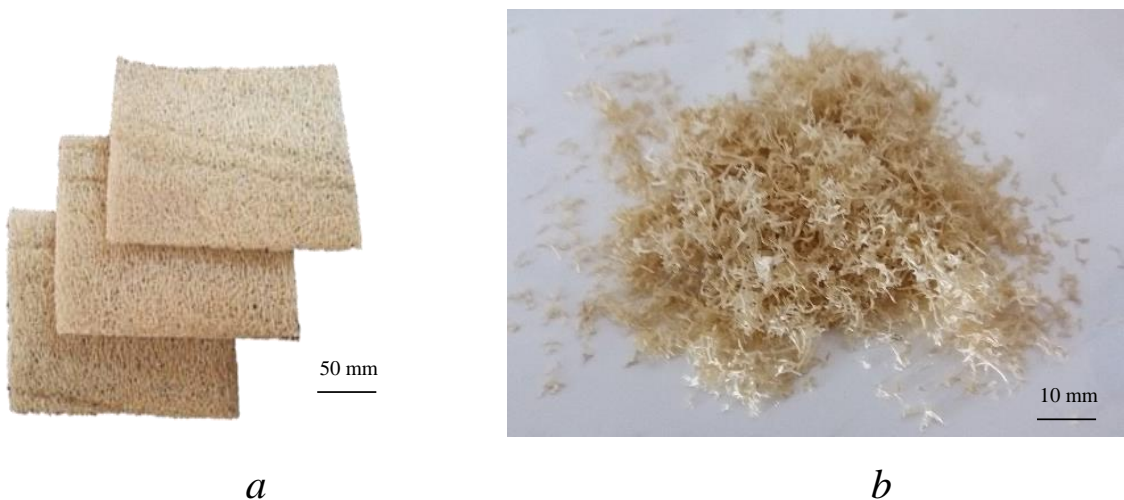

Figura 47 - Fibras de bucha vegetal. a) Manta fibrosa $\left(150 \times 200 \times 3 \mathrm{~mm}^{3}\right)$ b) Fibras curtas

Para a modificação química foram utilizados hidróxido de sódio 97\% ( $B$. Herzog), anidrido acético, 97.0\% (Vetec), ácido sulfúrico (95-99\%) (SigmaAldrich) e ácido acético (>=99\%) (Vetec).

\subsection{Modificação das fibras}

Foram realizados tratamentos superficiais para a modificação das fibras de bucha, com o objetivo de aumentar a compatibilidade e melhorar a adesão com matrizes poliméricas. Os métodos utilizados para a modificação superficial das fibras são listados no esquema da Figura 48.

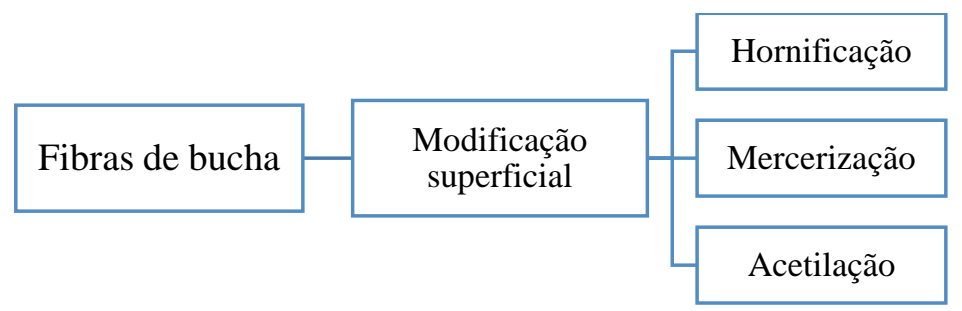

Figura 48 - Métodos de modificação superficial de fibras de bucha. 
Para o processo de hornificação as fibras de bucha foram colocadas em um recipiente com água quente durante 3 horas. Depois de retiradas do recipiente, as fibras foram secas no forno a uma temperatura de $80^{\circ} \mathrm{C}$ por 24 horas. Este processo foi repetido 5 vezes.

Para realizar a mercerização, as fibras foram imersas em solução aquosa de $\mathrm{NaOH}$ (grau analítico) $2 \%$ em peso, durante 90 min. Posteriormente, foram lavadas com água e finalmente secas no forno a $80{ }^{\circ} \mathrm{C}$.

Para a modificação superficial por acetilação, as fibras de bucha previamente mercerizadas foram imersas em ácido acético glacial durante aproximadamente 2 horas a temperatura ambiente e posteriormente em uma solução de anidrido acético, com ácido sulfúrico usado como catalisador por 15 minutos. As fibras foram retiradas da solução reagente e lavadas em seguida com água, até atingir pH entre 6 e 7. Finalmente foram secas na estufa a $80^{\circ} \mathrm{C}$ até manter um peso constante [318].

A modificação superficial das fibras de bucha foi verificada por microscopia eletrônica de varredura (MEV), espectroscopia na região do infravermelho com transformada de Fourier (FTIR) e difração de raios X (DRX).

\subsection{Caraterização das fibras de bucha}

Para definir o possível desempenho na aplicação destas fibras como material de reforço é preciso uma caracterização das suas propriedades. Segmentos das redes fibrosas foram caraterizadas estrutural, nanomecânicas e termicamente, tanto como recebidas quanto após os diferentes tratamentos superficiais realizados. A Figura 49 apresenta o esquema de caraterização das fibras.

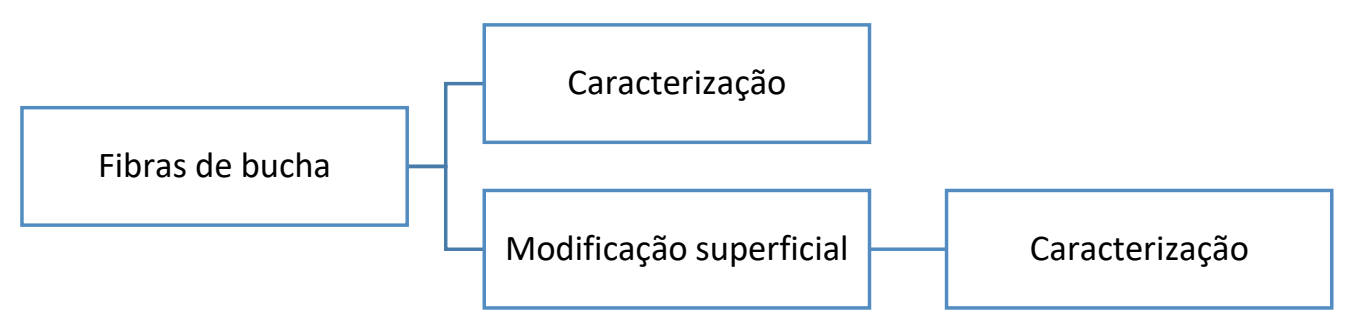




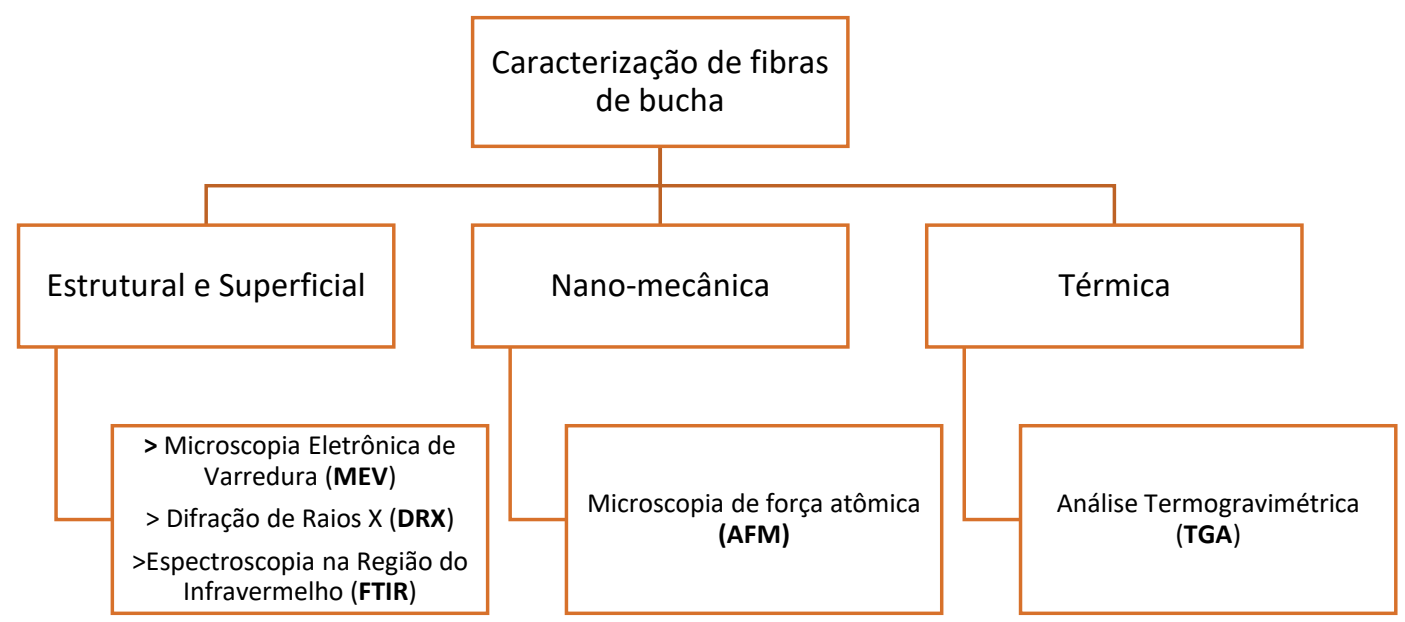

Figura 49 - Esquema da caraterização de fibras de bucha.

Para a realização dos ensaios de DRX, FTIR e TGA, as fibras de bucha correspondentes a cada amostra foram previamente moídas até se obter um pó fino usando um moinho de facas, SOLAB SL-30.

\subsubsection{Microscopia Eletrônica de Varredura (MEV)}

A análise por MEV da superfície e da seção transversal das fibras de bucha foi realizada no microscópio eletrônico de varredura JEOL JSM-6510LV, mostrado na Figura 50, usando o método de elétrons secundários e uma tensão de aceleração do feixe de elétrons de $10 \mathrm{kV}$.

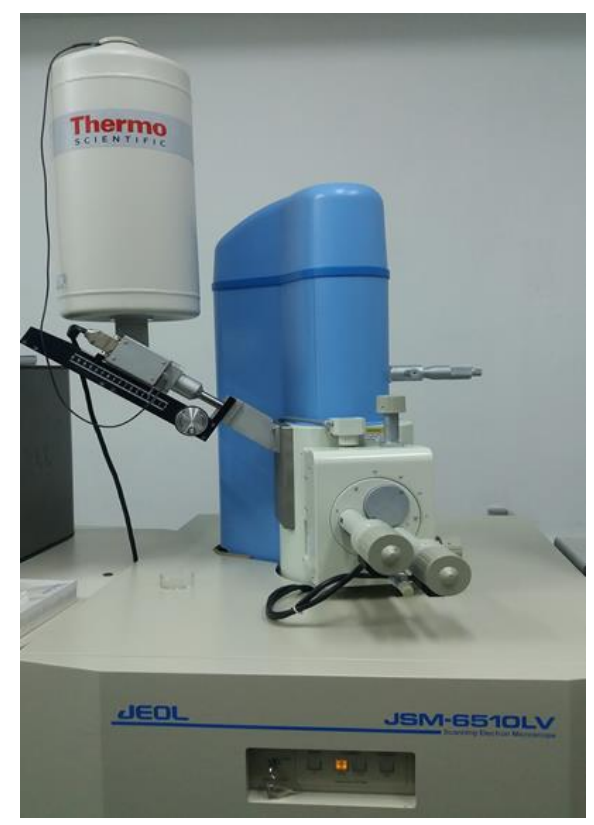

Figura 50 - Microscópio eletrônico de varredura JEOL JSM-6510LV 
A análise por MEV permitiu analisar detalhadamente a morfologia da superfície das fibras e foi utilizada para avaliar aspectos relacionados com o efeito dos tratamentos superficiais realizados. Foi realizada também, a determinação do diâmetro médio das fibras de bucha pela análise da seção transversal, utilizando para a preparação das fibras o procedimento de corte utilizado anteriormente por Navarro [181]. Posteriormente, as amostras de fibras de bucha foram metalizadas pela deposição catódica de ouro sobre a superfície de segmentos de fibras e sobre a seção transversal de fibras de bucha colocadas verticalmente na montagem da Figura 51

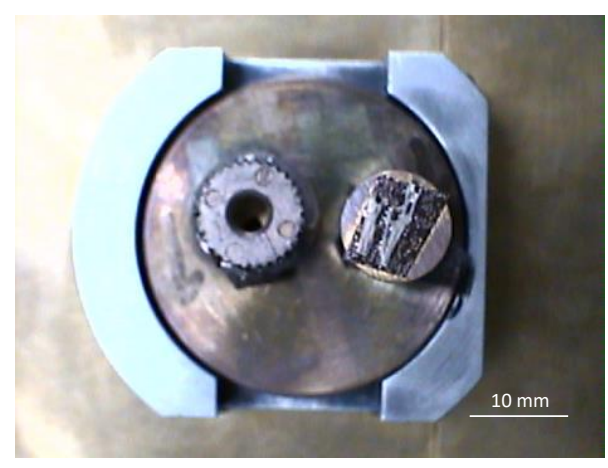

Figura 51 - Amostras de fibras de bucha para observação no MEV.

Na Figura 51, apresenta-se a vista superior da montagem realizada para a observação da seção transversal e a superfície das fibras. No lado direito da imagem são mostrados segmentos de fibras de bucha fixos em um substrato com ajuda de fita adesiva condutora para o análise da superfície e, no lado esquerdo se observa a engrenagem utilizada para manter as fibras na posição normal à superfície, durante o análise da seção transversal.

\subsubsection{Difração de Raios X (DRX)}

Os padrões de difração de raios-X das fibras com e sem modificação foram obtidos por meio de um difratômetro Bruker, da série D8 Discovery, com detector Lynxeye, com radiação de cobre $\mathrm{CuK} \alpha, \lambda=1,5418 \AA$, operando com tensão de 40 $\mathrm{kV}$ e corrente de $30 \mathrm{~mA}$, e com passo de $0,02^{\circ}$ por segundo. $\mathrm{O}$ ensaio foi realizado com variação do ângulo $(2 \theta)$ entre $5^{\circ} \mathrm{e} 70^{\circ}$. A porcentagem de cristalinidade das amostras foi calculada pelo métodos de subtração da área amorfa, de deconvolução dos picos e da altura dos picos. 
Para o primer método foi utilizada a eq. 16, que expressa a razão entre a área das regiões cristalinas $\left(\mathrm{A}_{\text {crist }}\right)$ e a área total $\left(A_{\text {total }}=A_{\text {amorfo }}+A_{\text {cristalino }}\right)$ [319].

$$
W_{C}(\%)=\frac{A_{\text {crist }}}{A_{\text {total }}} \times 100 \quad \text { Equação } 16
$$

Para o segundo método, as áreas dos picos cristalinos e do halo amorfo foram medidas pela deconvolução dos espectros com o software OriginPro, usando uma função gaussiana e o comando de ajuste de picos múltiplos.

\subsubsection{Espectroscopia no Infravermelho com transformada de Fourier (FTIR)}

A análise FTIR foi usada para a caracterização estrutural, pela determinação de grupos e compostos funcionais presentes na superfície das fibras. A eficiência dos tratamentos químicos realizados nas fibras foi verificada pela análise dos espectros na região do infravermelho entre $400 \mathrm{e}^{2} 4000 \mathrm{~cm}^{-1}$. As fibras como recebidas e com tratamento químico foram pulverizadas em um moinho obtendo um pó fino que foi seco em forno previamente à realização do ensaio. $\mathrm{O}$ equipamento usado foi um espectrofotômetro PerkinElmer, modelo Spectrum 400 (Figura 52) com uma resolução de $2 \mathrm{~cm}^{-1}$, operando com velocidade de varredura de $0,2 \mathrm{~cm} / \mathrm{s}$ e com o acessório de reflectância total atenuada (ATR).

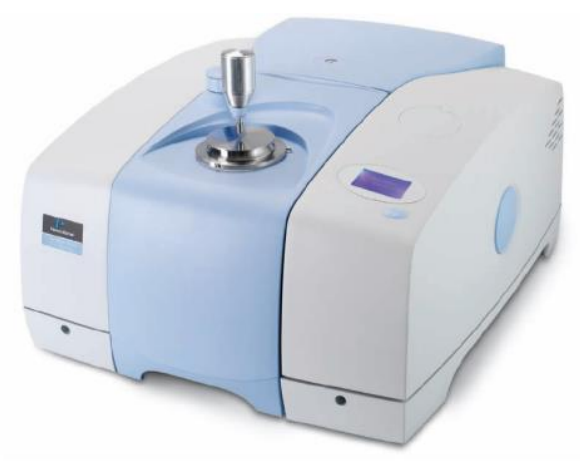

Figura 52 - Espectrofotômetro Perkin Elmer, modelo Spectrum 400.

\subsubsection{Microscopia de Força Atômica (AFM)}

Uma vez que o comprimento da fibra individual da bucha não é suficiente para a medição das propriedades mecânicas com ensaios de tração tradicionais, foi realizada uma caracterização nanomecânicas das fibras pela técnica AFM utilizando o equipamento Multimode-8 equipado com scanner e JV (125x125x5 $\mu \mathrm{m})$ mostrado na figura 53. 
O modo em contato intermitente (TM-AFM) foi usado para obter imagens da topografia e o modo Peak Force Tapping (PF) foi usado para obter o mapeamento das propriedades mecânicas.

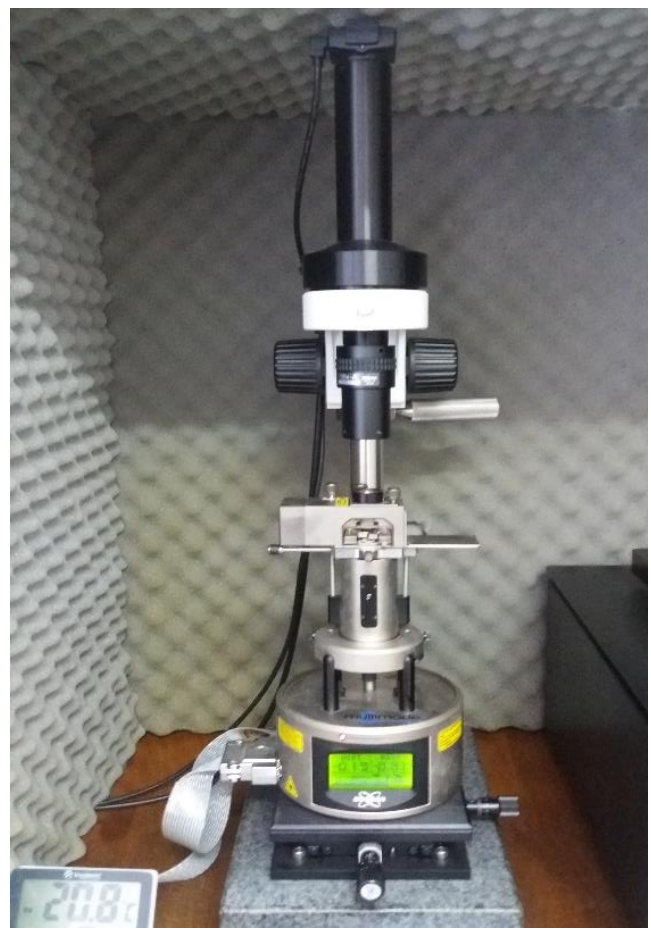

Figura 53 - Microscópio de força atômica (AFM) Multimode-8

As amostras analisadas foram tomadas da superfície interna da parede intermediaria de esponjas de bucha sem tratar (Figura 54a). Para a determinação do módulo por AFM inicialmente foram realizadas medições utilizando o método de calibração absoluto, com uma sonda tipo TAP525A (com uma frequência de ressonância de $525 \mathrm{kHz}$ e constante de mola nominal (k) de 200 N/m) (Figura $54 b$ ).
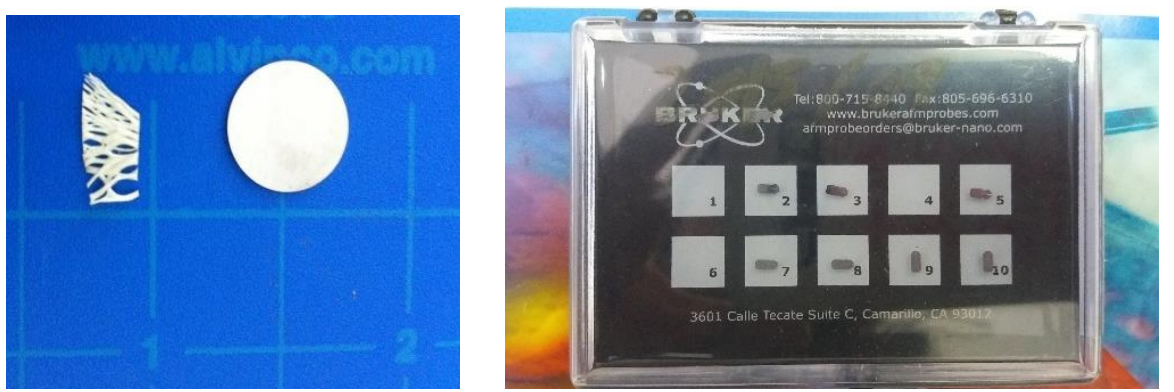

Figura 54 - (a) Amostra de fibras de bucha analisadas. (b) Sondas TAP525A utilizadas para a análise por AFM (para amostras com módulo de Young entre 1 e 20 GPa).

O modelo Derjaguin-Muller-Toporov (DMT) utilizado é descrito pela eq. 17 [290]: 


$$
F_{\text {tip }}=\frac{4}{3} E^{*} \sqrt{R d^{3}}+F_{a d h} \quad \text { Equação } 17
$$

Onde, $F_{t i p}$ é a força na ponta (obtida a partir da curva de força), $F_{a d h}$ é a força de adesão, $E^{*}$ é o módulo de Young reduzido, $R$ é o raio de curvatura da ponta e $d$ é a indentação. O módulo reduzido medido, $\mathrm{E}^{*}$, está relacionado com o módulo da amostra pela eq. 18 [290]:

$$
E^{*}=\left[\frac{1-v_{t}^{2}}{E_{t}}+\frac{1-v_{s}^{2}}{E_{s}}\right]^{-1}
$$

Equação 18

onde, $v_{\mathrm{t}}$ e $\mathrm{E}_{\mathrm{t}}$ são a razão de Poisson e o módulo de Young da ponta e $v_{\mathrm{s}}$ e $\mathrm{E}_{\mathrm{s}}$ são a razão de Poisson e o módulo de Young da amostra.

Para medições do módulo também foram utilizadas sondas de modelo RTESPA com uma frequência de ressonância de $300 \mathrm{kHz}$ e constante de mola nominal de $k=40 \mathrm{~N} / \mathrm{m}$.

\subsubsection{Análise Termogravimétrica (TGA)}

Foram realizadas análises termogravimétricas (TGA) em fibras de bucha vegetal moídas previamente em moinho de facas, sob atmosfera de nitrogénio (20 $\mathrm{ml} / \mathrm{min}$ ), utilizando o equipamento Pyris 1 TGA (PerkinElmer) mostrado na figura 55.

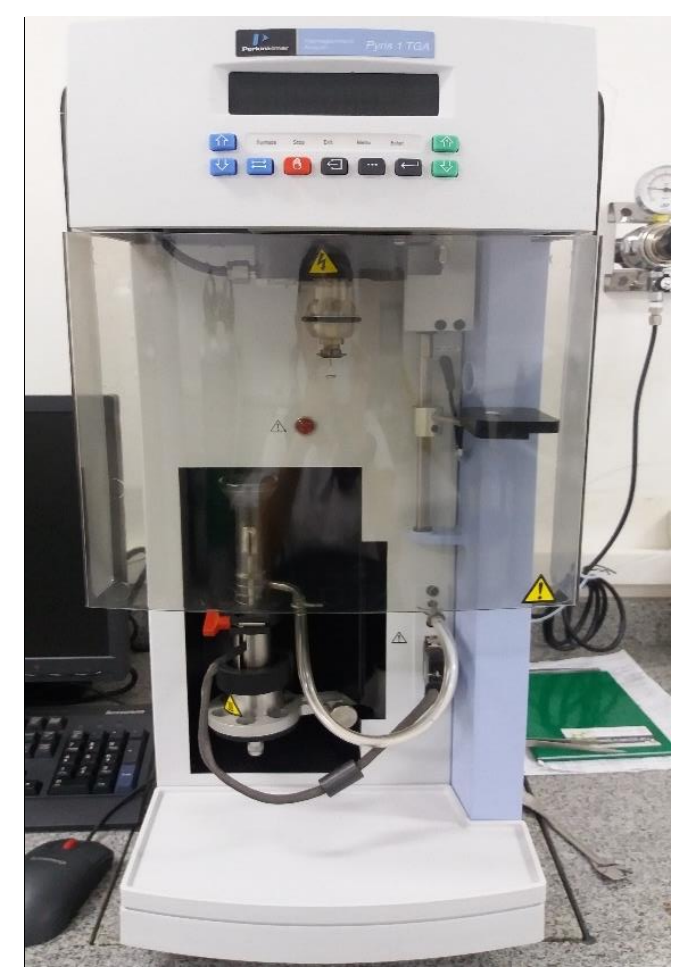

Figura 55 - Equipamento Pyris 1 TGA. 
Os ensaios foram executados com uma taxa de aquecimento de $10^{\circ} \mathrm{C} / \mathrm{min}$ entre $30^{\circ} \mathrm{C}$ e $650{ }^{\circ} \mathrm{C}$ com o objetivo de avaliar o comportamento térmico da estrutura fibrosa da bucha e estabelecer as temperaturas de degradação de seus principais componentes químicos e o efeito do tratamento superficial das fibras sobre a sua estabilidade térmica.

\subsection{Preparação de Resinas Epóxi}

O peso equivalente de epóxi (EEW) dos pré-polímeros e o peso equivalente amina (AHEW) dos agentes de cura utilizados foram tomados da ficha técnica dos reagentes. A isoforona diamina (IPDA) (Figura 56) com massa molar de 170,3 g/mol contém 4 átomos de hidrogênio ativos, portanto para a preparação da resina epóxi se utilizou um valor de $\mathrm{AHEW}=42,57 \mathrm{~g} / \mathrm{eq}$. Inicialmente foram preparadas resinas epóxi a partir de óleo de soja epoxidado (ESO) curadas com anidrido ftálico (PA) em presença de trietilamina (TEA) como catalizador, com diamina de isoforona (IPDA) e com fenalcaminas (NX); com as proporções mostradas na Tabela 11.<smiles>CC1(C)CC(N)CC(C)(CN)C1</smiles>

Figura 56 - Estrutura química da Isoforona Diamina (IPDA).

Tabela 11 - Formulação para a preparação de resinas a partir de óleo de soja epoxidado (ESO).

\begin{tabular}{|c|c|c|c|}
\hline Formulação & Pre-polímero & Agente de cura & \\
\hline $\mathrm{A}$ & ESO & PA + TEA & $\begin{array}{c}\text { Razão } \\
\text { molar=1 }\end{array}$ \\
\hline B & ESO & NX & phr=38,96 \\
\hline C & ESO & IPDA & phr=18,94 \\
\hline
\end{tabular}

Para a preparação da formulação $\mathrm{A}$, a mistura dos reagentes foi aquecida à temperatura de fusão do anidrido ftálico com agitação constante até apresentar uma aparência homogênea. A mistura foi vertida no molde metálico e depois de 24 horas de cura a temperatura ambiente, foram realizados processos de cura a $150^{\circ} \mathrm{C}$ por 15, 20 e $24 \mathrm{~h}$. A formulação de resinas preparadas a partir de éter diglicidílico de 
bisfenol A, de éter diglicidílico de cardanol e de éter diglicidílico de resorcinol são apresentadas nas Tabelas 12 .

Tabela 12 - Formulação para a preparação de resinas de bisfenol A (MC150/5), cardanol (NC-514) e resorcinol (RDGE-H).

\begin{tabular}{|c|c|c|c|}
\hline Formulação & Pré-polímero & Endurecedor & phr* \\
\hline D & Bisfenol & IPDA & 20,9 \\
\hline E & Bisfenol & NX & 40,2 \\
\hline F & Cardanol & NX & 23,43 \\
\hline G & Resorcinol & NX & 68,33 \\
\hline \multicolumn{3}{|c}{ * g de endurecedor para cada $100 \mathrm{~g}$ de pré-polímero } \\
\end{tabular}

Nas Tabelas 13 e 14 são apresentadas as formulações utilizadas para a preparação de resinas bisfenol com quantidades variáveis de ESO, e de resorcinol com quantidades variáveis de cardanol, curadas com IPDA e fenalcaminas NX. O valor de EEW para misturas de resina foi calculado usando a eq. 19 [320] e a razão estequiométrica dos reagentes (eq. 20) foi usada para determinar a quantidade de agente de cura por cem partes de resina (phr) [320].

$$
\begin{gathered}
E E W=\frac{\text { massa total da mistura }}{\frac{\text { massa }}{E E W_{1}}+\frac{\text { massa }_{2}}{E E W_{2}}} \\
p h r=\frac{A H E W}{E E W} \times 100
\end{gathered}
$$

Tabela 13 - Formulação de resinas preparadas a partir de misturas de bisfenol (MC150/5) e ESO.

\begin{tabular}{|c|c|c|c|}
\hline Formulação & Pré-polímeros & Endurecedor & phr* \\
\hline H & $70 \%$ ESO - 30\% Bisfenol & IPDA & 19,16 \\
\hline I & $50 \%$ ESO - 50\% Bisfenol & IPDA & 19,65 \\
\hline J & $30 \%$ ESO - 70\% Bisfenol & IPDA & 20,13 \\
\hline K & $30 \%$ ESO - 70\% Bisfenol & NX & 38,79 \\
\hline \multicolumn{3}{|c}{$* g$ de endurecedor para cada 100 g de pré-polímero } \\
\end{tabular}

Tabela 14 - Formulação para a preparação de resinas com conteúdo de cardanol (NC-514) e Resorcinol (RDGE-H).

\begin{tabular}{|c|c|c|c|}
\hline Formulação & Pre-polímero & Endurecedor & phr* \\
\hline L & $50 \%$ Cardanol - 50 \% Resorcinol & IPDA & 23,82 \\
\hline M & $50 \%$ Cardanol - 50\% Resorcinol & NX & 45,88 \\
\hline \multicolumn{3}{|c}{$*$ g de endurecedor para cada 100 g de pré-polímero } \\
\hline
\end{tabular}


As formulações foram preparadas sem uso de solvente. Para a preparação das formulações (B-M) os reagentes foram misturados manualmente a temperatura ambiente e as misturas foram vertidas no molde metálico e curadas durante 24 horas também a temperatura ambiente.

\subsection{Caraterização térmica de resinas}

As resinas preparadas foram caracterizadas por análise termogravimétrica (TGA) para determinar a estabilidade térmica, usando o equipamento Pyris 1 TGA (PerkinElmer). O ensaio foi realizado seguindo a norma ASTM D3418 na faixa de temperatura de 25 a $800{ }^{\circ} \mathrm{C}$ com taxa de aquecimento de $5^{\circ} \mathrm{C} / \mathrm{min}, 10^{\circ} \mathrm{C} / \mathrm{min}$ e $20^{\circ} \mathrm{C} / \mathrm{min}$, sob atmosfera de nitrogênio $(20 \mathrm{ml} / \mathrm{min})$.

\subsection{Caracterização mecânica das resinas}

Ensaios de flexão estática das resinas preparadas foram realizados em uma máquina universal de ensaios AME-2KN (Figura 57).

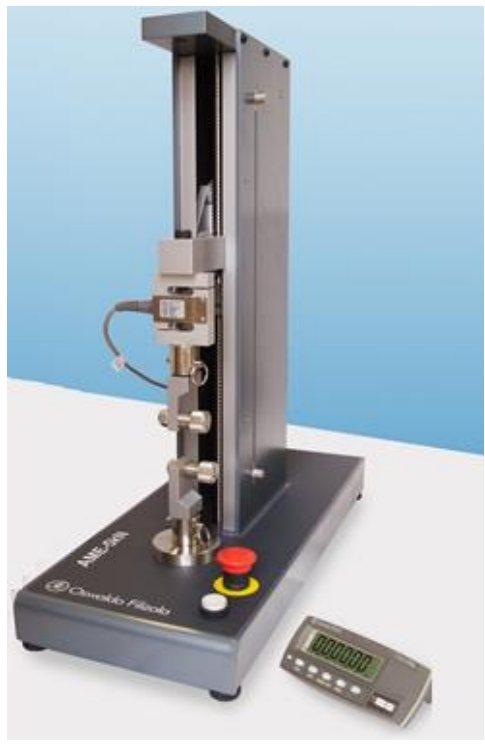

$a$

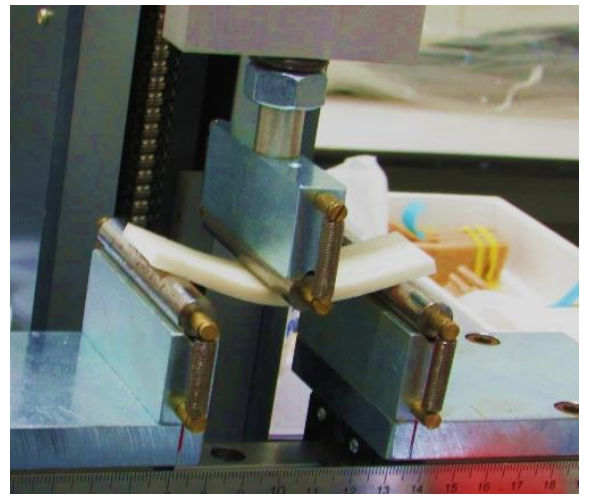

$b$

Figura 57 - (a) Máquina Universal de Ensaios - AME com 200kgf de capacidade. $(b)$ Detalhe do ensaio de flexão em três pontos do corpo de prova de resina 30\%ESO$70 \%$ Bisfenol A.

Foi usado o método de flexão de três pontos com uma velocidade de ensaio de $3 \mathrm{~mm} / \mathrm{min}$. A tensão, a deformação e o módulo dos corpos de prova foram determinados com base na norma ASTM D790 pelas equações 21 - 23. 


$$
\begin{aligned}
& \sigma_{f}=\frac{3 F L}{2 b h^{2}} \\
& \varepsilon=\frac{6 w h}{L^{2}} \\
& E_{f}=\frac{L^{3} F}{4 b h^{3} w}
\end{aligned}
$$

Equação 23

onde, $\sigma_{f}$ é a tensão de ruptura à flexão $(\mathrm{MPa}), \varepsilon$ a deformação, $\mathrm{F}$ a carga máxima aplicada (N) e L a distância entre apoios (64 mm) e as caraterísticas dos corpos de prova são representadas como h: espessura $(\sim 3 \mathrm{~mm})$, b: largura $(15 \mathrm{~mm}) . w$ é o deslocamento em flexão (mm).

\subsection{Fabricação de Compósitos}

Na Figura 58 é apresentado um diagrama com as resinas epóxi e os formatos das fibras que foram utilizados para a preparação dos compósitos e na tabela 15 estão listados os compósitos fabricados.

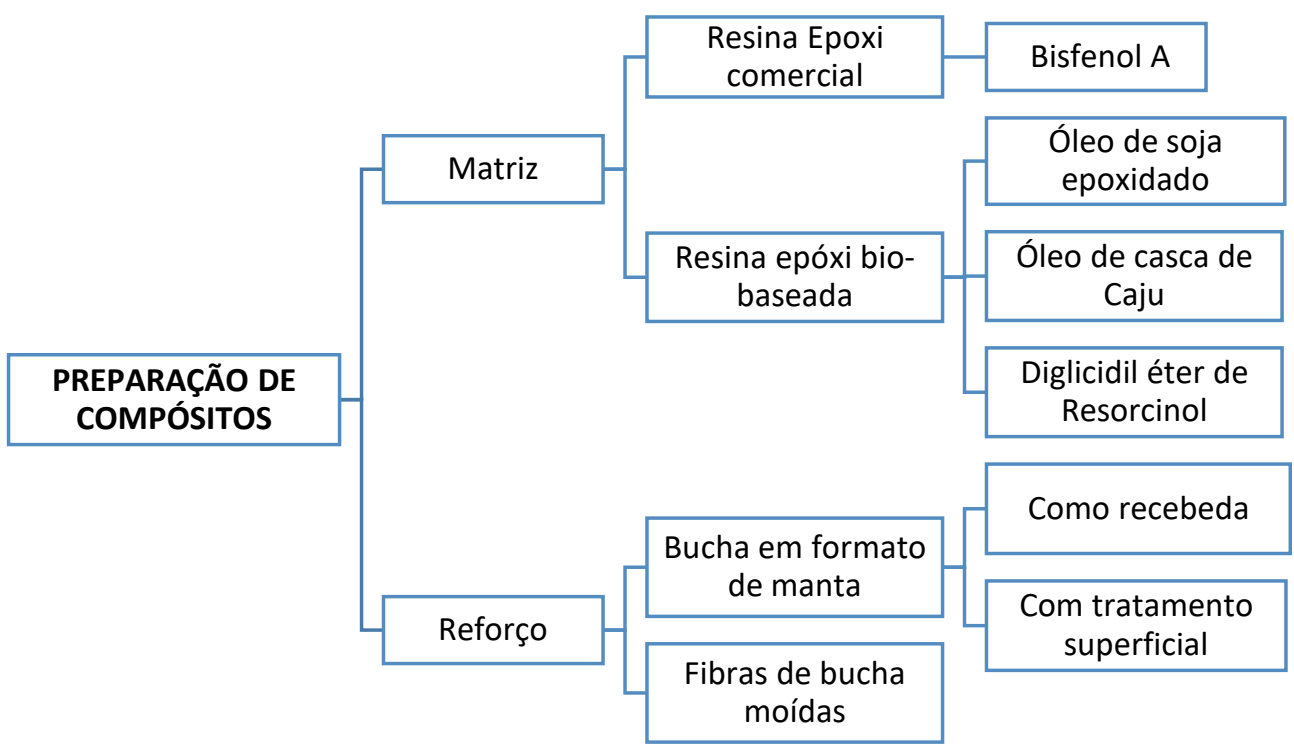

Figura 58 - Esquema dos componentes dos compósitos fabricados

Tabela 15 - Compósitos fabricados e caracterizados.

\begin{tabular}{|c|c|c|c|c|}
\hline & Resina & $\begin{array}{c}\text { Tipo de fibras de } \\
\text { bucha }\end{array}$ & $\begin{array}{c}\text { \% em } \\
\text { massa } \\
\text { de } \\
\text { fibras }\end{array}$ & Compósito \\
\hline 1 & Bisfenol A & Não tratadas & 10 & U10 \\
\hline 2 & Bisfenol A & Não tratadas & 20 & U20 \\
\hline 3 & Bisfenol A & Não tratadas & 30 & U40 \\
\hline 4 & Bisfenol A & Mercerizadas & 20 & M20 \\
\hline 5 & Bisfenol A & Mercerizadas & 30 & M30 \\
\hline
\end{tabular}




\begin{tabular}{|c|c|c|c|c|}
\hline 6 & Bisfenol A & Hornificadas & 20 & H20 \\
\hline 7 & Bisfenol A & Hornificadas & 30 & H30 \\
\hline 8 & Bisfenol A & Acetiladas & 20 & A20 \\
\hline 9 & Bisfenol A & Acetiladas & 30 & A30 \\
\hline 10 & Bisfenol A & Fibras curtas* & 20 & FC \\
\hline 11 & ESO 50\% & Não tratadas & 30 & ESO50- U30 \\
\hline 12 & ESO 30\% & Não tratadas & 30 & ESO-U30 \\
\hline 13 & ESO 30\% & Mercerizadas & 30 & ESO-M30 \\
\hline 14 & ESO 30\% & Hornificadas & 30 & ESO-H30 \\
\hline 15 & ESO 30\% & Fibras curtas* & 20 & ESO-FC \\
\hline 16 & Cardanol 50\% & Mercerizadas & 30 & C50-M30 \\
\hline
\end{tabular}

*Não tratadas

Compósitos de matriz epóxi com frações em peso de fibras de reforço variando entre 10 e $40 \%$ foram fabricados pelo método de lay-up manual (Figura 59). Previamente foi preparado o molde metálico com dimensões $150 \times 200 \times 3 \mathrm{~mm}^{3}$ pela limpeza seguida do recobrimento da superfície com cera desmoldante. Para a fabricação dos laminados, camadas de fibras de bucha, previamente cortadas em forma de manta e prensadas, foram impregnadas com a mistura dos componentes (resina epóxi e agente de cura). Posteriormente, as fibras foram distribuídas no molde com vista à obtenção de uma estrutura isotrópica. Finalmente, foi fechado o molde e foi aplicada uma pressão de moldagem de 5 ton. sobre o molde fechado.

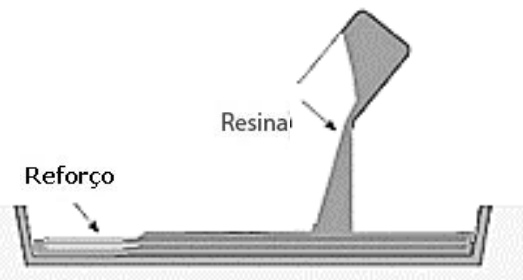

Figura 59 - Esquema de fabricação de compósitos reforçados com fibras de bucha pelo método de lay-up manual.

A cura foi realizada a temperatura ambiente, $25 \pm 3{ }^{\circ} \mathrm{C}$ e os compósitos foram retirados do molde depois de pelo menos 24 horas. De cada laminado foram usinados corpos de prova retangulares para a realização de ensaios mecânicos, como mostrado na Figura 60. 


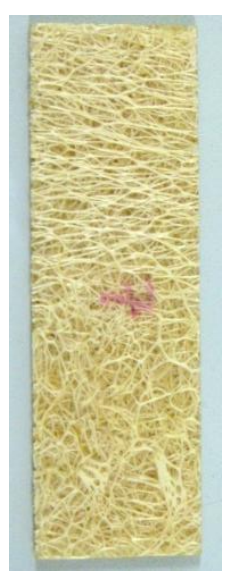

$a$

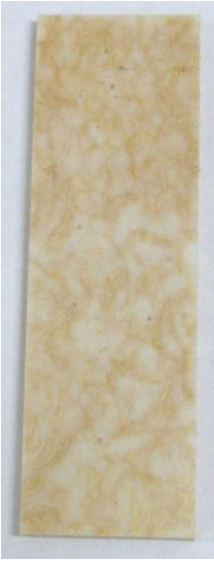

$b$

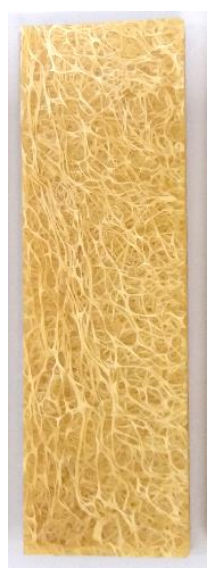

$c$

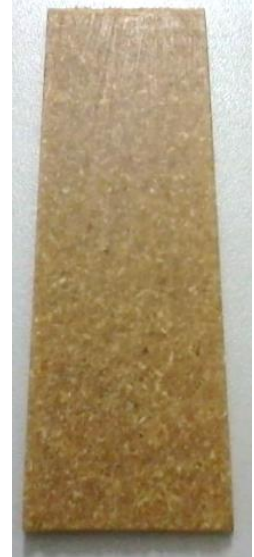

$d$

Figura 60 - Corpos de prova de compósitos $(80 \times 25 \times 3 \mathrm{~mm})(a)$ Bisfenol/fibras de bucha (b) ESO30/fibras de bucha (c) C50/fibras de bucha (d) Bisfenol/fibras curtas de bucha.

Compósitos reforçados com fibras de bucha moídas também foram fabricados misturando a resina epóxi com fibras da parte central da bucha pulverizadas em moinho de facas. Posteriormente, a mistura foi distribuída no molde (Figura 61) e depois de 30 minutos o molde foi fechado e foi aplicada uma pressão de moldagem de 5 ton. A cura foi realizada a temperatura ambiente, $25 \pm 3{ }^{\circ} \mathrm{C}$.

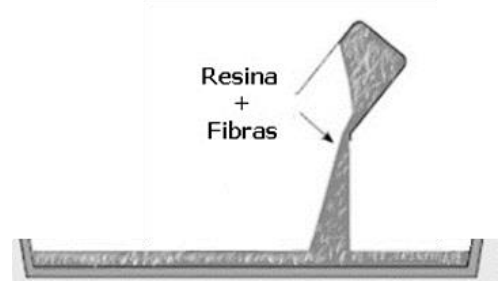

Figura 61 - Esquema de fabricação de compósitos reforçados com fibras de bucha curtas.

\subsection{Caraterização dos Compósitos}

A Figura 62 apresenta o fluxograma das técnicas usadas para caracterizar os compósitos fabricados. 


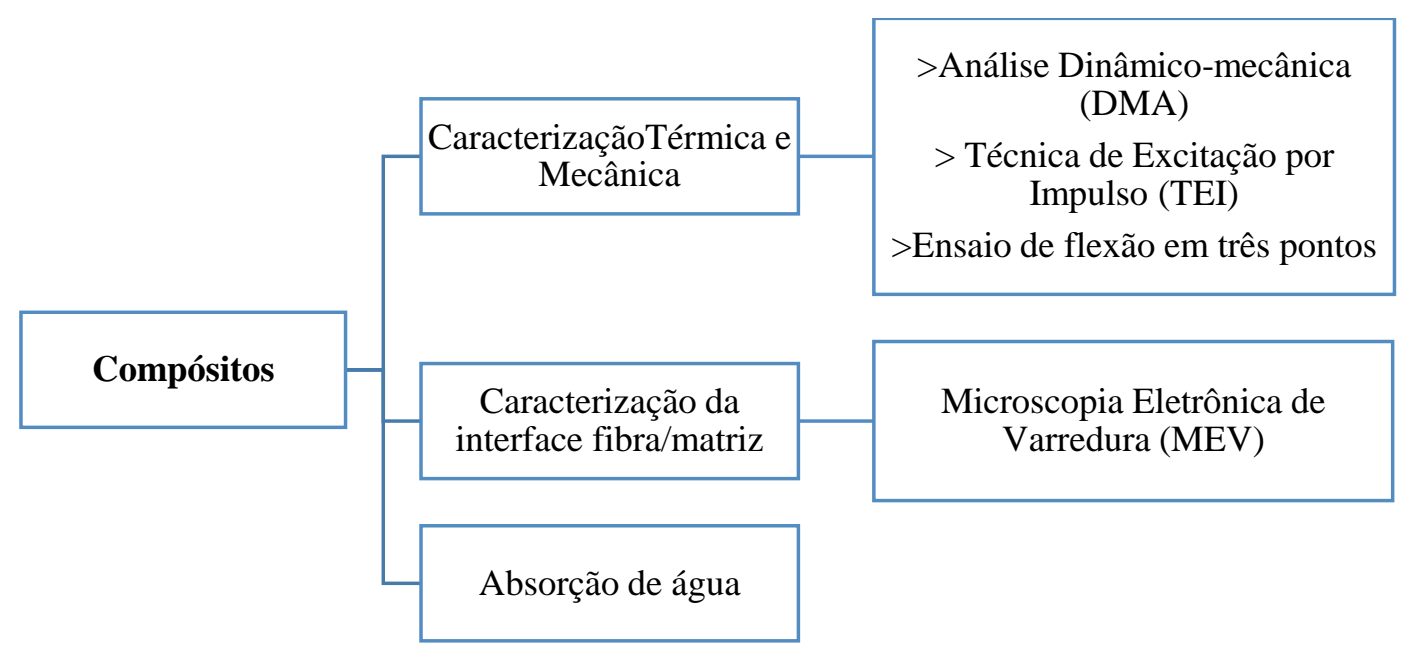

Figura 62 - Esquema da caraterização dos compósitos fabricados.

\subsubsection{Análise dinâmico-mecânica (DMA)}

A análise dinâmico-mecânica (DMA) das resinas usadas como matriz e dos compósitos fabricados, foi realizada utilizando o equipamento DMA7 (PerkinElmer) mostrado na Figura 63, com taxa de aquecimento $3^{\circ} \mathrm{C} / \mathrm{min}$ sob fluxo de nitrogênio a um caudal de $20 \mathrm{ml} / \mathrm{min}$. Os corpos de prova de formato retangular utilizados foram usinados das placas de compósito (Figura 64).

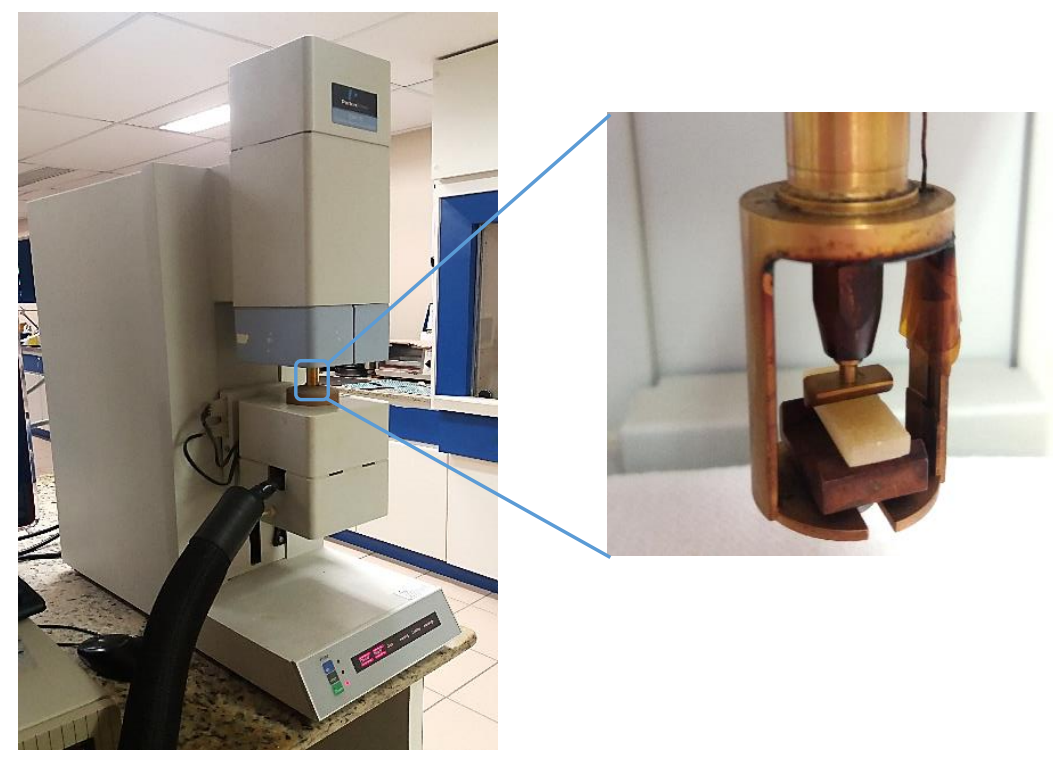

Figura 63 - Equipamento DMA7 (PerkinElmer). Detalhe do dispositivo de ensaio de flexão em três pontos empregado (Direita). 


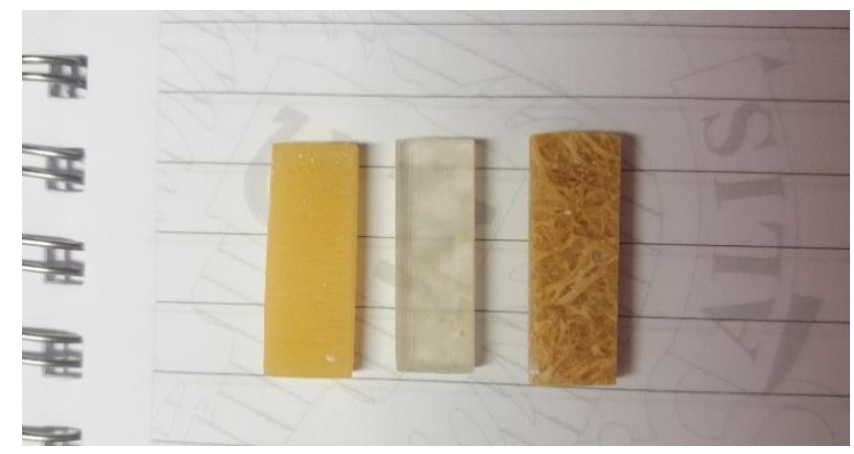

Figura 64 - Corpos de prova para o ensaio DMA com dimensões de 19,5 x 6,5 x 3 mm.

De esquerda à direita, resina de cardanol-resorcinol, resina de bisfenol, compósito cardanol-resorcinol/fibras de bucha.

Os parâmetros foram ajustados para operar a $1 \mathrm{~Hz}$ de frequência, $550 \mathrm{mN}$ de força estática, $500 \mathrm{mN}$ de força dinâmica. As curvas de variação do módulo de armazenamento $\left(E^{\prime}\right)$, do módulo de perda $\left(E^{\prime \prime}\right)$ e da $\tan \delta$ foram registradas simultaneamente na faixa de aquecimento utilizada de 0 a $180^{\circ} \mathrm{C}$. Esses parâmetros foram levantados também para a resinas puras. Para a determinação da temperatura de transição vítrea a partir do DMA foram tomados os procedimentos das normas ASTM E1640 para polímeros termorrígidos e ASTM D7028 para compósitos poliméricos.

\subsubsection{Ensaio não destrutivo: Técnica de Excitação por Impulso}

A caraterização mecânica dos compósitos fabricados foi realizada usando a técnica não destrutiva de excitação por impulso (TEI). Corpos de prova retangulares dos compósitos fabricados, com dimensões $80 \times 25 \times 3 \mathrm{~mm}^{3}$ (Figura 60), foram testados a temperatura ambiente com o equipamento Sonelastic ${ }^{\circledR}$ da ATCP Engenharia Física e seu software associado.

Inicialmente a massa e as dimensões dos corpos de prova foram medidas cuidadosamente com uma balança com precisão $( \pm 0,001 \mathrm{~g})$ e um paquímetro eletrônico $( \pm 0,01 \mathrm{~mm})$, respectivamente. Cada um dos corpos de prova foi adequadamente posicionado no equipamento e as condições de contorno (modos de vibração torsional e flexional) foram selecionadas (Figura 65). Os espécimes foram excitados utilizando um pulsador eletromagnético (Figura 66) que possui dois modos de operação: remoto e manual. Foi utilizado o modo remoto que permite a automatização das medições em função do tempo, e garante a reprodutibilidade da 
excitação por impulso. O módulo de elasticidade à flexão (E) e módulo de cisalhamento $(\mathrm{G})$ são calculados pelo software seguindo a norma ASTM E1876.
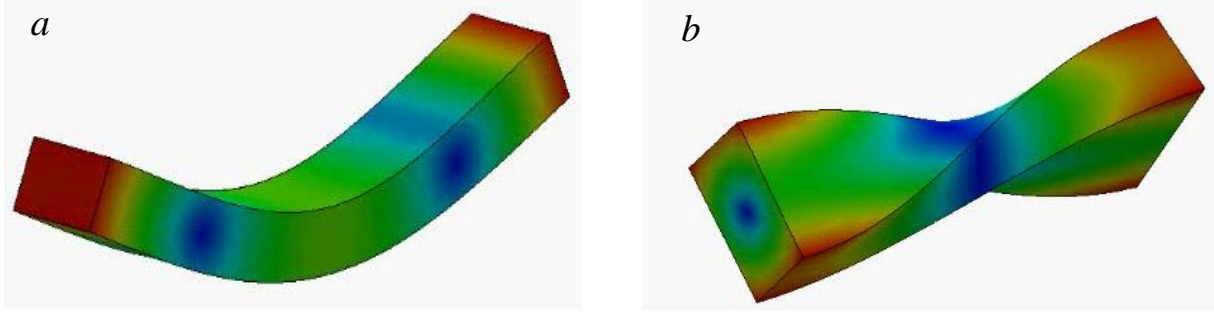

Figura 65 - Imagem ilustrativa de a) Modo fundamental flexional b) Modo fundamental de torção.
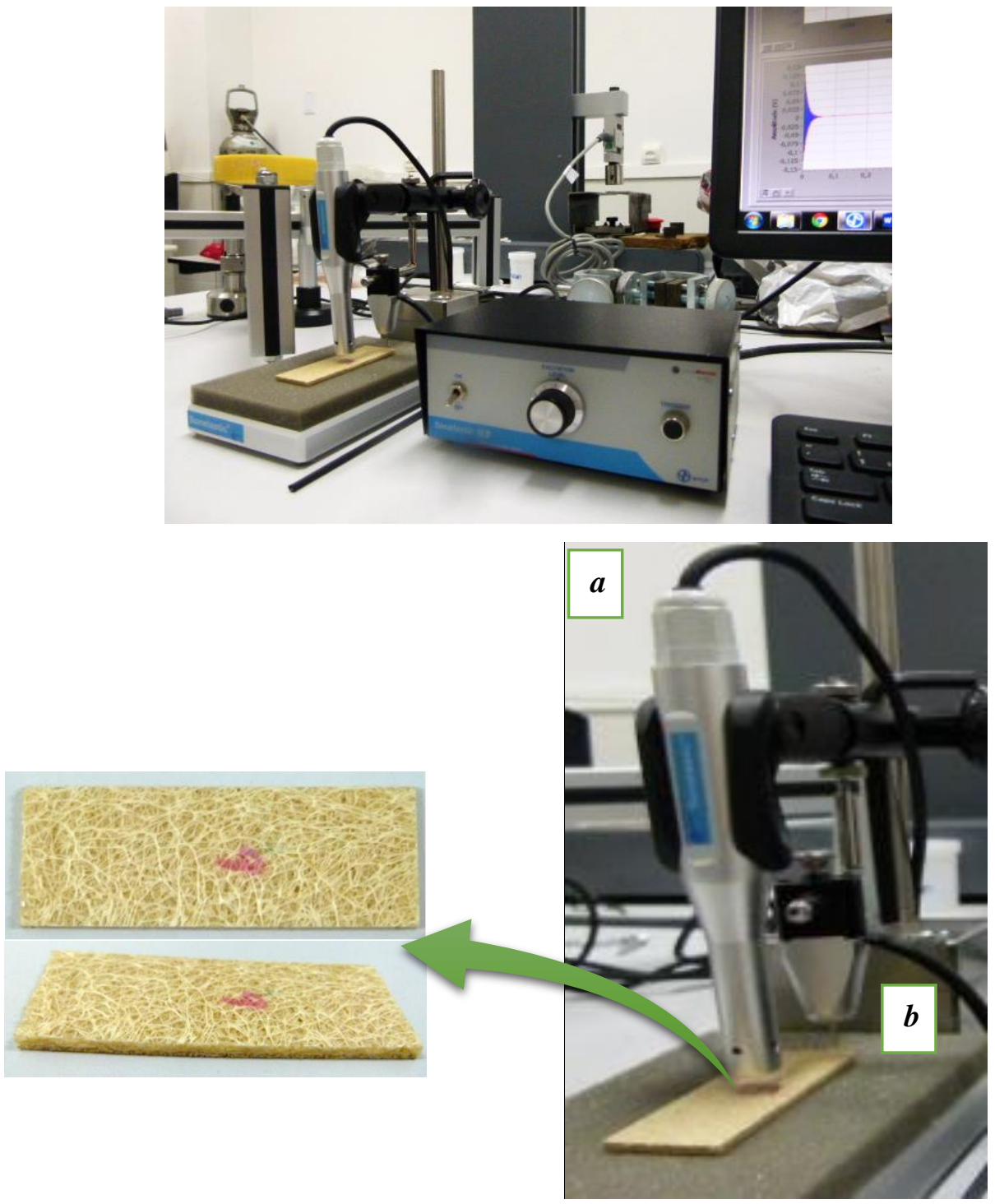

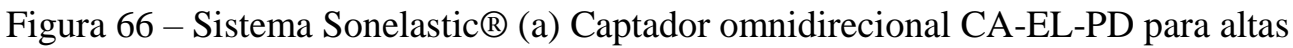
frequências (até $30 \mathrm{kHz}$ ). (b) Pulsador eletromagnético automático Sonelastic ${ }^{\circledR}$ IED.

A excitação foi realizada na extremidade dos corpos de prova ajustando o pulsador para atuar com uma intensidade de $7 \mathrm{~V}$ e duração de $1 \mathrm{~ms}$. As medições 
foram repetidas para cada espécimen até obter leituras de frequência consecutivas com coeficiente de variação menor que $1 \%$.

Foram realizadas 20 réplicas para dois corpos de prova de cada tipo de compósito fabricado. A frequência, módulo em flexão e amortecimento foi calculada pelo valor médio das leituras. O módulo e o amortecimento dos corpos de prova foram medidos também de forma periódica durante os ensaios de absorção realizados (Seção 4.3.3)

\subsubsection{Ensaio de flexão Estática}

Utilizando a mesma metodologia para a caracterização mecânica das resinas, foram analisados compósitos de matriz bisfenol/bucha sem tratamento, matriz Bisfenol/bucha tratada, ESO-Bisfenol/bucha sem tratamento, ESO-Bisfenol/bucha tratada, Cardanol-Resorcinol/bucha tratada. Compósitos Bisfenol/bucha envelhecidos com água destilada e água de mar também foram analisados. Foram realizadas cinco medições para cada compósito.

\subsubsection{Microscopia Eletrônica de Varredura (MEV)}

A análise por MEV também permitiu observar a superfície de fratura dos materiais compósitos usando imagens de elétrons secundários e uma tensão de aceleração por feixe de elétrons variando entre $15-20 \mathrm{kV}$. A montagem usada é mostrada na figura 67.
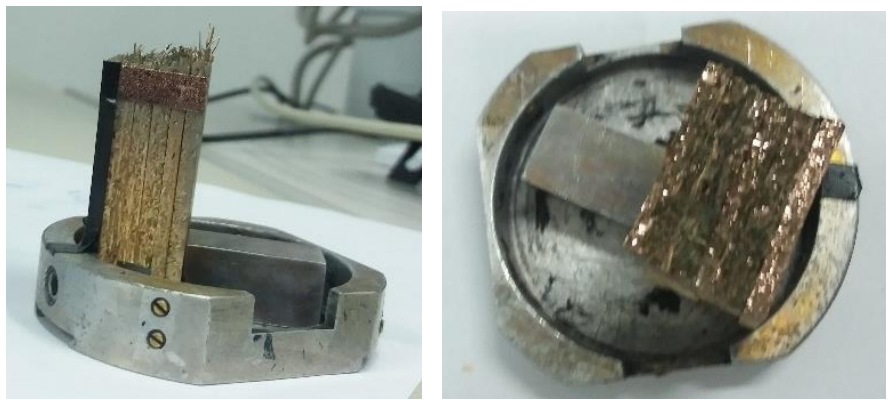

Figura 67 - Montagem de corpos de prova fraturados para observação por MEV.

As micrografias obtidas permitiram avaliar aspectos relacionados à interação da interface fibra-resina. 


\subsubsection{Absorção de água}

O uso de fibras naturais em aplicações nas quais o material está em ambientes úmidos requer uma boa compreensão do seu comportamento em contato com água. Neste trabalho, foram testados 22 corpos de prova de compósitos epóxi/bucha submersos em água destilada e água de mar artificial. Os ensaios foram realizados a temperatura ambiente e pressão atmosférica e a massa dos corpos de prova foi medida periodicamente durante 81 dias em água destilada e 144 dias em água de mar. Os ensaios de absorção se realizaram seguindo a norma ASTM D5229.

Para a preparação de água de mar sintética foi usada a fórmula do sal para aquários marinhos da marca Blue Treasure (Figura 68) que, segundo os fabricantes, contém todos os elementos fundamentais e possui uma composição balanceada de acordo com a composição natural de água de mar (Tabela 16). 350 gramas da mistura de sais foram misturados vigorosamente em 10 litros de água destilada até dissolver totalmente. Posteriormente foi verificado um valor de $\mathrm{pH}$ de 8,3.

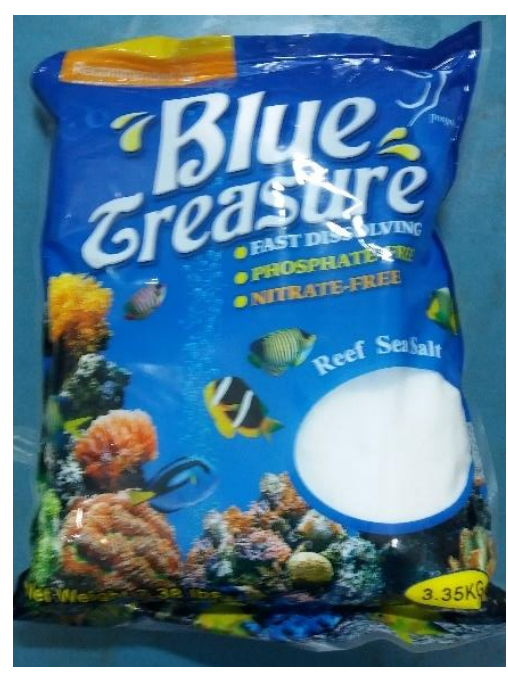

Figura 68 - Água de mar sintética Blue Treasure (Reef Sea Salt).

Tabela 16 - Análise técnico da água de mar sintética Blue Treasure e água de mar natural, fornecida pelos fabricantes.

\begin{tabular}{|c|c|c|}
\hline Itens $(\mathrm{mg} / \mathrm{L})$ & Água de mar sintética & Água de mar natural \\
\hline $\mathrm{Na}^{+}$ & $9300-9700$ & 9370 \\
$\mathrm{Mg}^{2+}$ & $1300-1450$ & 1240 \\
$\mathrm{~K}^{+}$ & $340-380$ & 326 \\
$\mathrm{Ca}^{2+}$ & $350-400$ & 343 \\
$\mathrm{Sr}^{2+}$ & $8,0-9,5$ & 6,86 \\
$\mathrm{Rb}^{2+}$ & $0,10-0,13$ & 0,1 \\
$\mathrm{Fe}$ & $0,06-0,20$ & 0,01 \\
\hline
\end{tabular}




\begin{tabular}{|c|c|c|}
\hline $\mathrm{Li}^{+}$ & $0,14-0,16$ & 0,14 \\
$\mathrm{Cl}^{-}$ & $17000-17600$ & 17000 \\
$\mathrm{SO}_{4}^{2-}$ & $2300-2430$ & 2273 \\
$\mathrm{Br}^{-}$ & $20-40$ & 56 \\
$\mathrm{~F}$ & $0,7-0,9$ & 1,1 \\
$\mathrm{~B}$ & $4,0-6,0$ & 3,94 \\
\hline
\end{tabular}

* O sal Blue Treasure também contém elementos-traço encontrados em água de mar natural, tais como Mn, Ba, Se, F, Br, Li, Zn, Al, Ni, Cs ,Co, B, V.

Antes do ensaio, foi realizado um procedimento de acondicionamento onde todos os espécimes foram secos em um forno $80^{\circ} \mathrm{C}$ até que não foi observada variação de massa significativa (aproximadamente 72 horas). A massa dos corpos de prova depois do acondicionamento foi reportada como $W_{b}$.

Inicialmente, os corpos de prova foram pesados e suas dimensões foram medidas e registradas. Posteriormente, realizou-se o teste, submergindo os corpos de prova em água destilada e em água de mar à temperatura ambiente e pesando os corpos de prova no final de cada intervalo de tempo, até atingir um valor de equilíbrio. Cada medição de massa foi registrada como $W_{i}$, juntamente com o correspondente tempo total decorrido e o intervalo de tempo desde a última pesagem. A porcentagem de variação da massa por absorção $(\Delta \boldsymbol{M})$ foi determinada em cada intervalo usando a eq. 24 [321].

$$
\Delta M_{i}(\%)=\left|\frac{W_{i}-W_{b}}{W_{b}}\right| \times 100
$$

Equação 24

onde, $W_{i}$ é a massa do corpo de prova em cada intervalo de tempo (g) e $W_{b}$ é a massa seca (inicial) do corpo de prova $(\mathrm{g})$.

O coeficiente de difusão $D$ é o parâmetro mais importante do modelo de Fick, que mostra a capacidade de as moléculas de água penetrarem dentro do material. Assumido que as condições de difusão 1-D são satisfeitas, o coeficiente de difusão foi calculado a partir dos dados experimentais usando a eq. 25 [321]:

$$
D=\pi\left(\frac{h}{4 M_{\infty}}\right)^{2}\left(\frac{M_{2}-M_{1}}{\sqrt{t_{2}}-\sqrt{t_{1}}}\right)^{2}
$$

onde: $h$ é a espessura meia do corpo de prova $[\mathrm{mm}], M_{m}$ é o conteúdo de umidade efetiva no equilíbrio [\%], $\left(M_{2}-M_{1}\right) /\left(\sqrt{t_{2}}-\sqrt{t_{1}}\right)\left[\mathrm{s}^{-1}\right]$ é a pendente de absorção de umidade inicial da curva $\Delta \mathrm{M}$ vs $\sqrt{t}$. 


\section{Resultados}

\subsection{Caracterização das fibras de bucha}

Fibras naturais em geral apresentam uma grande variação no que diz respeito ao diâmetro. No caso das fibras de bucha essa variação se apresenta ao longo do comprimento de cada fibra individual (Figura 69), assim como ao longo do comprimento da esponja (Figura 28a), sendo mais finas no seu extremo inferior e mais grossas no extremo superior, perto do pedúnculo. O diâmetro varia também nas diferentes regiões da bucha (exterior, central e interior, Figura 29).

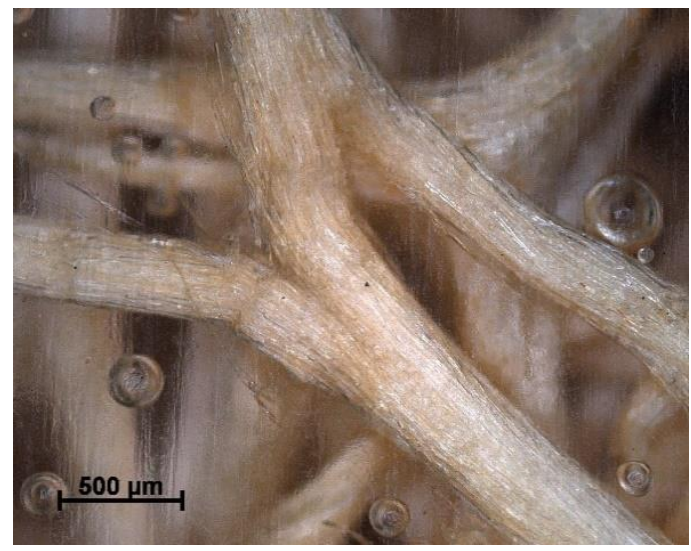

Figura 69 - Variação do diâmetro de fibras de bucha.

Amostras para a medição do diâmetro e área transversal das fibras de bucha foram tomadas da superfície externa de diferentes esponjas de bucha, à altura do comprimento médio e o corte foi realizado, como indicado na Figura 70, medindo a metade da fibra entre 2 bifurcações.

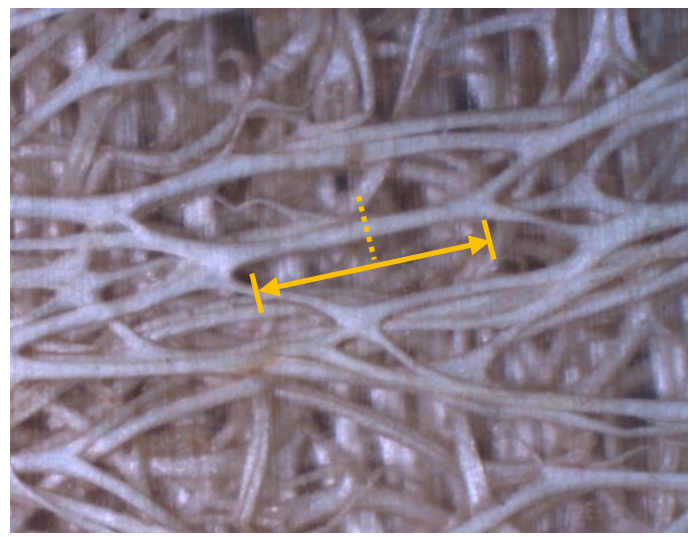

Figura 70 - Esquema da ubiquação do ponto de corte das fibras para a medição do diâmetro. 


\subsubsection{Microscopia Eletrônica de Varredura (MEV)}

Por meio da análise das fibras por micrografias de MEV, verificou-se que as fibras na superfície externa da bucha formam uma rede com fibras que se bifurcam ao longo da estrutura (Figura 71). As fibras individuais tem uma secção transversal arredondada com diâmetro variável e, assim como outras fibras lignocelulósicas [37], as fibras de bucha são compostas por micro células e um lúmen central como é mostrado na Figura 72. Estas micro células são coladas em conjunto por substâncias presentes na lamela média, principalmente hemiceluloses e lignina (Figura 73).

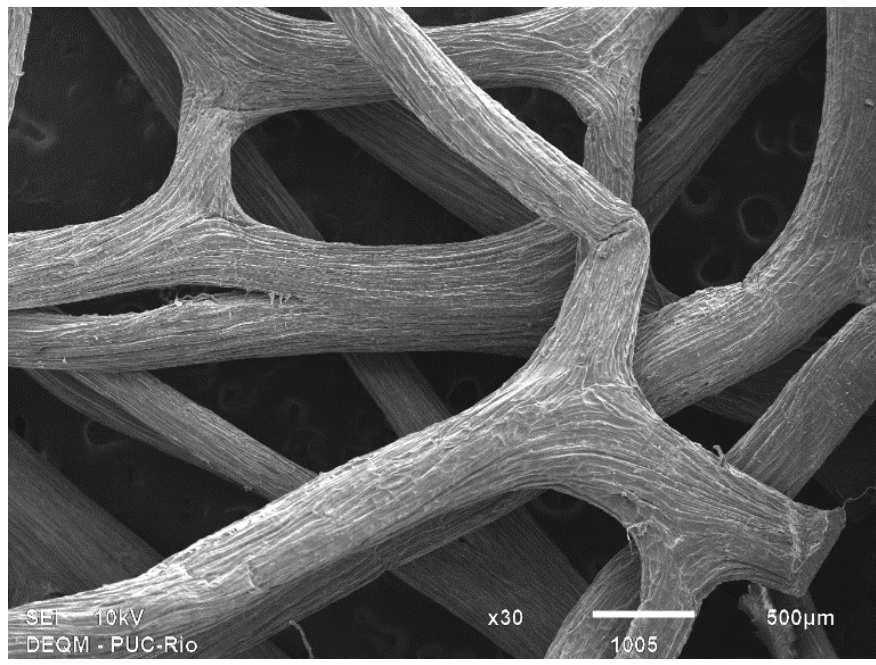

Figura 71 - Imagem por MEV de fibras de bucha na superfície externa da parede intermediária da esponja bucha (30x).
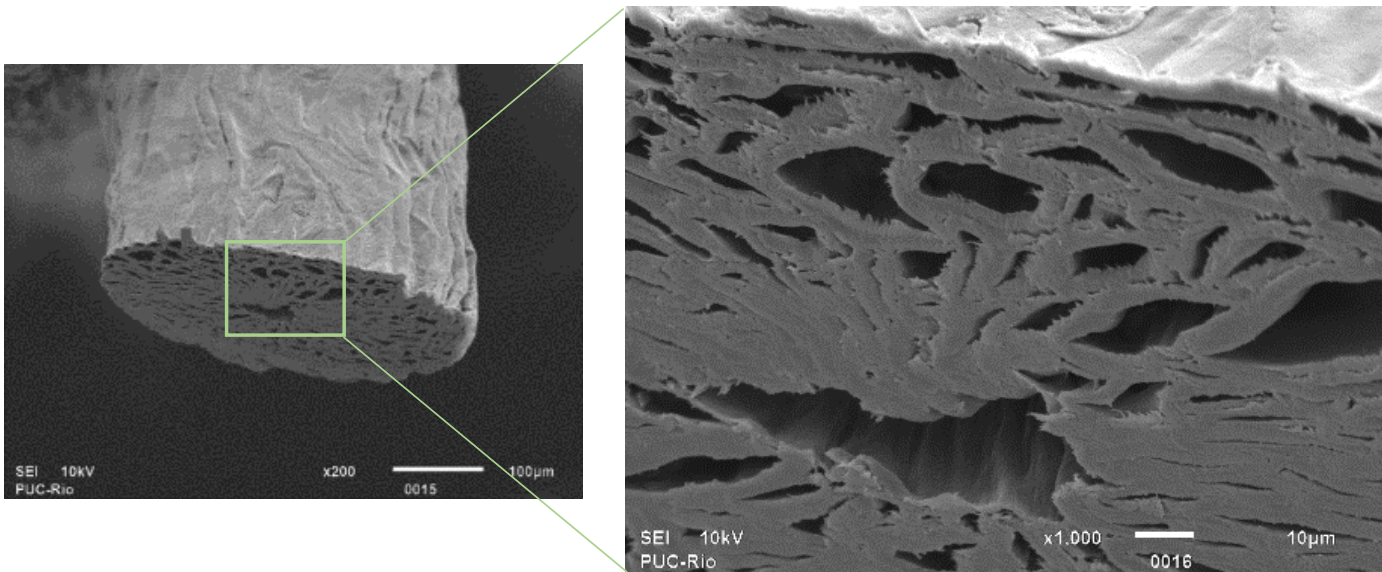

Figura 72 - Imagem por MEV da seção transversal de fibras na superfície externa da bucha 200x. Detalhe: Lúmen e micro células 1000x. 


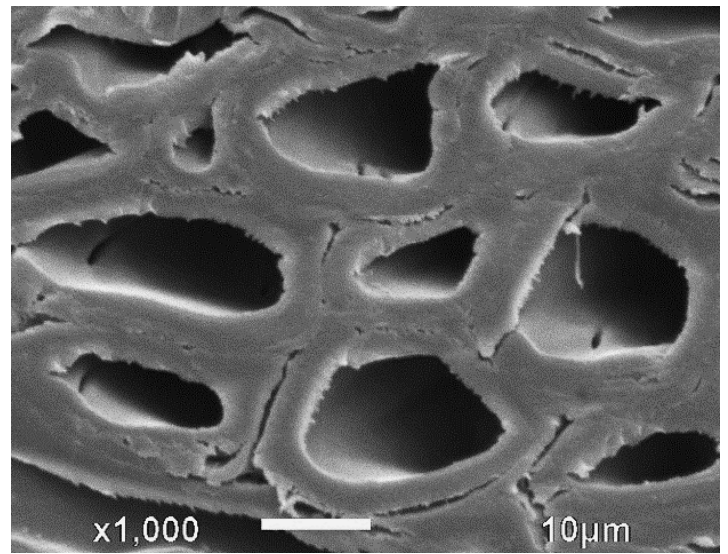

Figura 73 - Imagem por MEV de micro células na seção transversal de fibras de bucha.

Pelo processamento digital de imagens da seção transversal das fibras usando o programa imageJ (Figura 74), foi obtido um valor de diâmetro médio de 0,395 \pm $0,041 \mathrm{~mm}$ e uma área de seção transversal média de $0,067 \pm 0,018 \mathrm{~mm}^{2}$. O diâmetro obtido foi menor quando comparado com valores de diâmetro médio de $0,631 \pm 0,217 \mathrm{~mm}$ encontrados na literatura [206]. Por outro lado Satyanarayana, et al. (2007) [322] e Laidani, et al. (2012)[323] reportaram valores para o diâmetro de fibras de bucha entre 0,025-0,06 $\mathrm{mm}$ e entre 0,008-0,03 $\mathrm{mm}$. A grande diferença nos valores de diâmetro reportados por vários autores e o fato de não se possuir informação relacionada com a amostragem, está relacionado aos diversos fatores que podem afetar as dimensões das fibras, tais como a fertilidade do solo, por exemplo.

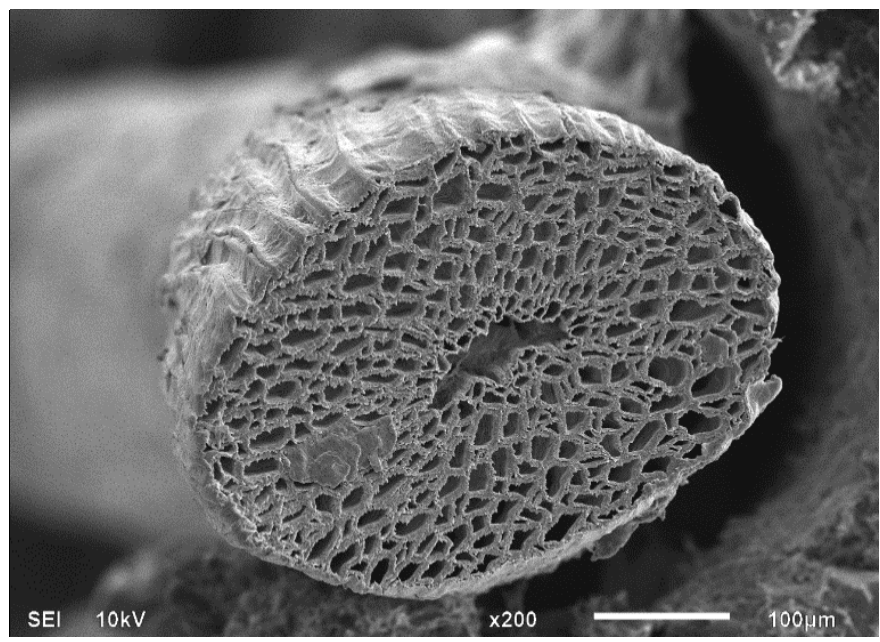

Figura 74 - Imagem por MEV da seção transversal de fibra individual da superfície externa da luffa. 200x. 
Por outro lado, no núcleo e na superfície interna da parede intermedia na bucha, se observou que a aglomeração de fibras com diâmetro variável resulta em conjuntos de fibras com áreas transversais de formato irregular e tamanho variável, como se observa nas Figuras 75 e 76.
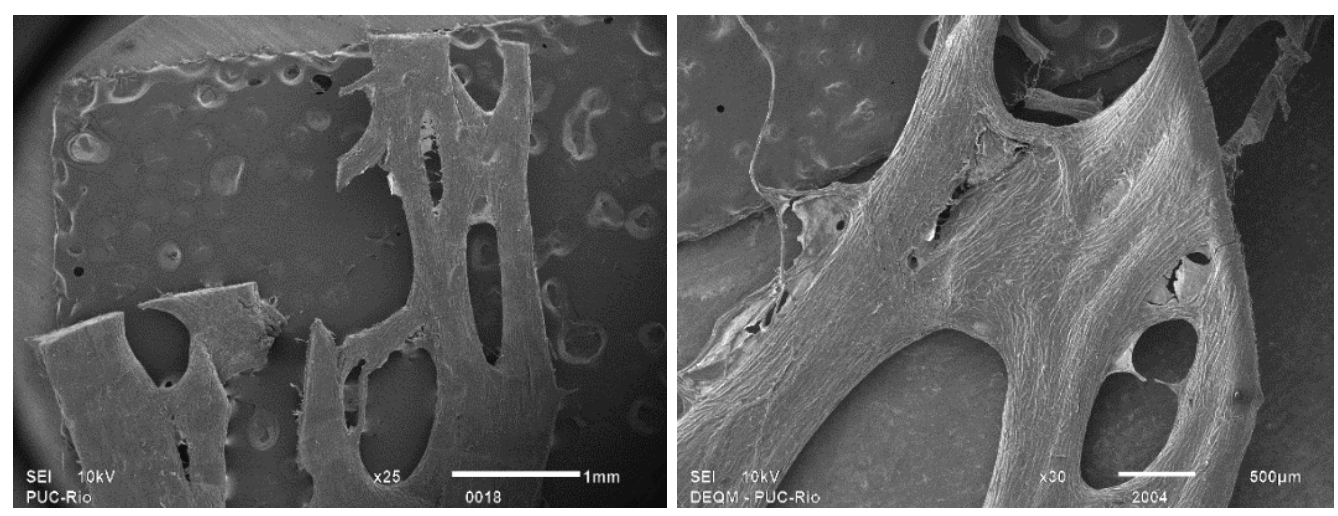

Figura 75 - Imagem por MEV do agrupamento de fibras na superfície interna e no núcleo da bucha
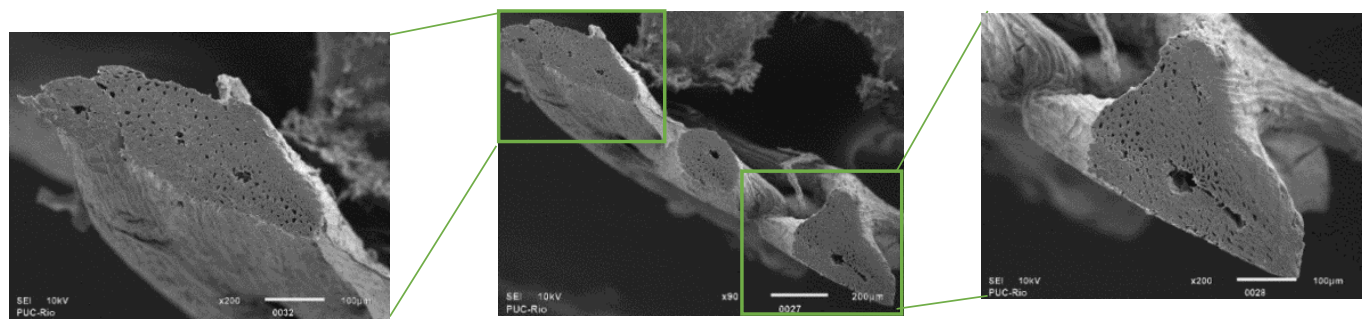

Figura 76 - Imagem por MEV da seção transversal de aglomerado de fibras no interior da bucha (superfície interna e núcleo da bucha) 90x. Detalhe: Secção transversal das fibras 200x.

Essa análise também permitiu também verificar aspectos relacionados com o efeito dos tratamentos superficiais realizados.

Na Figura 77 são mostradas micrografias obtidas por MEV que mostram o aspecto da superfície da bucha como recebida com a presença de sujeiras e elementos de aspecto gomoso espalhados sobre a superfície indicadas pelas setas azuis e uma camada fina sobre a superfície, indicada por setas brancas (Figura 77c). 


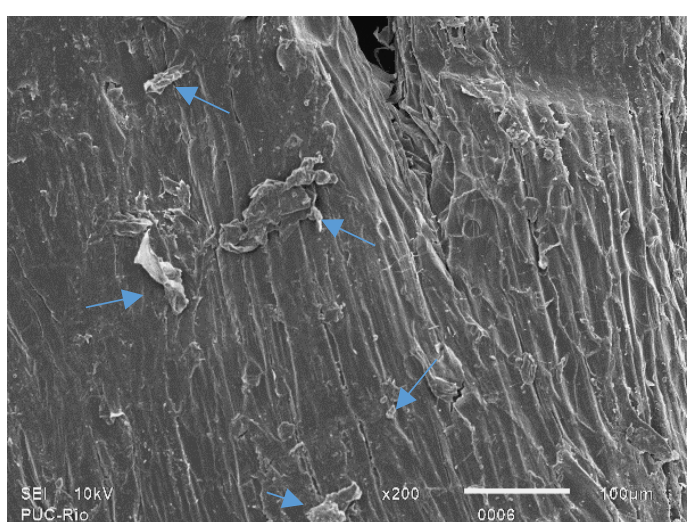

(a)

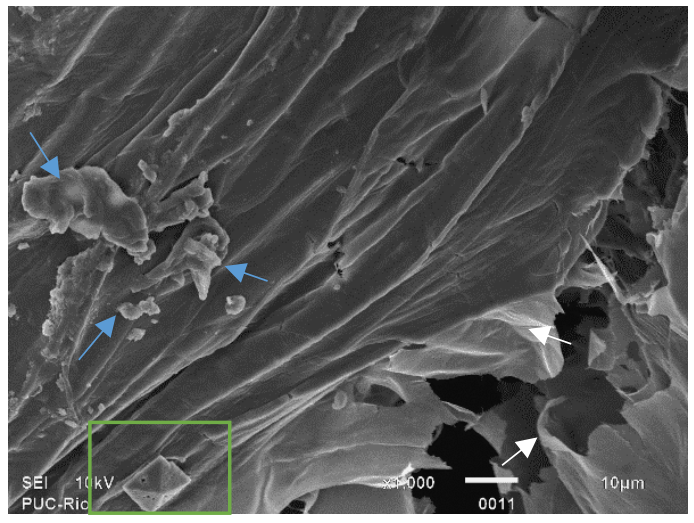

(c)

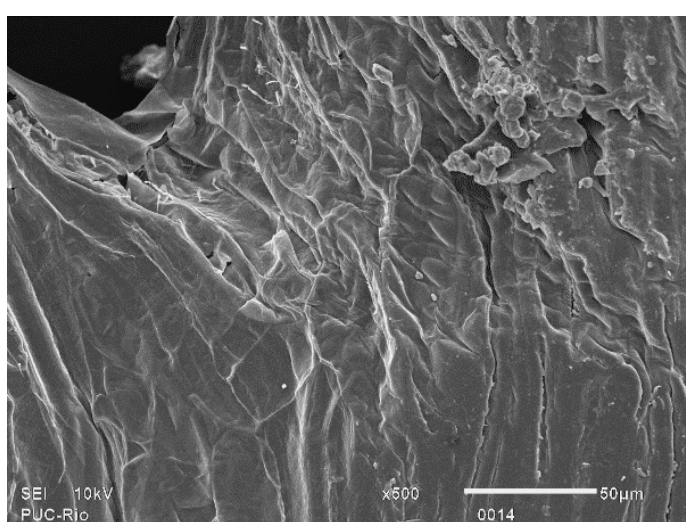

(b)

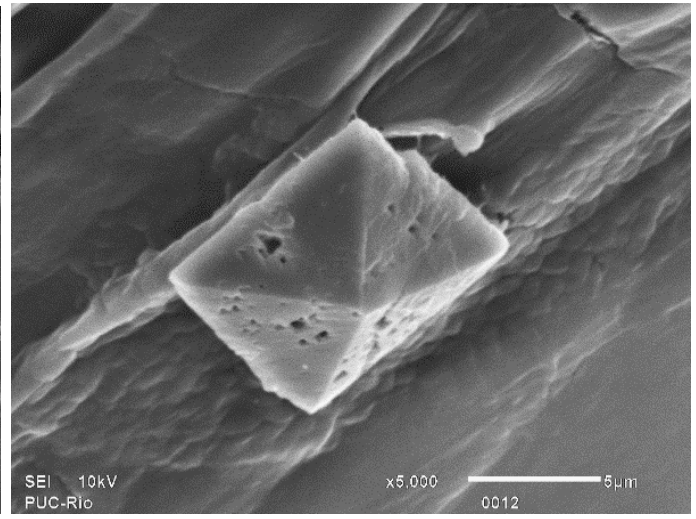

(d)

Figura 77 - Imagem por MEV de fibras de bucha sem tratamento. (a) 200x, (b) 500X, (c) 1000x, (d) 5000X.

Observou-se que o aspecto das fibras hornificadas com aumento de $30 \mathrm{x}$ (Figura 78a) foi similar ao encontrado para fibras de bucha sem tratamento. Uma superfície mais limpa com a remoção de sujeiras e a camada superficial depois do processo de hornificação, pelo efeito de 5 ciclos de secagem e umedecimento é observada nas Figuras 78b-78d.

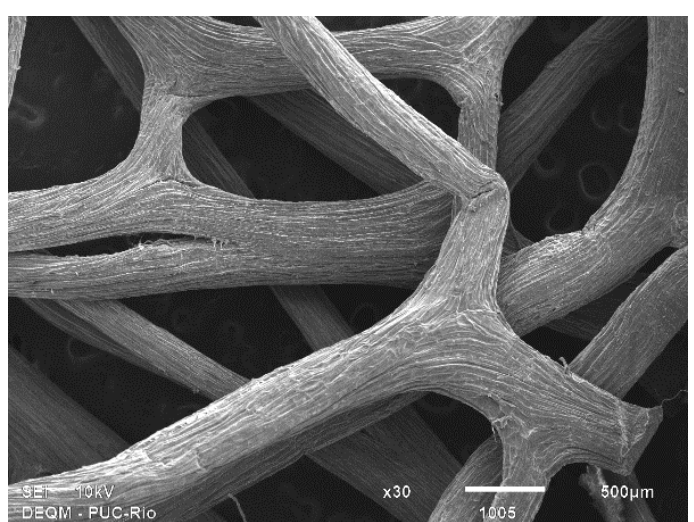

(a)

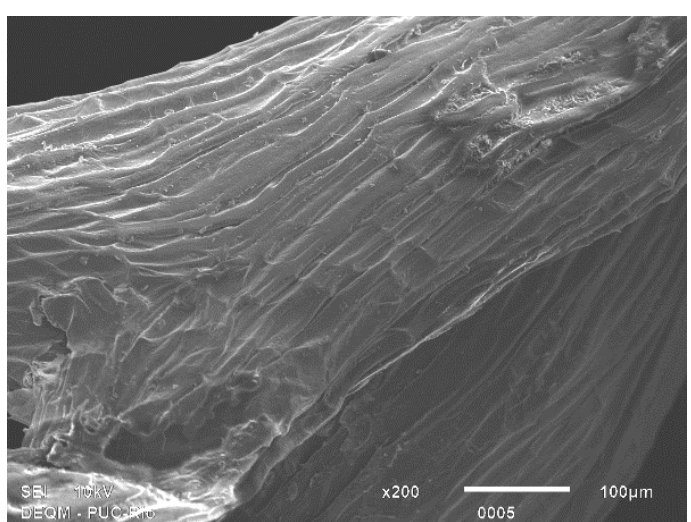

(b) 


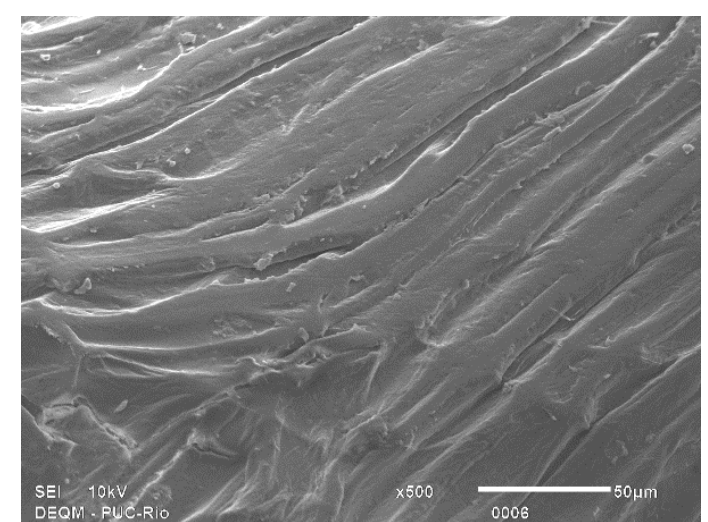

(b)

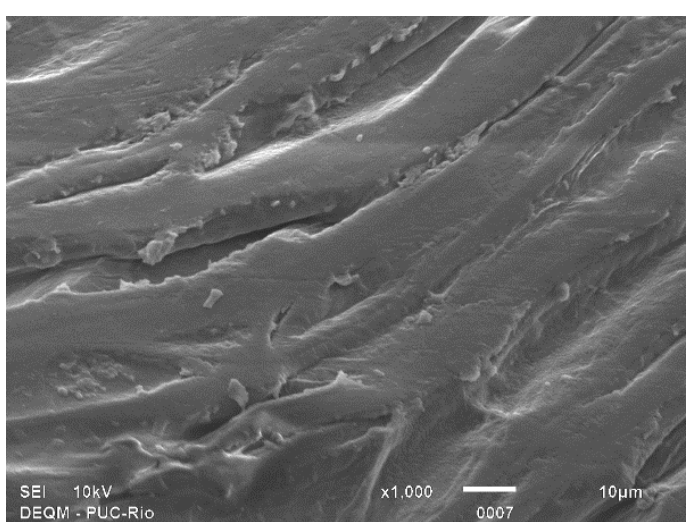

(d)

Figura 78 - Imagem por MEV de fibras de bucha hornificadas. (a) 30x, (b) 200x, (b) 500x, (c) 1000x.

A remoção de componentes superficiais permitiu a observação de outros elementos presentes na superfície das fibras. Em algumas regiões das fibras hornificadas foram observadas pequenas protuberâncias arredondadas mostradas na Figura 79. Estas protuberâncias foram analisadas por energia dispersiva de raios X (EDS) e associadas com a presença de estruturas com conteúdo de cálcio e silício que também foram encontradas em fibras de bucha anteriormente [236].

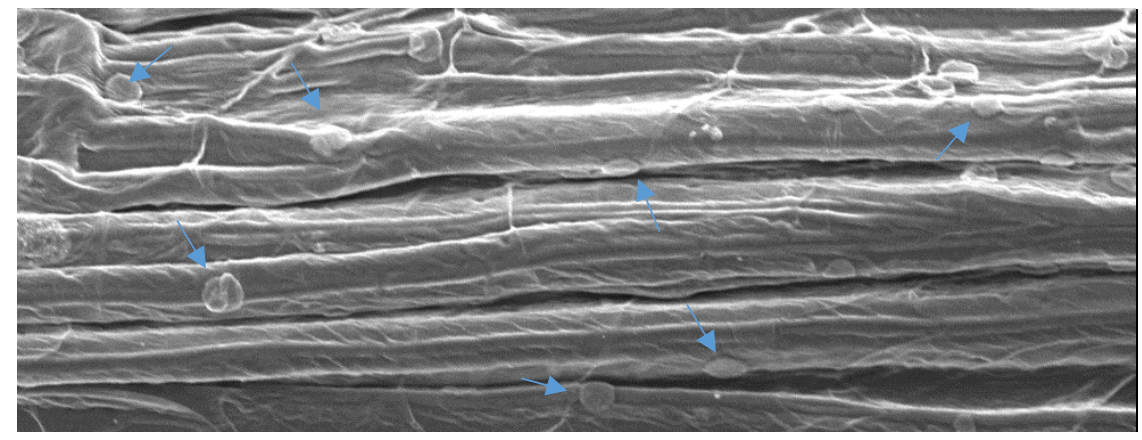

Figura 79 - Imagem por MEV da superfície da fibra de bucha hornificada.

Os resultados da análise por EDS realizada sobre a fibra e sobre uma das protuberâncias indicadas na Figura 79 são mostrados nas Figuras 80 e 81 respectivamente. 


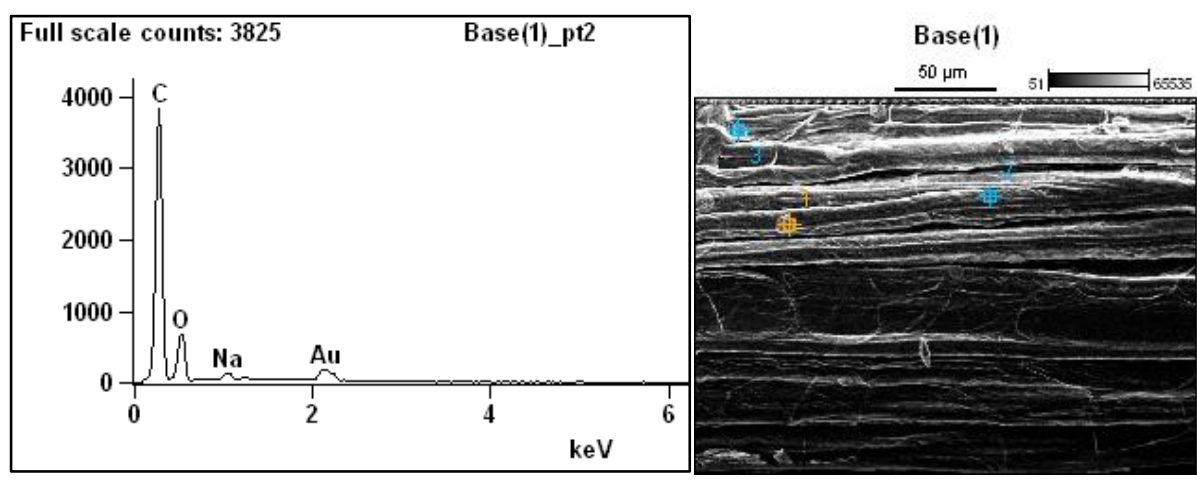

Figura 80 - Espectro EDS sobre a superfície da fibra de bucha hornificada.

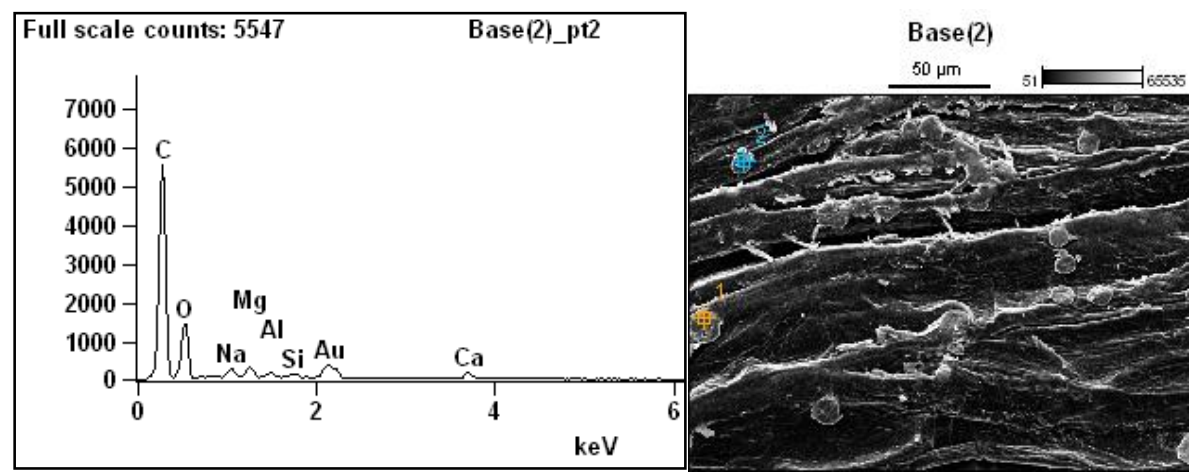

Figura 81 - Espectro EDS de protuberância sobre fibra de bucha hornificada.

A análise por EDS revelou que a fibra de bucha como qualquer matéria orgânica é composta essencialmente por carbono e oxigênio, enquanto que nas protuberâncias foi encontrada também a presença de magnésio, silício e alumínio. Os picos no espectro correspondentes ao ouro dizem respeito ao metal pulverizado utilizado para tornar a superfície da fibra condutora eléctrica.

A aparência da superfície da bucha após o tratamento alcalino é mostrada nas micrografias da Figura 82. Nas Figuras 82c e 82d é possível observar uma maior exposição da estrutura fibrilar interna, o que traz um aumento na rugosidade e na área de contato da superfície da fibra. $\mathrm{O}$ aspecto observado, junto com resultados de infravermelho, sugere a hidrólise de hemiceluloses da parede celular externa das fibras [236]. A possível remoção de hemicelulose e outros constituintes da superfície teria deixado espaços vazios, como indicado pelas setas amarelas na Figura $82 c$. 


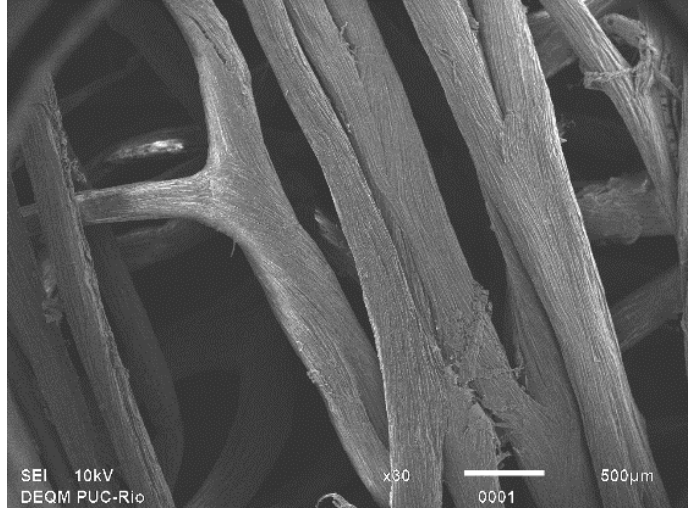

(a)

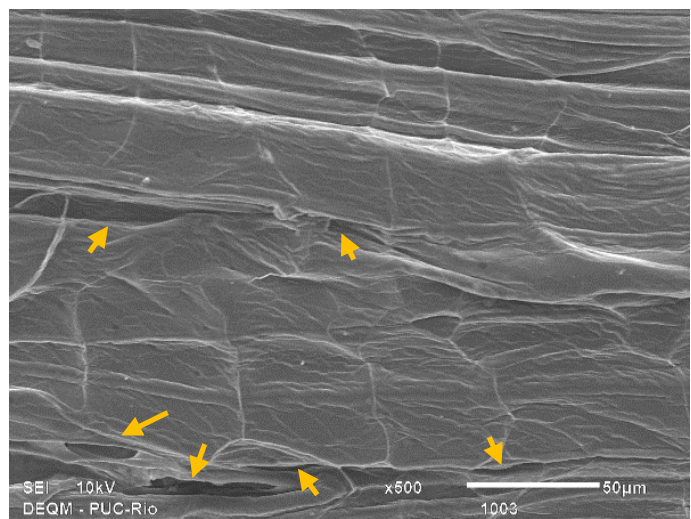

(c)

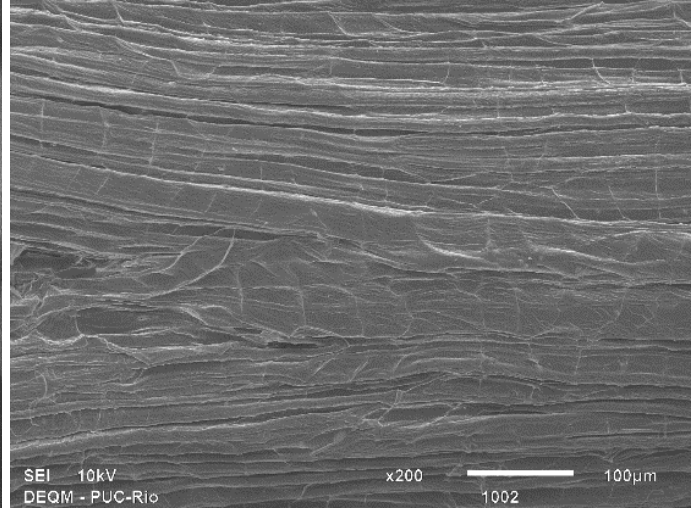

(b)

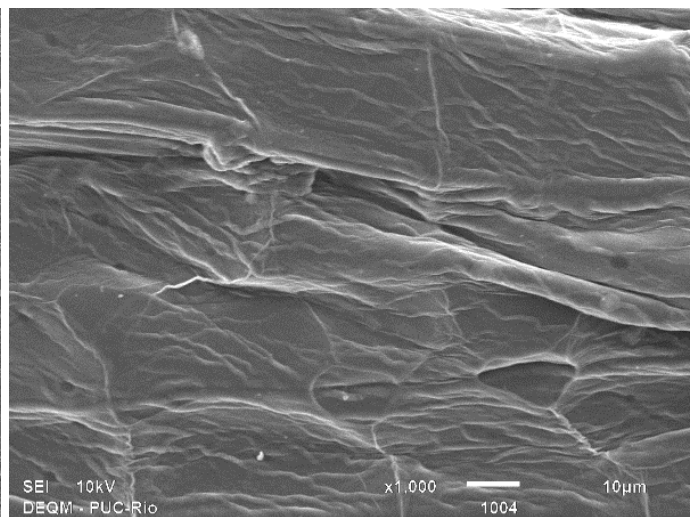

(d)

Figura 82 - Imagem por MEV de fibras de bucha mercerizadas (NaOH 2\%, 90 min). (a) 30x, (b) 200x, (c) 500x, (d) 1000x.

Na Figura 83 é mostrada a morfologia superficial das fibras depois do tratamento de acetilação. É ressaltado que a superfície mostra a existência de regiões atacadas onde as espirais helicoidais de celulose emergem da seção transversal fraturada e aparecem expostas como mostrado nas Figuras $83 b-83 d$.

Também são observadas algumas partículas ligadas à superfície da fibra que provavelmente sofreram a acetilação apenas com ácido acético como foi encontrado também por Mokaloba e Batane (2014) [234], e uma diminuição geral no diâmetro das fibras. 

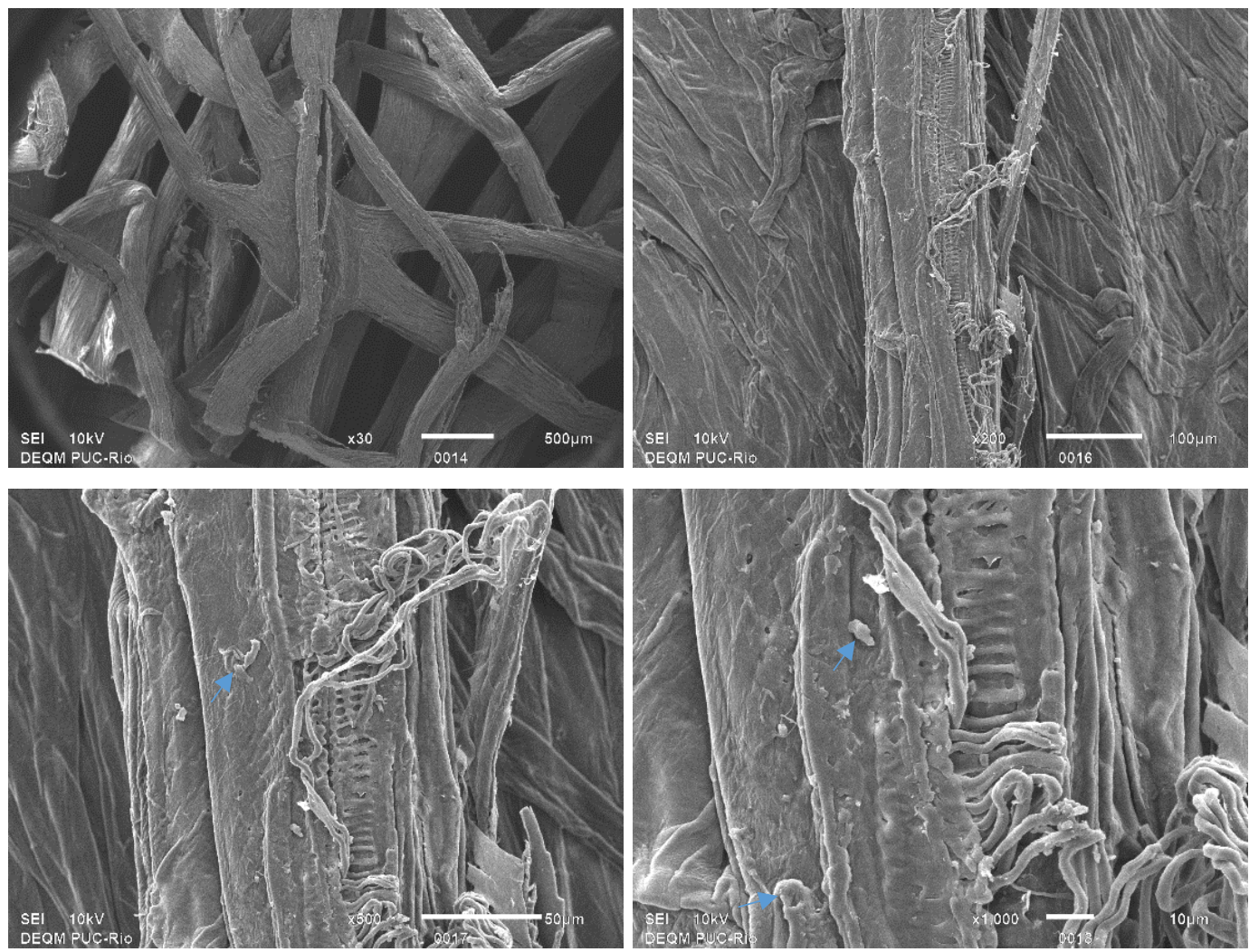

Figura 83 - Imagem por MEV de fibras de bucha acetiladas. (a) 30x, (b) 200x, (c) 500x, (d) $1000 x$.

Nas Figuras 82 e 83, observou-se que, com os tratamentos de mercerização e acetilação realizados foram removidas sujeiras espalhadas sobre a superfície das fibras de bucha sem tratar, assim como as protuberâncias observadas na superfície das fibras hornificadas. Análise da morfologia superficial por MEV indicaram alterações na topografia da superfície das fibras causadas pelos tratamentos de modificação de mercerização e acetilação.

\subsubsection{Difração de Raios X (DRX)}

Na Figura 84 são mostrados os difratogramas de raios $\mathrm{X}$ para as fibras de bucha não tratadas, mercerizadas, hornificadas e acetiladas, indicando as posições dos picos cristalinos mais acentuados. Para todos os difratogramas é observada uma banda de dispersão de fundo em aproximadamente $2 \theta=18^{\circ}$, que representa a presença de estruturas amorfas, e três picos de difração de Bragg acentuados. Isto é consoante com os difratogramas para outras fibras lignocelulósicas, com presença de picos de difração nos planos (101, 002 e 040), que são indicativos da difração de celulose I [272], [324], [325]. 


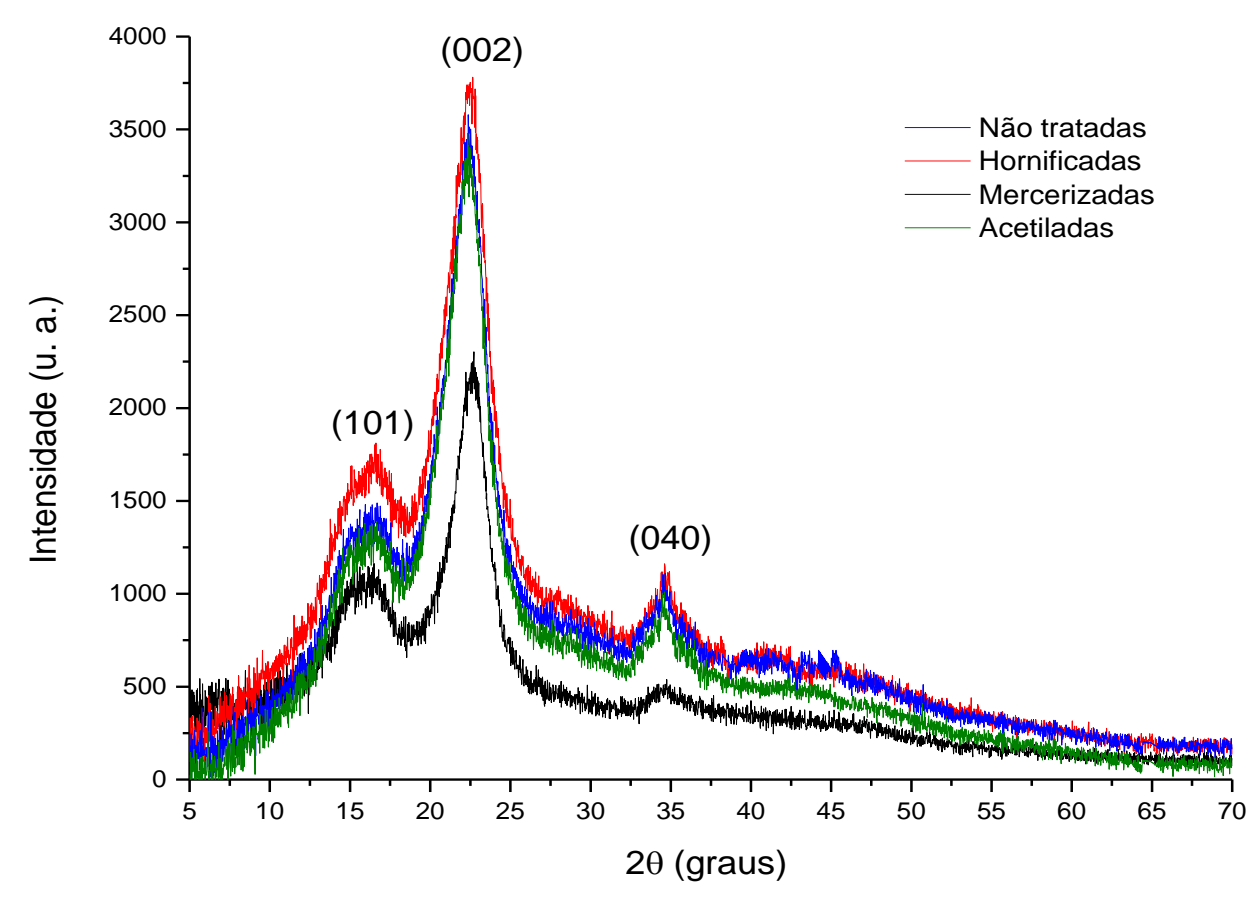

Figura 84 - Padrão DRX para a fibra de bucha

Outros autores reportaram a presença de reflexões nos planos (101) e (101) claramente distinguíveis com picos ao redor de $2 \theta=14^{\circ}$ e $2 \theta=16^{\circ}$ nos espectros de fibras de bananeira [326] e linho [228]. No entanto, nos espectros das fibras de bucha como recebida analisadas neste trabalho estes dois picos se sobrepõem, ao ponto que não são claramente visíveis e aparecem fundidos em um único pico largo, que aparece por volta de $2 \theta=16^{\circ}$, confirmando assim a presença de quantidades de materiais amorfos, tais como lignina, hemiceluloses e celulose amorfa. Por outro lado, não foi observado um ombro no pico de difração no plano (002), portanto não se pode afirmar que exista difração da celulosa no plano (021) nas amostras de fibra de bucha analisadas. O pico com a intensidade máxima de difração aparece por volta de $2 \theta=22^{\circ}$ e indica a difração de celulose cristalina I no plano cristalográfico (002). Um pico cristalino com reflexo de baixa intensidade perto de $34^{\circ}$ foi visível em todos os planos e corresponde à difração no plano (040) [8] [228].

É possível descrever as fibras de bucha seguindo o modelo de celulose bifásico de Fringed [327] que descreve as cadeias de celulose como contendo regiões cristalinas (ordenadas) e amorfas (menos ordenadas), ignorando uma pequena quantidade de matéria com uma ordem intermediária [325]. O índice de cristalinidade (IC) utilizado para descrever a quantidade relativa de material 
cristalino na celulose foi calculado a partir dos difratogramas das fibras de bucha obtidos por DRX. Ao longo dos últimos anos, verificou-se que o IC varia significativamente dependendo da escolha do método de medição [265], [266], [267],[328]. Neste estudo foram comparados os resultados obtidos a partir de três técnicas diferentes, utilizando difratogramas de DRX.

Para o cálculo da porcentagem de cristalinidade pelo método de subtração da área amorfa (método 1) foi utilizada a equação 22, que relaciona a área dos picos cristalinos e a área total. Ruland determinou como a base para este método a subtração de um padrão amorfo semelhante ao componente amorfo na amostra [329]. Alguns autores têm utilizado como padrão materiais como celulose moída, regenerada ou pó de lignina [272]. No entanto, é um procedimento que não está padronizado e requer vários ajustes para não gerar sinais negativos depois de subtrair o componente amorfo. Uma variação deste método é o uso de uma curva modelo para representar o halo amorfo [330], [331].

Assim, uma aproximação da contribuição amorfa foi determinada para cada espectro pelo ajuste de uma curva, como mostrado na Figura 85, usando um polinômio spline cúbico, com 8 pontos ajustáveis, depois de suavizar a curva pelo método Savitzky-Golay.

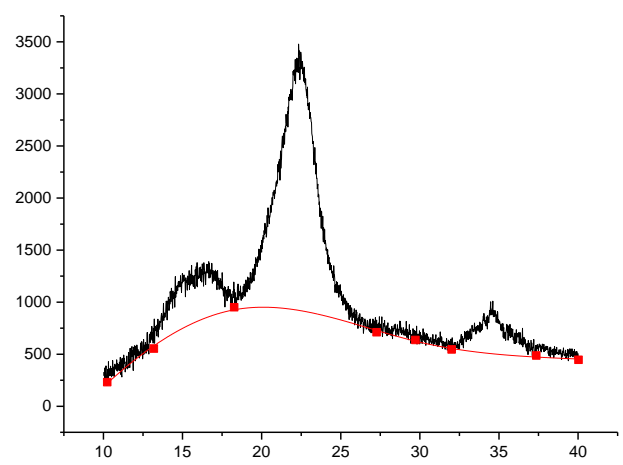

Figura 85 - Determinação de área amorfa no espectro DRX de fibra de bucha acetilada (Método 1).

A área total e a área dos picos cristalinos foram medidas a partir dos difratogramas de DRX, como mostrado nas Figuras 86 a 89. A área cristalina foi determinada pela subtração da área correspondente a parte amorfa do difratograma total. Os valores de IC encontrados pelo método 1 estão listados na tabela 17. 

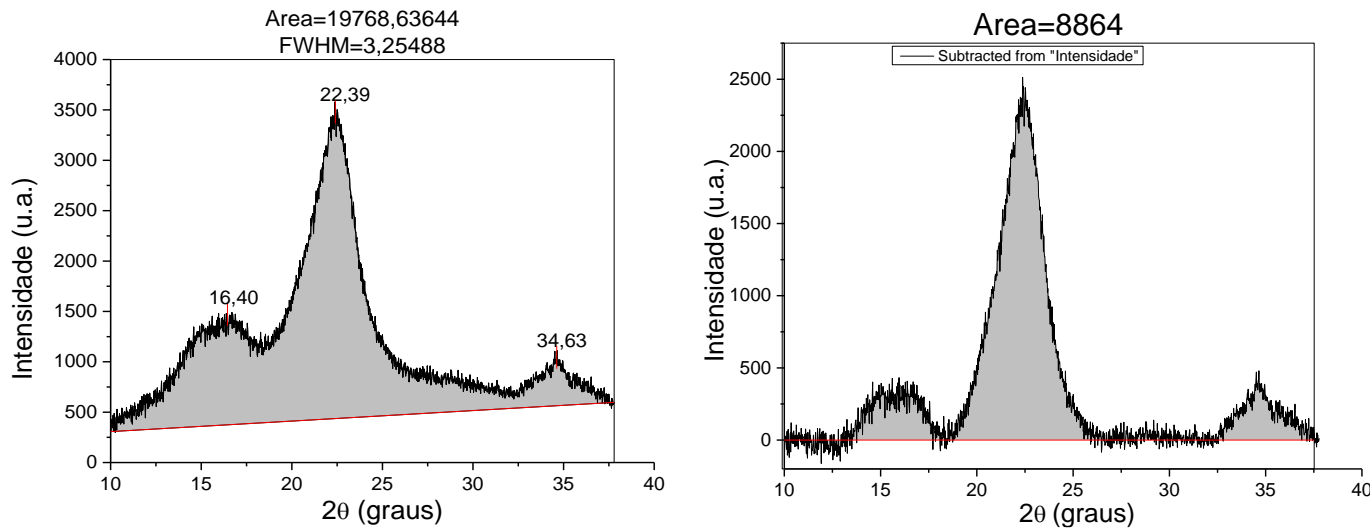

Figura 86 - Padrão de DRX para as fibra de bucha (a) Área total (amorfa + cristalina) (b) Área cristalina.
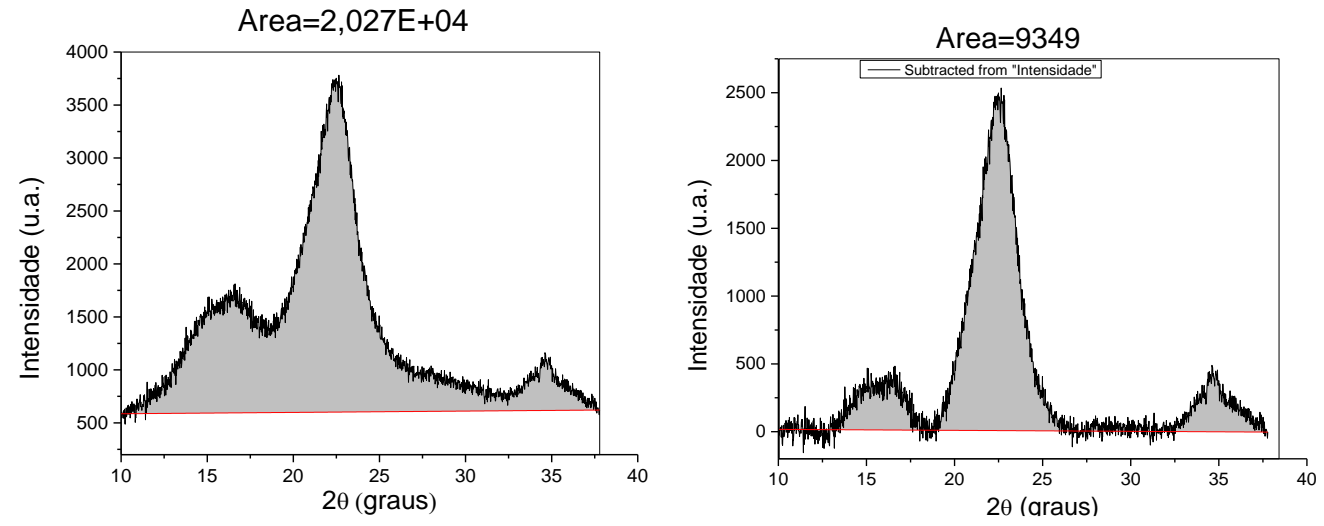

Figura 87 - Padrão DRX para fibras de bucha hornificadas (a) Área total (amorfa + cristalina) (b) Área cristalina.
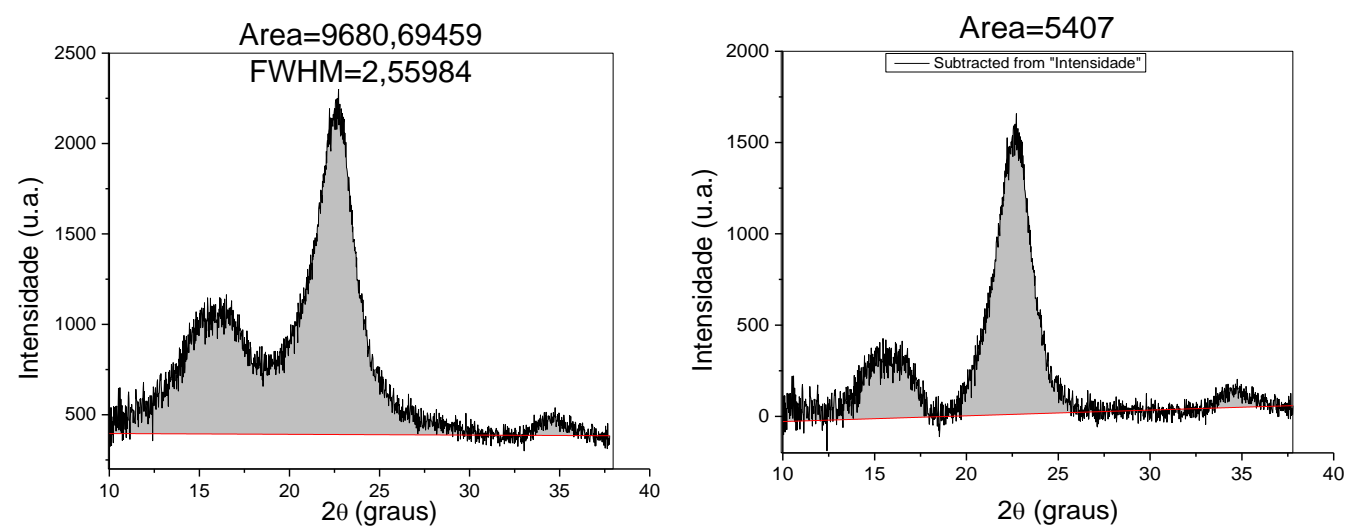

Figura 88 - Padrão DRX para fibras de bucha mercerizadas (a) Área total (amorfa + cristalina) (b) Área cristalina. 

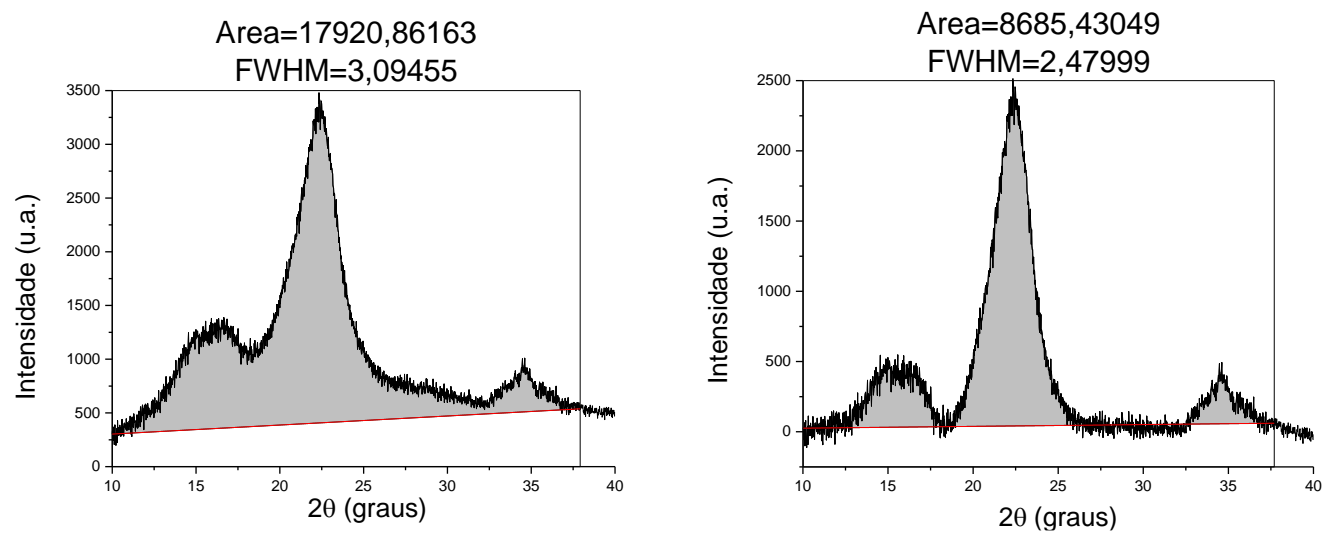

Figura 89 - Padrão DRX para fibras de bucha acetiladas a) Área total (amorfa + cristalina) b) Área cristalina.

Tabela 17 - Índice de cristalinidade de fibras de bucha pelo método 1 (subtração da área amorfa).

\begin{tabular}{|l|c|c|c|c|c|}
\hline & & $\begin{array}{c}\text { Fibras não } \\
\text { tratadas }\end{array}$ & $\begin{array}{c}\text { Fibras } \\
\text { Hornificadas }\end{array}$ & $\begin{array}{c}\text { Fibras } \\
\text { Mercerizadas }\end{array}$ & $\begin{array}{c}\text { Fibras } \\
\text { Acetiladas }\end{array}$ \\
\hline Área Total & [cps x deg] & 19770 & 20270 & 9681 & 17921 \\
\hline Área Cristalina & {$[\mathrm{cps} \times \mathrm{deg}]$} & 8864 & 9349 & 5407 & 8685 \\
\hline $\begin{array}{l}\text { Índice de } \\
\text { cristalinidade }\end{array}$ & $\%$ & 44,83 & 46,12 & 55,85 & 48,46 \\
\hline
\end{tabular}

Para o cálculo das áreas cristalinas foi utilizado também o método de deconvolução dos picos dos espectros DRX das fibras de bucha, designado como método 2. Na tabela 18 são apresentados os resultados de IC obtidos por este método e nas Figuras 90 a 93 são apresentados os resultados da separação das contribuições amorfa e cristalina por deconvolução com o programa Origin, usando o comando "ajuste de picos múltiplos" e assumindo função gaussiana.

Um pico largo por volta de $2 \theta=21,5^{\circ}$ foi atribuído à contribuição amorfa, como reportado na literatura [265], [326]. Para todos os casos obteve-se um coeficiente de correlação $\left(\mathrm{r}^{2}>0,9\right)$, indicando um ajuste adequado dos dados. No apêndice A1 são apresentados os valores de ajuste para a deconvolução de todos os espectros. 


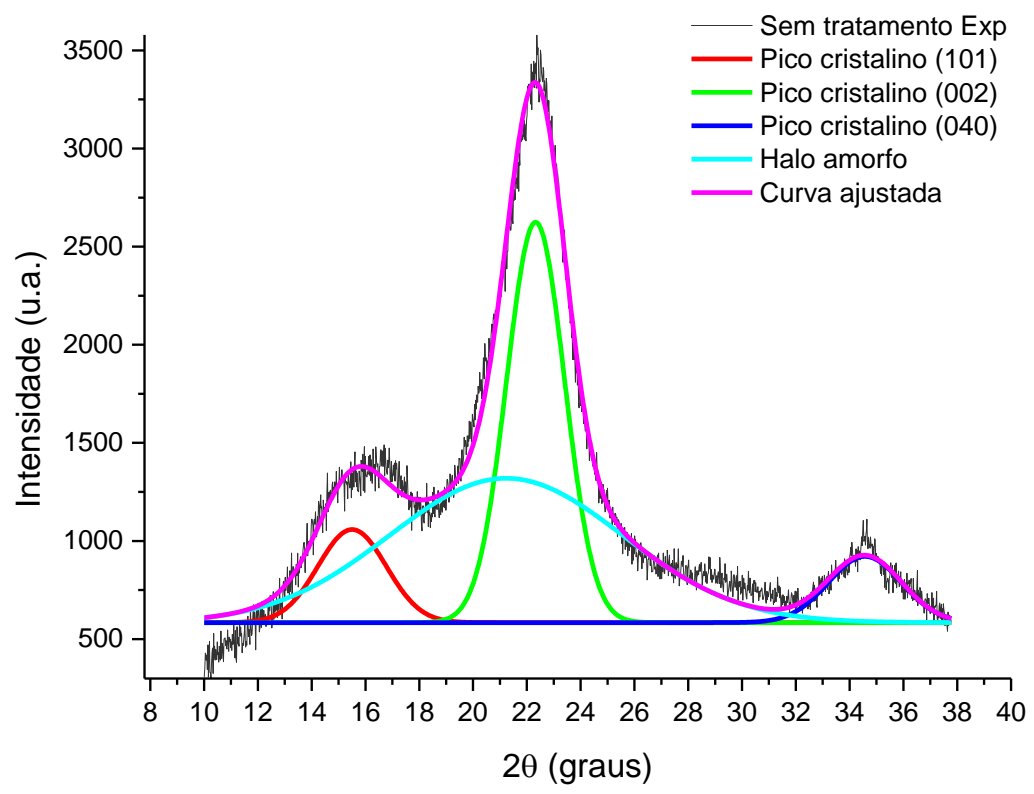

Figura 90 - Deconvolução dos picos no espectro DRX de fibras de bucha sem tratamento.

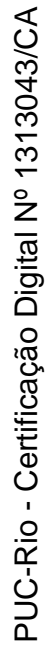

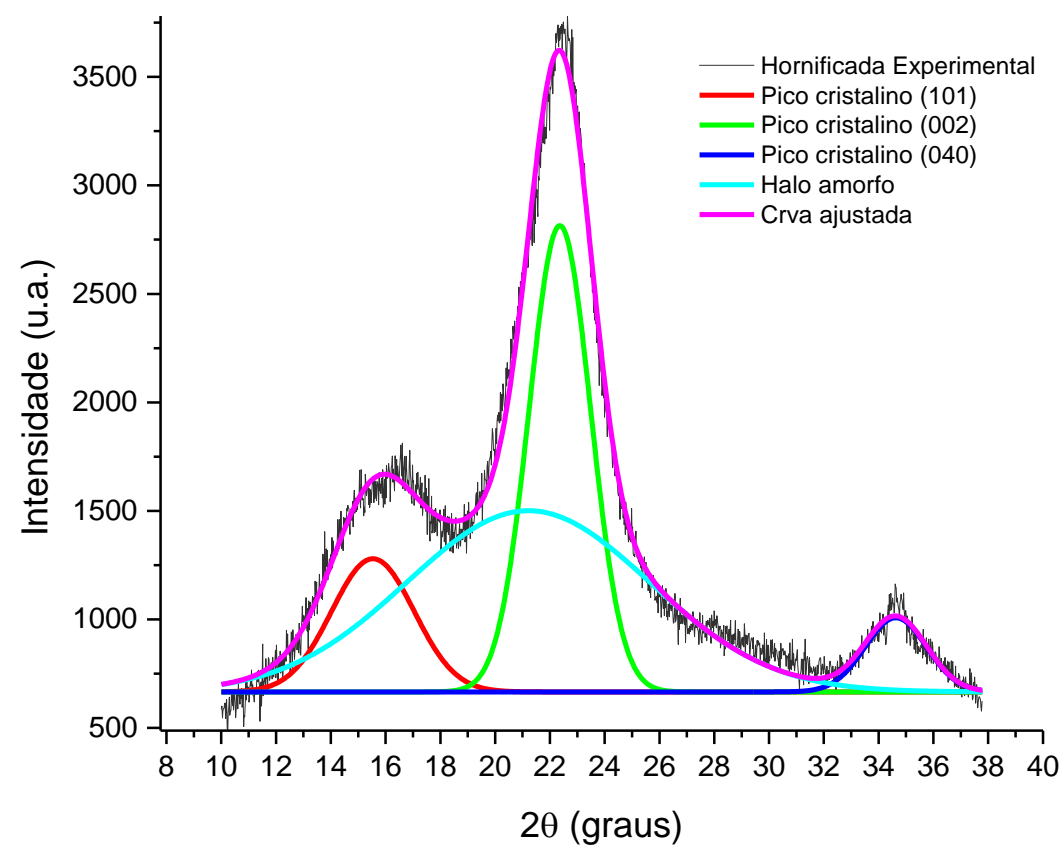

Figura 91 - Deconvolução dos picos no espectro DRX de fibras de bucha hornificadas. 


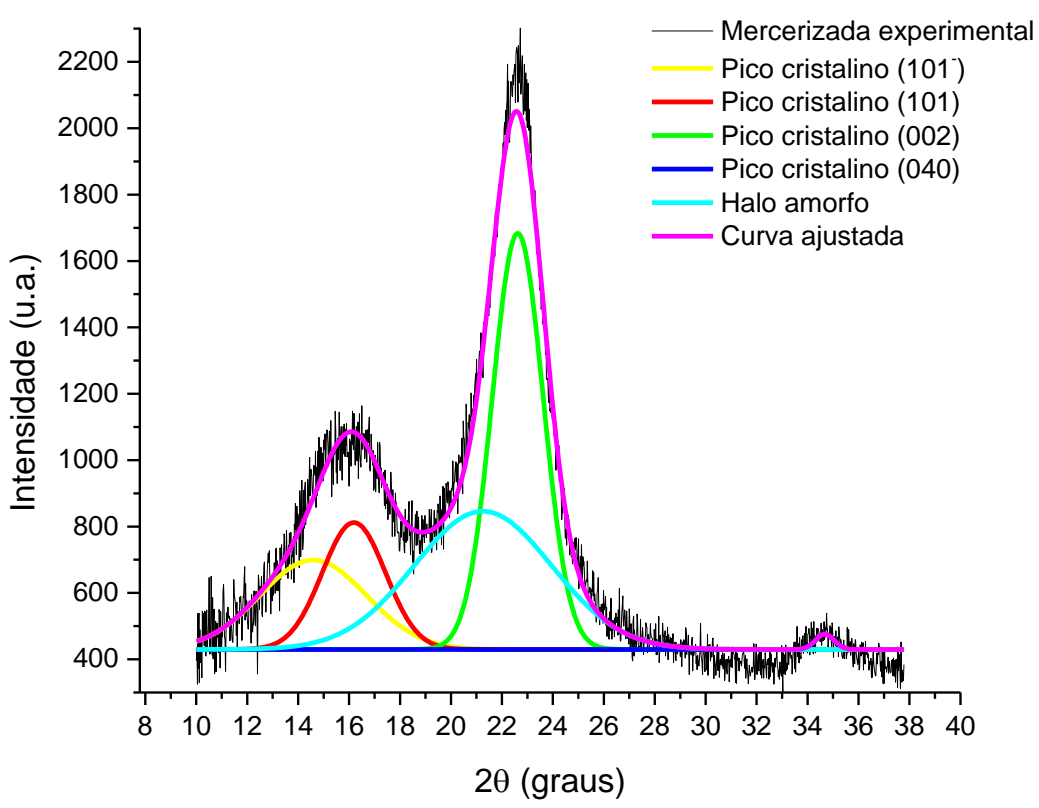

Figura 92 - Deconvolução dos picos no espectro DRX de fibras de bucha mercerizadas.

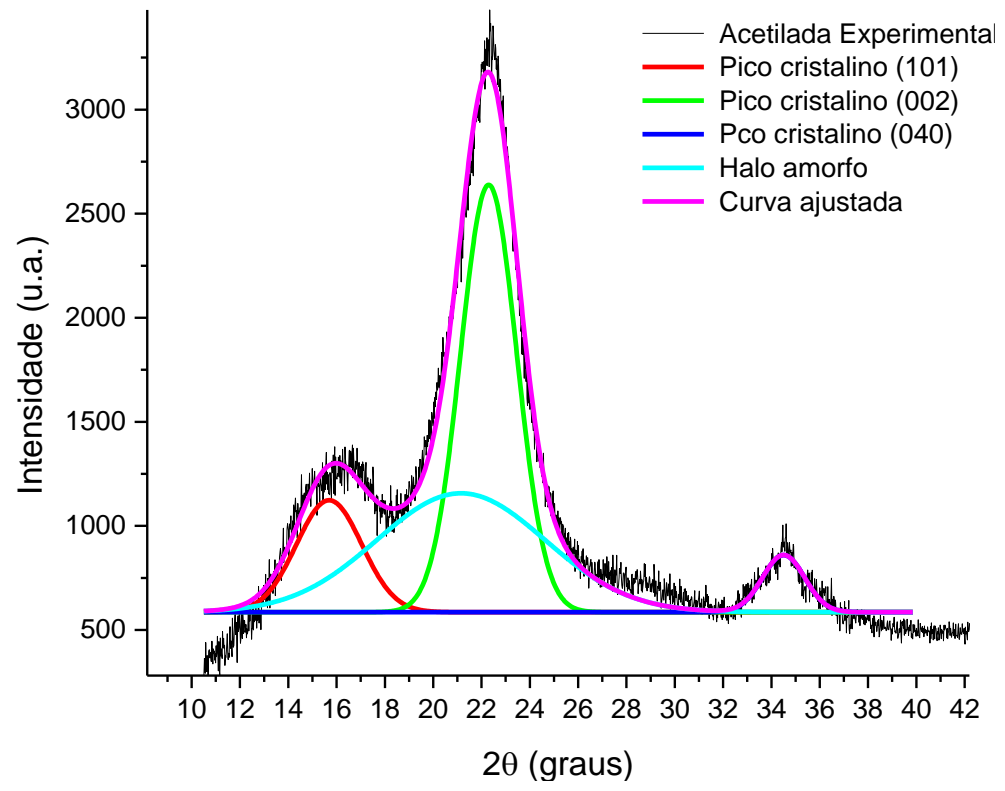

Figura 93 - Deconvolução dos picos no espectro DRX de fibras de bucha acetiladas.

A deconvolução dos picos do espectro das fibras com tratamento alcalino, mostrada na Figura 92, indicou a presença de um pico correspondente à difração no plano (10ī) que não foi possível visualizar nos outros difratogramas. 
Tabela 18 - Índice de cristalinidade de fibras de bucha pelo método 2 (deconvolução dos picos).

\begin{tabular}{|l|l|c|c|c|c|}
\hline & Unidade & $\begin{array}{c}\text { Fibras não } \\
\text { tratadas }\end{array}$ & $\begin{array}{c}\text { Fibras } \\
\text { Hornificadas }\end{array}$ & $\begin{array}{c}\text { Fibras } \\
\text { Mercerizadas }\end{array}$ & $\begin{array}{c}\text { Fibras } \\
\text { Acetiladas }\end{array}$ \\
\hline Área Total & [u.a. $\mathrm{x} \mathrm{deg}$ ] & 16141,50 & 16335,01 & 8593,17 & 13397,59 \\
\hline Área Cristalina & [u.a. x deg] & 8170,85 & 9367,31 & 5776,83 & 8406,28 \\
\hline $\begin{array}{l}\text { Índice de } \\
\text { cristalinidade }\end{array}$ & $\%$ & 50,62 & 57,34 & 67,23 & 62,74 \\
\hline
\end{tabular}

Os resultados do IC obtidos usando o método de Segal, baseado na medição da intensidade em dois pontos do difratograma e calculando a razão entre a intensidade do pico cristalino para o plano $002\left(\mathrm{I}_{(002)}\right.$ - $\left.\mathrm{I}_{(\text {Amorfa) }}\right)$ e a intensidade total, $I_{(002)}$, são apresentados na tabela 19. Este método exclui a contribuição dos outros picos cristalinos relevantes, assim como a largura dos picos [272]. No entanto, foi utilizado para ter uma base de comparação com valores encontrados na literatura [246].

Tabela 19 - Índice de cristalinidade de fibras de bucha pelo método 3 (altura dos picos).

\begin{tabular}{|c|c|c|c|c|c|}
\hline Fibras de bucha & $\mathbf{2} \boldsymbol{\theta}$ & $\begin{array}{c}\text { Intensidade } \\
\text { I(002) }\end{array}$ & $\mathbf{2} \boldsymbol{\theta}$ & $\begin{array}{c}\text { Intensidade } \\
\text { “amorfa" }\end{array}$ & IC (\%) \\
\hline Sem Tratamento & 22,2 & 3362,3 & 18,2 & 1154,03 & 65,68 \\
\hline Mercerizadas & 22,7 & 2247 & 18,5 & 726 & 67,69 \\
\hline Hornificadas & 22,3 & 3723 & 18,02 & 1301 & 65,06 \\
\hline Acetiladas & 22,22 & 3345 & 18,02 & 1059 & 68,34 \\
\hline
\end{tabular}

Embora seja um método simples e rápido, levou a valores de IC mais altos em comparação com os outros métodos. A diferença nos valores de IC obtidos por este método em relação aos anteriores está sustentada no fato de ter se assumido valores diferentes para a intensidade máxima da região amorfa. Nesse método foi assumido o centro do pico entre as reflexões para os planos 101 e 002 , isto é $2 \theta=18^{\circ}$, enquanto para os métodos da subtração da área amorfa e da deconvolução o valor do ápice do pico devido à estrutura amorfa da celulose foi encontrado sempre em valores acima de $2 \theta=20^{\circ}$, como é mostrado nas Figuras 85 a 93. Assim, a área correspondente à parte amorfa pelo método da altura resulta ser menor e dá como resultado IC maiores, se comparado com os outros métodos. 
Como pode se apreender dos dados nas tabelas 17, 18 e 19, há uma ligeira diferença na porcentagem cristalina das fibras de bucha obtida pelos métodos 1 e 2 , enquanto que o valor encontrado com o método da altura foi significativamente diferente. Além disso, no método das alturas não há diferença significativa do IC devido aos tratamentos.

Os valores de cristalinidade da bucha encontrados na literatura discordam entre si, havendo valores entre $48-82 \%$, segundo o método aplicado para seu cálculo. Tanobe et al (2005, Satyanarayana et al. (2007) encontraram valores de 59,1\% [201], [206], [322]. NagarajaGanesh et al. (2016) reportaram IC=58,68 [332]. Fibras de bucha com IC=50\% reportadas por Ghali et al. (2009) [244] e Guimarães et al. (2009) [333] e com IC=48,91 por Adewuyi e Pereira (2017) [334], estiveram mais próximos dos valores obtidos neste trabalho. Enquanto, Siqueira et al. (2010) e Laidani et al. (2012) reportaram fibras de bucha com IC mais elevados, com valores de $81,93 \%$ e $69 \%$, respectivamente [323].

Os resultados de IC revelaram alterações na estrutura cristalina após os tratamentos físico-químicos realizados nas fibras de bucha. Foi encontrado um aumento de $32 \%$ no índice de cristalinidade de fibras de bucha com tratamento alcalino segundo o método de deconvolução. Este resultado pode ter sido causado pela remoção de hemiceluloses, lignina e polissacáridos não celulósicos, como reportado por outros autores [206], [244], [335]. A eliminação destes compostos amorfos, responsável pelo aumento de cristalinidade nas fibras tratadas foi confirmada pela análise dos espectros FT-IR.

Também foi determinada uma variação na cristalinidade das fibras de bucha acetiladas de $24 \%$, pelo método de deconvolução, que pode ser causado pela remoção de lignina e substâncias amorfas extraídas da superfície das fibras. Por outro lado, nas fibras tratadas com o método da hornificação ocorreu um aumento de $13 \%$ no índice de cristalinidade, sugerindo uma possível mudança no empacotamento das cadeias de celulose [9]. 


\subsubsection{Espectroscopia do Infravermelho com transformada de Fourier (FTIR)}

A análise por infravermelho é frequentemente utilizada para determinar grupos funcionais ativos presentes nos constituintes principais das fibras lignocelulósicas (celulose, lignina e hemicelulose e pectina). Assim, os picos encontrados nos espectros de FTIR das fibras de bucha foram atribuídos principalmente aos grupos $\mathrm{O}-\mathrm{H}$ (hidroxila), $\mathrm{C}-\mathrm{H}, \mathrm{C}=\mathrm{O}, \mathrm{C}-\mathrm{C}$ e anéis aromáticos habitualmente presentes em fibras lignocelulósicas.

Na Figura 94, observam-se os espectros de infravermelho correspondentes às fibras de bucha como recebidas, hornificadas, mercerizadas e acetiladas, indicando as atribuições dos principais sinais e no apêndice A2 se encontram os espectros individuais indicando cada pico de absorção com maior detalhe. As posições das bandas foram consistentes com os dados na literatura publicados para bucha e outras fibras vegetais [233], [336], [337], [338], [339].

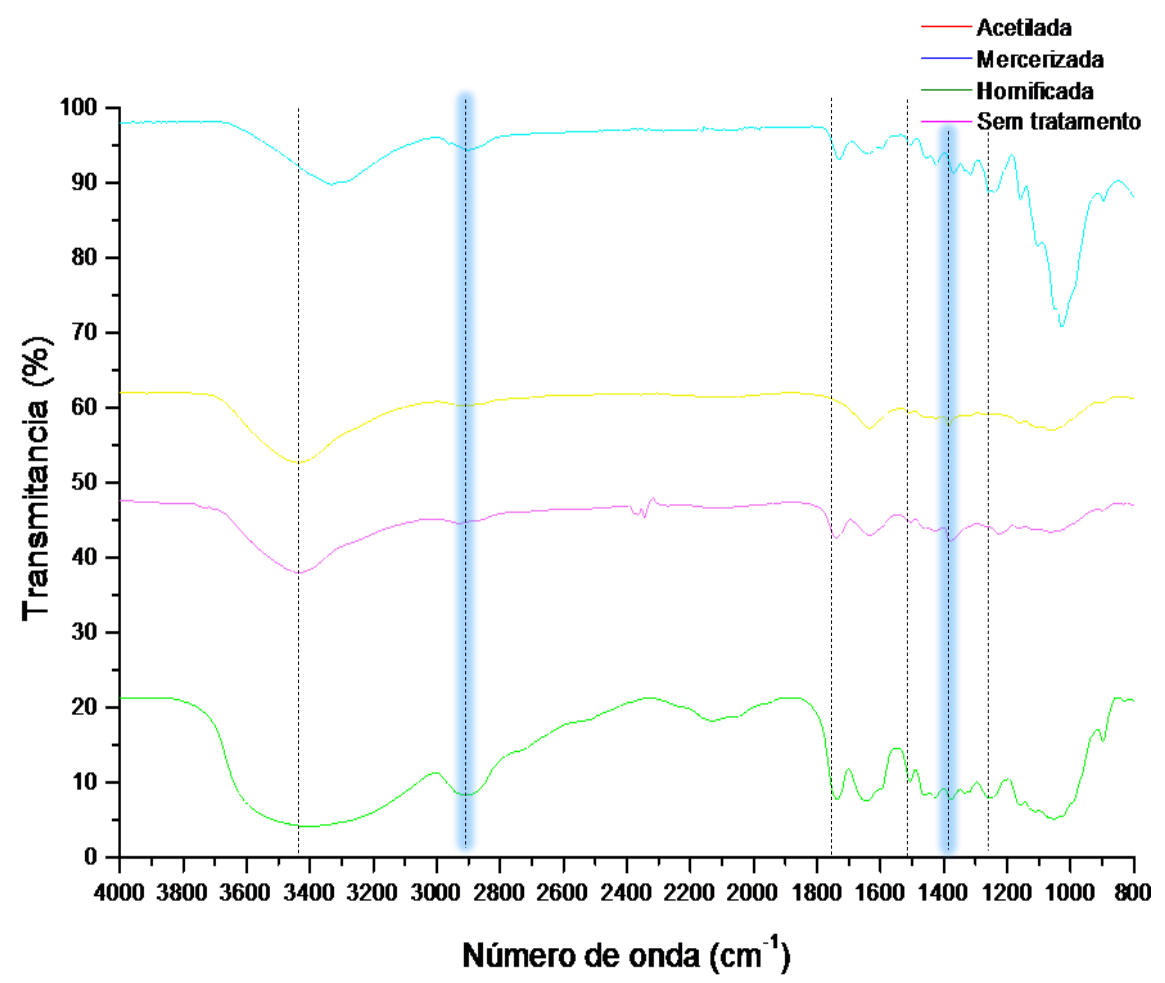

Figura 94 - Espectro FTIR das fibras de bucha como recebidas e com os diferentes tratamentos.

Na Tabela 20 são apresentadas As principais bandas características de absorção observadas nos espectros das fibras de bucha com e sem tratamentos, assim como a espécie química associada a cada sinal. 
As alterações observadas na grandeza dos sinais nos espectros de FTIR das fibras de bucha permitiram verificar a eficiência dos tratamentos químicos realizados na superfície. Na Figura 94 é mostrado que as fibras brutas e com tratamentos de mercerização e hornificação exibiram uma banda relevante ocorrendo na região entre 3434 - $3409 \mathrm{~cm}^{-1}$, que representa a vibração axial característica das hidroxilas presentes na celulose. O deslocamento da banda por volta de $3300 \mathrm{~cm}^{-1}$ no espectro das fibras acetiladas pode estar relacionado com a vibração de valência dos hidrogênios ligados aos grupos $\mathrm{OH}$ [338]. No caso das bandas por volta de $3400 \mathrm{~cm}^{-1}$, ocorre pela ligação intramolecular de hidrogênio de $\mathrm{O}(2) \mathrm{H}-\mathrm{O}(6)$, enquanto que nas bandas em $3300 \mathrm{~cm}^{-1}$ à ligação intramolecular de hidrogênio de $\mathrm{O}(3) \mathrm{H}$ - $\mathrm{O}$ (5)[337]. O alargamento desta banda pela presença de interações intermoleculares de ligação de hidrogênio é um indicativo da absorção de umidade. Observou-se a diminuição na intensidade desta banda nas fibras que foram expostas aos tratamentos superficiais confirmando assim alterações na estrutura da celulose [162], [221].

Tabela 20 - Picos características de absorção de fibra de bucha sem tratamento (N), Hornificadas (H), Mercerizadas (M) e Acetiladas (A) [162],[340][337].

\begin{tabular}{|c|c|c|c|c|c|c|}
\hline & $\mathbf{N}_{\left(\mathbf{c m}^{-1}\right)}$ & $\underset{\left(\mathbf{c m}^{-1}\right)}{\mathbf{H}}$ & $\underset{\left(\mathbf{c m}^{-1}\right)}{\mathbf{M}}$ & $\underset{\left(\mathbf{c m}^{-1}\right)}{\mathbf{A}}$ & Atribuição de pico & $\begin{array}{l}\text { Espécie } \\
\text { Química }\end{array}$ \\
\hline 1 & 3409,3 & 3433,6 & 3433,6 & 3333,3 & $\begin{array}{c}v \text { Estiramento Axial de } \\
(\mathrm{O}-\mathrm{H})\end{array}$ & $\begin{array}{c}\text { Água } \\
\alpha \text {-celulose }\end{array}$ \\
\hline 2 & 2911,7 & 2928 & 2925,9 & 2900,8 & $\begin{array}{c}v \text { Estiramento axial } \\
\left(\mathrm{CH}_{2}\right)\end{array}$ & $\begin{array}{c}\text { Celulose e } \\
\text { hemiceluloses }\end{array}$ \\
\hline 3 & 1736,5 & 1742,6 & - & - & $\begin{array}{l}v \text { Estiramento do grupo } \\
\text { carbonila }(\mathrm{C}=\mathrm{O})\end{array}$ & Hemiceluloses \\
\hline 4 & - & - & - & 1730,5 & $(\mathrm{C}=\mathrm{O})$ & Éster \\
\hline 5 & 1645,5 & 1627,3 & 1635,4 & 1639,4 & Dobramento $(\mathrm{O}-\mathrm{H})$ & Água absorvida \\
\hline 6 & 1508 & 1508 & 1508 & 1508 & $\begin{array}{l}v \text { Estiramento simétrico } \\
\text { aromático }(\mathrm{C}-\mathrm{O})\end{array}$ & Lignina \\
\hline 7 & 1429 & 1425 & 1421 & 1424,4 & $\begin{array}{l}\text { Vibração de dobramento } \\
\text { no plano }\left(\mathrm{CH}_{2}\right) \text { e }(\mathrm{O}-\mathrm{H})\end{array}$ & Celulose \\
\hline 8 & 1378,5 & 1380,5 & 1386,6 & 1369,9 & $\begin{array}{c}\delta \text { Deformação simétrica } \\
\text { e asimetrica }(\mathrm{C}-\mathrm{H})\end{array}$ & $\begin{array}{c}\text { Celulose e } \\
\text { hemicelulose }\end{array}$ \\
\hline 9 & 1334 & - & - & - & $\begin{array}{c}\text { Estiramento do anel } \\
\text { aromático } \\
\delta(\mathrm{CH}), v(\mathrm{C}-\mathrm{O})\end{array}$ & Lignina \\
\hline 10 & 1255 & - & - & 1258,52 & Estiramento $v(\mathrm{C}-\mathrm{O}-\mathrm{O})$ & $\begin{array}{l}\text { hemiceluloses } \\
\text { lignina }\end{array}$ \\
\hline 11 & 1046,7 & 1060,9 & 1065 & 1029,28 & $\begin{array}{c}\text { Vibrações de anel e } \\
\text { grupos laterais }(\mathrm{C}-\mathrm{H}) \text {, } \\
\text { Deformações }(\mathrm{C}-\mathrm{C}),(\mathrm{C}- \\
\mathrm{OH})\end{array}$ & $\begin{array}{c}\text { Celulose e } \\
\text { hemicelulose } \\
\text { Polissacarídeos }\end{array}$ \\
\hline 12 & 899,06 & 897,04 & 897,04 & 897,9 & $\begin{array}{c}\text { Deformação } \gamma(\mathrm{C}-\mathrm{H}) \\
\text { e (C-O-C) } \\
\text { estiramento }(\mathrm{C}-\mathrm{C}-\mathrm{H})\end{array}$ & Celulose amorfa \\
\hline
\end{tabular}


As bandas de absorção observadas por volta de $2900 \mathrm{~cm}^{-1}$, representam as vibrações causadas por deformações axiais e o estiramento simétrico e assimétrico de unidades metileno $\mathrm{CH}_{2}$, associados à celulose e hemiceluloses [162], [336]. Observou-se uma diminuição na intensidade das sinais principalmente para as fibras expostas ao tratamento alcalino e as fibras hornificadas, o que sugere a remoção de uma quantidade das hemiceluloses na suerfície por estes métodos. Bandas de absorção em 1736,5 e 1742,6 $\mathrm{cm}^{-1}$ para as fibras sem tratamento e hornificadas, respectivamente, são atribuídos à presença de grupos carbonila em hemiceluloses e lignina [336]. Essa banda não está presente no espectro FTIR das fibras de bucha que foram tratadas com solução de $\mathrm{NaOH}$, indicando a remoção efetiva de hemiceluloses por este método, como também foi reportado para o tratamento de fibras de bucha com $15 \%$ de $\mathrm{NaOH}$ [174] e outras fibras lignocelulósicas [341], [342].

No espectro das fibras acetiladas observou-se a diminuição da intensidade na banda em $3333 \mathrm{~cm}^{-1}$ e a intensificação da banda em 1730,5, o que indicaria a esterificação parcial dos grupos hidroxila na superfície das fibras, gerando a adição de novos grupos acetila à celulose como encontrado por D’Almeida et al. (2005) [162], [318]. A banda de absorção em $1508 \mathrm{~cm}^{-1}$ associada às ligações $\mathrm{C}=\mathrm{C}$ de anéis aromáticos, tipicamente presentes na macromolécula de lignina, apresenta maior intensidade no espectro das fibras não tratadas, entanto que é apenas perceptível no espectro das fibras mercerizadas. Este efeito tem sido encontrado também no estudo da bucha e outras fibras lignocelulósicas [174], [336], [343]. As bandas entre 1421 e $1429 \mathrm{~cm}^{-1}$ correspondentes à celulose, foram atribuídas ao movimento de dobramento do $\mathrm{CH}_{2}$ [221], [340]. As bandas que surgem por volta de $1380 \mathrm{~cm}^{-1}$, representam a vibração da ligação $\mathrm{C}-\mathrm{H}$ da estrutura da celulose e hemiceluloses. Igualmente, as sinais por volta de $1255 \mathrm{~cm}^{-1}$ presentes nas fibras brutas e associadas à vibração de ligações $\mathrm{C}-\mathrm{O}$, não aparecem no espectro da fibras mercerizadas, o que está associado com a remoção de cera na superfície de fibras vegetais [343], como encontrado depois da mercerização de outras fibras lignocelulósicas [233], [234]. A banda em $898 \mathrm{~cm}^{-1}$ está associada com ligações $\beta$-glucosídicas [336], [344] e sua a intensidade é maior para o espectro das fibras brutas. As bandas que estão ressaltadas no espectro da Figura 94 são usadas para o estudo da cristalinidade das amostras por meio da determinação da razão espectral 1375/2902 cm-1 [340], [345], [346]. Entretanto, essas análises não foram realizadas nesse trabalho. 


\subsubsection{Análise Termogravimétrica (TGA)}

A estabilidade térmica das fibras de bucha foi avaliada por TGA dentro da faixa de temperatura programada, da temperatura ambiente a $650^{\circ} \mathrm{C}$. A degradação térmica das fibras de bucha foi caracterizada por várias etapas. As principais etapas correspondem à evaporação da água contida nas fibras, a decomposição de hemicelulose e a decomposição de celulose, como mostrado na Figura 95 para fibras de bucha sem tratamento. Por outro lado, o passo relativo à decomposição de lignina ocorre em uma ampla faixa de temperaturas [174], [225].

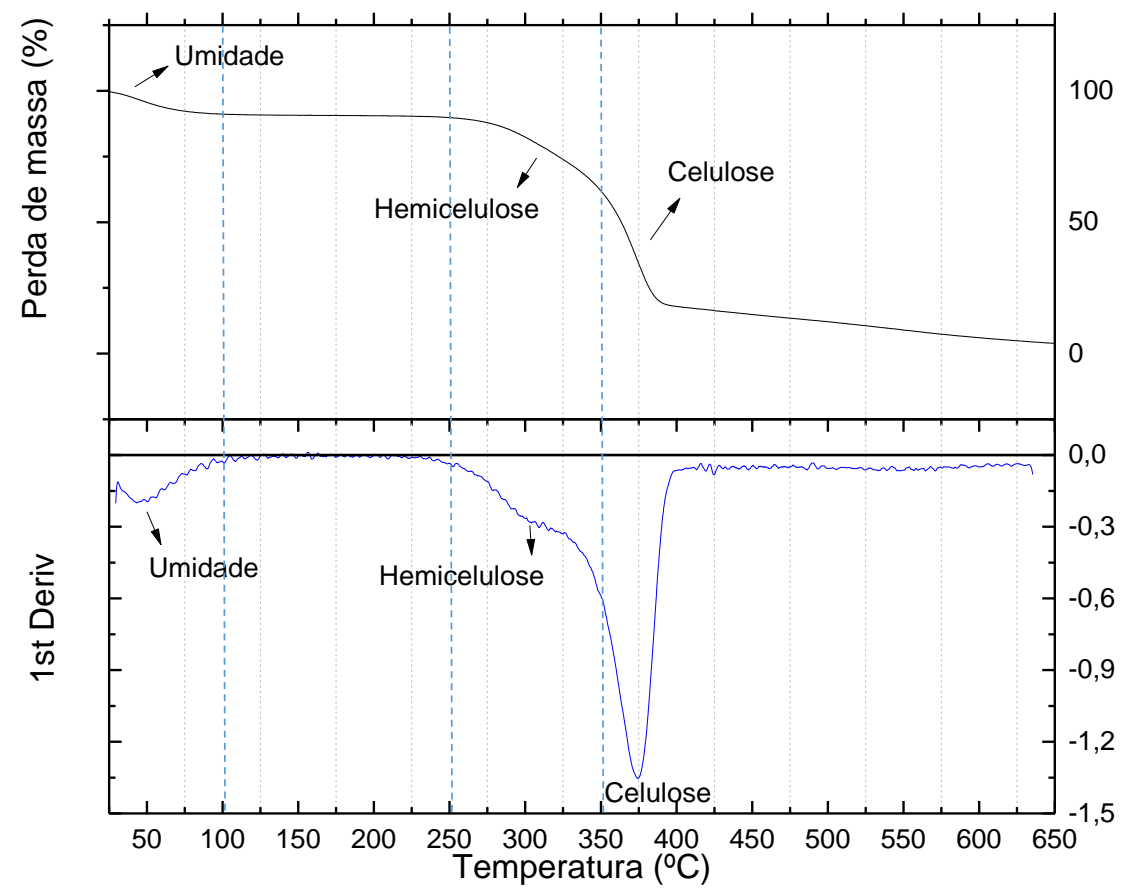

Figura 95 - Comportamento térmico de fibras de bucha.

Observou-se uma perda de massa inicial em baixas temperaturas relacionada frequentemente com a evaporação da umidade absorbida pelas fibras [22], [347], [348]. Notou-se também que na curva correspondente à primeira derivada aparece um ombro por volta de $300{ }^{\circ} \mathrm{C}$, que também tem sido encontrado na caracterização térmica de outras fibras lignocelulósicas como piaçava [174], [348], fibras de alcachofra [349] e sisal [342] e é explicado pela decomposição térmica de hemicelulose, ocorrendo entre 250 e $350{ }^{\circ} \mathrm{C}$ [174], [348], [349]. A taxa de degradação máxima, que envolve a decomposição de $\alpha$-celulose [348], foi encontrada em aproximadamente $375^{\circ} \mathrm{C}$ para as fibras de bucha. Em temperaturas entre 280 e $500^{\circ} \mathrm{C}$ tem-se considerado a decomposição da lignina presente em 
fibras vegetais [350], com o início da decomposição de anéis cíclicos acima de 400 ${ }^{\circ} \mathrm{C}$. A comparação das curvas de variação da massa versus temperatura, obtidas a partir da análise por TGA para as fibras de bucha, são apresentadas na Figura 96.

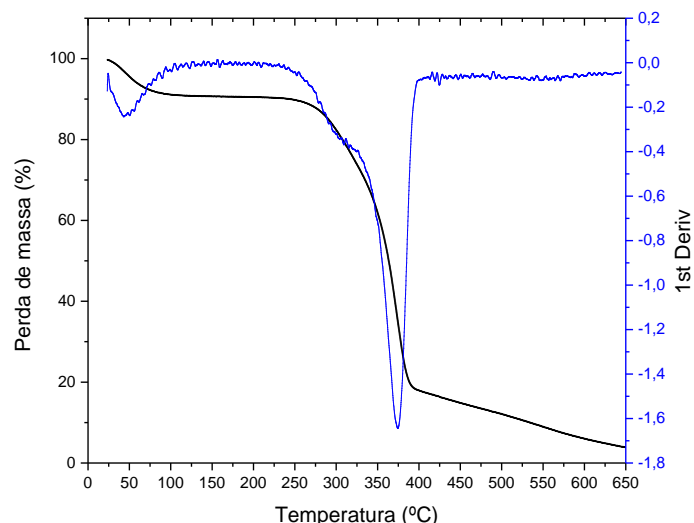

$\boldsymbol{a}$

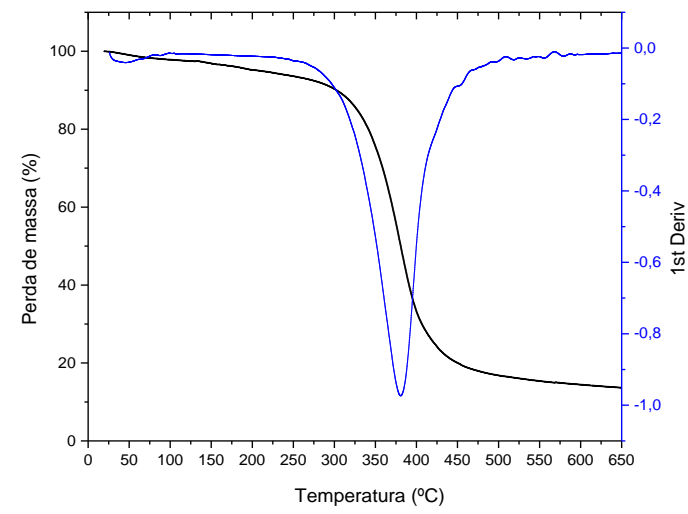

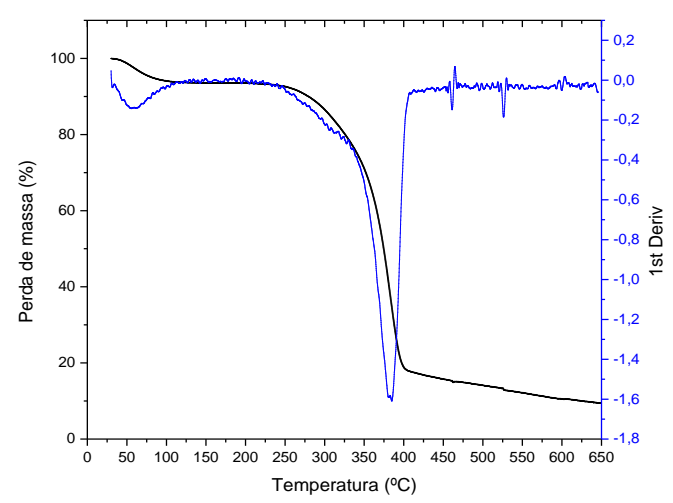

$b$

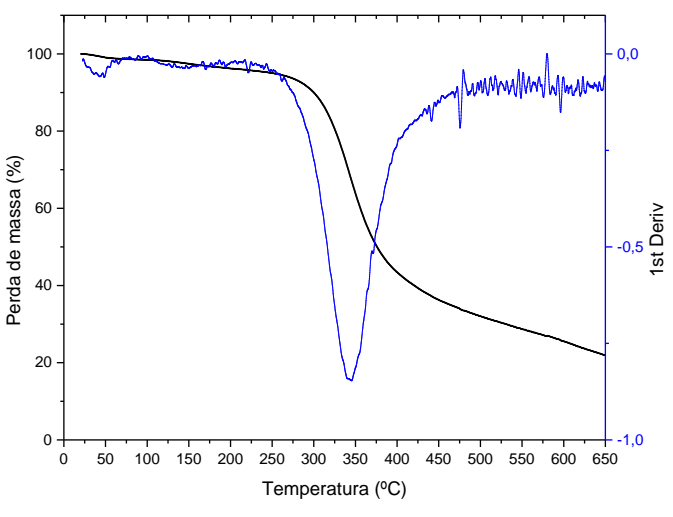

$d$

Figura 96 - Curva de perda de massa vs temperatura e primeira derivada para fibras de bucha (a) Sem tratamento. (b) Hornificadas. (c) Mercerizadas. (d) Acetiladas.

O início da decomposição térmica irreversível das fibras analisadas ocorreu em temperaturas acima de $200^{\circ} \mathrm{C}$, como foi reportado por d'Almeida [22]. Nas curvas da primeira derivada da perda de massa para as fibras tratadas por mercerização não está presente o segundo pico por volta de $300^{\circ} \mathrm{C}$, indicando a remoção de hemiceluloses, verificada também pela análise de infravermelho. D’Almeida encontrou este comportamento para fibras com tratamento alcalino realizado a temperatura ambiente durante uma hora [174]. Por outro lado, nas fibras tratadas por hornificação foi encontrado um pequeno pico, tipo ombro, associado com hemicelulose remanescente depois do tratamento. 
Na tabela 21 são apresentados os parâmetros obtidos por TGA. Observou-se que as fibras tratadas por hornificação e mercerização exibiram um ligeiro aumento na resistência térmica com temperaturas de degradação máxima deslocando-se para $385^{\circ} \mathrm{C}$ e $381^{\circ} \mathrm{C}$ respectivamente.

Tabela 21 - Parâmetros obtidos a partir da análise térmica de fibras de bucha.

\begin{tabular}{|c|c|c|c|}
\hline Fibras de bucha & $\begin{array}{c}\text { Temperatura de } \\
\text { máxima } \\
\text { degradação } \\
\left({ }^{\circ} \mathrm{C}\right)\end{array}$ & $\begin{array}{c}\text { T } \text { onset } \\
\left({ }^{\circ} \mathrm{C}\right)\end{array}$ & $\begin{array}{c}\text { Porcentagem de } \\
\text { resíduos } \\
(\%)\end{array}$ \\
\hline Sem tratamento & 374,6 & 330,0 & 3,9 \\
\hline Hornificadas & 385,0 & 348,2 & 9,4 \\
\hline Mercerizadas & 380,7 & 340,1 & 13,7 \\
\hline Acetiladas & 345,3 & 311,4 & 21,9 \\
\hline
\end{tabular}

No entanto, foi observada uma caída na temperatura de degradação máxima das fibras acetiladas para $342,4^{\circ} \mathrm{C}$, este resultado não foi análogo aos valores obtidos por outros autores. D'Almeida et al. (2006) encontraram um ligeiro aumento na estabilidade térmica depois da acetilação de fibras de bucha de 380 a $386^{\circ} \mathrm{C}$ [347] e Bledzki et al. (2008) [230] reportaram um aumento de $319^{\circ} \mathrm{C}$ a 360 ${ }^{\circ} \mathrm{C}$, depois da acetilação de fibras de linho [230]. Este resultado pode indicar que o tratamento químico realizado neste trabalho alterou a estrutura das fibras comprometendo sua estabilidade térmica. De fato, a análise por MEV mostra uma alteração significativa na estrutura da fibra (Figura 83)

\subsubsection{Microscopia de Força Atômica (AFM)}

Na Figura 97 são apresentadas imagens por AFM da seção de fibras de bucha. A imagem da superfície de uma fibra tomada da superfície interior (Figura 97a) realça a presença de nanofibras com diâmetros entre 15-35 nm sem um arranjo definido. Para as fibras da seção externa analisadas, a topografia de AFM exibe um arranjo longitudinal de microfibras com um diâmetro de $2,5 \mu \mathrm{m}$, a partir das quais saem outras microfibras menores com diâmetro entre 0,5-1 $\mu$ m entrelaçadas entre si (Figura 97b). 


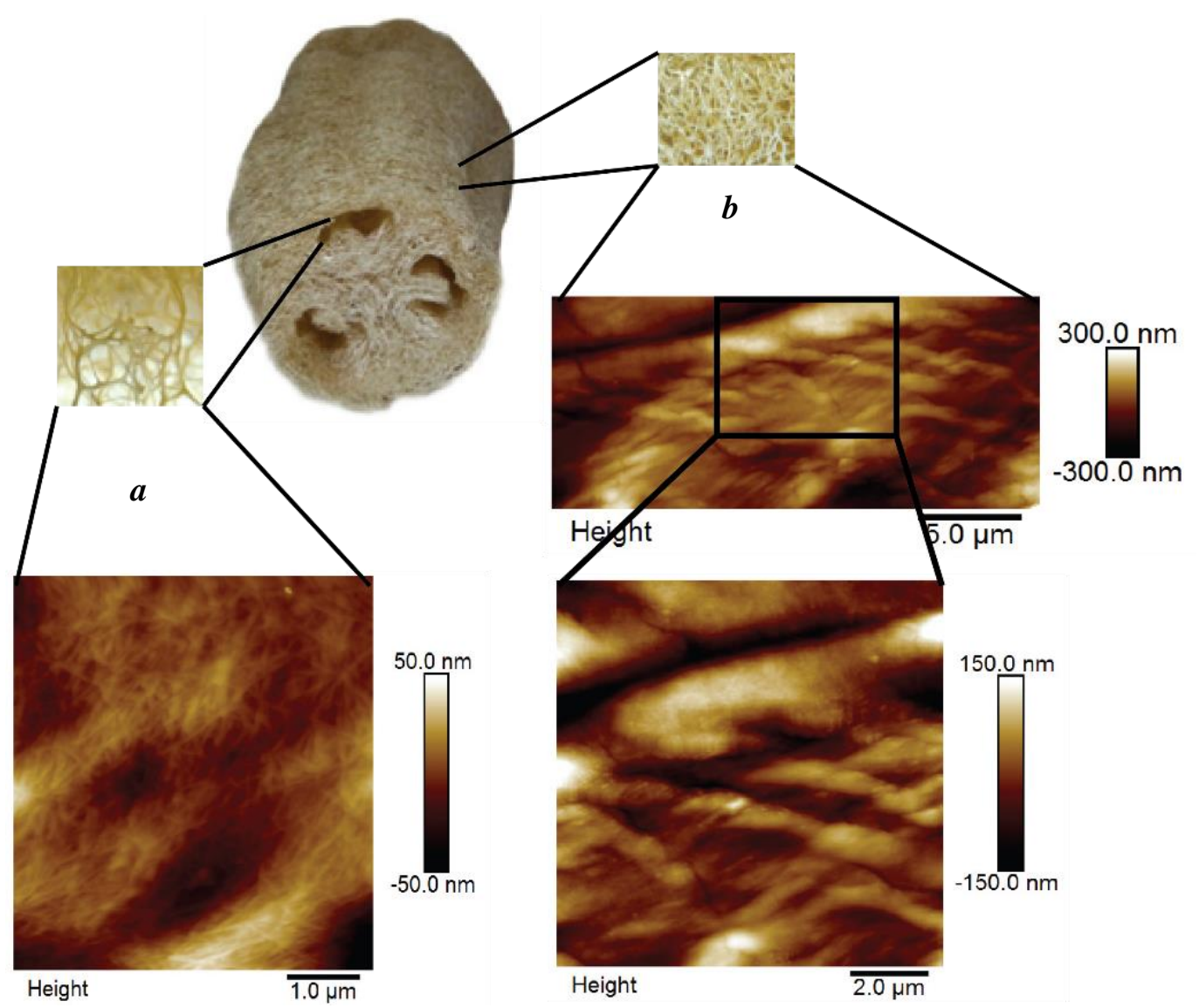

Figura 97 - Imagens AFM no modo de contato intermitente (Peak Force Tapping Mode)

(a) a seção interior $(5 \times 5 \mu \mathrm{m})$ e (b) seção exterior $(10 \times 10 \mu \mathrm{m})$ de fibras de bucha.

Inicialmente, foi utilizado o método de calibração absoluto para obter o módulo de Young. O módulo medido por AFM pelo modelo Derjaguin-MullerToporov (DMT) (Equação 17), equivale ao módulo de Young para um material isotrópico elástico ideal. Foi preciso seguir vários passos de calibração e conhecer a força, o raio da curvatura da ponta utilizada e a indentação. Depois de calibrar a sensibilidade de deflexão da amostra e definir o valor da constante de mola, foi ajustada a força aplicada para obter uma deformação adequada e, finalmente, se realizou a calibração do raio de curvatura da ponta. O raio de curvatura $(\mathrm{R})$ no ápice da ponta no momento do ensaio foi entre 8 - $11 \mathrm{~nm}$ e o módulo da fibra de bucha medido apresentou valores de módulo próximos ao poliestireno, com módulo de Young nominal de 2,7 GPa.

O método relativo, é outro método de calibração que usa uma amostra de referência com módulo conhecido para ajustar a relação $(k / \sqrt{R})$ com uma profundidade de indentação dada. De acordo com o modelo DMT (eq. 26) [290]: 


$$
E^{*}=\frac{3\left(F-F_{a d h}\right)}{4\left(\sqrt{R d^{3}}\right)}
$$

Equação 26

onde,

$$
k=F \cdot \Delta z
$$

Equação 27

Então

$$
E \propto \frac{k}{\sqrt{R}}
$$

O procedimento para a calibração por este método leva menos tempo que pelo método absoluto pois não é necessária a medição precisa do raio final da ponta nem da constante de mola. Assim, para a aquisição de imagens e a determinação das propriedades nano-mecânicas em várias amostras de fibras de bucha, foi utilizado o método relativo usando uma amostra de referência de poliestireno e uma sonda R-TESPA.

Na Figura 98 é mostrada uma imagem da superfície de uma amostra de fibra de bucha medida pelo modo de contato intermitente (Peak Force Tapping Mode) (TM-AFM) usado para obter imagens topográficas da superfície de fibras de bucha.

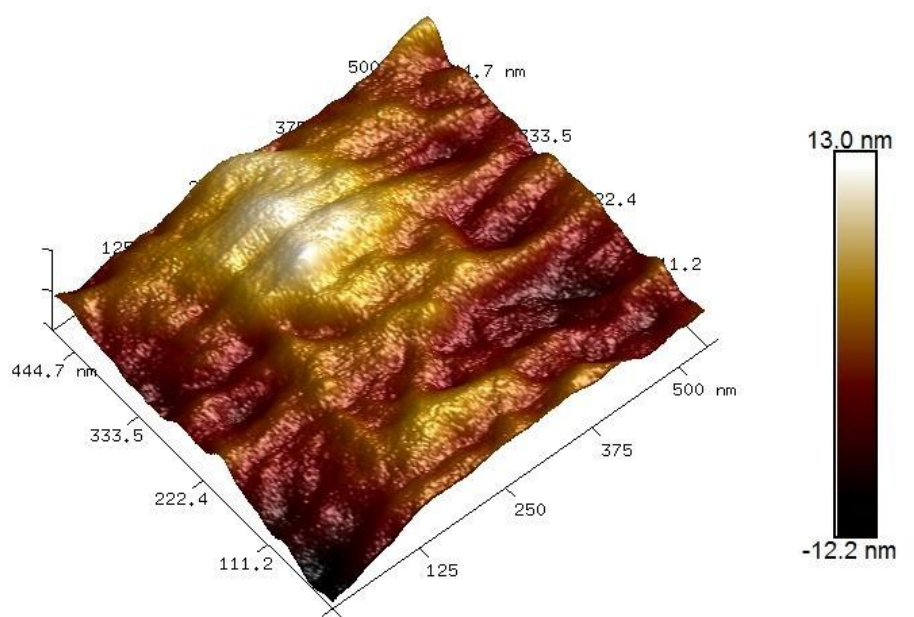

Figura 98 - Imagem 3D da superfície de fibra de bucha indicando a altura em nm.

A análise da superfície e a caracterização nano-mecânica das fibras no interior da bucha é apresentada nas Figuras 99 a 102. São mostrados também os resultados da medida quantitativa das propriedades nano-mecânicas (QNM) da seção transversal das regiões das fibras de bucha selecionadas. Dentro de cada região foram determinadas propriedades nano-mecânicas com valores de módulo dependentes da topografia da amostra. 

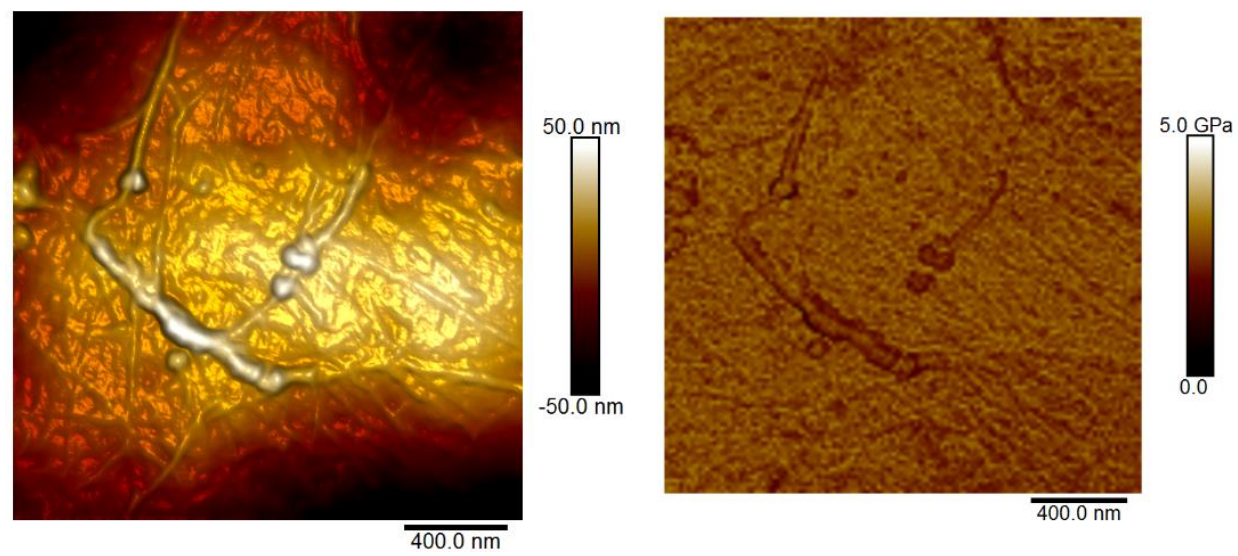

Figura 99 - (a) Imagem (PeakForce) $(2 \times 2 \mu \mathrm{m})$ da topografia de fibras de bucha. (b) imagem PF-QNM $(2 \times 2 \mu \mathrm{m})$ possui informação do módulo de Young.

As imagens da topografia de Peak Force Tapping novamente revelam uma rede de nano-fibras com uma rugosidade variável com valor médio de 12,8 nm, nas amostras que foram medidas.
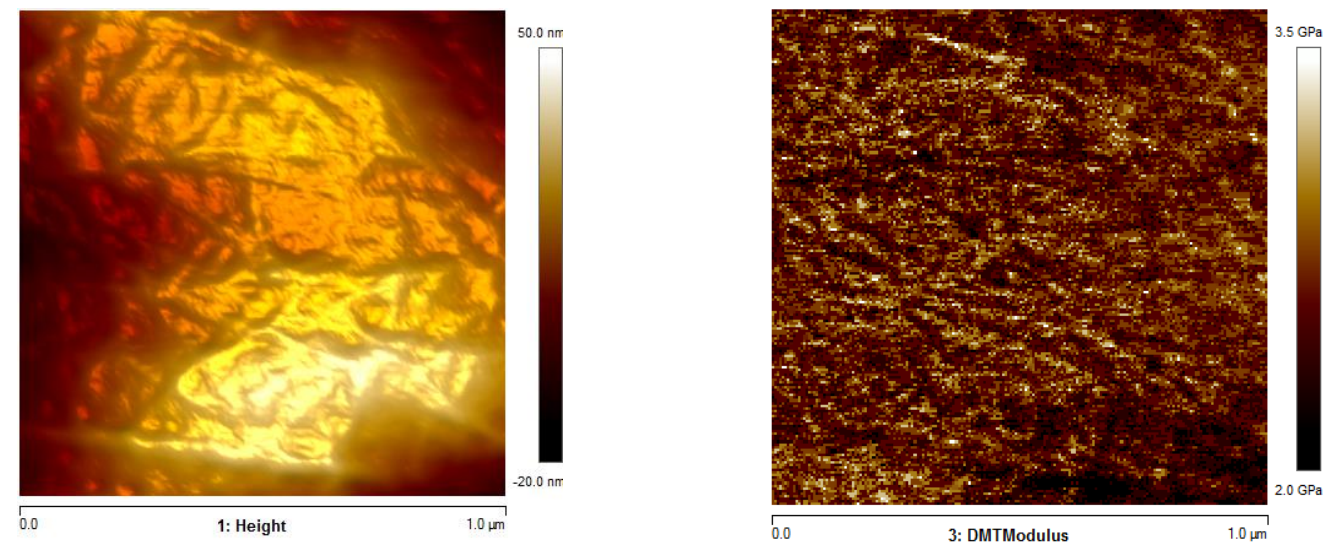

Figura 100 - (a) Imagem Peak Force Tapping $(1 \times 1 \mu \mathrm{m})$ da topografia de fibras de bucha. (b) Imagem PF QNM (1 x $1 \mu \mathrm{m})$ possui informação do módulo de Young.
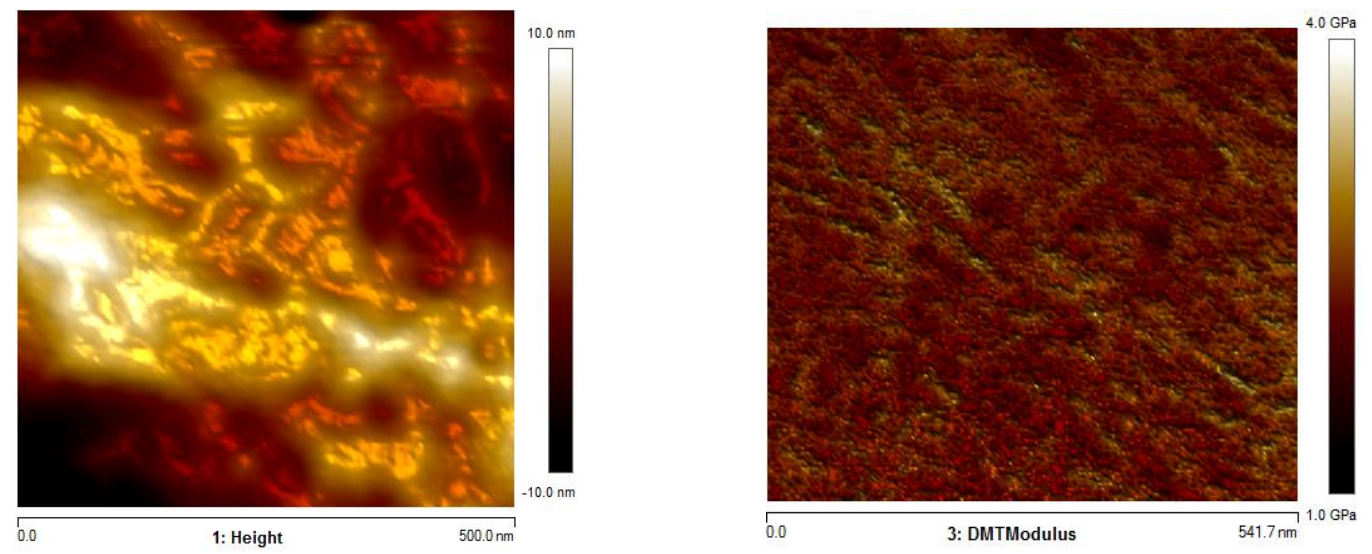

Figura 101 - (a) Imagem Peak Force Tapping (500 x 500nm) da topografia de fibras de bucha. (b) Imagem PF QNM (500 x 500nm) possui informação do módulo de Young. 
O módulo de elasticidade medido por AFM apresentou uma variação dependendo da topografia da superfície. Assim, os valores mais baixos correspondem as regiões mais obscuras, tais como espaços entre as nanofibras. Como observado nas Figuras 99 a 101, a partir da medição das propriedades nano mecânicas na superfície de fibras no interior da bucha foram encontrados valores de módulo variando entre 1 e $4 \mathrm{GPa}$. A Figura 102 mostra fibras bem definidas, cujo o módulo de Young medido em vários pontos sobre sua superfície apresentou um valor máximo de $4 \mathrm{GPa}$. Os resultados de distância e a diferencia entre a altura mínima e máxima nas seções definidas no perfil são também apresentados, na Figura 103.
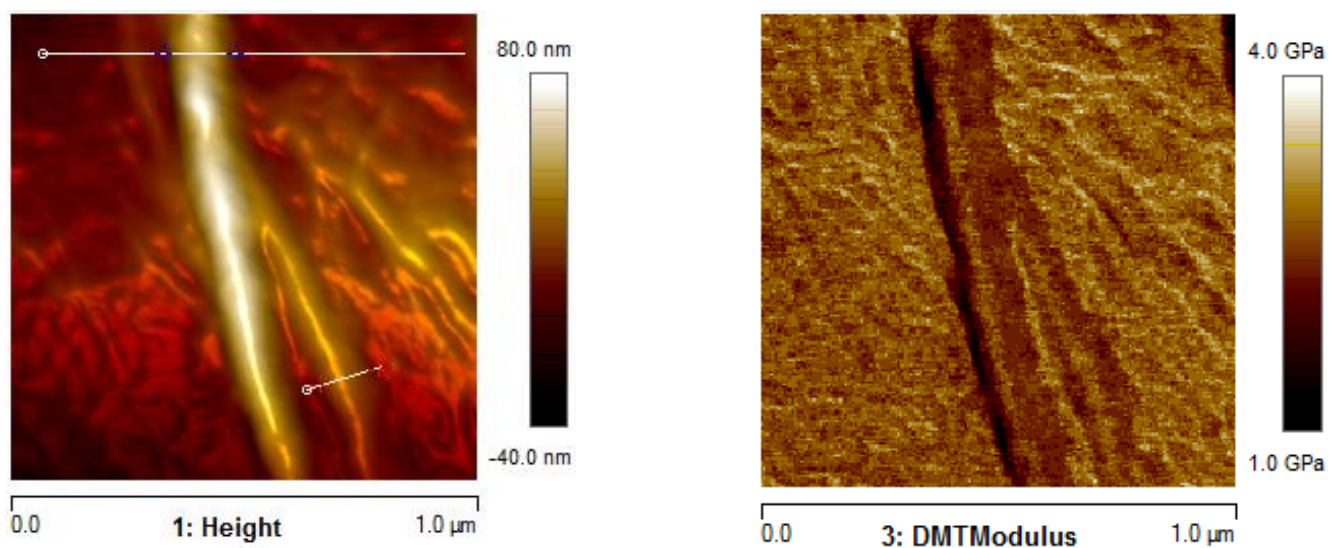

Figura 102 - (a) Imagen Peak Force Tapping $(1 \times 1 \mu \mathrm{m})$ da topografia de fibras de bucha. (b) Imagem PF QNM (1 x $1 \mu \mathrm{m})$ possui informação do módulo de Young.

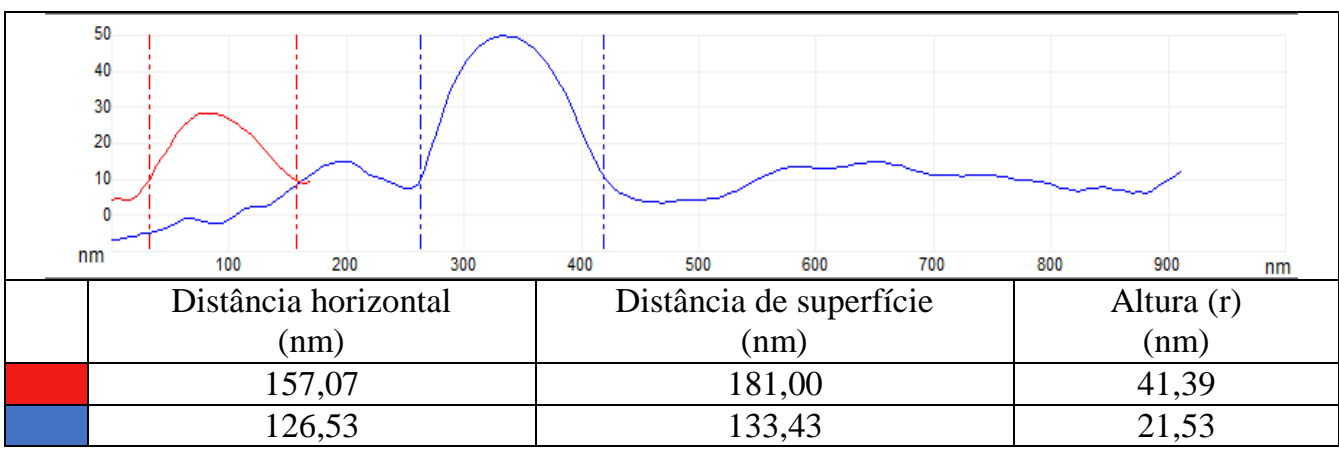

Figura 103 - Perfil da superfície nas seções selecionadas da Figura 102.

Com os resultados das medições do módulo de Young obtidos neste trabalho, foi construído um diagrama de Ashby, apresentado no apêndice A4. Nesse diagrama são comparadas as propriedades mecânicas de fibras de bucha vegetal com as propriedades de fibras lignocelulósicas comuns usadas também como reforços de materiais compósitos [182]. 


\subsection{Caracterização Térmica de Resinas epóxi}

As resinas preparadas com ESO curadas com anidrido apresentaram caraterísticas físicas indesejáveis sendo quebradas em fragmentos ao ser manipuladas ou apresentando uma alta flexibilidade. Os tempos e temperaturas de cura utilizados na preparação de resinas ESO+bisfenol curadas com PA nos testes preliminares foram aumentadas porém, não ofereceram resultados favoráveis e continuaram apresentando características físicas não apropriadas para sua manipulação, pelo que foram descartadas.

O critério utilizado para a escolha das resinas utilizadas como matriz para a fabricação dos compósitos foi o de estabilidade térmica. Na tabela 22 são apresentadas as oito formulações das resinas que foram preparadas utilizando dois agentes de cura diferentes e os parâmetros medidos por TGA. No apêndice 5 são apresentados os termogramas mostrando o início da degradação e as temperaturas de degradação máxima de resinas listadas na tabela 22. Os agentes de cura utilizados foram diamina de isoforona (IPDA) uma poliamina ciclo alifática primária, e uma fenalcamina baseada no líquido da casca de caju (NX-5620).

Tabela 22 - Temperaturas de início de degradação $\left(\mathrm{T}_{\text {onset }}\right)$ e temperaturas de pico $\left(\mathrm{T}_{\mathrm{p}}\right)$ de resinas epóxi preparadas.

\begin{tabular}{|c|c|c|c|c|c|c|}
\hline & Resina & Catalizador & $\mathrm{T}_{\text {onset }}$ & $\begin{array}{c}\mathrm{T}_{\mathrm{p}} 1 \\
\left({ }^{\circ} \mathrm{C}\right)\end{array}$ & $\begin{array}{c}\mathrm{T}_{\mathrm{p}} 2 \\
\left({ }^{\circ} \mathrm{C}\right)\end{array}$ & $\begin{array}{c}\mathrm{T}_{\mathrm{p}} 3 \\
\left({ }^{\circ} \mathrm{C}\right)\end{array}$ \\
\hline 1 & Cardanol & $\mathrm{NX}$ & 266,7 & 291,4 & 398,0 & 451,1 \\
\hline 2 & Resorcinol & $\mathrm{NX}$ & 251,5 & 282,3 & 378,5 & 460,6 \\
\hline 3 & Bisfenol & $\mathrm{NX}$ & 359,2 & 390,8 & & \\
\hline 4 & Bisfenol & IPDA & 361,2 & 401,5 & & \\
\hline 5 & ESO30-bisfenol70 & IPDA & 360,6 & 401,9 & & \\
\hline 6 & $\begin{array}{c}\text { Cardanol50- } \\
\text { Resorcino150 }\end{array}$ & IPDA & 362,7 & 392,6 & 432,9 & \\
\hline 7 & $\begin{array}{c}\text { Cardanol50- } \\
\text { Resorcinol50 }\end{array}$ & $\mathrm{NX}$ & 249,5 & 283,4 & 399,9 & 450,2 \\
\hline 8 & ESO30-bisfenol70 & $\mathrm{NX}$ & 259,5 & 287,6 & 397,9 & 460,2 \\
\hline
\end{tabular}

Foi observado que a temperatura de início de degradação de resinas puras de cardanol curada com fenalcaminas NX (1) e resorcinol curado com NX (2) apresentaram temperaturas de início de degradação baixas ao se comparar com os parâmetros da resina bisfenol curada com NX (3). A resina (4) é uma resina comercial de bisfenol A, usada em este trabalho como referência para a comparação 
das propriedades de resinas preparadas a partir de óleos vegetais epoxidados ESO e cardanol.

Foram avaliadas também misturas de resinas com proporção de bisfenol na sua formulação. A resina de bisfenol curada com fenalcamina (NX) (3), de bisfenol curada com diamina de isoforona (IPDA) (4), de e bisfenol + óleo de soja epoxidado curada com IPDA (5) apresentaram estabilidade térmica até temperaturas entre 359 e $361{ }^{\circ} \mathrm{C}$, seguido por decomposição de um único passo, na faixa de temperatura de 391 a $402{ }^{\circ} \mathrm{C}$. A resina preparada com $50 \%$ cardanol $+50 \%$ resorcinol curada com IPDA (6) apresentou decomposição em dois passos, com temperatura de picos de 393 e $433{ }^{\circ} \mathrm{C}$ e temperatura de início de degradação de $363{ }^{\circ} \mathrm{C}$. A mesma proporção de reagentes curados com fenalcamina (7) deixou como resultado uma resina com temperatura de início de degradação $249,5^{\circ} \mathrm{C}$ e decomposição com temperatura de pico de 283,400 e $450{ }^{\circ} \mathrm{C}$.

Igualmente, a mistura bisfenol+ESO curada com fenalcamina NX (8) apresentou valores de $\mathrm{T}_{\text {onset }}$ de $260{ }^{\circ} \mathrm{C}$, inferior aos resultados indicados para essa mesma mistura curada com diamina IPDA (5), além de ter decomposição em 3 passos. Os termogramas TGA das Figuras 104 e 105 mostram a comparação dos termogramas de resinas cardanol/resorcinol (50\%) e ESO30-bisfenol70 curadas com fenalcamina (NX) e diamina (IPDA).

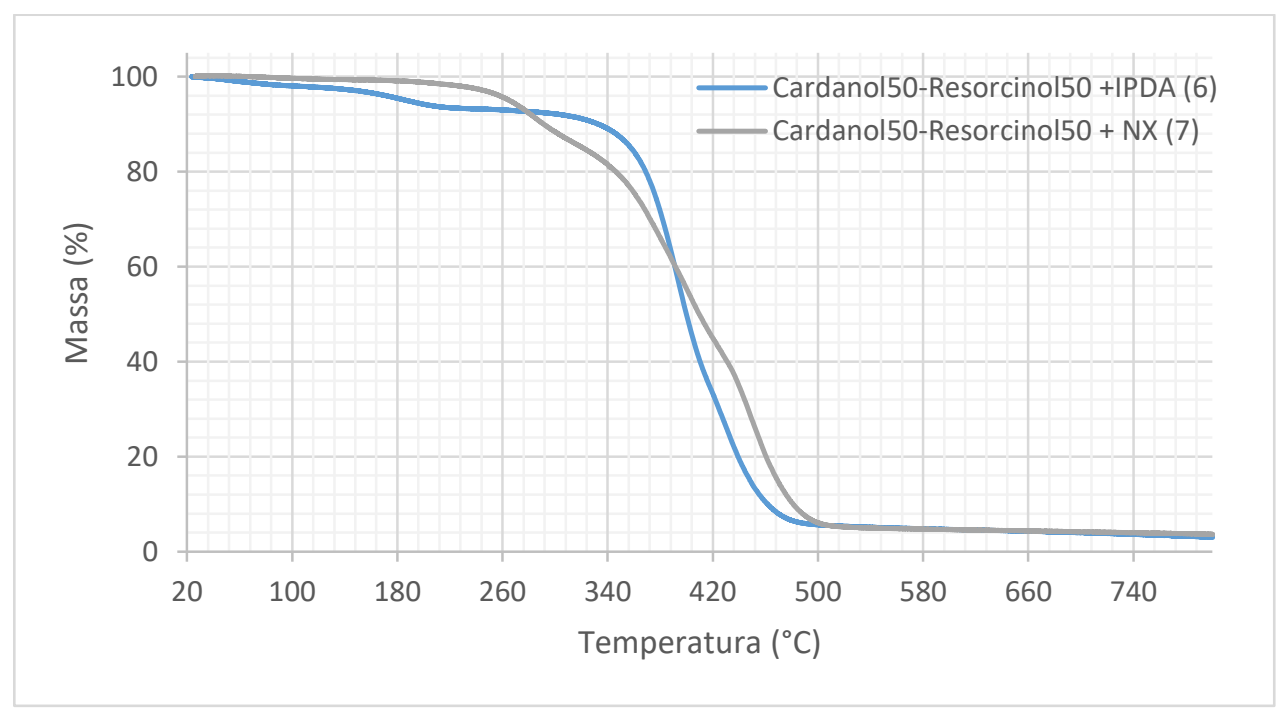

Figura 104 - Termograma de resina Cardanol/Resorcinol (50\%) curada com fenalcamina NX. 


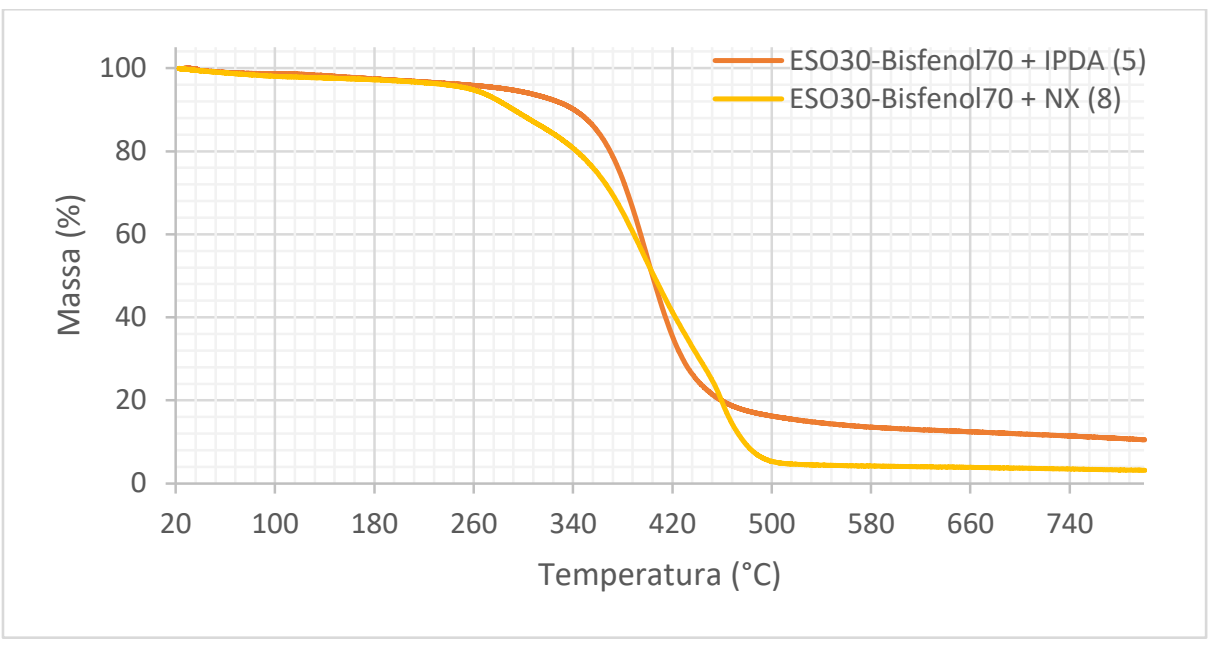

Figura 105 - Termograma de resina Cardanol/Resorcinol (50\%) curada com diamina IPDA.

Observou-se que o agente de cura utilizado teve um grande efeito sobre a estabilidade térmica das resinas. Sendo que as resinas preparadas utilizando fenalcaminas NX como agente de cura apresentaram temperaturas de início de degradação menores em todos os casos analisados (Apêndice 5), foram descartadas para a cura das resinas utilizadas como matrizes na fabricação de compósitos neste trabalho.

As melhores condições de resistência térmica com base nos dados obtidos da análise termogravimétrica foram obtidas para os sistemas epóxi (5) e (6), ambos curados com diamina. A tabela 23 apresenta a numeração e a abreviatura assignadas para essas resinas e que serão usadas no texto.

Tabela 23 - Resinas utilizadas para a preparação de matriz epóxi.

\begin{tabular}{|c|c|c|}
\hline & Resina & \\
\hline 4 & Bisfenol A + IPDA & B \\
\hline 5 & Óleo de soja epoxidado (30\%) - Bisfenol A (70\%) + IPDA & ESO30 \\
\hline 6 & Cardanol (50\%) - Resorcinol (50\%) + IPDA & C50 \\
\hline
\end{tabular}

Em função da escolha das resinas descrita acima, apenas para esses três sistemas escolhidos foi feita a análise da energia de ativação. A energia de ativação (Ea) para a decomposição térmica de tais resinas foi determinada por meio da equação de Kissinger (Equação 11) e comparada com os resultados para a resina comercial de (Bisfenol+IPDA) (4). 
Na tabela 24 são apresentados os parâmetros de ajuste calculados. Os resultados indicaram que para o início da degradação térmica da resina de bisfenol é necessário um incremento de energia de 57,96\% com relação à resina de bisfenol com de óleo de soja epoxidado e de $26,5 \%$ comparado com a resina preparada a partir de óleo epoxidado de cardanol. Esses dados indicam que o sistema cardanolresorcinol pode ser uma boa escolha para substituir o sistema bisfenol+IPDA clássico.

Tabela 24 - Parâmetros de ajuste da equação de Kissinger para as resinas Bisfenol, ESOBisfenol e Cardanol-Resorcinol curadas com amina IPDA.

\begin{tabular}{|c|c|c|c|c|c|}
\hline & Resina & $\boldsymbol{M}$ & $\boldsymbol{b}$ & $\begin{array}{c}\boldsymbol{E}_{\boldsymbol{a}} \\
(\mathbf{K J} / \mathbf{m o l})\end{array}$ & $\ln \boldsymbol{A}$ \\
\hline 4 & $\mathrm{~B}$ & 24,12 & 25,02 & 200,54 & 28,21 \\
\hline 5 & $\mathrm{ESO} 30$ & 10,14 & 4,29 & 84,29 & 6,61 \\
\hline 6 & $\mathrm{C} 50$ & 17,73 & 15,93 & 147,39 & 18,81 \\
\hline
\end{tabular}

\subsubsection{Analise Dinâmico-Mecânica (DMA)}

As Figuras 106 a 108 correspondem às curvas associadas aos parâmetros dinâmico-mecânicos E', E” e tan $\delta$ em função da temperatura, medido por DMA, para os sistemas epóxi curados com diamina. Ou seja, as resinas que posteriormente foram utilizadas como matriz na fabricação dos compósitos. A Figura 106 mostra a comparação dos resultados de módulo de armazenamento para as resinas puras de bisfenol (B), ESO-bisfenol (ESO30) e cardanol-resorcinol (C50) curadas com IPDA, apresentados na tabela 23. É observada a diminuição nos valores do módulo de armazenamento (E') com o aumento da temperatura, como esperado, e que ocorre devido à diminuição da rigidez da matriz epóxi, ocasionada pela mobilidade das cadeias poliméricas. 


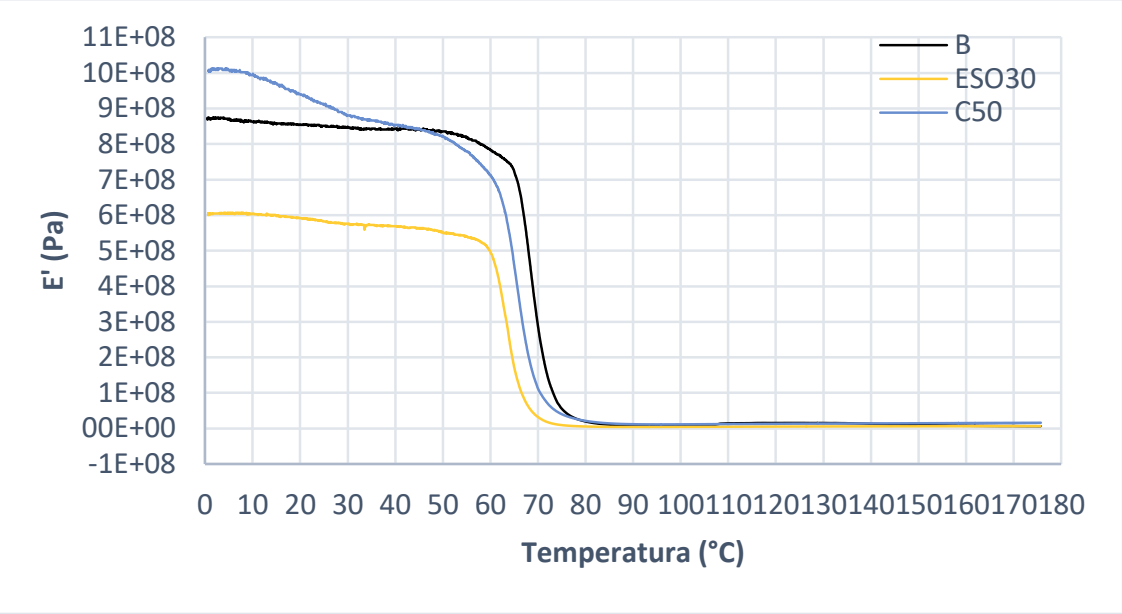

Figura 106 - Módulos de armazenamento para resinas epóxi de bisfenol, ESO-bisfenol e cardanol-resorcinol.

$\mathrm{Na}$ temperatura inicial, a resina de cardanol apresentou maior rigidez, em relação às resinas de bisfenol e ESO-bisfenol. No entanto, a resina de bisfenol apresentou uma maior estabilidade com o aumento da temperatura e, por volta de $45^{\circ} \mathrm{C}$, passou a ter maiores valores de E' em comparação com as outras resinas. Por outro lado, os valores de E' da resina ESO30 foram consideravelmente menores do que os obtidos para a resina de bisfenol, o que quer dizer que a adição de ESO deu origem a um aumento da mobilidade de cadeias dentro das redes ESO-bisfenol. A temperatura de onset $\left(\mathrm{T}_{\text {onset }}\right)$ determinada nas curvas da Figura 106 - pela intersecção das linhas tangentes durante o início do relaxamento de transição vítrea - é um indicativo da temperatura de transição vítrea $\left(\mathrm{T}_{\mathrm{g}}\right)$. Na tabela 25 são apresentados os valores de $\mathrm{T}_{\text {onset }}$ assim determinados para as resinas B, ESO30 e C50. Foi observada a diminuição da temperatura de onset com a adição de ESO.

Tabela 25 - Temperaturas de onset medidas nas curvas de E' versus temperatura.

\begin{tabular}{|c|c|c|}
\hline$\#$ & Material & Tonset $\left({ }^{\circ} \mathbf{C}\right)$ \\
\hline 4 & B & 65,0 \\
\hline 5 & ESO30 & 59,5 \\
\hline 6 & C50 & 61,9 \\
\hline
\end{tabular}

Na tabela 26, são mostrados os módulos de armazenamento das resinas a uma temperatura próxima à temperatura ambiente $\left(30^{\circ} \mathrm{C}\right)$, uma temperatura perto da temperatura de transição vítrea $\left(60^{\circ} \mathrm{C}\right)$ e uma temperatura perto do final do ensaio $\left(150^{\circ} \mathrm{C}\right)$. 
Tabela 26 - Módulos de armazenamento (MPa) para as resinas puras a diferentes temperaturas.

\begin{tabular}{|c|c|c|c|c|}
\hline \multirow{2}{*}{ Material } & \multicolumn{3}{|c|}{ Temperatura $\left({ }^{\circ} \mathbf{C}\right)$} \\
\cline { 3 - 5 } & & $\mathbf{3 0}$ & $\mathbf{6 0}$ & $\mathbf{1 5 0}$ \\
\hline 4 & $\mathrm{~B}$ & 848,7 & 784,3 & 9,3 \\
\hline 5 & $\mathrm{ESO} 30$ & 574,3 & 495,6 & 6,0 \\
\hline 6 & $\mathrm{C} 50$ & 880,5 & 712,6 & 14,6 \\
\hline
\end{tabular}

Pode-se notar que a resina C50, baseada em cardanol e resorcinol, teve um comportamento muito próximo com a resina $\mathrm{B}$, baseada em bisfenol A comercial, tomada como base para a comparação dos materiais fabricados neste trabalho.

As Figura 107 e 108 apresentam as curvas que mostram a variação de $\tan \delta$ e E" com a temperatura, respectivamente.

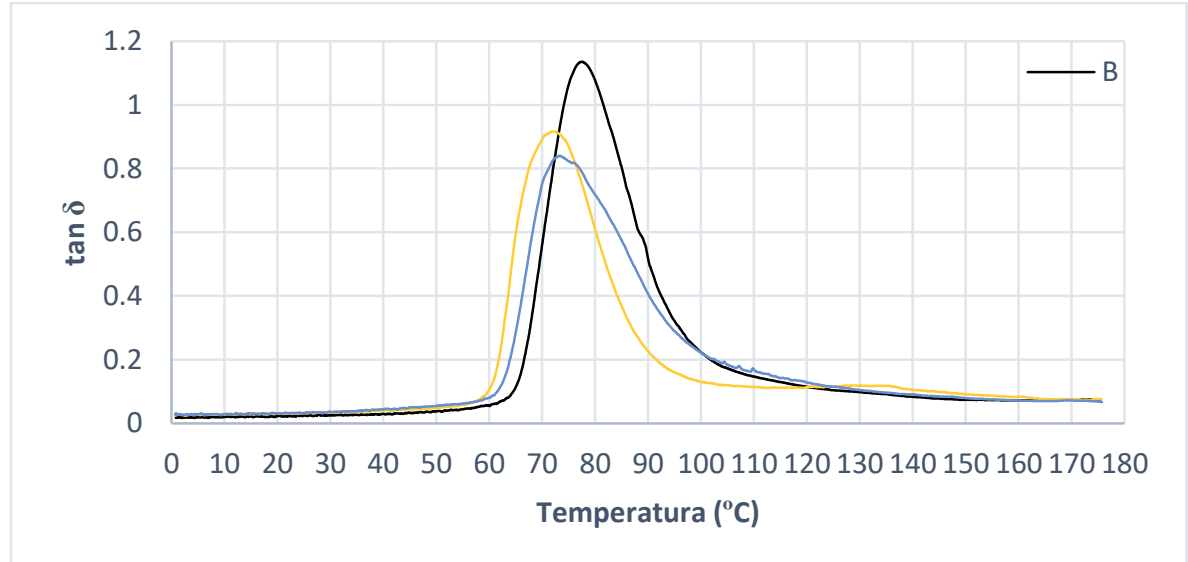

Figura 107 - Tan $\delta$ para resinas epóxi de bisfenol, ESO-bisfenol e cardanol-resorcinol.

Na Figura 107 observou-se que o pico máximo de $\tan \delta$ para a resina B foi estreito e bem definido, indicando uma estrutura de rede uniforme. Com relação as resinas ESO30 e C50 foi notado que a largura do pico aumentou ligeiramente. Isso sugere que essas resinas têm uma região de transição vítrea mais larga, devido às redes heterogêneas ESO-bisfenol e cardanol-resorcinol. Além disso, ao comparar as curvas de $\tan \delta$ para as resinas de bisfenol e ESO-bisfenol, foi observada uma diminuição na altura do pico máximo de $\tan \delta$ com a adição de ESO. 


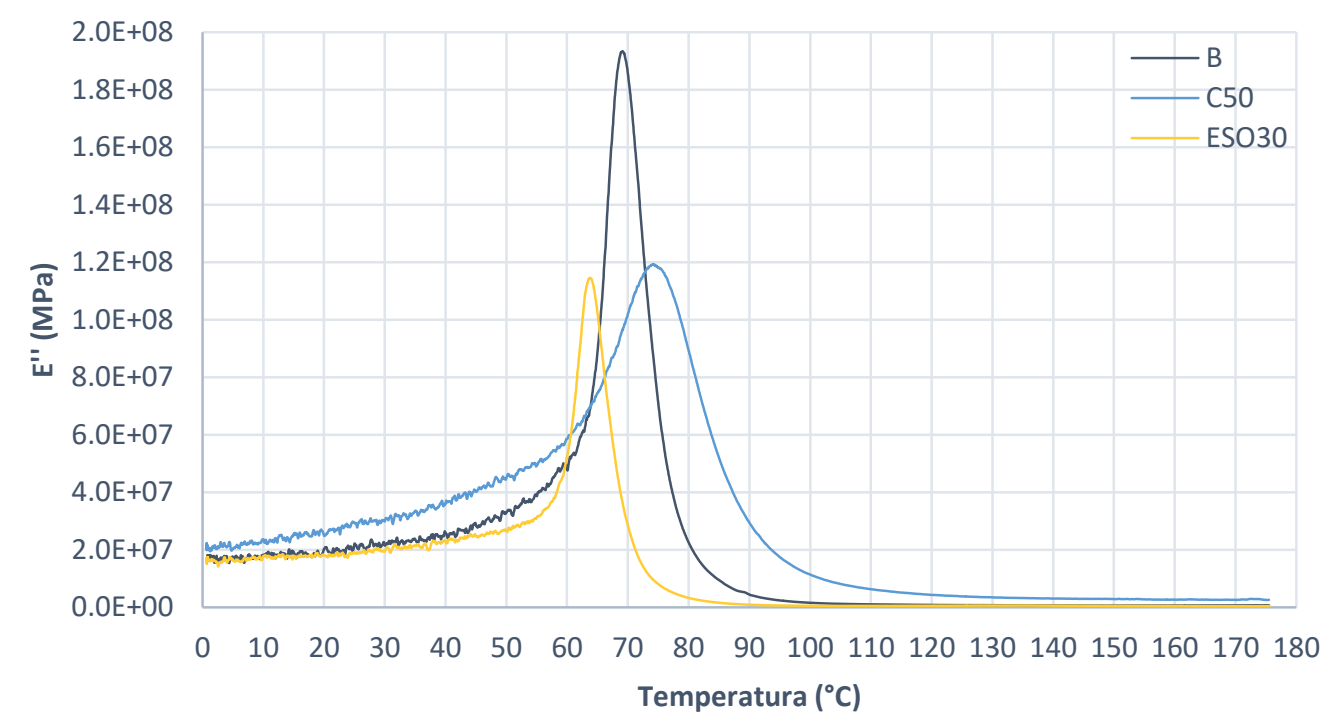

Figura 108 - Módulo de perda para resinas epóxi de bisfenol, ESO-bisfenol e cardanolresorcinol.

A temperatura na qual o fator de amortecimento e o módulo de perda são máximos também é considerada um indicativo da transição vítrea. Portanto, foram identificados os valores dos picos para cada uma das curvas de fator de amortecimento $(\tan \delta)$ e de módulo de perda (E'), que correspondem a transformações na estrutura do material caracterizadas pela sua temperatura. $\mathrm{Na}$ tabela 27 são apresentados os valores de $\mathrm{T}_{\mathrm{g}}$ determinados a partir dessas curvas.

Tabela 27 - Temperaturas de transição vítrea medidas nas curvas de $\tan \delta$ e E'.

\begin{tabular}{|c|c|c|c|}
\hline \multirow{2}{*}{$\#$} & \multirow{2}{*}{ Material } & Tan $\boldsymbol{\delta}$ máx. & E" máx. \\
\cline { 3 - 4 } & & $\mathbf{T}_{\mathbf{g}}\left({ }^{\mathbf{o}} \mathbf{C}\right)$ & $\mathbf{T}_{\mathbf{g}}\left({ }^{\circ} \mathbf{C}\right)$ \\
\hline 4 & $\mathrm{~B}$ & 77,51 & 69,00 \\
\hline 5 & $\mathrm{ESO} 30$ & 72,24 & 63,81 \\
\hline 6 & $\mathrm{C} 50$ & 73,84 & 66,11 \\
\hline
\end{tabular}

Dos resultados da tabela 27 pode se observar que a partir das medidas no pico máximo das curvas de $\tan \delta$ foram obtidos valores de $\mathrm{T}_{\mathrm{g}}$ maiores que os medidos no pico máximo das curvas de E'. Por sua vez, foi notado que os valores de $\mathrm{T}_{\mathrm{g}}$ obtidos a partir das curvas de E' estão mais próximos àqueles obtidos a partir das curvas do módulo de perda. A obtenção de valores de $\mathrm{T}_{\mathrm{g}}$ superiores, a partir das curvas de $\tan \delta$, tem sido observado por outros autores, tendo em vista que a $\mathrm{T}_{\mathrm{g}}$ das 
curvas E' e E'" correspondem a pontos médios na região de transição vítrea, enquanto o pico máximo da curva tan $\delta$ aparece no final de tal transição [301], [351].

\subsection{Caraterização de Compósitos Epóxi/Bucha}

Na tabela 28 são apresentadas as resinas utilizadas como matrizes poliméricas neste trabalho, enquanto na tabela 29 aparecem listados os compósitos fabricados, assim como a abreviatura para cada um, que será usada na análise dos resultados.

Tabela 28 - Resinas preparadas e usadas como matriz.

\begin{tabular}{|c|c|c|}
\hline & Resina & \\
\hline I & Bisfenol A (DGEBA) & B \\
\hline II & Óleo de soja epoxidado (50\%) - Bisfenol A (50\%) & ESO50 \\
\hline III & Óleo de soja epoxidado (30\%) - Bisfenol A (70\%) & ESO30 \\
\hline IV & Cardanol (50\%) - Resorcinol (50\%) & C50 \\
\hline
\end{tabular}

Na tabela 28 pode ser observado que uma formulação de óleo de soja epoxidado com bisfenol A com 50\% de cada componente (ESO50) também foi empregada. Essa nova formulação foi testada tendo em vista que a formulação 30/70 (ESO30) teve um valor de $\mathrm{Tg}$ de $72,24{ }^{\circ} \mathrm{C}$ (embora o modulo de armazenamento fosse de apenas 574,3 MPa). O aumento da porcentagem de óleo de soja tornaria essa matriz mais atrativa ambientalmente. Por outro lado, placas de resinas de cardanol puro foram fabricadas, porém, este material apresentou um comportamento mais flexível que o razoável para a caraterização mecânica e uma temperatura de início de degradação de apenas $266,7^{\circ} \mathrm{C}$ por TGA, razão pela qual não foram incluídas para uso como matriz na fabricação dos compósitos.

Tabela 29 - Compósitos fabricados.

\begin{tabular}{|c|c|c|c|c|}
\hline & Resina & $\begin{array}{c}\text { Tipo de fibras de } \\
\text { bucha }\end{array}$ & $\begin{array}{c}\text { \% em } \\
\text { massa } \\
\text { de } \\
\text { fibras }\end{array}$ & Compósito \\
\hline 1 & B & Não tratadas & 10 & U10 \\
\hline 2 & B & Não tratadas & 20 & U20 \\
\hline 3 & B & Não tratadas & 40 & U40 \\
\hline 4 & B & Mercerizadas & 20 & M20 \\
\hline 5 & B & Mercerizadas & 30 & M30 \\
\hline 6 & B & Hornificadas & 20 & H20 \\
\hline
\end{tabular}




\begin{tabular}{|c|c|c|c|c|}
\hline 7 & B & Hornificadas & 30 & H30 \\
\hline 8 & B & Acetiladas & 20 & A20 \\
\hline 9 & B & Acetiladas & 30 & A30 \\
\hline 10 & B & Fibras curtas* & 20 & FC \\
\hline 11 & ESO50 & Não tratadas & 30 & ESO50- U30 \\
\hline 12 & ESO30 & Não tratadas & 30 & ESO-U30 \\
\hline 13 & ESO30 & Mercerizadas & 30 & ESO-M30 \\
\hline 14 & ESO30 & Hornificadas & 30 & ESO-H30 \\
\hline 15 & ESO30 & Fibras curtas* & 20 & ESO-FC \\
\hline 16 & C50 & Mercerizadas & 30 & C50-M30 \\
\hline
\end{tabular}

*Não tratadas

Em total foram fabricadas 20 placas com dimensões $150 \times 200 \times 3 \mathrm{~mm}^{3}(4$ placas de resina pura e 16 placas de materiais compósitos). De cada placa fabricada foram cortados 11 corpos de prova ( $80 \mathrm{~mm}$ de comprimento, $25 \mathrm{~mm}$ de largura), como mostrado na Figura 109.

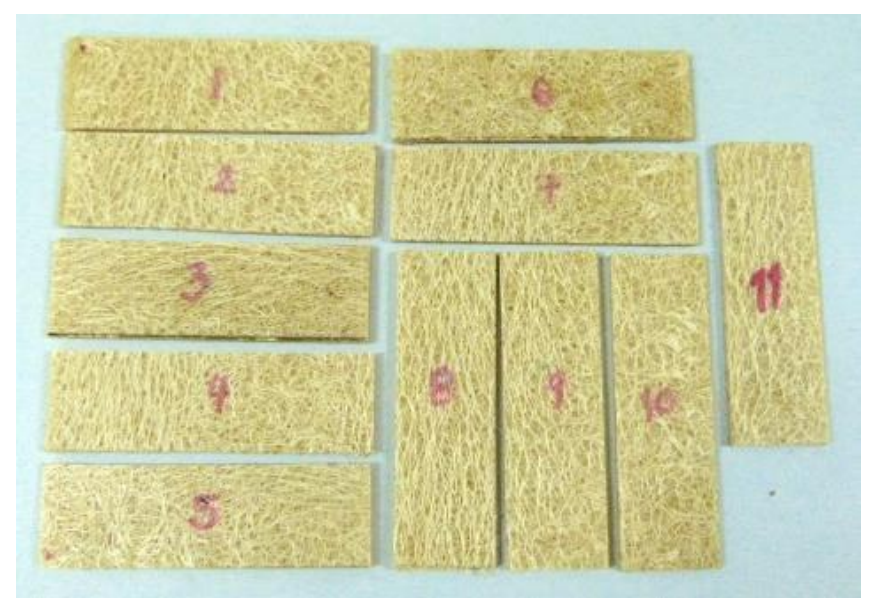

Figura 109 - Corpos de prova de compósitos Bisfenol/bucha mercerizada.

Na Figura 110 é apresentado o fluxograma com as técnicas usadas para caracterizar os compósitos fabricados neste trabalho. 


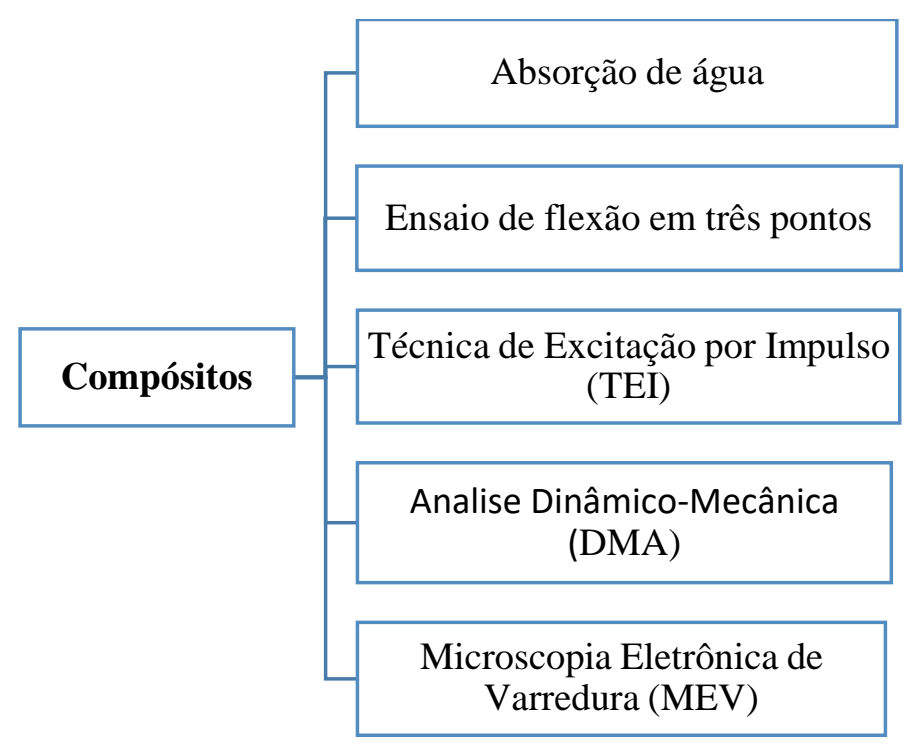

Figura 110 - Esquema da caraterização dos compósitos fabricados.

Os 11 corpos de prova foram ensaiados pela técnica não destrutiva de excitação por impulso. Dos espécimes, quatro foram usados para os ensaios de absorção de água, e cinco para a caracterização mecânica por flexão em três pontos. Corpos de prova menores (19 x $6 \mathrm{~mm}$ ) foram cortados também para usar na análise dinâmico-mecânica por DMA.

A aparência dos compósitos fabricados com mantas de fibra de bucha e com fibras curtas de bucha é mostrada na Figura 111.
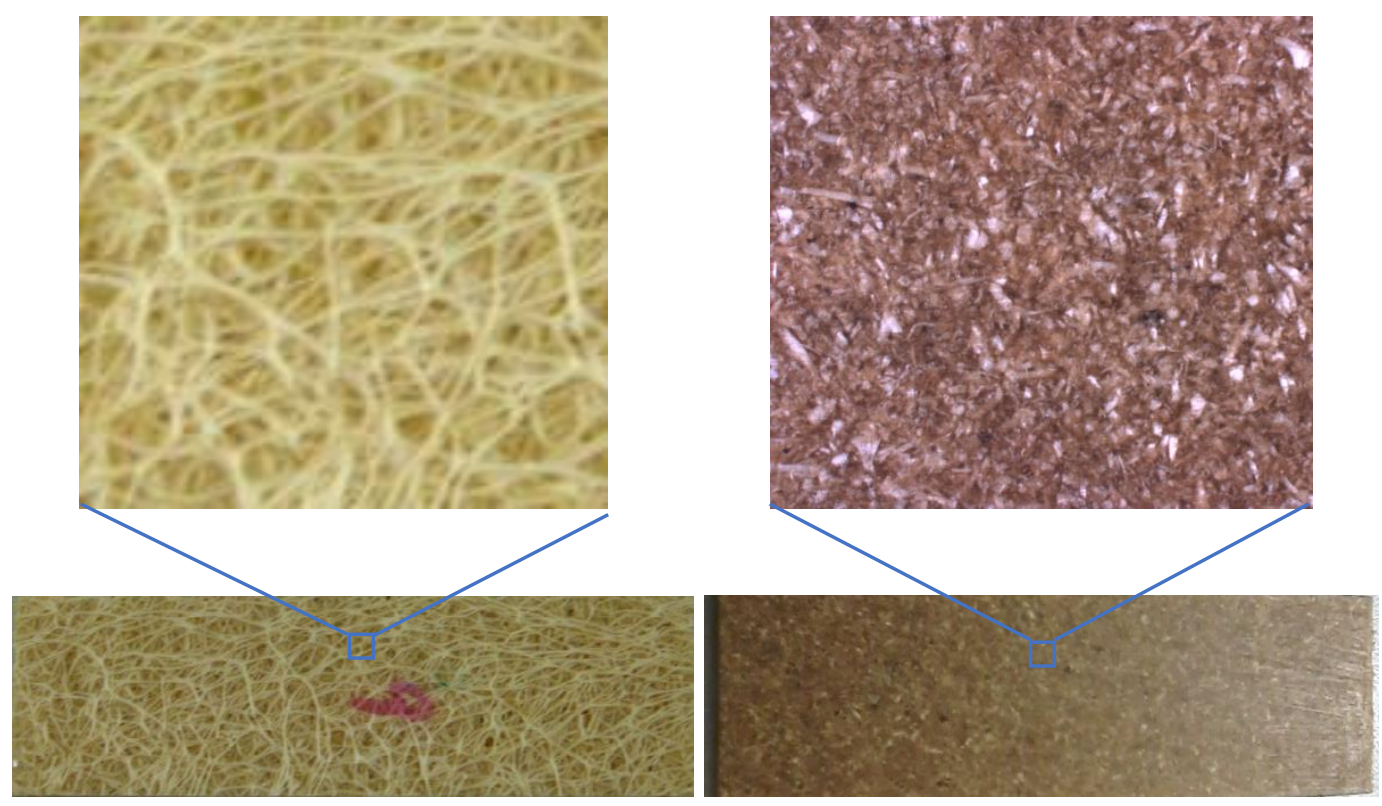

Figura 111 - Corpo de prova de compósito epóxi/bucha fabricado a partir de (a) manta de bucha; (b) fibras curtas (moídas) de bucha. 


\subsubsection{Absorção de Água}

A massa de água absorvida na saturação $\left(M_{\infty}\right)$ foi determinada para cada material. Do critério da eq. 29 e da análise das curvas foi determinado o tempo de saturação, no qual os corpos de prova alcançaram o equilíbrio de umidade efetivo:

$$
\left|\frac{W_{i}-W_{i-1}}{W_{b}}\right|<0,00020
$$

Equação 29

onde, $W$ é a massa do corpo de prova. O índice $i$ indica o valor em cada intervalo, $i-1$ o valor da pesagem anterior, $b$ valor inicial (antes da exposição em água).

Nos gráficos da evolução da umidade absorvida $\Delta \mathrm{M}$ (porcentagem em peso) em função da raiz quadrada do tempo (Figuras 112-115) se observou ganho de massa com uma região inicial linear discernível. Portanto, se considerou que para $\mathrm{M} \% / \mathrm{M}_{\infty}<0,5$ os materiais apresentaram comportamento de difusão Fickiano. Assim, o coeficiente de difusão $D$ foi determinado a partir da inclinação da parte inicial da curva $\mathrm{M}_{\mathrm{t}} \mathrm{vs}$. $\sqrt{t}$, da quantidade de água absorvida no equilíbrio $\mathrm{M}_{\infty} \mathrm{e}$ da espessura dos corpos de prova, utilizando a equação 20 . Para valores de $\mathrm{M} \% / \mathrm{M}_{\infty}$ maiores que 0,5 se observou que as curvas apresentaram uma variação típica, com dois estágios de difusão e por causa desses desvios do comportamento Fickiano não foi possível ajustar os dados aos modelos simplificados convencionais de Fick.

O ajuste dos dados foi realizado utilizando o modelo proposto por McKague (eq. 30), o qual foi utilizado para estudos anteriores de compósitos poliéster/bucha [218]. O ajuste dos dados com a eq. 30 apresentou valores altos de coeficiente de correlação, indicando que o modelo foi adequado.

$$
\frac{M_{\%}}{M_{\infty}}=\tanh \left[\frac{4}{h} \times \sqrt{\frac{D t}{\pi}}\right]
$$

Por outro lado, sendo que muitas fibras interceptam as bordas livres e dado que a difusividade perpendicular à espessura calculada não tem em consideração a absorção através das bordas, foi realizada uma correção dos valores obtidos, usando a eq. 31 [352], [353].

$$
D_{x}=D\left(1+\frac{h}{l}+\frac{h}{w}\right)^{-2}
$$

Equação 31

onde $l, w$ e h são a altura, a largura e a espessura do corpo de prova, respectivamente. Nas tabelas 30 e 31 são mostrados os valores de $D$ para os compósitos analisados em água destilada e água de mar, respectivamente. 
Tabela 30 - Parâmetros de difusão para os compósitos bisfenol/bucha em água destilada.

\begin{tabular}{|c|c|c|c|c|c|}
\hline \multicolumn{2}{|c|}{ Compósito } & $\boldsymbol{M}_{\infty}$ & $\begin{array}{c}\boldsymbol{D} \\
\left(\mathbf{1 0}^{-\mathbf{6}} \mathbf{m m}^{2} / \mathbf{s}\right)\end{array}$ & $\begin{array}{c}\boldsymbol{D}_{\boldsymbol{x}} \\
\left(\mathbf{1 0}^{-6} \mathbf{m m}^{2} / \mathbf{s}\right)\end{array}$ & $\mathbf{r}^{\mathbf{2}}$ \\
\hline 1 & $\mathrm{U} 10$ & 19,28 & 2,90 & 3,36 & 0,996 \\
\hline 2 & $\mathrm{U} 20$ & 25,41 & 3,15 & 3,65 & 0,997 \\
\hline 3 & $\mathrm{U} 40$ & 31,84 & 4,7 & 5,44 & 0,997 \\
\hline 4 & M20 & 11,78 & 3,05 & 3,53 & 0,990 \\
\hline 5 & M30 & 15,91 & 4,09 & 4,73 & 0,995 \\
\hline 6 & H20 & 11,98 & 2,10 & 2,43 & 0,997 \\
\hline 7 & H30 & 15,81 & 2,98 & 3,45 & 0,997 \\
\hline 8 & A20 & 17,41 & 2,35 & 2,72 & 0,996 \\
\hline 9 & A30 & 18,37 & 2,79 & 3,23 & 0,994 \\
\hline
\end{tabular}

Tabela 31 - Parâmetros de difusão para os compósitos bisfenol/bucha em água de mar.

\begin{tabular}{|c|c|c|c|c|c|}
\hline Compósito & & $\begin{array}{c}\mathbf{M} \infty \\
(\%)\end{array}$ & $\begin{array}{c}\boldsymbol{D} \\
\left(\mathbf{I 0}^{-\mathbf{6}}\right. \\
\left.\mathbf{m m}^{2} / \mathbf{s}\right)\end{array}$ & $\begin{array}{c}\boldsymbol{D}_{\boldsymbol{x}} \\
\mathbf{( 1 0}^{-\boldsymbol{6}} \\
\mathbf{m m}^{\mathbf{2}} \mathbf{s} \boldsymbol{)}\end{array}$ & $\boldsymbol{r}$ \\
\hline 1 & $\mathrm{U} 10$ & 18,80 & 1,67 & 1,93 & 0,989 \\
\hline 2 & $\mathrm{U} 20$ & 25,40 & 2,22 & 2,57 & 0,995 \\
\hline 3 & $\mathrm{U} 40$ & 35,42 & 2,27 & 2,63 & 0,989 \\
\hline 4 & $\mathrm{M} 20$ & 10,04 & 1,20 & 1,39 & 0,996 \\
\hline 5 & $\mathrm{M} 30$ & 15,96 & 2,94 & 3,40 & 0,990 \\
\hline 6 & $\mathrm{H} 20$ & 11,70 & 1,51 & 1,75 & 0,995 \\
\hline 7 & $\mathrm{H} 30$ & 17,46 & 1,61 & 1,86 & 0,993 \\
\hline 8 & $\mathrm{~A} 20$ & 15,13 & 1,45 & 1,68 & 0,990 \\
\hline 9 & $\mathrm{~A} 30$ & 16,28 & 1,61 & 1,86 & 0,986 \\
\hline 10 & $\mathrm{FC}$ & 13,87 & $5,62 \mathrm{E}-07$ & $6,505 \mathrm{E}-7$ & 0,998 \\
\hline
\end{tabular}

Os resultados obtidos para os valores corrigidos do coeficiente de difusão $\left(D_{x}\right)$ apresentaram ordem de grandeza e valores de $\mathbf{M}_{\infty}$ comparáveis aos reportados para compósitos poliéster/fibra de bucha [218], [241], [354] e outros compósitos reforçados com fibras vegetais [353]. Porém, valores de umidade absorvida na saturação e os coeficientes de difusão foram maiores do que os encontrados para outros compósitos com fibras naturais [314], [355]. Isso ocorre como consequência do arranjo tridimensional das fibras da esponja de bucha, fazendo que uma grande quantidade de fibras seja interceptada na superfície dos materiais compósitos, permitindo à água atingir o interior do compósito com mais facilidade [218].

Dos resultados das tabelas 30 e 31 pode se destacar que a quantidade de fibras nos compósitos, assim como também os tratamentos realizados, tiveram uma grande influência na quantidade de água absorvida no equilíbrio, $\mathbf{M}_{\infty}$. Também foi observado que para compósitos com $20 \%$ em peso de fibras, a quantidade de água absorvida no equilíbrio $\left(\mathrm{M}_{\infty}\right)$ foi por volta de 10 e $25 \%$ nos compósitos com fibras mercerizadas e não tratadas, respectivamente. É possível que, no caso dos 
compósitos com fibras de bucha sem tratamento, a fraca adesão na interfase fibra/resina favorecesse a formação de vazios entre a matriz e as fibras, permitindo que moléculas de água penetrassem no compósito, deixando valores de $\mathrm{M}_{\infty} \mathrm{e}$ taxas de difusão maiores. O objetivo dos tratamentos realizados nas fibras foi obter uma maior aderência com as resinas. Assim, a modificação superficial pode ter ocasionado a redução na quantidade e o volume de vazios e, por conseguinte, a penetração ou o armazenamento de moléculas de água através da interface foi restringida [356].

Os gráficos do valor médio da umidade absorvida $\Delta \mathrm{M}$ (porcentagem em peso) versus a raiz quadrada do tempo, são mostrados nas Figuras 112 a 115.
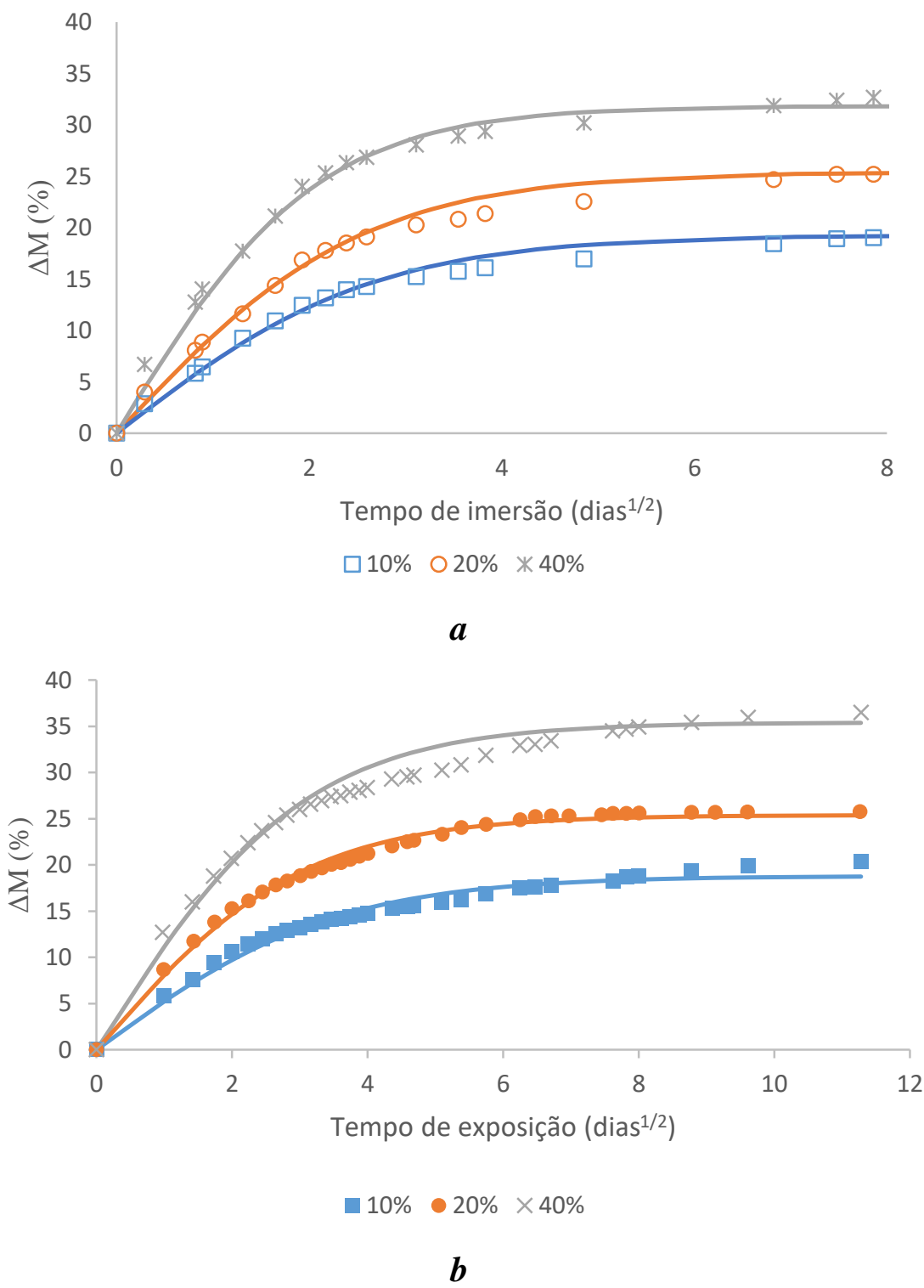

Figura 112 - Variação de massa com $\sqrt{\mathrm{t}}$ para compósitos com fibras de bucha sem modificação em (a) água destilada (b) água de mar. 
Como observado na Figura 112, ao aumentar a fração de fibra nos compósitos, houve um aumento considerável de $\mathrm{M}_{\infty}$, sendo que o maior efeito foi causado em compósitos com $40 \%$ de fibras de bucha. Esta tendência foi encontrada também no ensaio realizado em água destilada. Em compósitos reforçados com outras fibras lignocelulósicas tem se encontrado também este comportamento [357], [358], [359], [360]. De fato, esse comportamento era esperado, devido ao caráter higroscópico das fibras lignocelulósicas. Assim, o efeito da fração de fibras no compósito sobre a quantidade de umidade absorvida no equilíbrio, que depende fortemente da composição das fibras, pode levar a perdas críticas nas propriedades mecânicas [356], [361], [362]. Este efeito não é apresentado em compósitos reforçados com fibras sintéticas, onde para compósitos de matriz polimérica foi reportado o aumento de apenas $0,1 \%$ no valor de $\mathrm{M}_{\infty}$ com um aumento no teor de fibras de vidro de 25 a $65 \%$ [363].

O mecanismo de difusão predominante para a absorção de água por parte de fibras sem tratamento superficial está relacionado com a composição das fibras, sendo que a absorção de água em fibras lignocelulósicas é causada principalmente pelas ligações de hidrogênio entre os grupos hidroxila livres nas moléculas de celulose e as moléculas de água [354]. Celino et al. realizaram estudos sobre o comportamento hidrofílico de fibras naturais e sua relação com a presença de grupo hidroxilo livre na sua estrutura [364]. Assim, a alta quantidade de hemicelulose presente nas fibras de bucha - sendo este o componente da parede celular que mais afinidade tem com a água [240], [356], - foi decisiva na interpretação dos resultados obtidos.

Na Figura 113 são apresentadas as curvas de variação de massa versus a raiz do tempo para compósitos com bucha mercerizada. Como foi encontrado nos ensaios de infravermelho, hemiceluloses superficiais foram eliminadas das fibras de bucha com o tratamento alcalino pelo que a afinidade com umidade deveria ser menor. Como apresentado nas tabelas 30 e 31, as fibras não tratadas apresentaram maior absorção de umidade e coeficientes de difusão com valores mais altos quando comparadas com os compósitos com fibras mercerizadas, confirmando esta hipótese. Resultados similares foram obtidos ao comparar os dados de absorção com os compósitos de fibras hornificadas e acetiladas, nas Figuras 114 e 115. 

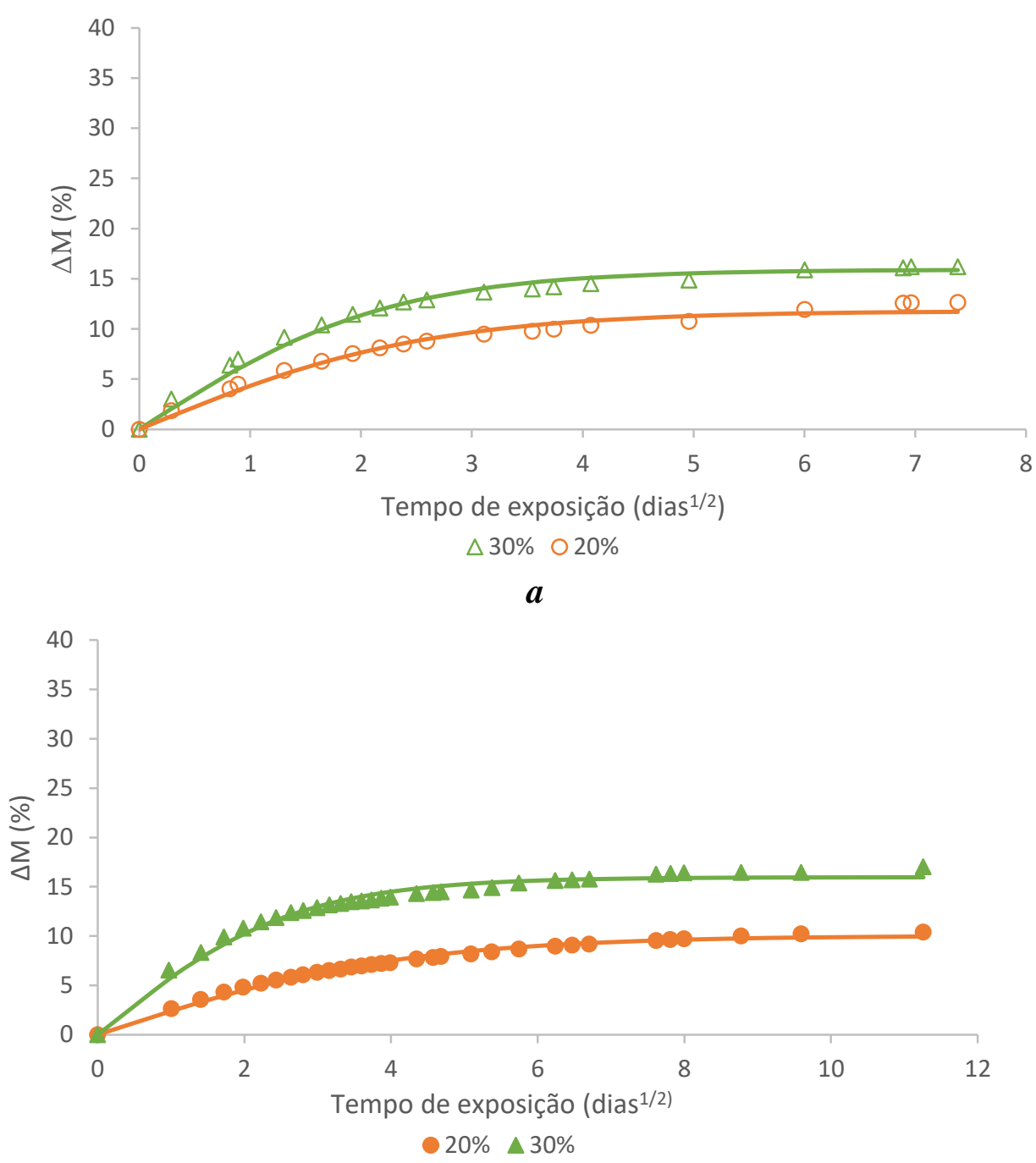

$b$

Figura 113 - Variação de massa com $\sqrt{\mathrm{t}}$ para compósitos com fibras de bucha mercerizadas em (a) água destilada (b) água de mar.

Da mesma forma, nas fibras modificadas por mercerização a absorção de água de mar nos compósitos caiu ao redor de 15,4\%, enquanto que, para fibras modificadas por hornificação e acetilação, a diminuição foi de 13,4 e 10,4\%, respectivamente. Por outro lado, nos ensaios em água destilada M $\infty$ caiu 13,4 \% em compósitos com fibras mercerizadas e hornificadas e $8 \%$ para compósitos com fibras acetiladas. 

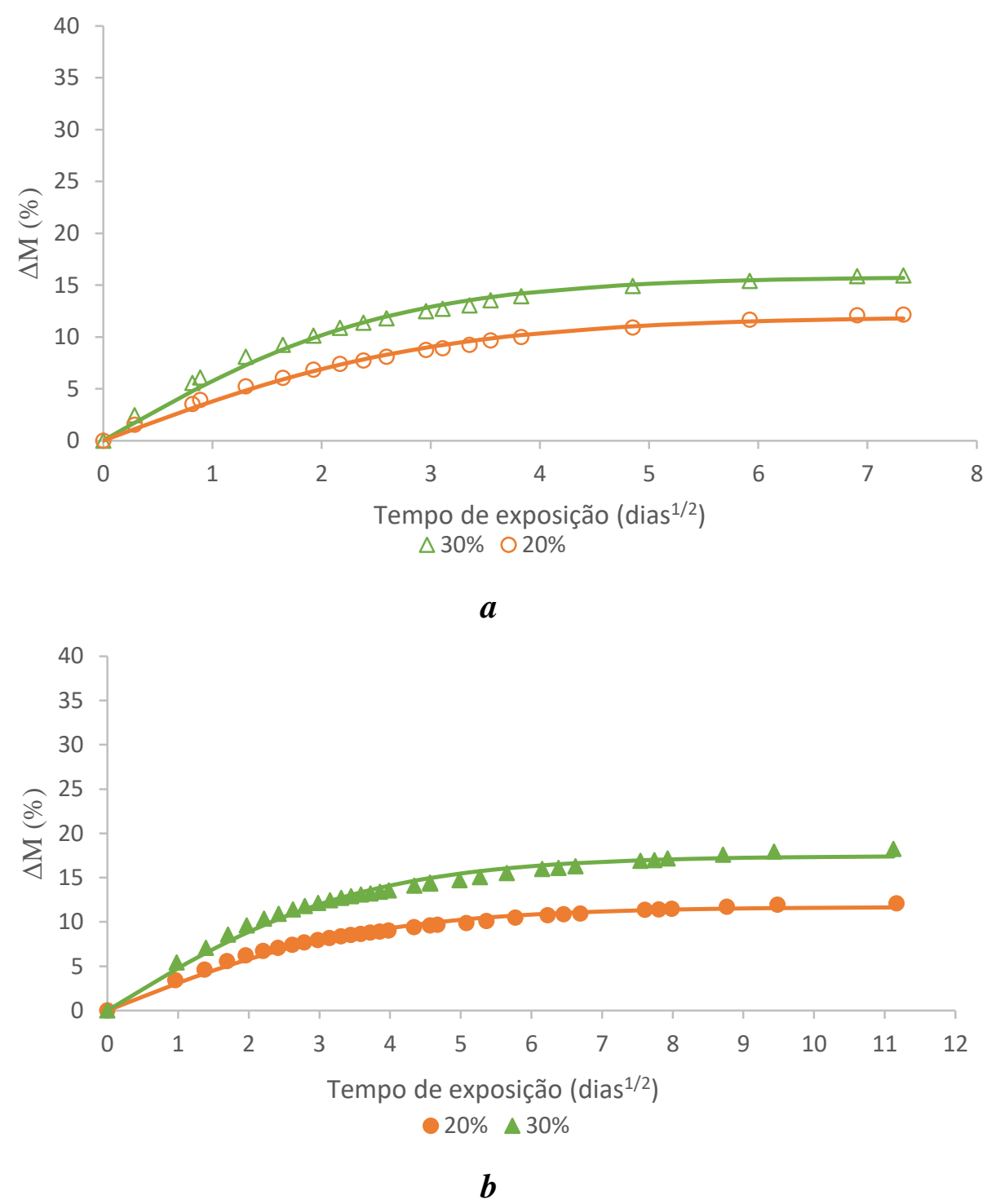

Figura 114 - Variação de massa com $\sqrt{t}$ para compósitos com fibras de bucha hornificadas em (a) água destilada (b) água de mar.

Das curvas da Figura 115 foi possível verificar que, embora os compósitos com fibras acetiladas apresentem também uma redução nos coeficientes de difusão e na quantidade M\% absorvida na saturação, se comparados com os compósitos com fibras sem modificação, tal redução foi independente do conteúdo de fibra nos compósitos, apresentando apenas uma ligeira diferença nos valores de $\mathbf{M}_{\infty}$ ao aumentar o teor de fibras de 20 a 30\%. Além disso, é possível notar que no caso especifico do compósito com $40 \%$ de fibras naturais e para os compósitos com fibras de bucha acetiladas foi mais evidente um comportamento de difusão afastado da difusão linear de Fick com desvios pronunciados nas curvas da variação de massa com o tempo. Estes desvios estão associados a possíveis danos na estrutura 
dos materiais [218] o que confirmaria o dano estrutural causado nas fibras pelo tratamento de acetilação realizado.
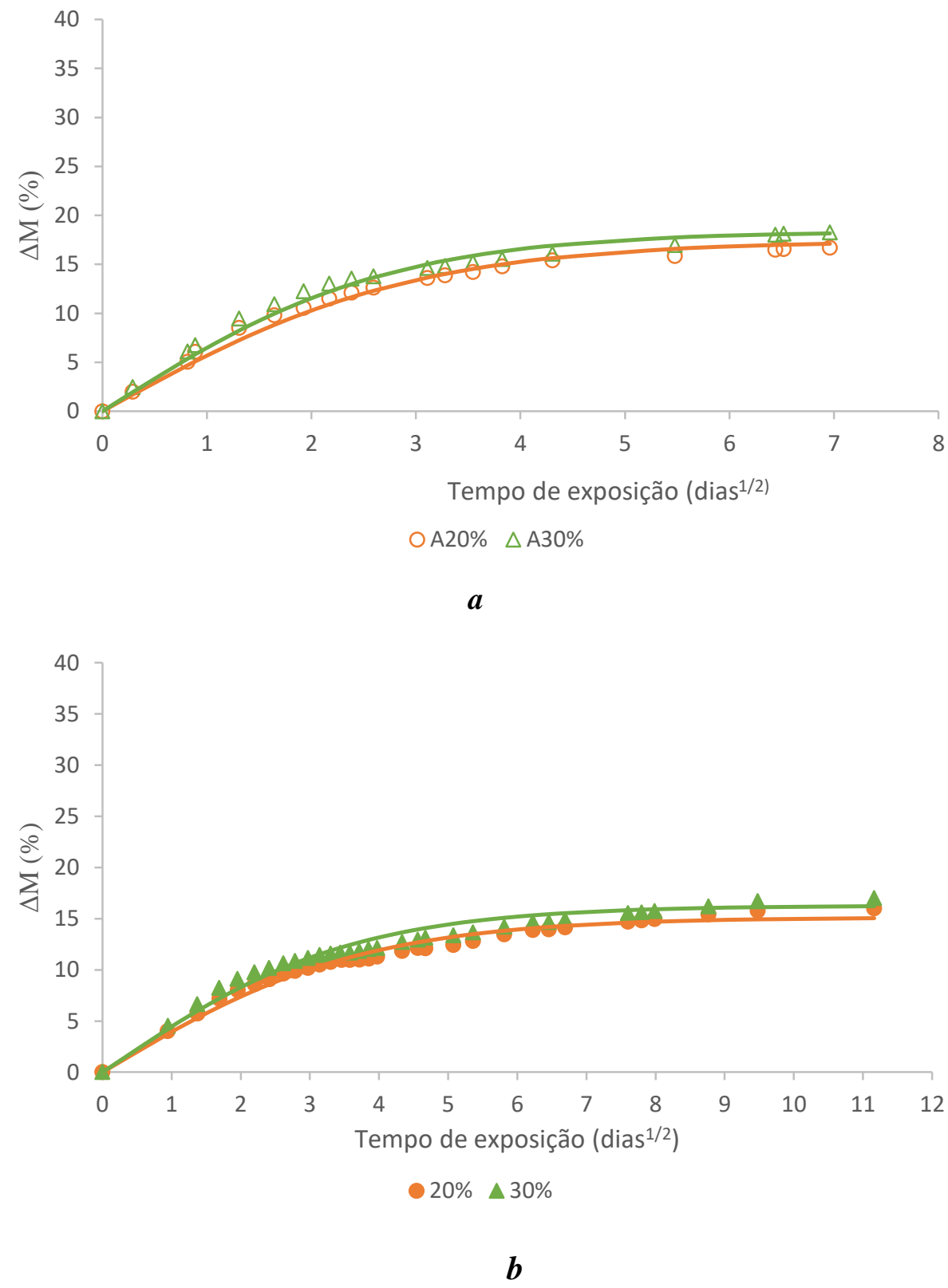

Figura 115 - Variação de massa com $\sqrt{t}$ para compósitos com fibras de bucha acetiladas em (a) água destilada (b) água de mar.

Neste trabalho foi observada uma redução na taxa de difusão e na quantidade de absorção de água dos compósitos com fibras tratadas, embora cada tratamento tenha mudado a estrutura da fibra de uma maneira diferente. $\mathrm{O}$ tratamento alcalino resultou na redução da hidrofilicidade pela redução de hemicelulose e a lixiviação da camada de cera superficial das fibras, enquanto que o tratamento de acetilação 
resultou na redução da hidrofilicidade pela substituição parcial dos grupos $\mathrm{OH}$ por grupos acetila nas fibras [347].

Os efeitos da absorção de umidade nos compósitos serão analisados também na seção correspondente à caracterização mecânica por ensaios de flexão (seção 4.3.2) e análise de excitação por impulso (seção 4.3.3). Após a imersão em água do mar, a aparência superficial dos laminados mudou gradualmente. As amostras eram transparentes antes do ensaio e a maioria passou a apresentar opacidade depois da primeira semana de imersão, como mostrado nas Figuras no apêndice A3. A quantidade de fibras teve também influência no grau de inchação observado como protuberâncias maiores na superfície que diminuíram depois de alguns dias de finalizado o ensaio.

\subsubsection{Técnica de flexão em três pontos}

A análise do comportamento mecânico dos materiais foi realizada pelo ensaio de flexão de três pontos e pela técnica de excitação por impulso. As curvas tensãodeformação obtidas por meio do ensaio de flexão em três pontos foram utilizadas para determinar parâmetros, tais como, o módulo de elasticidade à flexão (E), a tensão máxima $\left(\boldsymbol{\sigma}_{\max }\right)$, a deformação uniforme máxima $\left(\boldsymbol{\varepsilon}_{\boldsymbol{m a x}}\right)$ e a densidade de energia de deformação dos materiais, calculada a partir da área sob a curva tensãodeformação. O valor médio para esses parâmetros, obtido como resultado de ensaios de flexão realizados para 5 corpos de prova de cada tipo de resina é apresentado na tabela 32 .

Tabela 32 - Valores médios de parâmetros do ensaio de flexão em três pontos para resinas epóxi bisfenol, ESO-bisfenol e resorcinol.

\begin{tabular}{|c|c|c|c|c|c|c|}
\hline Resina & $\begin{array}{c}\sigma_{\max } \\
(\mathbf{M P a})\end{array}$ & $\begin{array}{c}\mathbf{C V} \\
(\%)\end{array}$ & $\begin{array}{c}\boldsymbol{\varepsilon}_{\max } \\
(\%)\end{array}$ & $\begin{array}{c}\mathbf{C V} \\
(\%)\end{array}$ & $\begin{array}{c}\mathbf{E} \\
(\mathbf{G P a})\end{array}$ & $\begin{array}{c}\mathbf{C V} \\
(\%)\end{array}$ \\
\hline $\mathrm{B}$ & $65,7 \pm 4,8$ & 7,3 & $3,6 \pm 1,9$ & 5,2 & $1,8 \pm 0,2$ & 10,3 \\
\hline $\mathrm{ESO} 30$ & $69,5 \pm 10,8$ & 15,5 & $4,1 \pm 0,2$ & 5,4 & $2,2 \pm 0,4$ & 19,8 \\
\hline $\mathrm{R}$ & $40,1 \pm 2,5$ & 6,0 & $5,2 \pm 0,2$ & 3,6 & $0,9 \pm 0,1$ & 10,4 \\
\hline
\end{tabular}

A resina preparada com $30 \%$ de ESO e $70 \%$ de Bisfenol A aumentou ligeiramente o valor da tensão máxima, se comparada com o valor para a resina de bisfenol A puro. Como foi encontrado na literatura, óleos de soja epoxidados tem sido usados para o melhoramento das propriedades de resinas epóxi convencionais 
[105], obtendo a rigidez e resistência necessárias para algumas aplicações finais [55]. Não foi possível realizar o ensaio de flexão da resina de cardanol puro por causa da sua flexibilidade.

Na figura 116 é mostrado o valor médio da medição de 5 corpos de prova para as resinas puras e o compósito de cardanol-resorcinol. Nas figuras 118 e 120 são mostrados os resultados (de acordo com a numeração da tabela 29 da página 142) da medição de 5 corpos de prova para compósitos de bisfenol e de ESO30, respectivamente.

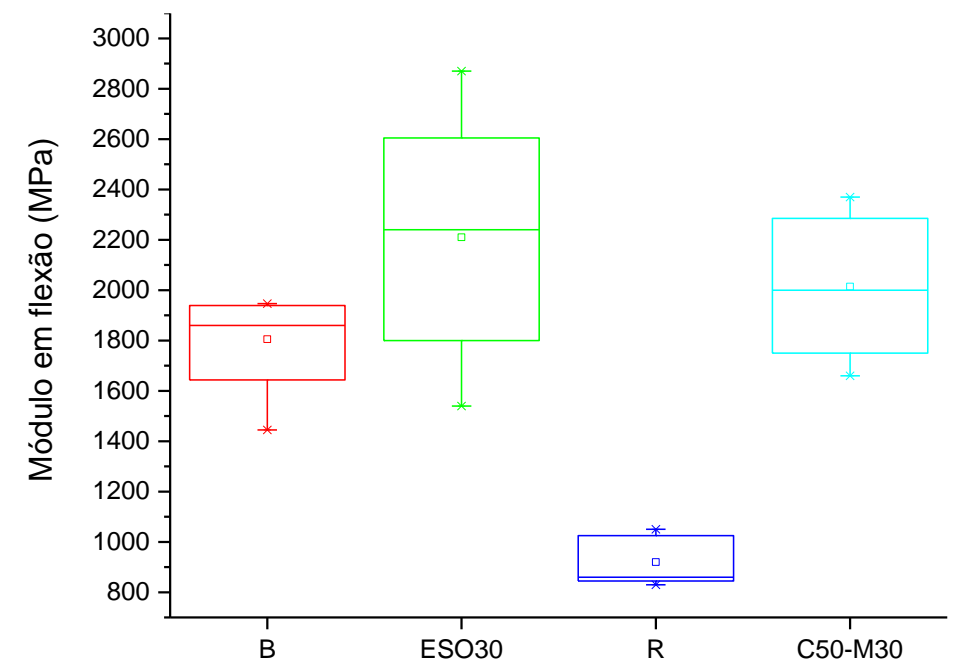

Figura 116 - Comparação da média do módulo em flexão de resinas puras e do compósito C50-M30 usando o teste LSD de Fisher, com nível de significância de 0,05.

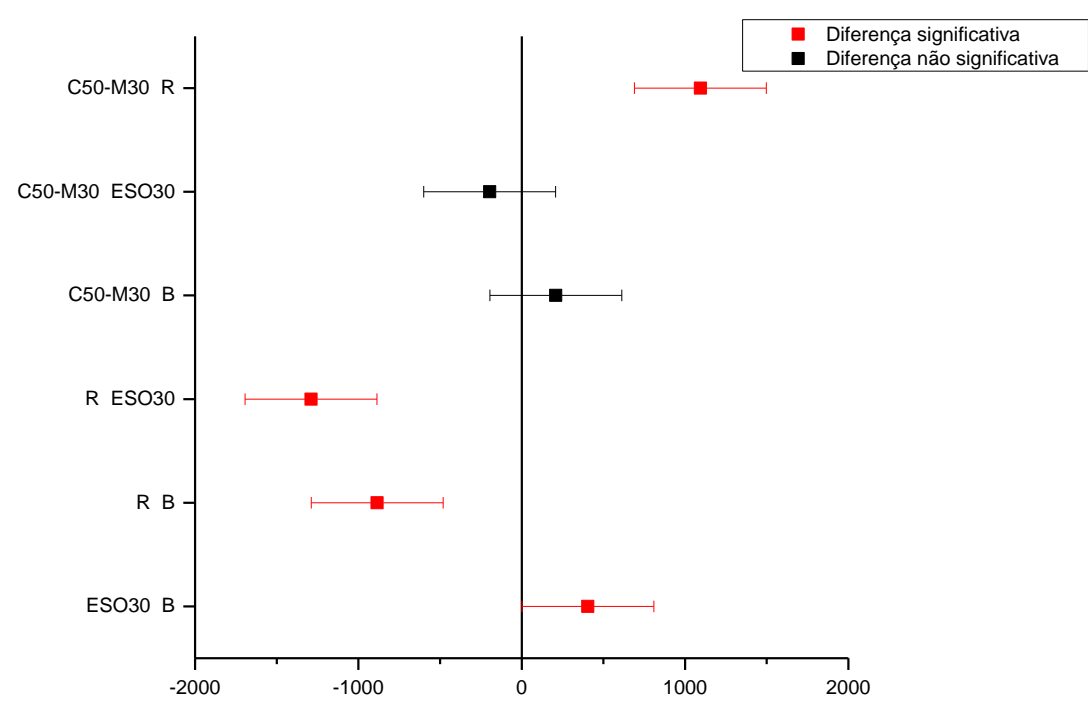

Figura 117 - Valores médios de módulo em flexão de resinas puras e do compósito C50 com $30 \%$ de fibras de bucha mercerizadas.

A comparação dos resultados de módulo da resina pura de resorcinol (R) com o compósito C50-M30, nas figuras 116 e 117, indicaram uma diferença significativa 
do comportamento mecânico pela adição da resina de cardanol e das fibras de bucha na formulação do material. Estes resultados podem indicar que a adesão das fibras de bucha com a matriz polimérica utilizada foi boa e como consequência o efeito do reforço com as fibras de bucha melhorou as propriedades mecânicas.

Por outro lado, nas figuras 118 e 119 é notado que os compósitos fabricados com matriz de ESO30 e fibras de bucha apresentaram propriedades mecânicas menores em relação à resina pura, indicando que a interface fibra/matriz não foi suficientemente forte para permitir uma transferência efetiva de tensão para as fibras.

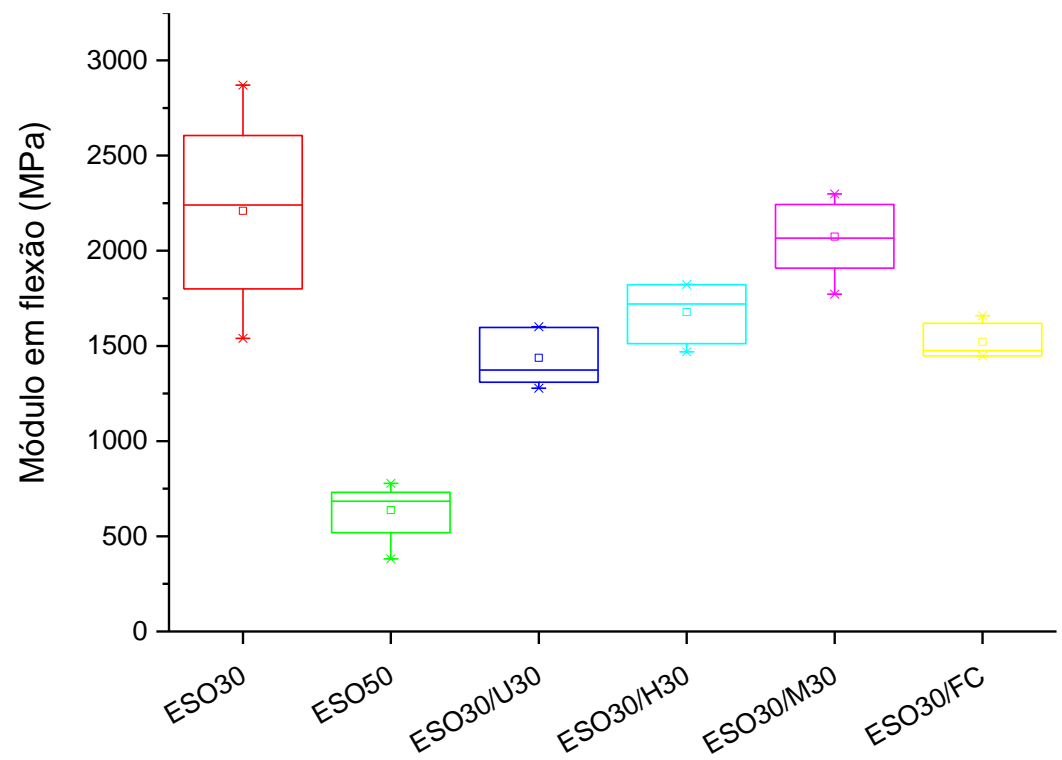

Figura 118 - Valores médios de módulo em flexão de resinas ESO30 e ESO50 e compósitos ESO30 com fibras de bucha.

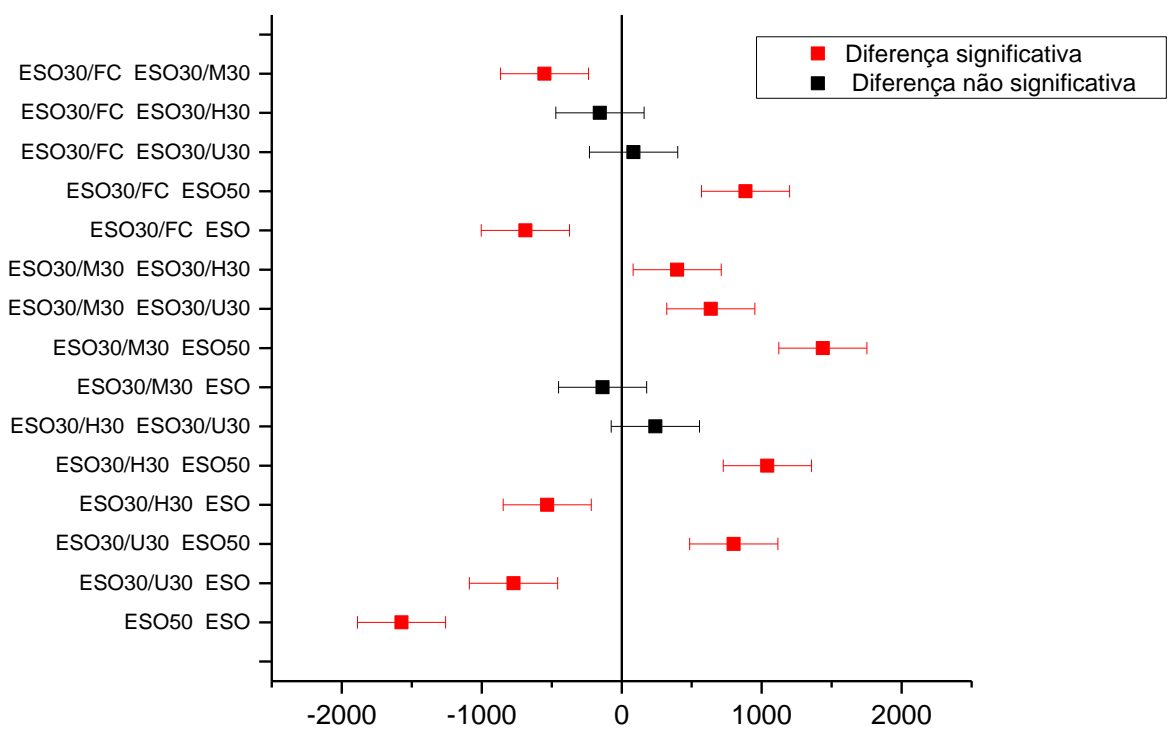

Figura 119 - Comparação da média do módulo em flexão de compositos de ESO usando o teste LSD de Fisher, com nível de significância de 0,05. 
No entanto, compósitos de matriz ESO com $30 \%$ de fibras de bucha mercerizadas (ESO30-M30) apresentaram as melhores propriedades, com módulo em flexão de 2,03 $\pm 0,17 \mathrm{GPa}$. Esse resultado sugere que o tratamento de mercerização nas fibras de bucha, com um aumento de $15 \%$ no módulo em flexão estática frente aos compósitos ESO30-U30, foi efetivo para a melhora da adesão por ancoragem mecânica com a resina com conteúdo de ESO. Por outro lado, a melhora na adesão também pode ser devida à afinidade química entre os grupos presentes no óleo de soja epoxidado e os grupos funcionais na superfície da fibra depois do tratamento.

No caso dos compósitos fabricados com matriz de bisfenol, nas figuras $120 \mathrm{e}$ 121 são mostrados os resultados que indicaram que os compósitos que apresentaram as melhores propriedades mecânicas foram aqueles fabricados com $30 \%$ de fibras de bucha tratadas. Os compósitos de bisfenol com 30\% de fibras de bucha hornificadas apresentaram os maiores valores com módulo em flexão de 3,39 \pm 0,19 GPa. No entanto, embora os compósitos com fibras tratadas apresentaram um ligeiro aumento no módulo com relação aos compósitos fabricados com fibras sem tratamento, não houve uma diferença significativa entre os compósitos com 30\% de fibras mercerizadas, hornificadas e acetiladas.

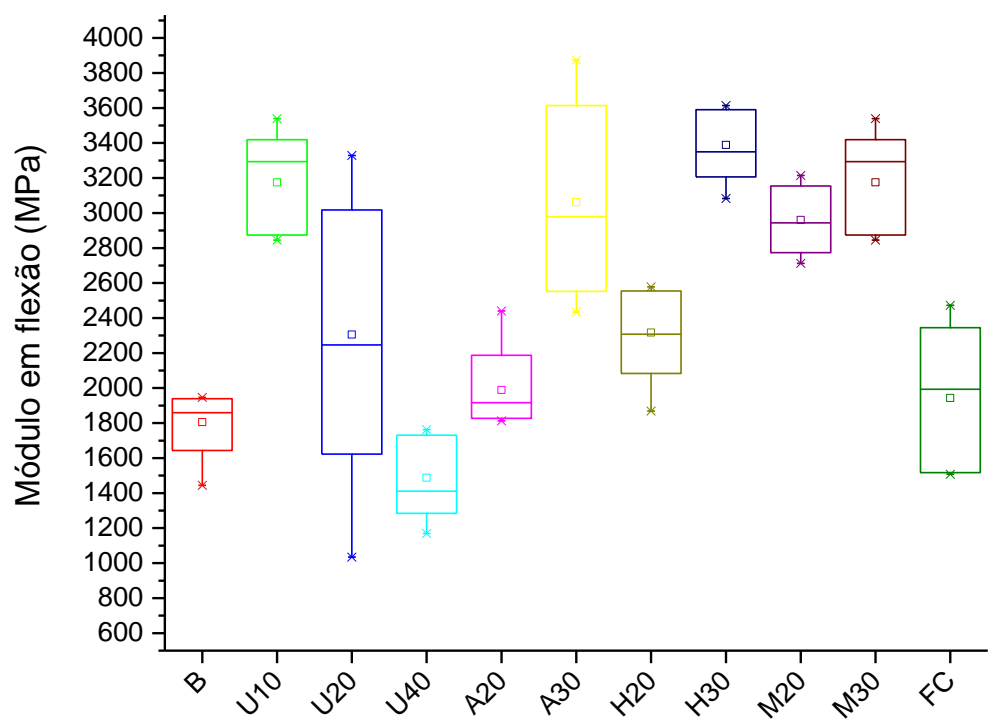

Figura 120 - Valores médios de módulo em flexão de compósitos bisfenol com fibras de bucha.

Por outro lado, nos compósitos fabricados com $20 \%$ de fibras tratadas por mercerização foi encontrada uma melhora significativa no módulo. Com um 
aumento de 29\% no módulo em flexão estática frente aos compósitos com fibras de bucha sem tratar.

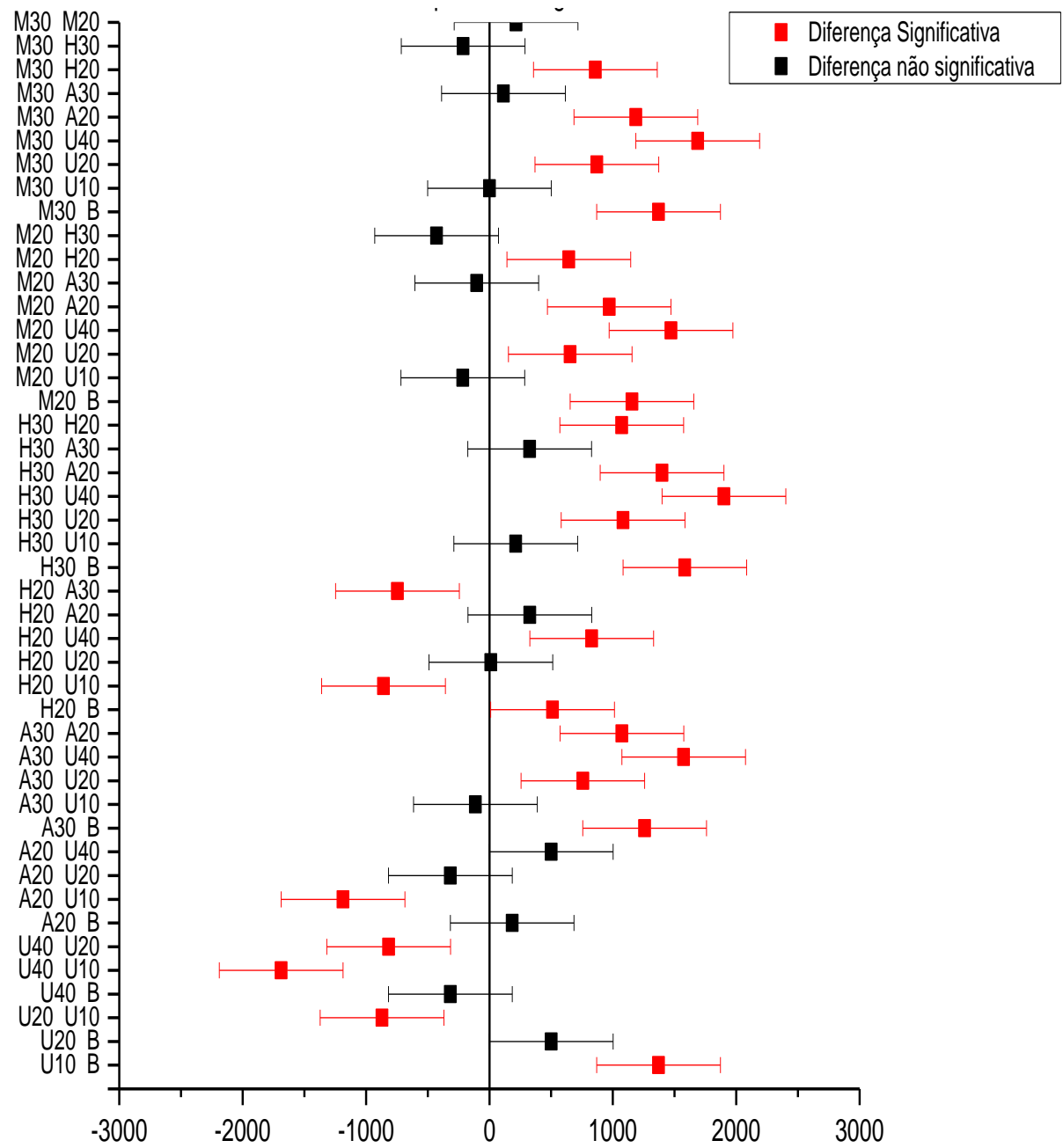

Figura 121 - Comparação da média do módulo em flexão de compositos de bisfenol usando o teste LSD de Fisher, com nível de significância de 0,05.

Na Figura 122 são mostrados os gráficos típicos de tensão - deformação para as resinas puras e nas Figuras 123 a 125 gráficos correspondentes aos compósitos reforçados com $30 \%$ de fibras de bucha, onde pode ser visto o efeito da adição das fibras no tipo de fratura nos compósitos. 


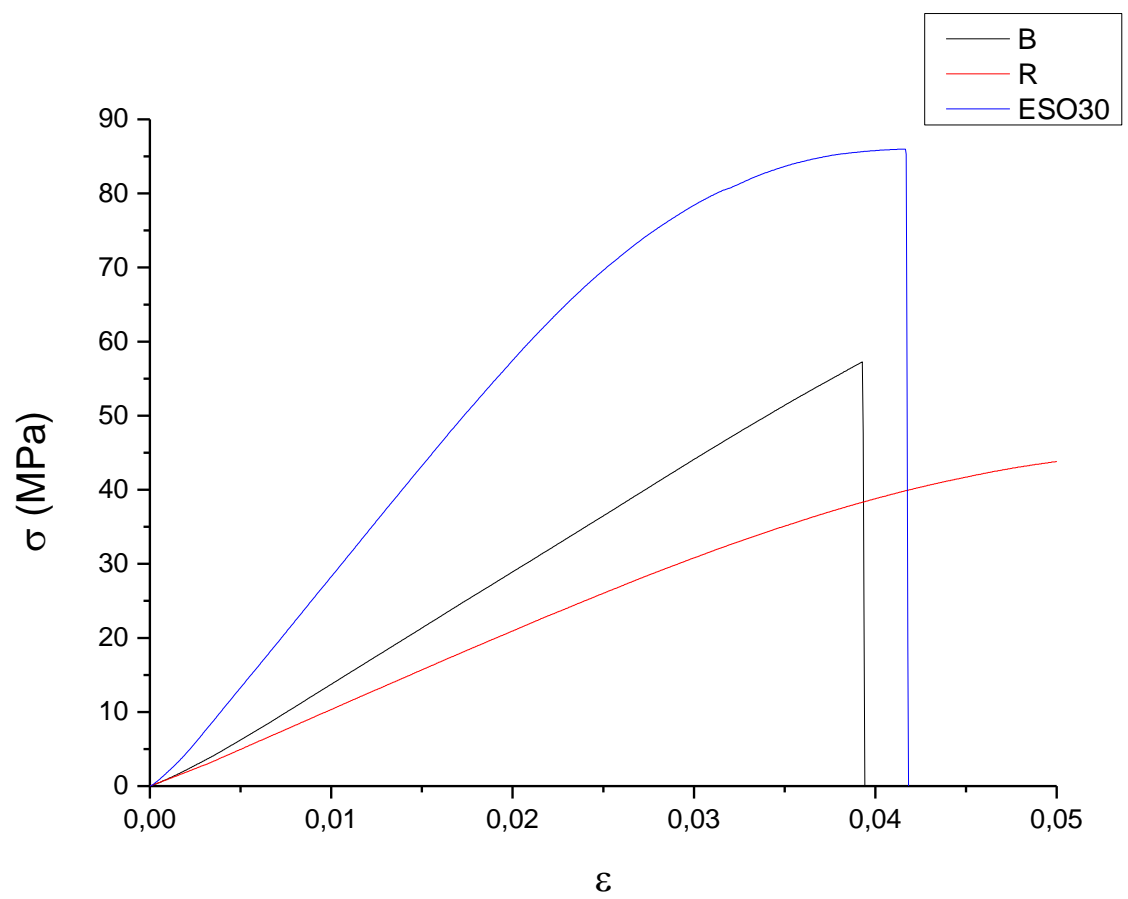

Figura 122 - Curva tensão - deformação para resinas bisfenol (B), resorcinol (R) e ESObisfenol (ESO30).

O resultado do ensaio de flexão das resinas revelou uma melhora nas propriedades em flexão da resina ESO30 em comparação com a resina de bisfenol A, pela presença da longa cadeia alifática do óleo de soja.

A Figura 123 mostra a curva de tensão - deformação para os compósitos com $30 \%$ de fibras de bucha. Ao contrário da curva para a resina de bisfenol pura (B) observada na figura 122 que mostrou um comportamento totalmente frágil, compósitos com fibras de bucha sem tratamento superficial apresentaram mudanças no modo de fratura. Assim, a adição de fibras de bucha conferiu ao material um tipo de fratura mais controlada pelo efeito do desvio das trincas. No entanto, os compósitos com 20 e $40 \%$ de fibras de bucha não tratadas apresentaram valores de módulo em flexão menores e não foi observada uma mudança significativa nos resultados, se comparados com a resina de bisfenol pura (Figura 121).

Por outro lado, para compósitos de bisfenol com $30 \%$ de fibras de bucha tratadas a rigidez aumentou significativamente como observado nos resultados mostrados na figura 120. Embora as curvas de tensão -deformação para os compósitos com fibras de bucha tratadas por acetilação e hornificação não tenham mostrado uma mudança radical no tipo de fratura, os corpos de prova dos 
compósitos ensaiados não apresentaram fratura abrupta e não foram quebrados totalmente durante o ensaio como foi o caso dos corpos de prova das resinas puras.

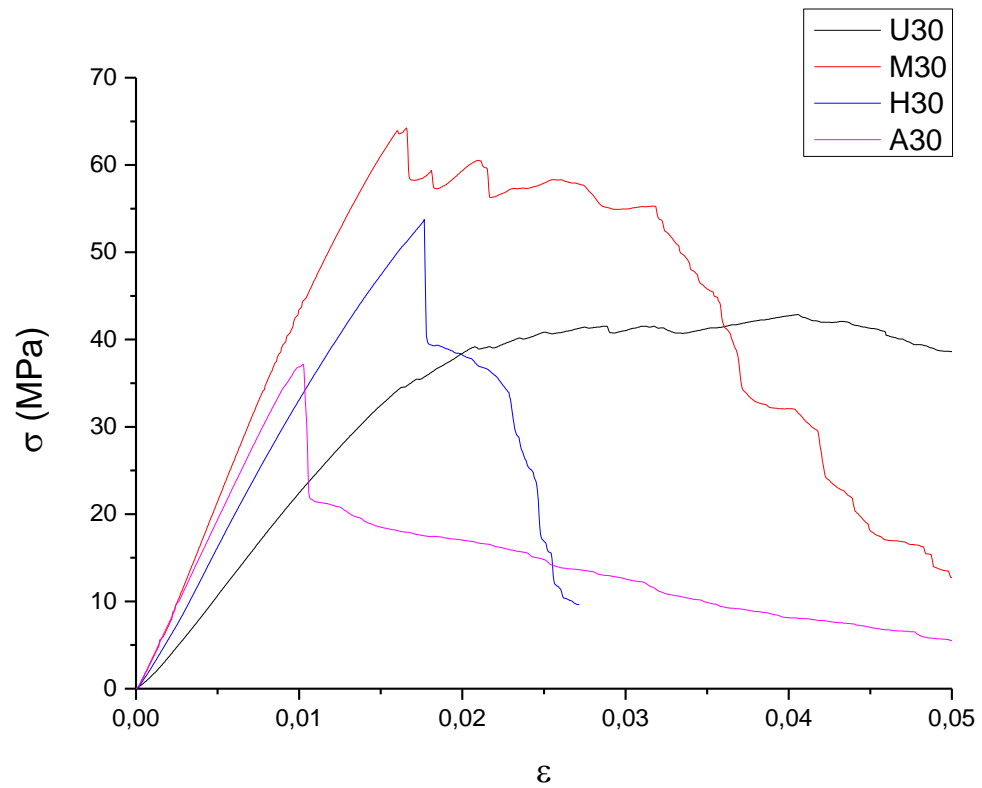

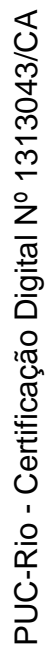

Figura 123 - Curva tensão - deformação para compósitos de bisfenol reforçados com $30 \%$ fibras de bucha sem tratamento (U30) e tratadas por mercerização (M30), hornificação (H30) e acetilação (A30).

Além de ter um aumento significativo no módulo, compósitos de matriz bisfenol com fibras de bucha mercerizadas apresentaram também um tipo de fratura menos abrupta e não foram completamente quebrados durante o ensaio.

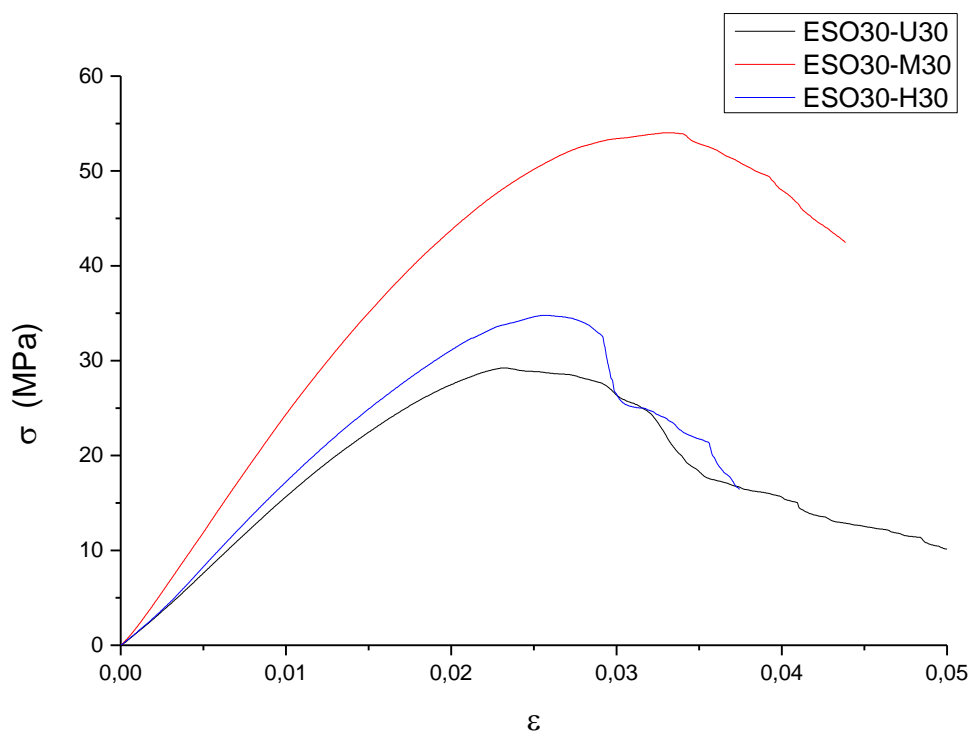

Figura 124 - Curva tensão - deformação para compósitos ESO-bisfenol reforçados com $30 \%$ fibras de bucha sem tratamento (U30) e tratadas por mercerização (M30) e hornificação (H30). 
Para os compósitos ESO30/bucha (Figura 124) foi observada uma fratura mais suave e os corpos de prova não foram quebrados totalmente durante o ensaio como foi o caso dos corpos de prova da resina ESO30 sem fibras. Os compósitos com matriz ESO30 e 30\% de fibras de bucha não tratadas e hornificadas apresentaram uma diminuição significativa no módulo em flexão, enquanto que para os compósitos com 30\% de fibras de bucha mercerizadas não foi observada uma mudança significativa nos valores de módulo, em comparação com a resina ESO30. Uma melhora na adesão das fibras tratadas por mercerização com a matriz de ESO30 estaria relacionada com os valores de rigidez encontrados.

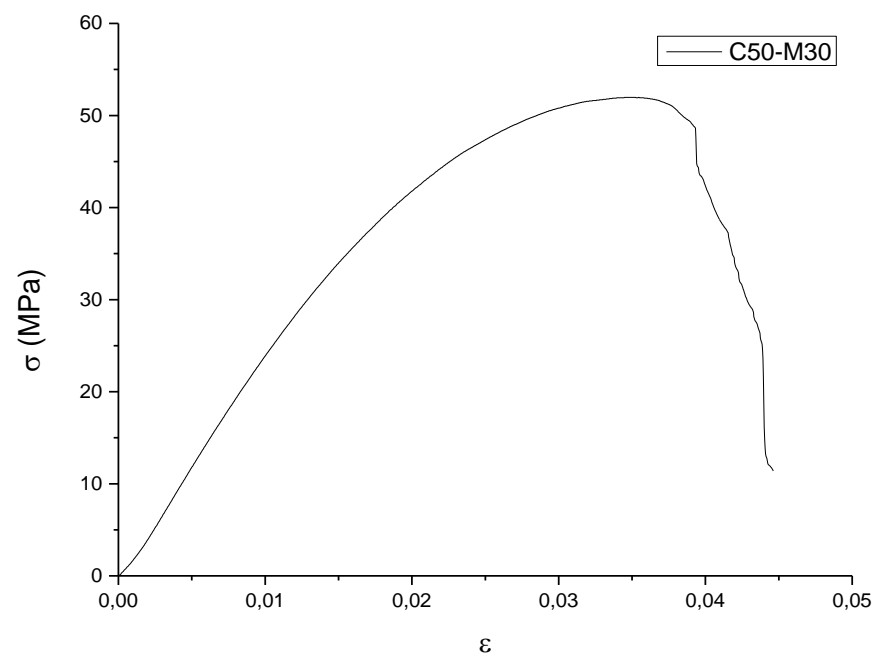

Figura 125 - Curva tensão - deformação para compósito de resina cardanol reforçado com fibras $30 \%$ de bucha mercerizada (C50-M30).

A curva tensão-deformação para o compósito C50-M30 mostrado na figura 125 e os resultados mostrados na figura 117 indicaram que houve um aumento significativo no módulo em flexão de resinas de resorcinol puro pela adição de $30 \%$ de fibras de bucha mercerizadas e 50\% de resina baseada em cardanol. $\mathrm{O}$ aumento considerável na rigidez seria uma indicação da forte adesão na interface fibra / matriz, o que foi corroborado pela análise da superfície de fratura do material (figura 153).

\subsubsection{Técnica de Excitação por Impulso (TEI)}

Ensaios não-destrutivos foram usados para a análise do módulo elástico e do amortecimento nos materiais fabricados. Depois da excitação do corpo de prova como descrito na metodologia, a resposta acústica - que depende das suas 
dimensões e propriedades elásticas - é capturada e processada pelo software (Figura 126). As frequências presentes nesta sinal permitem a determinação precisa dos módulos. $\mathrm{O}$ amortecimento $(\xi)$ corresponde à taxa de atenuação da oscilação, e caracteriza quão rápido decai a amplitude de vibração após a excitação mecânica. Essa propriedade está diretamente relacionada com os mecanismos internos de dissipação de energia, como, por exemplo, o atrito interno [276].

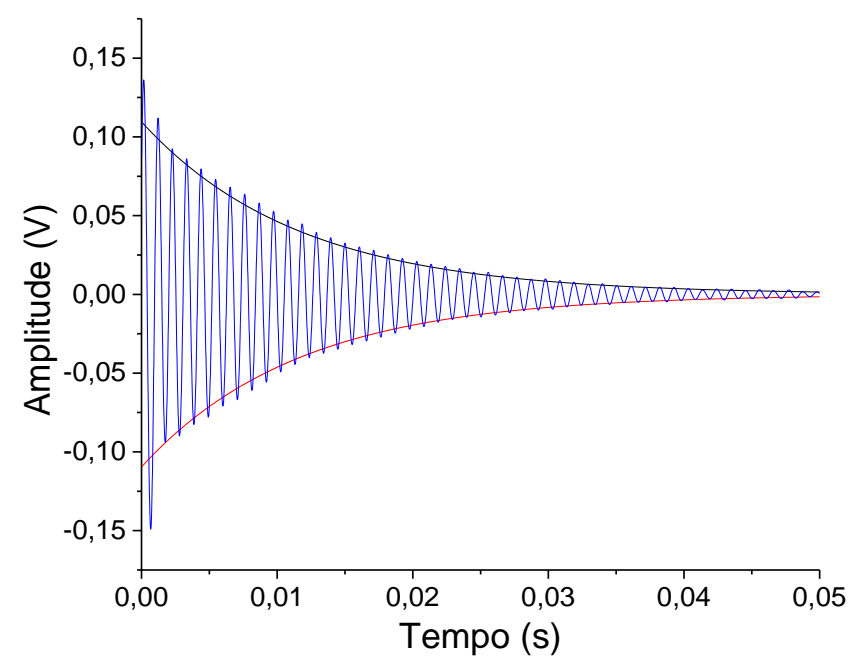

Figura 126 - Sinal no tempo de ressonância para o compósito epóxi bisfenol/bucha natural, após a excitação por impulso mecânico.

Na tabela 33 são apresentados apresenta os valores de módulo encontrados por meio da técnica de excitação por impulso para as resinas utilizadas como matriz e na tabela 34 são mostrados os valores do módulo para os compósitos.

Tabela 33 - Módulo elástico de resinas epóxi por TEI.

\begin{tabular}{|c|c|c|c|}
\hline Resina & Módulo (GPa) & Desvio padrão & $\begin{array}{c}\text { Coeficiente de } \\
\text { variação (\%) }\end{array}$ \\
\hline B & 3,56 & 0,01 & 0,14 \\
\hline ESO30 & 2,29 & 0,01 & 0,26 \\
\hline Resorcinol & 2,50 & 0,01 & 0,57 \\
\hline
\end{tabular}

A TEI foi capaz de oferecer respostas rápidas e coeficientes de variação menores. Por este método foram obtidos valores de módulo de elasticidade com coeficientes de variação inferiores a $3 \%$, o que, por sua vez, é contrário à técnica de flexão em três pontos que gerou resultados com valores mais dispersos, dada a sensibilidade dos efeitos locais que apresenta o procedimento estático. 
Tabela 34 - Valor médio para o módulo de elasticidade em flexão e amortecimento de compósitos.

\begin{tabular}{|c|c|c|c|}
\hline & Compósito & $\begin{array}{c}\text { Amortecimento } \\
\left(\mathbf{1} \times \mathbf{1 0}^{-4}\right)\end{array}$ & $\begin{array}{c}\text { Coeficiente de } \\
\text { variação (\%) }\end{array}$ \\
\hline 1 & U10 & $166,10 \pm 2,32$ & 1,40 \\
\hline 2 & U20 & $160,30 \pm 5,27$ & 3,29 \\
\hline 3 & U40 & $170,45 \pm 6,81$ & 4,00 \\
\hline 4 & M20 & $168,7 \pm 0,75$ & 0,45 \\
\hline 5 & M30 & $171,03 \pm 9,21$ & 5,38 \\
\hline 6 & H20 & $141,76 \pm 5,08$ & 3,58 \\
\hline 7 & H30 & $167,82 \pm 1,94$ & 1,16 \\
\hline 8 & A20 & $178,50 \pm 6,36$ & 3,56 \\
\hline 9 & A30 & $178.87 \pm 11,28$ & 6,32 \\
\hline 10 & FC & $190,59 \pm 2,71$ & 1,42 \\
\hline 11 & ESO50-U30 & $284,00 \pm 3,86$ & 1,36 \\
\hline 12 & ESO-U30 & $190,81 \pm 10,40$ & 5,45 \\
\hline 13 & ESO-M30 & $216,68 \pm 3,10$ & 1,43 \\
\hline 14 & ESO-H30 & $200,13 \pm 1,42$ & 0,71 \\
\hline 15 & ESO-FC & $200,13 \pm 1,42$ & 0,71 \\
\hline 16 & C50-M30 & $225,71 \pm 1,94$ & 0,86 \\
\hline & & & \\
\hline
\end{tabular}

A diferença nos valores de módulo obtidos com TEI e a técnica de flexão em três pontos é causada por fatores inerentes ao equipamento utilizado, sendo que os acessórios de medida, a rigidez do próprio quadro de força da máquina universal, a precisão do equipamento, e arredondamentos nos cálculos entre outros fatores, vão influenciar os resultados [276].

\subsubsection{Efeito do teor de fibras}

A adição das fibras de bucha gerou uma perda de propriedades mecânicas, se comparados os módulos com os valores para a resina de bisfenol usada como matriz. O efeito do teor de fibra pode ser observado na Figura 127, onde se mostra o valor de módulo para compósitos de bisfenol com 10, 20 e 40\% de fibra de bucha sem tratamento. Com o aumento do teor de fibras de 10 a $20 \%$ foi observado um incremento no módulo com respeito à resina de bisfenol, porém, a adição de um conteúdo de fibras acima dessa quantidade causo uma diminuição no módulo dos 
materiais. Por outro lado, também foi notado um aumento no amorteciemnto dos compósitos com relação à resina pura.
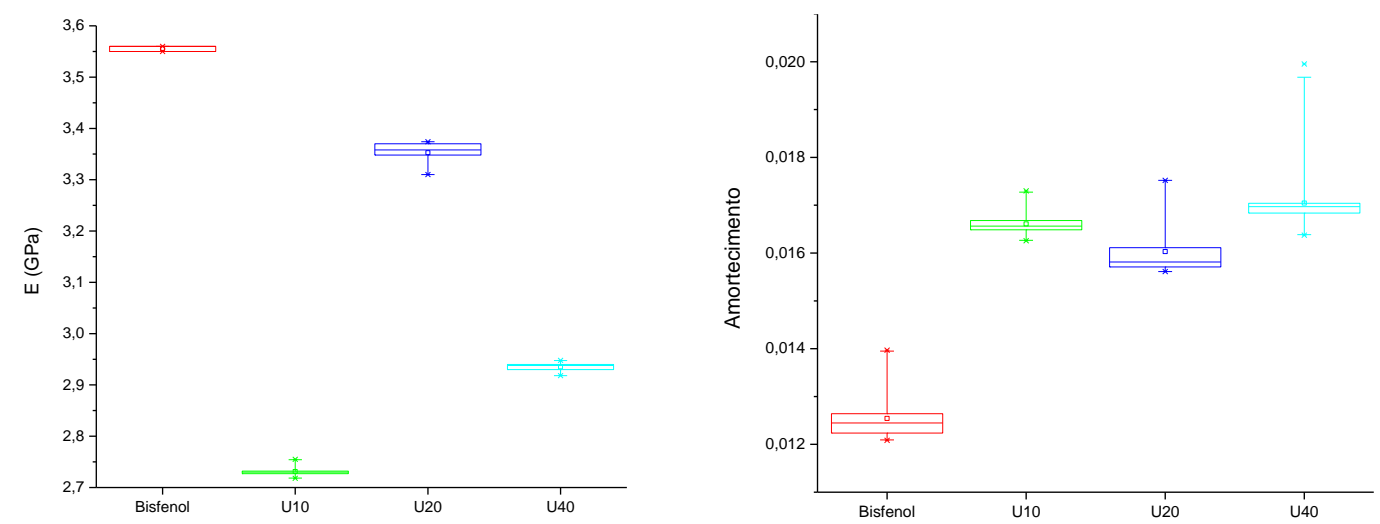

Figura 127 - Efeito do teor de fibras nos compósitos bisfenol/bucha sem tratamento.

Na figura 128 são mostrados os resultados para compósitos de matriz ESO e cardanol reforçados com $30 \%$ de fibras de bucha.

Adicionalmente foi encontrado que não houve diferença significativa no módulo de compósitos fabricados com $20 \%$ de fibras de bucha sem modificação e os compósitos fabricados com as fibras curtas. Os valores médios para esses compósitos são apresentados na tabela 35 .

Tabela 35 - Valor médio para o módulo de compósitos com matriz bisfenol.

\begin{tabular}{|c|c|c|c|c|}
\hline & Compósito & E (GPa) & Desvio padrão & $\begin{array}{c}\text { Coeficiente de } \\
\text { variação (\%) }\end{array}$ \\
\hline 2 & U20 & 3,35 & 0,02 & 0,64 \\
\hline 10 & FC & 3,44 & 0,01 & 0,37 \\
\hline
\end{tabular}

\subsubsection{Efeito do tipo de resina}

Na Figura 128 é apresentado o efeito do tipo de matriz sobre o módulo e o amortecimento de compósitos fabricados com $30 \%$ de fibras mercerizadas. O módulo de elasticidade dos compósitos foi maior se comparado com o valor obtido para a resina pura correspondente em cada caso. O compósito M30 apresentou o maior valor de módulo de elasticidade e um incremento de $10 \%$ com respeito à resina de bisfenol. No entanto, os compósitos de ESO e Cardanol apresentaram 
incrementos no valor do módulo de 26 e $30 \%$ respectivamente, com relação às resinas sem reforço.

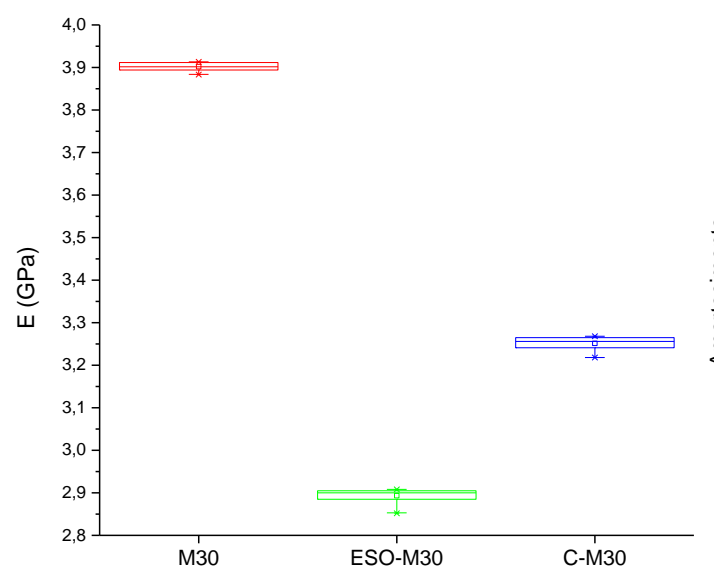

$a$

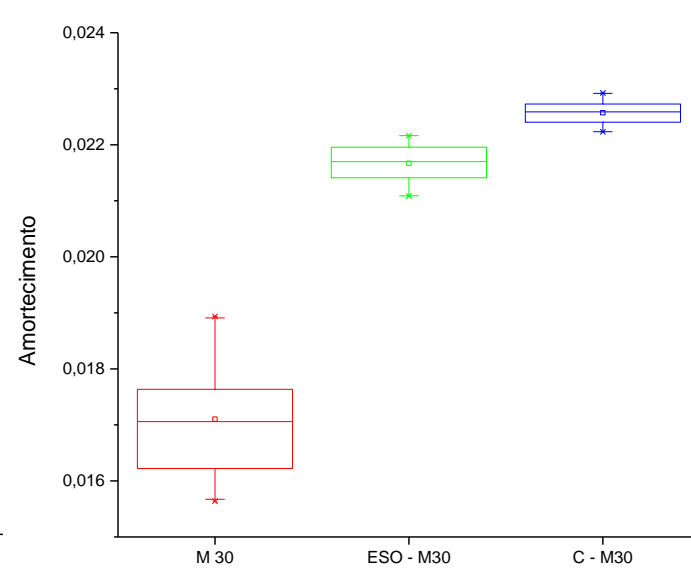

$b$

Figura 128 - Propriedades elásticas de compósitos com $30 \%$ de fibras de bucha mercerizada, e matriz de resina bisfenol, ESO-bisfenol e cardanol-resorcinol. (a) Módulo (b) amortecimento

Também foi observado que os compósitos com matriz de resina a base de óleos vegetais epoxidados (ESO30 e C50) apresentaram fator de amortecimento maior, se comparados com o compósito matriz de bisfenol A M30.

\subsubsection{Efeito do tipo de tratamento nas fibras}

Para compósitos bisfenol se encontrou que o tratamento de mercerização conferiu um incremento no módulo de elasticidade do compósito. Esses valores sugerem uma melhora na interfase fibra matriz que aportou melhoras nas propriedades mecânicas do compósito. A análise ANOVA indicou uma diferença significativa nos valores do módulo elástico dos compósitos fabricados com fibras tratadas e não tratadas, exceto para os compósitos fabricados com $20 \%$ de bucha sem tratamento e com $20 \%$ de bucha acetilada onde a diferença dos valores não foi significativa, como é mostrado na Figura 129. No entanto, esses resultados para os corpos de prova dos compósitos com $20 \%$ de fibras de bucha acetiladas apresentaram uma dispersão maior, causada possivelmente por defeitos observados no corpo de prova, tais como bolhas de ar. 

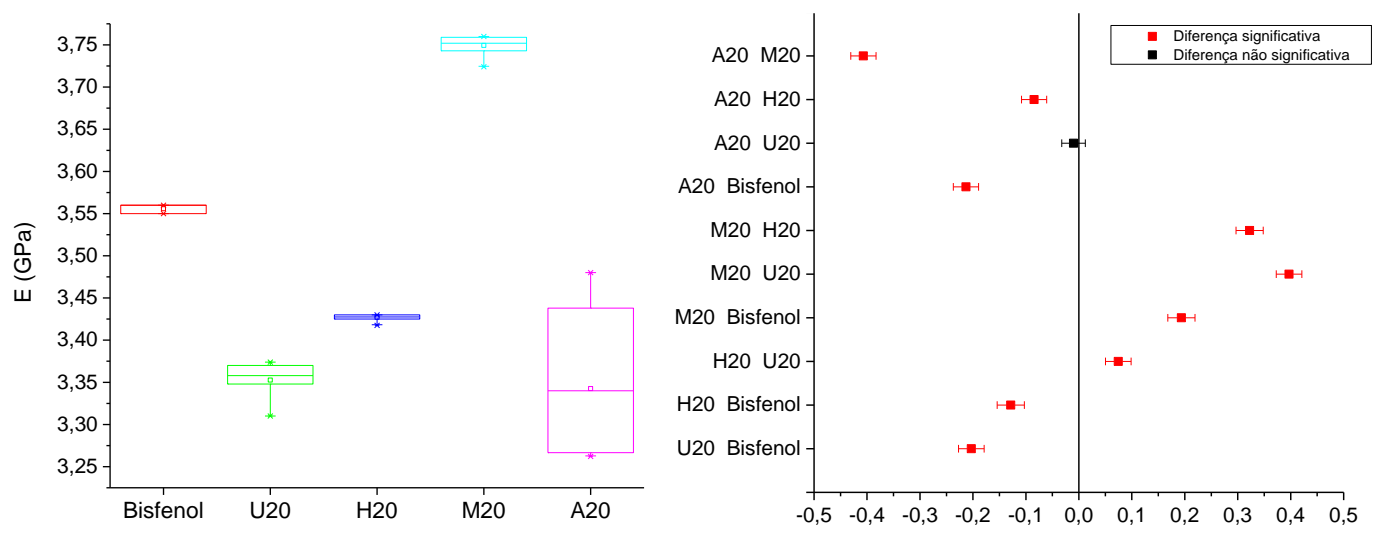

Figura 129 - Módulo de resina bisfenol e compósitos bisfenol/bucha 20\%, com diferentes tratamentos. Comparação da média usando o teste LSD de Fisher, com nível de significância de 0,05 .

Por outro lado, para compósitos com $30 \%$ de fibras de bucha os resultados mostrados na Figura 130 indicaram uma melhora sobre o módulo dos compósitos avaliados, em relação aos compósitos com fibras não tratada, com todos os tratamentos realizados.
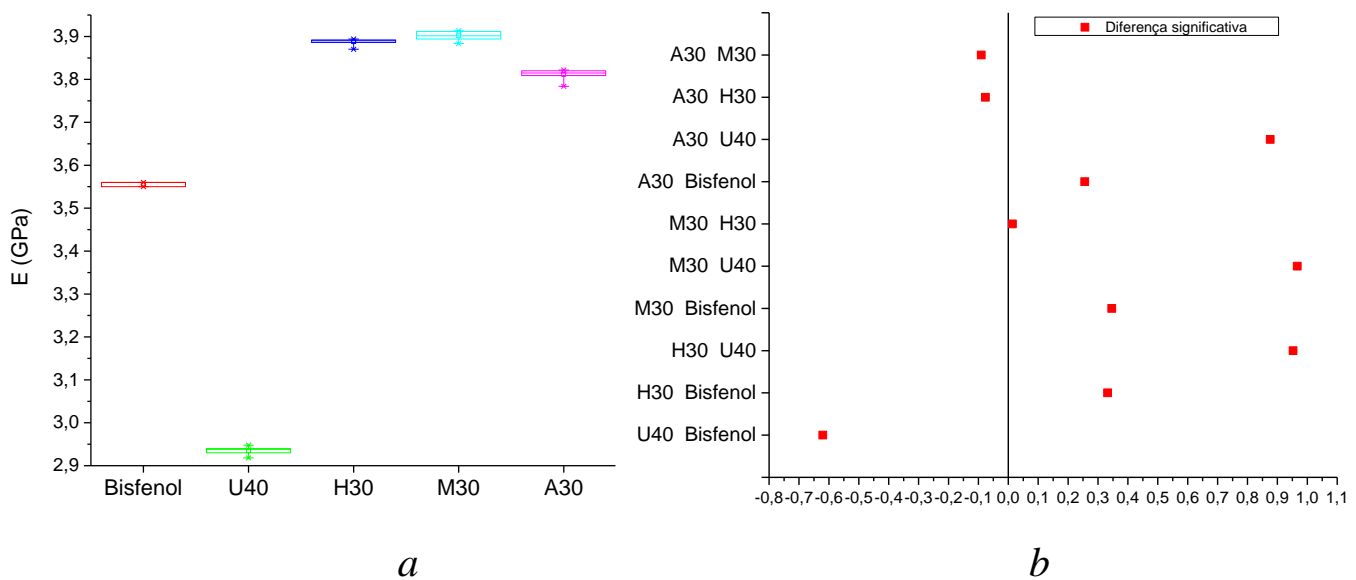

Figura 130 - (a) Módulo de resina bisfenol e compósitos bisfenol/Bucha 30\% com diferentes tratamentos. (b) Comparação da média usando o teste LSD de Fisher, com nível de significância de 0,05 .

Segundo os resultados do teste LSD de Fisher mostrados também na Figura 130, a diferença estadística entre os diferentes tipos de tratamento foi significativa para um nível de significância de 0,05. No entanto, a melhora das propriedades obtida nos compósitos com fibras tratadas por hornificação e mercerização foi muito próxima.

A figura 131 apresenta os resultados de módulo dinâmico para resinas com 30 e $50 \%$ de ESO e para os compósitos de matriz ESO30 e C50 com 30\% de fibras 
de bucha. Os compósitos ESO30-M30 demostraram ter um aumento de 27\% no módulo dinâmico frente aos compósitos ESO30-U30 o que, como foi analisado na seção 4.3.2, sugere uma melhora de adesão na interfase fibra-matriz.

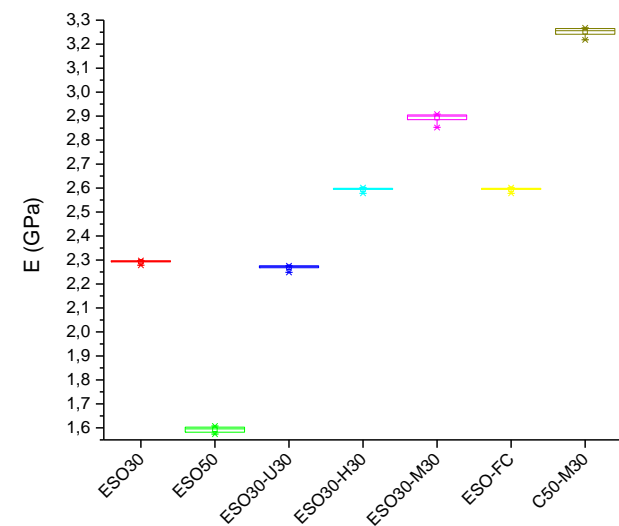

$a$

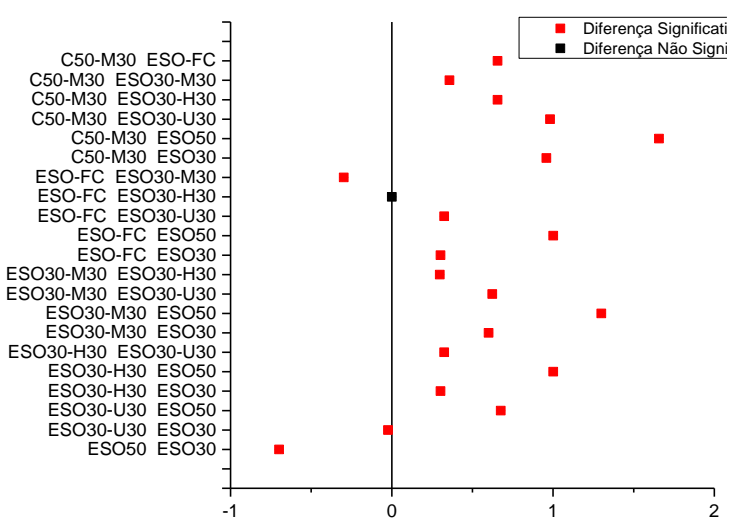

$b$

Figura 131 - (a) Módulo de resinas ESO30 e ESO50 e compósitos ESO/Bucha e C50/Bucha. (b) Comparação da média usando o teste LSD de Fisher, com nível de significância de 0,05 .

\subsubsection{Efeito do tempo de imersão em água sobre as propriedades mecânicas dos materiais.}

Por meio da técnica de excitação por impulso foi possível realizar medições do módulo elástico e do amortecimento dos corpos de prova, em diferentes intervalos de tempo durante o tempo em que as amostras ficaram imersas (81 dias em água destilada e 144 dias em água de mar). Para cada intervalo de tempo foram tomadas 10 medições dos parâmetros mecânicos e para cada tipo de material foi realizada uma réplica. O número de medições foi limitado pelo tempo que os corpos de prova podiam estar fora da água durante o ensaio de absorção [321]. Nas Figuras 132 a 135 são ilustrados os resultados do módulo de elasticidade obtidos para os compósitos de bisfenol/bucha. 


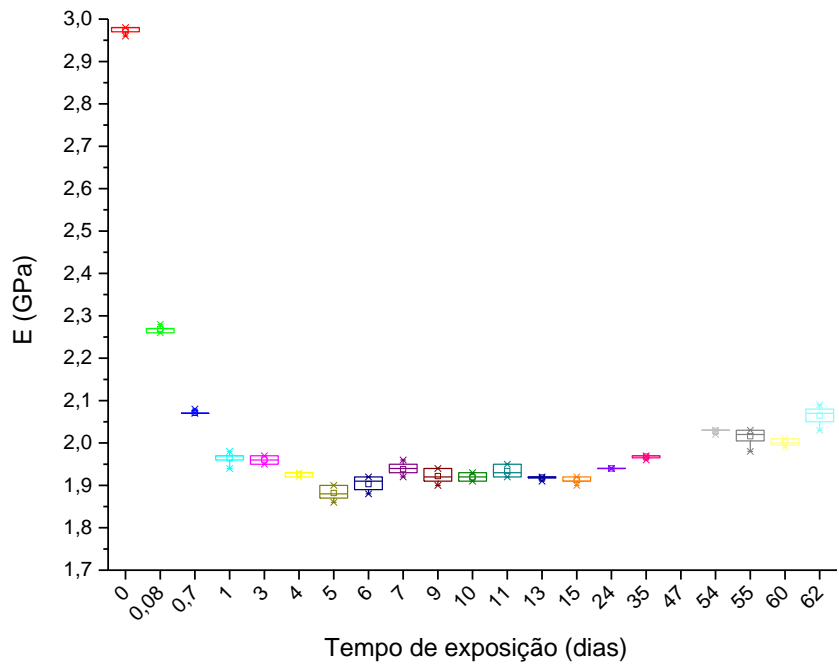

Figura 132 - Evolução do módulo de elasticidade em flexão com o tempo de imersão em água destilada, para compósitos com fibras de bucha sem tratamento.

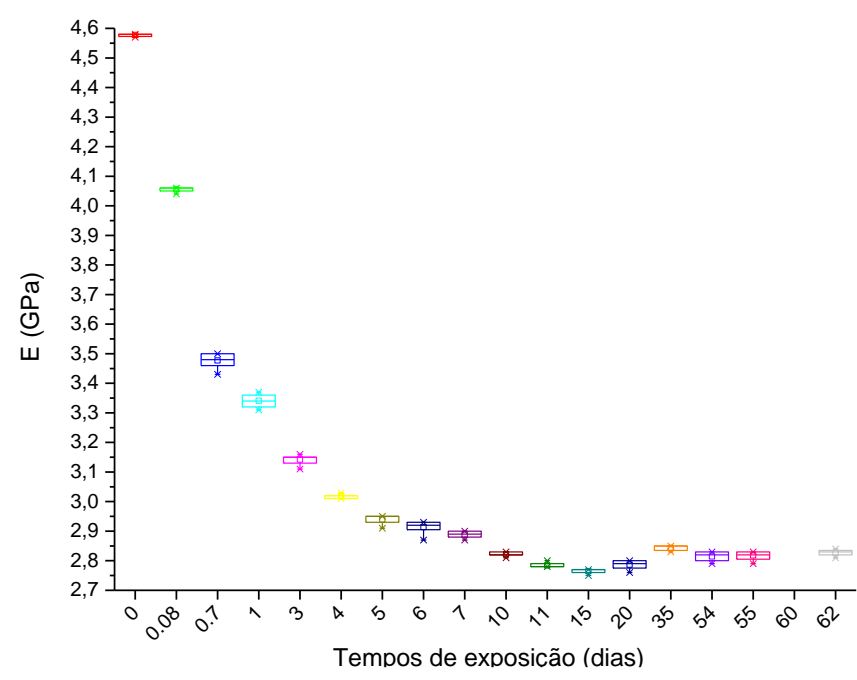

Figura 133 - Evolução do módulo de elasticidade em flexão com o tempo de imersão em água destilada, para compósitos com fibras de bucha mercerizadas.

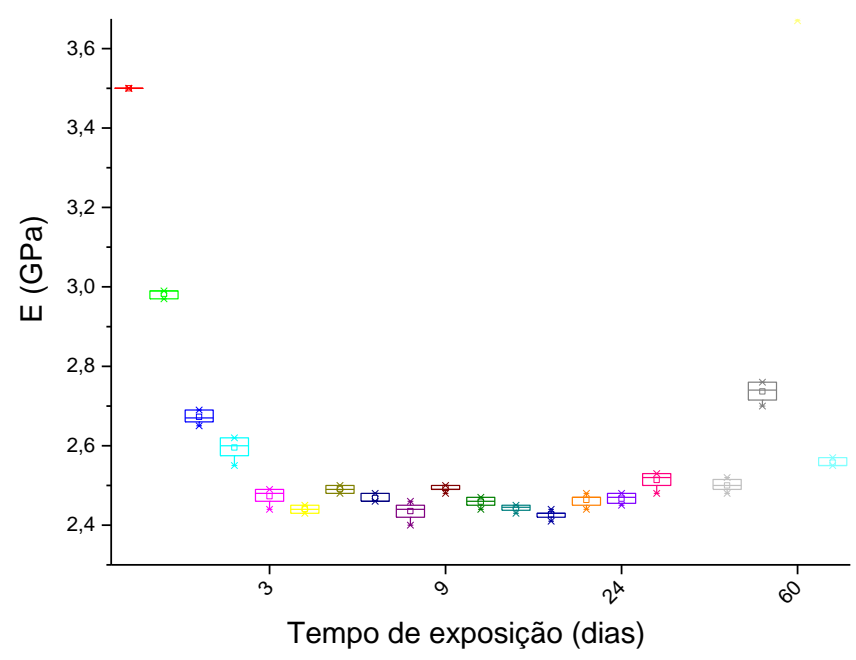

Figura 134 - Evolução do módulo de elasticidade em flexão com o tempo de imersão em água destilada, para compósitos com fibras de bucha hornificadas. 


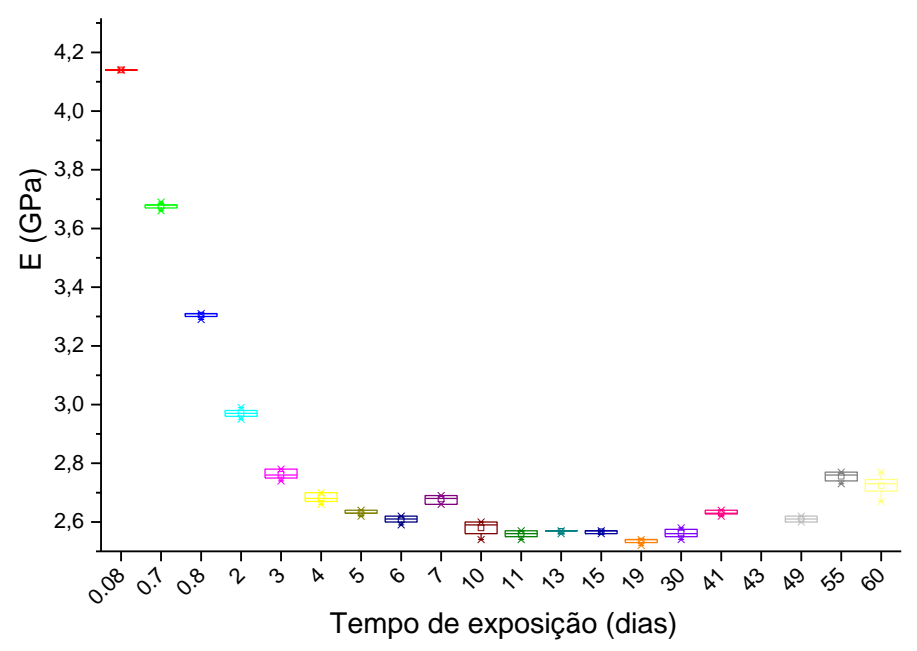

Figura 135 - Evolução do módulo de elasticidade em flexão com o tempo de imersão em água destilada, para compósitos com fibras de bucha acetiladas.

Nessas figuras é mostrada a variação no módulo de elasticidade durante o ensaio de absorção em água destilada, com uma tendência similar em todos os compósitos Independiente do tratamento das fibras. Observou-se que a imersão nas primeiras horas levou a uma perda de rigidez importante em todos os materiais testados. Os principais mecanismos que levam à degradação física e química de resinas epóxi foram previstos por outros autores [356], [361], [365], [366], [367]. Alguns dos mecanismos envolvidos dizem respeito à interface fibra-matriz que deve ser considerada como uma terceira fase e um canal para penetração de água. Então, moléculas de água reagindo quimicamente ou ficando presas na resina, na interface ou na superfície da fibra, podem aumentar a heterogeneidade do material e causar certos fenômenos que alterariam as propriedades mecânicas, irreversivelmente [352], [368].

No entanto, depois da queda nos valores para o módulo de elasticidade nas primeiras horas de imersão houve uma estabilização dos valores dos módulos registrados, o que poderia estar relacionado com a saturação do material. Na Figura 136 é apresentada a relação dos dados de ganho de massa e a perda de propriedades mecânicas com o tempo de imersão em água de mar para o corpo de prova correspondente a bisfenol/bucha acetilada. Esse efeito foi apresentado em todos os corpos de prova ensaiados tanto no ensaio em água destilada quanto em água de mar. 


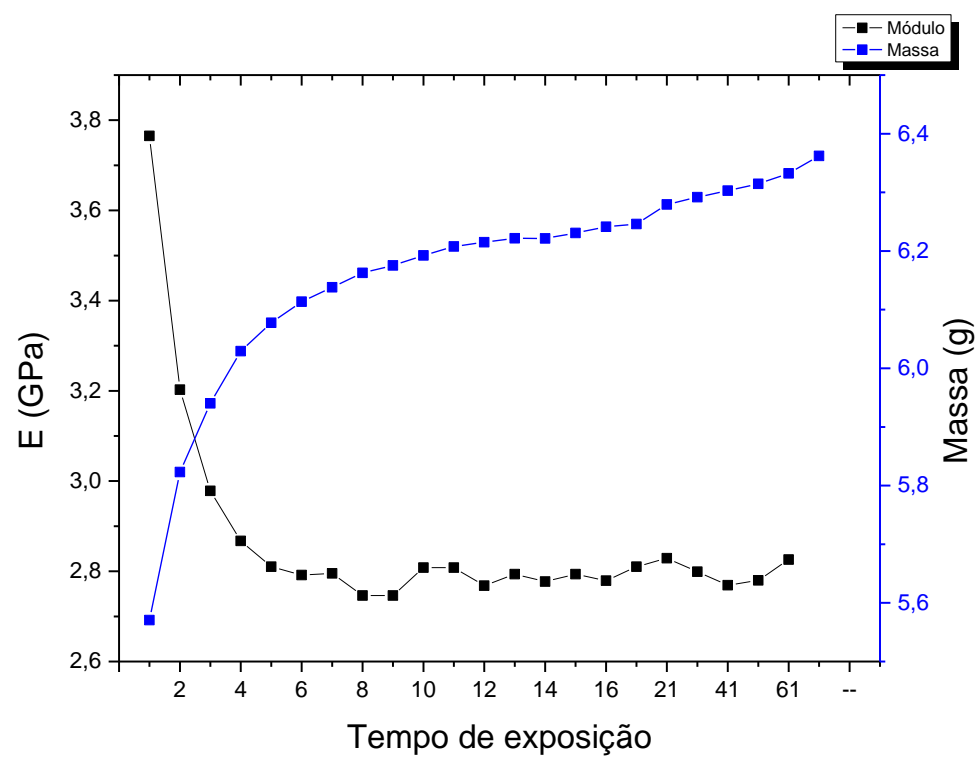

Figura 136 - Dados de módulo de elasticidade e massa dos corpos de prova de compósitos bisfenol/bucha acetilada (A20) em água de mar.

Os valores de módulo elástico médio registrados para vários tempos durante o ensaio de absorção em água de mar são apresentados na tabela 36 e na figura 137 são comparados os resultados do módulo elástico medidos pela técnica de excitação por impulso antes da imersão em água e depois de finalizado o ensaio de absorção em água de mar e secos os corpos de prova.

Tabela 36 - Variação média do módulo elástico em função do tempo de imersão em água de mar.

\begin{tabular}{|c|c|c|c|c|c|}
\hline & \multicolumn{5}{|c|}{ Tempo (h) } \\
\hline Material & 24 & 48 & 168 & 360 & 1488 \\
\hline U10 & $2,95 \pm 0,03$ & $2,04 \pm 0,08$ & $2,1 \pm 0,04$ & $2,12 \pm 0,03$ & $2,18 \pm 0,03$ \\
\hline U20 & $3,72 \pm 0,29$ & $2,78 \pm 0,16$ & $2,66 \pm 0,20$ & $2,65 \pm 0,15$ & $2,66 \pm 0,20$ \\
\hline U40 & $3,07 \pm 0,01$ & $2,12 \pm 0,04$ & $2,07 \pm 0,03$ & $2,13 \pm 0,01$ & $2,11 \pm 0,07$ \\
\hline M20 & $3,98 \pm 0,01$ & $2,65 \pm 0,01$ & $2,66 \pm 0,01$ & $2,63 \pm 0,01$ & $2,61 \pm 0,01$ \\
\hline M30 & $4,23 \pm 0,09$ & $3,62 \pm 0,33$ & $3,37 \pm 0,18$ & $3,25 \pm 0,18$ & $3,1 \pm 0,13$ \\
\hline H20 & $3,75 \pm 0,02$ & $2,71 \pm 0,02$ & $2,62 \pm 0,01$ & $2,61 \pm 0,01$ & $2,59 \pm 0,02$ \\
\hline H30 & $4,09 \pm 0,23$ & $3,29 \pm 0,27$ & $3,12 \pm 0,27$ & $3,01 \pm 0,21$ & $3,01 \pm 0,16$ \\
\hline A20 & $3,55 \pm 0,27$ & $2,72 \pm 0,17$ & $2,59 \pm 0,18$ & $2,55 \pm 0,11$ & $2,51 \pm 0,12$ \\
\hline A30 & $3,57 \pm 0,27$ & $2,83 \pm 0,21$ & $2,56 \pm 0,33$ & $2,58 \pm 0,29$ & $2,56 \pm 0,30$ \\
\hline FC & $3,61 \pm 0,13$ & $3,17 \pm 0,16$ & $2,99 \pm 0,18$ & $2,85 \pm 0,20$ & $2,75 \pm 0,17$ \\
\hline B & $3,8 \pm 0,01$ & $3,67 \pm 0,01$ & $3,69 \pm 0,01$ & $3,69 \pm 0,01$ & $3,66 \pm 0,01$ \\
\hline
\end{tabular}




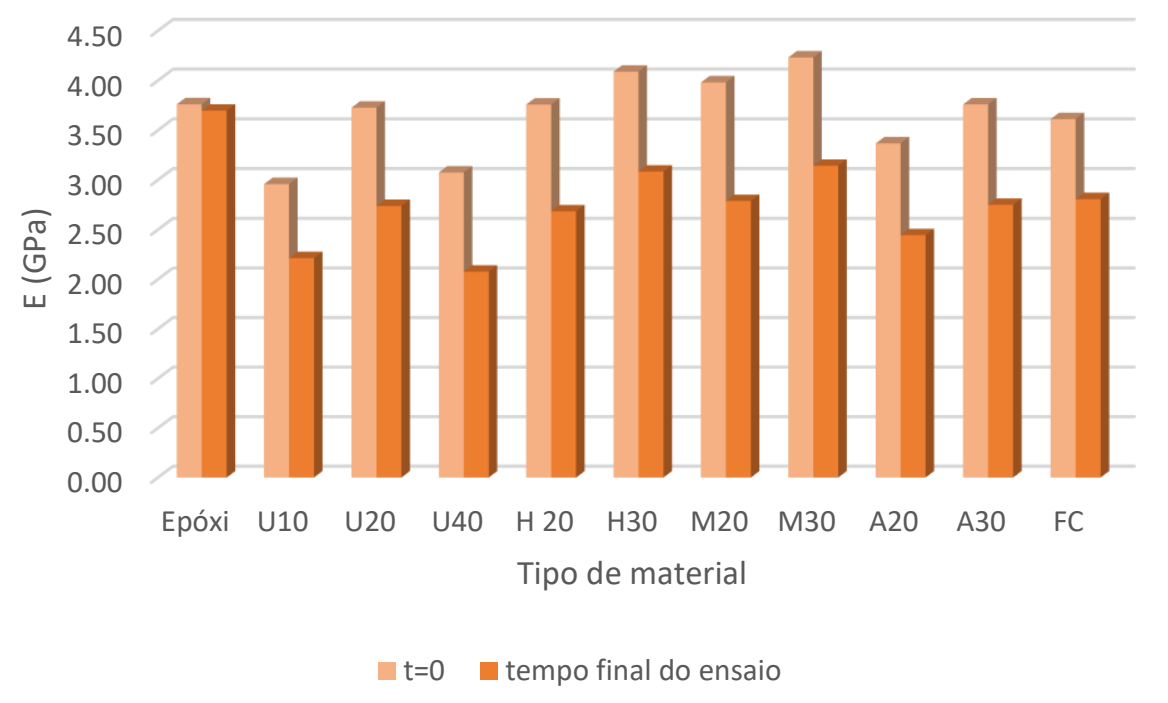

Figura 137 -Variação do módulo elástico dos materiais com a absorção em água de mar.

O módulo da resina pura foi apenas levemente afetado pela imersão em água de mar durante 144 dias. Os compósitos com fibras curtas apresentaram uma queda no valor do módulo por volta de $22 \%$. Em quanto que, como também pode observarse na Tabela 37, houve uma diminuição nos valores do módulo dos compósitos fabricados com fibra de bucha em forma de manta entre 25 e $32 \%$. Dessa forma, foi possível obter a variação das propriedades mecânicas de cada espécime em função do tempo de imersão.

Tabela 37 - Variação do módulo elástico dos materiais com a absorção em água de mar.

\begin{tabular}{|c|c|c|c|c|c|}
\hline & $\begin{array}{c}\text { Módulo } \\
\text { Inicial } \\
(\mathrm{GPa}) \\
\mathrm{t}=0\end{array}$ & $\begin{array}{c}\text { Desvio } \\
\text { padrão }\end{array}$ & $\begin{array}{c}\text { Módulo } \\
\text { Final } \\
(\mathrm{GPa}) \\
\mathrm{t}=144 \text { dias }\end{array}$ & $\begin{array}{c}\text { Desvio } \\
\text { padrão }\end{array}$ & $\Delta \mathrm{E}(\%)$ \\
\hline Epóxi & 3,76 & 0,028 & 3,70 & 0,028 & 1,70 \\
\hline U10 & 2,96 & 0,006 & 2,21 & 0,024 & 25,18 \\
\hline U20 & 3,73 & 0,002 & 2,74 & 0,061 & 26,53 \\
\hline U40 & 3,07 & 0,003 & 2,08 & 0,026 & 32,43 \\
\hline H 20 & 3,76 & 0,004 & 2,68 & 0,012 & 28,59 \\
\hline H30 & 4,09 & 0,005 & 3,08 & 0,011 & 24,57 \\
\hline M20 & 3,98 & 0,002 & 2,79 & 0,023 & 29,97 \\
\hline M30 & 4,23 & 0,006 & 3,14 & 0,039 & 25,74 \\
\hline A20 & 3,37 & 0,006 & 2,44 & 0,040 & 27,40 \\
\hline A30 & 3,76 & 0,004 & 2,75 & 0,012 & 26,85 \\
\hline FC & 3,61 & 0,004 & 2,81 & 0,007 & 22,27 \\
\hline
\end{tabular}


Durante a imersão em água, observou-se um aumento no fator de amortecimento dos compósitos analisados como mostrado nas Figuras 138 a 141. Os dados também mostraram uma tendência similar, com um aumento de amortecimento nos primeiros dias e a estabilização dos valores quando atingida a saturação.

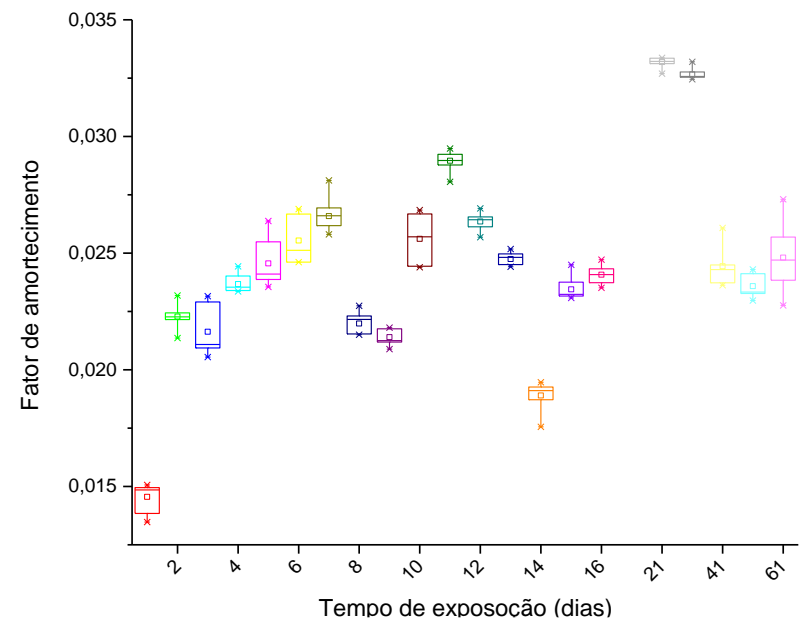

Figura 138 - Evolução do fator de amortecimento com o tempo de imersão em água destilada, para compósitos com fibras de bucha sem tratamento.

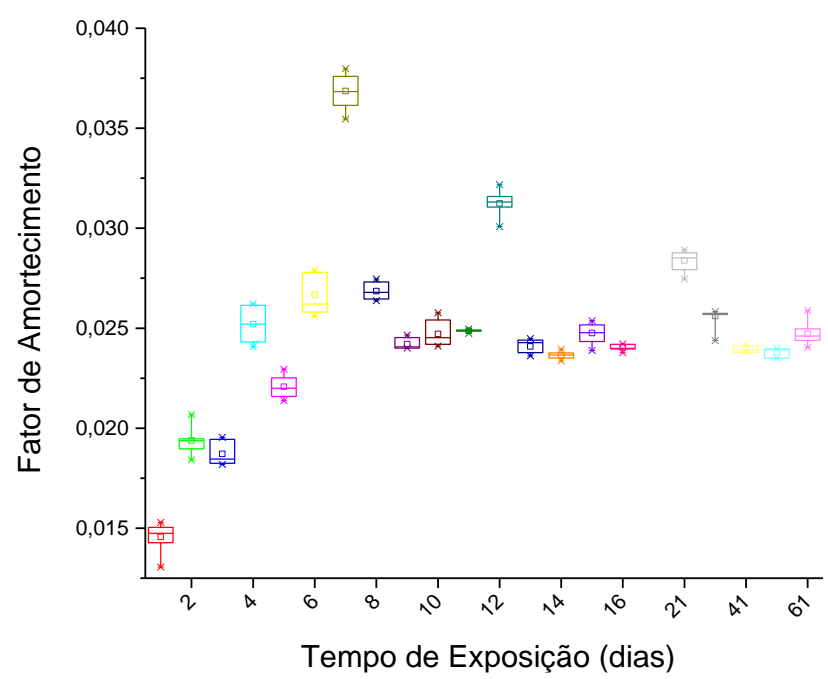

Figura 139 - Evolução do fator de amortecimento com o tempo de imersão em água destilada, para compósitos com fibras de bucha mercerizada. 


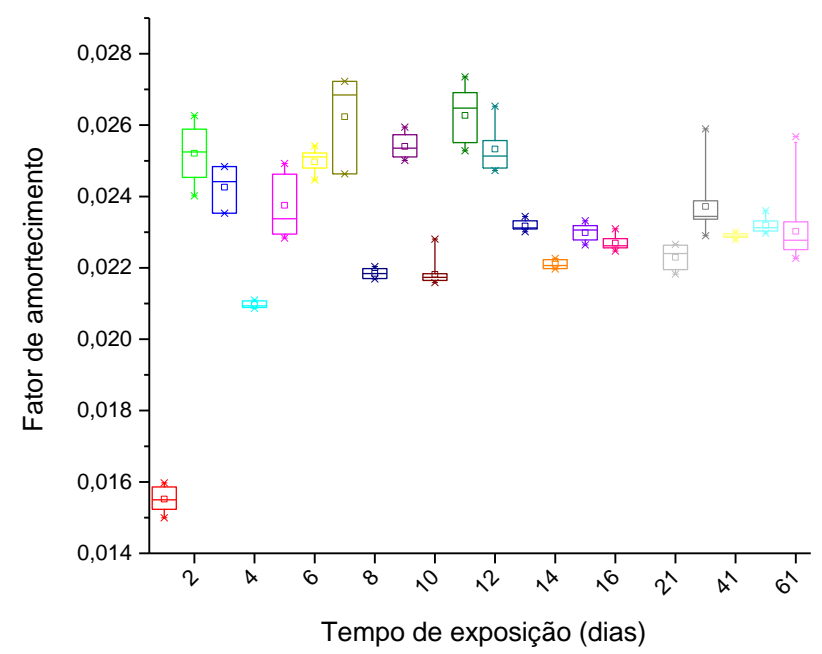

Figura 140 - Evolução do fator de amortecimento com o tempo de imersão em água destilada, para compósitos com fibras de bucha hornificada.

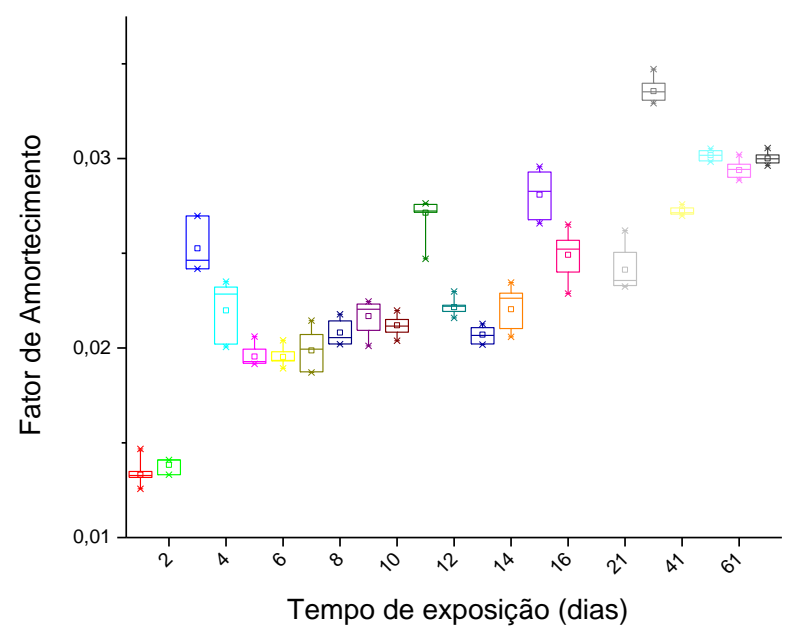

Figura 141 - Evolução do fator de amortecimento com o tempo de imersão em água destilada, para compósitos com fibras de bucha acetilada.

O fator de amortecimento para cada material ao final do ensaio de absorção em água de mar é mostrado na Figura 142. Observa-se que os compósitos com fibras tratadas apresentaram valores de amortecimento menores comparados com os compósitos com fibra sem tratar. 


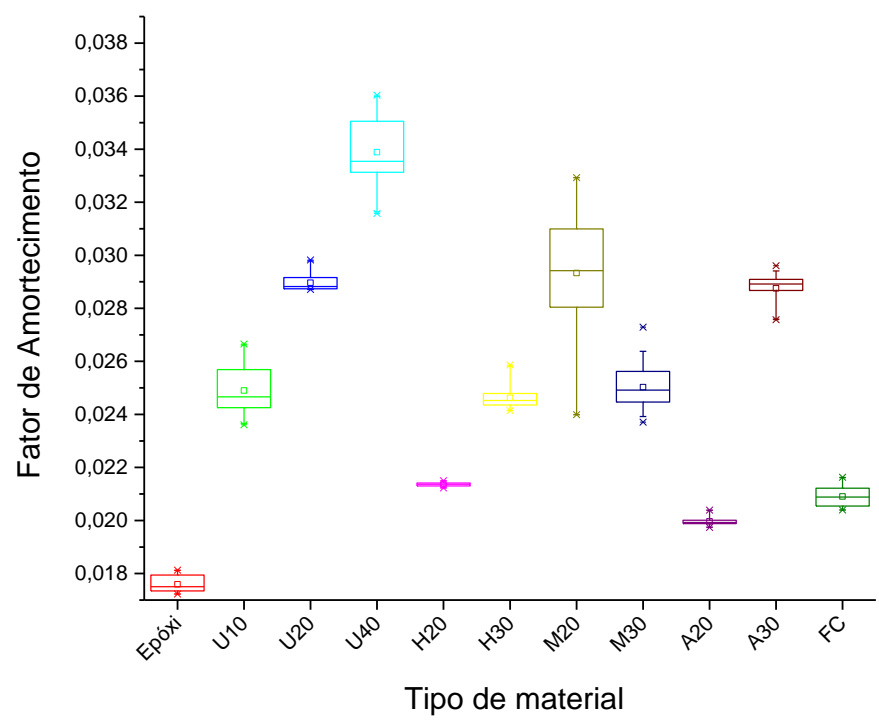

Figura 142 - Valores de amortecimento para materiais depois do ensaio de absorção em água de mar.

Assim mesmo, observou-se que para os compósitos com $20 \%$ de peso em fibras foi obtido um valor de amortecimento menor em todos os casos, sendo que para o compósito com fibras curtas foi apresentado também um valor baixo. Compósitos reforçados com $40 \%$ de peso em fibras de bucha sem modificação apresentaram o maior valor de amortecimento.

Na Figura 143 são comparados os resultados do amortecimento dos materiais antes do início do ensaio de absorção em água de mar e ao final do ensaio.

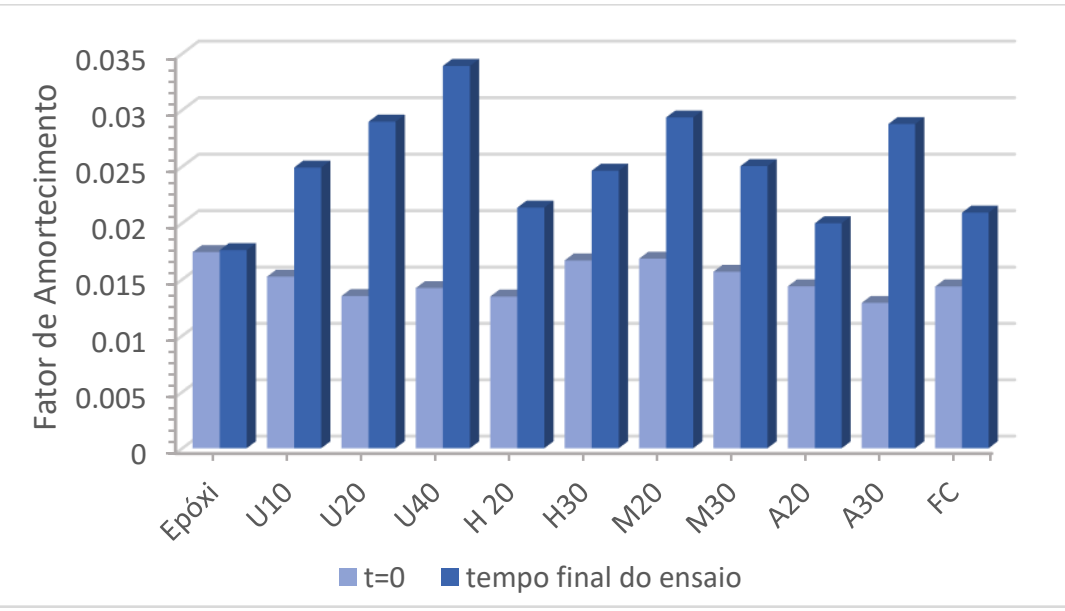

Figura 143 - Variação do amortecimento dos materiais com a absorção em água de mar.

Observou-se que antes de realizar o ensaio a resina pura apresentou valores de amortecimento maior ao ser comparada com os compósitos. No entanto, o aumento nos valores de amortecimento na resina pura durante o ensaio foi 
praticamente nulo. Por outro lado, os materiais compósitos tiveram um aumento considerável no valor do amortecimento depois da absorção de água. $\mathrm{O}$ valor de amortecimento teve a tendência de aumentar com o teor de fibra no compósito, exceto para o compósito com fibras mercerizadas, uma vez que se obteve com ele uma diminuição no valor de amortecimento. Notou-se que para o compósito com $40 \%$ de fibras foi obtido o maior valor de amortecimento no final da absorção. Igualmente para os compósitos com 30\% de fibras acetiladas se encontrou um aumento de $58 \%$ no valor de amortecimento. Isso pode ser indicativo do que aconteceria na interface fibra/matriz. Uma boa interação das fibras com a matriz, com maior adesão e menos vazios entre a fibra e a resina, levaria a ter uma menor variação do fator de amortecimento ao final do ensaio de absorção de água. Enquanto uma interface com fraca adesão das fibras e vazios que podem ser preenchidos com água causando o inchamento das fibras levaria aumentos no fator de amortecimento medido nos compósitos. Da mesmo forma um aumento na quantidade de fibras com fraca adesão contribuiria com esse aumento.

\subsubsection{Análise da superfície de fratura}

- Superfície de fratura de resinas sem reforço

Nas Figuras 144 a 146 são apresentadas as micrografias por MEV da superfície de fratura das resinas B, R e ESO30. Micrografias por MEV da superfície de fratura da resina epóxi bisfenol na figura 144a mostra as marcas características da fratura de um polímero frágil [369]. Podem ser vistos inúmeros pontos de iniciação de trincas secundarias (indicados com setas azuis). A região mostrada representa a região denominada de propagação final de fratura, indicando que as regiões de iniciação global da fratura e de transição foram pequenas (A região analisada está próxima à borda). Esses aspectos indicam a falta de ductilidade, o que confere com a curva tensão deformação desse polímero (Figura 122). A borda entre os diversos planos de fratura ocorre preferencialmente em degraus bruscos, o que também indica pouca capacidade de deformação [370]. 


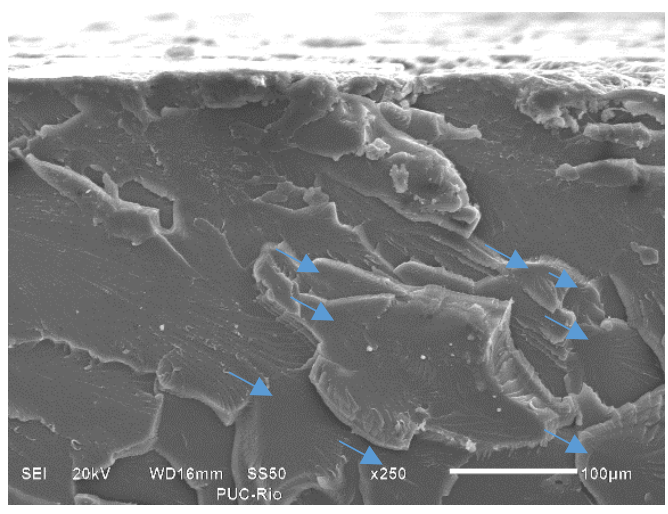

(a)

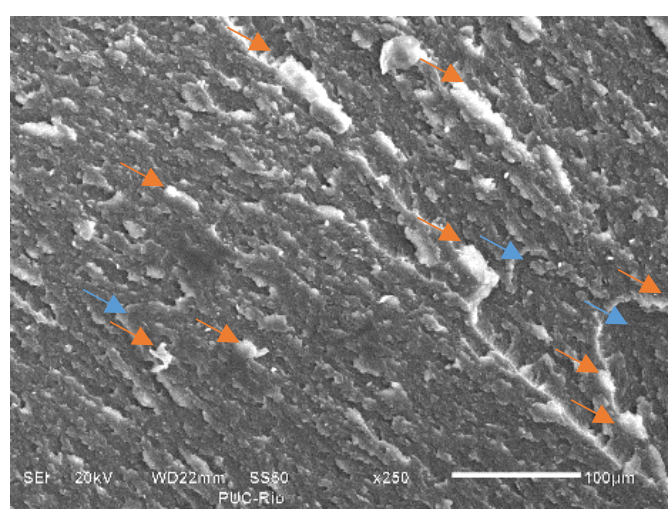

(b)

Figura 144 - Detalhe da superfície de fratura de resina (a) Bisfenol. 250x. (b) ESO30. 250x.

Na Figura $144 b$ é possível ver a diferença de comportamento da resina ESO30, onde há formação de inúmeras estrias (setas laranja) e as bordas das facetas apresentam-se rugosas.

Embora mantenha ainda o aspecto geral de fratura frágil, a fratura da resina resorcinol (Figura 145), mostra a formação de estrias (setas laranja) e uma transição mais suave entre os planos de fratura (indicados por setas brancas). Isso indica maior capacidade de deformação [370].

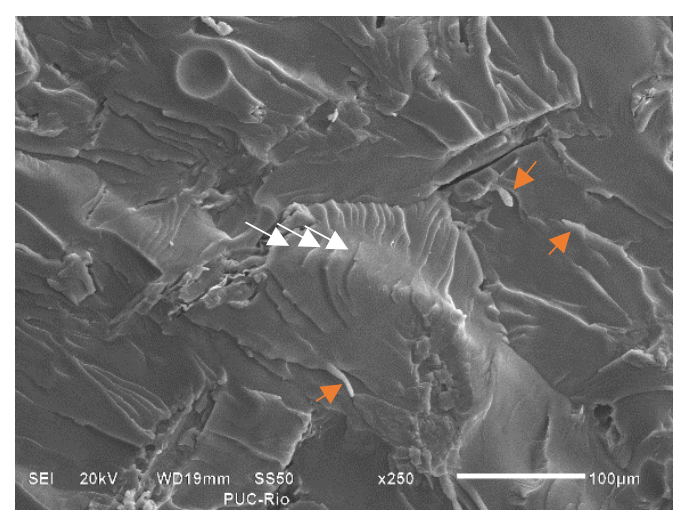

Figura 145 - Detalhe da superfície de fratura de resina de resorcinol. 250x.

A diferença da capacidade de deformação entre as matrizes B e ESO30 pode ser avaliada ainda observando a região do final de fratura, Figura 146. Nessa Figura se observam aspectos fractográficos semelhantes a "marcas de rio". A quantidade dessas marcas foi associado ao fator de intensidade de tensões $\left(K_{I C}\right)$ em resinas poliéster [371]. O número de marcas de rio maior e com bordas menos definidas indica maior capacidade de deformação. 

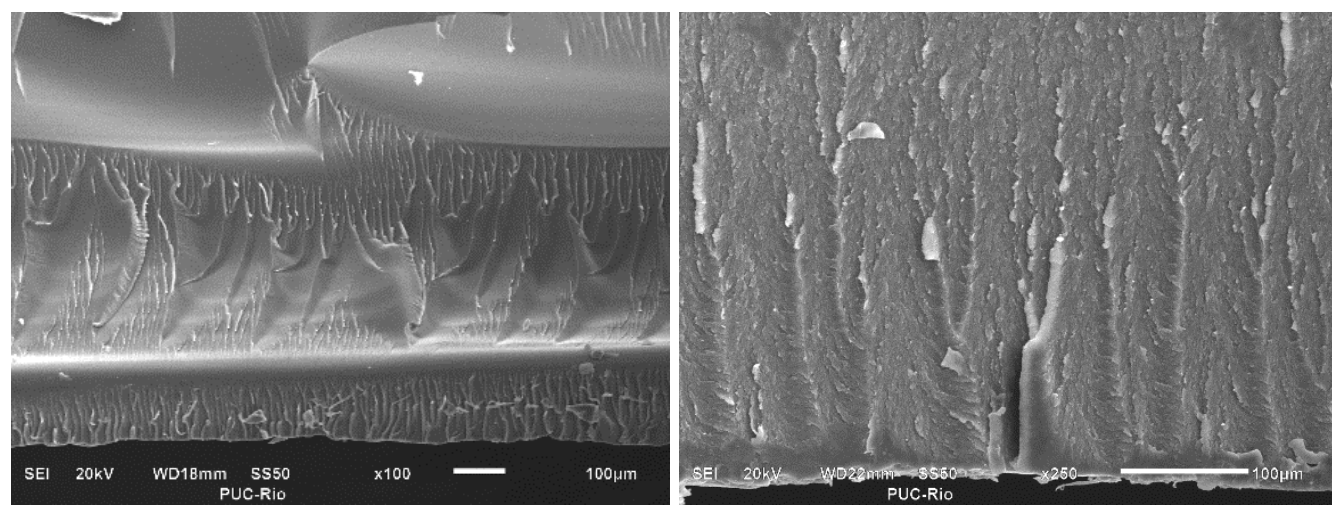

Figura 146 - Detalhe da superfície de fratura de resina (a) bisfenol 100x. (b) ESO30 250x.

Pode se observar que a matriz ESO 30 tem maior número de estrias contínuas e com bordas menos abruptas, e não foi observada uma região com superfície lisa como na resina bisfenol.

- Superfície de fratura de compósitos epóxi/bucha

Por outro lado, os compósitos submetidos ao ensaio de flexão, ao contrário das resinas que apresentaram uma falha frágil e abrupta, não foram quebrados pela força aplicada durante o ensaio. Assim, para a observação da superfície por MEV foi necessário quebrar os corpos de prova manualmente depois de realizar o ensaio. O comportamento observado é devido ao fato de que as fibras de bucha causam o desvio das trincas na matriz, causando um comportamento com fratura controlada e, assim, impedem a ruptura abrupta do material. Esse aspecto por si só é uma característica positiva da inclusão das fibras de bucha nessas matrizes poliméricas. A análise da superfície da fratura dos compósitos revelou a influência que os tratamentos realizados nas fibras tiveram sobre a interface fibra/matriz.

\section{- Compósitos bisfenol/bucha sem tratamento}

Como pode ser visto nas Figuras 147 e 148, correspondentes à superfície dos compósitos fabricados com resina bisfenol e 10 e $20 \%$ de fibras de bucha sem tratamento respectivamente, uma grande proporção das fibras expostas na superfície de fratura apresentou espaços na interface fibra/matriz (indicados com setas laranja). Também houve fibras arrancadas que deixaram vazios (indicados 
com setas azuis) e marcas de impressão (ressaltadas com círculos). Essas características observadas evidenciaram a fraca adesão das fibras de bucha sem tratamento com a matriz epóxi de bisfenol.

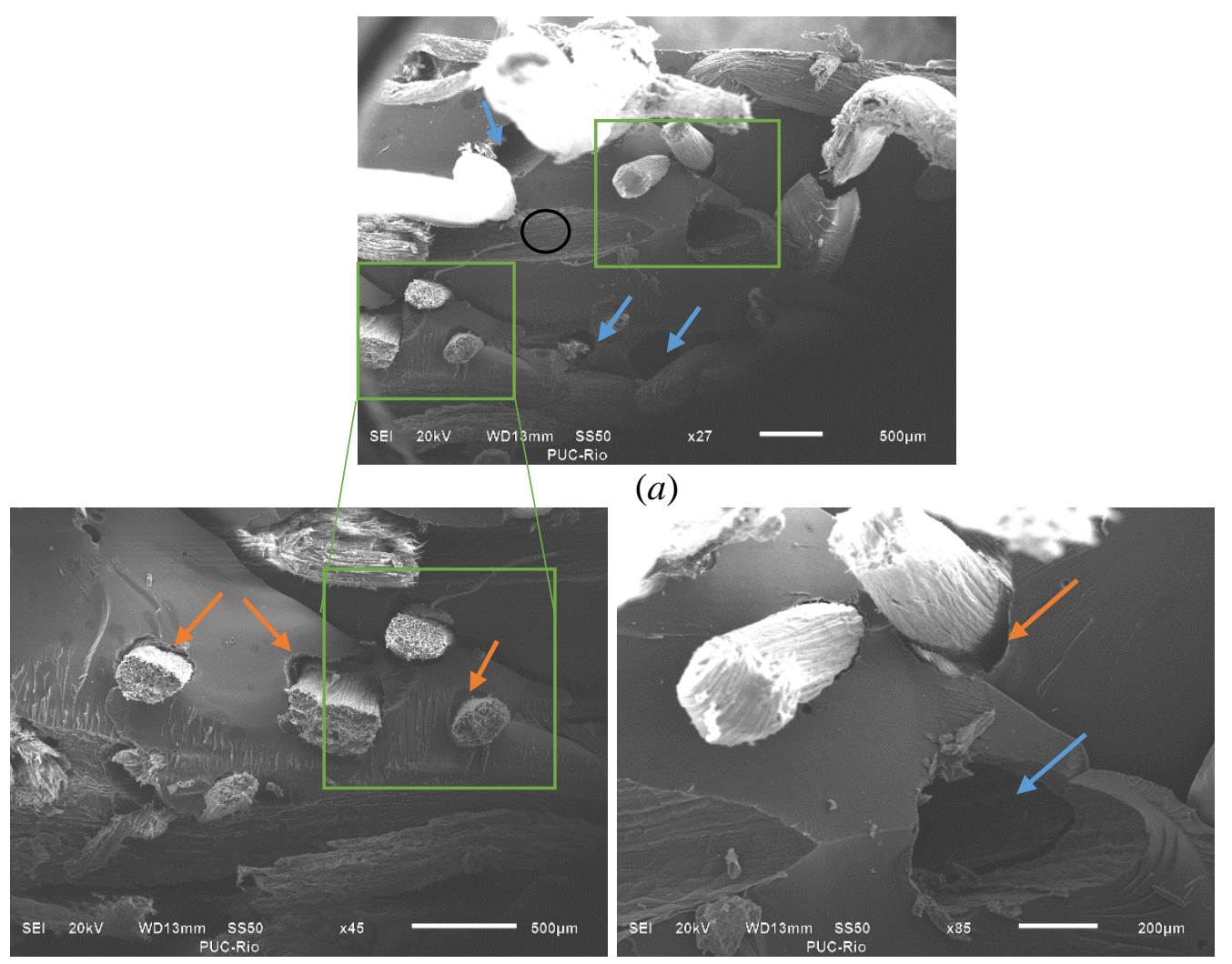

(b)

(c)

Figura 147 - (a) Detalhe da interface fibra/resina na superfície de fratura de compósitos bisfenol com 10\% de fibras de bucha sem tratamento (U10). 27x. (b) Detalhe a 45x. (c) Detalhe a $85 x$.

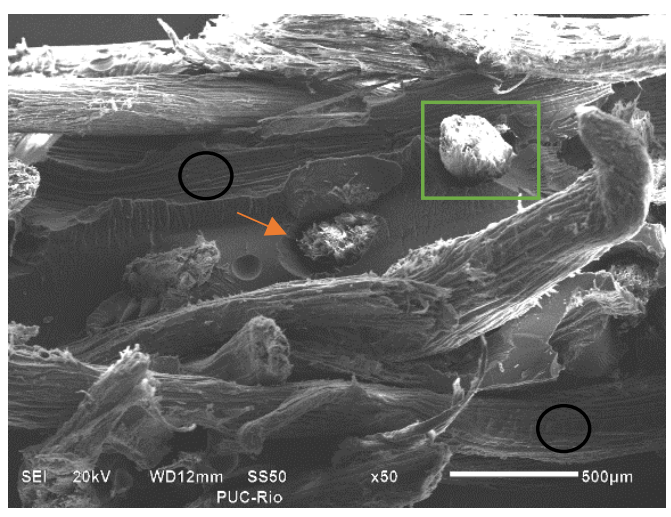

(a)

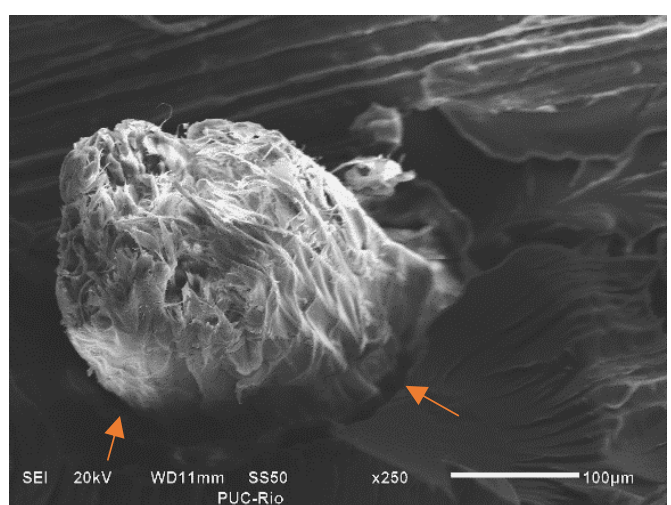

(b)

Figura 148 - (a) Superfície de fratura de compósito bisfenol com 20\% de bucha sem tratamento (U20). 50x. (b) Detalhe a 250x. 
A Figura 149 apresenta a superfície de fratura do compósito de bisfenol com $40 \%$ de fibras de bucha e como mostrado na micrografia, também existe uma grande quantidade de fibras descoladas da matriz, que indica uma fraca adesão na interface fibra/matriz.

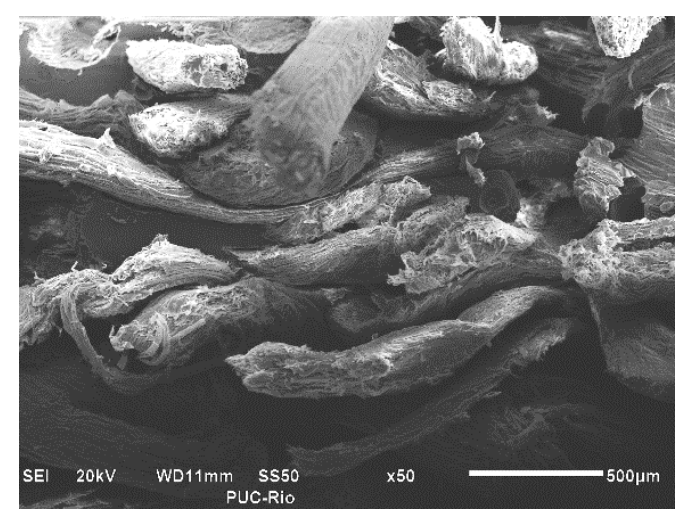

Figura 149 - Superfície de fratura de compósito bisfenol com $40 \%$ de bucha sem tratamento (U40), 50x.

\section{- Compósitos bisfenol/bucha mercerizada}

Na Figura 150 é mostrada a superfície de fratura dos compósitos com fibras tratadas por mercerização, onde se observou a interfase fibra/matriz. Não é possível apreciar uma melhora na adesão das fibras pelo aumento na área superficial da fibra pelo tratamento. Assim o tratamento de mercerização aparentemente não contribuiu com o melhor ancoramento mecânico das fibras com a matriz.

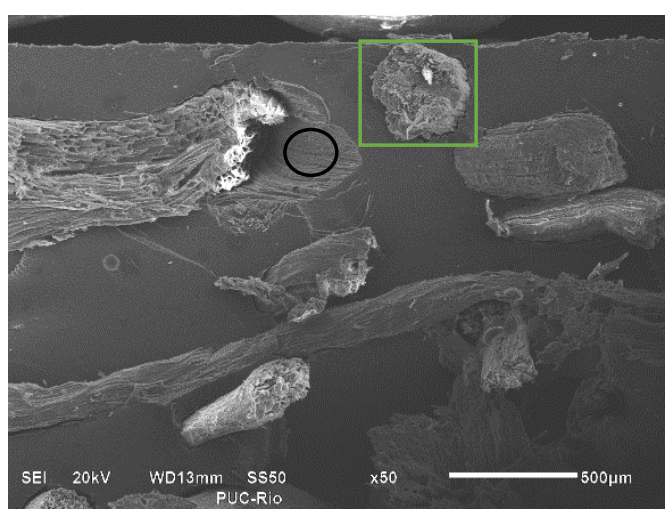

(a)

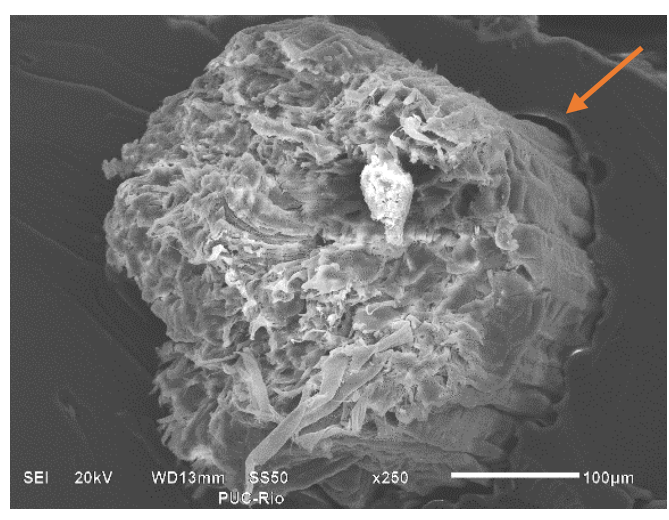

(b)

Figura 150 - (a) Superfície de fratura de compósito bisfenol com $20 \%$ de bucha mercerizada (M20). 50x. (b) Detalhe a 250x. 


\section{- Compósitos bisfenol/bucha hornificada}

A Figura 151 mostra a superfície de fratura para o compósito com fibras de bucha hornificadas. Nela pode-se ver a presença de trincas devido à fratura frágil da matriz epóxi de bisfenol. Foi notado que, ainda com um menor número de fibras arrancadas, a interface fibra/matriz não mostrou uma melhora significativa na adesão, em comparação com o observado na Figura 139 para a superfície de fratura do compósito com $20 \%$ de fibras de bucha sem tratar.

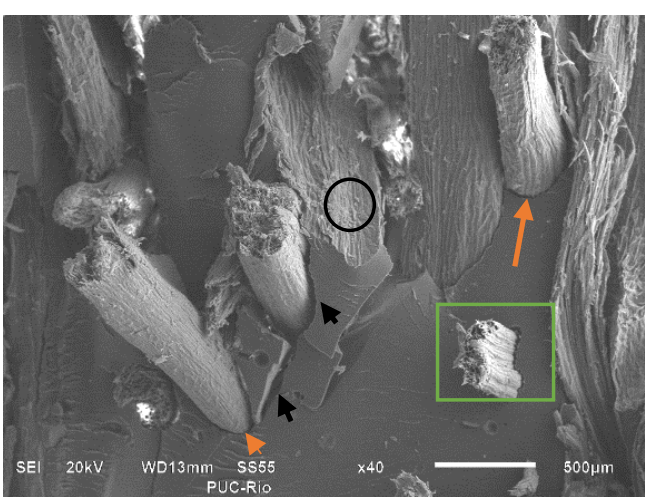

(a)

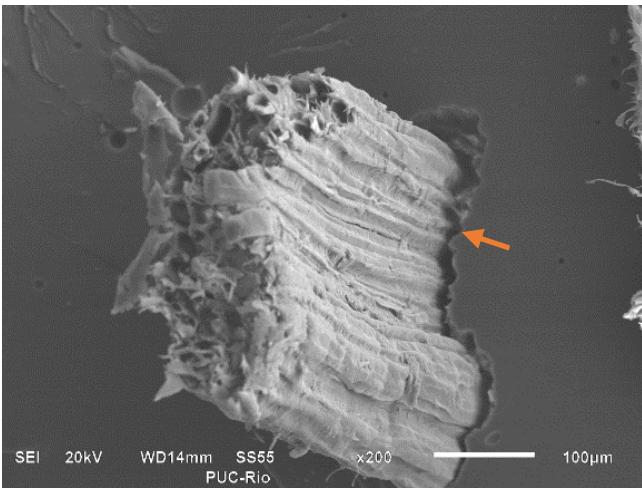

(b)

Figura 151 - (a) Superfície de fratura de compósito bisfenol com $20 \%$ de bucha hornificada (H20). 40x. (b) Detalhe a 200x.

\section{- Compósitos bisfenol/bucha acetilada}

Na Figura 152 é apresentada a superfície de fratura do compósito com fibras acetiladas. Pode-se observar que a adesão entre as fibras e a matriz foi melhorada e que ocorreu uma grande quantidade de fratura das fibras na superfície. Isto possivelmente foi causado pela maior exposição da celulose que poderia ter causado uma maior interligação fibra-matriz [234], melhorando a transferência de carga.

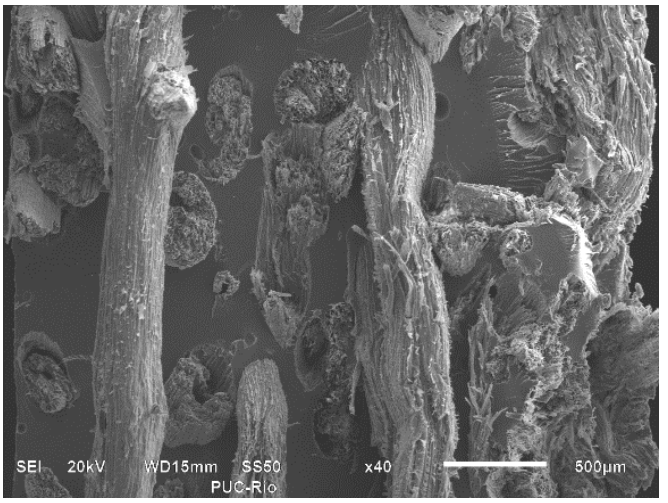

(a)

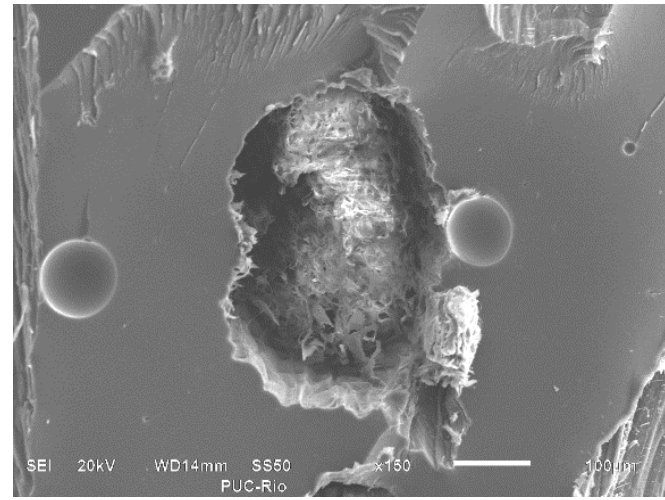

(b)

Figura 152 - (a) Superfície de fratura de compósito bisfenol com 30\% de bucha acetilada (A20). 40x. (b) Detalhe a 150x. 


\section{- Compósitos C50/bucha mercerizada}

A superfície de fratura do compósito cardanol-resorcinol com fibras de bucha tratadas por mercerização é apresentada na Figura 153. Pode se observar que as fibras foram totalmente molhadas pela resina e esse compósito teve uma interface caracterizada pela forte adesão das fibras e a matriz, sem a presença de vazios na interface nem a ocorrência de fibras puxadas para fora ou arrancadas.

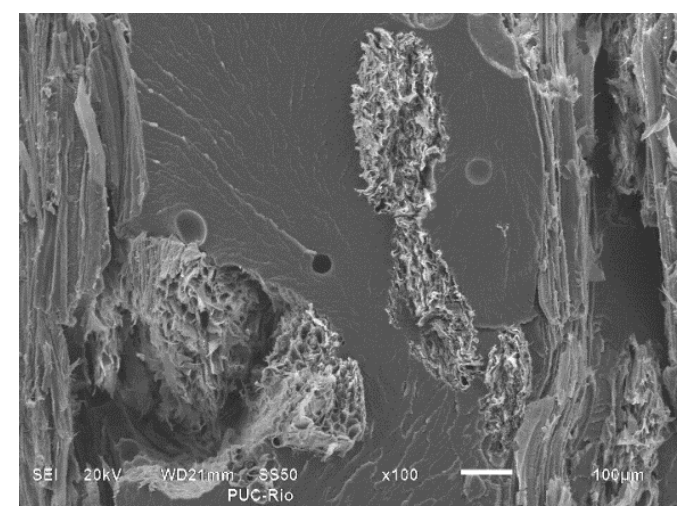

$a$

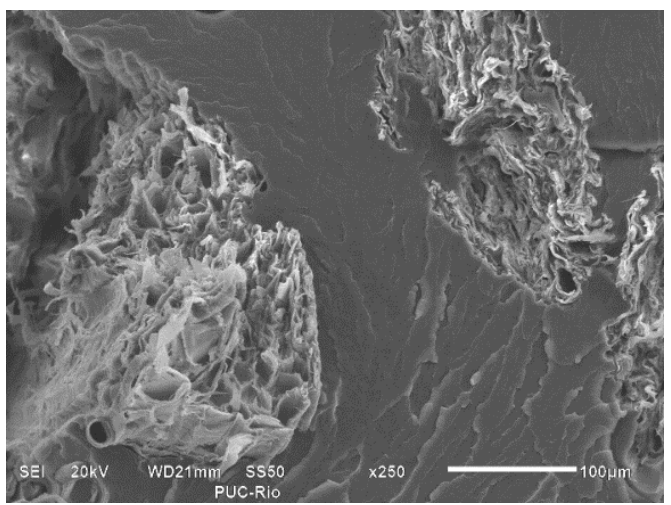

$b$

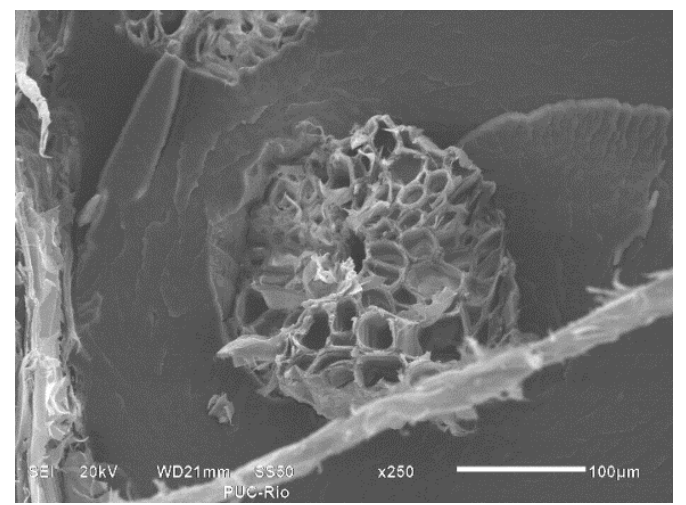

$c$

Figura 153 - Superfície de fratura de compósito cardanol-resorcinol com 30\% de fibras de bucha mercerizadas. (a) 100x. (b) (c) 250x.

Essa análise indicou que a combinação de fibras de bucha mercerizadas e resina cardanol-resorcinol aparentemente mostra uma grande perspectiva de uso.

\subsubsection{Analise Dinâmico-Mecânica (DMA)}

Por meio dessa análise, notou-se que as propriedades dinâmico-mecânicas dos materiais compósitos foram influenciadas pelo teor de fibras de bucha, pelos tratamentos das fibras e pelo tipo de matriz utilizada. 
A Figura 154 mostra os resultados da análise dinâmico-mecânica (DMA) realizada em compósitos com matriz epóxi bisfenol, ESO-bisfenol e cardanolresorcinol com $30 \%$ de fibras de bucha mercerizadas. Foi observado que à temperatura ambiente os compósitos M30 e C50-M30 apresentaram módulos de armazenamento maiores, em relação ao material com matriz ESO-Bisfenol, o que indica que este último material possui uma menor rigidez. Enquanto que, a partir de temperaturas próximas a $100{ }^{\circ} \mathrm{C}$, o compósito com matriz de cardanol-resorcinol apresentou os melhores valores de E' comparado com os outros compósitos. Na tabela 38 são apresentados os valores para o módulo de armazenamento de tais compósitos em diferentes temperaturas.

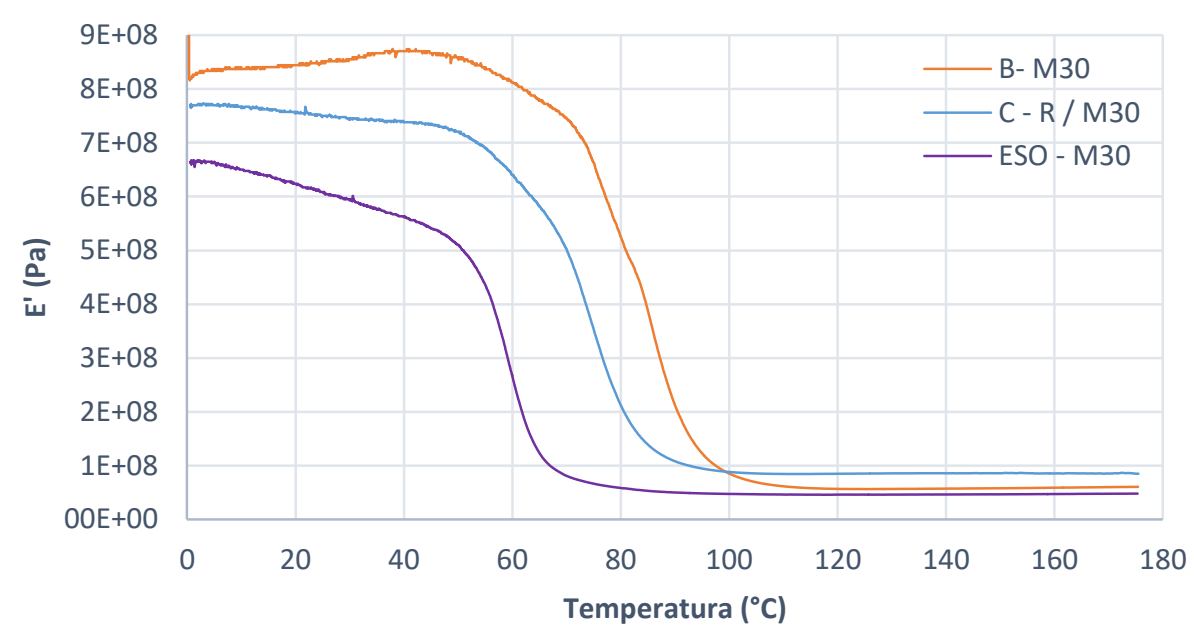

Figura 154 - Módulo de armazenamento de compósitos com 30\% de fibras de bucha mercerizada.

Tabela 38 - Módulo de Armazenamento (MPa) para compósitos com 30\% de fibras de bucha mercerizada e, matriz bisfenol, cardanol resorcinol e ESO-bisfenol.

\begin{tabular}{|c|c|c|c|c|}
\hline \multirow{2}{*}{ Material } & \multicolumn{3}{|c|}{ Temperatura $\left({ }^{\circ} \mathbf{C}\right)$} \\
\cline { 3 - 5 } & & $\mathbf{3 0}$ & $\mathbf{7 0}$ & $\mathbf{1 5 0}$ \\
\hline 5 & M30 & 855,4 & 746,7 & 57,7 \\
\hline 13 & ESO30-M30 & 593,2 & 80,9 & 46,5 \\
\hline 16 & C50-M30 & 743,2 & 502,2 & 85,7 \\
\hline
\end{tabular}

Dos resultados na tabela 38 , apreende-se que a $30^{\circ} \mathrm{C}$ o compósito com matriz de resina C50-M30 apresenta uma maior rigidez que o compósito com ESObisfenol, embora ambos compósitos fabricados com as resinas sintetizadas a partir de óleos vegetais apresentem menor rigidez em comparação com compósitos de 
matriz de resina bisfenol convencional. Por outro lado, a altas temperaturas a resina de cardanol-resorcinol apresenta o maior valor de E'.

Na Figura 155, mostra-se uma comparação entre as curvas de variação do módulo de armazenamento (E') com a temperatura, para a resina de bisfenol e compósitos com porcentagens de 10, 20 e 40\% de fibra de bucha sem tratamento. $\mathrm{Na}$ Figura pode-se observar que, exceto para o compósito com $10 \%$ de fibras de bucha, o valor de $E$ ' a temperatura ambiente é maior nos compósitos, se comparado com o valor observado para a resina sem adição de fibras. Isso aconteceu inclusive no caso do compósito reforçado com fibras de bucha moídas. No entanto, em temperaturas acima de aproximadamente $70^{\circ} \mathrm{C}$, o compósito com $10 \%$ de fibras de bucha também apresentou valores de $E$ ' maiores que a resina.

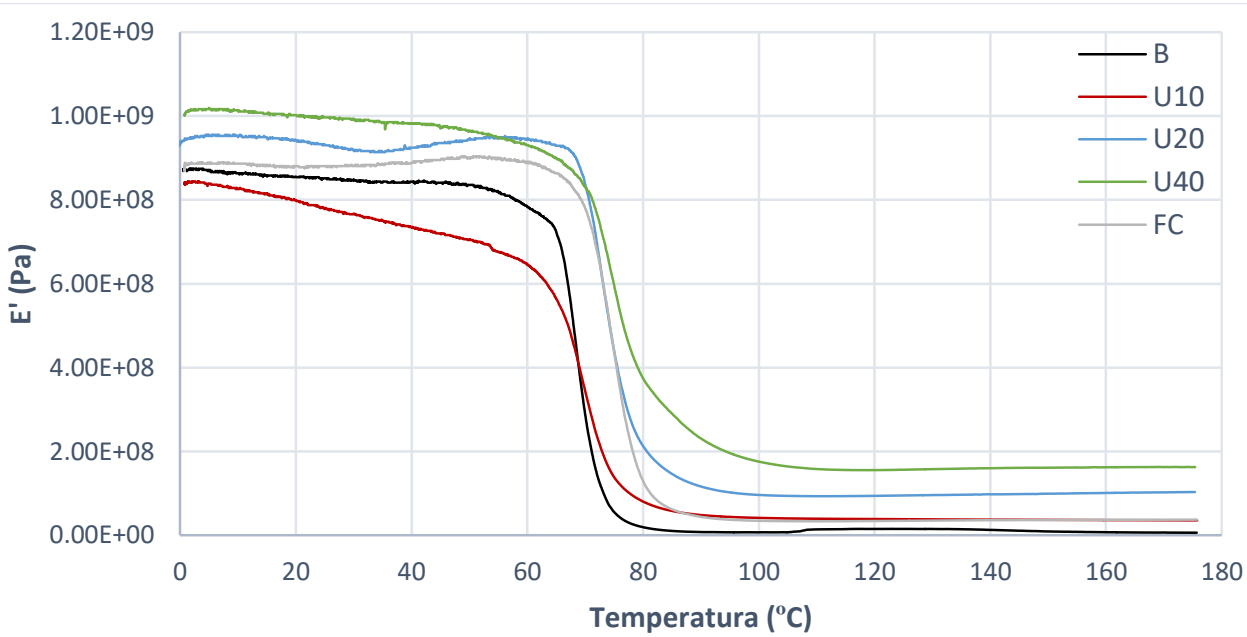

Figura 155 - Módulo de armazenamento de resina epóxi bisfenol e compósitos Epóxi/Bucha sem tratamento com diferentes porcentagens de fibra de bucha.

Na tabela 39 são apresentados os valores de E' para diferentes temperaturas na resina e os compósitos reforçados com as fibras sem modificação.

Tabela 39 - Módulo de armazenamento (MPa) para resina bisfenol e compósitos com 10, 20 e $30 \%$ de fibra de bucha sem tratar.

\begin{tabular}{|c|c|c|c|c|}
\hline \multirow{2}{*}{ Material } & \multicolumn{3}{|c|}{ Temperatura $\left({ }^{\circ} \mathbf{C}\right)$} \\
\cline { 3 - 5 } & & $\mathbf{3 0}^{\circ} \mathbf{C}$ & $\mathbf{7 0}^{\circ} \mathbf{C}$ & $\mathbf{1 5 0}^{\circ} \mathbf{C}$ \\
\hline I & B & 848,7 & 284,9 & 9,3 \\
\hline 1 & U10 & 766,6 & 341,7 & 37,1 \\
\hline 2 & U20 & 916,3 & 836,5 & 99,4 \\
\hline 3 & U40 & 990,8 & 831,2 & 161,3 \\
\hline 10 & FC & 880,4 & 777,9 & 36,69 \\
\hline
\end{tabular}


A $70{ }^{\circ} \mathrm{C}$ houve aumento no módulo de armazenamento para os três compósitos em relação à resina pura. O valor de E' aumentou por volta de $200 \%$ para compósito com 20 e $40 \%$ de fibras e apresentou um aumento de aproximadamente $20 \%$ em compósitos com 10\% de fibras, em comparação com a resina pura. A temperaturas maiores, a influência do reforço foi ainda mais evidente e foi observada uma elevada redução dos valores de $\mathrm{E}^{\prime}$ para a resina pura. Esse comportamento confirmou que a incorporação das fibras de bucha restringe a mobilidade das macromoléculas da matriz polimérica, dando como resultado o aumento nos valores de módulo de armazenamento dos compósitos, como esperado [174], [372], [373], [374]. Também foi constatado que, nos compósitos com mais de $10 \%$ de fibras de bucha em seu peso, foi apresentado um deslocamento para temperaturas maiores no início da queda do módulo de armazenamento (Tonset), o que sugere um efeito de reforço dinâmico com a incorporação das fibras. Na Figura 156 são mostradas as curvas de variação E' com a temperatura para a resina C50 e o seu compósito com $30 \%$ de fibras de bucha mercerizadas.

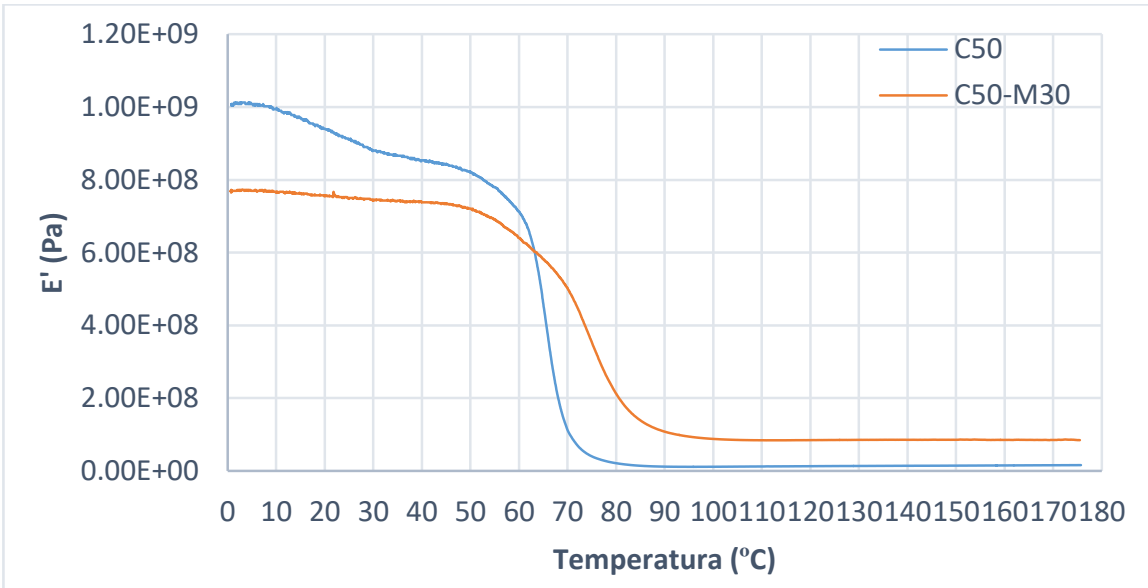

Figura 156 - Módulo de armazenamento de resina cardanol-resorcinol e o compósito com $30 \%$ de fibra de bucha mercerizada.

Da Figura e dos valores de E' para diferentes temperaturas apresentados na tabela 40 deve se ressaltar que a adição de fibras tratadas melhorou as propriedades do compósito em relação à resina pura somente a partir de temperaturas próximas a $70{ }^{\circ} \mathrm{C}$. 
Tabela 40 - Módulo de armazenamento (MPa) para resina cardanol-resorcinol e o compósito com $30 \%$ de fibra de bucha mercerizada.

\begin{tabular}{|c|c|c|c|c|}
\hline \multirow{2}{*}{} & \multirow{2}{*}{ Material } & \multicolumn{3}{|c|}{ Temperatura $\left({ }^{\circ} \mathrm{C}\right)$} \\
\cline { 3 - 5 } & & 30 & 70 & 150 \\
\hline IV & C50 & 880,5 & 111,9 & 14,6 \\
\hline 16 & C50-M30 & 743,2 & 502,2 & 85,7 \\
\hline
\end{tabular}

Na Figura 157 se apresenta a variação do módulo de armazenamento com a temperatura, para a resina de bisfenol e os compósitos com fibras tratadas. Foi encontrado um deslocamento para temperaturas de início da transição vítrea ( $\left.\mathrm{T}_{\text {onset }}\right)$ maior em tais compósitos, se comparado com o comportamento da resina pura, o que sugere um efeito de reforço dinâmico por parte das fibras. Como não foi possível obter um compósito com $30 \%$ de fibras não tratadas, foram comparados os resultados com os obtidos para compósitos com $40 \%$ de fibras não tratadas.

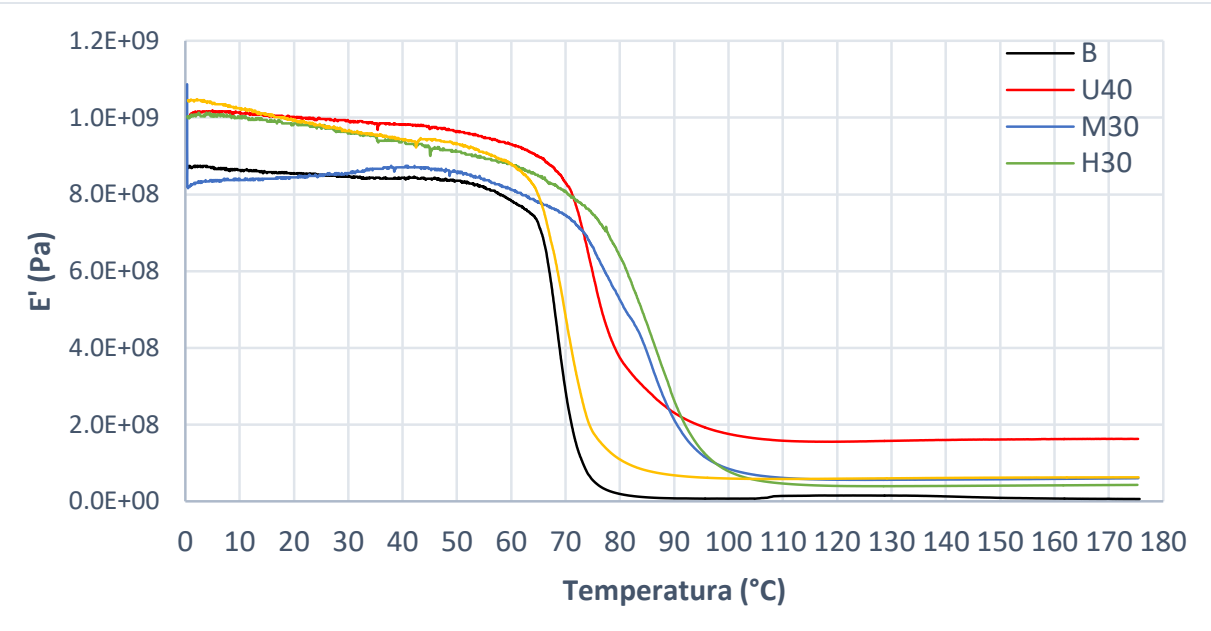

Figura 157 - Módulo de armazenamento de compósitos de matriz epóxi bisfenol reforçados com $30 \%$ de fibras de bucha com e sem tratamento.

Na tabela 41 são apresentados os valores de E' para diferentes temperaturas durante o ensaio de DMA dos materiais com 30 e $40 \%$ de fibras de bucha. 
Tabela 41 - Módulos de armazenamento para resina bisfenol e compósitos com 30\% de fibras de bucha tratadas.

\begin{tabular}{|c|c|c|c|c|}
\hline \multirow{2}{*}{$\#$} & \multirow{2}{*}{ Material } & \multicolumn{3}{|c|}{ Temperatura $\left({ }^{\mathbf{}} \mathbf{C}\right)$} \\
\cline { 3 - 5 } & & $\mathbf{3 0}$ & $\mathbf{7 0}$ & $\mathbf{1 5 0}$ \\
\hline I & B & 848,7 & 284,9 & 9,3 \\
\hline 3 & U40 & 990,8 & 831,2 & 161,3 \\
\hline 5 & M30 & 855,4 & 746,7 & 57,7 \\
\hline 7 & H30 & 958,5 & 806,6 & 41,1 \\
\hline 9 & A30 & 964,9 & 481,7 & 61,9 \\
\hline
\end{tabular}

Nota-se que os compósitos com $40 \%$ de fibras de bucha não tratadas apresentaram módulos de armazenamento maiores, quando comparados aos obtidos para compósitos reforçados com 30\% de fibras de bucha tratadas. Esso pode ter relação com a maior quantidade de fibras.

Na tabela 42 são apresentados os resultados para o módulo de armazenamento de compósitos com $20 \%$ de fibras de bucha tratadas e não tratadas. Tais resultados indicaram que, em baixas temperaturas, as fibras sem tratamento e as fibras mercerizadas conferem aos compósitos uma maior rigidez, ao contrário das fibras acetiladas e hornificadas que mostraram valores iniciais de módulo menores. Quando a temperatura atinge $70^{\circ} \mathrm{C}$ os compósitos reforçados com fibras de bucha acetiladas e hornificadas apresentam valores similares à resina e os compósitos com fibras sem tratamento presentam valores maiores e similares aos compósitos com fibras mercerizadas. No entanto, por volta de $80^{\circ} \mathrm{C}$ os compósitos com fibras acetiladas apresentaram valores maiores de E', comparado com os outros compósitos com fibras tratadas.

Tabela 42 - Módulos de armazenamento para resina bisfenol e compósitos com 20\% de fibras de bucha.

\begin{tabular}{|c|c|c|c|c|}
\hline \multirow{2}{*}{$\#$} & \multirow{2}{*}{ Material } & \multicolumn{3}{|c|}{ Temperatura $\left({ }^{\mathbf{O}} \mathbf{C}\right)$} \\
\cline { 3 - 5 } & & $\mathbf{3 0}$ & $\mathbf{7 0}$ & $\mathbf{1 5 0}$ \\
\hline I & B & 848,7 & 284,9 & 9,3 \\
\hline 2 & U20 & 916,3 & 836,5 & 99,4 \\
\hline 4 & M20 & 933,2 & 819,3 & 57,2 \\
\hline 6 & H20 & 701,8 & 578,6 & 49,5 \\
\hline 8 & A20 & 736,7 & 209,5 & 120,6 \\
\hline
\end{tabular}


Na Figura 158 são apresentadas as curvas da variação do módulo de armazenamento com a temperatura, para a resina ESO30 e seus compósitos. Foi encontrado um aumento considerável no módulo de armazenamento, assim como um aumento na estabilidade térmica, para o compósito reforçado com fibras tratadas por hornificação.

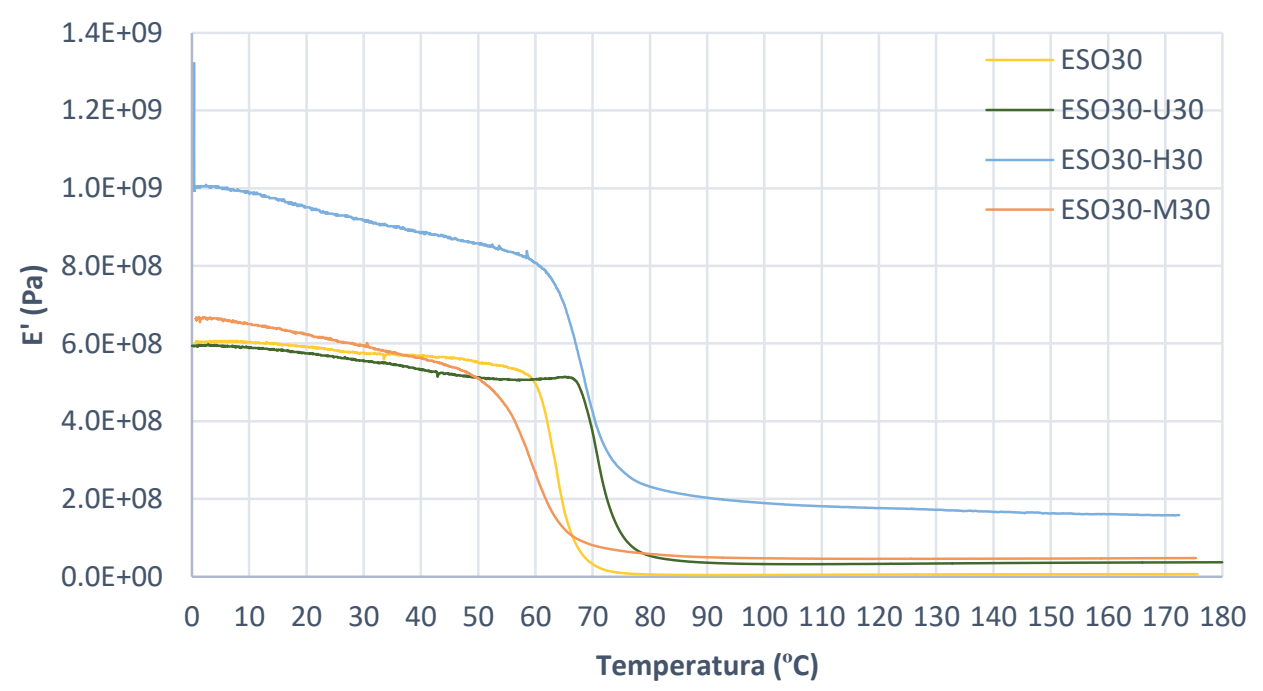

Figura 158 - Módulo de armazenamento de resina epóxi ESO30 e seus compósitos com $30 \%$ de fibras de bucha, com e sem tratamento.

Na tabela 43 são apresentados os resultados para o módulo da resina ESO30 e seus compósitos para diferentes temperaturas. Nota-se que os compósitos reforçados com fibras tratadas por mercerização também possuem um ligeiro aumento no módulo de armazenamento, em temperaturas baixas e em temperaturas acima de $65^{\circ} \mathrm{C}$, em relação à resina ESO30 pura. No entanto, o compósito com fibras não tratadas apresentou aumento nos valores de E', com relação à resina pura, apenas em temperaturas acima de $60{ }^{\circ} \mathrm{C}$.

Tabela 43 - Módulos de armazenamento para resina ESO30 e compósitos com 30\% de fibras de bucha.

\begin{tabular}{|c|c|c|c|c|}
\hline \multirow{2}{*}{} & \multirow{2}{*}{ Material } & \multicolumn{3}{|c|}{${\text { Temperatura }\left({ }^{\circ} \mathbf{C}\right)}$} \\
\cline { 3 - 5 } & & $\mathbf{3 0}$ & $\mathbf{7 0}$ & $\mathbf{1 5 0}$ \\
\hline III & ESO30 & 574,3 & 32,1 & 6,0 \\
\hline 12 & ESO30-U30 & 556,3 & 367,2 & 35,5 \\
\hline 13 & ESO30-M30 & 593,2 & 80,9 & 46,5 \\
\hline 14 & ESO30-H30 & 917,1 & 423,0 & 162,6 \\
\hline
\end{tabular}


Os aumentos nos valores de E' a temperatura ambiente estão associados a uma melhor adesão na interface fibra/matriz de compósito, obtida com os tratamentos de hornificação e $\mathrm{NaOH}$ das fibras.

Na Figura 159 são mostradas as curvas da variação da $\tan \delta$ com a temperatura para a resina epóxi de cardanol-resorcinol e o compósito com $30 \%$ de fibras de bucha mercerizadas. Nessa Figura pode se observar que os valores de amortecimento obtidos para a resina pura foram maiores que para o compósito, concordando assim com a literatura consultada [174], [373], [374], [375]. Nas Figuras 133 - 135 pode se observar que foi encontrado o mesmo comportamento ao comparar os resultados obtidos para as resinas de bisfenol e ESO-bisfenol com seus compósitos.

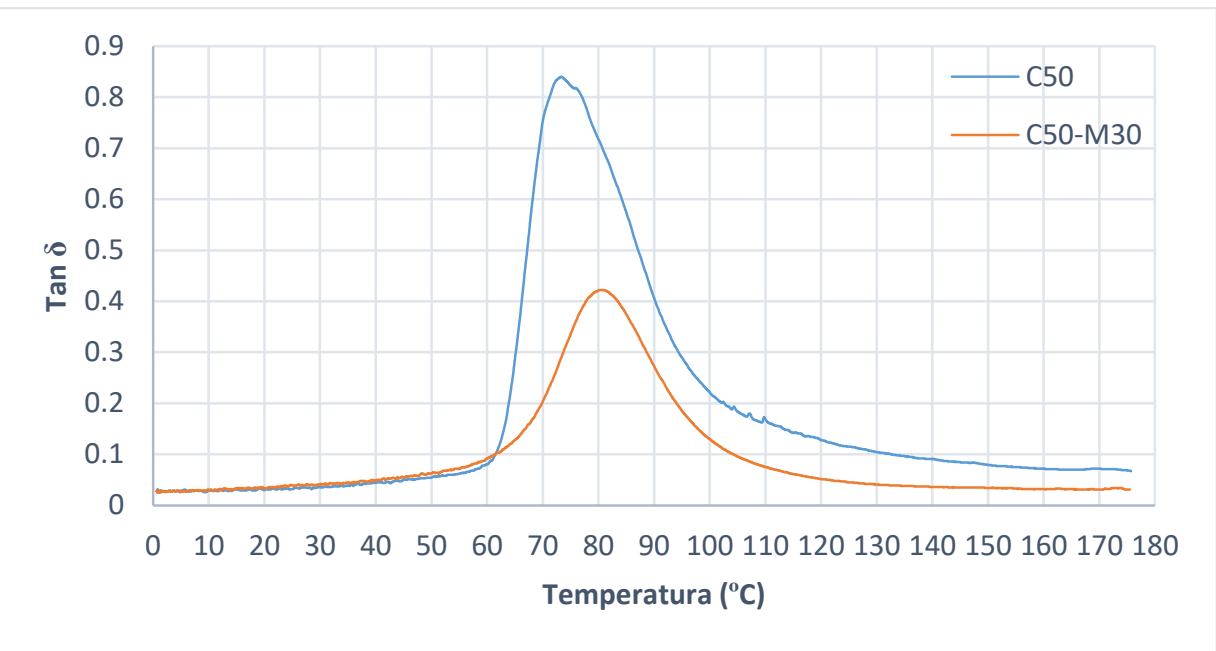

Figura 159 - Tan $\boldsymbol{\delta}$ de resina cardanol-resorcinol e o compósito com30\% de fibras de bucha mercerizada.

Na Figura 160 são apresentadas as curvas da variação de tan $\delta$ com a temperatura para a resina epóxi de bisfenol e os compósitos com diferentes porcentagens de fibra de bucha sem tratamento. Nessa Figura pode-se observar que os valores de $\tan \delta$ apresentados pela resina também foram maiores e que com uma maior quantidade de fibras de bucha foram obtidos valores de tan $\delta$ menores. 


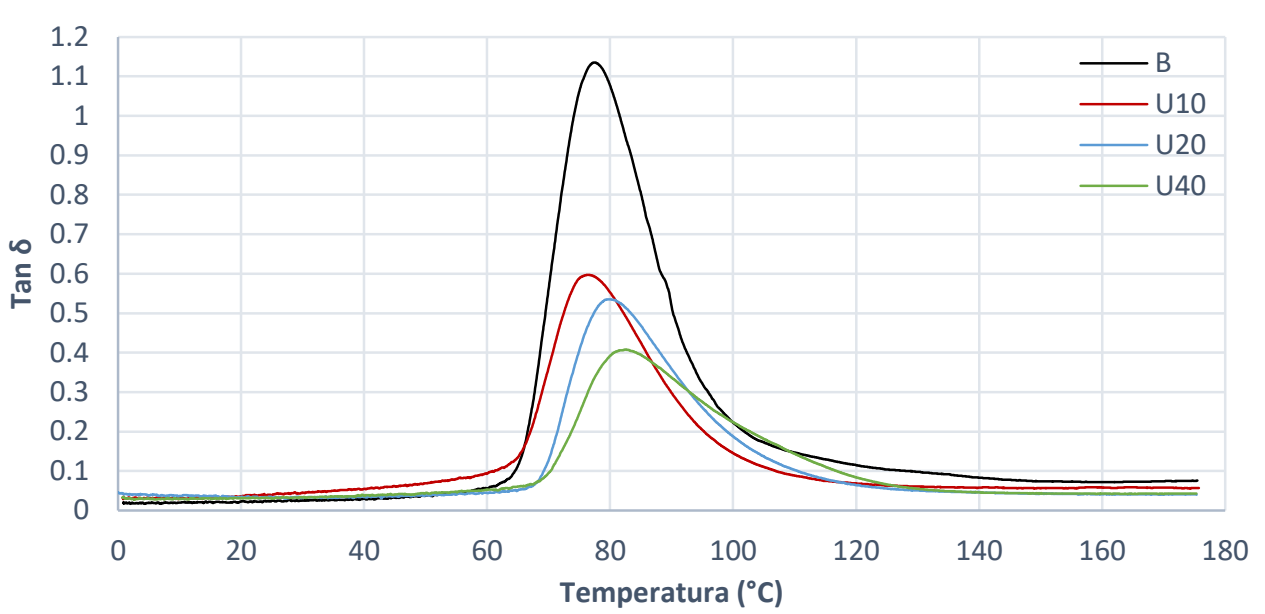

Figura 160 - Tan $\boldsymbol{\delta}$ de resina epóxi bisfenol e compósitos de matrix epóxi bisfenol reforçados com 10, 20 e $40 \%$ de fibras de bucha.

Na Figura 161 são apresentados os valores máximos de $\tan \delta$ para a resina bisfenol e seus compósitos com fibras tratadas e não tratadas. Também é notada uma tendência de diminuição dos valores de $\tan \delta$ com o aumento na porcentagem de fibras para os compósitos com as fibras tratadas. Ou seja, o mesmo efeito constatado no gráfico da Figura 154 foi observado ao comparar os valores de tan $\delta$ máximos da resina bisfenol com os valores obtidos para compósitos com fibras tratadas. Essa influência da porcentagem de fibra nos compósitos sobre a dissipação da energia vibracional pode ser atribuída à menor quantidade de matriz, que, por sua vez, é a responsável pela dissipação da energia [174], [373].

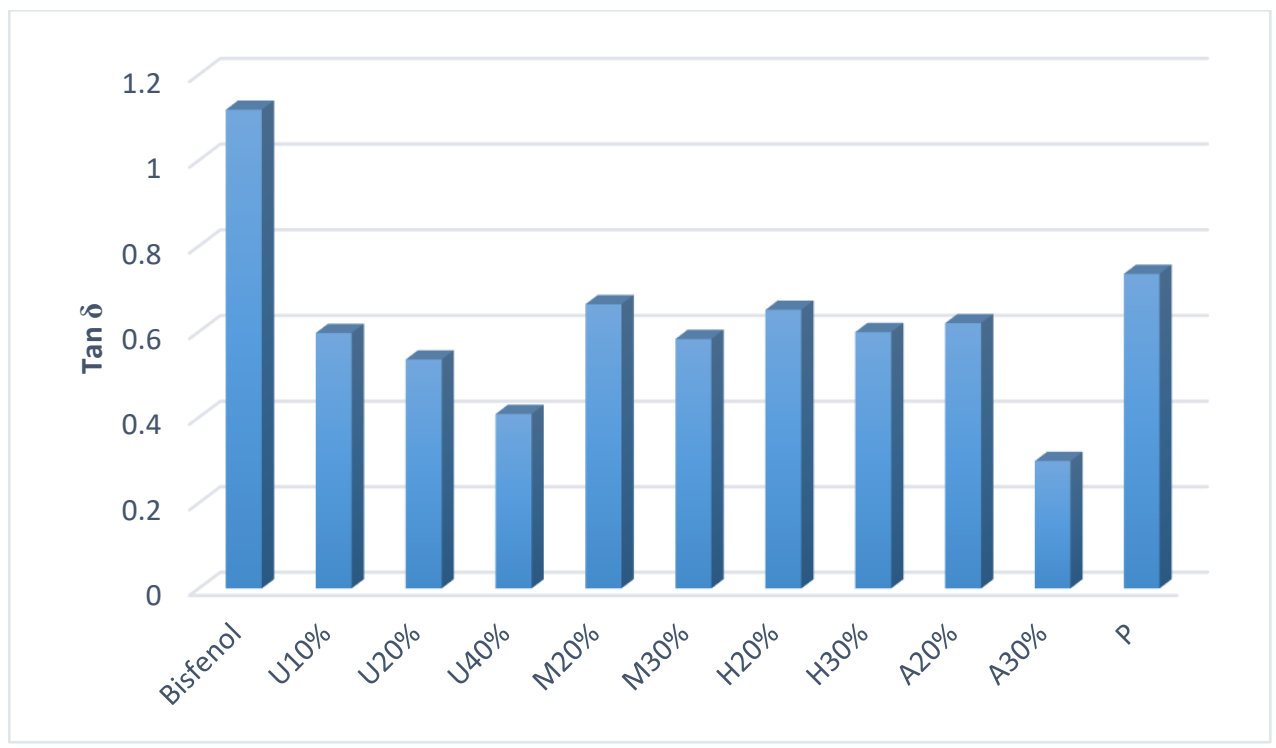

Figura 161 - Valores de Tan $\boldsymbol{\delta}$ para a resina de bisfenol e para os compósitos bisfenol/bucha fabricados. 
Na Figura 161 também foi possível observar que os compósitos com fibras tratadas apresentaram valores de $\tan \delta$ maiores que os compósitos com fibras sem tratamento, exceto no caso dos compósitos com $30 \%$ de fibras acetiladas, nos quais o valor foi muito menor, o que indica uma menor capacidade de dissipação de energia, isto é, uma melhor adesão na interface fibra-matriz como resultado deste tratamento.

Na Figura 162 estão indicados os valores máximos de $\tan \delta$ para a resina ESO30 e seus compósitos, também notando-se uma diminuição nos valores de tan $\delta$ com a adição das fibras na matriz. Além disso, os compósitos mostraram valores de $\tan \delta$ menores para os compósitos com fibras tratadas por mercerização e hornificação, contrário ao comportamento observado para os compósitos com matriz de bisfenol na Figura 161. Esse resultado indica que houve um melhoramento na adesão interfacial entre as fibras de bucha tratadas e a resina com conteúdo de ESO.

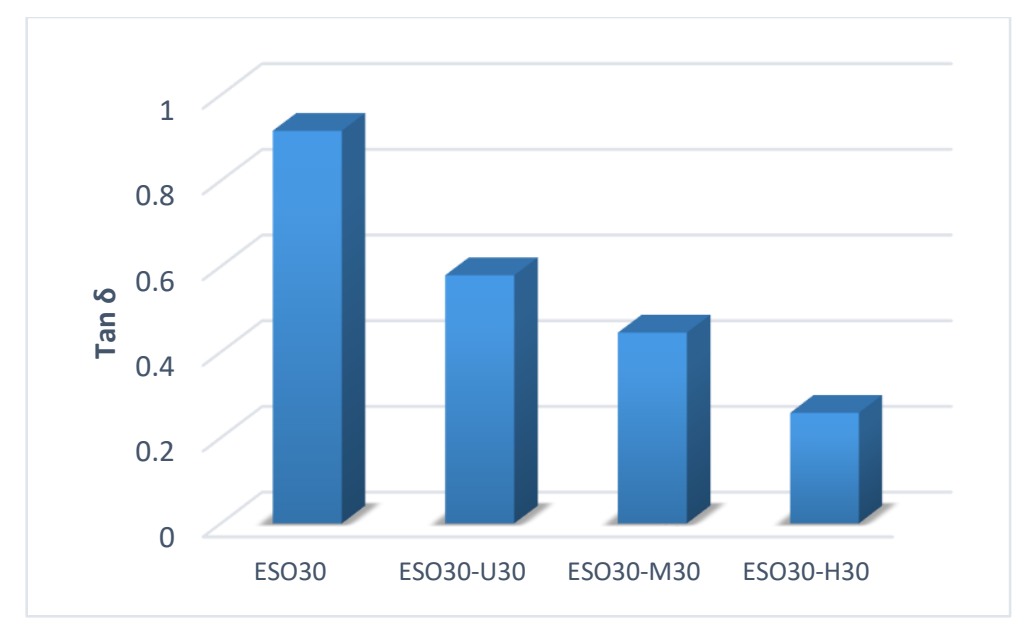

Figura 162 - Valores máximos de tan $\boldsymbol{\delta}$ para a resina ESO-bisfenol e compósitos ESObisfenol/fibras de bucha.

Na Figura 163 são apresentadas as curvas de módulo de perda contra a temperatura para a resina B e os compósitos U10, U20 E U40. Os compósitos apresentaram módulos de perda menores que os apresentados pela resina. Também foi possível observar que a posição dos picos máximos do módulo de perda apresentaram um deslocamento para temperaturas mais elevadas, com o aumento no teor de fibra nos compósitos. 


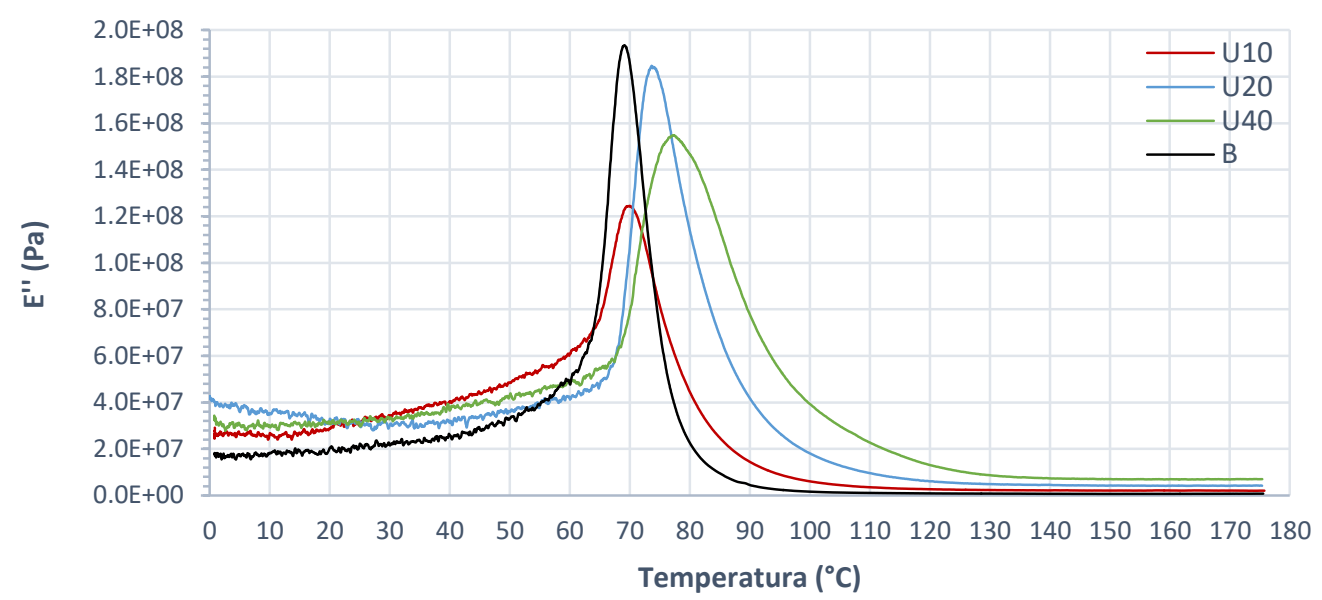

Figura 163 - Módulo de perda de resina epóxi bisfenol e compósitos de matriz epóxi bisfenol reforçados com 10, 20 e $40 \%$ de fibras de bucha.

Na Figura 164 é mostrado o resultado de módulo de perda para a resina B em comparação com os compósitos U40, M30, H30 e A30. Foi observado que as temperaturas correspondentes ao pico de E' máximo dos compósitos com fibras hornificadas e mercerizadas foram maiores que para os compósitos U40 e A30.

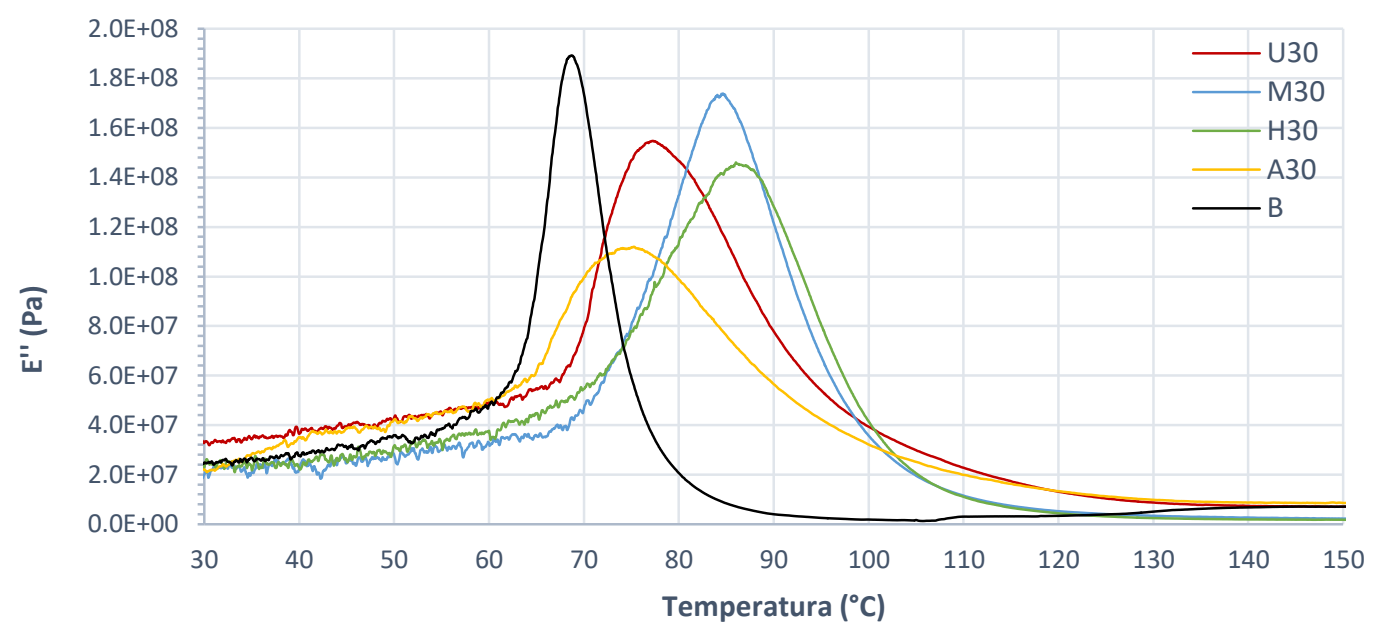

Figura 164 - Módulo de perda de compósitos de matriz epóxi bisfenol reforçados com $30 \%$ de fibras de bucha com e sem tratamento.

Na Figura 165 são apresentadas as curvas do módulo de perda para a resina ESO-bisfenol e os compósitos com fibras sem tratamento e tratadas. Os resultados mostraram que o compósito reforçado com fibras de bucha sem tratamento apresentou maiores valores de módulo de perda e maior temperatura para E", máximo. Foi observado que o compósito reforçado com fibras de bucha sem tratar apresentou valores de E" muito próximos aos valores para a resina pura. No 
entanto, a temperatura onde E" atinge o valor máximo foi maior para o compósito, quando comparado à resina. O compósito com fibras tratadas com hornificação também apresentou uma temperatura maior no valor máximo de E', porem um valor de módulo de perda menor do que a resina ESO30. Para o compósito com fibras tratadas por mercerização, tanto o valor de E' quanto a temperatura para E" máximo foram menores em comparação com a resina.

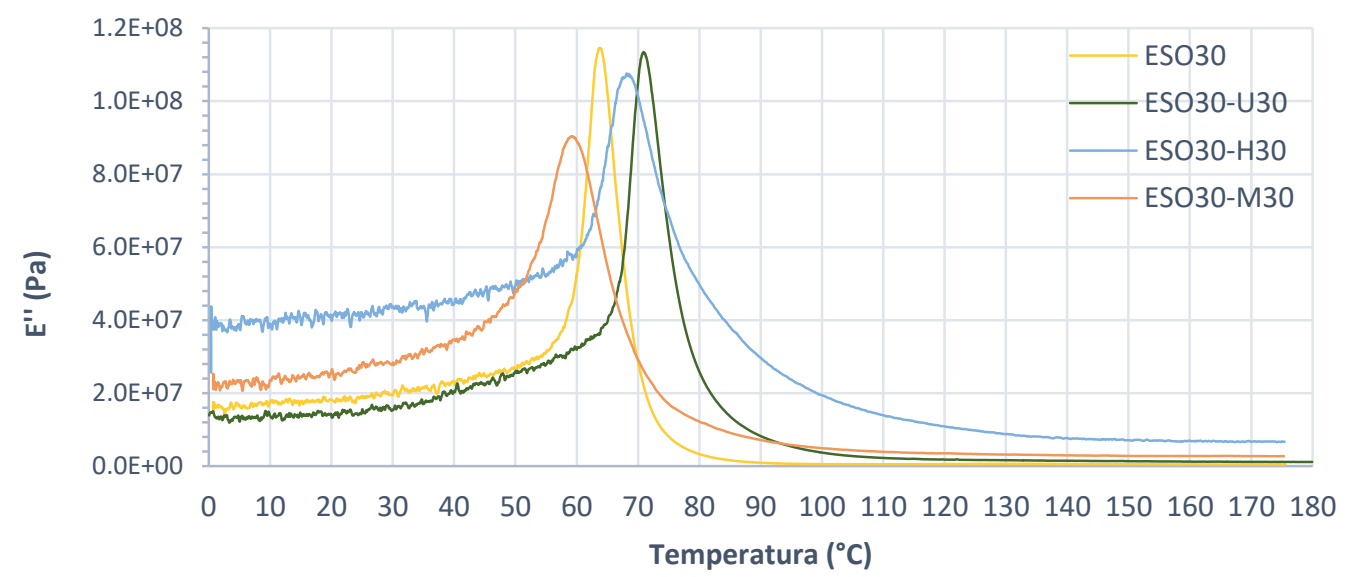

Figura 165 - Módulo de perda de resina ESO-bisfenol e compósitos reforçados com 30\% de fibras de bucha com e sem tratamento.

Na Figura 166 são mostradas as curvas para o módulo de perda da resina cardanol-resorcinol e o compósito C50-M30 cujo valor do módulo de perda foi menor. No entanto, o valor de temperatura correspondente ao valor máximo de E', foi maior para o compósito em comparação com o valor para a resina C50.

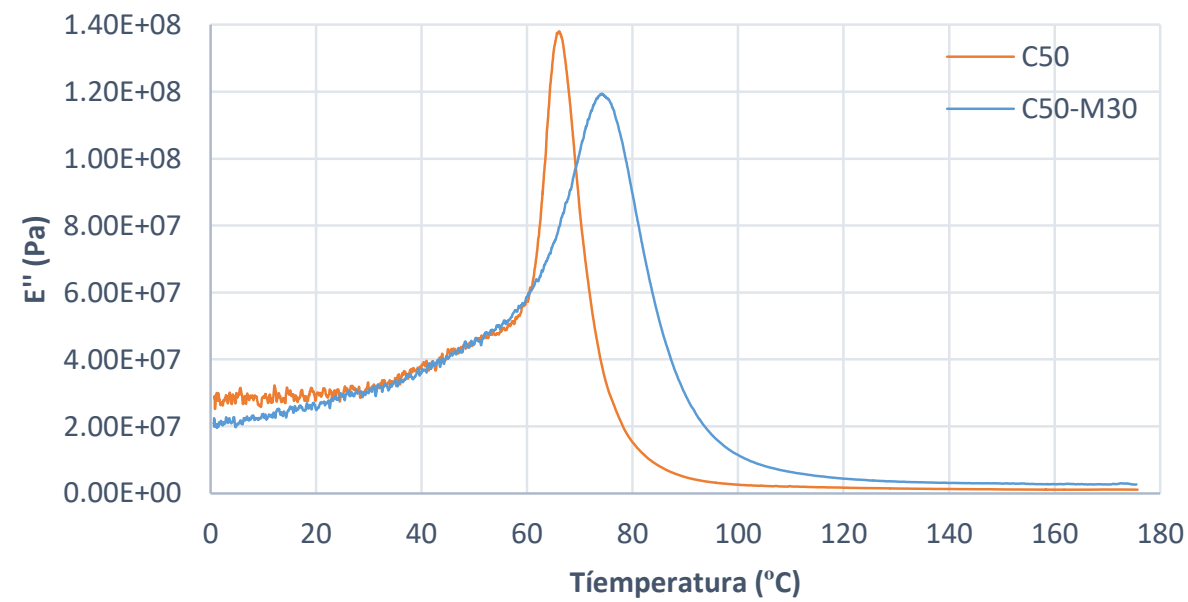

Figura 166 - Módulo de perda de resina cardanol-resorcinol e compósitos com 30\% de fibras de bucha mercerizadas. 


\subsubsection{Temperatura de transição vítrea}

A temperatura de transição vítrea $\left(\mathrm{T}_{\mathrm{g}}\right)$ dos materiais foi determinada a partir dos valores obtidos a partir dos ensaios DMA, nos picos máximos das curvas de $\tan \delta$ e $E$ "' contra temperatura. Na tabela 44 são apresentados os resultados das temperaturas de transição vítrea determinadas a partir dos valores máximos de tan $\delta$ e E" para as resinas e os compósitos ensaiados. A variação da $T_{g}$ assim estimada permitiu analisar a evolução das transições estruturais ocorrendo nos materiais com a incorporação de diferentes porcentagens de fibras de bucha nas resinas epóxi e pelos diferentes tratamentos realizados nas fibras.

Tabela 44 - Temperaturas de transição vítrea medidas nas curvas de tan $\delta$ e E’'.

\begin{tabular}{|c|c|c|c|}
\hline \multirow{2}{*}{$\#$} & \multirow{2}{*}{ Material } & Tan $\boldsymbol{\delta}$ máx. & E" máx. \\
\cline { 3 - 4 } & & $\left.\mathbf{T}_{\mathbf{g}}{ }^{\mathbf{}}{ }^{\mathbf{}} \mathbf{C}\right)$ & $\mathbf{T}_{\mathbf{g}}\left({ }^{\circ} \mathbf{C}\right)$ \\
\hline I & B & 77,51 & 68,68 \\
\hline III & ESO30 & 72,24 & 63,81 \\
\hline IV & C50 & 73,84 & 66,11 \\
\hline 1 & U10 & 76,28 & 69,97 \\
\hline 2 & U20 & 79,84 & 73,75 \\
\hline 3 & U40 & 82,59 & 77,12 \\
\hline 4 & M20 & 79,54 & 72,98 \\
\hline 5 & M30 & 91,80 & 84,54 \\
\hline 6 & H20 & 81,03 & 74,56 \\
\hline 7 & H30 & 95,34 & 86,50 \\
\hline 8 & A20 & 76,03 & 70,51 \\
\hline 9 & A30 & 80,51 & 74,47 \\
\hline 10 & FC & 81,75 & 74,79 \\
\hline 13 & ESO30-M30 & 64,78 & 59,36 \\
\hline 14 & ESO30-H30 & 72,52 & 68,10 \\
\hline 16 & C50-M30 & 80,56 & 74,46 \\
\hline
\end{tabular}

Dos dados das tabelas 44 e 45 , pode se concluir que a $\mathrm{Tg}$ dos compósitos aumenta com o aumento do conteúdo de fibra de bucha acima de $10 \%$. Como a porcentagem de fibras teve um efeito sobre a temperatura de transição vítrea dos compósitos, esse comportamento indica que a interação das fibras e a matriz epóxi aumentou a estabilidade térmica dos compósitos em relação à resina epóxi, sugerindo que a interação das fibras de bucha com a resina permite a transferência efetiva dos esforços da matriz para a fibra, como reportado em outros trabalhos para 
compósitos reforçados com fibras lignocelulósicas [372], [373], [376], [377] [378], [379][378], [380]. Assim, o aumento para temperaturas maiores com o aumento na proporção de fibras de bucha acima de $10 \%$, confirma o resultado obtido nas curvas do módulo de armazenamento.

Tabela 45 - Valores máximos de $\tan \delta$ e E", temperaturas de transição vítrea medidas nas curvas de E', E', e tan $\delta$.

\begin{tabular}{|c|c|c|c|c|}
\hline$\#$ & Material & $\begin{array}{c}\text { E'onset } \\
(\mathbf{M P a})\end{array}$ & Tan $\boldsymbol{\delta}$ máx. & $\begin{array}{c}\text { E" máx. } \\
(\mathbf{M P a})\end{array}$ \\
\hline $\mathrm{I}$ & $\mathrm{B}$ & 825,74 & 1,135 & 189,15 \\
\hline 3 & ESO30 & 556,17 & 0,916 & 114,57 \\
\hline 4 & $\mathrm{C} 50$ & 758,36 & 0,836 & 137,98 \\
\hline 1 & $\mathrm{U} 10$ & 659,51 & 0,597 & 124,46 \\
\hline 2 & $\mathrm{U} 20$ & 955,51 & 0,535 & 184,42 \\
\hline 3 & $\mathrm{U} 40$ & 957,68 & 0,408 & 154,59 \\
\hline 4 & M20 & 939,00 & 0,664 & 194,36 \\
\hline 5 & M30 & 822,46 & 0,583 & 173,64 \\
\hline 6 & H20 & 711,43 & 0,651 & 138,11 \\
\hline 7 & H30 & 904,71 & 0,599 & 145,12 \\
\hline 8 & A20 & 892,10 & 0,620 & 158,65 \\
\hline 9 & A30 & 747,32 & 0,298 & 111,11 \\
\hline 10 & FC & 875,10 & 0,735 & 167,63 \\
\hline 13 & ESO30-U30 & 515,59 & 0,579 & 113,44 \\
\hline 14 & ESO30-M30 & 537,91 & 0,445 & 90,393 \\
\hline 15 & ESO30-H30 & 815,27 & 0,258 & 107,30 \\
\hline 16 & C50-M30 & 712,84 & 0,422 & 119,12 \\
\hline
\end{tabular}




\section{Conclusões}

Os resultados de espectroscopia no infravermelho (FTIR) indicaram a remoção de hemicelulose e lignina das superfície das fibras, verificando a efetividade do tratamento de mercerização realizados nas fibras de bucha. Além disso, resultados de DRX mostraram um aumento de $33 \%$ no índice de cristalinidade de fibras mercerizadas que indicaria a remoção de lignina e hemiceluloses amorfas da superfície com o tratamento. Por outro lado, resultados de ensaios por TGA nas fibras de bucha mostraram um aumento na estabilidade térmica das fibras hornificadas e mercerizadas com temperaturas de degradação máxima de 385 e $380,7^{\circ} \mathrm{C}$ respectivamente, frente a $374,6^{\circ} \mathrm{C}$ para fibras de bucha vegetal não tratada. Pelo mapeamento das propriedades nanomecânicas de fibras de bucha por microscopia de força atômica se encontraram valores de módulo de Young de fibras de bucha entre 1 e $4 \mathrm{GPa}$. Tendo em vista que nas esponjas utilizadas neste trabalho não foi possível encontrar fibras de bucha com comprimento maior a $2,5 \mathrm{~cm}$ (sem bifurcações) necessárias para a determinação do módulo de Young por ensaios de tração, o uso do AFM constituiu uma alternativa válida.

Neste trabalho foi observada uma redução na taxa de difusividade e na capacidade de absorção de água dos compósitos com fibras tratadas por hornificação, acetilação e mercerização. Compósitos reforçados com $20 \%$ de fibras de bucha hornificadas apresentaram uma redução de $33,42 \%$ no valor de coeficiente de difusão com relação aos compósitos com fibras sem tratar. Assim, o tratamento de hornificação constitui um método efetivo para o tratamento superficial de fibras de bucha vegetal quanto à redução na capacidade de absorção de água dos compósitos bisfenol/bucha, sem o uso de reagentes químicos que podem afetar as suas propriedades mecânicas.

Resultados da análise dinâmico-mecânica indicaram que a adição de entre $20 \%$ e $40 \%$ de fibras de bucha causou uma melhora nas propriedades visco-elásticas e um aumento na estabilidade térmica dos compósitos bisfenol-bucha. Com a adição de $20 \%$ de fibras de bucha se obteve um aumento de aproximadamente $7{ }^{\circ} \mathrm{C}$ na temperatura de transição vítrea e com adição de $40 \%$ de fibras um aumento por volta de $12{ }^{\circ} \mathrm{C}$. A temperatura ambiente se obteve um aumento de $8 \%$ no valor do 
módulo de armazenamento de compósitos com $20 \%$ de fibras e um aumento de E' por volta de $17 \%$ em compósitos com $40 \%$ de fibras de bucha.

Resultados da análise dinâmico-mecânica dos compósitos com matriz com conteúdo de ESO e reforçados com 30\% de fibras hornificadas ESO30-H30 mostraram um aumento módulos de armazenamento a temperatura ambiente $\left(30^{\circ} \mathrm{C}\right)$ de $917 \mathrm{MPa}$, frente a valores de $\mathrm{E}^{\prime}=556 \mathrm{MPa}$, para o compósito com fibras sem tratamento ESO30-U30. Além disso, os compósitos com matriz ESO30 e fibras de bucha em forma de manta apresentaram modos de fratura controlada.

O sistema 50\% Cardanol - 50\% resorcinol curado com IPDA (C50) com energia de ativação de $147 \mathrm{KJ} / \mathrm{mol}$, temperatura de transição vítrea de $74^{\circ} \mathrm{C}$ e módulo de armazenamento de 880,5 $\mathrm{MPa}$, pode ser uma boa escolha para substituir o sistema bisfenol clássico com valores de $\mathrm{Ea}=200 \mathrm{KJ} / \mathrm{mol}, \mathrm{Tg}=77,5^{\circ} \mathrm{C}$ e $\mathrm{E}$ ' $=849$ MPa. A observação por MEV da interface de fibras de bucha mercerizadas e resina epóxi com 50\% de cardanol epoxidado, C50, revelaram uma grande afinidade, indicada pela boa adesão fibra matriz. As propriedades mecânicas e térmicas de compósitos com matriz C50 com 30\% de fibras de bucha mercerizada (C50-M30) analisadas por DMA e flexão, mostraram que o material poderia ter grande potencial para seu uso como um substituto mais sustentável das resinas com conteúdo de bisfenol.

\subsection{Sugestões para Trabalhos Futuros}

- Para trabalhos futuros se recomenda aprofundar no estúdio das propriedade nanomecânicas de fibras lignocelulósicas por microscopia de força atômica realizando a indentação da seção transversal e correlacionando os resultados de módulo de Young encontrados por tração com resultados obtidos a partir de AFM.

- Recomenda-se o estudo da mudança estrutural da seção transversal de fibras de bucha tratadas por hornificação. 
- Recomenda-se também, ampliar o estudo de compósitos de cardanolresorcinol com outras fibras lignocelulósicas e outros tratamentos superficiais.

- Ampliar a análise por MEV dos sistemas matriz/fibras com tratamento que mostraram maior interação, como é o caso dos compósitos ESO30 com fibras de bucha tratadas.

- Realizar estudos de FTIR nos compósitos para verificar reações químicas ocorrendo entre os grupos epóxi presentes na resina e os grupos hidroxila da celulose.

- O estudo de compósitos com matriz baseada em óleos vegetais epoxidados com nanofibras cristalinas, obtidas a partir de fibras de bucha e outras fibras lignocelulósicas, como agente de reforço. 


\section{Referências bibliográficas}

[1] H. Q. Q. Pham, M.J. Marks, e M. J. Marks, "Epoxy Resins", in Encyclopedia of Polymer Science and Technology, vol. 4, John Wiley \& Sons, Inc., 2002, p. 347-471.

[2] B. Ellis, Chemistry and Technology of Epoxy Resins. 1993.

[3] C. A. May, Org., Resins for Aerospace, vol. 132. 1980.

[4] C. A. May, Epoxy resins: chemistry and technology. 1987.

[5] W. Brostow, S. H. Goodman, e J. Wahrmund, "Epoxies", in Handbook of Thermoset Plastics., $3^{\circ}$ ed, H. Dodiuk e S. Goodman, Orgs. Else, 2014, p. 191-248.

[6] B. S. Rubin, "Bisphenol A: An endocrine disruptor with widespread exposure and multiple effects", J. Steroid Biochem. Mol. Biol., vol. 127, no 1-2, p. 27-34, 2011.

[7] P. Fenichel, N. Chevalier, e F. Brucker-Davis, "Bisphenol A: An endocrine and metabolic disruptor", Ann. Endocrinol. (Paris)., vol. 74, n० 3, p. 211-220, 2013.

[8] J. R. Rochester, "Bisphenol A and human health: A review of the literature", Reprod. Toxicol., vol. 42, p. 132-155, 2013.

[9] A. Shuyana e D. Rementeria, "Efectos del bisfenol A en la reproducción", 2016.

[10] L. Kanerva, R. Jolanki, O. Tupasela, L. Halmepuro, H. Keskinen, T. Estlander, e M. L. Sysilampi, "Immediate and delayed allergy from epoxy resins based on diglycidyl ether of bisphenol A", Scand. J. Work. Environ. Heal., vol. 17, nº 3, p. 208-215, 1991.

[11] J. H. Kang, F. Kondo, e Y. Katayama, "Human exposure to bisphenol A", Toxicology, vol. 226, n²-3, p. 79-89, 2006.

[12] N. Karak, Vegetable Oil-Based Polymers. Woodhead Publishing Limited, 2012.

[13] M. N. Belgacem e A. Gandini, "Monomers, Polymers and Composites from Renewable Resources", in Monomers, Polymers and Composites from Renewable Resources, $1^{\circ}$ ed, 2008, p. 39-66.

[14] S. Miao, P. Wang, Z. Su, e S. Zhang, "Vegetable-oil-based polymers as future polymeric biomaterials", Acta Biomater., vol. 10, $\mathrm{n}^{\circ} 4$, p. 
1692-1704, 2014.

[15] G. Lligadas, J. C. Ronda, M. Galià, e V. Cádiz, "Renewable polymeric materials from vegetable oils: A perspective", Mater. Today, vol. 16, no 9, p. 337-343, 2013.

[16] D. Nazire e P. Nancy, "Green Biorenewable Composites: From Knowledge to Growth", V. K. Thakur e K. Michael, Orgs. Apple academic Press, 2015, p. 161-199.

[17] J. Bai, Advanced Fibre-Reinforced Polymer (FRP) Composites for Structural Applications, $1^{\circ} \mathrm{ed}$. Elsevier, 2013.

[18] F. Galembeck, "Materiais Avançados 2010-2022”, 2010, p. 268-272.

[19] K. Wötzel, R. Wirth, e M. Flake, "Life cycle studies on hemp fibre reinforced components and ABS for automotive parts", Die Angew. Makromol. Chemie, vol. 272, no 1, p. 121-127, 1999.

[20] M. a. Dweib, B. Hu, a. O'Donnell, H. W. Shenton, e R. P. Wool, "All natural composite sandwich beams for structural applications", Compos. Struct., vol. 63, n² 2, p. 147-157, 2004.

[21] A. K. Mohanty, M. Misra, e L. T. Drzal, "Sustainable Bio-Composites from Renewable Resources: Opportunities and Challenges in the Green Materials World", J. Polym. Environ., vol. 10, nº April, p. 1926, 2002.

[22] C. A. Boynard e J. R. M. D. D'Almeida, "Morphological Characterization and Mechanical Behavior of Sponge Gourd (Luffa Cylindrica)- Polyester Composite Materials", Polym. Plast. Technol. Eng., vol. 39, n 3, p. 489-499, 2000.

[23] H. Johnson, "Luffa, Sponge Gourd, Chinese Okra", Agriculture, p. 4, 1991.

[24] A. H. Michelena, J. Graham-Jones, J. Summerscales, e W. Hall, "Ecofriendly Flax Fibre/Epoxy Resin/Composite System for Surfboard Production", in Natural Fibres: Advances in Science and Technology Towards Industrial Applications, Springer, 2016, p. 267-277.

[25] T. Gurunathan, S. Mohanty, e S. K. Nayak, "A review of the recent developments in biocomposites based on natural fibres and their application perspectives", Compos. Part A Appl. Sci. Manuf., vol. 77, p. 1-25, 2015. 
[26] A. K. Bledzki e J. Gassan, "Composites reinforced with cellulose based fibres", Prog. Polym. Sci., vol. 24, n² 2, p. 221-274, 1999.

[27] G. Marsh, "Next step for automotive materials", Mater. Today, vol. 6, n० 4, p. 36-43, 2003.

[28] M. A. Ulysséa e M. Silvestro, "ENVIROMENTAL FRIENDLY SURFBOARDS BUILD OUT OF AGAVE WOOD, EXOTIC INVASIVE SPECIES ON BRAZILIAN NATIVE VEGETATION", 1980.

[29] R. Fangueiro e S. Rana, Orgs., Natural Fibres: Advances in Science and Technology Towards Industrial Applications. Springer, 2015.

[30] P. E. A. Grijó e P. Brügger, "Estudo Preliminar para Gestão Ambiental na Produção de Pranchas de Surfe", 2011.

[31] L. A. Pilato e M. J. Michno, Advanced composite materials. Springer Science \& Business Media.

[32] P. K. Mallick, Fiber-Reinforced Composites. Materials, Manufacturing and Design, $3^{\circ}$ ed. CRC Press, 2008.

[33] J. R. M. D'Almeida e S. N. Monteiro, "Role of the resin matrix/hardener ratio on the mechanical properties of low volume fraction epoxy composites", Adv. Perform. Mater., vol. 4, n 3, p. 285-295, 1997.

[34] W. D. J. Callister e D. G. Rethwisch, Materials science and engineering: an introduction, $8^{\circ}$ ed. 2010.

[35] K. Begum e M. a Islam, "Natural Fiber as a substitute to synthetic fiber in polymer composites: A review", Res. J. Eng. Sci., vol. 2, n 3, p. 46-53, 2013.

[36] V. K. Thakur e M. K. Thakur, "Processing and characterization of natural cellulose fibers/thermoset polymer composites.", Carbohydr. Polym., vol. 109, p. 102-17, ago. 2014.

[37] O. Faruk, A. K. Bledzki, H.-P. Fink, e M. Sain, "Biocomposites reinforced with natural fibers: 2000-2010", Prog. Polym. Sci., vol. 37, no 11, p. 1552-1596, nov. 2012.

[38] T. Sathishkumar, P. Navaneethakrishnan, S. Shankar, R. Rajasekar, e N. Rajini, "Characterization of natural fiber and composites - A review”, J. Reinf. Plast. Compos., vol. 32, no 19, p. 1457-1476, jul. 2013.

[39] S. N. Monteiro, K. G. Satyanarayana, A. S. Ferreira, J. B. Neto, T. G. 
Portela, e V. Researcher, "Selection of high strength natural fibers", Rev. Matéria, vol. 15, nº 4, p. 488-505, 2011.

[40] K. G. Satyanarayana, K. Sukumaran, R. S. Mukherjee, C. Pavithran, e S. G. K. Piuai, "Natural Fibre-Polymer Composites", vol. 12, n August 1989, p. 117-136, 1990.

[41] M. Biron, Thermosets and composites: material selection, applications, manufacturing and cost analysis. Elsevier Ltd, 2013.

[42] H. Dodiuk e S. H. Goodman, Orgs., Handbook of thermoset plastics, $3^{\circ}$ ed. Elsevier, 2013.

[43] D. Ratna, Handbook of Thermoset Resins. 2009.

[44] A. Kelly, Org., Concise Encyclopedia of Composite Materials. Elsevier Ltd, 1994.

[45] Michel Biron, "No Title", in Thermosets and composites: material selection, applications, manufacturing and cost analysis, Elsevier Ltd, 2013, p. 1-24.

[46] J.-P. Pascault, J. Verdu, Roberto J. J. Williamns, Jean-Pierre Pascault, H. Sautereau, J. Verdu, e Roberto J. J. Williamns, "Thermosetting Polymers", in Thermosetting Polymers, in Handbook of Polymer Synthesis, Characterization, and Processing, E. SaldívarGuerra e E. Vivaldo-Lima, Orgs. John Wiley \& Sons, Inc., 2013, p. 478.

[47] "Bisfenol e epicloroidrina", 2014. [Online]. Available at: http://www.ensinandoeaprendendo.com.br/wpcontent/uploads/2014/05/polimer-reticulado.jpg.

[48] N. Karak, "Vegetable oils and their derivatives", in Vegetable oilbased polymers: Properties,processing and applications, 2012, p. 54-95.

[49] "Epicerol of Solvay". [Online]. Available at: http://www.solvay.com/en/markets-and-products/featuredproducts/epicerol.html. [Acessado: 09-set-2015].

[50] B. M. Bell, J. R. Briggs, R. M. Campbell, S. M. Chambers, P. D. Gaarenstroom, J. G. Hippler, B. D. Hook, K. Kearns, J. M. Kenney, W. J. Kruper, D. James Schreck, C. N. Theriault, e C. P. Wolfe, "Glycerin as a renewable feedstock for epichlorohydrin production. 
The GTE process", Clean - Soil, Air, Water, vol. 36, n 8, p. 657-661, 2008.

[51] J. Łukaszczyk, B. Janicki, e M. Kaczmarek, "Synthesis and properties of isosorbide based epoxy resin", Eur. Polym. J., vol. 47, no 8, p. 1601-1606, 2011.

[52] S. Benyahya, C. Aouf, S. Caillol, B. Boutevin, J. P. Pascault, e H. Fulcrand, "Functionalized green tea tannins as phenolic prepolymers for bio-based epoxy resins", Ind. Crops Prod., vol. 53, p. 296-307, 2014.

[53] C. Aouf, S. Benyahya, A. Esnouf, S. Caillol, B. Boutevin, e H. Fulcrand, "Tara tannins as phenolic precursors of thermosetting epoxy resins", Eur. Polym. J., vol. 55, p. 186-198, 2014.

[54] M. Stemmelen, F. Pessel, V. Lapinte, S. Caillol, J. P. Habas, e J. J. Robin, "A fully biobased epoxy resin from vegetable oils: From the synthesis of the precursors by thiol-ene reaction to the study of the final material", J. Polym. Sci. Part A Polym. Chem., vol. 49, $\mathrm{n}^{\circ}$ 11, p. 2434-2444, 2011.

[55] S. Ma, T. Li, X. Liu, e J. Zhu, "Research progress on bio-based thermosetting resins", Polym. Int., vol. 65, no 2, p. 164-173, 2016.

[56] E. A. Baroncini, S. Kumar Yadav, G. R. Palmese, e J. F. Stanzione, "Recent advances in bio-based epoxy resins and bio-based epoxy curing agents", J. Appl. Polym. Sci., vol. 133, no 45, p. 1-19, 2016.

[57] X. Yang, C. Wang, S. Li, K. Huang, M. Li, W. Mao, S. Cao, e J. Xia, "Study on the synthesis of bio-based epoxy curing agent derived from myrcene and castor oil and the properties of the cured products", RSC Adv., vol. 7, n 1, p. 238-247, 2017.

[58] "Global Soybean Production 2015-2016". [Online]. Available at: http://www.globalsoybeanproduction.com/previous-year.asp.

[59] The Observatory of Economic Complexity, "Soybean oil trade", 2014. [Online]. Available at: http://atlas.media.mit.edu/en/profile/hs92/1507/.

[60] "No Title", 4 de janeiro de 2016. [Online]. Available at: http://www.projetosojabrasil.com.br/exporta-complexo-soja-2015/.

[61] Z. S. Petrovic, A. Guo, I. Javni, e W. Zhang, "Plastics and Composites 
from Soybean Oil", in Natural Fibers, Plastics and Composites, Frederick T. Wallenberger e N. E. Weston, Orgs. Kluwer Academic Publ ishers, 2004, p. 369.

[62] T. S. Omonov e J. M. Curtis, "Plant Oil-Based Epoxy Intermediates for Polymers", in Bio-Based Plant Oil Polymers and Composites, S. A. Madbouly, C. Zhang, e M. R. Kessler, Orgs. Elsevier, 2016, p. 232.

[63] M. N. Gandini e B. Alessandro, "Materials from Vegetable Oils: Major Sources, Properties and Applications", in Monomers, Polymers and Composites from Renewable Resources, M. N. Belgacem e A. Gandini, Orgs. Elsevier, 2008, p. 562.

[64] "Fats, Oils, Fatty Acids, Triglycerides - Chemical Structure". [Online]. Available at: http://www.scientificpsychic.com/fitness/fattyacids2.html.

[65] "Top-notch technology in production of oils and fats". [Online]. Available at: http://www.chempro.in/fattyacid.htm.

[66] J. T. P. Derksen, F. Petrus Cuperus, e P. Kolster, "Renewable resources in coatings technology: a review", Prog. Org. Coatings, vol. 27, no 1-4, p. 45-53, 1996.

[67] M. a R. Meier, J. O. Metzger, e U. S. Schubert, "Plant oil renewable resources as green alternatives in polymer science.", Chem. Soc. Rev., vol. 36, n 11, p. 1788-1802, 2007.

[68] A. Adhvaryu e S. Z. Erhan, "Epoxidized soybean oil as a potential source of high-temperature lubricants", Ind. Crop. Prod., vol. 15, n 3 , p. 247-254, 2002.

[69] X. Wu, X. Zhang, S. Yang, H. Chen, e D. Wang, "The study of epoxidized rapeseed oil used as a potential biodegradable lubricant", J. Am. Oil Chem. Soc., vol. 77, n 5, p. 561-563, 2000.

[70] C. Bueno-Ferrer, M. C. Garrigós, e A. Jiménez, "Characterization and thermal stability of poly (vinyl chloride) plasticized with epoxidized soybean oil for food packaging", Polym. Degrad. Stab., vol. 95, n 11 , p. 2207-2212, 2010.

[71] N. B. Samarth e P. a Mahanwar, "Modified Vegetable Oil Based Additives as a Future Polymeric Material - Review", Open J. Org. Polym. Mater., vol. 5, nº January, p. 1-22, 2015. 
[72] E. Sharmin, F. Zafar, D. Akram, M. Alam, e S. Ahmad, "Recent advances in vegetable oils based environment friendly coatings: $A$ review", Ind. Crops Prod., vol. 76, nº October, p. 215-229, 2015.

[73] P. Czub, "Application of modified natural oils as reactive diluents for epoxy resins.", Macromol. Symp., vol. 242, n 1, p. 60-64, 2006.

[74] N. Karak, "Vegetable oil-based epoxies", in Vegetable oil-based polymers, Woodhead Publishing Limited, 2012, p. 54-95.

[75] L. Montero De Espinosa e M. A. R. Meier, "Plant oils: The perfect renewable resource for polymer science?!", Eur. Polym. J., vol. 47, nº 5, p. 837-852, 2011.

[76] F. Seniha Güner, Y. Yağci, e A. Tuncer Erciyes, "Polymers from triglyceride oils", Prog. Polym. Sci., vol. 31, n 7, p. 633-670, 2006.

[77] E. V. Santiago e S. H. López, "Acrylated-Epoxidized Soybean OilBased Polymers and their use in the generation of electrically conductive polymer composites", Soybean - Bio-Active Compd., p. 231-263, 2013.

[78] S. J. Park, F. L. Jin, e J. R. Lee, "Synthesis and thermal properties of epoxidized vegetable oil.", Macromol. Rapid Commun., vol. 25, n 6, p. 724-727, 2004.

[79] J. M. Pin, N. Sbirrazzuoli, e A. Mija, "From epoxidized linseed oil to bioresin: An overall approach of epoxy/anhydride cross-linking", ChemSusChem, vol. 8, n 7, p. 1232-1243, 2015.

[80] C. A. Ulven, D. P. Wiesenborn, J. D. Espinoza, e Pérez, "Epoxidized high-oleic vegetable oils applied to composites", vol. 53, $\mathrm{n}^{\circ} 4$, p. 1167-1174, 2010.

[81] S. J. Park, F. L. Jin, e J. R. Lee, "Effect of biodegradable epoxidized castor oil on physicochemical and mechanical properties of epoxy resins", Macromol. Chem. Phys., vol. 205, n 15, p. 2048-2054, 2004.

[82] T. Saurabh, dr.Patnaik M., Bhagat S.L., e Prof.Renge V.C, "Studies on Synthesis of Biobased Epoxide Using Cottonseed Oil”, J. Adv. Eng. Res. Stud., vol. 1, n² 2, p. 279-284, 2012.

[83] S. Ahmad, F. Naqvi, E. Sharmin, e K. L. Verma, "Development of amine-acid cured Annona squamosa oil epoxy anticorrosive polymeric coatings", Prog. Org. Coatings, vol. 55, n³ 3, p. 268-275, 
2006.

[84] R. Raghavachar, R. J. Letasi, P. V. Kola, Z. Chen, e J. L. Massingill, "Rubber-toughening epoxy thermosets with epoxidized crambe oil", J. Am. Oil Chem. Soc., vol. 76, no 4, p. 511-516, 1999.

[85] C. Guo, L. Zhou, e J. Lv, "Mesua ferrea L. Seed Oil-Based Epoxy Resins", J. Appl. Polym. Sci., vol. 118, p. 128-134, 2010.

[86] O. S. Yemul, B. S. Dawane, e I. G. Shaikh, "Biodegradable Bioepoxy Resin from Mahua oil", vol. 2, no 1, p. 13-18, 2013.

[87] O. Markets, "Vernonia galamensis", vol. 62, n 5, p. 934-939, 1985.

[88] S. N. Khot, J. J. Lascala, E. Can, S. S. Morye, G. I. Williams, G. R. Palmese, S. H. Kusefoglu, e R. P. Wool, "Development and application of triglyceride-based polymers and composites", J. Appl. Polym. Sci., vol. 82, n 3, p. 703-723, 2001.

[89] M. Galià, L. M. de Espinosa, J. C. Ronda, G. Lligadas, e V. Cádiz, "Vegetable oil-based thermosetting polymers", Eur. J. Lipid Sci. Technol., vol. 112, no 1, p. 87-96, 2010.

[90] U. Biermann, W. Friedt, S. Lang, W. Lühs, G. Machmüller, J. Metzger, e M. P. Schneider, "New syntheses with oils and fats as renewable raw materials for the chemical industry", Angew. Chemie Int. Ed., vol. 39, no 13, p. 2206-2224, 2000.

[91] S. A. Madbouly, C. Zhang, e M. R. Kessler, Orgs., Bio-based Plant oil polymers and composites. 2011.

[92] S. Sinadinović-Fišer, M. Janković, e Z. S. Petrović, "Kinetics of in situ epoxidation of soybean oil in bulk catalyzed by ion exchange resin", J. Am. Oil Chem. Soc., vol. 78, n 7, p. 725-731, 2001.

[93] T. Vlček e Z. S. Petrović, "Optimization of the chemoenzymatic epoxidation of soybean oil", J. Am. Oil Chem. Soc., vol. 83, n 3, p. 247-252, 2006.

[94] V. V. Goud, N. C. Pradhan, e A. V. Patwardhan, "Epoxidation of karanja (Pongamia glabra) oil by H2O2", J. Am. Oil Chem. Soc., vol. 83, no 7, p. 635-640, 2006.

[95] P. Saithai, J. Lecomte, E. Dubreucq, e V. Tanrattanakul, "Effects of different epoxidation methods of soybean oil on the characteristics of acrylated epoxidized soybean oil-co-poly(methyl methacrylate) 
copolymer", Express Polym. Lett., vol. 7, no 11, p. 910-924, 2013.

[96] M. Fariasa, M. Martinelli, e G. K. Rolimb, "Immobilized molybdenum acetylacetonate complex on montmorillonite $\mathrm{K}-10$ as catalyst for epoxidation of vegetable oils", Appl. Catal. A Gen., vol. 403, nº 2, p. 119-127, 2011.

[97] W. F. Baughman e G. Jamieson, "The Chemical Composition of Soya Bean Oil”, J. Am. Chem. Soc., vol. 44, no 12, p. 2947-2952, 1922.

[98] D. Ratna e A. K. Banthia, "Epoxidized soybean oil toughened epoxy adhesive", J. Adhes. Sci. Technol., vol. 14, no 1, p. 15-25, 2000.

[99] C. L. Petzhold, A. P. O. Costa, e A. E. Gerbase, "Dynamic mechanical and thermal behavior of epoxy resins based on soybean oil", J. Am. Oil Chem. Soc., vol. 79, nº 8, p. 797-802, 2002.

[100] F. I. Altuna, L. H. Esposito, R. A. Ruseckaite, e P. M. Stefani, "Thermal and mechanical properties of anhydride-cured epoxy resins with different contents of biobased epoxidized soybean oil", J. Appl. Polym. Sci., vol. 120, p. 789-798, 2011.

[101] T. Tsujimoto, T. Takayama, e H. Uyama, "Biodegradable shape memory polymeric material from epoxidized soybean oil and polycaprolactone", Polymers (Basel)., vol. 7, no 10, p. 2165-2174, 2015.

[102] "Phenalkamine cure agents", https://www.cardolite.com/phenalkamine. .

[103] G. M. Roudsari, A. K. Mohanty, e M. Misra, "Study of the Curing Kinetics of Biobased Epoxy Resin in the Presence of a Biobased Hardener", ACS Sustain. Eng., n Epon 828, p. 2111-2118, 2014.

[104] J. V Crivello, R. Narayan, e S. S. Sternstein, "Fabrication and Mechanical Characterization of Glass Fiber Reinforced UV-Cured Composites from", J. Appl. Polym. Sci., vol. 64, n 11, p. 2073-2087, 1997.

[105] A. P. Gupta, S. Ahmad, e A. Dev, "Modification of Novel Bio-Based Resin-Epoxidized Soybean Oil by Conventional Epoxy Resin", Polym. Eng. Sci., p. 1087-1091, 2011.

[106] S. J. Park, F. L. Jin, e J. R. Lee, "Thermal and mechanical properties of tetrafunctional epoxy resin toughened with epoxidized soybean oil", 
Mater. Sci. Eng. A, vol. 374, no 1-2, p. 109-114, 2004.

[107] F. L. Jin e S. J. Park, "Impact-strength improvement of epoxy resins reinforced with a biodegradable polymer", Mater. Sci. Eng. A, vol. 478, $n^{0} 1-2$, p. 402-405, 2008.

[108] G. Liang e K. Chandrashekhara, "Cure kinetics and rheology characterization of soy-based epoxy resin system", J. Appl. Polym. Sci., vol. 102, n 4, p. 3168-3180, 2006.

[109] V. Flanigan, "Soybean Based Epoxy Resin and Methods of Making and Use", 2013.

[110] J. Zhu, K. Chandrashekhara, V. Flanigan, e S. Kapila, "Curing and Mechanical Characterization of a Soy-Based Epoxy Resin System", J. Appl. Polym. Sci., vol. 91, p. 3513-3518, 2004.

[111] A. Shabeer, A. Garg, S. Sundararaman, K. Chandrashekhara, V. Flanigan, e S. Kapila, "Dynamic mechanical characterization of a soy based epoxy resin system", J. Appl. Polym. Sci., vol. 98, n 4, p. 1772-1780, 2005.

[112] L. R. D. A. Shabeer, S. Sundararaman, K. Chandrashekhara, "Physicochemical Properties and Fracture Behavior of Soy-Based Resin", J. Appl. Polym. Sci., vol. 105, p. 656-663, 2007.

[113] F. L. Jin e S. J. Park, "Thermomechanical behavior of epoxy resins modified with epoxidized vegetable oils", Polym. Int., vol. 57, n 4, p. 577-583, 2008.

[114] Z. Liu e S. Z. Erhan, "Preparation of soybean oil polymers with high molecular weight", J. Polym. Environ., vol. 18, n 3, p. 243-249, 2010.

[115] A. P. Gupta, S. Ahmad, e A. Dev, "Development of Novel Bio-Based Soybean Oil Epoxy Resins as a Function of Hardener Stoichiometry", Polym. Plast. Technol. Eng., vol. 49, nº 7, p. 657-661, 2010.

[116] J. M. España, L. Sánchez-Nacher, T. Boronat, V. Fombuena, e R. Balart, "Properties of biobased epoxy resins from epoxidized soybean oil (ESBO) cured with maleic anhydride (MA)", JAOCS, J. Am. Oil Chem. Soc., vol. 89, n 11, p. 2067-2075, 2012.

[117] R. Wang e T. P. Schuman, "Vegetable oil-derived epoxy monomers and polymer blends: A comparative study with review", Express Polym. Lett., vol. 7, nº 3, p. 272-292, 2012. 
[118] M. D. Samper, V. Fombuena, T. Boronat, D. García-Sanoguera, e R. Balart, "Thermal and mechanical characterization of epoxy resins (ELO and ESO) cured with anhydrides", JAOCS, J. Am. Oil Chem. Soc., vol. 89, n 8, p. 1521-1528, 2012.

[119] "Cashew nuts, fresh or dried trade", http://atlas.media.mit.edu/en/profile/hs92/080130/, 2014. .

[120] E. M. Papademetriou, M. K. Herath, "Integrated production practices of cashew in Asia", in RAP Publication (FAO)., 1998.

[121] S. E. Mazzetto, D. Lomonaco, e G. Mele, "Oleo da castanha de caju: Oportunidades e desafios no contexto do desenvolvimento e sustentabilidade industrial”, Quim. Nova, vol. 32, n 3, p. 732-741, 2009.

[122] E. A. Taiwo, "Cashew Nut Shell Oil - A Renewable and Reliable Petrochemical Feedstock", in Advances in Petrochemicals, V. Patel, Org. 2015, p. 3-26.

[123] T. Rosen e D. B. Fordice, "Cashew nut dermatitis", South. Med. J., vol. 87, n4, p. 543-546, 1994.

[124] U. Talasila e K. B. Shaik, "Quality, spoilage and preservation of cashew apple juice: A review”, J. Food Sci. Technol., vol. 52, nº 1, p. 54-62, 2015.

[125] "http://fotos.estadao.com.br/fotos/cultura,tratado-com-jeito-o-cajuvira-doce-salgado-suco-vinho-caipirinha,191874". .

[126] International Nut \& Dried Fruit Council, "INC Global Statistical Review 2014-2015”, 2015.

[127] "Municípios no Brasil que comercializam Castanha e Caju", http://legacy.dataviva.info/pt/apps/builder/tree_map/secex/all/020801 /all/bra/?color=color\&depth=bra_9\&year=2014\&controls=false\&size= export_val, 2014. .

[128] J. H. Tyman, Synthetic and natural phenols. Elsevier, 1996.

[129] P. H. Gedam e P. S. Sampathkumaran, "Cashew nut shell liquid: Extraction, chemistry and applications", Prog. Org. Coatings, vol. 14, $\mathrm{n}^{\circ} 2$, p. 115-157, 1986.

[130] M. C. Lubi e E. T. Thachil, "Cashew nut shell liquid (CNSL) - a versatile monomer for polymer synthesis", Des. Monomers Polym., 
vol. 3, no 2, p. 123-153, 2000.

[131] P. Kumar, R. Paramashivappa, P. J. Vithayathil, P. V. Subba, e S. Rao, "Process for Isolation of Cardanol from Technical Cashew Anacardium occidentale L .) Nut Shell Liquid", J. Agric. Food Chem., vol. 50, p. 4705-4708, 2002.

[132] "No Title", $\quad$ http://www.eattheweeds.com/wpcontent/uploads/2015/10/CashewFruit.jpg. .

[133] "No Title", http://www.Icbuffalo.com/cardanol/. .

[134] "No Title", http://business.google.com/website/monalisa-cashewproduct. .

[135] V. S. Balachandran, S. R. Jadhav, P. K. Vemula, e G. John, "Recent advances in cardanol chemistry in a nutshell: from a nut to nanomaterials", Chem. Soc. Rev., vol. 42, no 2, p. 427-438, 2013.

[136] R. Amorati, G. F. Pedulli, L. Valgimigli, O. a. Attanasi, P. Filippone, C. Fiorucci, e R. Saladino, "Absolute rate constants for the reaction of peroxyl radicals with cardanol derivatives", J. Chem. Soc. Perkin Trans. 2, vol. 4, no 11, p. 2142-2146, 2001.

[137] G. Mele e G. Vasapollo, "Fine Chemicals and New Hybrid Materials From Cardanol”, Mini. Rev. Org. Chem., vol. 5, p. 243-253, 2008.

[138] E. Can, E. Kinaci, e G. R. Palmese, "Preparation and characterization of novel vinyl ester formulations derived from cardanol", Eur. Polym. J., vol. 72, p. 129-147, 2015.

[139] A. Devi e D. Srivastava, "Cardanol-based novolac-type phenolic resins. I. A kinetic approach", J. Appl. Polym. Sci., vol. 102, n 3, p. 2730-2737, 2006.

[140] N. Le Huong, N. H. Nieu, T. T. M. Tan, e U. J. Griesser, "Cardanolphenol-formaldehyde resins. Thermal analysis and characterization", Macromol. Mater. Eng., vol. 243, n 1, p. 77-85, 1996.

[141] S. Dworakowska, A. Cornille, D. Bogdal, B. Boutevin, e S. Caillol, "Formulation of bio-based epoxy foams from epoxidized cardanol and vegetable oil amine", Eur. J. Lipid Sci. Technol., vol. 117, n 11, p. 1893-1902, 2015.

[142] S. Kanehashi, K. Yokoyama, R. Masuda, T. Kidesaki, K. Nagai, e T. Miyakoshi, "Preparation and characterization of cardanol-based 
epoxy resin for coating at room temperature curing", J. Appl. Polym. Sci., vol. 130, n 4, p. 2468-2478, 2013.

[143] C. Voirin, S. Caillol, N. V. Sadavarte, B. V. Tawade, B. Boutevin, e P. P. Wadgaonkar, "Functionalization of cardanol: towards biobased polymers and additives", Polym. Chem., vol. 5, no 9, p. 3142-3162, 2014.

[144] M. Sultania, J. S. P. Rai, e D. Srivastava, "Process modeling, optimization and analysis of esterification reaction of cashew nut shell liquid (CNSL)-derived epoxy resin using response surface methodology", J. Hazard. Mater., vol. 185, no 2-3, p. 1198-1204, 2011.

[145] Z. Liu, J. Chen, G. Knothe, X. Nie, e J. Jiang, "Synthesis of Epoxidized Cardanol and Its Antioxidative Properties for Vegetable Oils and Biodiesel”, ACS Sustain. Chem. Eng, vol. 4, n 3, p. 901-906, 2016.

[146] M. Sultania, J. S. P. Rai, e D. Srivastava, "Studies on the synthesis and curing of epoxidized novolac vinyl ester resin from renewable resource material", Eur. Polym. Journal, vol. 46, n 10, p. 2019-2032, 2010.

[147] E. Darroman, N. Durand, B. Boutevin, e S. Caillol, "Improved cardanol derived epoxy coatings", Prog. Org. Coatings, vol. 91, n JANUARY, p. 9-16, 2016.

[148] R. Ambrožič, U. Šebenik, e M. Krajnc, "Synthesis, curing kinetics, thermal and mechanical behavior of novel cardanol-based benzoxazines", Polymer (Guildf)., vol. 76, p. 203-212, 2015.

[149] R. L. Quirino, T. F. Garrison, e M. R. Kessler, "Matrices from vegetable oils, cashew nut shell liquid, and other relevant systems for biocomposite applications", Green Chem., vol. 16, no 4, p. 17001715, 2014.

[150] P. Kasemsiri, A. Neramittagapong, e P. Chindaprasirt, "Curing kinetic, thermal and adhesive properties of epoxy resin cured with cashew nut shell liquid", Thermochim. Acta, vol. 600, p. 20-27, 2015.

[151] P. MB, P. RG, e P. VS, "Effects of reactive diluent diepoxidized cardanol and epoxy fortifier on curing kinetics of epoxy resin", J. Therm. Anal. Calorim., vol. 35, p. 47-57, 1989. 
[152] F. Jaillet, E. Darroman, A. Ratsimihety, R. Auvergne, B. Boutevin, e S. Caillol, "New biobased epoxy materials from cardanol", Eur. J. Lipid Sci. Technol., vol. 116, n 1, p. 63-73, 2014.

[153] R. Auvergne, S. Caillol, G. David, B. Boutevin, e J. P. Pascault, "Biobased thermosetting epoxy: Present and future", Chem. Rev., vol. 114, no 2, p. 1082-1115, 2014.

[154] R. Ambrožič, U. Šebenik, e M. Krajnc, "Epoxy emulsions stabilized with reactive bio-benzoxazine surfactant from epoxidized cardanol for coatings", Eur. Polym. J., vol. 81, p. 138-151, 2016.

[155] D. Ratna, "Thermal properties of thermosets", in Thermosets: Structure, properties and applications, Qipeng Guo, Org. 2012, p. 6288.

[156] J. M. Raquez, M. Deléglise, M. F. Lacrampe, e P. Krawczak, "Thermosetting (bio)materials derived from renewable resources: A critical review", Prog. Polym. Sci., vol. 35, n 4, p. 487-509, 2010.

[157] W. R. Ashcroft, "Curing agents for epoxy resins", in Chemistry and Technology of Epoxy Resins, Springer Netherlands, 1993, p. 37-71.

[158] M. Fache, C. Mont??r??mal, B. Boutevin, e S. Caillol, "Amine hardeners and epoxy cross-linker from aromatic renewable resources", Eur. Polym. J., vol. 73, p. 344-362, 2015.

[159] P. Morgan, "Polymer Matrices for Carbon Fiber Composites", in Carbon Fibers and Their Composites, Taylor \& Francis, 2005.

[160] M. Kathalewar e A. Sabnis, "Effect of molecular weight of phenalkamines on the curing, mechanical, thermal and anticorrosive properties of epoxy based coatings", Prog. Org. Coatings, vol. 84, p. 79-88, 2015.

[161] Y. Liu, J. Wang, e S. Xu, "Synthesis and curing kinetics of cardanolbased curing agents for epoxy resin by in situ depolymerization of paraformaldehyde", J. Polym. Sci. Part A Polym. Chem., vol. 52, nº 4, p. 472-480, 2014.

[162] A. L. F. S. D'Almeida, V. Calado, D. W. Barreto, e J. R. M. D'Almeida, "Acetilação da fibra de bucha (Luffa cylindrica)", Polímeros, vol. 15, $n^{\circ}$ 1, p. 59-62, 2005.

[163] K. Goda e Y. Cao, "Research and Development of Fully Green 
Composites Reinforced with Natural Fibers", J. Solid Mech. Mater. Eng., vol. 1, n 9, p. 1073-1084, 2007.

[164] M. John e S. Thomas, "Biofibres and biocomposites", Carbohydr. Polym., vol. 71, n 3, p. 343-364, fev. 2008.

[165] R. M. Kozłowski, Handbook of natural fibres. 2012.

[166] O. Faruk e M. S. Ain, Developments in Fiber-Reinforced Polymer (FRP) Composites for Civil Engineering. Elsevier, 2013.

[167] D. B. Dittenber e H. V. S. GangaRao, "Critical review of recent publications on use of natural composites in infrastructure", Compos. Part A Appl. Sci. Manuf., vol. 43, n 8, p. 1419-1429, ago. 2012.

[168] R. Ulrich, D. J. Nickel, e S. Herrmann, "High Performance Applications of Plant Fibres in Aerospace and Related Industries", in Natural Fibres Performance Forum, 1999.

[169] V. M. Fonseca, V. J. Fernandas, L. H. De Carvalho, e J. R. M. D'Almeida, "Evaluation of the mechanical properties of sisal-polyester composites as a function of the polyester matrix formulation", J. Appl. Polym. Sci., vol. 94, p. 1209-1217, 2004.

[170] Y. Li, Y.-W. Mai, e L. Ye, "Sisal fibre and its composites: a review of recent developments", Compos. Sci. Technol., vol. 60, n 2000, p. 2037-2055, 2000.

[171] S. N. Monteiro, L. A. H. Terrones, e J. R. M. D'Almeida, "Mechanical performance of coir fiber/polyester composites", Polym. Test., vol. 27, $n^{\circ}$ 5, p. 591-595, ago. 2008.

[172] O. L. S. Alsina, L. H. De Carvalho, F. G. Ramos Filho, e J. R. M. D'Almeida, "Thermal properties of hybrid lignocellulosic fabricreinforced polyester matrix composites", Polym. Test., vol. 24, p. 8185, 2005.

[173] H. P. S. A. Khalil, I. U. H. Bhat, M. Jawaid, A. Zaidon, D. Hermawan, e Y. S. Hadi, "Bamboo fibre reinforced biocomposites: A review", Mater. Des., vol. 42, p. 353-368, 2012.

[174] D'Almeida A. L. F. S., "Influência de Tratamentos Superficiais no Comportamento Mecânico de Compósitos Poliméricos Reforçados por Fibras Lignocelulósicas", Universidade Federal do Rio de Janeiro (UFRJ), 2007. 
[175] J. F. de Deus, S. N. Monteiro, e J. R. M. d'Almeida, "Effect of drying, molding pressure, and strain rate on the flexural mechanical behavior of piassava (Attalea funifera Mart) fiber-polyester composites", Polym. Test., vol. 24, n 6, p. 750-755, set. 2005.

[176] M. Desousa, S. Monteiro, e J. D'Almeida, "Evaluation of pretreatment, size and molding pressure on flexural mechanical behavior of chopped bagasse-polyester composites", Polym. Test., vol. 23, n' 3, p. 253-258, maio 2004.

[177] G. C. Stael, M. I. B. Tavares, e J. R. M. D'Almeida, "Impact behavior of sugarcane bagasse waste-EVA composites", Polym. Test., vol. 20, p. 869-872, 2001.

[178] K. Murali Mohan Rao, K. Mohana Rao, e a. V. Ratna Prasad, "Fabrication and testing of natural fibre composites: Vakka, sisal, bamboo and banana", Mater. Des., vol. 31, no 1, p. 508-513, 2010.

[179] R. S. Bacellar, "Caracterização microestrutural e mecânica de resíduos da agroindústria", Pontifícia Universidade Católica do Rio de Janeiro, 2010.

[180] X. Hou, F. Sun, D. Yan, H. Xu, Z. Dong, Q. Li, e Y. Yang, "Preparation of lightweight polypropylene composites reinforced by cotton stalk fibers from combined steam flash-explosion and alkaline treatment", J. Clean. Prod., p. 1-9, 2014.

[181] C. I. T. Navarro, "Caracterização Microestrutural das Fibras Naturais : Etlingera elatior, Costus e Helicônia bihai Claudia Ines Telleria Navarro Caracterização Microestrutural das Fibras Naturais: Etlingera elatior, Costus, Helicônia bihai", Pontificia Universidade Católica, 2011.

[182] M. M. F. Ashby, Materials Selection in Mechanical Design, $4^{\circ}$ ed. Elsevier, 2011.

[183] M.-J. Le Guen, R. H. Newman, A. Fernyhough, S. J. Hill, e M. P, "Correlations Between the Physiochemical Characteristics of Plant Fibres and Their Mechanical Properties", in Natural Fibres: Advances in Science and Technology Towards Industrial Applications, Springer, 2015.

[184] U. G. K. Wegst e M. F. Ashby, "The mechanical efficiency of natural 
materials", Philos. Mag., vol. 21, n² 21, p. 2167-2181, 2004.

[185] C. B. Pacheco, "Síntesis de carboximetilcelulosa ( CMC ) a partir de pastas de plantas anuales", Universitat Rovira i Virgili, 2002.

[186] E. Sjöström, Wood chemistry, fundamentals and applications, vol. 252. Academic Press, Inc, 1993.

[187] G. Cheng, X. Zhang, B. Simmons, e S. Seema, "Theory, practice and prospects of $\mathrm{X}$-ray and neutron scattering for lignocellulosic biomass characterization: towards understanding biomass pretreatment", Energy Environ. Sci.

[188] L. Berglund, "New concepts in natural fibre composites", in Proceedings of the 27th Risø International Symposium on Materials Science: Polymer Composite Materials for Wind Power Turbines NEW, 2006, p. 1-9.

[189] O. Gifford e P. Drive, "Velcro mechanics in wood", Nat. Mater., vol. 2, no 12, p. 775-776, 2003.

[190] A. Carlos e V. Seniuk, "Caracterização Físico-Química de Materiais Baseados em Celulose", Centro de desenvolvimento da tecnologia nuclear - CDTN, 2008.

[191] R. E. Alves, "Caracterização de fibras lignocelulósicas pré-tratadas por meio de técnicas espectroscópicas e microscópicas ópticas de alta resolução", Universidade de São Paulo, 2011.

[192] K. H. Gardner e J. Blackwell, "The hydrogen bonding in native cellulose", Biochim. Biophys. Acta (BBA)-General Subj., vol. 343, n 1, p. 232-237, 1974.

[193] H. Zhu, W. Luo, P. N. Ciesielski, Z. Fang, J. Y. Zhu, G. Henriksson, M. E. Himmel, e L. Hu, "Wood-Derived Materials for Green Electronics, Biological Devices, and Energy Applications", Chem. Rev., vol. 116, n 16, p. 9305-9374, 2016.

[194] L. V. A. Gurgel, "Mercerização e modificação química de celulose e bagaço de cana-de-açúcar com anidrido succínico e trietilenotetramina: Preparação de novos materiais quelantes para a adsorção de $\mathrm{Pb}$ (II), Cd (II), Cr (VI) e Cu (II)", 2007.

[195] A. Brandt, J. Gräsvik, J. P. Hallett, e T. Welton, "Deconstruction of lignocellulosic biomass with ionic liquids", Green Chem., vol. 15, nº 3 , 
p. 550-583, 2013.

[196] U. Klock, G. I. B. Muñiz, J. H. Anzaldo, e A. Andrade, "Química da Madeira", Universidade Federal do Paraná, 2005.

[197] G. Neutelings, "Lignin variability in plant cell walls: Contribution of new models", Plant Sci., vol. 181, n 4, p. 379-386, 2011.

[198] M. W. K. P. Silva, R. H. G. Ranil, e R. M. Fonseka, "Luffa cylindrica (L.) M . Roemer (Sponge Gourd- Niyan wetakolu): An Emerging High Potential Underutilized Cucurbit", Trop. Agric. Researc, vol. 23, n 2 , p. 186-191, 2012.

[199] "Luffa aegyptiaca (loofah)". [Online]. Available at: http://www.cabi.org/isc/datasheet/31693.

[200] "No Title", http://www.cabi.org/isc/datasheet/31693. .

[201] K. G. Satyanarayana, F. Wypych, J.L.Guimarães, S. C. Amico, T. H. D. Sydenstricker, e L. P. Ramos, "Studies on Natural Fibers of Brazil and Green Composites", Met. Mater. Process., vol. 17, $\mathrm{n}^{\circ} 3-4, \mathrm{p}$. 183-194, 2005.

[202] R. D. Anandjiwala, Textiles for sustainable development. Nova Publishers, 2007.

[203] O. Faruk e M. Sain, Orgs., Biofiber Reinforcement in Composite. Elsevier.

[204] G. Siqueira, J. Bras, e A. Dufresne, "Luffa cylindrica as a lignocellulosic source of fiber, microfibrillated cellulose and cellulose nanocrystals", BioResources, vol. 5, n², p. 727-740, 2010.

[205] I. O. Oboh e E. O. Aluyor, "Luffa cylindrica - an emerging cash crop", African J. Agric. Res., vol. 4, nº August, p. 727-740, 2009.

[206] V. O. a. A. Tanobe, T. H. D. D. Sydenstricker, M. Munaro, e S. C. Amico, "A comprehensive characterization of chemically treated Brazilian sponge-gourds (Luffa cylindrica)", Polym. Test., vol. 24, nº 4, p. 474-482, jun. 2005.

[207] M. P. Oliveira, "Propriedades mecânicas e térmicas dos compósitos poliméricos reforçados por fibras de bucha", Instituto Militar de Engenharia, Rio de Janeiro, 2013.

[208] M. Paglicawan, "Loofah fiber as reinforcement material for composite", ... J. Sci., vol. 134, nº December, p. 113-120, 2005. 
[209] J. Shen, Y. Min Xie, X. Huang, S. Zhou, e D. Ruan, "Mechanical properties of luffa sponge.", J. Mech. Behav. Biomed. Mater., vol. 15, p. 141-52, nov. 2012.

[210] A. Saeed e M. Iqbal, "Loofa (Luffa cylindrica) Sponge: Review of Development of the Biomatrix as a Tool for Biotechnological Applications", Biotechnol. Prog., vol. 29, n 3, p. 573-600, 2014.

[211] Saueprasearsit, "Biosorption of lead $(\mathrm{Pb2}+)$ by Luffa cylindrica Fiber...Saueprasearsit et al., 2010.pdf”. 2010.

[212] I. Oboh, E. Aluyor, e T. Audu, "Post-treatment of Produced water before discharge using Luffa cylindrica", Leonardo Electron. J. Pract. Technol., vol. 7, n 14, p. 57-64, 2009.

[213] I. O. Oboh, E. O. Aluyor, e T. O. K. Audu, "Application of Luffa Cylindrica in Natural form as Biosorbent to Removal of Divalent Metals from Aqueous Solutions - Kinetic and Equilibrium Study", Einschlag, F.S.G. (Ed.), Waste Water-Treatment Reutil. InTech, vol. 546, p. 195-212, 2011.

[214] T. M. Mugambi, "Removal of textile dyes from aqueous solutions using luffa cylindrica of kenya origin: kinetic and equilibrium sorption studies", University of Nairobi, 2009.

[215] O. Segun Esan, O. Nurudeen Abiola, O. Owoyomi, C. Olumuyiwa Aboluwoye, e M. Olubunmi Osundiya, "Adsorption of Brilliant Green onto Luffa Cylindrical Sponge: Equilibrium, Kinetics, and Thermodynamic Studies", ISRN Phys. Chem., vol. 2014, p. 1-12, 2014.

[216] J. C. O. Macuja, L. N. Ruedas, e R. C. Nueva España, "Utilization of cellulose from Luffa cylindrica fiber as binder in acetaminophen tablets", Adv. Environ. Chem., vol. 2015, p. 1-8, 2015.

[217] A. I. Bamgboye e O. O. Oniya, "Fuel properties of loofah (Luffa cylindrica L.) biofuel blended with diesel", African J. Environ. Sci. Technol., vol. 6, nº September, p. 346-352, 2012.

[218] C. A. Boynard e J. R. M. D'Almeida, "Water absorption by sponge gourd ( luffa cylindrica ) -polyester composite materials", J. Mater. Sci. Lett., vol. 8, p. 1789-1791, 1999.

[219] C. a. Boynard e J. R. M. D’Almeida, "Morphological Characterization 
and Mechanical Behavior of Sponge Gourd ( Luffa Cylindrica )Polyester Composite Materials", Polym. Plast. Technol. Eng., vol. 39, n० 3, p. 489-499, maio 2000.

[220] K. Kaewtatip e J. Thongmee, "Studies on the structure and properties of thermoplastic starch/luffa fiber composites", Mater. Des., vol. 40, p. 314-318, set. 2012.

[221] L. Ghali, M. Aloui, M. Zidi, H. Bendaly, S. M'sahli, e F. Sakli, "Effect of Chemical Modification of Luffa Cylindrica Fibers on The Mechanical and Hygrothermal Behaviours of Polyester/Luffa Composites", Bioresources, vol. 6, p. 3836-3849, 2011.

[222] V. Tanobe, T. Flores-Sahagun, S. Amico, G. Muniz, e K. Satyanarayana, "Sponge Gourd (Luffa Cylindrica) Reinforced Polyester Composites: Preparation and Properties", Def. Sci. J., vol. 64, no 3, p. 273-280, maio 2014.

[223] "Effects of natural fibre surface on composite properties : a review", eddBE2011 Proc., p. 94-99, 2007.

[224] X. Li, L. G. Tabil, e S. Panigrahi, "Chemical treatments of natural fiber for use in natural fiber-reinforced composites: A review", J. Polym. Environ., vol. 15, n 1, p. 25-33, 2007.

[225] A. L. F. S. Almeida, J. R. M. Almeida, D. W. Barreto, e V. Calado, "Effect of Surface Treatments on the Thermal Behavior and Tensile Strength of Piassava ( Attalea funifera ) Fibers", J Appl Polym Sci, vol. 120, p. 2508-2515, 2011.

[226] F. T. Wallenberger e N. Weston, Orgs., Natural Fibers, Plastics and Composites. Kluwer Academic Publishers, 2003.

[227] M. J. John e R. D. Anandjiwala, "Recent Developments in Chemical Modification and Characterization of Natural Fiber-Reinforced Composites", Polym. Polym. Compos., vol. 29, n 2, p. 187-207, 2008.

[228] V. Tserki, N. E. Zafeiropoulos, F. Simon, e C. Panayiotou, "A study of the effect of acetylation and propionylation surface treatments on natural fibres", Compos. Part A Appl. Sci. Manuf., vol. 36, no 8, p. 1110-1118, ago. 2005.

[229] D. K. Himadri Das, "Recent Development of Fiber Reinforced 
Composite Materials", Biosens. Nanotechnol., vol. 37, p. 441-495, 2014.

[230] A. K. Bledzki, A. A. Mamun, M. Lucka-Gabor, e V. S. Gutowski, "The effects of acetylation on properties of flax fibre and its polypropylene composites", Express Polym. Lett., vol. 2, n 6, p. 413-422, 2008.

[231] Santino de Melo, "Investigação das propriedades mecânicas e adesão interfacial dos compósitos de polipropileno virgem e reciclado reforçados com fibras e microfibras de bambu", Universidade Federal do Ceará, 2016.

[232] N. E. Zafeiropoulos, D. R. Williams, C. A. Baillie, e F. L. Matthews, "Engineering and characterization of t", Compos. Part A, vol. 33, p. 1083-1093, 2002.

[233] S. L. Fávaro, T. A. Ganzerli, A. G. V de Carvalho Neto, O. R. R. F. da Silva, e E. Radovanovic, "Chemical, morphological and mechanical analysis of sisal fiber-reinforced recycled high-density polyethylene composites", Express Polym. Lett., vol. 4, n 8, p. 465-473, 2010.

[234] N. Mokaloba e R. Batane, "The effects of mercerization and acetylation treatments on the properties of sisal fiber and its interfacial adhesion characteristics on polypropylene", Int. J. Eng. Sci. Technol., vol. 6, nº 4, p. 83-97, 2014.

[235] N. . Zafeiropoulos, C. . Baillie, e J. . Hodgkinson, "Engineering and characterisation of the interface in flax fibre/polypropylene composite materials. Part II. The effect of surface treatments on the interface", Compos. Part A Appl. Sci. Manuf., vol. 33, n 9, p. 1185-1190, set. 2002.

[236] C. A. Boynard, S. N. Monteiro, e J. R. M. D'Almeida, "Aspects of alkali treatment of sponge gourd (Luffa cylindrica) fibers on the flexural properties of polyester matrix composites", J. Appl. Polym. Sci., vol. 87, no 12, p. 1927-1932, 2003.

[237] I. Van de Weyenberg, T. Chi Truong, B. Vangrimde, e I. Verpoest, "Improving the properties of UD flax fibre reinforced composites by applying an alkaline fibre treatment", Compos. Part A Appl. Sci. Manuf., vol. 37, n 9, p. 1368-1376, 2006.

[238] L. Yan, N. Chouw, e X. Yuan, "Improving the mechanical properties 
of natural fibre fabric reinforced epoxy composites by alkali treatment", J. Reinf. Plast. Compos., vol. 31, n 6, p. 425-437, fev. 2012.

[239] A. C. H. Barreto, D. S. Rosa, P. B. A. Fechine, e S. E. Mazzetto, "Properties of sisal fibers treated by alkali solution and their application into cardanol-based biocomposites", Compos. Part $A$ Appl. Sci. Manuf., vol. 42, nº 5, p. 492-500, 2011.

[240] A. Orue, A. Eceiza, C. Peña-Rodriguez, e A. Arbelaiz, "Water uptake behavior and young modulus prediction of composites based on treated sisal fibers and poly(lactic acid)", Materials (Basel)., vol. 9, $\mathrm{n}^{\circ}$ 5, p. 1-15, 2016.

[241] S. K. Saw, R. Purwar, S. Nandy, J. Ghose, e G. Sarkhel, "Fabrication, Characterization, and Evaluation of Luffa cylindrica Fiber Reinforced Epoxy Composites", Bioresources, vol. 8, p. 4805-4826, 2013.

[242] M. Y. Hashim, M. N. Roslan, A. M. Amin, A. Mujahid, e A. Zaidi, "Mercerization Treatment Parameter Effect on Natural Fiber Reinforced Polymer Matrix Composite : A Brief Review", World Acad. Sci. Eng. Technol., vol. 6, n 8, p. 1638-1644, 2012.

[243] A. Razera, "Fibras lignocelulósicas como agente de reforço de compósitos de matriz fenólica e lignofenólica", Universidade de São Paulo, 2006.

[244] L. Ghali, S. Msahli, M. Zidi, e F. Sakli, "Effect of pre-treatment of Luffa fibres on the structural properties", Mater. Lett., vol. 63, n 1, p. 6163, jan. 2009.

[245] F. L. Bastian, C. D. E. Fibras, e C. D. E. Sisal, "Estudo da Influência do Tratamento Alcalino/Mecânico nas Propriedades Mecânicas de Compósitos de Fibras Curtas de Sisal", Universidad Federal de Rio de Janeiro, 2014.

[246] J. F. Revol, A. Dietrich, e D. A. I. Goring, "Effect of mercerization on the crystallite size and crystallinity index in cellulose from different sources", Can. J. Chem., vol. 65, no 8, p. 1724-1725, 1987.

[247] A. Orue, A. Jauregi, U. Unsuain, J. Labidi, A. Eceiza, e A. Arbelaiz, "The effect of alkaline and silane treatments on mechanical properties and breakage of sisal fibers and poly(lactic acid)/sisal fiber 
composites", Compos. Part A Appl. Sci. Manuf., vol. 84, p. 186-195, 2016.

[248] L. Y. Mwaikambo e M. P. Ansell, "Hemp fibre reinforced cashew nut shell liquid composites", Compos. Sci. Technol., vol. 63, n 9, p. 1297-1305, 2003.

[249] N. Sgriccia, M. C. Hawley, e M. Misra, "Characterization of natural fiber surfaces and natural fiber composites", Compos. Part A Appl. Sci. Manuf., vol. 39, n 10, p. 1632-1637, 2008.

[250] A. C. H. Barreto, M. A. Esmeraldo, D. S. Rosa, P. B. A. Fechine, e S. E. Mazzetto, "Cardanol Biocomposites Reinforced with Jute Fiber: Microstructure, Biodegradability, and Mechanical Properties", Polym. Compos., vol. 16, n 2, p. 1928-1937, 2010.

[251] B. F. Yousif, A. Shalwan, C. W. Chin, e K. C. Ming, "Flexural properties of treated and untreated kenaf/epoxy composites", Mater. Des., vol. 40, p. 378-385, 2012.

[252] A. A. Brancato, "Effect of Progressive Recycling on Cellulose Fiber Surface Properties", 2008.

[253] J. M. B. Fernandes Diniz, M. H. Gil, e J. A. A. M. Castro, "Hornification - Its origin and interpretation in wood pulps", Wood Sci. Technol., vol. 37, nº 6, p. 489-494, 2004.

[254] S. F. D. Santos, G. H. D. Tonoli, J. E. B. Mejia, J. Fiorelli, e H. Savastano Jr, "Non-conventional cement-based composites reinforced with vegetable fibers: A review of strategies to improve durability", Mater. Construcción, vol. 65, p. 317, 2015.

[255] J. Claramunt, M. Ardanuy, J. A. García-Hortal, e R. D. T. Filho, "The hornification of vegetable fibers to improve the durability of cement mortar composites", Cem. Concr. Compos., vol. 33, n 5, p. 586-595, 2011.

[256] J. E. M. Ballesteros, "Compósitos cimentícios reforçados com polpa celulósica tratada por hornificação para aplicação em construções rurais", Universidade de São Paulo, 2014.

[257] P. R. L. Lima, S. R. Ferreira, e T. Filho, "Effect of sisal fiber hornification on the adhesion with portland cement matrices", Rev. Matéria, vol. 17, nº 2, p. 1024-1034, 2012. 
[258] S. R. Ferreira, P. R. . Lima, F. A. Silva, e R. D. Toledo Filho, "Effect of Sisal Fiber Hornification on the Fiber-Matrix Bonding Characteristics and Bending Behavior of Cement Based Composites", Key Eng. Mater., vol. 600, p. 421-432, 2014.

[259] Č. Iveta, F. Kacik, A. Geffert, e D. Kacikova, "The Effects of Paper Recycling and its Environmental Impact", in Environmental Management in Practice, 2011, p. 330-350.

[260] S. R. Ferreira, F. de Andrade Silva, P. R. L. Lima, e R. D. Toledo Filho, "Effect of Natural Fiber Hornification on the Fiber Matrix Interface in Cement Based Composite Systems", Key Eng. Mater., vol. 668, p. 118-125, 2015.

[261] A. D. French, "Idealized powder diffraction patterns for cellulose polymorphs", Cellulose, vol. 21, n² 2, p. 885-896, 2014.

[262] J. F. Revol, A. Dietrich, e D. A. I. Goring, "Effect of mercerization on", no 18, p. 0-1, 1987.

[263] A. K. Bledzki e O. Faruk, "Wood fibre reinforced polypropylene composites: effect of fibre geometry and coupling agent on physicomechanical properties", Appl. Compos. Mater., vol. 10, n 6, p. 365379, 2003.

[264] M. Y. Ioelovich e G. P. Veveris, "Determination of Cellulose Crystallinity by X-ray Diffraction Method", vol. 80, n May, 1987.

[265] S. Park, J. O. Baker, M. E. Himmel, P. A. Parilla, e D. K. Johnson, "Cellulose crystallinity index: measurement techniques and their impact on interpreting cellulase performance.", Biotechnol. Biofuels, vol. 3, no 1, p. 10, 2010.

[266] R. Evans, A. F. A. Wallis, R. H. Newman, U. C. Roick, e I. D. Suckling, "Changes in Cellulose Crystallinity During Kraft Pulping: Comparison of Infrared, X-ray Diffraction and Solid State NMR Results", Holzforschung, vol. 49, nº 6, p. 498-504, 1995.

[267] A. Thygesen, J. Oddershede, H. Lilholt, A. B. Thomsen, e K. Stahl, "On the determination of crystallinity and cellulose content in plant fibres”, Cellulose, vol. 12, nº 6, p. 563-576, 2005.

[268] N. Terinte, R. Ibbett, e K. C. Schuster, "Overview on Native Cellulose and Microcrystalline Cellulose I Structure Studied By X-Ray 
Diffraction ( Waxd ): Comparison Between Measurement Techniques", Lenzinger Berichte, vol. 89, p. 118-131, 2011.

[269] M. Åkerholm, B. Hinterstoisser, e L. Salmén, "Characterization of the crystalline structure of cellulose using static and dynamic FT-IR spectroscopy”, Carbohydr. Res., vol. 339, n 3, p. 569-578, 2004.

[270] K. Schenzel, S. Fischer, e E. Brendler, "New method for determining the degree of cellulose I crystallinity by means of FT Raman spectroscopy", Cellulose, vol. 12, n 3, p. 223-231, 2005.

[271] L. Segal, J. J. Creely, A. E. Martin, e C. M. Conrad., "An empirical method for estimating the degree of crystallinity of native cellulose using X-ray diffractometer", Text. Res. J., vol. 29, p. 786-794, 1959.

[272] C. J. Garvey, I. H. Parker, e G. P. Simon, "On the interpretation of Xray diffraction powder patterns in terms of the nanostructure of cellulose I fibres", Macromol. Chem. Phys., vol. 206, n 15, p. 15681575, 2005.

[273] E. L. Hult, T. Iversen, e J. Sugiyama, "Characterization of the supermolecular structure of cellulose in wood pulp fibres", Cellulose, vol. 10, n०2, p. 103-110., 2003.

[274] J. He, S. Cui, e S. Y. Wang, "Preparation and crystalline analysis of high-grade bamboo dissolving pulp for cellulose acetate", J. Appl. Polym. Sci., vol. 107, n², p. 1029-1038, 2008.

[275] G. Jayme e H. Knolle, "The empirical X-ray determination of the degree of crystallinity of cellulosic material”, Papier, vol. 18, p. 249255, 1964.

[276] L. B. Otani, P. Gutemberg, E. Aparecida, M. Morales, e H. A. Pereira, "Caracterização dos módulos elásticos de madeiras e derivados utilizando a Técnica de Excitação por Impulso", 2014.

[277] L. B. Otani, H. A. Pereira, D. D. Melo, e S. C. Amico, "Caracterização dos módulos elásticos de compósitos utilizando a Técnica de Excitação por Impulso”, 2014.

[278] ASTME1876, "Standard Test Method for Dynamic Young 's Modulus , Shear Modulus, and Poisson's Ratio by Impulse Excitation of Vibration 1", Annu. B. ASTM Stand., vol. i, p. 1-15, 2015. 
rio.br/20309/historia_forcaAtomica2.html. .

[280] P. S. P. Herrmann, M. a. P. Da Silva, R. Bernardes Fo, A. E. Job, L. a Colnago, J. E. Frommer, e L. H. . Mattoso, "Microscopia de varredura por força: uma ferramenta poderosa no estudo de polímeros", Polímeros, vol. 7, n 4, p. 51-61, 1997.

[281] M. Scientiae, "MICROSCOPIA DE FORÇA ATÔMICA IN-SITU DE SUPERFÍCIES DE VIÇOSA MINAS GERAIS - BRASIL", 2008.

[282] A.-Y. Jee e M. Lee, "Comparative analysis on the nanoindentation of polymers using atomic force microscopy", Polym. Test., vol. 29, n ${ }^{0} 1$, p. 95-99, 2010.

[283] K. Liang, S. Q. Shi, e G. Wang, "Effect of Impregnated Inorganic Nanoparticles on the Properties of the Kenaf Bast Fibers", p. 242254, 2014.

[284] Y. Wu, S. Wang, D. Zhou, C. Xing, Y. Zhang, e Z. Cai, "Evaluation of elastic modulus and hardness of crop stalks cell walls by nanoindentation", Bioresour. Technol., vol. 101, nº 8, p. 2867-2871, 2010.

[285] a Demichelis, S. Pavarelli, L. Mortati, G. Sassi, e M. Sassi, "Study on the AFM Force Spectroscopy method for elastic modulus measurement of living cells", J. Phys. Conf. Ser., vol. 459, p. 12050, 2013.

[286] N. E. Kurland, Z. Drira, e V. K. Yadavalli, "Measurement of nanomechanical properties of biomolecules using atomic force microscopy", Micron, vol. 43, n 2-3, p. 116-128, 2012.

[287] S. D. Hudson, V. Zhurov, V. Grbic, M. Grbic, e J. L. Hutter, "Measurement of the elastic modulus of spider mite silk fibers using atomic force microscopy.", J. Appl. Phys., vol. 113, no 15, p. 154307, 2013.

[288] N. Behary e A. Perwuelz, "Atomic Force Microscopy - For Investigating Surface Treatment of Textile Fibers", in Atomic Force Microscopy - Imaging, Measuring and Manipulating Surfaces at the Atomic Scale, V. Bellitto, Org. 2012, p. 231-256.

[289] C. Díaz, "Técnicas micro-nanoscópicas utilizadas para el estudio de los biofilms.", in Adherencia y colonización de Pseudomonas fluorescens sobre sustratos sólidos: influencia de la topografía y 
composición química de la superficie, 2011, p. 45-60.

[290] B. Pittenger, N. Erina, e C. Su, "Quantitative Mechanical Property Mapping at the Nanoscale with PeakForce QNM", Burker Appl. Note, vol. 128, p. 1-12, 2009.

[291] J. J. Roa, G. Oncins, J. Díaz, F. Sanz, e M. Segarra, "Calculation of Young 's Modulus Value by Means of AFM", p. 27-36, 2011.

[292] G. Anderson, D. C. Lopes, H. Duarte, R. Ronald, e M. Zamora, "Estudos de superfícies em escala nanométrica com o Microscópio de Força Atômica", vol. 2, p. 1-9, 2012.

[293] W. Gindl e T. Schöberl, "The significance of the elastic modulus of wood cell walls obtained from nanoindentation measurements", Compos. Part A Appl. Sci. Manuf., vol. 35, no 11, p. 1345-1349, 2004.

[294] D. Page, F. Elhosseiny, K. Winkler, e A. Lancaster, "Elastic modulus of single wood pulp fibres", Tappi, vol. 60, n 4, p. 114-117, 1977.

[295] W. T. Y. Tze, S. Wang, T. G. Rials, G. M. Pharr, e S. S. Kelley, "Nanoindentation of wood cell walls: Continuous stiffness and hardness measurements", Compos. Part A Appl. Sci. Manuf., vol. 38, no 3, p. 945-953, 2007.

[296] L. Zou, H. Jin, W.-Y. Lu, e X. Li, "Nanoscale structural and mechanical characterization of the cell wall of bamboo fibers", Mater. Sci. Eng. C, vol. 29, p. 1275-1379, 2009.

[297] X. Xi, S. H. Kim, e B. Tittmann, "Atomic force microscopy based nanoindentation study of onion abaxial epidermis walls in aqueous environment", J. Appl. Phys., vol. 117, nº 2, 2015.

[298] H. E. Kissinger, "Reaction Kinetics in Differential Thermal Analysis", Anal. Chem., vol. 29, no 11, p. 1702-1706, 1957.

[299] F. Ferdosian, Z. Yuan, M. Anderson, e C. C. Xu, "Thermal Performance and Thermal Decomposition Kinetics of Lignin-Based Epoxy Resins", J. Anal. Appl. Pyrolysis, vol. 119, p. 124-132, 2016.

[300] A. K. Mohanty, M. Misra, e L. T. Drzal, Natural Fibers, Biopolymers, and Biocomposites. 2005.

[301] a K. Saha, S. Das, D. Bhatta, e B. C. Mitra, "Study of Jute Fiber Reinforced Polyester Composites”, J. Appl. Polym. Sci., vol. 71, p. 1505-1513, 1999. 
[302] S. C. Neto, "DMA - O que é preciso saber antes de sua utilização (parte III)", Brazilian J. Therm. Anal., vol. 3, n 1, p. 26-29, 2014.

[303] N. P. Lorandi, M. O. H. Cioffi, e H. O. Jr, "Análise Dinâmico-Mecânica de Materiais Compósitos Poliméricos Dynamic Mechanical Analysis ( DMA ) of Polymeric Composite Materials", Sci. cum Ind., vol. 4, n 13 , p. 48-60, 2016.

[304] T. G. Kannan, Green Composites from Natural Resources, vol. 17, n 5. 2014.

[305] S. Jager, R. Balthazard, M. Vicent, A. Dahoun, e E. Mortier, "Dynamic thermo-mechanical properties of various flowable resin composites", J. Clin. Exp. Dent., vol. 8, n 5, p. 0-0, 2016.

[306] R. Morgan, J. O'Neal, e D. Fanter, "The effect of moisture on the physical and mechanical integrity of epoxies", Polym. Mech., p. 751764, 1980.

[307] M. Tajvidi e A. Takemura, "Recycled Natural Fiber Polypropylene Composites: Water Absorption/Desorption Kinetics and Dimensional Stability", J. Polym. Environ., vol. 18, n 4, p. 500-509, 2010.

[308] N. A. Zulkarnain, "Degradability of Bamboo Fibre Reinforced polyester composites", 2014.

[309] I. Ghasemi e B. Kord, "Long-term Water Absorption Behaviour of Polypropylene/Wood Flour/Organoclay Hybrid Nanocomposite", Iran. Polym. J., vol. 18, no 9, p. 683-691, 2009.

[310] E. A. OSMAN, A. VAKHGUELT, I. SBARSKI, e S. A. MUTASHER, "Kenaf/Recycled Jute Natural Fibers Unsaturated Polyester Composites: Water Absorption/Dimensional Stability and Mechanical Properties", Int. J. Comput. Mater. Sci. Eng., vol. 1, nº 1, p. 1250010 , 2012.

[311] J. Graham-Jones e J. (Eds. ). Summerscales, Marine applications of advanced fibre-reinforced composites. Woodhead Publishing. Woodhead Publishing, 2015.

[312] J. Jedidi, F. Jacquemin, e A. Vautrin, "Accelerated hygrothermal cyclical tests for carbon/epoxy laminates", Compos. Part A Appl. Sci. Manuf., vol. 37, n 4, p. 636-645, 2006.

[313] P. Davies e Y. D. Rajapakse, Orgs., Durability of composites in a 
marine environment. Springer Science \& Business Media., 2013.

[314] O. L. S. Alsina, L. H. de Carvalho, F. G. Ramos Filho, e J. R. M. d'Almeida, "Immersion Temperature Effects on the Water Absorption Behavior of Hybrid Lignocellulosic Fiber Reinforced-Polyester Matrix Composites", Polym. Plast. Technol. Eng., vol. 46, n 5, p. 515-520, 2007.

[315] W. K. Loh, A. D. Crocombe, M. M. A. Wahab, e I. A. Ashcroft, "Modelling anomalous moisture uptake, swelling and thermal characteristics of a rubber toughened epoxy adhesive", Int. J. Adhes. Adhes., vol. 25, p. 1-12, 2005.

[316] E. L. McKague, R. J.D., e Halkias J.E., "Moisture Diffusion in Reinforced Plastics", J. Eng. Mater. Technol, vol. 98, no 1, p. 92-95, 1976.

[317] N. Venkateshwaran, A. ElayaPerumal, A. Alavudeen, e M. Thiruchitrambalam, "Mechanical and water absorption behaviour of banana/sisal reinforced hybrid composites", Mater. Des., vol. 32, $\mathrm{n}^{\circ}$ 7, p. 4017-4021, 2011.

[318] A. L. F. . D'Almeida, J. R. M. D'Almeida, V. Calado, e D. W. Barreto, "Desenvolvimento de um tratamento químico superficial para aumentar a adesão da interface fibra de bucha (luffa cilindrica) resina poliéster", 2003.

[319] K. Karimi e M. J. Taherzadeh, "A critical review of analytical methods in pretreatment of lignocelluloses: Composition, imaging, and crystallinity", Bioresour. Technol., vol. 200, p. 1008-1018, 2016.

[320] A. Maiorana, L. Ren, G. Lo Re, S. Spinella, C. Y. Ryu, P. Dubois, e R. A. Gross, "Bio-based epoxy resin toughening with cashew nut shell liquid-derived resin", Green Mater., vol. 3, n 3, p. 80-92, 2015.

[321] ASTM standard, "ASTM D 5229- 92 - Standard Test Method for Moisture Absorption Properties and Equilibrium Conditioning of Polymer Matrix Composite Materials", Annu. B. ASTM Stand., vol. 92, p. 1-13, 2010.

[322] K. Satyanarayana, J. Guimaraes, e F. Wypych, "Studies on lignocellulosic fibers of Brazil. Part I: Source, production, morphology, properties and applications", Compos. Part A Appl. Sci. Manuf., vol. 
38, no 7, p. 1694-1709, jul. 2007.

[323] Y. Laidani, S. Hanini, G. Mortha, e G. Heninia, "Study of a fibrous annual plant, Luffa Cylindrica for paper application Part I: Characterization of the Vegetal", Iran. J. Chem. Chem. Eng., vol. 31, no 4, p. 119-129, 2012.

[324] C. Guo, L. Zhou, e J. Lv, "Effects of expandable graphite and modified ammonium polyphosphate on the flame-retardant and mechanical properties of wood flour-polypropylene composites", Polym. Polym. Compos., vol. 21, n 7, p. 449-456, 2013.

[325] X. Xu, F. Liu, L. Jiang, J. Y. Zhu, D. Haagenson, e D. P. Wiesenborn, "Cellulose Nanocrystals vs. Cellulose Nano fibrils: A Comparative Study on Their Microstructures and Effects as Polymer Reinforcing Agents", ACS Appl. Mater. Interfaces, vol. 5, p. 2999-3009, 2013.

[326] M. K. D. Rambo e M. M. C. Ferreira, "Determination of Cellulose Crystallinity of Banana Residues Using Near Infrared Spectroscopy and Multivariate Analysis", J. Braz. Chem. Soc., vol. 26, n 7, p. 14911499, 2015.

[327] T. Wüstenberg, Cellulose and Cellulose Derivatives in the Food Industry: Fundamentals and Applications. 2015.

[328] J. I. TOMAZ, R. M. A. G.; BITENCOURT, E.; SABINO, N. P.; KONDO, "Determinação Dos Índices De Cristalinidade de fibras celulósicas", Bragantia, vol. 53, n 1, p. 121-126, 1994.

[329] W. Ruland, "X-ray determination of crystallinity and diffuse disorder scattering", Acta Crystallogr., vol. 14, nº 11, p. 1180-1185, 1961.

[330] O. Dupont, a. Jonas, e R. Legras, "Adaptation of the Rietveld Method to the Characterization of the Lamellar Microstructure of Polymers", Mater. Sci. Forum, vol. 278-281, p. 127-132, 1998.

[331] S. Brückner, "Estimation of the background in powder diffraction patterns through a robust smoothing procedure", J. Appl. Crystallogr., vol. 33, n³ II, p. 977-979, 2000.

[332] B. NagarajaGanesh e R. Muralikannan, "Extraction and characterization of lignocellulosic fibers from Luffa cylindrica fruit", Int. J. Polym. Anal. Charact., vol. 5341, nº January, p. 1-8, 2016.

[333] J. L. Guimarães, E. Frollini, C. G. da Silva, F. Wypych, e K. G. 
Satyanarayana, "Characterization of banana, sugarcane bagasse and sponge gourd fibers of Brazil", Ind. Crops Prod., vol. 30, n 3, p. 407-415, 2009.

[334] A. Adewuyi e F. V. Pereira, "Isolation and surface modification of cellulose from underutilized Luffa cylindrica sponge: A potential feed stock for local polymer industry in Africa", J. Assoc. Arab Univ. Basic Appl. Sci., vol. In Press., 2017.

[335] A. A. Guilherme, P. V. F. Dantas, E. S. Santos, F. A. N. Fernandes, e G. R. Macedo, "Evaluation of composition, characterization and enzymatic hydrolysis of pretreated sugar cane bagasse", Brazilian J. Chem. Eng., vol. 32, no 1, p. 23-33, 2015.

[336] K. O. Reddy, B. Ashok, K. R. N. Reddy, Y. E. Feng, J. Zhang, e a. V. Rajulu, "Extraction and Characterization of Novel Lignocellulosic Fibers From Thespesia Lampas Plant", Int. J. Polym. Anal. Charact., vol. 19, no 1, p. 48-61, 2014.

[337] D. Dai e M. Fan, "Investigation of the dislocation of natural fibres by Fourier-transform infrared spectroscopy", Vib. Spectrosc., vol. 55, n 2, p. 300-306, 2011.

[338] M. Fan, D. Dai, e B. Huang, "Fourier Transform Infrared Spectroscopy for Natural Fibres", Fourier Transform - Mater. Anal., p. 45-68, 2012.

[339] N. Stevulova, J. Cigasova, A. Estokova, E. Terpakova, A. Geffert, F. Kacik, E. Singovszka, e M. Holub, "Properties characterization of chemically modified hemp hurds", Materials (Basel)., vol. 7, n 12, p. 8131-8150, 2014.

[340] M. L. Nelson e R. T. O'Connor, "Relation of certain infrared bands to cellulose crystallinity and crystal lattice type. Part II. A new infrared ratio for estimation of crystallinity in celluloses I and II", J. Appl. Polym. Sci., vol. 8, n 3, p. 1325-1341, 1964.

[341] A. L. F. S. D'Almeida, V. Calado, D. W. Barreto, e J. R. M. D'Almeida, "Efeito do tratamento de mercerização em fibras de curauá (Ananas erectfolius)", 8 Congresso Brasileiro de Polímeros. p. 12-13, 2005.

[342] P. Gañán e I. Mondragon, "Surface modification of fique fibers. Effect on their physico-mechanical properties", Polym. Compos., vol. 23, $\mathrm{n}^{\circ}$ 3, p. 383-394, 2002. 
[343] A. I. S. Brígida, V. M. A. Calado, L. R. B. Gonçalves, e M. A. Z. Coelho, "Effect of chemical treatments on properties of green coconut fiber", Carbohydr. Polym., vol. 79, n 4, p. 832-838, 2010.

[344] Heitor Luiz Ornaghi, "Comportamento térmico de fibras vegetais e propriedades dinâmico-mecânicas de compósitos poliméricos com fibra de sisal", Universisade Federal do Rio Grande do Sul, 2014.

[345] F. Carrillo, X. Colom, J. J. Suñol, e J. Saurina, "Structural FTIR analysis and thermal characterisation of lyocell and viscose-type fibres", Eur. Polym. J., vol. 40, n 9, p. 2229-2234, 2004.

[346] C. Parida, S. K. Dash, e C. Pradhan, "FTIR and Raman Studies of Cellulose Fibers of Luffa cylindrica", Open J. Compos. Mater., vol. 5, $n^{\circ}$ January, p. 5-10, 2015.

[347] A. L. F. S. D'Almeida, D. W. Barreto, V. Calado, e J. R. M. D'Almeida, "Effects of derivatization on sponge gourd (Luffa cylindrica) fibres", Polym. Polym. Compos., vol. 14, n 1, p. 73-80, 2006.

[348] A. L. F. S. D'Almeida, D. W. Barreto, V. Calado, e J. R. M. D'Almeida, "Thermal analysis of less common lignocellulose fibers", J. Therm. Anal. Calorim., vol. 91, n 2, p. 405-408, 2008.

[349] S. N. Monteiro, V. Calado, F. M. Margem, e R. J. S. Rodriguez, "Thermogravimetric Stability Behavior of Less Common Lignocellulosic Fibers - a Review", J. Mater. Res. Technol., vol. 1, n 3, p. 189-199, 2012.

[350] F. Tomczak, "Estudos sobre a estrutura e propriedades de fibras de coco e curauá do Brasil", Universidade Federal do Paraná, 2010.

[351] M. Akay, "Aspects of dynamic mechanical analysis in polymeric composites", Compos. Sci. Technol., vol. 47, n 4, p. 419-423, 1993.

[352] B. Dewimille e A. R. Bunsell, "The modelling of hydrothermal aging in glass fibre reinforced epoxy composites", J. Phys. D. Appl. Phys., vol. 15, no 10, p. 2079-2091, 2000.

[353] F. H. M. M. Costa e J. R. M. D. Almeida, "Effect of Water Absorption on the Mechanical Properties of Sisal and Jute Fiber Composites", Polym. Plast. Technol. Eng., vol. 38, n 5, p. 1081-1094, 1999.

[354] H. Demir, U. Atikler, D. Balköse, e F. Tıhmınlığlu, "The effect of fiber surface treatments on the tensile and water sorption properties of 
polypropylene-luffa fiber composites", Compos. Part A Appl. Sci. Manuf., vol. 37, n 3, p. 447-456, mar. 2006.

[355] M. F. E. Silva e R. F. Carvalho, "Moisture Influence on Mechanical Properties of the Composite Sisal / Polyester", 2016.

[356] Z. N. Azwa, B. F. Yousif, A. C. Manalo, e W. Karunasena, "A review on the degradability of polymeric composites based on natural fibres", Mater. Des., vol. 47, p. 424-442, 2013.

[357] M. Tajvidi e G. Ebrahimi, "Water Uptake and Mechanical Characteristics of Natural Filler - Polypropylene Composites", J. Appl. Polym. Sci., vol. 88, p. 941-946, 2003.

[358] 2005 A. Arbelaiz, B. Fernández, J. Ramos, A. Retegi, R. Llano-Ponte, and I. Mondragon, "Mechanical properties of short flax fibre bundle/polypropylene composites: Influence of matrix/fibre modification, fibre content, water uptake and recycling," Compos. Sci., "No Title".

[359] J. 2007 H. Dhakal, Z. Zhang, and M. Richardson, "Effect of water absorption on the mechanical properties of hemp fibre reinforced unsaturated polyester composites," Compos. Sci. Technol., vol. 67, no. 7-8, pp. 1674-1683, "No Title".

[360] "S.-H. Lee and S. Wang, 'Biodegradable polymers/bamboo fiber biocomposite with bio-based coupling agent,' Compos. Part A Appl. Sci. Manuf., vol. 37, no. 1, pp. 80-91, Jan. 2006."

[361] A. R. Feiferis e J. R. . D'Almeida, "Evaluation of Water Absorption Effects on the Mechanical Properties and Sound Propagation Behavior of Polyester Matrix- Sponge Gourd Reinforced Composite", 26 J. Compos. Biodegrad. Polym., vol. 4, p. 26-31, 2016.

[362] P. A. Santos, M. A. S. Spinacé, K. K. G. Fermoselli, e M.-A. de Paoli, "Efeito da Forma de Processamento e do Tratamento da Fibra de Curauá nas Propriedades de Compósitos com Poliamida-6", Polímeros Ciência e Tecnol., vol. 19, nº 1, p. 31-39, 2009.

[363] 1980 A. Loos, G. Springer, B. Sanders, and R. Tung, "Moisture Absorption of Polyester-E Glass Composites," J. Compos. Mater., vol. 14, no. 2, pp. 142-154, "No Title".

[364] 2013. A. Célino, S. Fréour, F. Jacquemin, and P. Casari, 
"Characterization and modeling of the moisture diffusion behavior of natural fibers," J. Appl. Polym. Sci., vol. 130, no. 1, pp. 297-306, "No Title".

[365] J. Mercier, A. Bunsell, P. Castaing, e J. Renard, "Characterisation and modelling of aging of composites", Compos. Part A Appl. Sci. Manuf., vol. 39, n 2, p. 428-438, 2008.

[366] E. Brun, P. Rain, G. Teissèdre, C. Guillermin, e S. Rowe, "Hygrothermal aging of a filled epoxy resin", 2007 Int. Conf. Solid Dielectr. ICSD, p. 239-242, 2007.

[367] G. M. Odegard e A. Bandyopadhyay, "Physical aging of epoxy polymers and their composites", J. Polym. Sci. Part B Polym. Phys., vol. 49, n²4, p. 1695-1716, 2011.

[368] R. D. Adams e M. M. Singh, "The effect of immersion in sea water on the dynamic properties of fibre-reinforced flexibilised epoxy composites", Compos. Struct., vol. 31, n² 2, p. 119-127, 1995.

[369] L. Plangsangmas, J. J. Mecholsky, e A. B. Brennan, "Determination of Fracture Toughness of Epoxy", J. Appl. Polym. Sci., vol. 72 (2), n June, p. 257-268, 1999.

[370] M. Atsuta e D. T. Turner, "Fractography of highly crosslinked polymers", J. Mater. Sci. Lett., vol. 1, n 4, p. 167-169, 1982.

[371] J. A. P. Malheiros, E. E. A. Aragão, e J. R. M. D’Almeida, "Superfície de Fratura de Resina Poliéster -Características", Anais do II II Simpósio Brasileiro de Microscopia Eletrônica MICROMAT, São Paulo, p. 217-220, 1990.

[372] B. Wielage, T. Lampke, H. Utschick, e F. Soergel, "Processing of natural-fibre reinforced polymers and the resulting dynamicmechanical properties", J. Mater. Process. Technol., vol. 139, n 1-3 SPEC, p. 140-146, 2003.

[373] D. Ray, B. K. Sarkar, S. Das, e A. K. Rana, "Dynamic mechanical and thermal analysis of vinylester-resin-matrix composites reinforced with untreated and alkali-treated jute fibres", Compos. Sci. Technol., vol. 62, no 7-8, p. 911-917, 2002.

[374] M. K. Gupta e R. K. Srivastava, "Effect of sisal fibre loading on dynamic mechanical analysis and water absorption behaviour of jute 
fibre epoxy composite", Mater. Today Proc., vol. 2, n 4-5, p. 29092917, 2015.

[375] P. Joseph, G. Mathew, K. Joseph, G. Groeninckx, e S. Thomas, "Dynamic mechanical properties of short sisal fibre reinforced polypropylene composites", Compos. Part A Appl. Sci. Manuf., vol. 34, p. 275-290, 2003.

[376] M. Jacob, B. Francis, e S. Thomas, "Dynamical mechanical analysis of sisal/oil palm hybrid fiber-reinforced natural rubber composites", Polym. Compos., p. 671-680, 2006.

[377] H. L. Ornaghi, A. S. B. R. Fiorio, A. J. Zattera, e S. C. Amico, "Mechanical and Dynamic Mechanical Analysis of Hybrid Composites Molded by Resin Transfer Molding", J. Appl. Polym. Sci., vol. 118, p. 887-896, 2010.

[378] S. Mohanty, S. K. Verma, e S. K. Nayak, "Dynamic mechanical and thermal properties of MAPE treated jute/HDPE composites", Compos. Sci. Technol., vol. 66, n 3-4, p. 538-547, 2006.

[379] a K. Rana, B. C. Mitra, e a N. Banerjee, "Short jute fiber-reinforced polypropylene composites: Dynamic mechanical study", J. Appl. Polym. Sci., vol. 71, n 4, p. 531-539, 1999.

[380] J. I. Margem, "Estudo das características estruturais e propriedades de compósitos poliméricos reforçados com fibras de malva", Universidade Estadual do Norte Fluminense, 2013. 


\section{Apêndice A1 - Valores de ajuste para a deconvolução de espectros DRX}

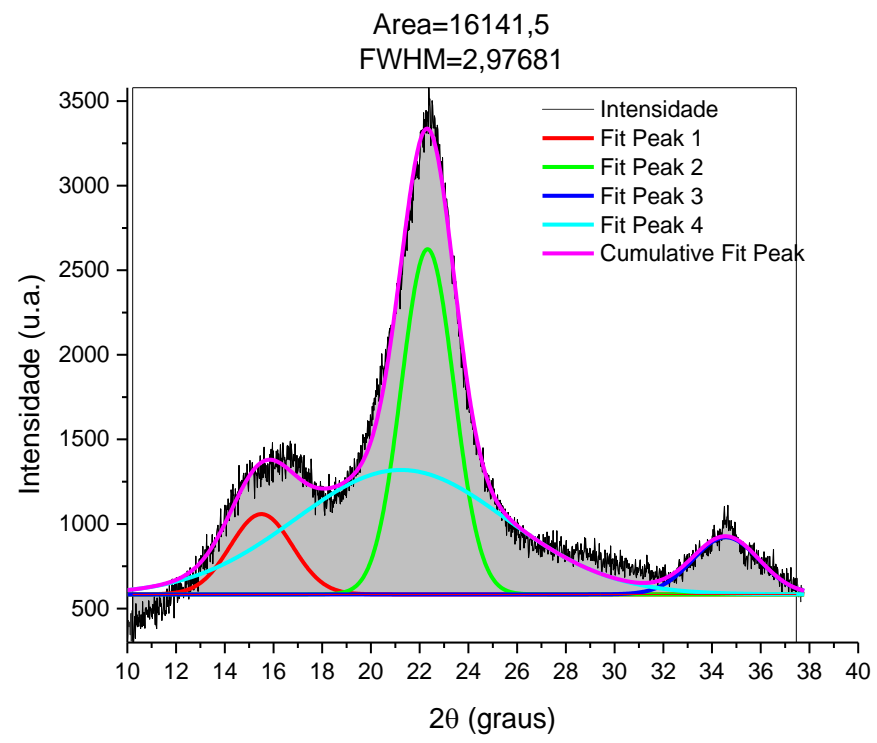

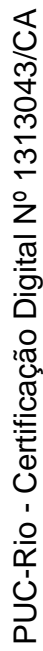

Figura A1.1 - Deconvolução dos picos no espectro DRX de fibras de bucha sem tratamento. Área da curva ajustada.

Tabela A1.1 - Parâmetros de ajuste da curva pelo modelo Gaussiano.

\begin{tabular}{|l|r|}
\hline Reduced Chi-Sqr & 7238,24835 \\
\hline Residual Sum of Squares & $1,03 E+07$ \\
\hline Adj. R-Square & 0,98394 \\
\hline
\end{tabular}

\begin{tabular}{|r|r|r|r|}
\hline & & & $\begin{array}{r}\text { Standard } \\
\text { Error }\end{array}$ \\
\hline Peak1(Intensidade) & y0 & 583,86 & 18,70 \\
\hline Peak1(Intensidade) & xc & 15,50 & 0,03 \\
\hline Peak1(Intensidade) & $\mathrm{A}$ & 1509,75 & 140,00 \\
\hline Peak1(Intensidade) & $\mathrm{w}$ & 2,99 & 0,14 \\
\hline Peak2(Intensidade) & $\mathrm{xc}$ & 22,33 & 0,01 \\
\hline Peak2(Intensidade) & $\mathrm{A}$ & 5508,66 & 102,24 \\
\hline Peak2(Intensidade) & $\mathrm{w}$ & 2,54 & 0,03 \\
\hline Peak3(Intensidade) & $\mathrm{xc}$ & 34,57 & 0,05 \\
\hline Peak3(Intensidade) & $\mathrm{A}$ & 1152,44 & 105,99 \\
\hline Peak3(Intensidade) & $\mathrm{w}$ & 3,21 & 0,19 \\
\hline Peak4(Intensidade) & $\mathrm{xc}$ & 21,23 & 0,14 \\
\hline Peak4(Intensidade) & $\mathrm{A}$ & 7970,66 & 489,80 \\
\hline Peak4(Intensidade) & $\mathrm{w}$ & 10,18 & 0,58 \\
\hline
\end{tabular}




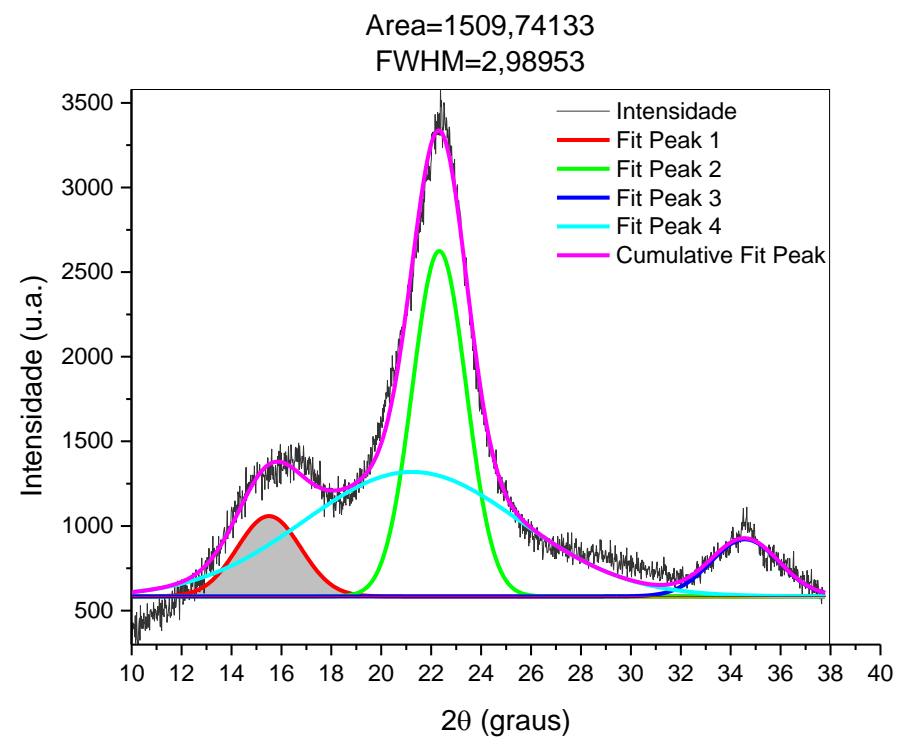

Figura A1.2 - Deconvolução dos picos no espectro DRX de fibras de bucha sem tratamento. Área do pico cristalino (101).

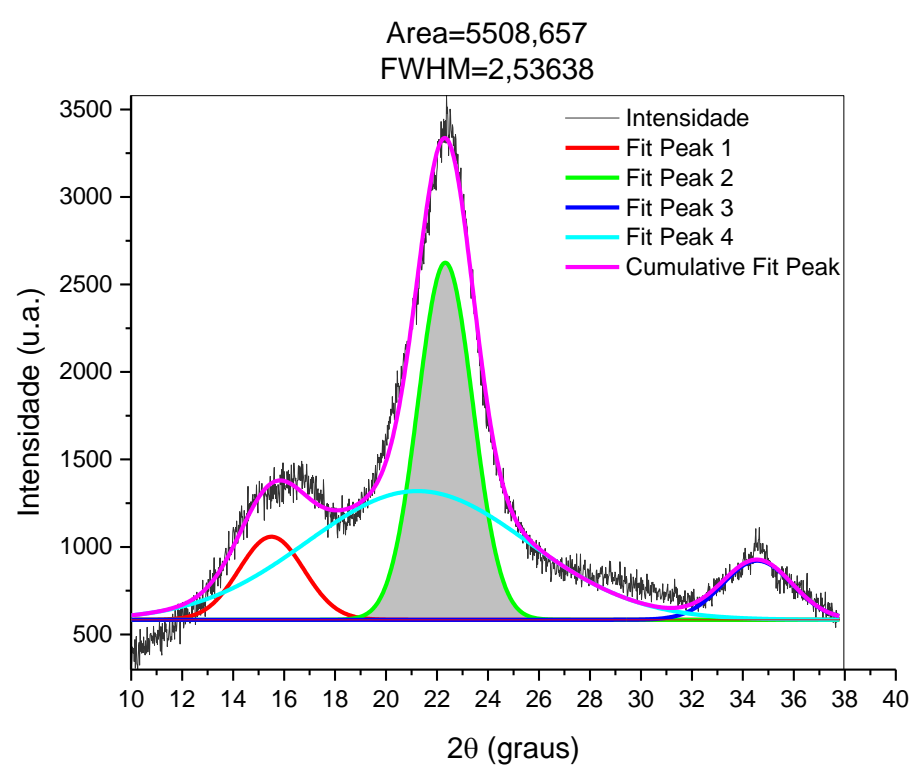

Figura A1.3 - Deconvolução dos picos no espectro DRX de fibras de bucha sem tratamento. Área do pico cristalino (002). 


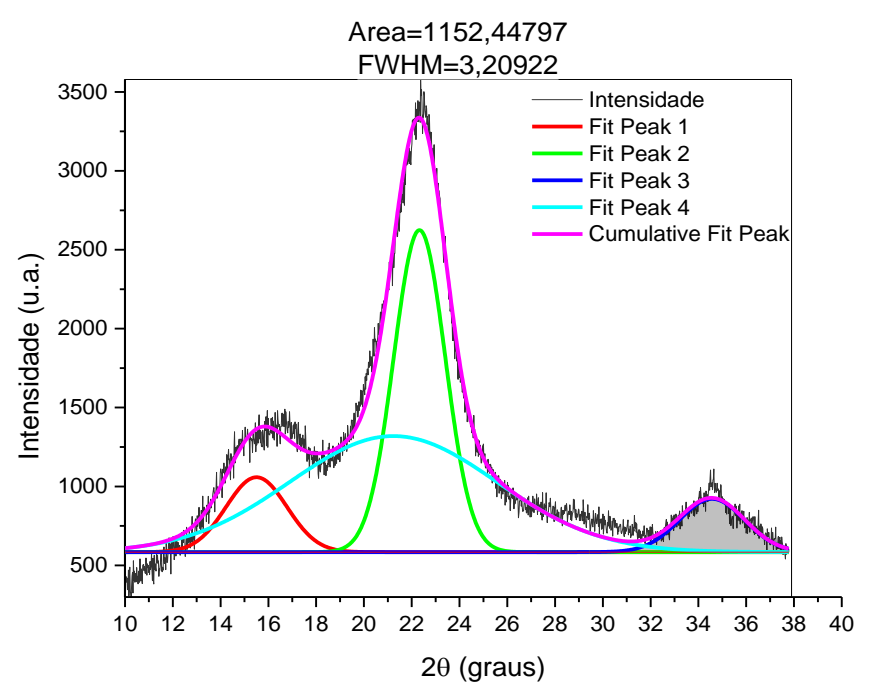

Figura A1.4 - Deconvolução dos picos no espectro DRX de fibras de bucha sem tratamento. Área do pico cristalino (040).

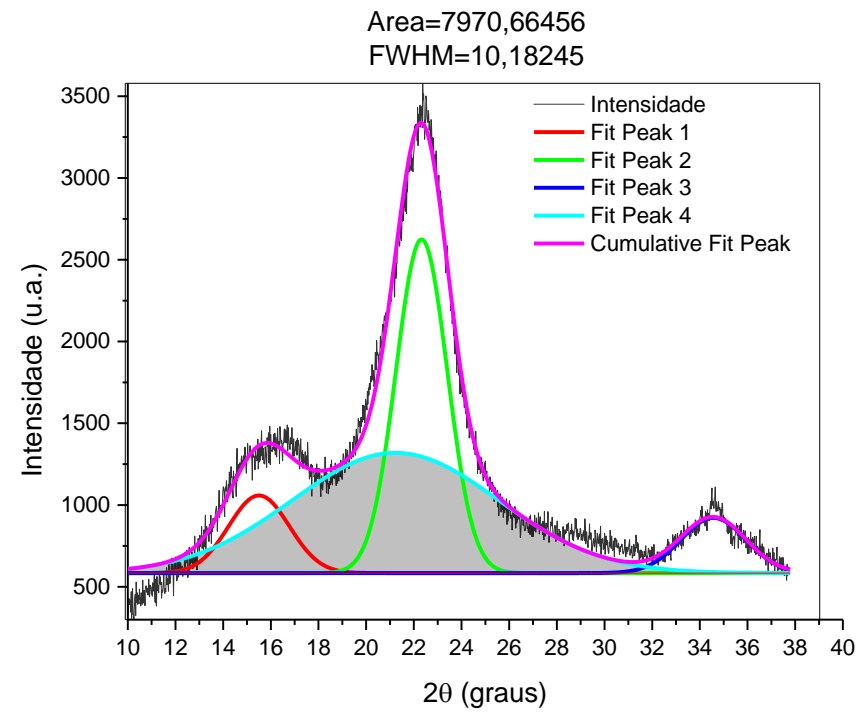

Figura A1.5 - Deconvolução dos picos no espectro DRX de fibras de bucha sem tratamento. Área do pico amorfo. 
Deconvolução dos picos no espectro DRX de fibras de bucha hornificadas.

Tabela A1.2 - Parâmetros de ajuste da curva pelo modelo Gaussiano.

\begin{tabular}{|c|c|}
\hline Equation & $\begin{array}{r}y=y 0+A /\left(w^{*} \operatorname{sqrt}\left(P I /\left(4^{*} \ln (2)\right)\right)\right)^{*} \exp (- \\
\left.4^{*} \ln (2)^{*}(x-x c)^{\wedge} 2 / w^{\wedge} 2\right)\end{array}$ \\
\hline $\begin{array}{l}\text { Reduced } \\
\text { Chi-Sqr }\end{array}$ & 7021,18025 \\
\hline $\begin{array}{ll}\text { Adj. } & \text { R- } \\
\text { Square } & \\
\end{array}$ & 0,98696 \\
\hline $\begin{array}{l}\text { Fit } \\
\text { Status }\end{array}$ & Succeeded(100) \\
\hline
\end{tabular}

\begin{tabular}{|r|r|r|r|}
\hline & & Value & $\begin{array}{r}\text { Standard } \\
\text { Error }\end{array}$ \\
\hline Peak(Intensidade) & y0 & 745,2 & 6,8 \\
\hline Peak1(Intensidade) & xc & 15,6 & 0,0 \\
\hline Peak1(Intensidade) & $\mathrm{A}$ & 2983,9 & 221,7 \\
\hline Peak1(Intensidade) & $\mathrm{W}$ & 3,8 & 0,1 \\
\hline Peak2(Intensidade) & xc & 22,4 & 0,0 \\
\hline Peak2(Intensidade) & $\mathrm{A}$ & 5821,4 & 176,1 \\
\hline Peak2(Intensidade) & $\mathrm{W}$ & 2,7 & 0,0 \\
\hline Peak3(Intensidade) & xc & 34,6 & 0,0 \\
\hline Peak3(Intensidade) & $\mathrm{A}$ & 562,1 & 35,3 \\
\hline Peak3(Intensidade) & $\mathrm{W}$ & 1,8 & 0,1 \\
\hline Peak4(Intensidade) & Xc & 21,3 & 0,2 \\
\hline Peak4(Intensidade) & $\mathrm{A}$ & 6967,7 & 232,5 \\
\hline Peak4(Intensidade) & $\mathrm{W}$ & 8,2 & 0,5 \\
\hline
\end{tabular}




\section{Deconvolução dos picos no espectro DRX de fibras de bucha Mercerizadas.}

Tabela A1.3 - Parâmetros de ajuste da curva pelo modelo Gaussiano.

\begin{tabular}{|l|r|}
\hline Equation & \multicolumn{1}{|c|}{$\begin{array}{c}y=y 0+A /\left(w^{*} \operatorname{sqrt}\left(P I /\left(4^{*} \ln (2)\right)\right)\right)^{*} \\
\exp \left(-4^{*} \ln (2)^{*}(x-x c)^{\wedge} 2 / w^{\wedge} 2\right)\end{array}$} \\
\hline Reduced Chi-Sqr & 3385,44519 \\
\hline Adj. R-Square & 0,98134 \\
\hline Fit Status & Succeeded(100) \\
\hline
\end{tabular}

\begin{tabular}{|r|c|r|r|}
\hline & & Value & $\begin{array}{c}\text { Standard } \\
\text { Error }\end{array}$ \\
\hline Peak1(Intensidade) & y0 & 429,7 & 3,1 \\
\hline Peak1(Intensidade) & Xc & 14,6 & 1,7 \\
\hline Peak1(Intensidade) & $\mathrm{A}$ & 1410,1 & 1208,2 \\
\hline Peak1(Intensidade) & $\mathrm{W}$ & 4,9 & 1,3 \\
\hline Peak2(Intensidade) & $\mathrm{xc}$ & 16,2 & 0,1 \\
\hline Peak2(Intensidade) & $\mathrm{A}$ & 1188,0 & 900,5 \\
\hline Peak2(Intensidade) & $\mathrm{w}$ & 2,9 & 0,5 \\
\hline Peak3(Intensidade) & $\mathrm{xc}$ & 22,6 & 0,0 \\
\hline Peak3(Intensidade) & $\mathrm{A}$ & 3136,9 & 166,1 \\
\hline Peak3(Intensidade) & $\mathrm{w}$ & 2,4 & 0,0 \\
\hline Peak4(Intensidade) & $\mathrm{xc}$ & 34,7 & 0,1 \\
\hline Peak4(Intensidade) & $\mathrm{A}$ & 41,8 & 12,7 \\
\hline Peak4(Intensidade) & $\mathrm{w}$ & 0,9 & 0,3 \\
\hline Peak5(Intensidade) & $\mathrm{xc}$ & 21,3 & 0,5 \\
\hline Peak5(Intensidade) & $\mathrm{A}$ & 2816,3 & 277,0 \\
\hline Peak5(Intensidade) & $\mathrm{w}$ & 6,4 & 0,8 \\
\hline
\end{tabular}


Deconvolução dos picos no espectro DRX de fibras de bucha Acetiladas.

Tabela A1.4 - Parâmetros de ajuste da curva pelo modelo Gaussiano.

\begin{tabular}{|c|c|}
\hline Equation & $\begin{array}{l}y=y 0+A /\left(w^{*} \operatorname{sgrt}\left(P I /\left(4^{*} \ln (2)\right)\right)\right) * \\
\exp \left(-4^{*} \ln (2)^{*}(x-x c)^{\wedge} 2 / w^{\wedge} 2\right)\end{array}$ \\
\hline Reduced Chi-Sqr & 7509,6361 \\
\hline Adj. R-Square & 0,98277 \\
\hline Fit Status & Succeeded(100) \\
\hline
\end{tabular}

\begin{tabular}{|r|r|r|r|}
\hline & & Value & \multicolumn{2}{|c|}{$\begin{array}{c}\text { Standard } \\
\text { Error }\end{array}$} \\
\hline Peak1(A) & y0 & 585,5 & 5,8 \\
\hline Peak1(A) & xc & 15,7 & 0,0 \\
\hline Peak1(A) & A & 1821,8 & 180,5 \\
\hline Peak1(A) & w & 3,2 & 0,1 \\
\hline Peak2(A) & y0 & 585,5 & 5,8 \\
\hline Peak2(A) & xc & 22,3 & 0,0 \\
\hline Peak2(A) & A & 5986,1 & 178,8 \\
\hline Peak2(A) & w & 2,7 & 0,0 \\
\hline Peak3(A) & y0 & 585,5 & 5,8 \\
\hline Peak3(A) & xc & 34,5 & 0,0 \\
\hline Peak3(A) & A & 598,4 & 36,3 \\
\hline Peak3(A) & w & 2,0 & 0,1 \\
\hline Peak4(A) & y0 & 585,5 & 5,8 \\
\hline Peak4(A) & xc & 21,1 & 0,2 \\
\hline Peak4(A) & A & 4991,3 & 189,2 \\
\hline Peak4(A) & w & 8,2 & 0,6 \\
\hline
\end{tabular}


Apêndice A2 - Espectro FTIR das fibras de bucha.

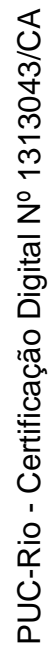

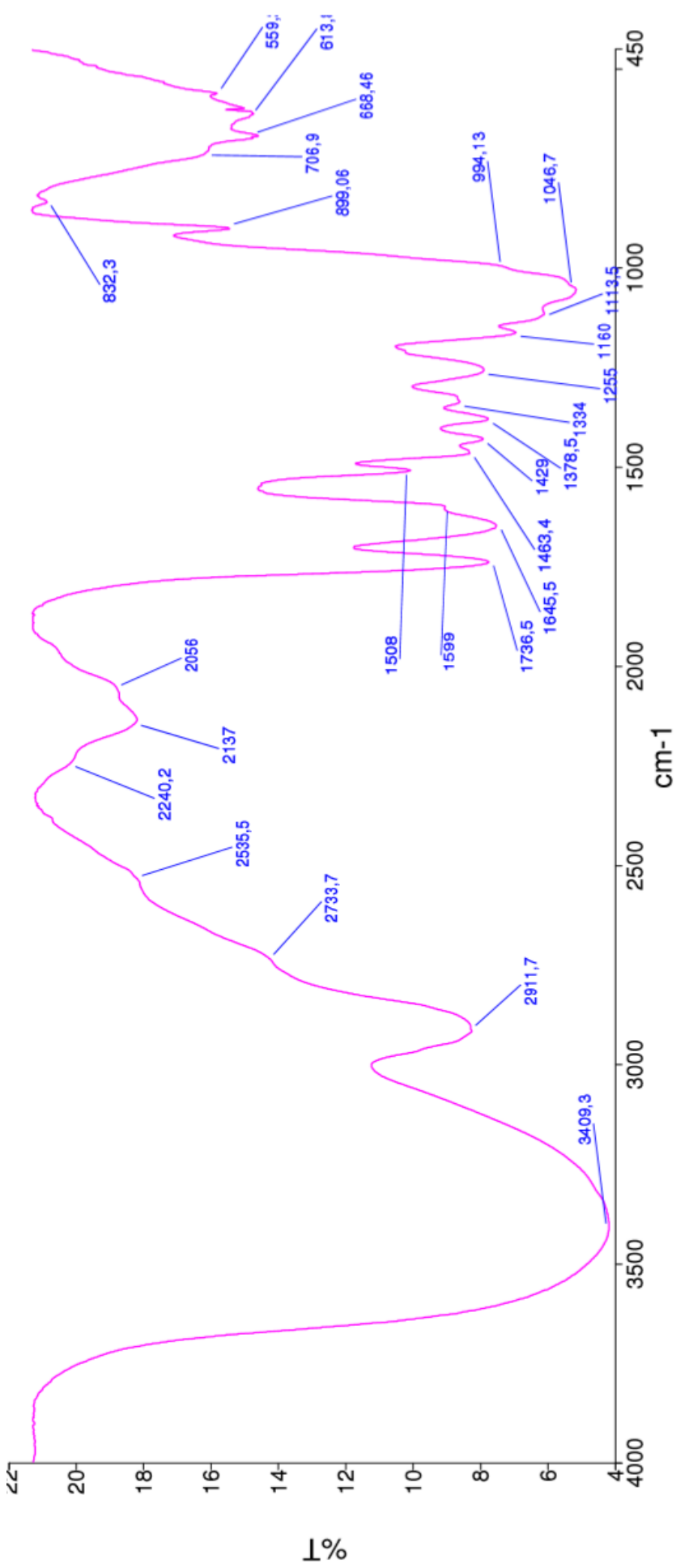

Figura A2.1 - Espectro FTIR das fibras de bucha sem tratamento. 


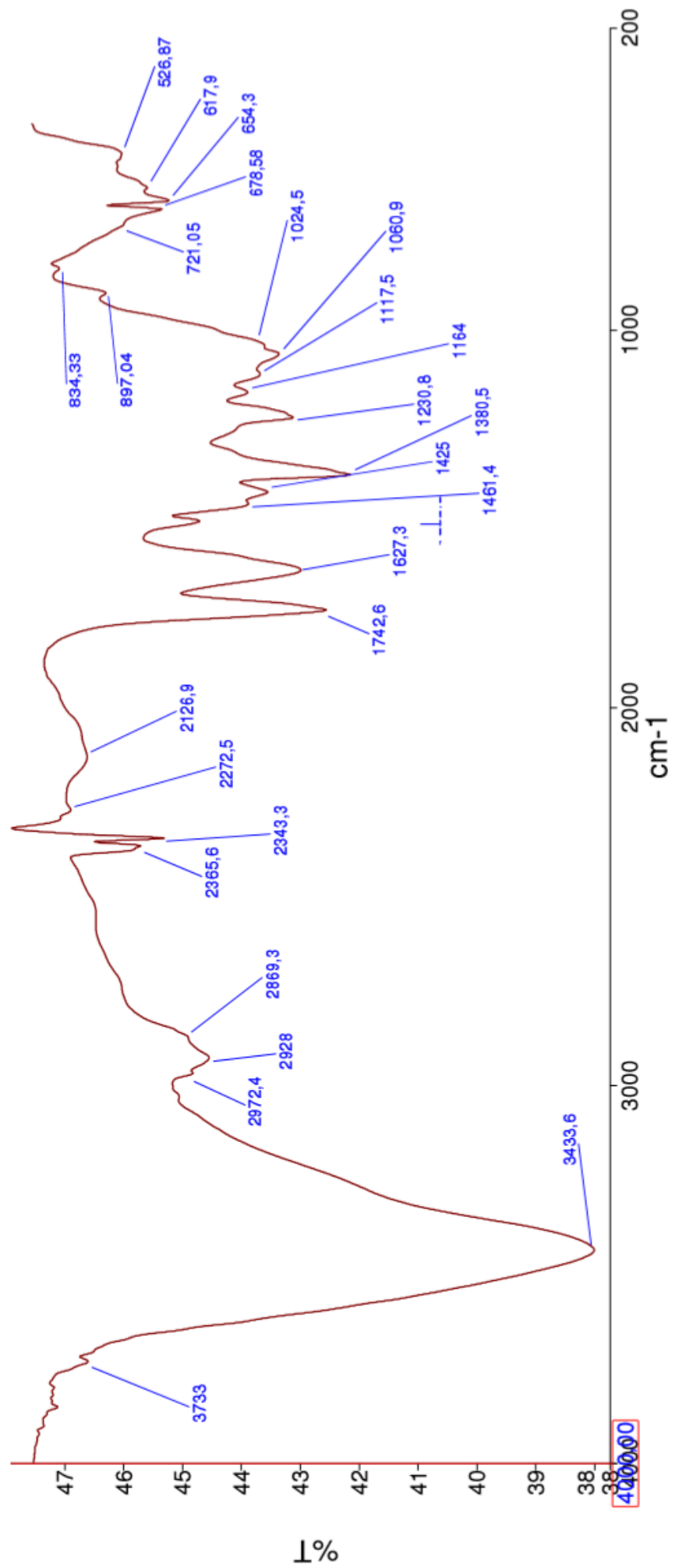

Figura A2.2 - Espectro FTIR das fibras de bucha hornificadas. 


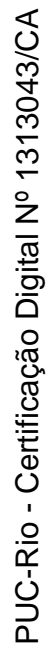

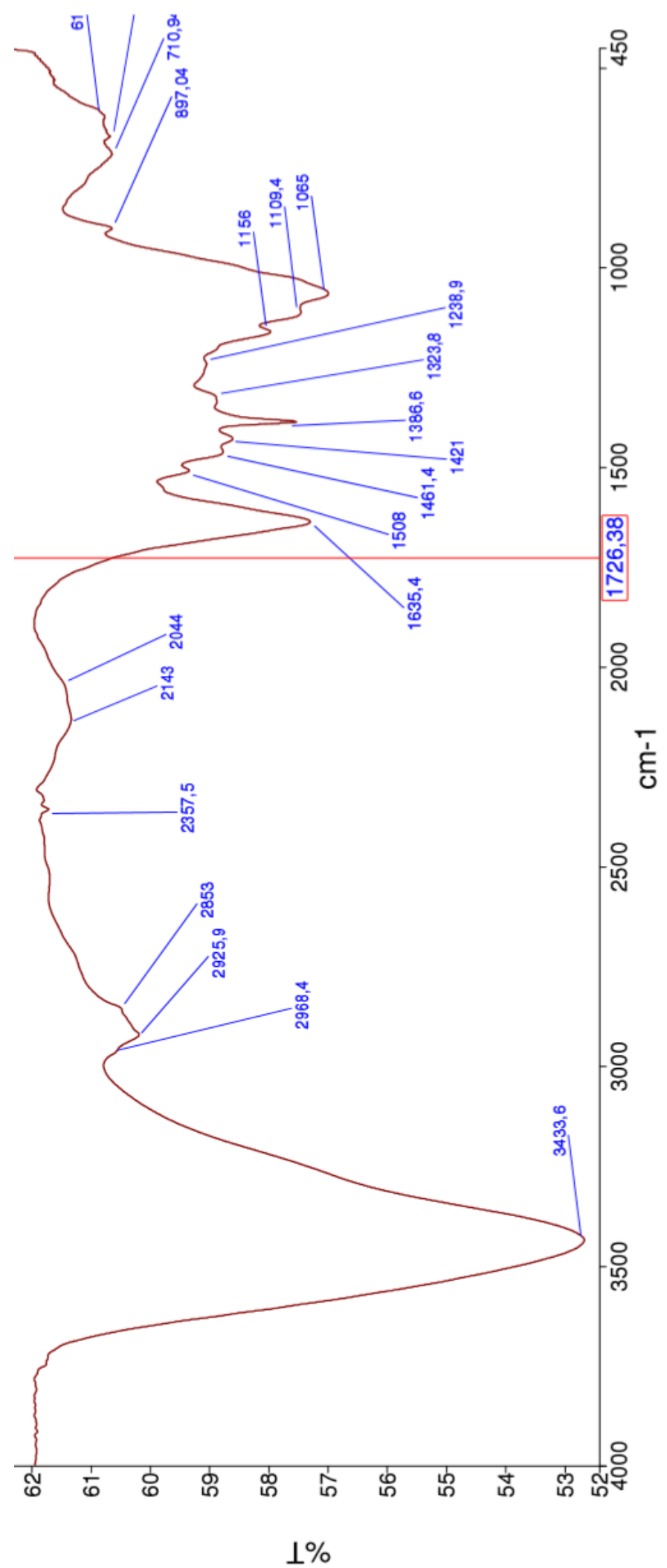

Figura A2.3 - Espectro FTIR das fibras de bucha mercerizadas. 


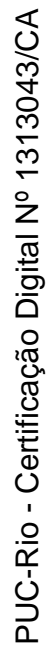

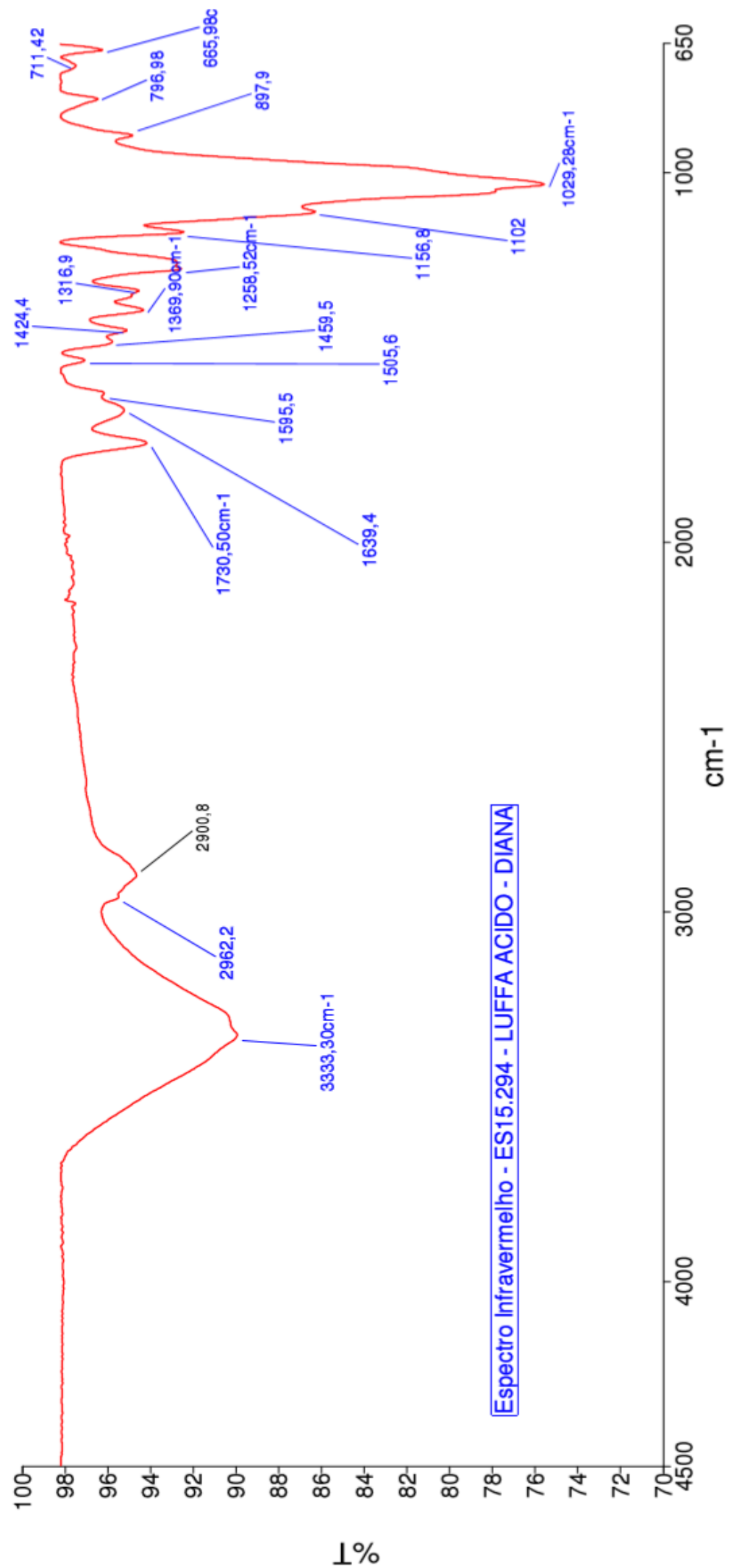

Figura A2.4 - Espectro FTIR das fibras de bucha acetiladas. 


\section{Apêndice A3 - Aparência superficial dos compósitos} bisfenol/bucha antes e após de absorção em água de mar.
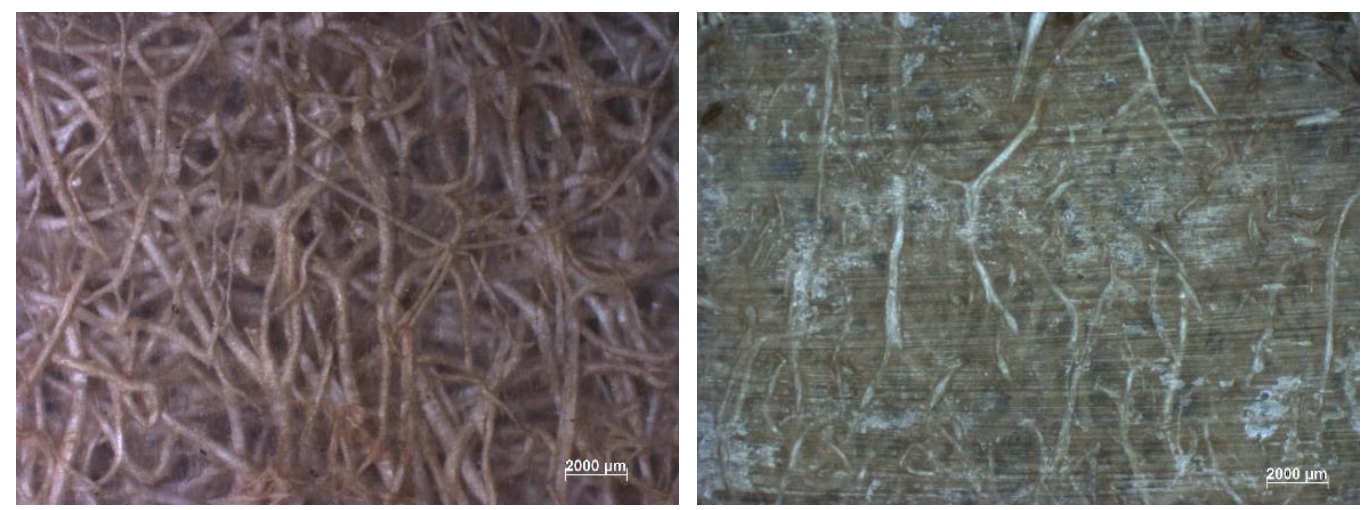

U10
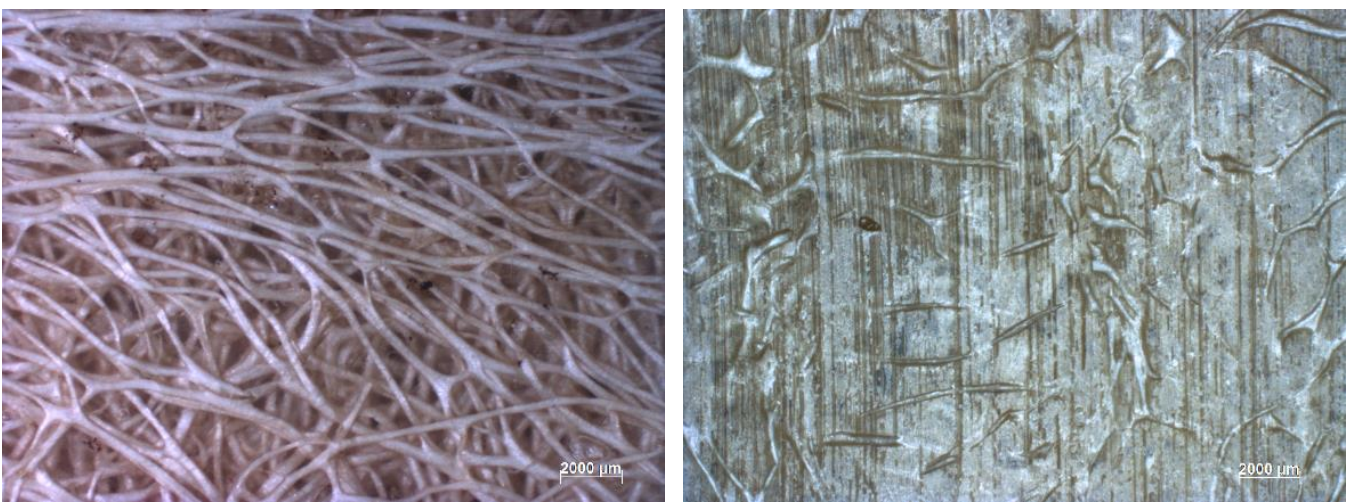

$\mathrm{U} 20$
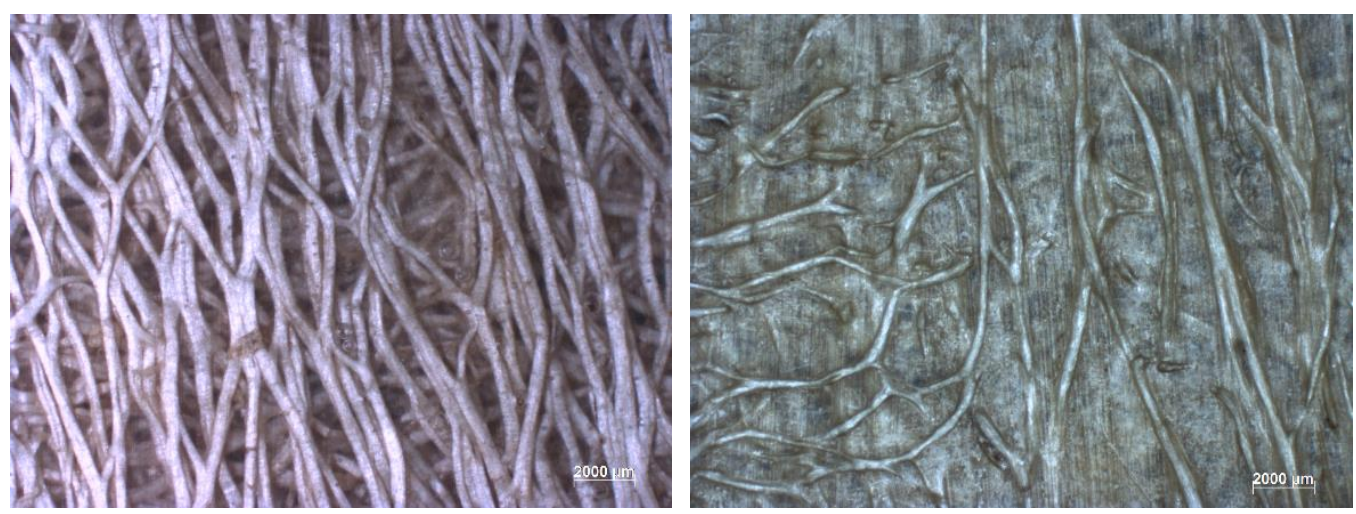

$\mathrm{U} 40$

Figura A3.1 - Imagens do stereo microscópio da superfície de compósito bisfenol/bucha não tratada, antes de condicionado (esquerda) e depois de absorção em água de mar (direita). 


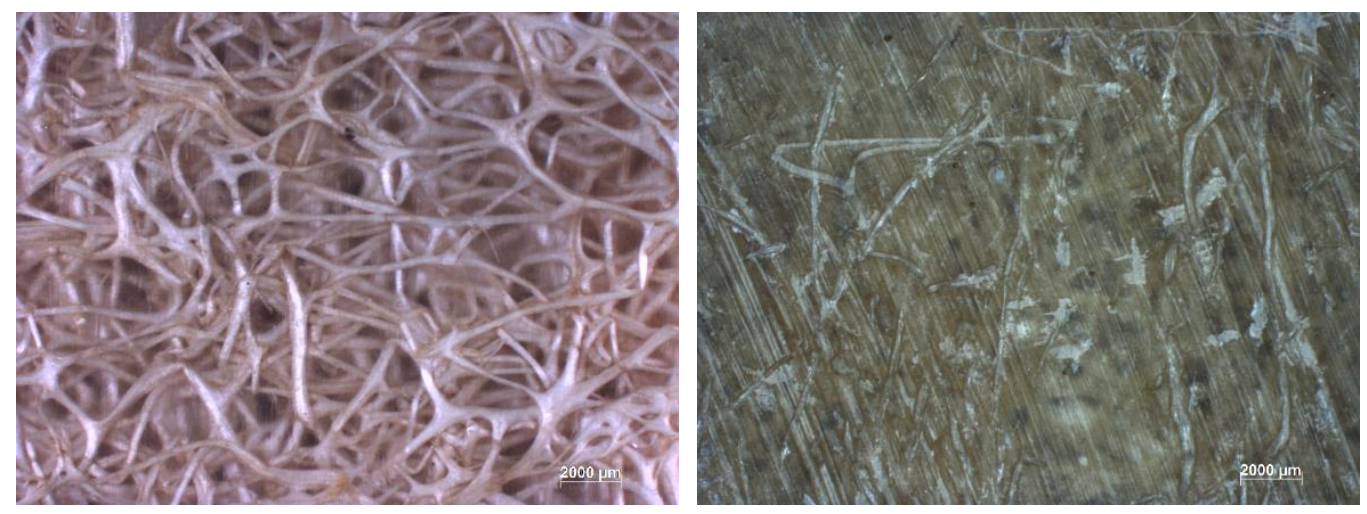

H20

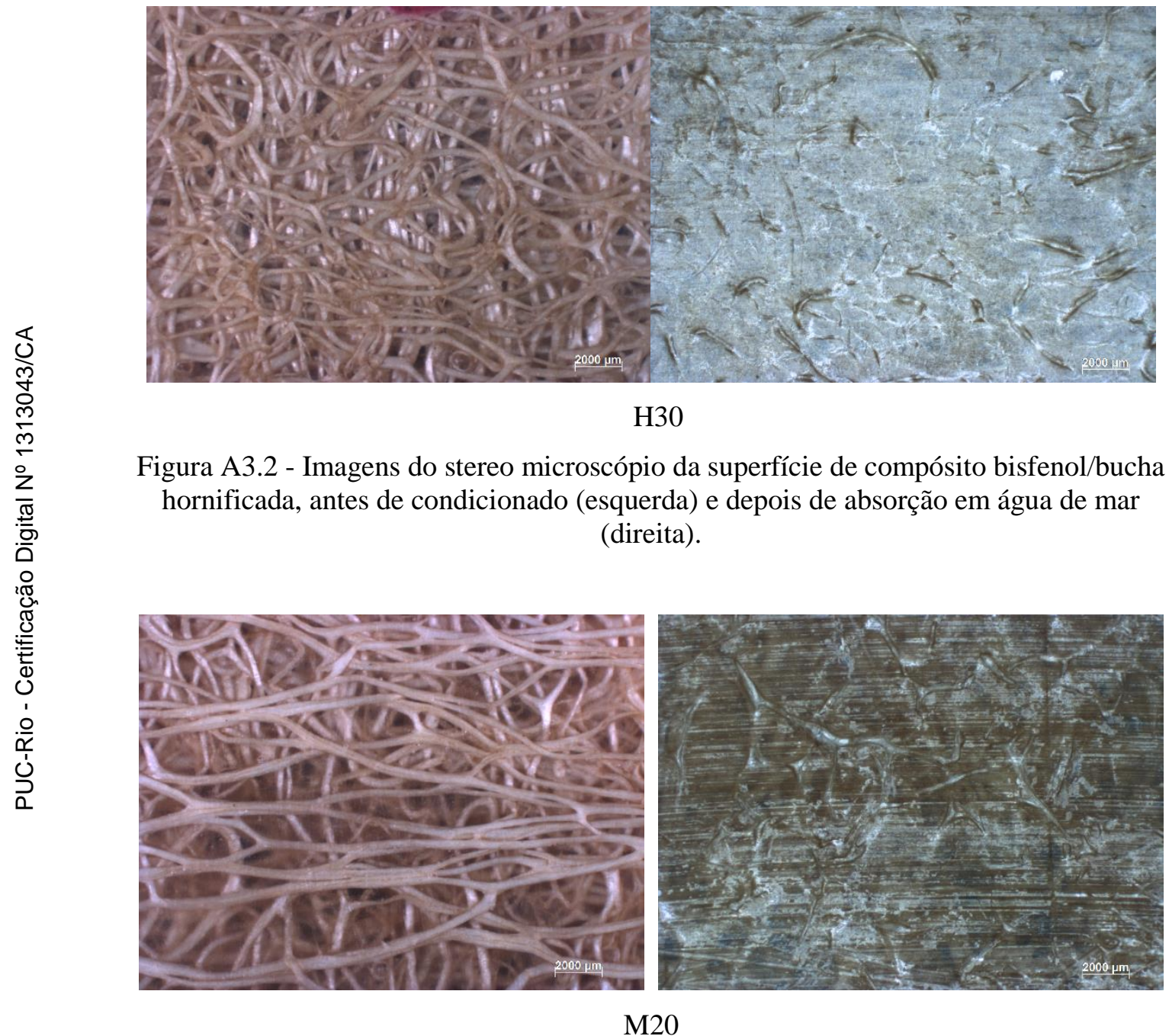

M20 

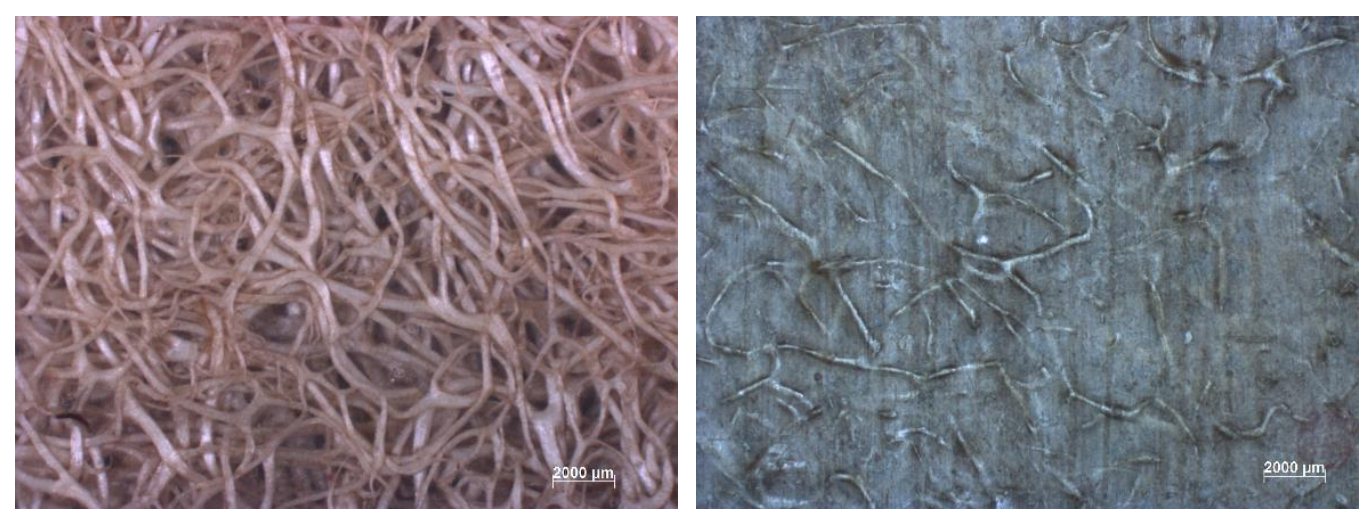

M30

Figura A3.3 - Imagens do stereo microscópio da superfície de compósito bisfenol/bucha mercerizada, antes de condicionado (esquerda) e depois de absorção em água de mar (direita).
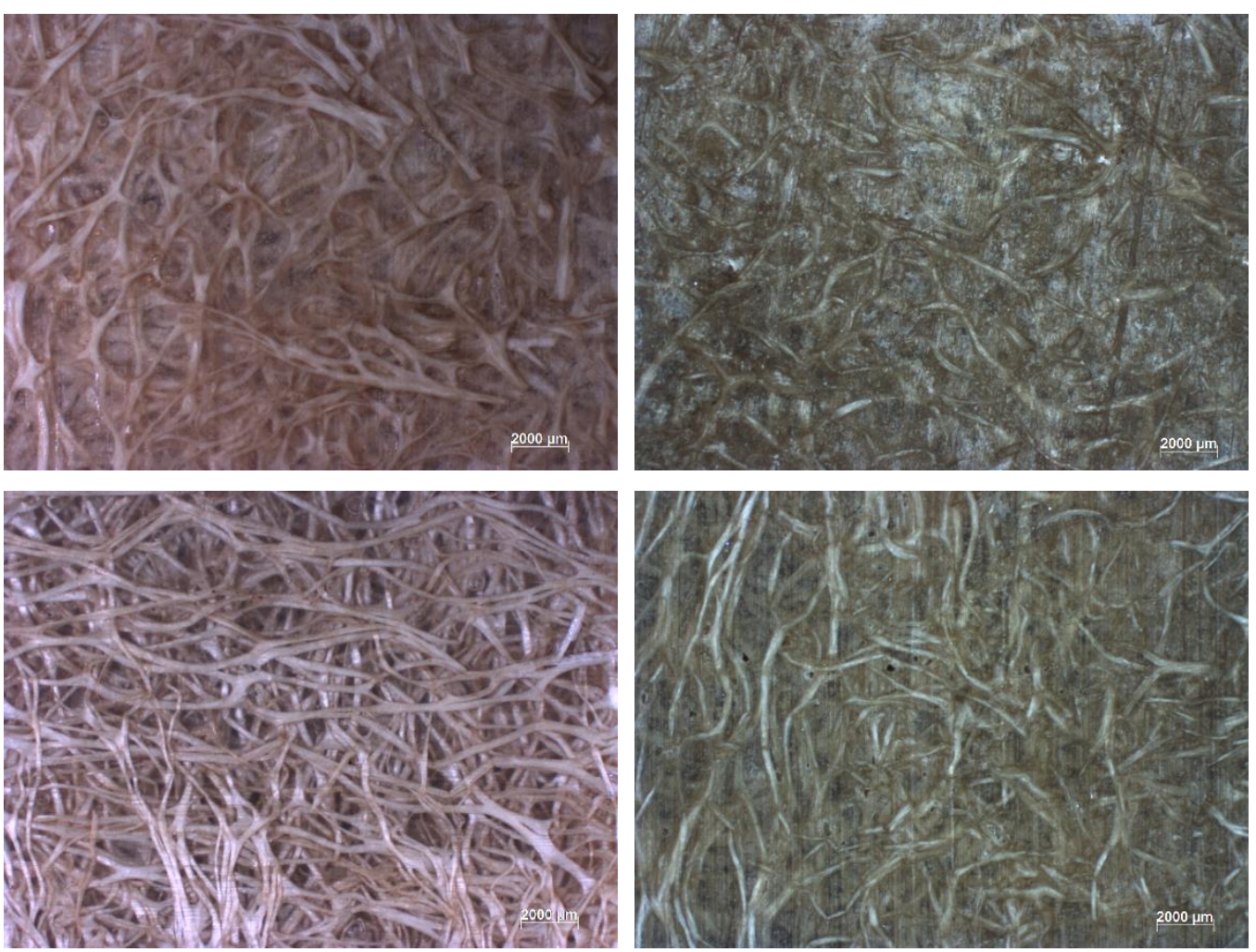

Figura A3.4 - Imagens do stereo microscópio da superfície de compósito bisfenol/bucha acetilada, antes de condicionado (esquerda) e depois de absorção em água de mar (direita). 

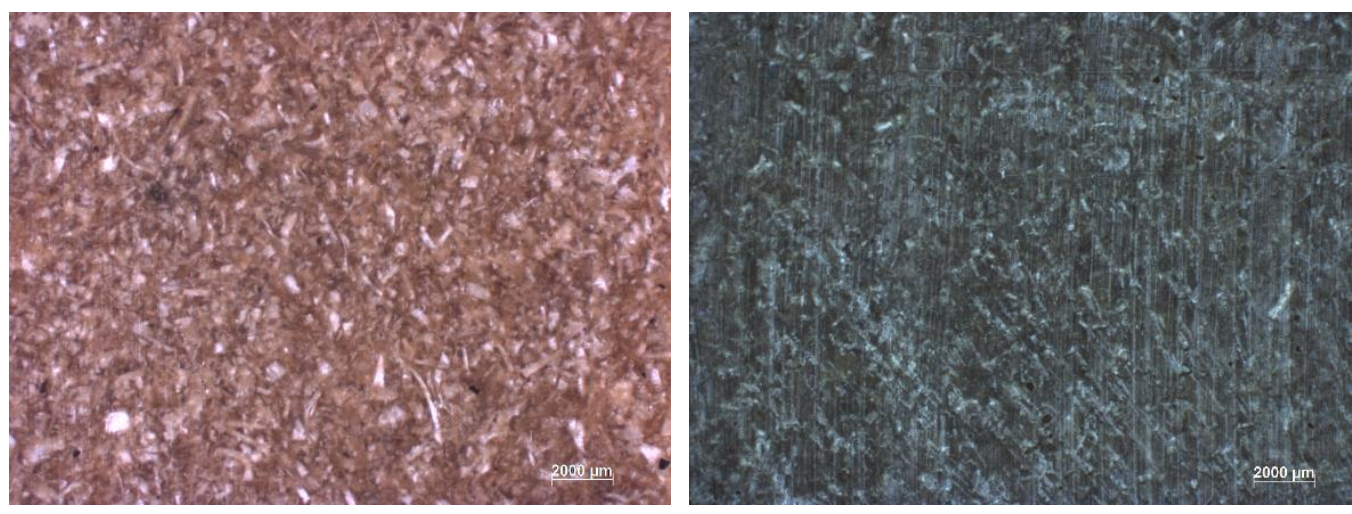

FC

Figura A3.5 - Imagens do stereo microscópio da superfície de compósito bisfenol/fibras curtas de bucha, antes de condicionado (esquerda) e depois de absorção em água de mar (direita). 


\section{Apêndice A4 - Módulo de Young vs Densidade}

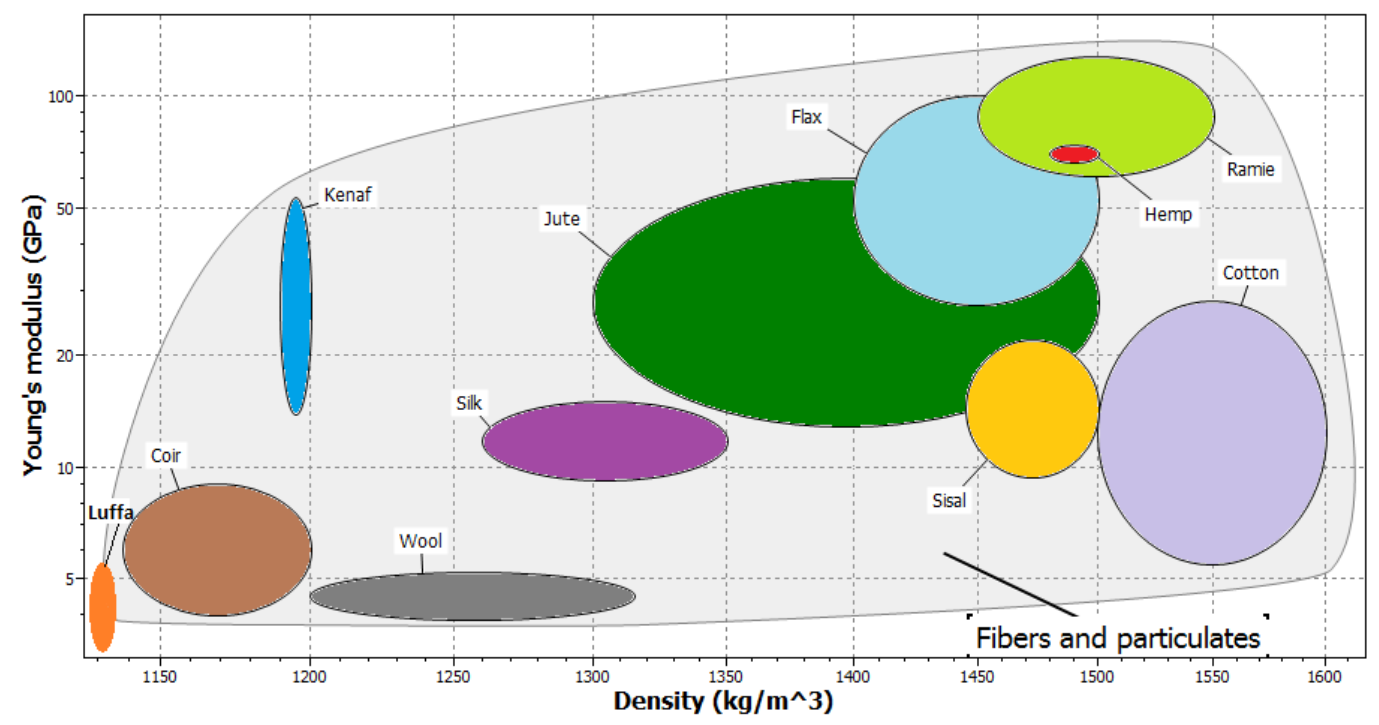

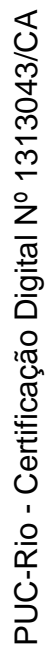

Figura A4.1. Diagrama de propriedades de fibras naturais - Módulo de Young vs Densidade. 


\section{Apêndice A5 -Termogramas por TGA das resinas} analisadas

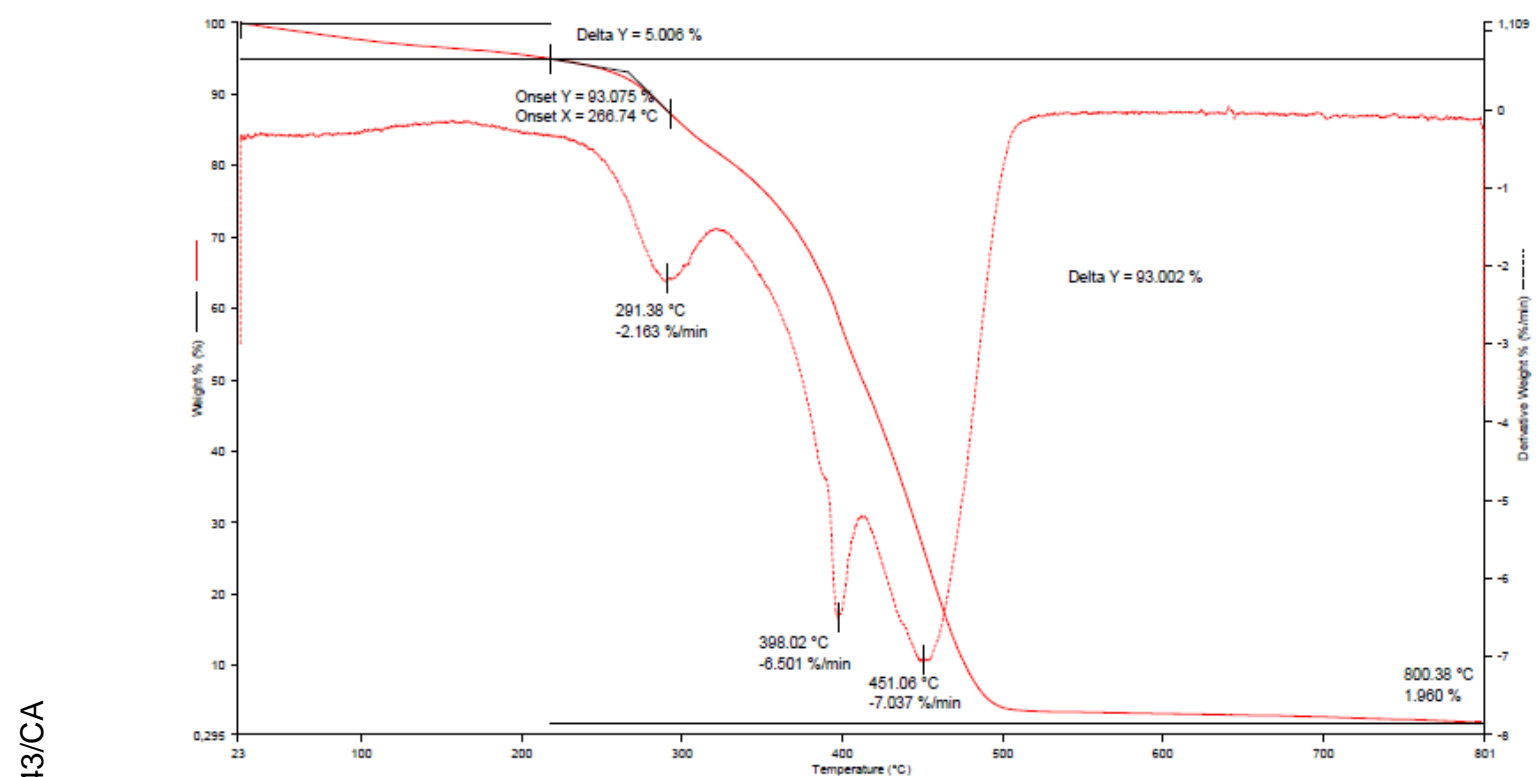

Figura A5.1. Curvas TG e DTG para resina: Cardanol + NX-5620 (1)

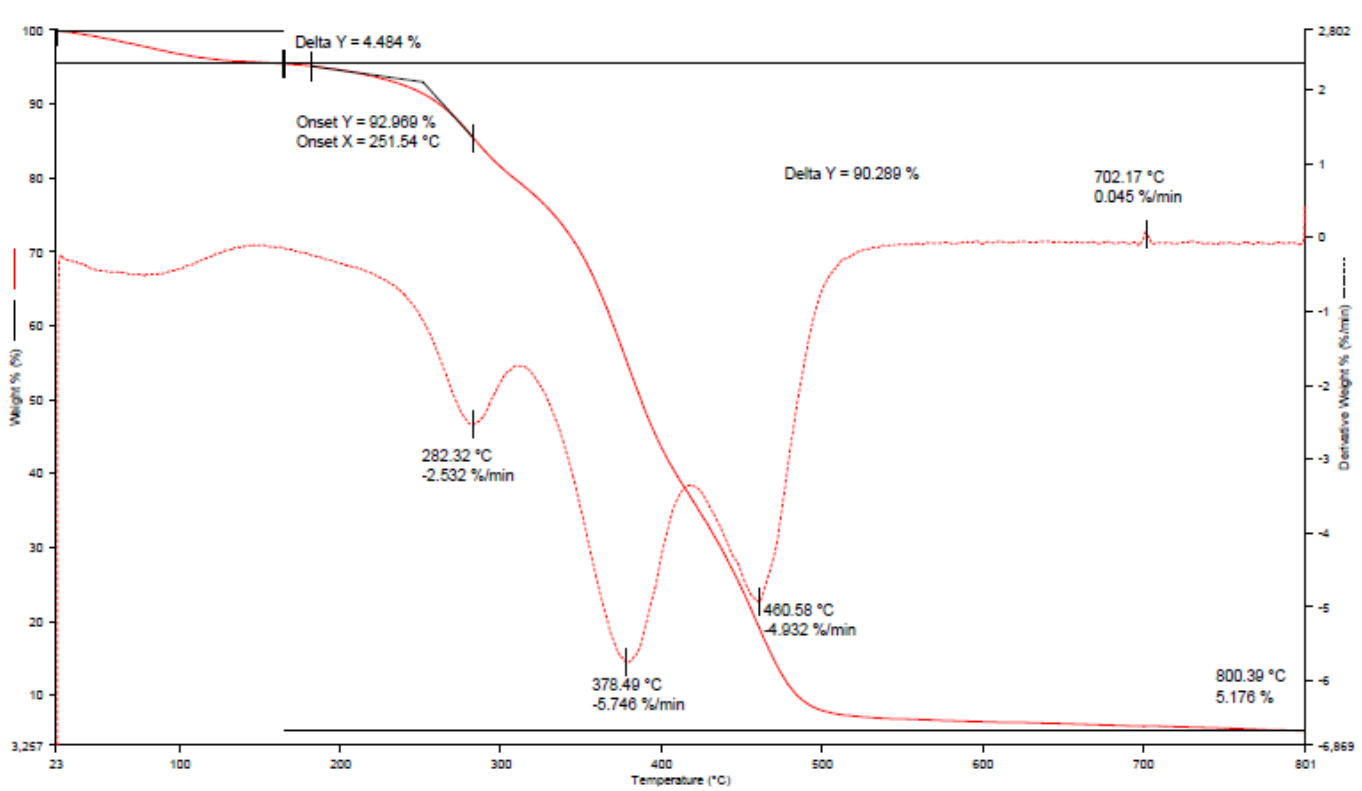

Figura A5.2. Curvas TG e DTG para resina: Resorcinol + NX-5620 (2) 


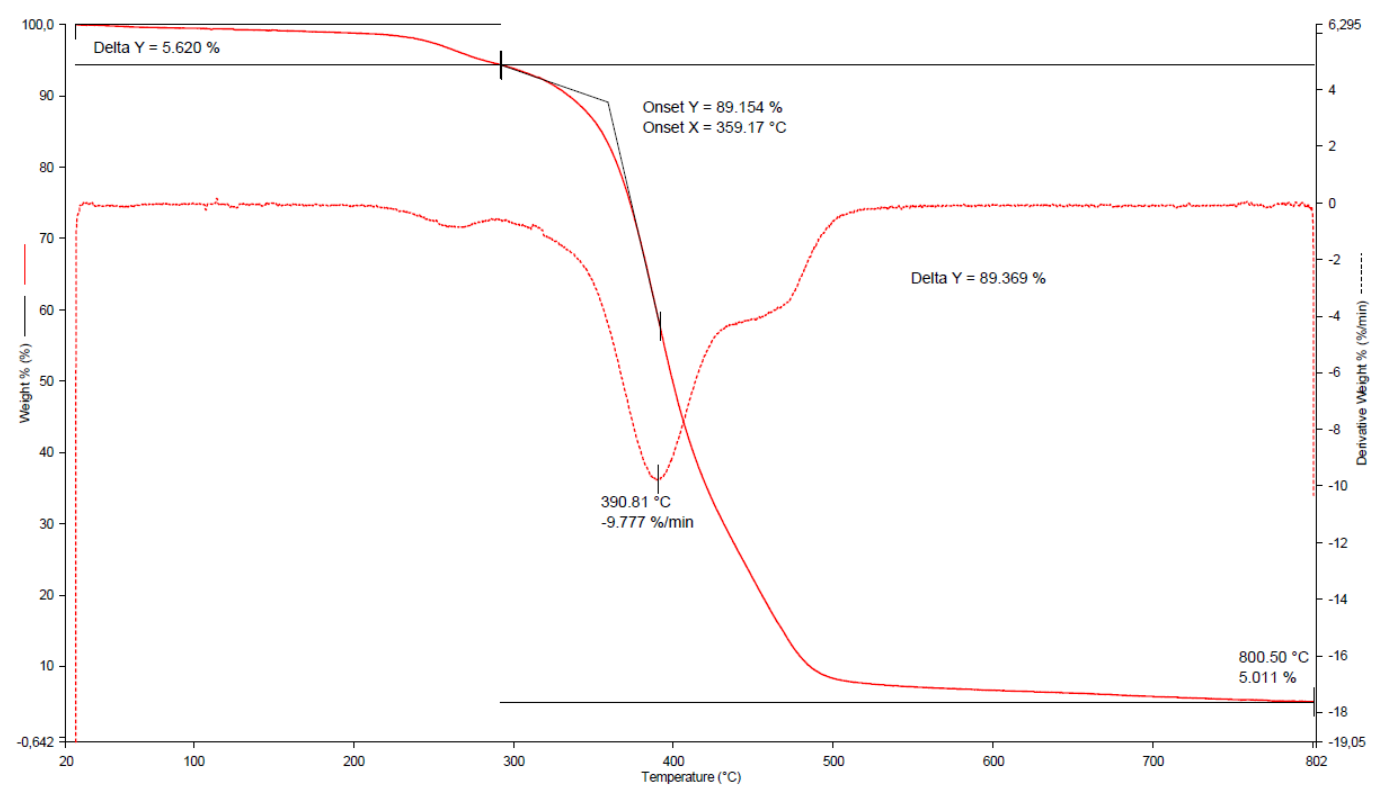

Figura A5.3. Curvas TG e DTG para resina: Bisfenol + NX-5620 (3)

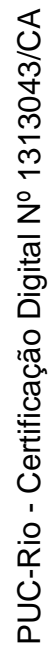

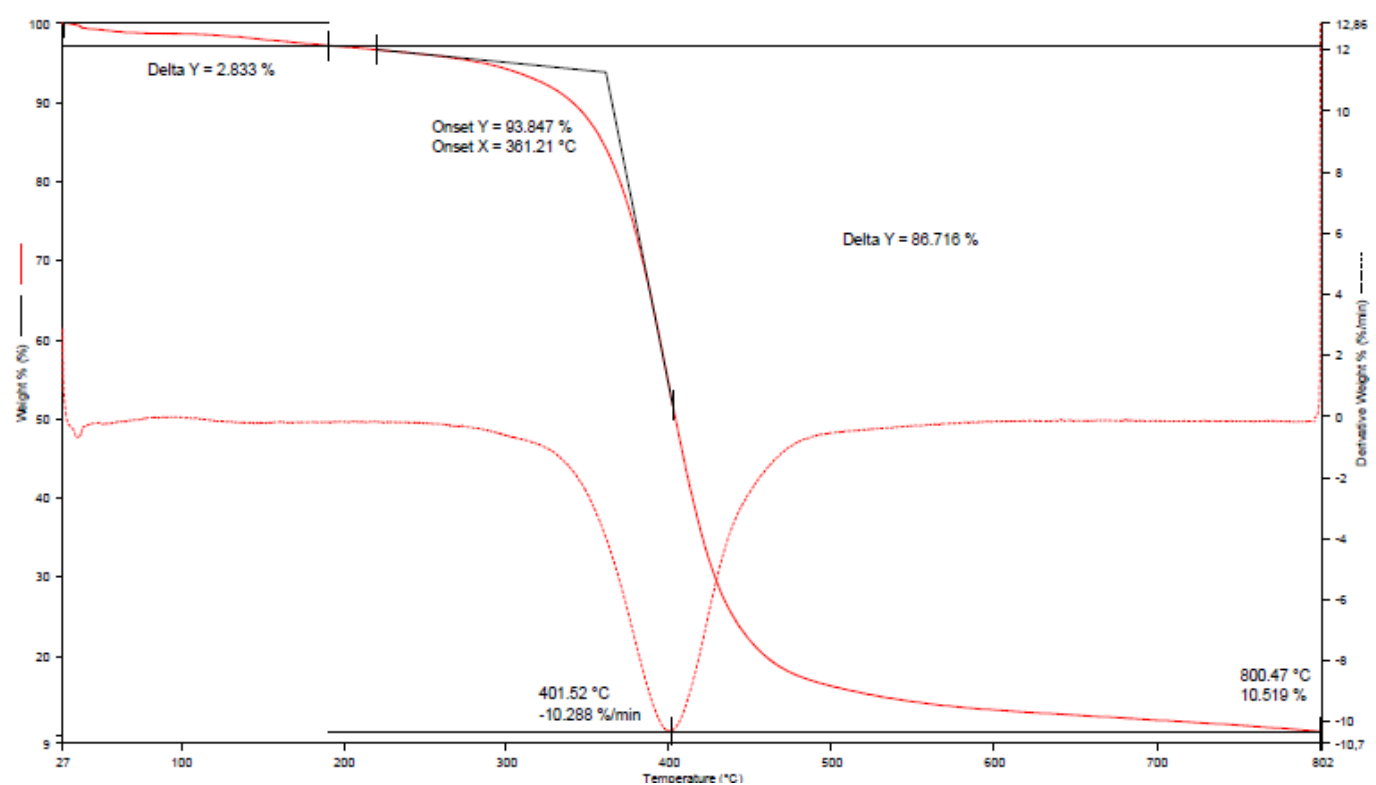

Figura A5.4. Curvas TG e DTG para resina: Bisfenol + IPDA (4) 


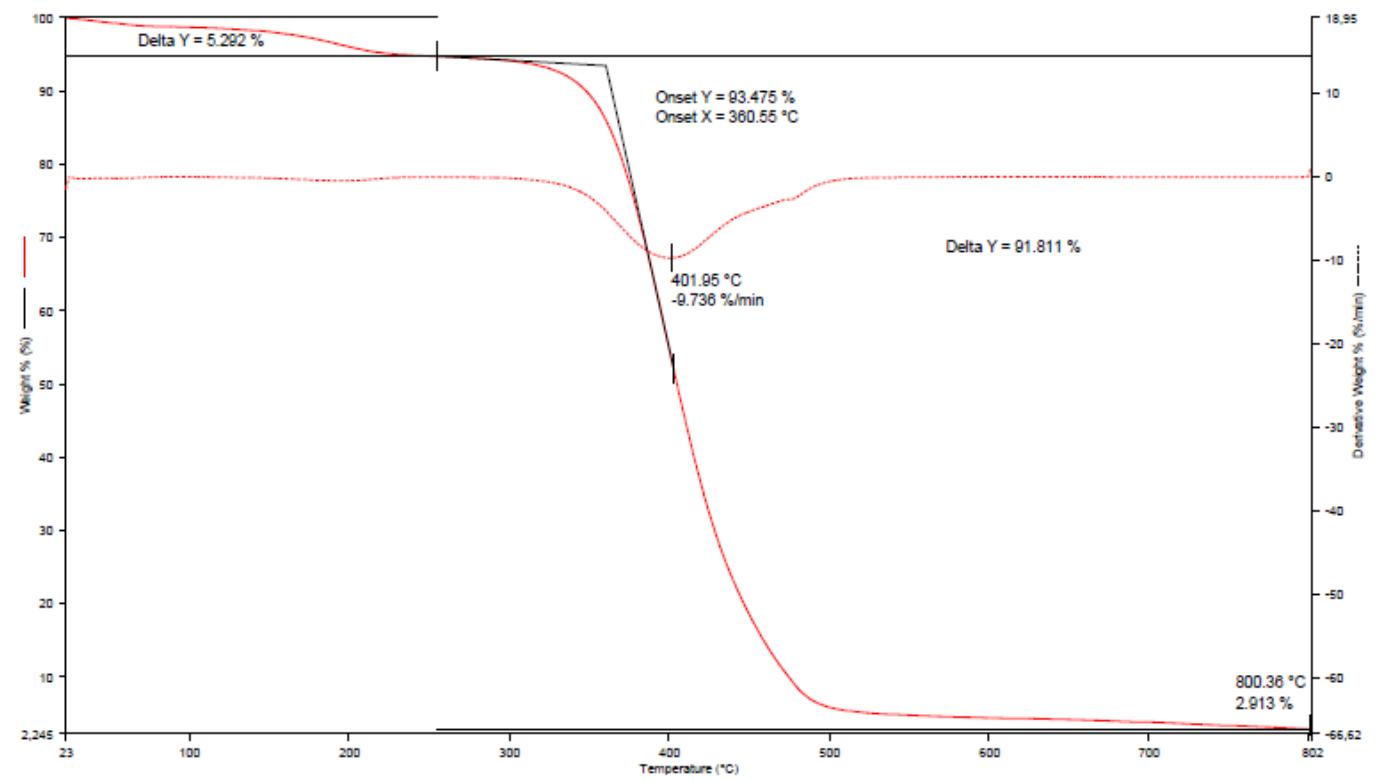

Figura A5.5. Curvas TG e DTG para resina: ESO30-bisfenol70 + IPDA (5)

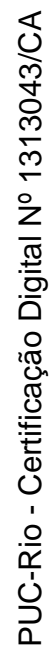

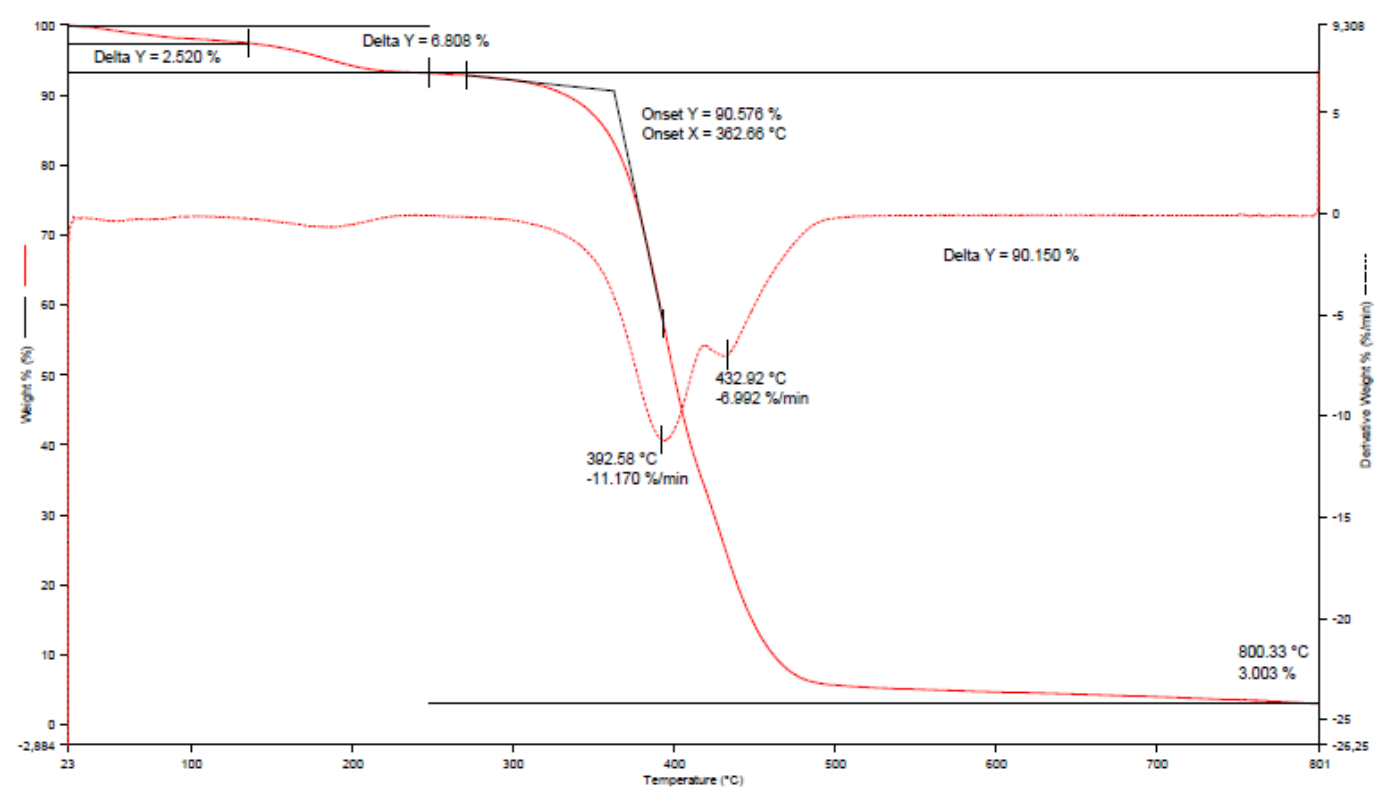

Figura A5.6. Curvas TG e DTG para resina: Cardanol50-Resorcinol50 + IPDA (6) 


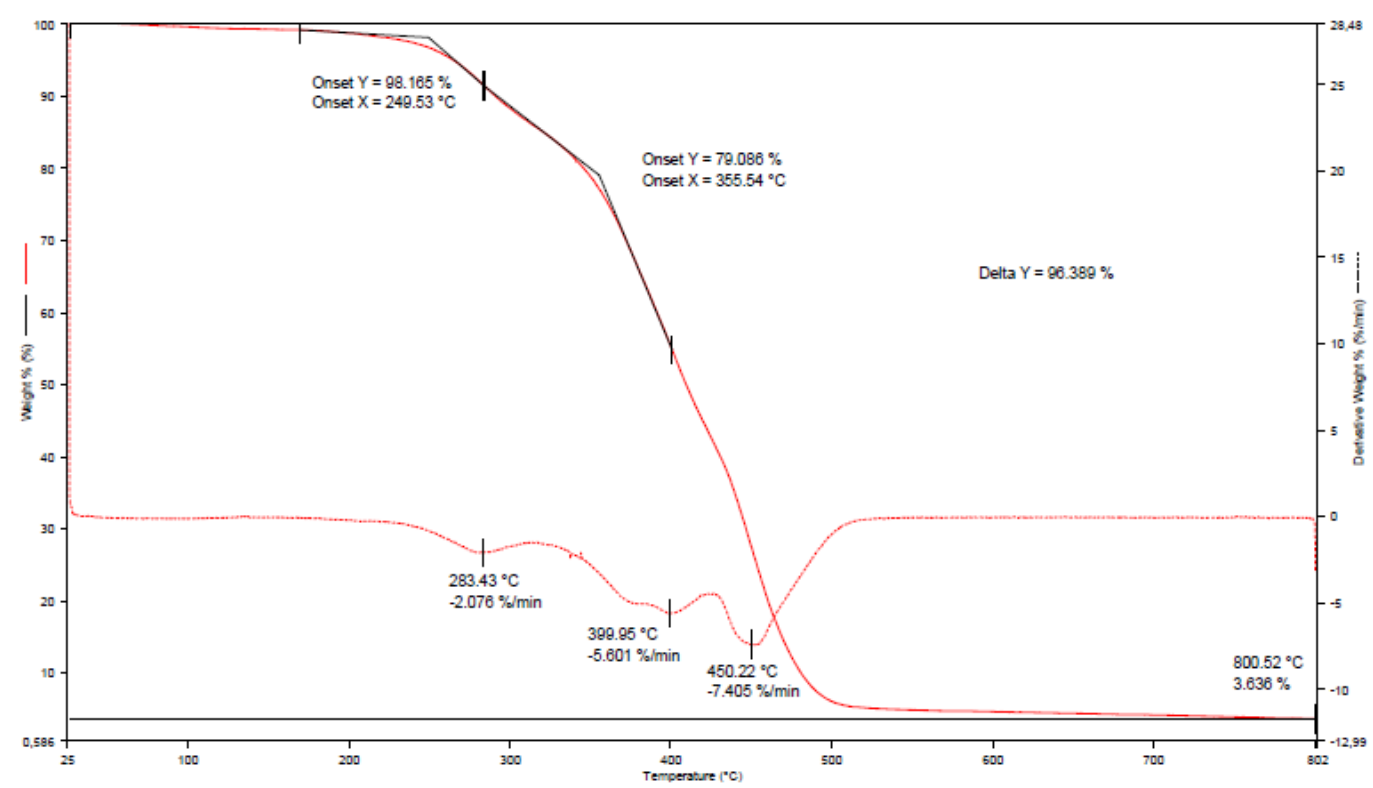

Figura A5.7. Curvas TG e DTG para resina: Cardanol50-Resorcinol50 + NX-5620 (7)

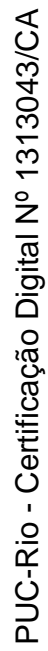

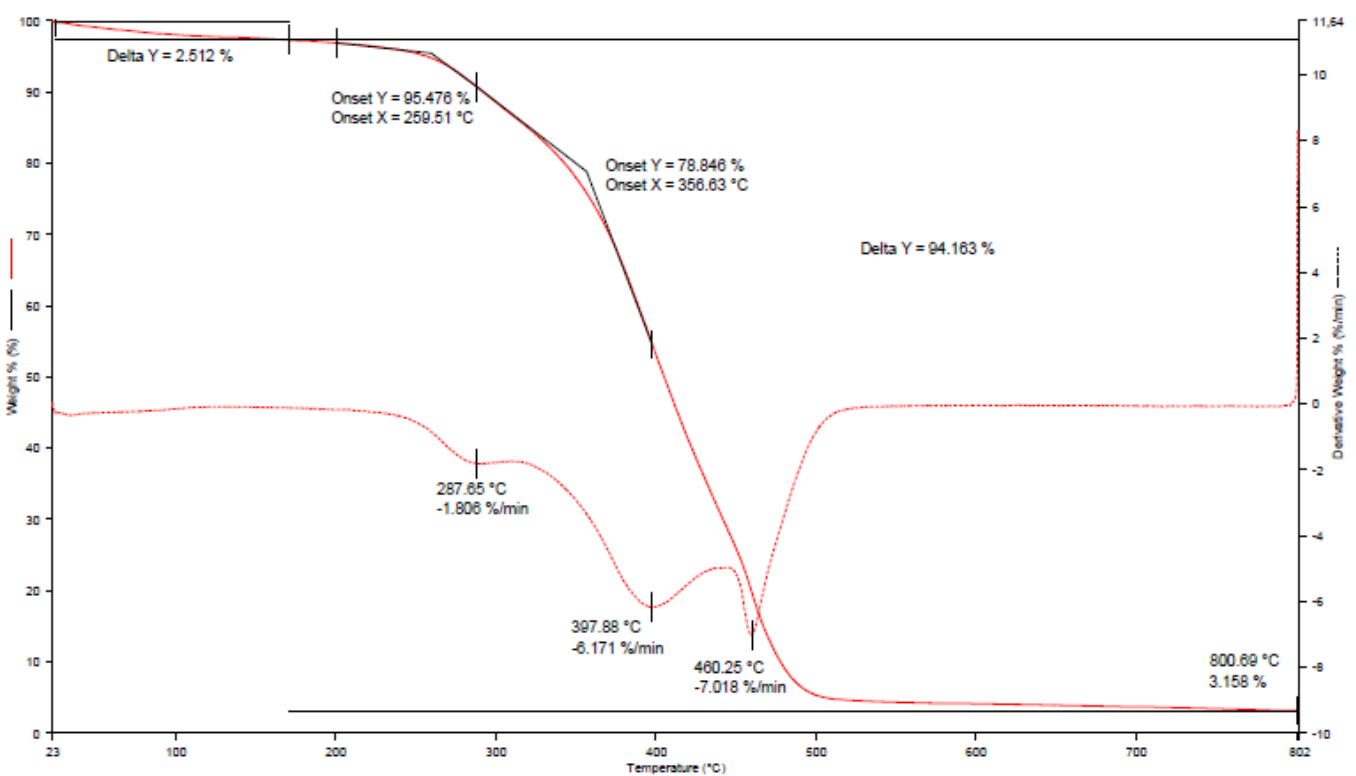

Figura A5.8. Curvas TG e DTG para resina: ESO30-bisfenol70 + NX-5620 (8) 


\section{Apêndice A6 - Curvas tensão-deformação}
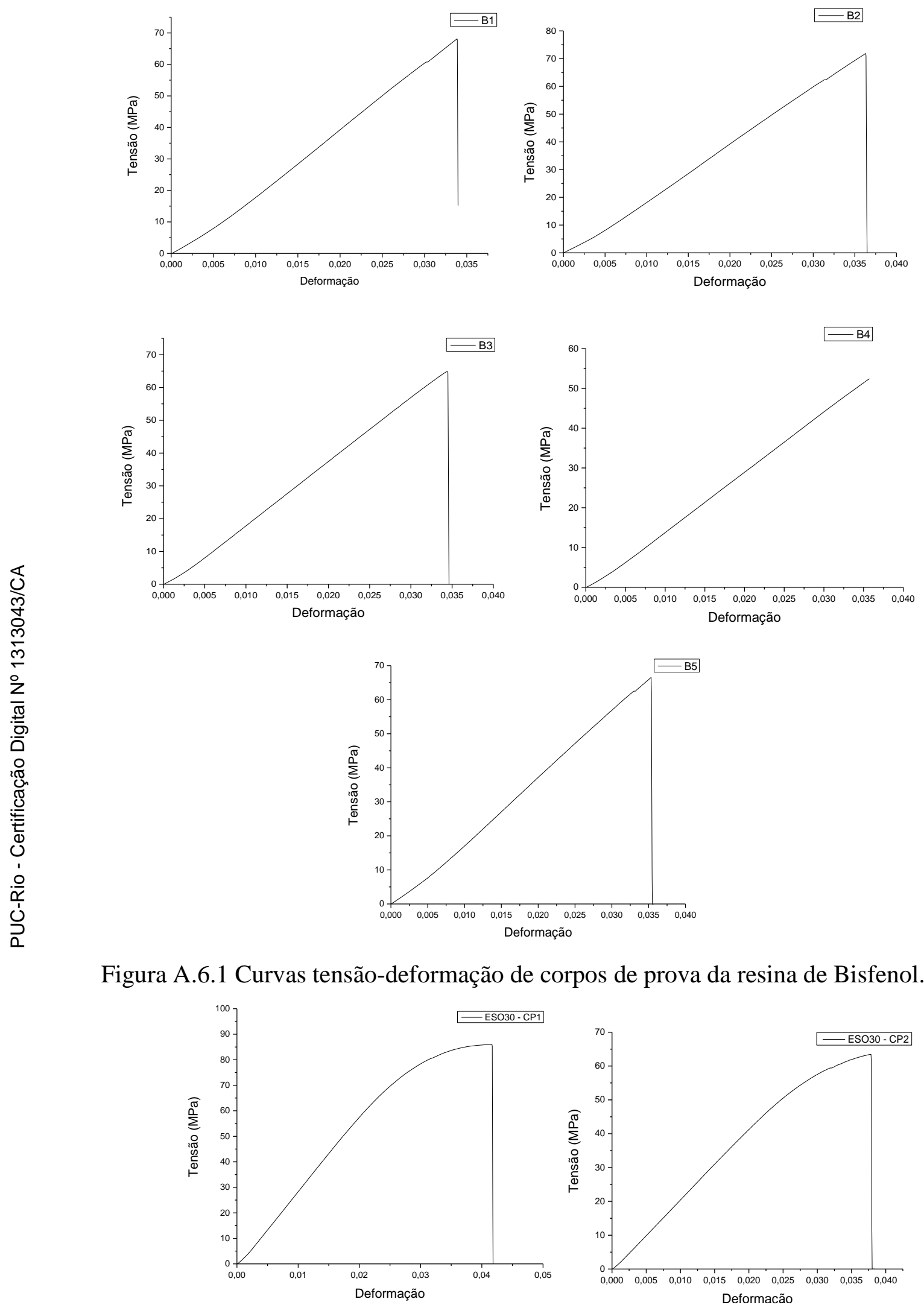

Figura A.6.1 Curvas tensão-deformação de corpos de prova da resina de Bisfenol.
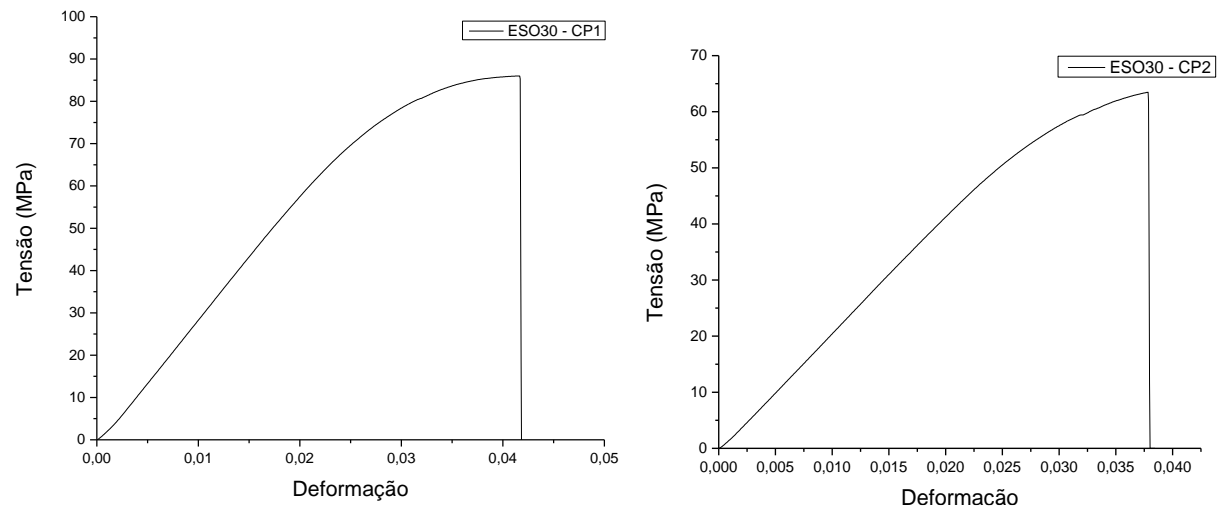

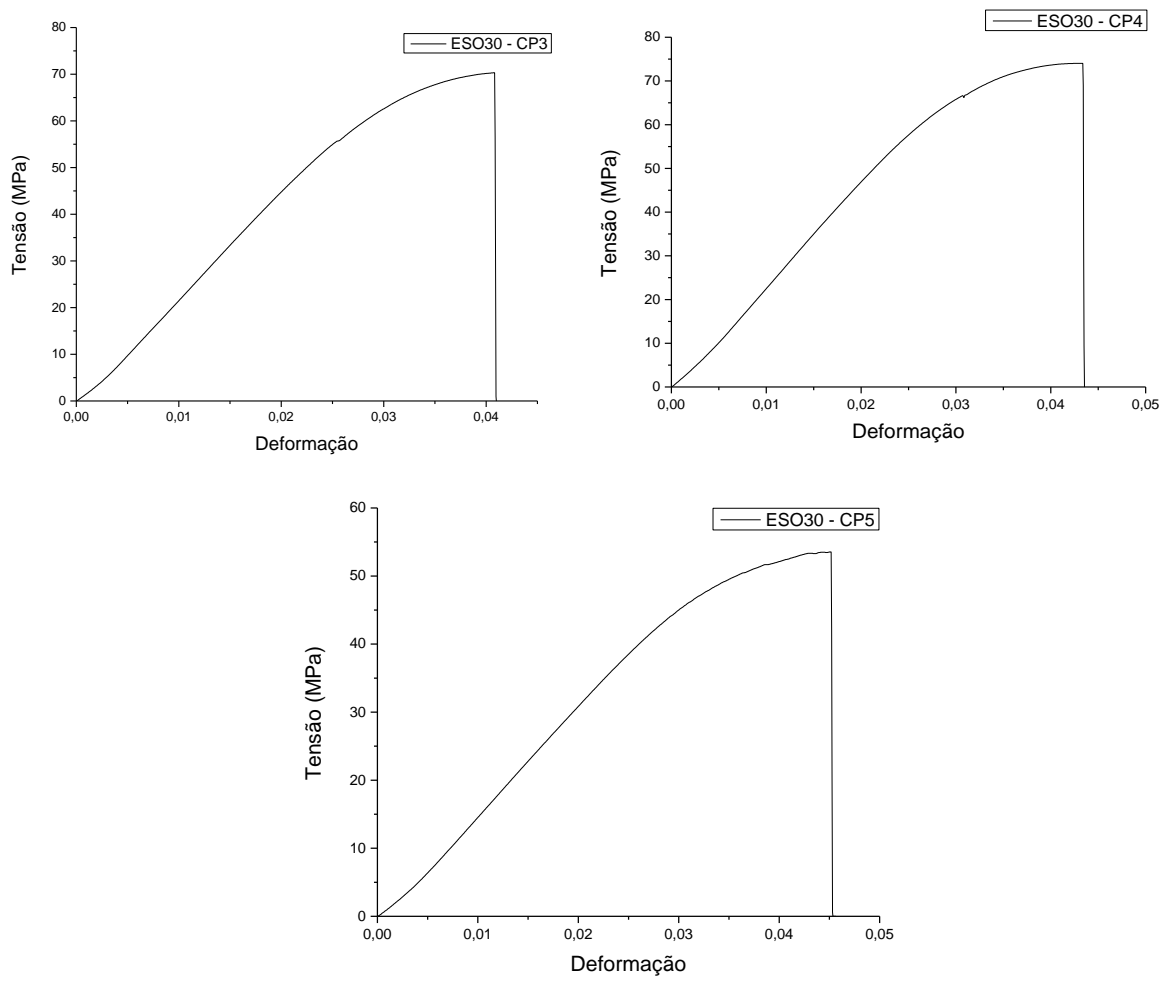

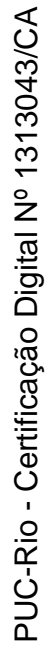

Figura A.6.2 Curvas tensão-deformação de corpos de prova da resina ESO30.
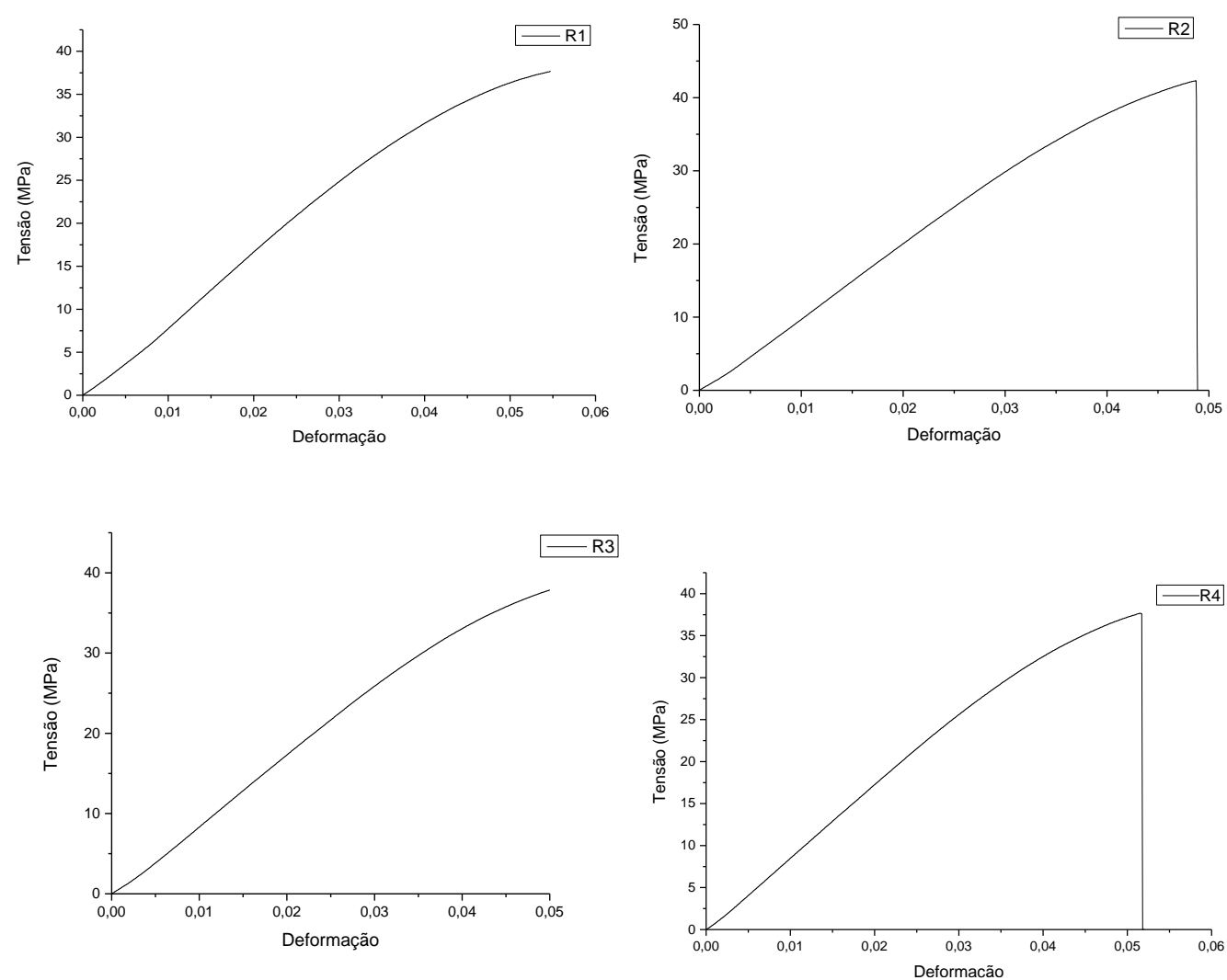


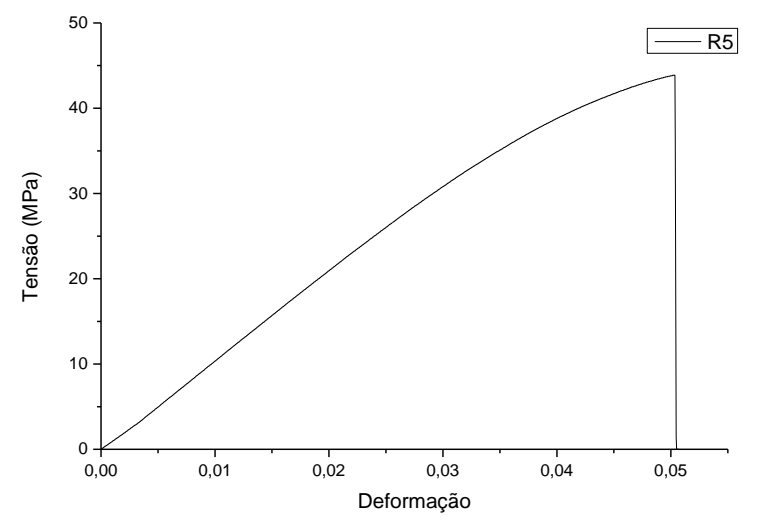

Figura A.6.3 Curvas tensão-deformação de corpos de prova resina de Resorcinol.
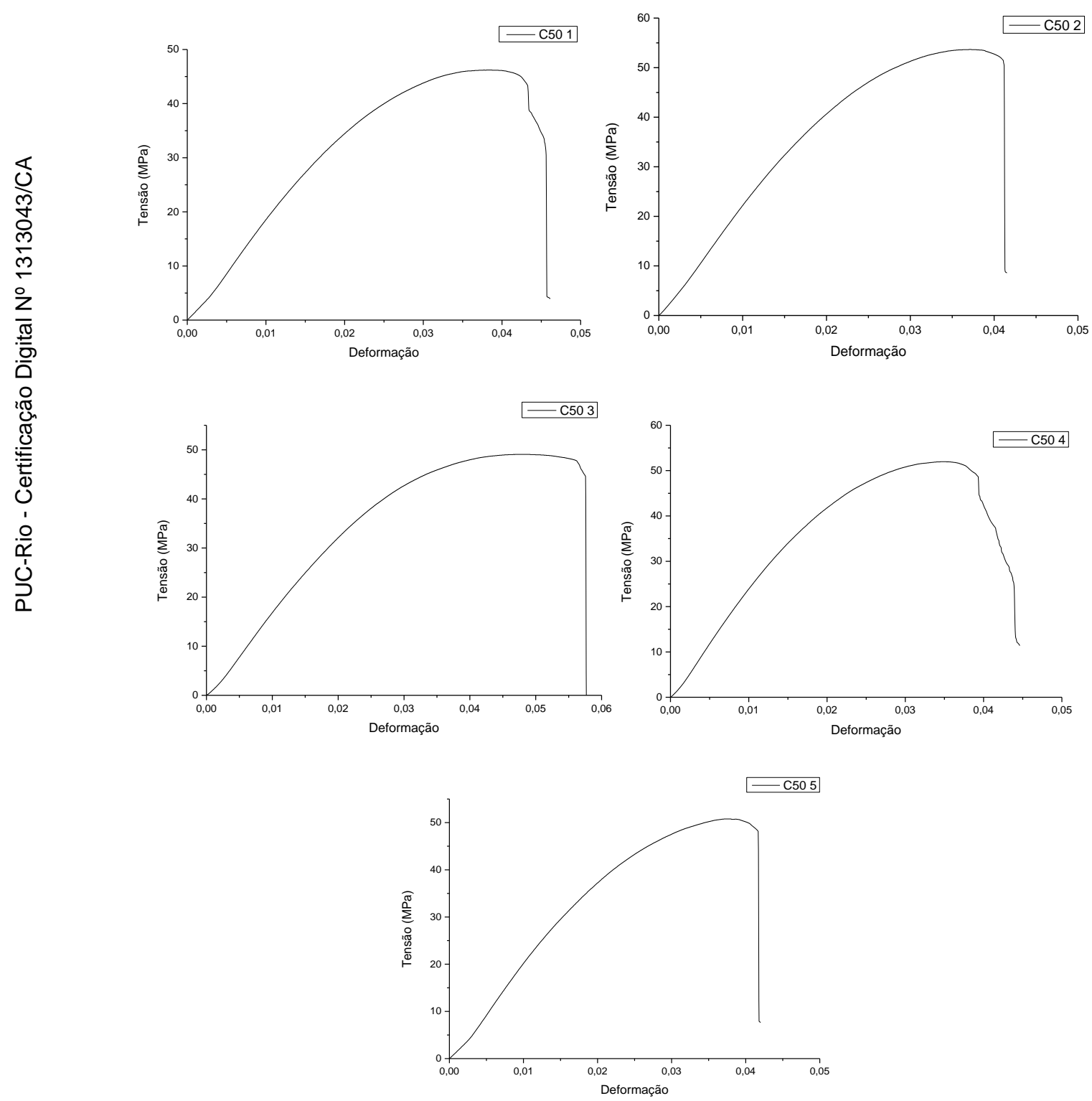

Figura A.6.4 Curvas tensão-deformação de corpos de prova da resina C50. 

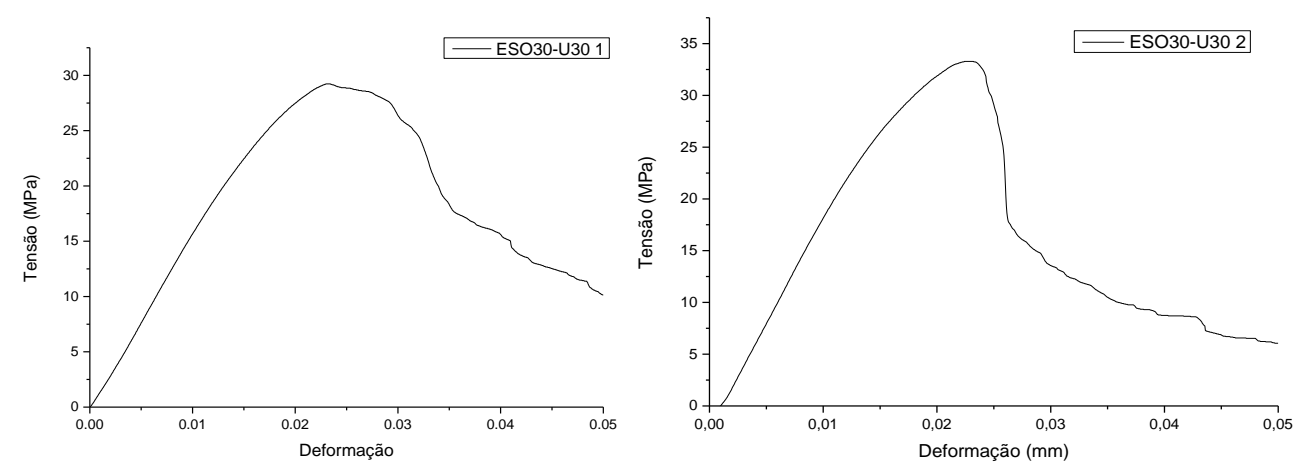

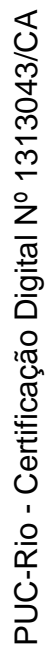
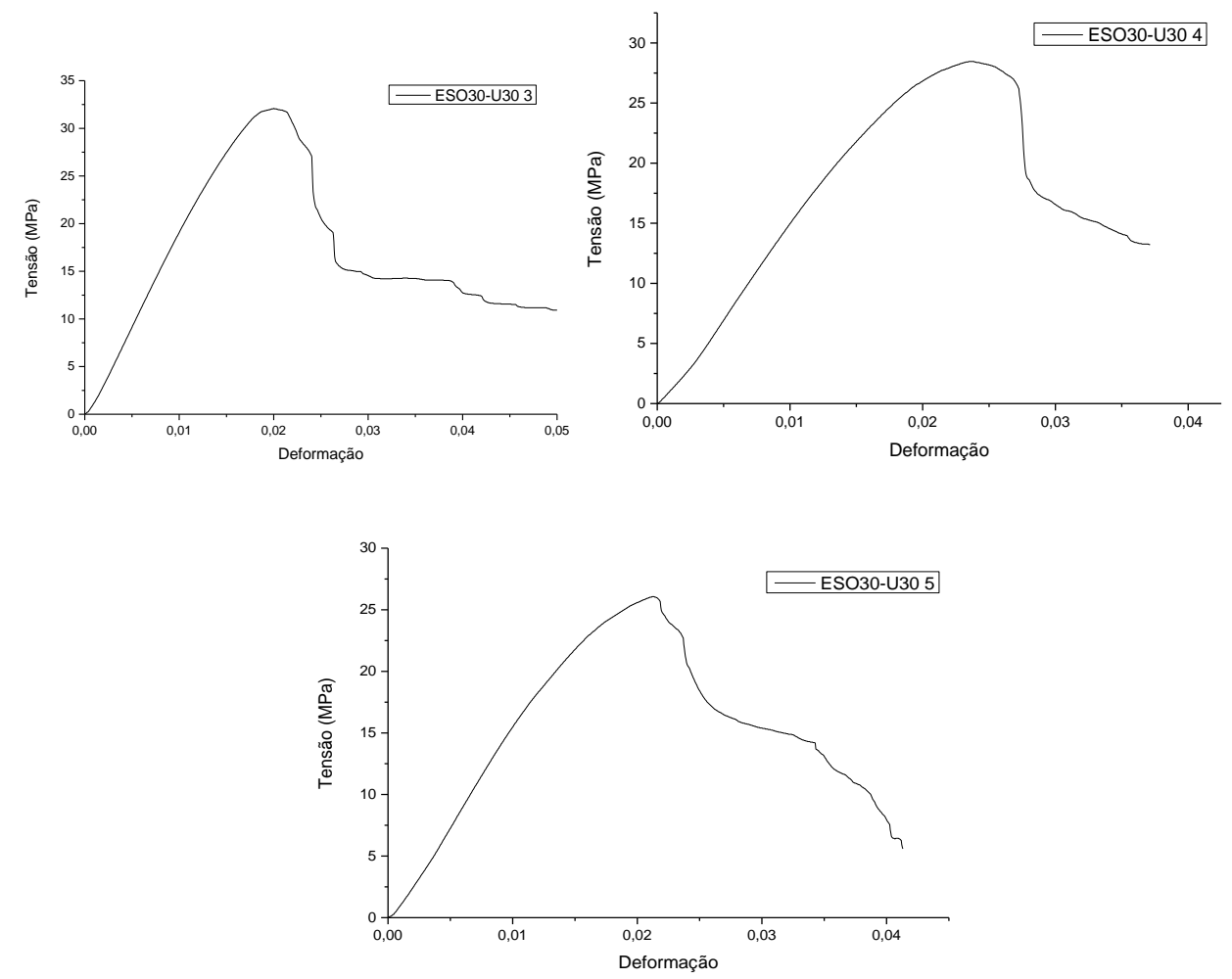

Figura A.6.5 Curvas tensão-deformação de corpos de compósito ESO30-U30.

\section{ESO30-H30}
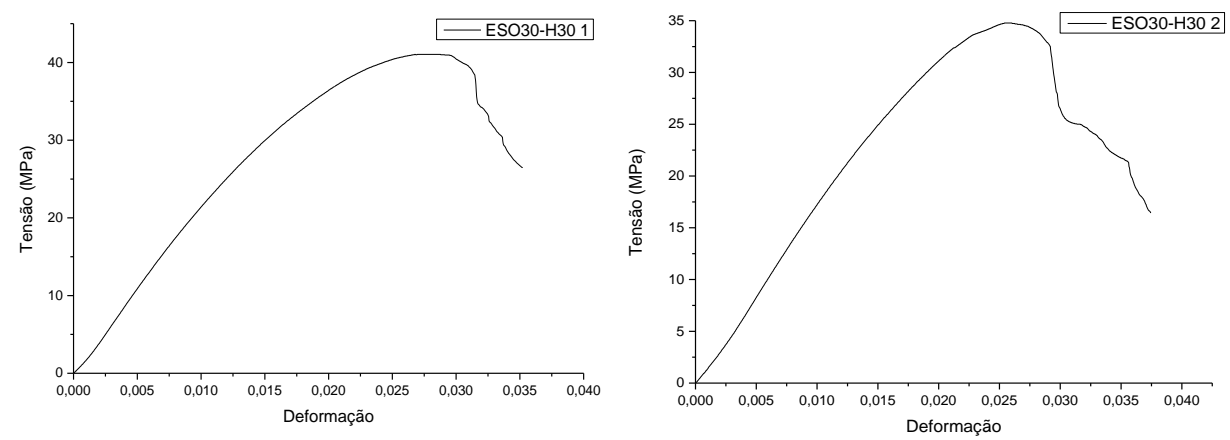

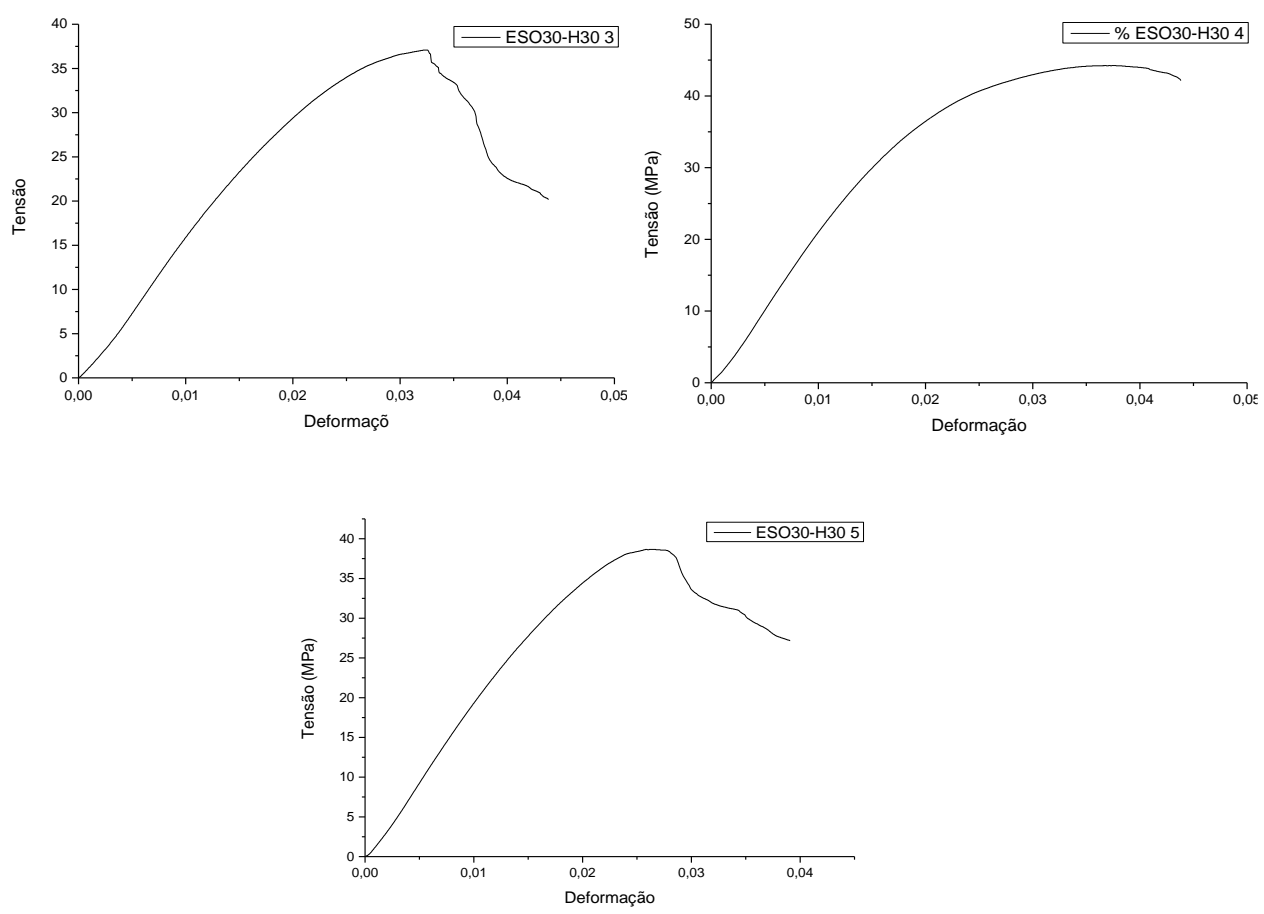

Figura A.6.6 Curvas tensão-deformação de corpos de compósito ESO30-H30.

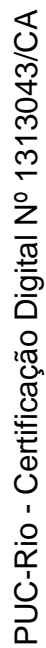

\section{ESO30-M30}
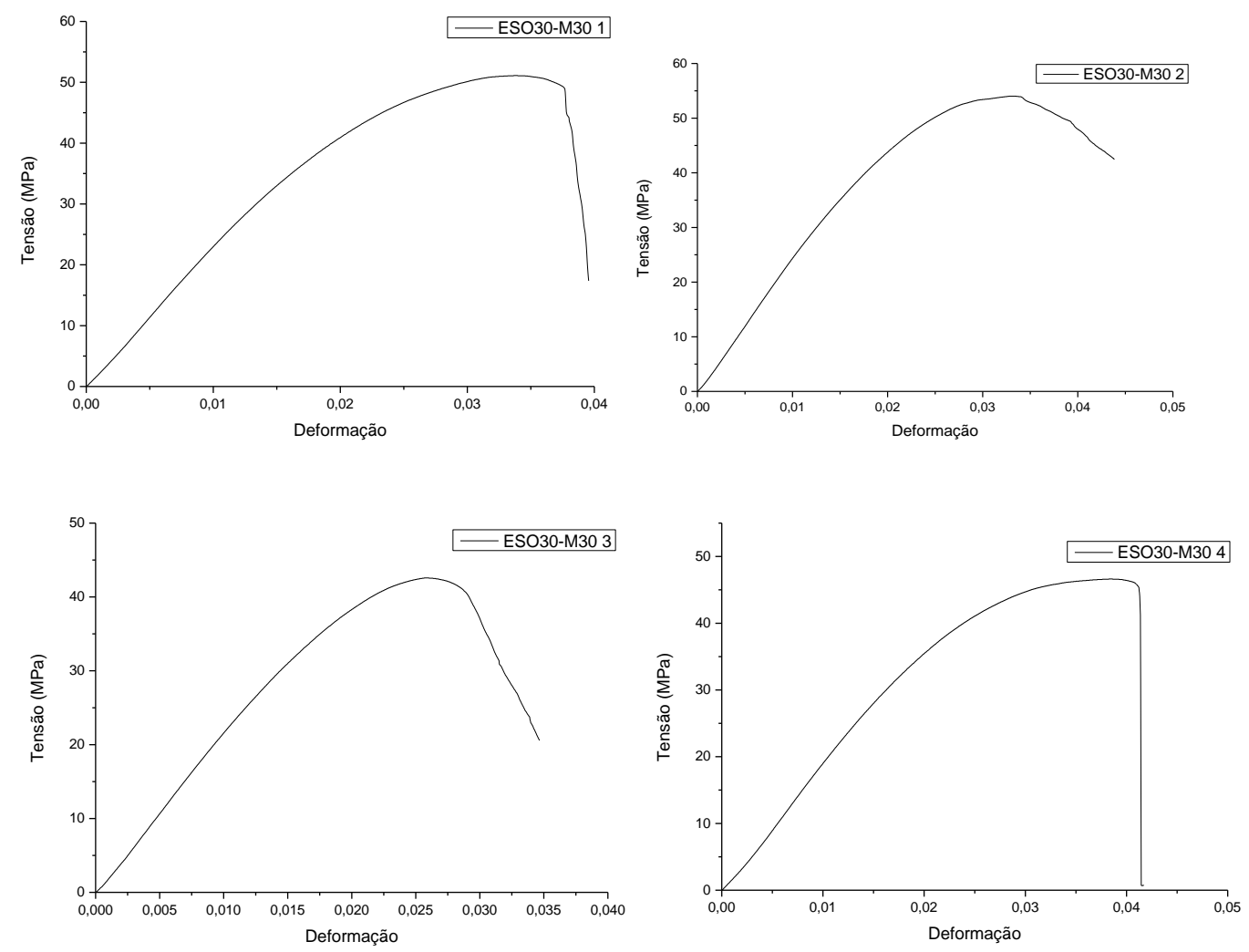


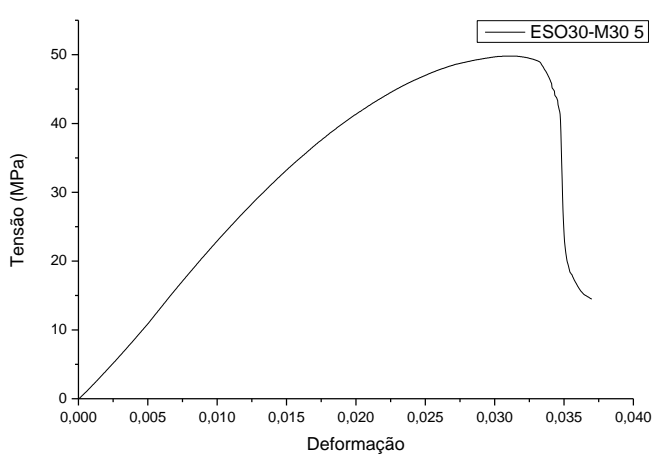

Figura A.6.7 Curvas tensão-deformação de corpos de compósito ESO30-M30.
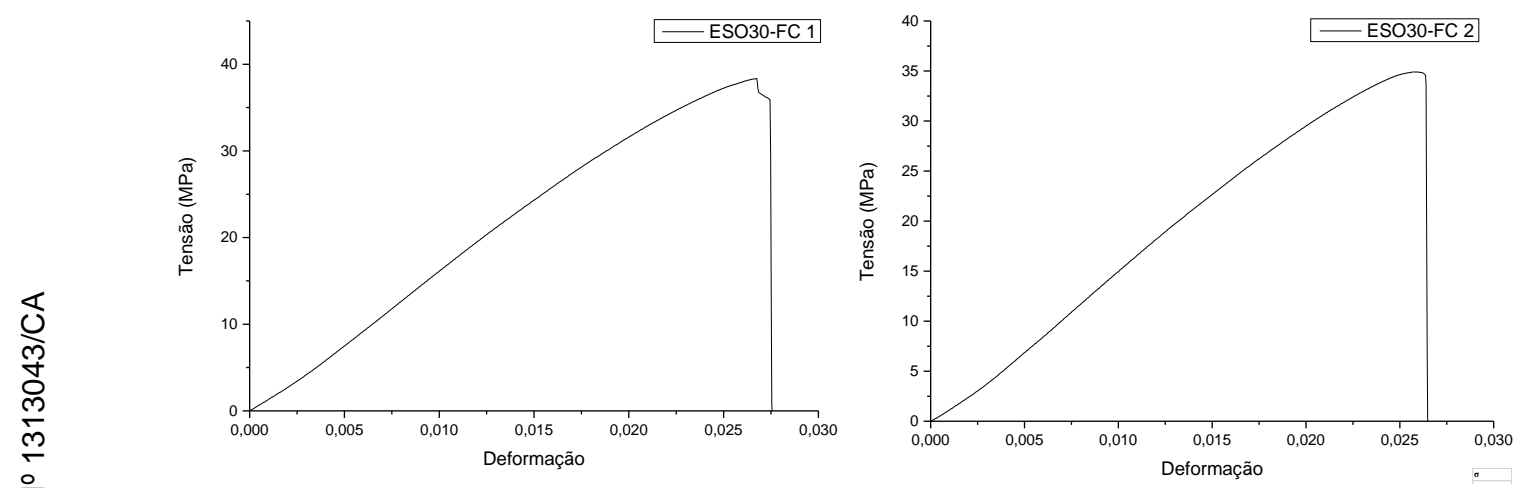

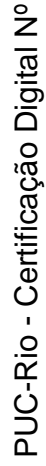
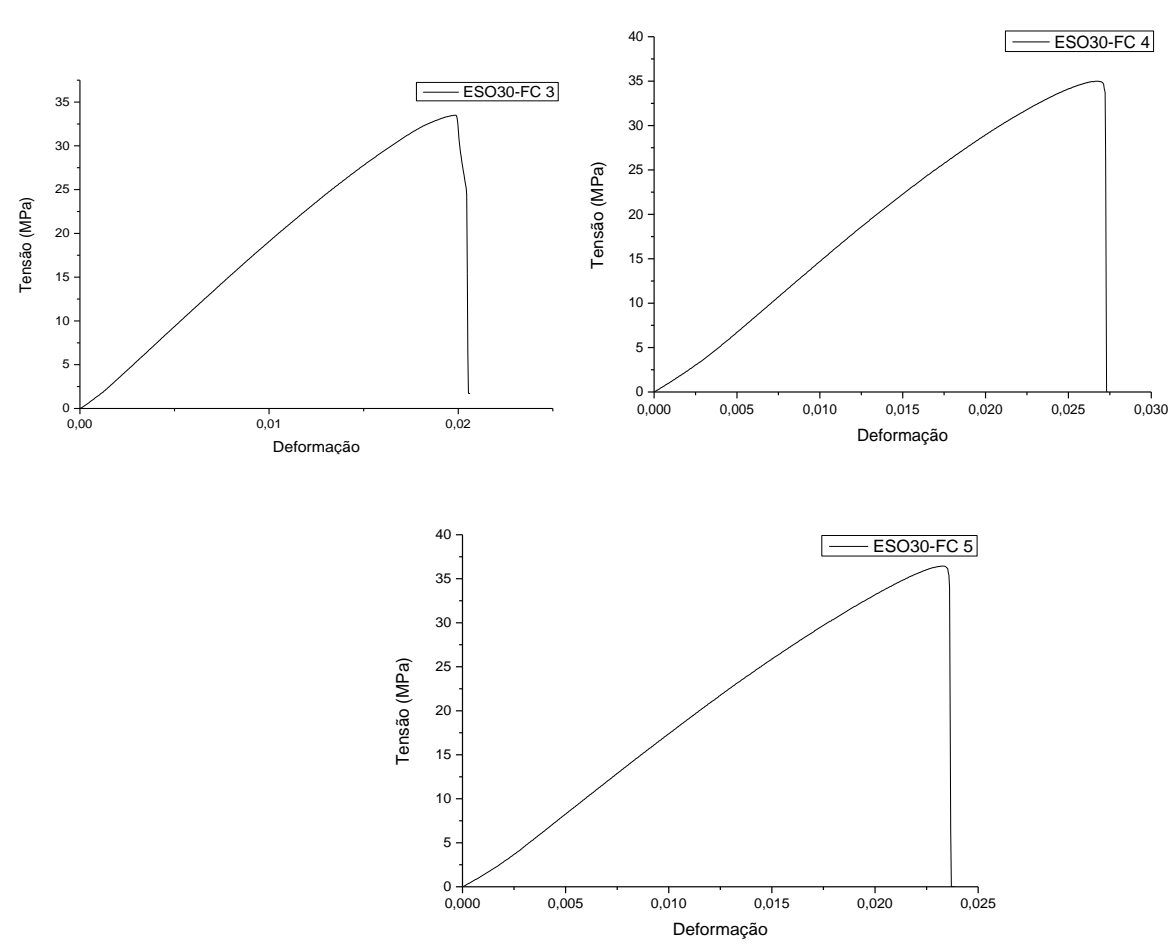

Figura A.6.8 Curvas tensão-deformação de corpos de compósito ESO30-FC. 

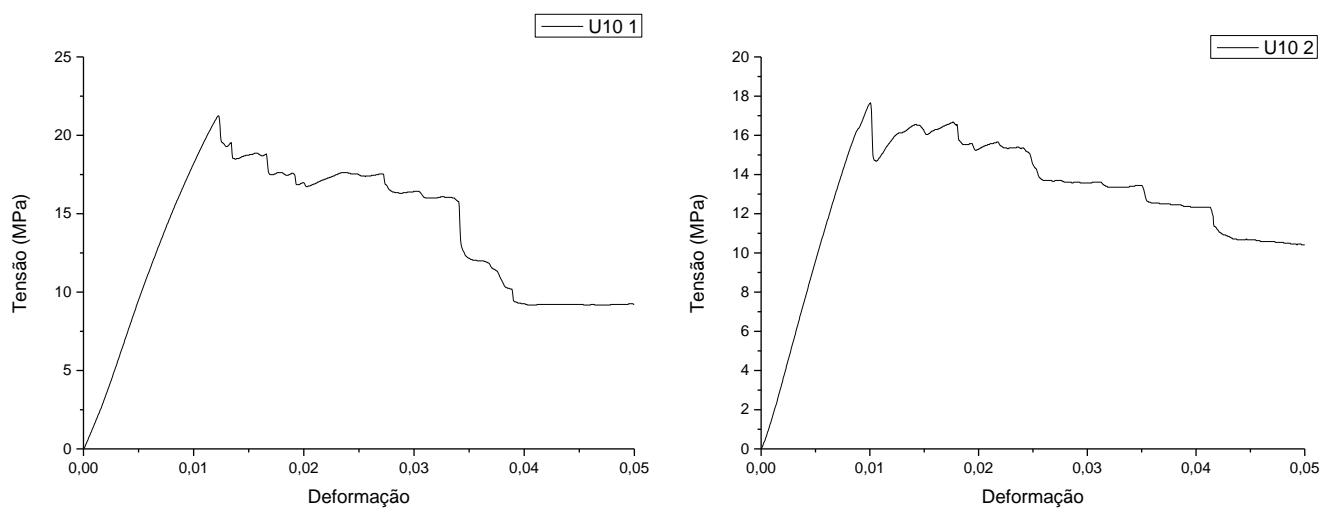

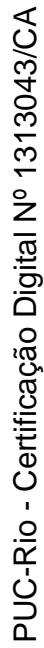
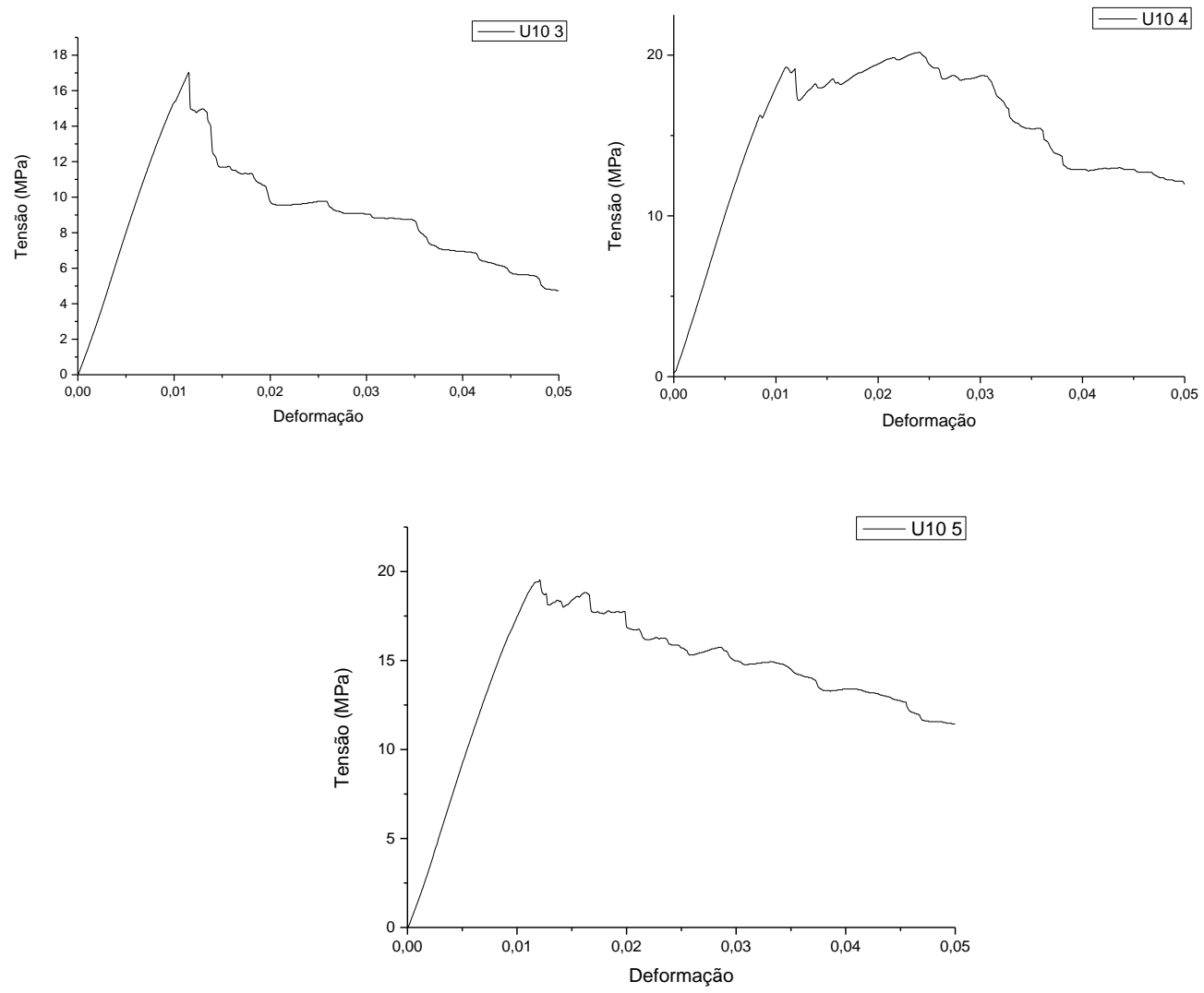

Figura A.6.9 Curvas tensão-deformação de corpos de compósito U10.
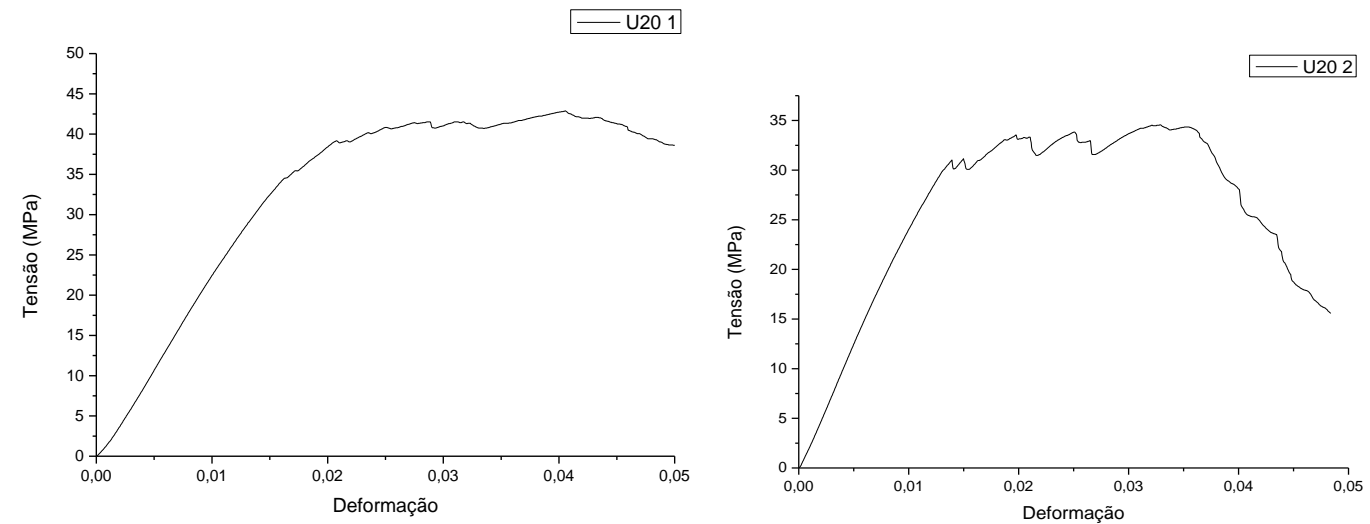

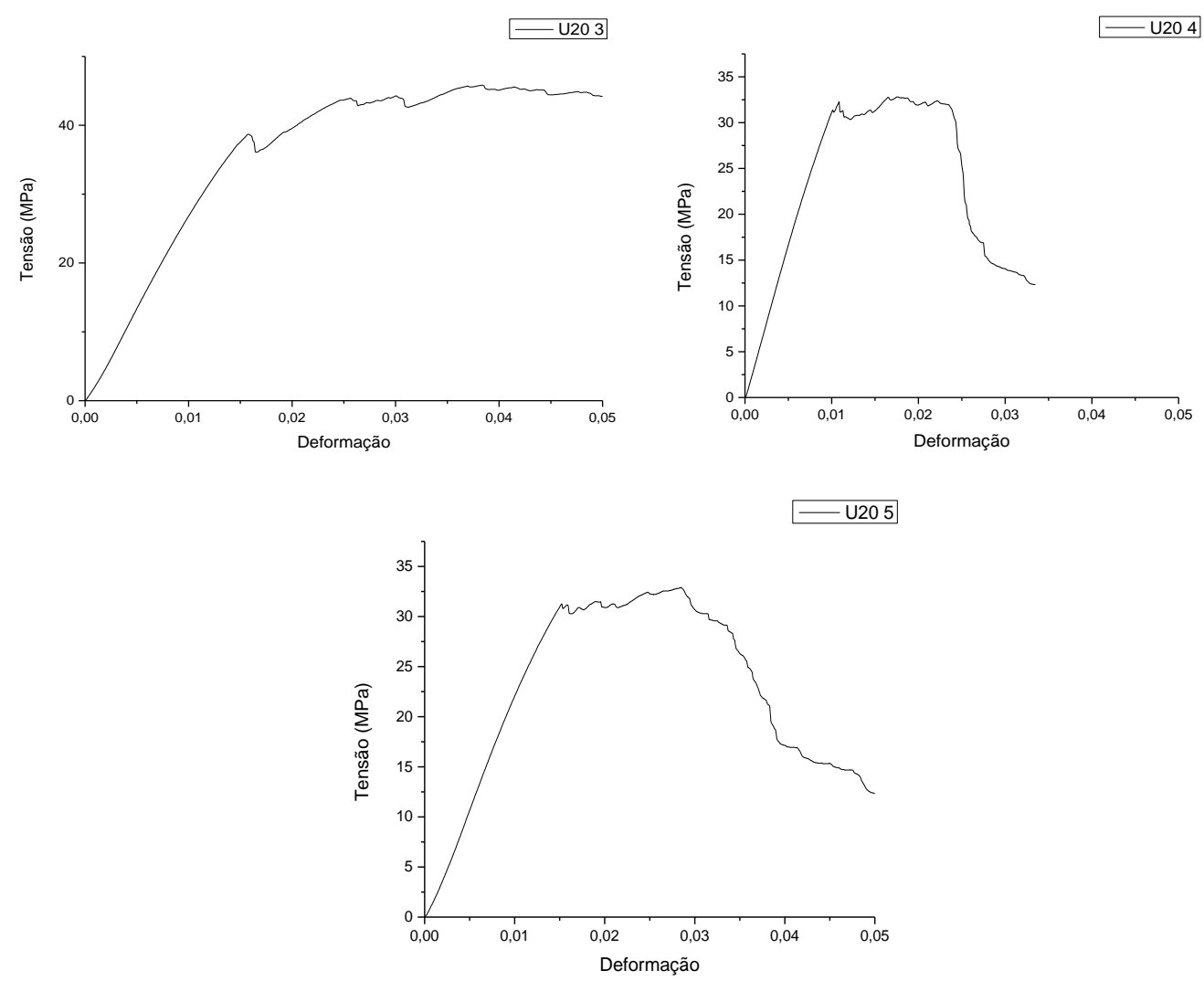

Figura A.6.10 Curvas tensão-deformação de corpos de compósito U20.

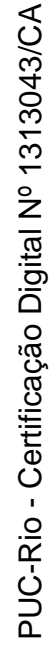
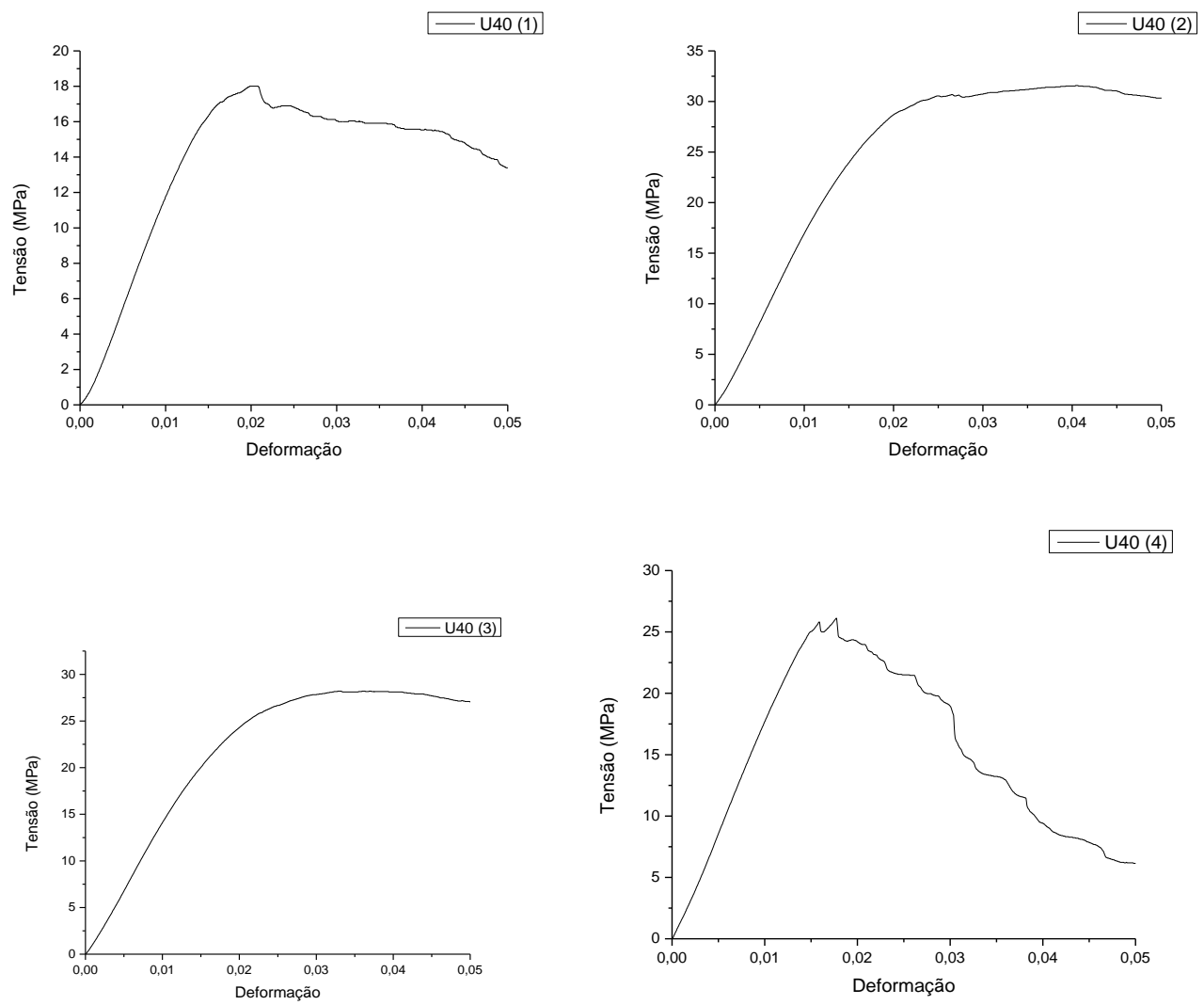


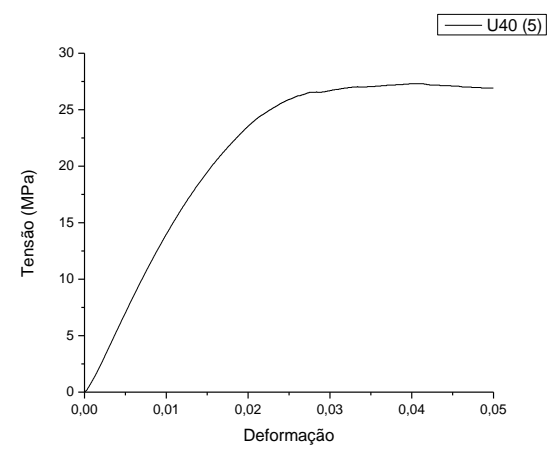

Figura A.6.11 Curvas tensão-deformação de corpos de compósito U40.

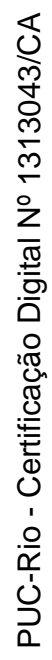
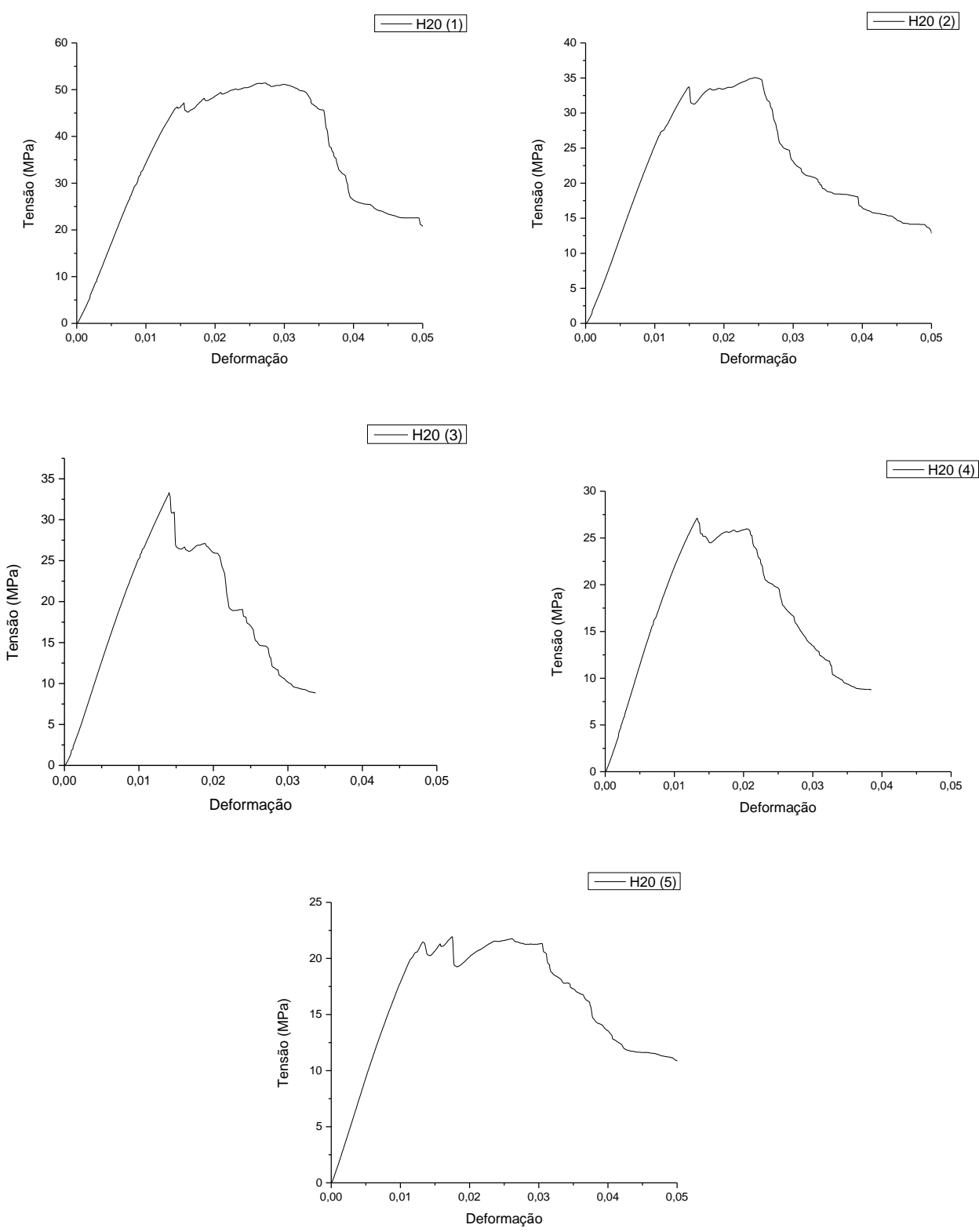

Figura A.6.12. Curvas tensão-deformação de corpos de compósito H20. 
H30
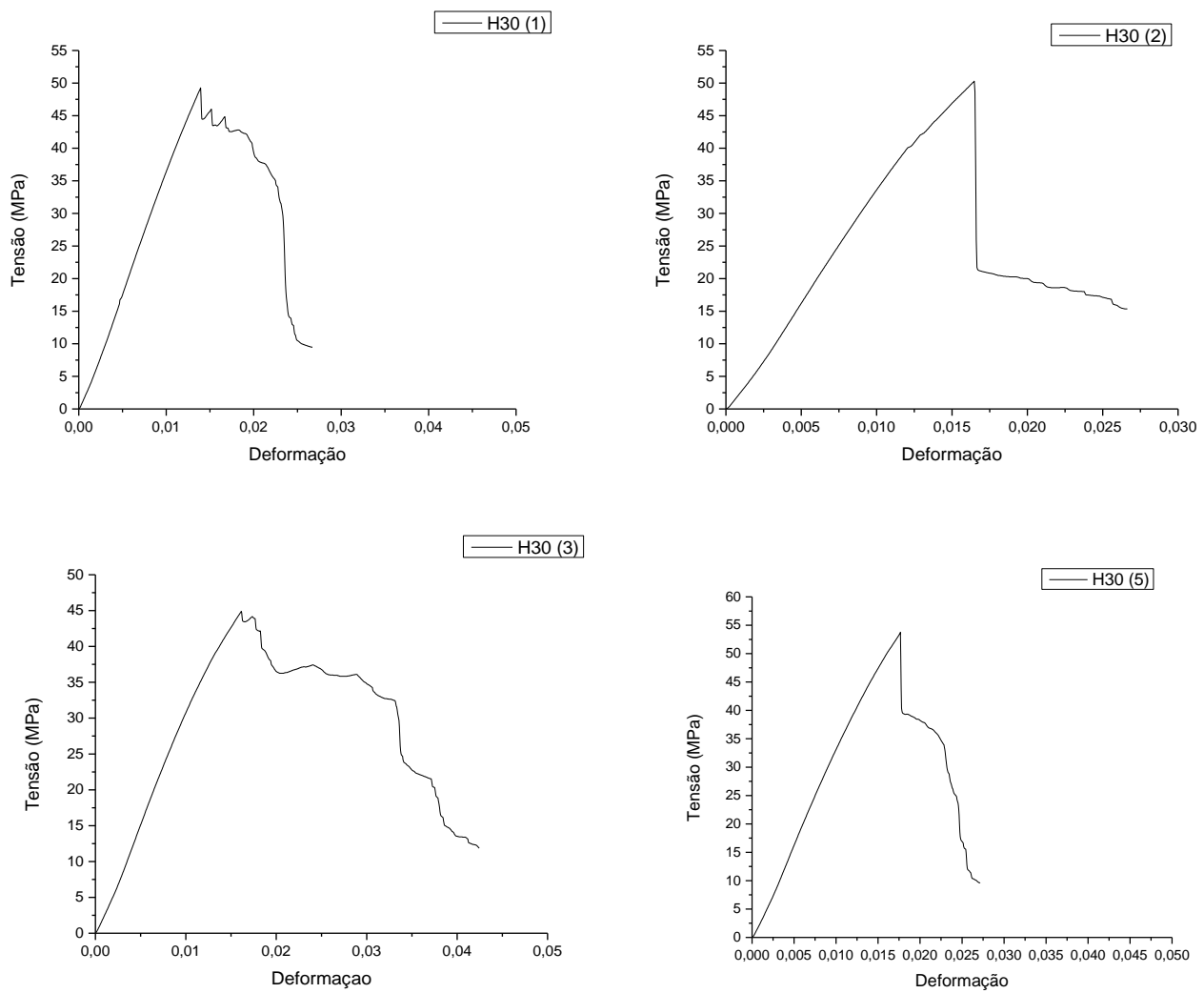

Figura A.6.13 Curvas tensão-deformação de corpos de compósito H30.

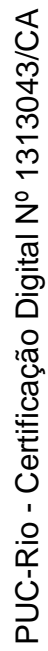
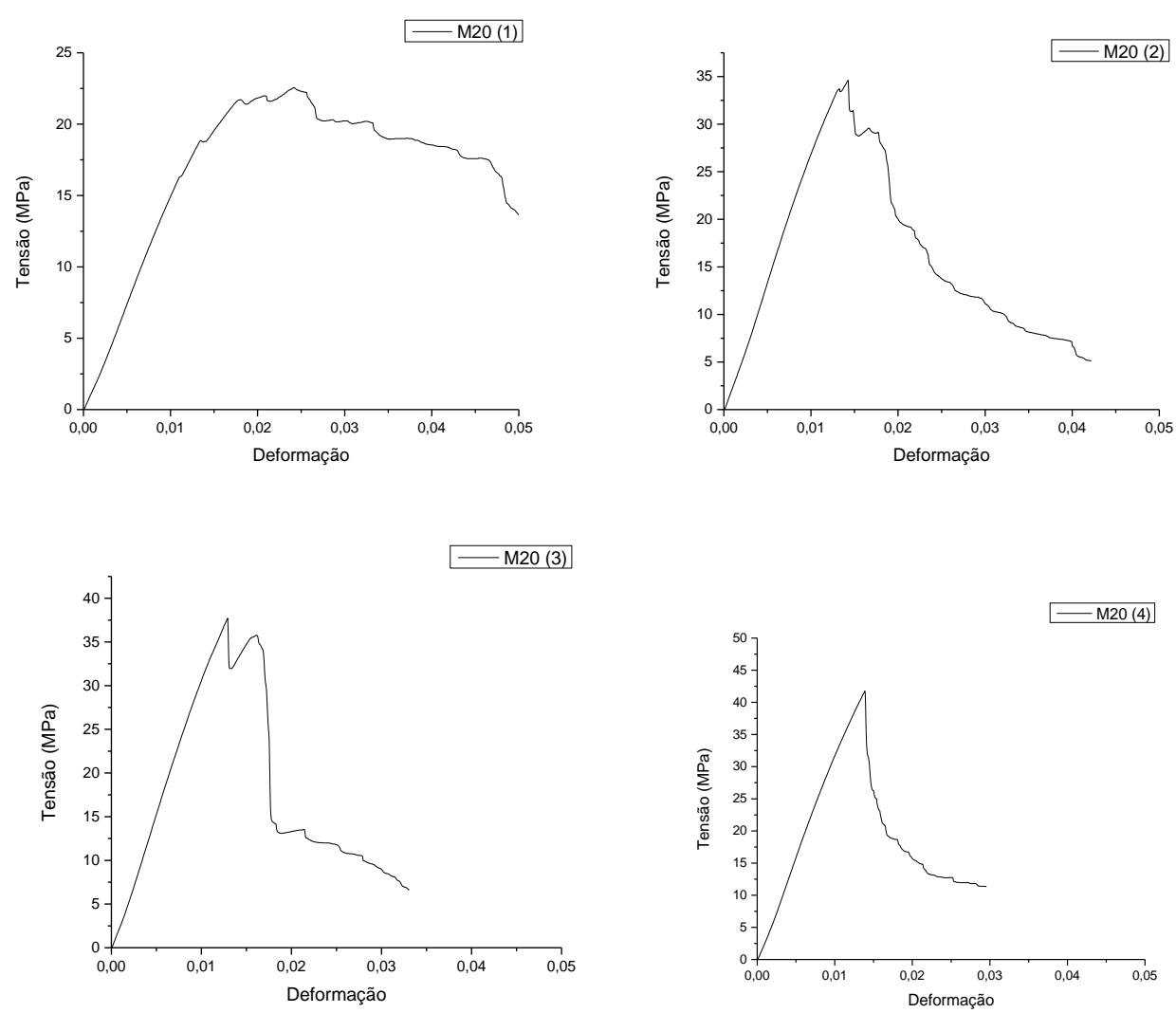


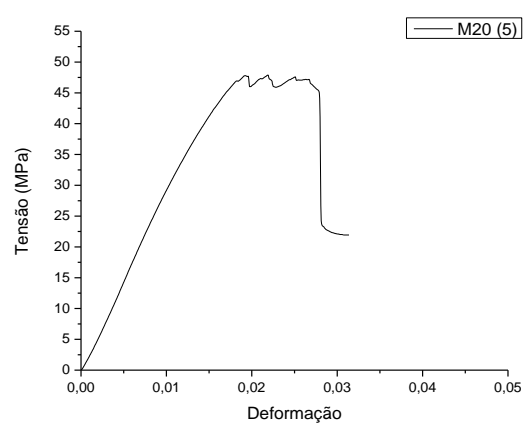

Figura A.6.14 Curvas tensão-deformação de corpos de compósito M20.
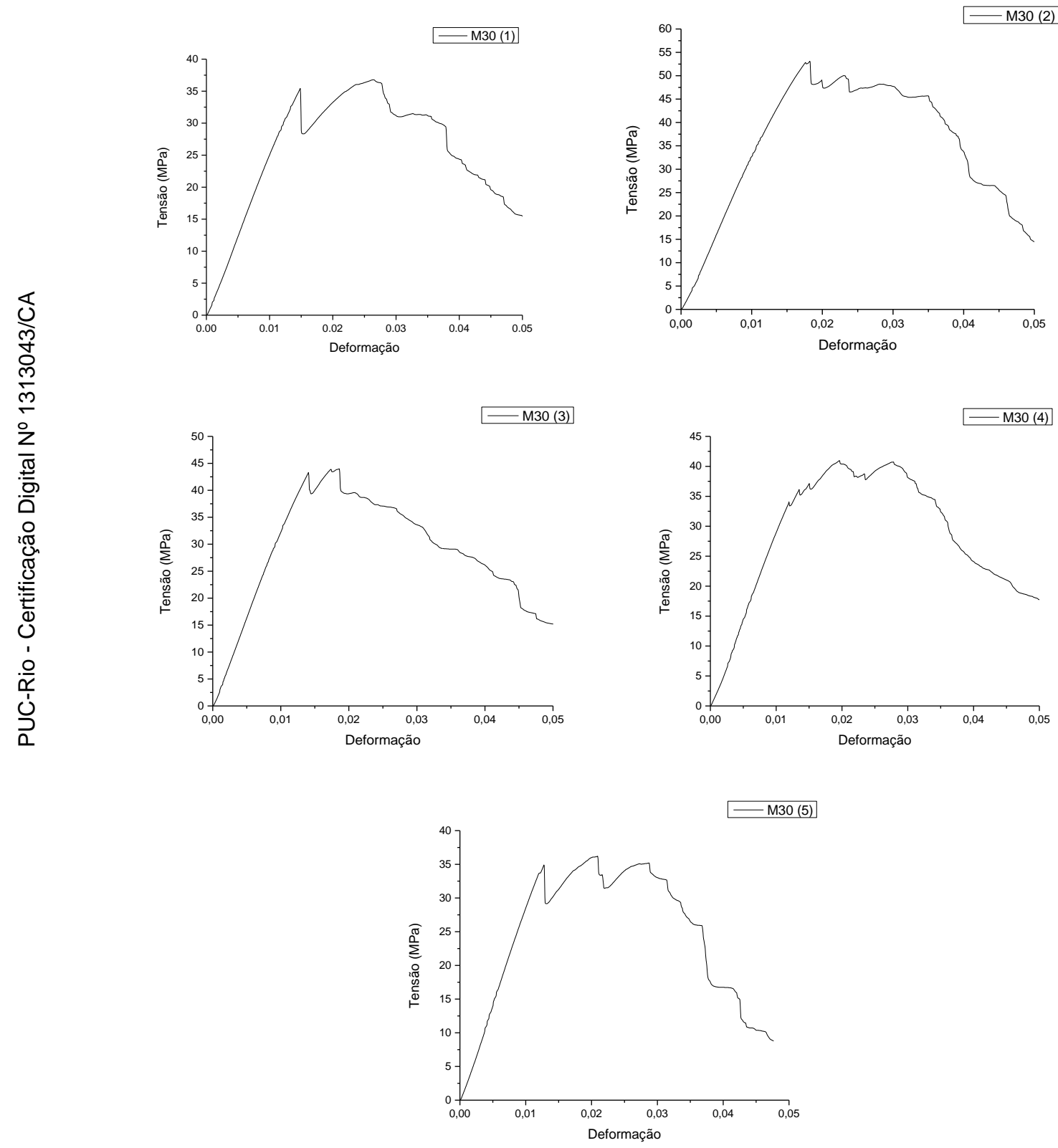

Figura A.6.15 Curvas tensão-deformação de corpos de compósito M30. 

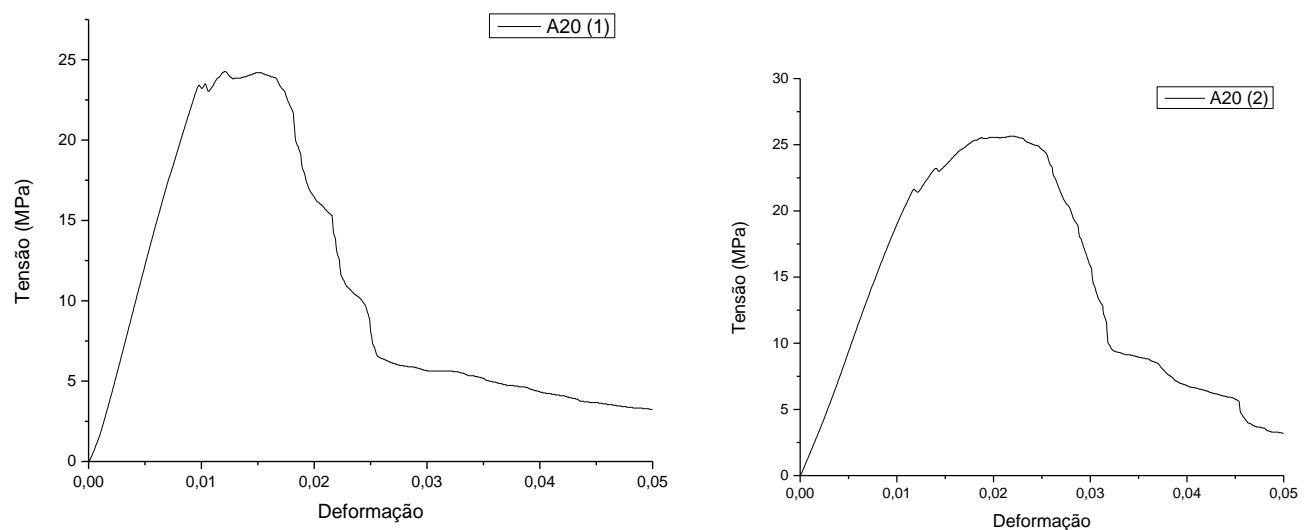

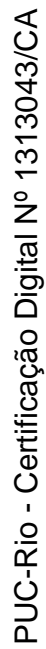
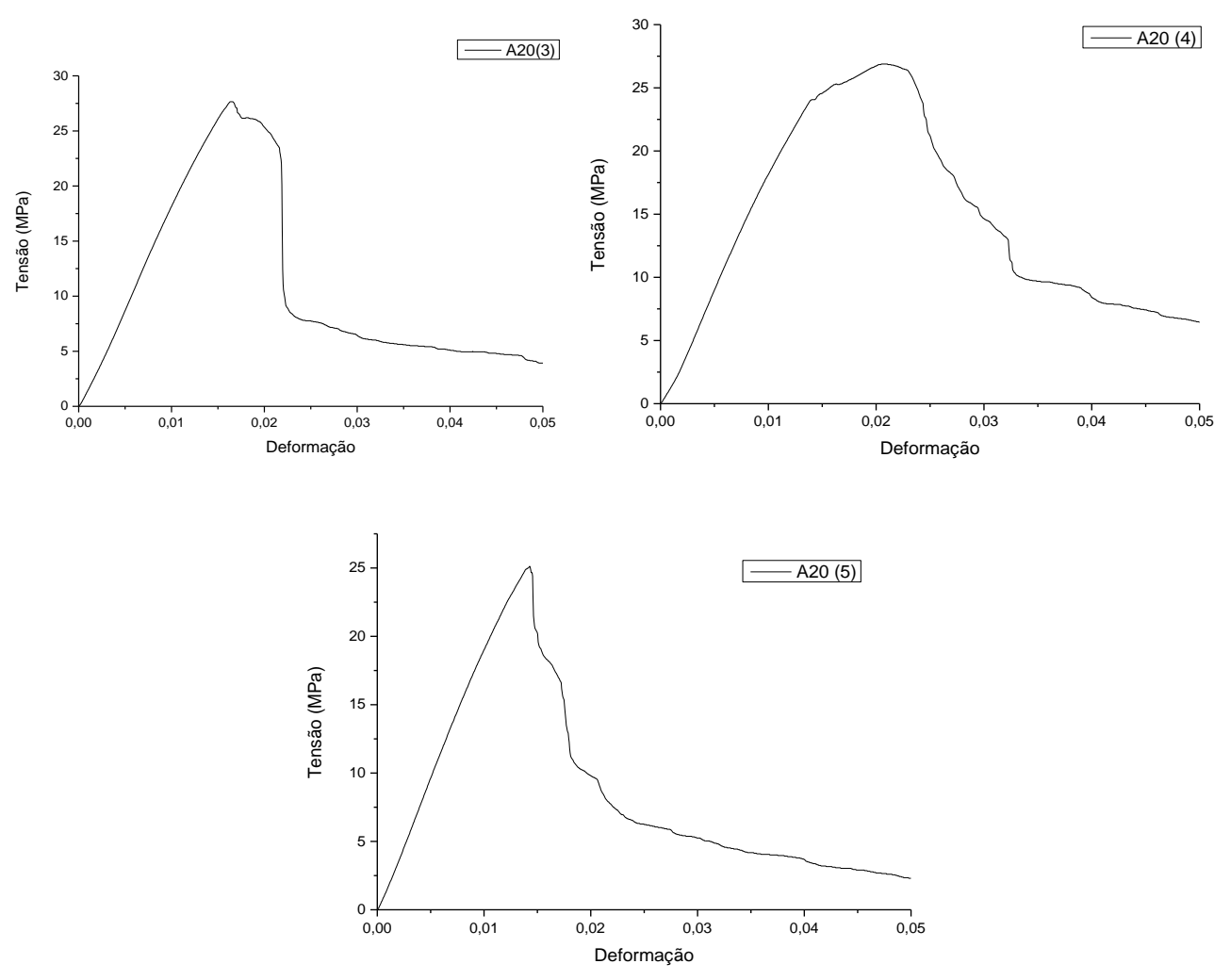

Figura A.6.16. Curvas tensão-deformação de corpos de compósito A20.
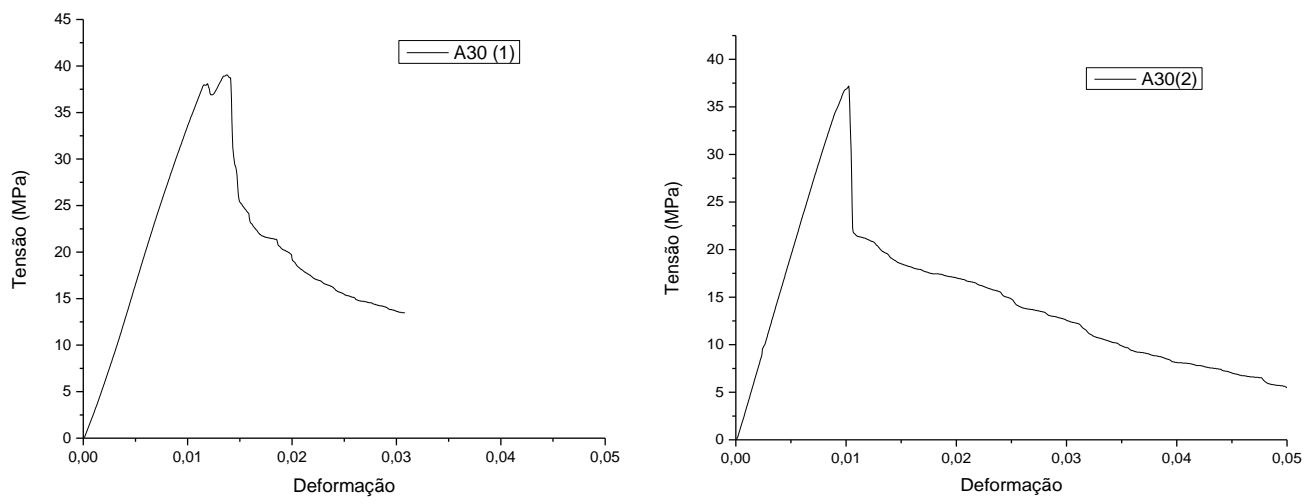

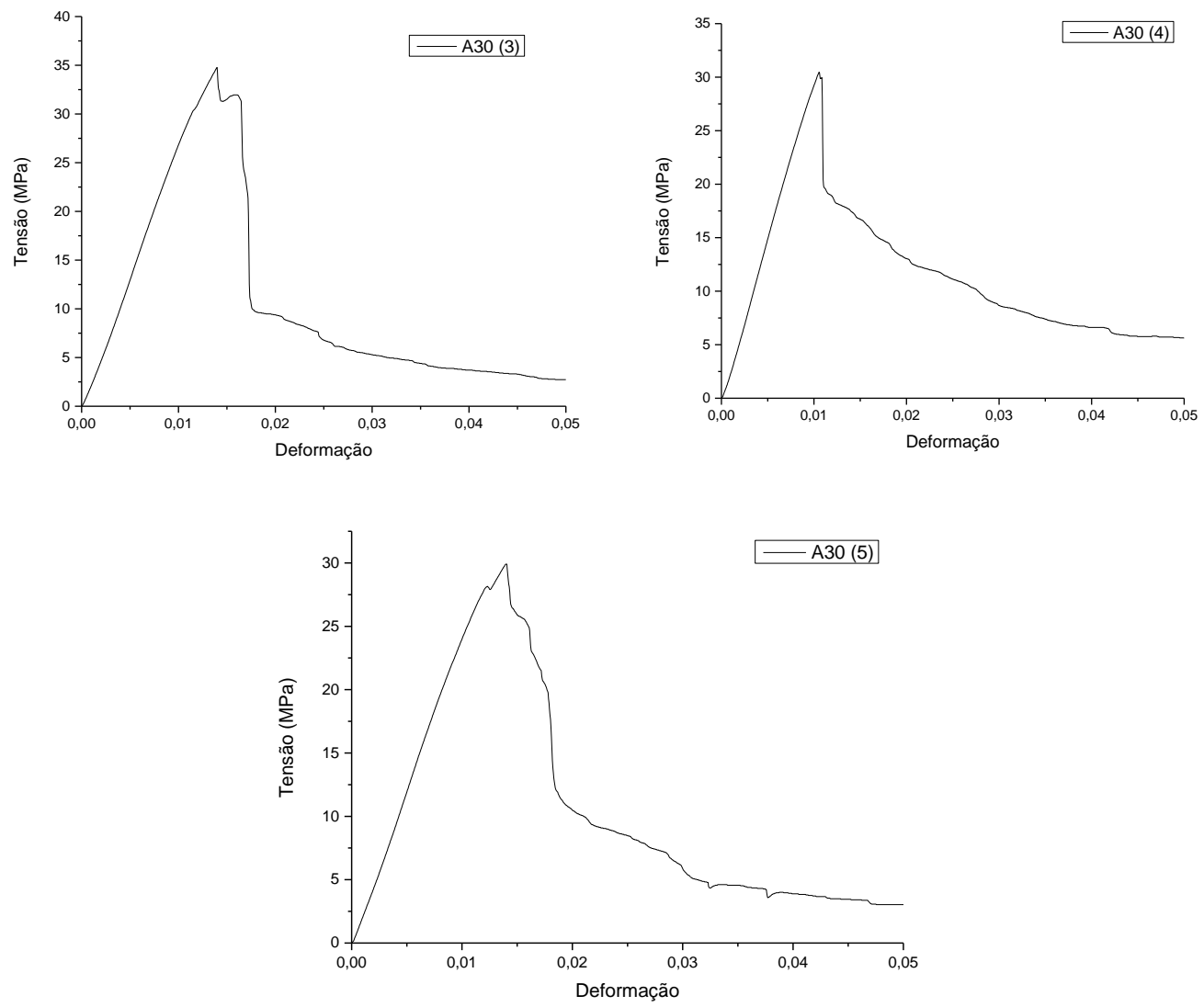

Figura A.6.17. Curvas tensão-deformação de corpos de compósito A30.

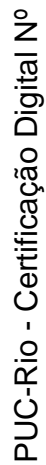

